\title{
A GRAMMAR OF NAHAVAQ (MALAKULA, VANUATU)
}

A thesis submitted to Victoria University of Wellington in fulfilment of the requirements for the degree of

Doctor of Philosophy

in Linguistics

School of Linguistics and Applied Language Studies Te Whare Wānanga o te Ūpoko o te Ika a Māui

Victoria University of Wellington

Wellington, New Zealand 2009 


\begin{abstract}
This thesis is a descriptive grammar of Nahavaq, an Oceanic language spoken by about 700 people in the Sinesip cultural area of Malakula, Vanuatu. Nahavaq was previously undescribed, and this grammar is based on data collected by the researcher over a total of nine months in the Sinesip area. The thesis includes a sociolinguistic overview of the Nahavaq-speaking community and descriptions of phonetics, phonology, mophology, syntax, semantics, and discourse.

Noteworthy features of Nahavaq include: (i) two classes of bilabial consonants, which are distinguished by palatalisation and velarisation; (ii) two reduplicative verbal prefixes, which partially overlap in function; (iii) a base-20 numeral system with subbases of five and ten; (iv) nouns which include an accreted article; (v) serial verb constructions; and (vi) nine different surface forms for expressing possession relationships.
\end{abstract}

The attached DVD contains a Nahavaq-English glossary, along with recordings and transcriptions of Nahavaq texts for reference purposes. 


\section{Acknowledgements}

Throughout this research project, I have received support from a number of different sources.

I would first like to thank my primary supervisor Elizabeth Pearce for her support, advice, feedback, and discussion, and also my secondary supervisor Laurie Bauer for his insightful contributions.

I am grateful for the financial contributions made by the Australian Linguistics Society, the Hans Rausing Endangered Languages Project, Victoria University's $\mathrm{PhD}$ Scholarship/Assistantship, and the Faculty of Humanities and Social Sciences at Victoria University.

My research depended heavily on my fieldwork, and I was lucky to be hosted by a wonderful community. I would like to thank the Sinesip people for their help and support, particularly Elsie and Herol Alick, and Kelina Massing Tamwat. I would also like to thank Tom Alick, Terry Crowley, Priscilla Olul, and the Vanuatu Cultural Centre for introducing me to the Nahavaq community.

I had help in proofreading and formatting from my family and friends: Danielle Davies, Marianna Kennedy, Gail Dimock, and Andy Gibson.

And finally, I wish to acknowledge the support that I got from my partner, Giles McNeill. He provided me with encouragement, videography, and companionship through the good and the bad. 


\section{Abbreviations}

$\begin{array}{ll}\text { BIS } & \text { Bislama } \\ \text { PAN } & \text { Proto Austronesian } \\ \text { PMP } & \text { Proto Malayo-Polynesian } \\ \text { PNCV } & \text { Proto North Central } \\ & \text { Vanuatu } \\ \text { POc } & \text { Proto Oceanic } \\ \text { PVM1 } & \text { Post Verbal Modifier 1 } \\ \text { PVM2 } & \text { Post Verbal Modifier 2 } \\ \text { SNS } & \text { Nahavaq } \\ \text { SVC } & \text { Serial Verb Construction } \\ \text { V1 } & \text { first verb of a SVC } \\ \text { V2 } & \text { second verb of a SVC } \\ & \\ 1 & \text { first person } \\ 2 & \text { second person } \\ 3 & \text { third person } \\ \text { adj } & \text { adjective } \\ \text { AFFIRM } & \text { affirmative marker } \\ \text { ASS } & \text { associative marker } \\ \text { COMPL } & \text { complementiser } \\ \text { COP } & \text { copula } \\ \text { DEF } & \text { definite } \\ \text { DEM } & \text { demonstrative } \\ \text { DIST } & \text { distal } \\ \text { DU } & \text { dual } \\ \text { DUP } & \text { reduplication } \\ \text { EMPH } & \text { emphatic marker } \\ \text { EX } & \text { exclusive } \\ \text { FILL } & \text { filler } \\ \text { FOC } & \text { focus marker } \\ \text { ID } & \text { identification particle } \\ \text { IN } & \text { inclusive } \\ & \end{array}$

$\begin{array}{ll}\text { INDEF } & \text { indefinite } \\ \text { INSTR } & \text { instrumental } \\ \text { INTENS } & \text { intensifier } \\ \text { INTERJ } & \text { interjection } \\ \text { IRR } & \text { irrealis } \\ \text { LOC } & \text { locative } \\ \text { MV } & \text { historical } m \text { V- prefix } \\ \text { n } & \text { noun } \\ \text { NEG } & \text { negative } \\ \text { NI } & \text { ni- nominal prefix } \\ \text { NOM } & \text { nominalising suffix } \\ \text { NONSP } & \text { non-specific } \\ \text { NV } & n \text { V- nominal prefix } \\ \text { OBL } & \text { oblique } \\ \text { ORD } & \text { ordinal prefix } \\ \text { PART } & \text { particle } \\ \text { PERF } & \text { perfect } \\ \text { PERS } & \text { person } \\ \text { PL } & \text { plural } \\ \text { POSS } & \text { possessive } \\ \text { PREP } & \text { preposition } \\ \text { PRO } & \text { nominal pro-form head } \\ \text { PROX } & \text { proximal } \\ \text { R } & \text { realis } \\ \text { REL } & \text { relative clause marker } \\ \text { SG } & \text { singular } \\ \text { SUBJ } & \text { subject } \\ \text { TAG } & \text { tag question particle } \\ \text { V } & \text { verb } \\ \text { V.i } & \text { intransitive verb } \\ \text { V.t } & \text { transitive verb } \\ & \end{array}$




\section{Table of contents}

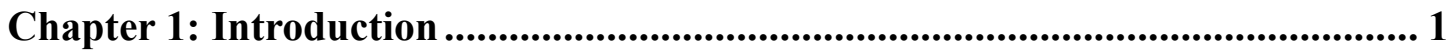

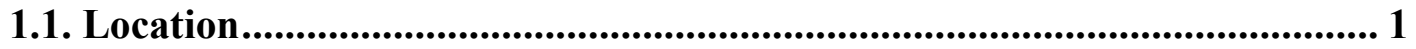

1.2. Genetic affiliation............................................................................ 3

1.3. Sociolinguistic overview ................................................................... 6

1.3.1. Language inventory ............................................................................. 6

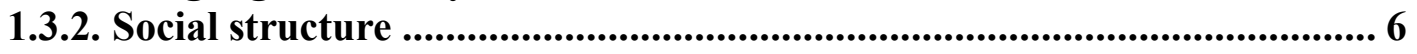

1.3.3. Education...................................................................................... 7

1.3.4. Occupation ...................................................................................... 7

1.3.5. The status of Nahavaq....................................................................... 7

1.3.6. Endangerment .......................................................................................... 7

1.3.6.1. Intergenerational Language Transmission: 5 (stable yet threatened) .. 8

1.3.6.2. Absolute Number of Speakers: approximately 700 ............................... 8

1.3.6.3. Proportion of Speakers within the Total Population: 4 (Unsafe).......... 8

1.3.6.4. Shifts in Domains of Language Use: 4 (Multilingual parity)................ 9

1.3.6.5. Response to New Domains and Media: 0 (Inactive)............................. 9

1.3.6.6. Materials for Language Education and Literacy: 1............................... 9

1.3.6.7. Governmental \& Institutional Language Attitudes and Policies including Official Status \& Use: 4 (Differentiated support) .............................. 9

1.3.6.8. Community Members' Attitudes toward Their Own Language: 4.... 10

1.3.6.9. Amount and Quality of Documentation: 3 (Fair) ................................ 10

1.3.7. Variation within Nahavaq ........................................................................ 10

1.4. Previous work on Nahavaq..................................................................... 11

1.5. The current study................................................................................. 12

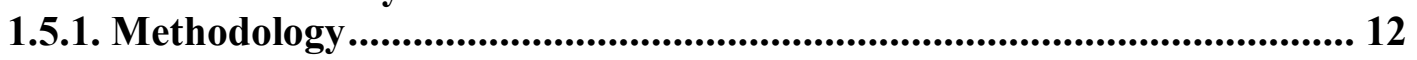

1.5.1.1. Text analysis ................................................................................... 13

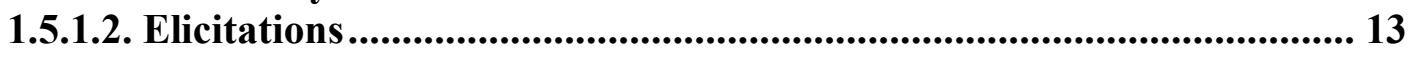

1.5.1.3. Archiving ..................................................................................... 14

1.5.1.4. Analysis and description ..................................................................... 14

1.5.2. Corpus .................................................................................................................... 15

1.6. Brief typological overview ........................................................................ 15

1.7. Organisation of the thesis .................................................................................... 16

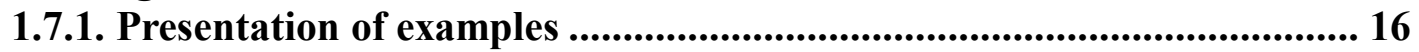

Chapter 2: Phonology .................................................................................................... 17

2.1. Consonants ....................................................................................... 17

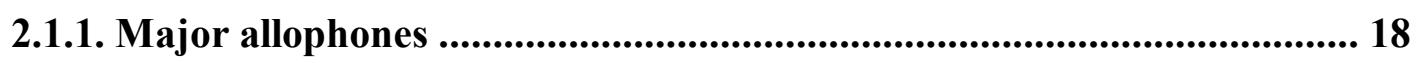

2.1.1.1. Glottal stop ....................................................................................... 18

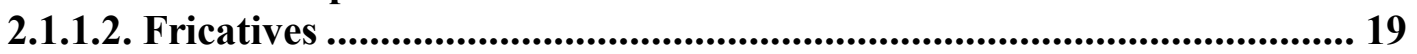

2.1.1.3. Voiceless stops ........................................................................................... 20

2.1.1.4. Prenasalised stops ............................................................................. 21

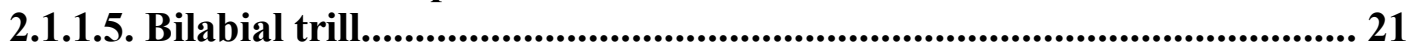

2.1.1.6. Alveolar trill .......................................................................................... 22

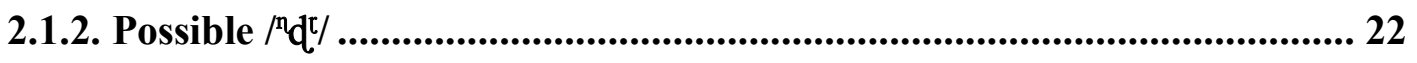

2.1.3. Labiovelar-bilabial distinction ................................................................ 23

2.1.3.1. Phonetic difference................................................................................... 24

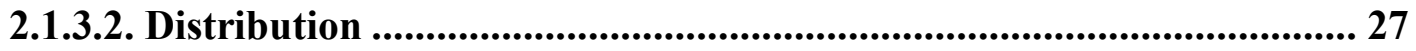

2.1.3.3. Split markedness ......................................................................... 27

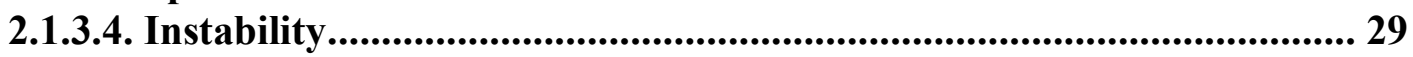




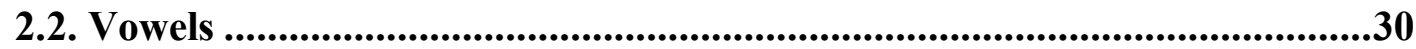

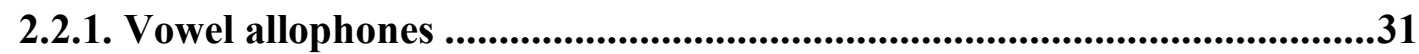

2.3. Phonotactics and the syllable........................................................................33

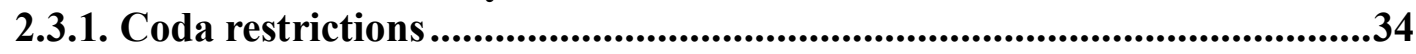

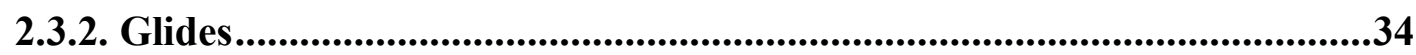

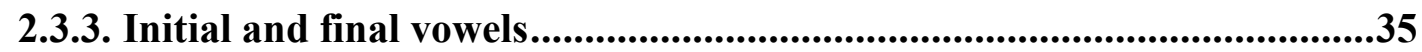

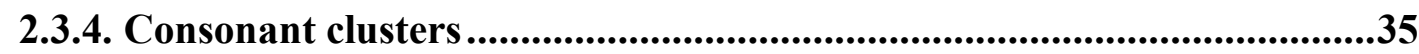

2.3.5. Borrowed syllables ...........................................................................36

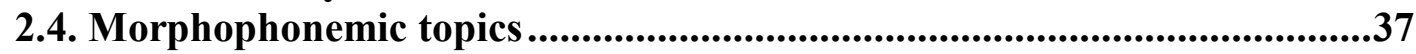

2.4.1. Morpheme-boundary processes ..................................................................37

2.4.2. Vowel harmony and assimilation .........................................................38

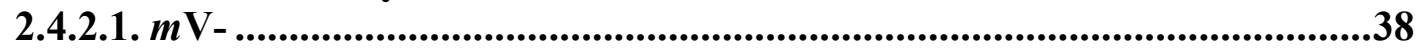

2.4.2.2. In verbal prefixes ........................................................................39

2.4.2.3. Across glottals ................................................................................39

2.4.3. High vowel deletion .................................................................................39

2.4.3.1. Isolated lexical examples..............................................................................40

2.4.3.2. $T(i)$ - prefixation .................................................................................40

2.4.3.3. $M b$ - prefixation.........................................................................................40

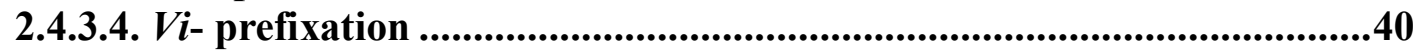

2.4.4. Labial harmony .....................................................................................41

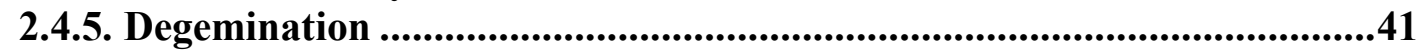

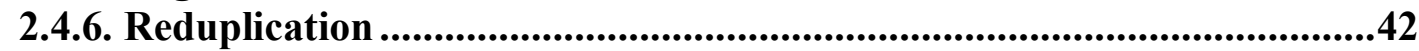

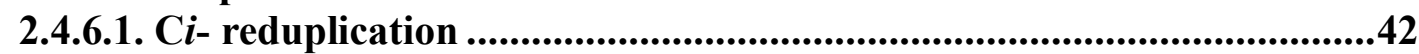

2.4.6.2. Reduplication on monosyllabic roots .................................................43

2.4.7. Nominal prefix $(n \mathrm{~V}-)$.............................................................................45

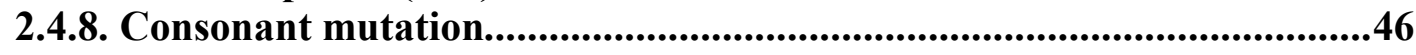

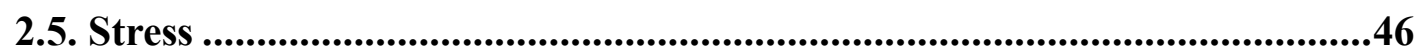

2.5.1. Researcher perception ...........................................................................46

2.5.2. Speaker perceptions............................................................................47

2.5.3. Acoustic analysis .............................................................................................48

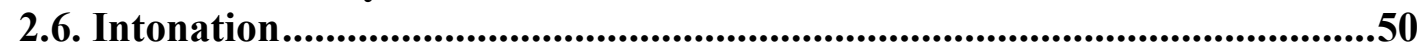

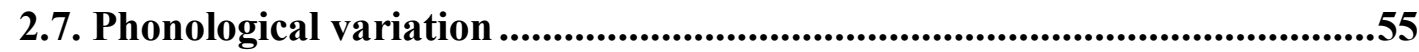

2.7.1. [BILABIAL] $u$ - [LABIOVELAR] $i$ alternation ...............................................55

2.7.2. Loss of final prenasalised stops ...........................................................56

2.7.3. Glottal deletion.............................................................................56

2.7.4. $/ \mathrm{w} / \mathrm{-} / \mathrm{h} /$ alternation............................................................................55

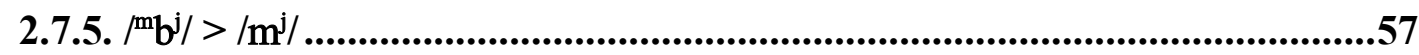

2.7.6. $/$ ew/ > /ow/ ...........................................................................................................55

2.8. The phonological word .......................................................................57

2.8.1. Serial verb-like constructions .............................................................57

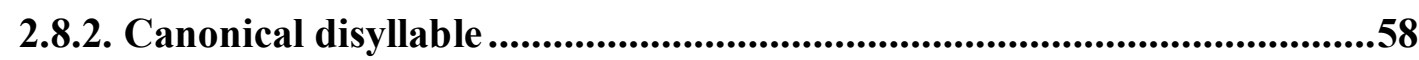

2.9. Orthography .........................................................................................59

Chapter 3: Noun phrase ...................................................................................62

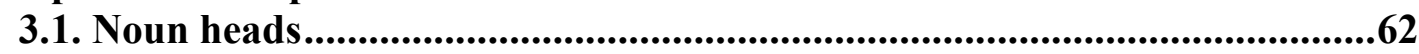

3.1.1. Directly possessed nouns...............................................................................62

3.1.2. Indirectly possessed nouns........................................................................67

3.1.2.1. Pronouns.....................................................................................................67

3.1.2.1.1. Personal pronouns...........................................................................67

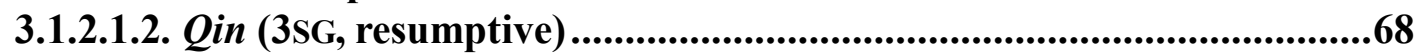


3.1.2.1.3. Co-referential pronouns.............................................................69

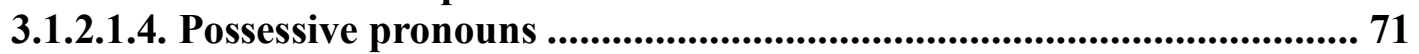

3.1.2.2. Demonstrative pronouns................................................................. 71

3.1.2.3. Interrogative nouns (iyaq 'who' and na-havaq 'what')...................... 72

3.1.2.4. Proper nouns ................................................................................... 72

3.1.2.4.1. Place names .............................................................................. 72

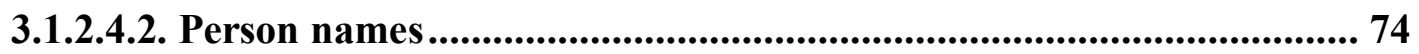

3.1.2.5. Locational and temporal nouns ................................................................ 75

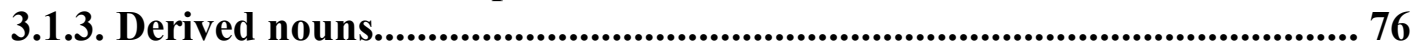

3.1.3.1. Ni-VERB-yen ............................................................................................ 76

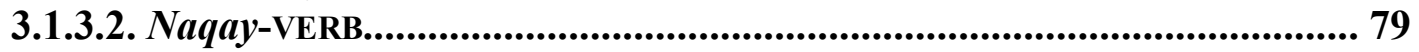

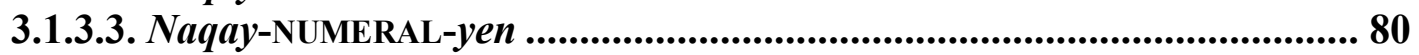

3.1.3.4. Ø-derivation (nouns and verbs) ........................................................ 81

3.1.3.5. Compound nouns ........................................................................... 82

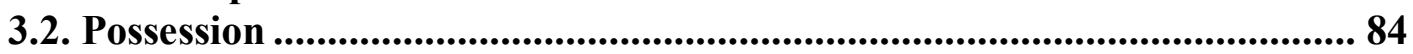

3.2.1. Possessive constructions with directly possessed nouns......................... 84

3.2.1.1. Direct possession with possessor suffix................................................ 84

3.2.1.2. Direct possession with possessor NP ..................................................... 85

3.2.1.3. Special -yen construction for close kinship terms ..............................86 86

3.2.2. Possessive constructions with indirectly possessed nouns ...................... 87

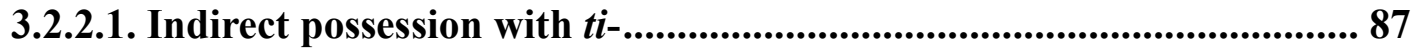

3.2.2.2. Possessive prefix constructions: $n$ agcu- namwu- nin-....................... 88

3.2.2.3. Possessive $-y e n$ constructions .............................................................. 89

3.2.2.4. Associative constructions (nin) ......................................................... 90

3.3. Pre-nominal modifiers .......................................................................... 93

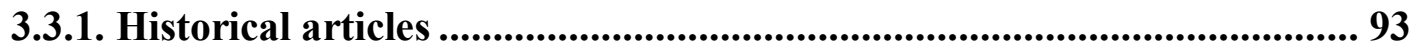

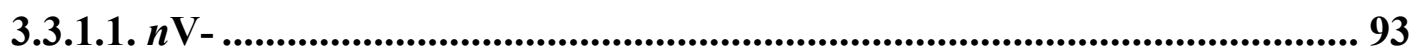

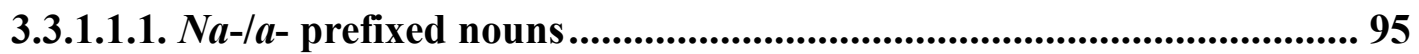

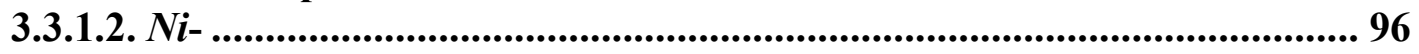

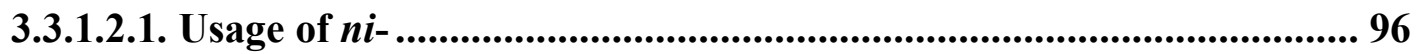

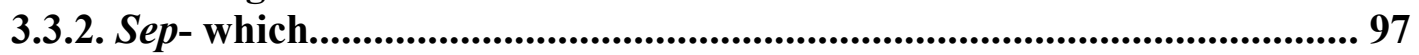

3.4. Post-nominal modifiers .............................................................................. 98

3.4.1. Quantifiers................................................................................................ 98

3.4.2. Number particles............................................................................ 99

3.4.3. Indefinite articles ...............................................................................100

3.4.3.1. Sut non-specific...............................................................................100

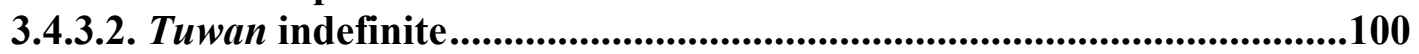

3.4.4. Demonstrative determiners ...................................................................101

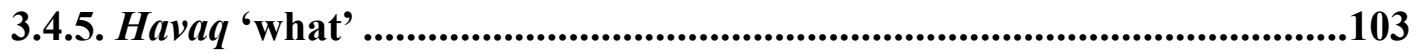

3.4.6. Timbeh 'which' ...........................................................................103

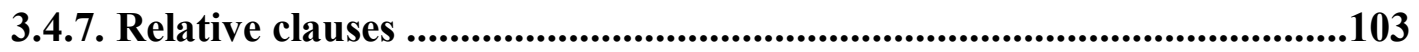

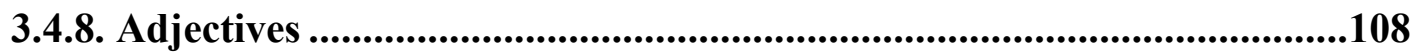

3.4.8.1. Body part attribute constructions .......................................................110

3.4.9. Nominal modification by verbal modifiers............................................110

3.4.9.1. Mbwaq 'sorry' ...............................................................................111

3.4.9.2. Ndalis 'again (another)' ..................................................................111

3.4.9.3. Sombo-n 'alone-3SG' ..........................................................................112

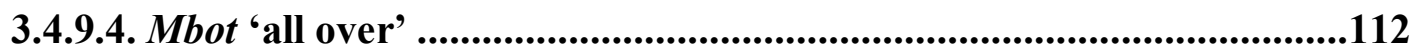

3.4.9.5. Mwin-(lis) 'other'......................................................................................113

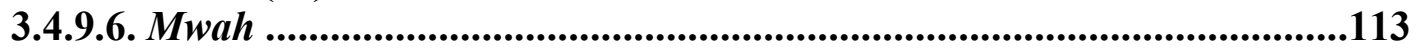




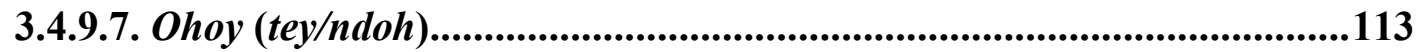

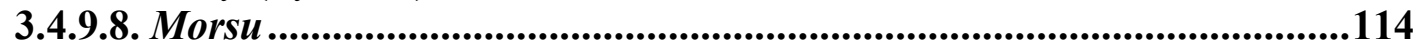

3.4.10. Ordering of post-nominal modifiers..........................................................115

3.5. Headless noun phrases...................................................................................116

3.6. Coordination of noun phrases ...........................................................118

3.6.1. Juxtaposed NPs .....................................................................................118

3.6.2. Inclusory constructions with personal pronouns...................................118

3.6.3. Mbon qin ...........................................................................................119

3.6.4. Luqur 'with' .................................................................................119

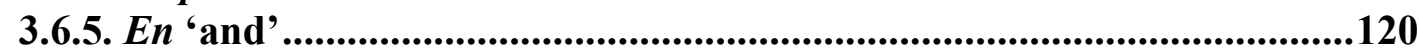

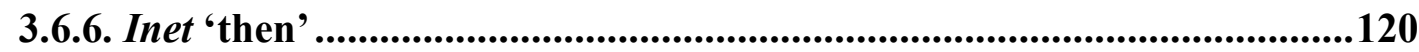

Chapter 4: Verb Phrase ............................................................................121

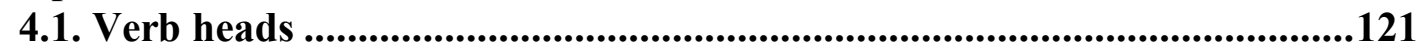

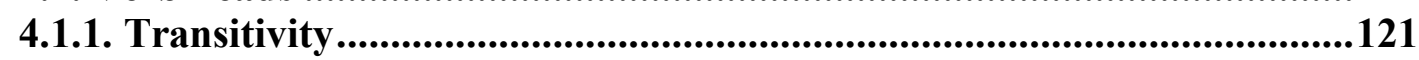

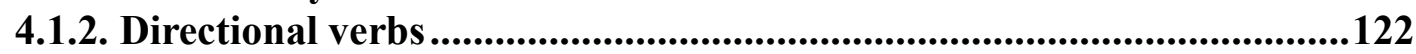

4.1.3. Vestigial transitive suffixes ............................................................125

4.1.4. Vestigial *ma- prefix ......................................................................................126

4.1.5. Adjectives ....................................................................................................128

4.1.6. Quantifiers ...................................................................................128

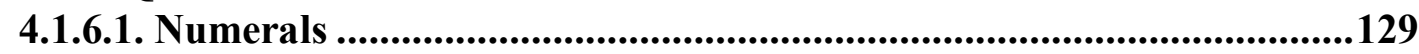

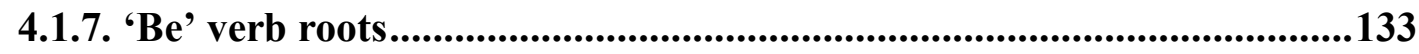

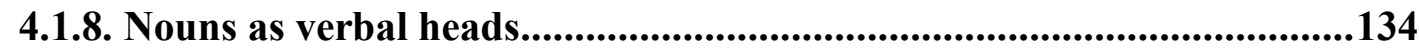

4.1.9. Object incorporation......................................................................135

4.2. Subject/mood prefix...............................................................................135

4.2.1. Person/mood prefixes...............................................................................136

4.2.2. Functions of realis and irrealis mood .....................................................137

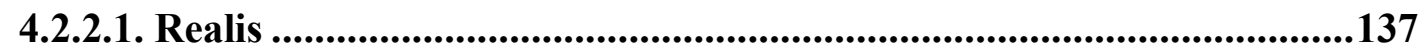

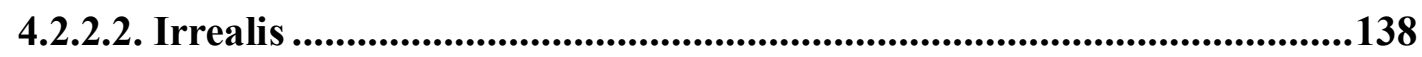

4.2.2.2.1. Future .........................................................................................138

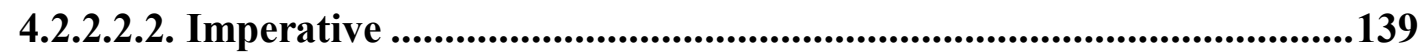

4.2.2.2.3. Hypothetical .............................................................................139

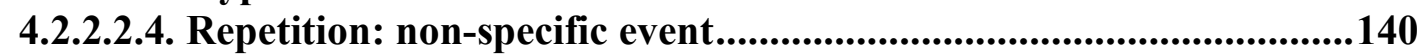

4.2.2.3. Mood with quantifiers........................................................................140

4.3. Negation of VP ...................................................................................... 141

4.4. Third order prefixes .....................................................................142

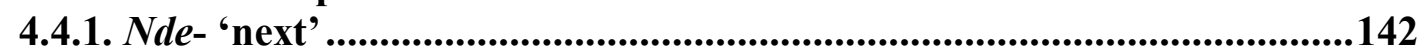

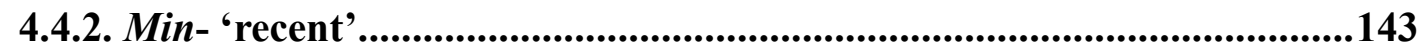

4.4.3. $V i$ - 'go/inchoative/copular' ..................................................................144

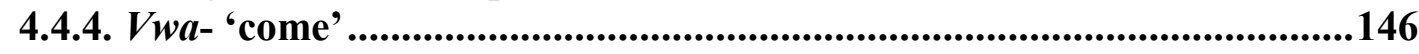

4.5. Reduplication ....................................................................................147

4.5.1. The functions of verbal reduplication ..................................................147

4.5.1.1. Multiple objects...............................................................................148

4.5.1.2. Multiple subject..............................................................................148

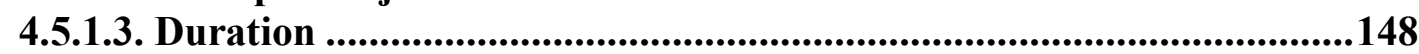

4.5.1.4. Habit or typical behaviour.............................................................149

4.5.1.5. Reduplication with numbers..............................................................150

4.5.1.6. Reduplication with object incorporation ...........................................151

4.5.1.7. Unpredictable Derivation ..........................................................................151

4.5.1.8. No difference in meaning .......................................................................152

4.5.1.9. Apparent reduplication..............................................................152 
4.5.2. Double reduplication............................................................................153

4.6. Serial Verb Constructions .................................................................153

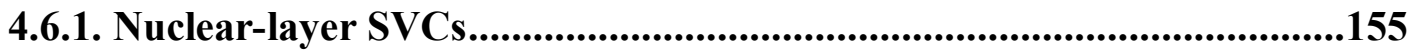

4.6.1.1. Phonological words and nuclear-layer SVCs ..................................155

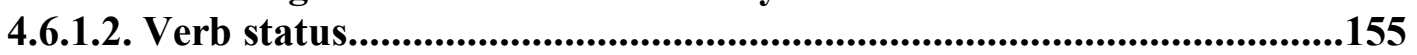

4.6.1.3. Classes of nuclear-layer SVCs .........................................................157

4.6.1.3.1. V1 results in V2 ............................................................................158

4.6.1.3.1.1. Reduplication on cause-effect SVCs ................................................160

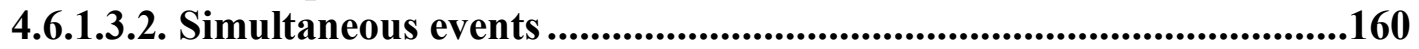

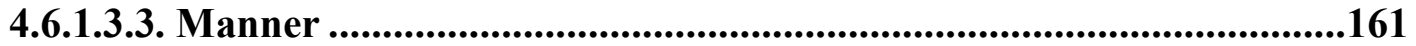

4.6.1.4. Former V2s...................................................................................162

4.7. Post-verbal-modifier-1 .....................................................................162

4.7.1. Result PVM1 .......................................................................................163

4.7.1.1. Sar 'remain' ........................................................................................163

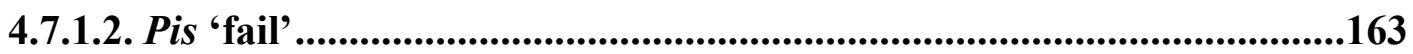

4.7.1.3. Pileh 'mess up'...........................................................................163

4.7.2. Manner PVM1.................................................................................164

4.7.2.1. Lalaq 'quietly' ................................................................................164

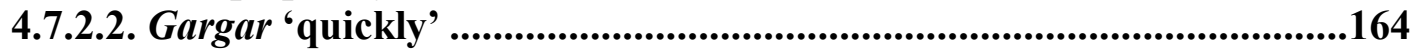

4.7.2.3. Ndag 'carefully' .............................................................................165

4.7.2.4. Mbot 'all over' ...............................................................................165

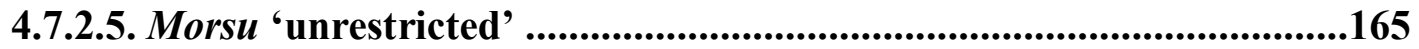

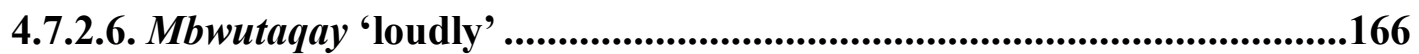

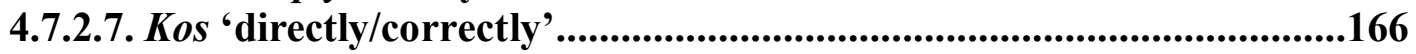

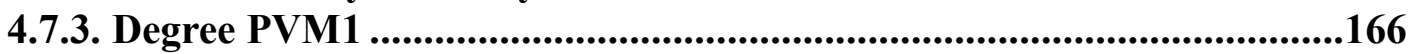

4.7.3.1.1. Taqtaq 'a little' ...................................................................................166

4.7.3.1.2. Liglig 'very/too much' .................................................................167

4.7.3.1.3. Mbwutaqay 'very' ...........................................................................167

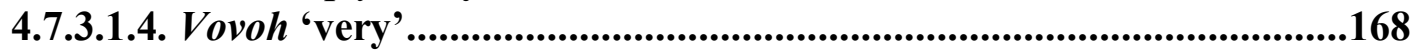

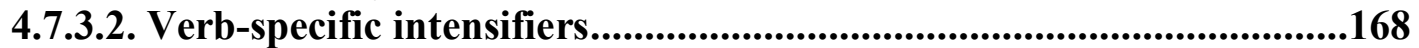

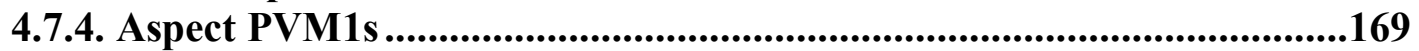

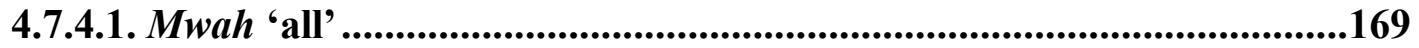

4.7.4.2. Tartar 'always' ........................................................................................170

4.7.4.3. Gcot 'for the last time'.......................................................................171

4.7.4.4. Malas 'never/yet' ...........................................................................171

4.7.4.5. Mbaqsiq 'ahead/beforehand' .........................................................172

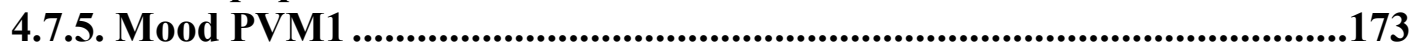

4.7.5.1. Gcow 'confirm/emphasis' ...................................................................173

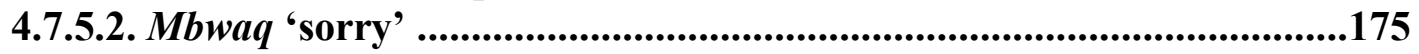

4.7.5.3. Ohoy 'simply, freely, insignificant' .............................................175

4.7.5.4. Mwin 'first' ................................................................................................176

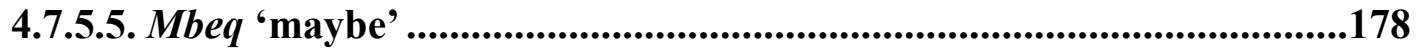

4.7.5.6. Sam 'beware' .........................................................................................178

4.7.6. Miscellaneous PVM1s .........................................................................179

4.7.6.1. Ndal 'back' ...................................................................................179

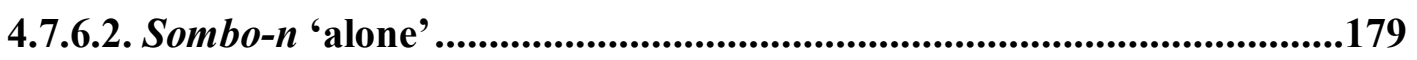

4.8. Post-verbal-modifier-2 (PVM2)..................................................................180

4.8.1. Ndoh (perfect aspect) .....................................................................................180

4.8.2. Lis 'again' .........................................................................................................181

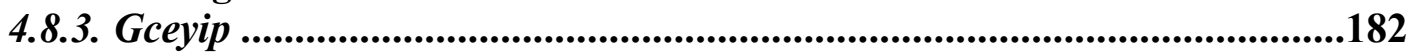


4.9. Object.

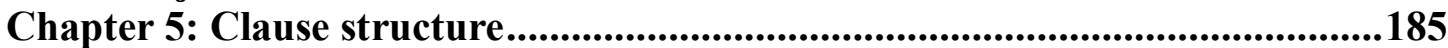

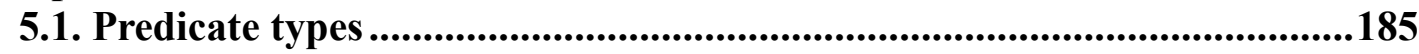

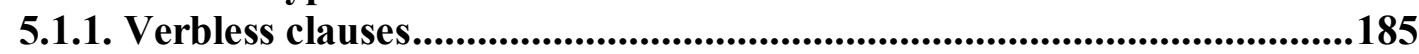

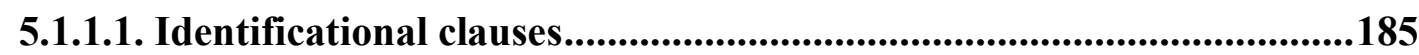

5.1.1.2. Equational clauses.............................................................................186

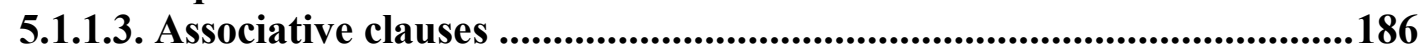

5.1.2. Verbal clauses ...............................................................................187

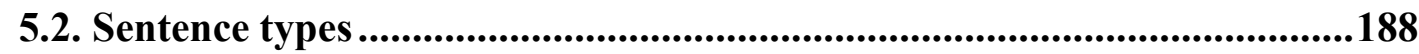

5.2.1. Declarative .............................................................................................188

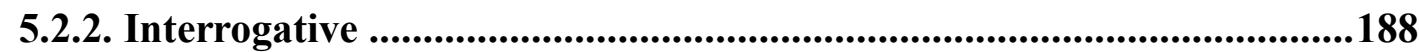

5.2.2.1. Polar questions .............................................................................188

5.2.2.2. Content questions.............................................................................190

5.2.2.3. Non-interrogative uses of question words .......................................192

5.2.3. Imperative ..............................................................................................193

5.3. Clause modification .........................................................................................195

5.3.1. Negation .......................................................................................................195

5.3.2. Spatial and temporal adjuncts to clauses ...........................................197

5.3.2.1. Locational and temporal nouns ....................................................198

5.3.2.2. IV-prefixed nouns...............................................................................201

5.3.2.3. Prepositions .................................................................................203

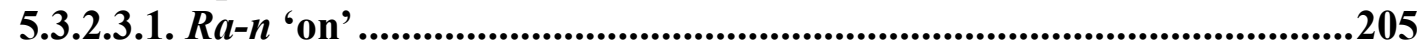

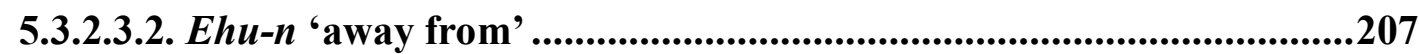

5.3.2.3.3. Ndilqi-n 'away from' .......................................................................207

5.3.2.3.4. Embu-n 'down in' ............................................................................208

5.3.2.3.5. Evu-n 'under, carrying' ...........................................................................208

5.3.2.3.6. Silevu-n 'under' ..........................................................................208

5.3.2.3.7. Mbigce-n 'beneficiary' ....................................................................209

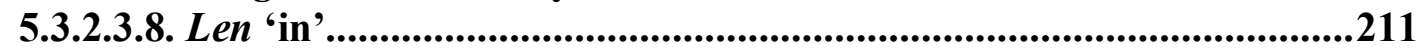

5.3.2.3.9. Hur 'near, about'...................................................................212

5.3.2.3.10. Luqur 'with' .............................................................................212

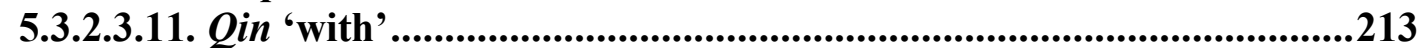

5.3.2.3.12. Qin (OBLIQUE) ...............................................................................213

5.3.2.3.13. Gcen 'for/because of' ...............................................................216

5.3.2.4. Directional particles (mbey and mbweleg) ..........................................216

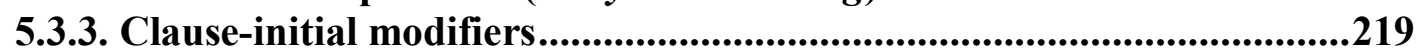

5.4. Subordinate clauses ...........................................................................221

5.4.1. Complement clauses.........................................................................222

5.4.1.1. Interrogative complement clauses ....................................................225

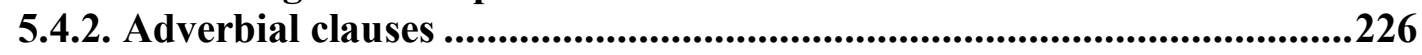

5.4.2.1. Adverbial clauses without subordinators..........................................2227

5.4.2.2. Adverbial clauses with subordinators ................................................228

5.4.2.2.1. Gcen 'because' ..............................................................................229

5.4.2.2.2. Konoq 'if' .................................................................................229

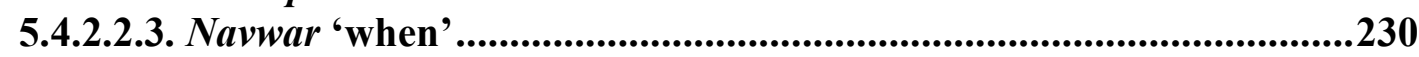

5.4.2.2.4. Mbaqnder 'until' ..........................................................................231

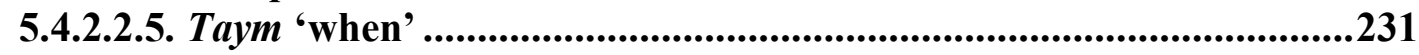

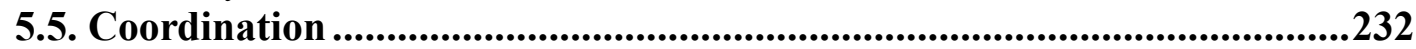

5.5.1. En 'and' ..........................................................................................................233

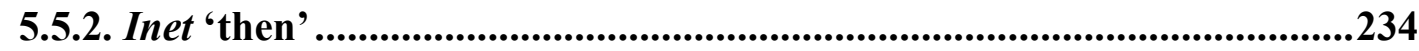


5.5.3. Qet 'then/but'

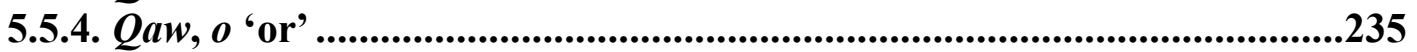

5.6. Core-layer serial verb constructions …................................................236

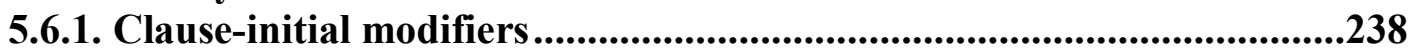

5.6.2. Verb + complement clause .................................................................2238

5.6.3. Verb of motion + activity ....................................................................238

5.6.4. Clause + duration/multiplicative/manner .........................................239

5.6.5. Causative (gcur) ..........................................................................................241

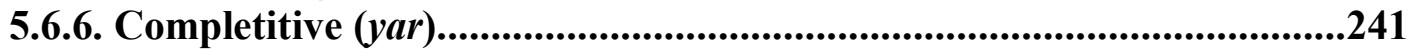

5.6.7. Quotative marker (vwer) ..............................................................242

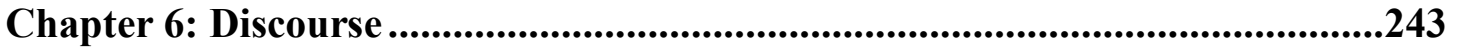

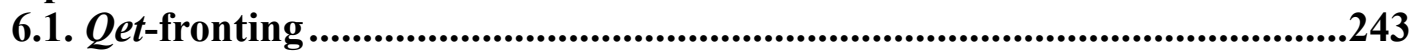

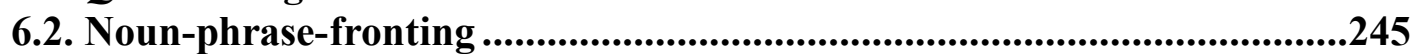

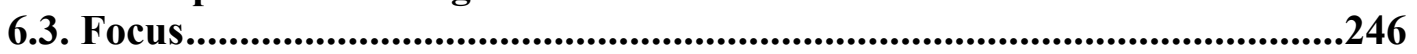

6.3.1. Contrastive focus particle $m i$..........................................................246

6.3.2. Non-contrastive focus particle tey ...................................................247

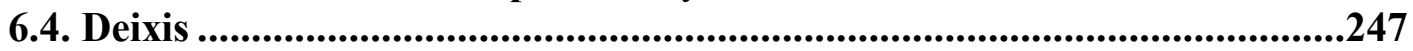

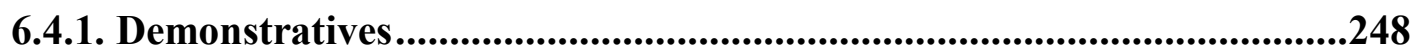

6.4.2. Directional verbs and directional particles .......................................251

6.4.3. Directional verbal prefixes (vwa- and $v i$-) .........................................252

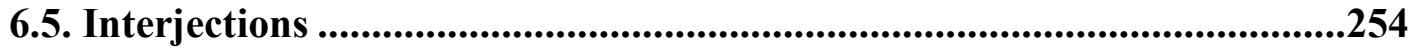

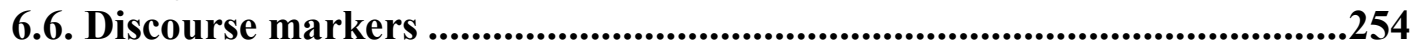

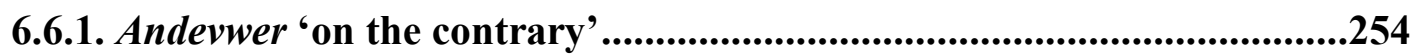

6.6.2. Inoq revwer (approximation/hesitation marker) ..................................255

6.6.3. Iyar en (transition marker) .....................................................................256

6.6.4. Qet (continuation marker) ..................................................................257

6.7. Hesitation phenomena ..........................................................................257

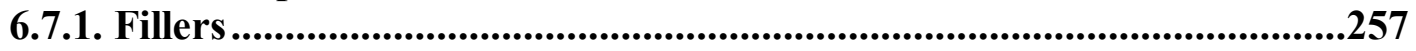

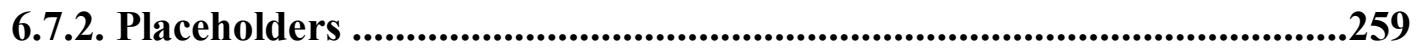

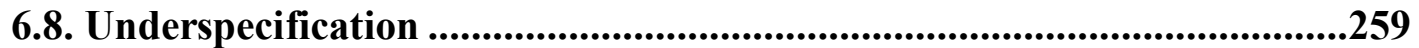

6.8.1. Unspecified agent ...........................................................................259

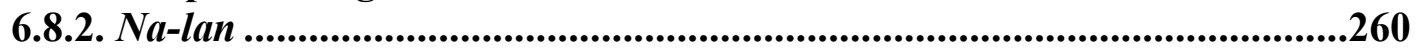

6.9. Taboo avoidance .........................................................................................261

6.10. Repetition .................................................................................262

6.10.1. Head-tail linkage .......................................................................262

6.10.2. Verb phrase repetition ....................................................................263

6.11. Quoted speech ..............................................................................264

Appendix 1: Consonant contrasts .......................................................................266

Appendix 2: Reduplication of monosyllabic roots..................................................270

Appendix 3: Adjectives...........................................................................................2274

Appendix 4: Vestigial *ma- prefixes ..................................................................2276

Appendix 5: Audio text metadata ................................................................280 


\section{Chapter 1: Introduction}

The Nahavaq language (SNS) is spoken by approximately 700 people in the Sinesip cultural area on the island of Malakula (Vanuatu). ${ }^{1}$ The location of Vanuatu is shown in Figure 1, and Figure 2 shows the location of the Nahavaq-speaking area within Vanuatu. The name, Nahavaq, literally means 'what?'”

Figure 1: Vanuatu within the southwest Pacific

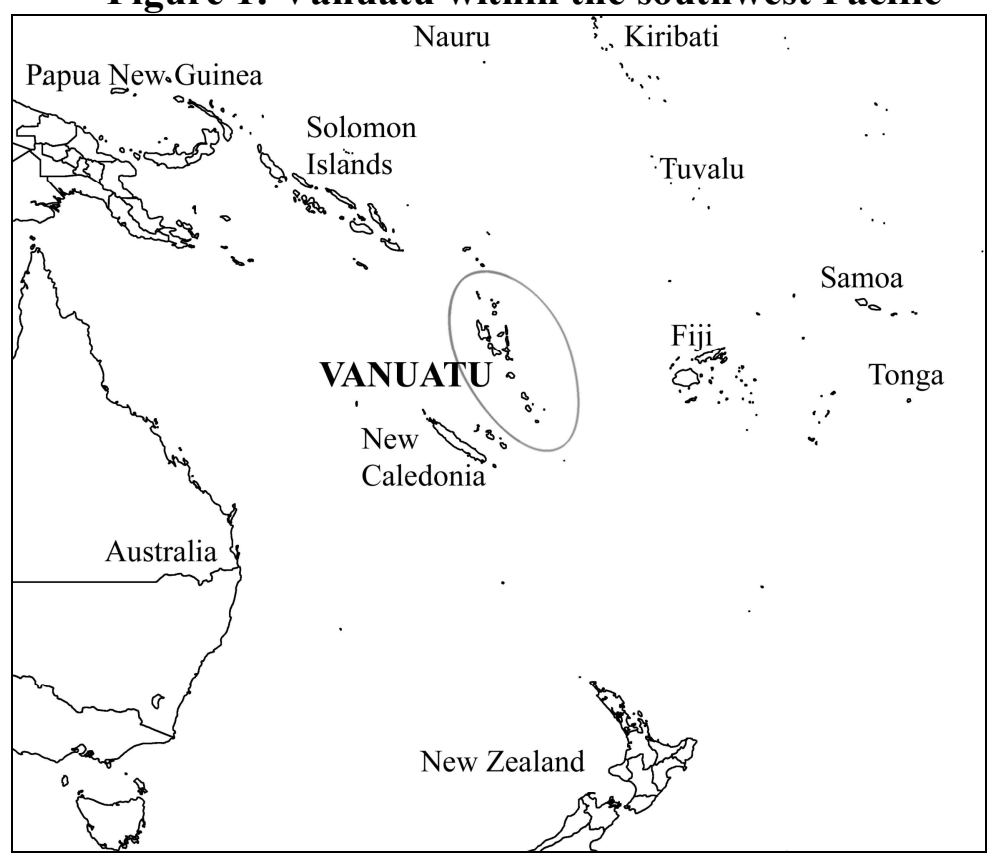

\subsection{Location}

Nahavaq is one of the 106 languages of Vanuatu (Lynch and Crowley 2001: 4). With only about 200,000 people, Vanuatu has the highest density of languages in the world. Few of these languages have been well described. Lynch and Crowley (2001: 19) describe only four of the 106 languages as 'well described' and twelve as 'reasonably well known and well described'. That leaves 11 described as 'middling', 31 as 'not well known', 35 as 'poorly known', and 13 with no information in print. While there

\footnotetext{
${ }^{1}$ Notes on alternate names: The Republic of Vanuatu was previously known as the New Hebrides. Malakula has alternate spellings, Malekula and Mallicolo. The Nahavaq language has been referred to with a variety of spellings and different names. It has been spelled Nahava, without any representation of the glottal stop at the end of the word. Crowley (1998b: 102) refers to Nāva as a possible dialect of Nahava, but in fact it is just a variant pronunciation of Nahavaq (see section $2.7 .3 \mathrm{on} / \mathrm{h} / \mathrm{deletion}$ ), and the Nāti language is referred to by many Nahavaq speakers as Nahati. It has also been referred to as South West Bay after the general area where it is located, but this is a problematic name because there are a number of languages in the area. It has been referred to as Sinesip, which is the name of the cultural area where Nahavaq is the language. It has been referred to as Seniang, which according to locals means 'that place over there'. The Ethnologue code for Nahavaq is SNS (Lewis 2009), but this code also includes the name Na'ahai, which refers to a different language (MLX).

${ }^{2}$ Many other language names around Malakula including Na'ahai, Ninde, Nasvang, Navwien (Charpentier 1982), Neve'ei (Musgrave 2007: 3), Nāti (Crowley 1998b: 147), Nese (Crowley 2006c: 1 ), also mean 'what'. It is my belief that this pattern comes from interactions when people meet strangers and attempt to speak a language to them. Then if the other person does not understand what is said, they will naturally say, 'What?' in their language or possibly another that they think their interlocutor will understand. That word for 'what?' becomes a symbol of the language that the other person wants to communicate in and thereby becomes the name for the language.
} 
has been a little more descriptive progress made in the last few years since that publication, the overall picture remains the same--most of Vanuatu's languages are not well-described.

Figure 2: Malakula within Vanuatu and languages within Malakula Map on left from Crowley (2006a). Map on right shows show approximate locations of Malakula languages prior to European contact. Dotted lines separate dialects; solid lines separate languages. Locations are based on Lynch and Crowley (2001), Charpentier (1982), and Crowley (2006a; 2006c). Grey areas represent extinct languages. Black areas were not known to be inhabited.

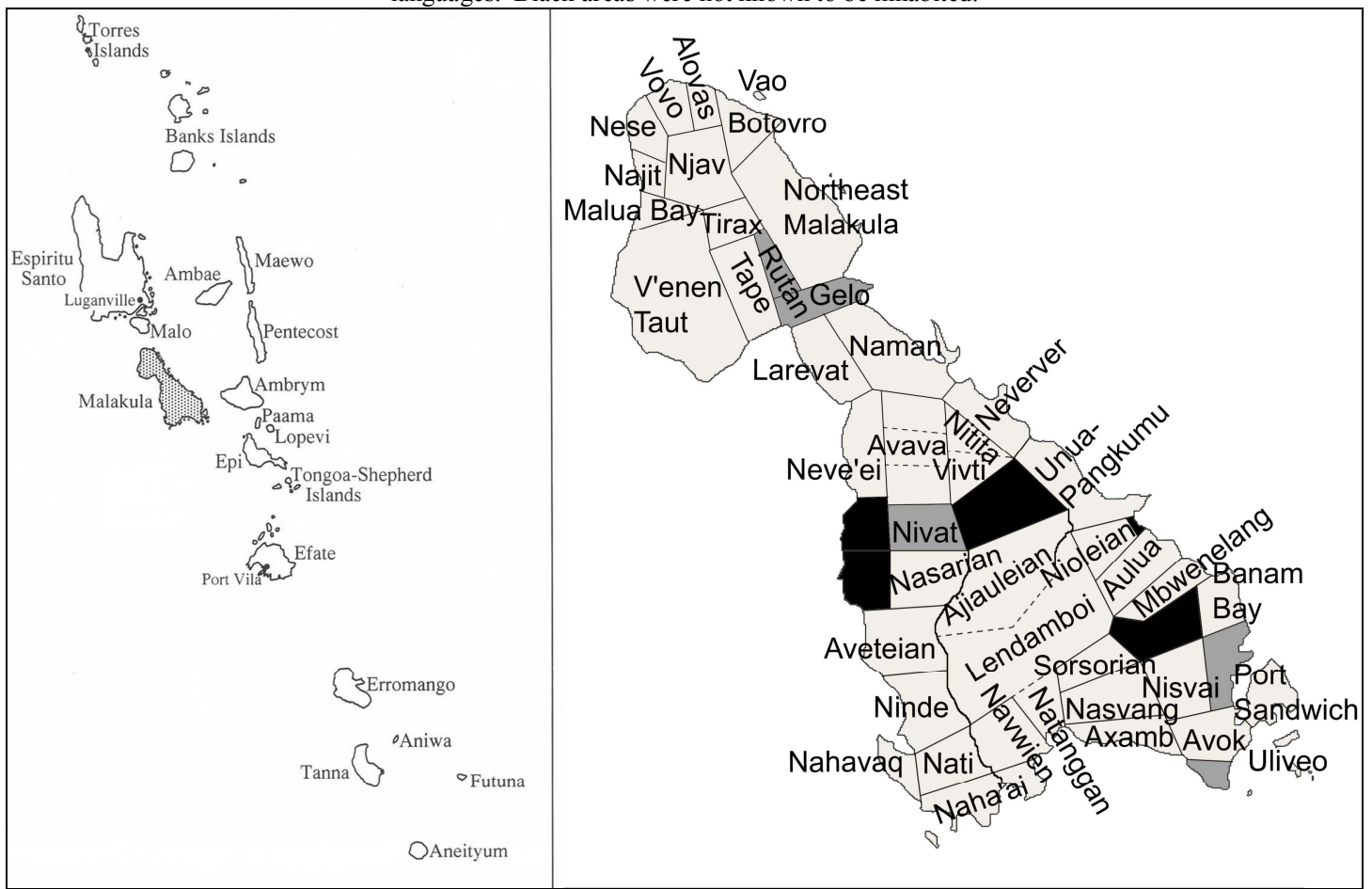

Malakula is the second largest island in Vanuatu. Malakula, with an estimated population of around 27,000 and at least 39 identified languages (Lynch and Crowley 2001: 67-90), has an average language size of around 700 speakers. Nahavaq is therefore fairly average in terms of number of speakers.

Until recently, only three of Malakula's languages - V'ënen Taut (Fox 1979), Port Sandwich (Charpentier 1979), and Nāti (Crowley 1998b) — were described in any detail. But recent publication on Avava, Naman, Nese, Tape, and Neve'ei (Crowley 2006a; Crowley 2006b; Crowley 2006c; Crowley 2006d; Musgrave 2007)(Crowley 2006a; 2006d; 2006b; 2006c; Musgrave 2007) have substantially increased knowledge of Malakula languages. However, there is much more work to be done on Malakula. In addition to this grammar, there are seven projects currently under way on Malakula languages. ${ }^{3}$

The Sinesip area is in the South West Bay area of Malakula. Deacon (1934: 5) describes the traditional boundaries of the Sinesip cultural area as from Caroline Bay

\footnotetext{
${ }^{3}$ Researchers currently working on Vanuatu languages: Elizabeth Pearce (Victoria University) working on Unua, Martin Paviour-Smith (Massey University) working on Aulua, Julie Barbour (Waikato University) who recently submitted a PhD thesis on Neverver, Amanda Brotchie (University of Melbourne) who recently submitted a PhD thesis on Tirax, Anastasia Riehl (University of Toronto) working on Na'ahai, and David Healey (SIL) working on Uliveo.
} 
in the South to the north side of the entrance of the lagoon in the North. This continues to be the case to the present day (Figure 3). However, the settlement patterns have changed substantially since European contact. In the past, the population was divided into sub-tribes, nakamals. Each nakamal had its own tract of land within the Sinesip area, and within each nakamal, the population of each nakamal was scattered in small settlements throughout its land. In effect, the population was spread throughout the interior of the Sinesip area. However, with the arrival of missionaries in the 1890 s, people were encouraged to settle in larger coastal villages. The villages of Vorlesles, Mbenewur, and Lembinwen were populated through this movement. The shift to larger coastal villages is now complete with none of the traditional village locations being continuously inhabited to the present day. Later in the 1960s and 1970s, the villages of Luqmow and Witavaq were founded, and in the early 2000s, Elu village was founded. The current approximate populations of the villages are: Lembinwen 350, Luqmow 150, Witavaq 140, Mbenewur 30, Elu 25, and Vorlesles 5.

Figure 3: Modern villages of the Sinesip area

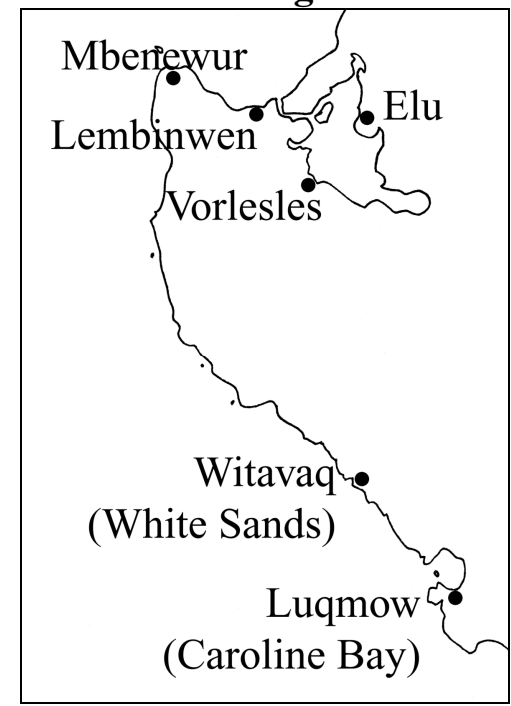

\subsection{Genetic affiliation}

All of Vanuatu's languages are part of the Oceanic family within the Austronesian family. With the exception of a few Polynesian outliers, they all belong to the Southern Oceanic linkage discussed in Lynch et al. (2002: 112). From that point, subgrouping becomes more controversial. Clark (1985) had classified all Malakula languages within a North-Central Vanuatu family (a subgroup of what is being called Southern Oceanic here). Within North-Central Vanuatu, two subgroups were proposed: Northern Vanuatu and Central Vanuatu, which includes Malakula languages. However, rather than grouping Central Vanuatu languages with Northern Vanuatu languages, Lynch (2000a) groups Central Vanuatu with its southern neighbours in Nuclear Southern Oceanic linkage. In both proposals, the languages of Malakula are related to the languages of Ambrym, Paama, Epi, the Shepherd Islands, some languages of Pentecost, and the languages of Efate, though the situation with Efate becomes poorly defined as it lies on a border area (Lynch et al. 2002: 112-114). ${ }^{4}$ Another approach to subgrouping within Vanuatu was Tryon's (1976) lexicostatistical

\footnotetext{
${ }^{4}$ Tryon's (1976: 59) Central sub-group also includes some languages of Santo.
} 
survey which identified a Malakula Coastal Sub-group (which includes Nahavaq) within the North and Central New Hebrides Group (Figure 4).

\section{Figure 4: Tryon's (1976) classification of languages within Vanuatu}

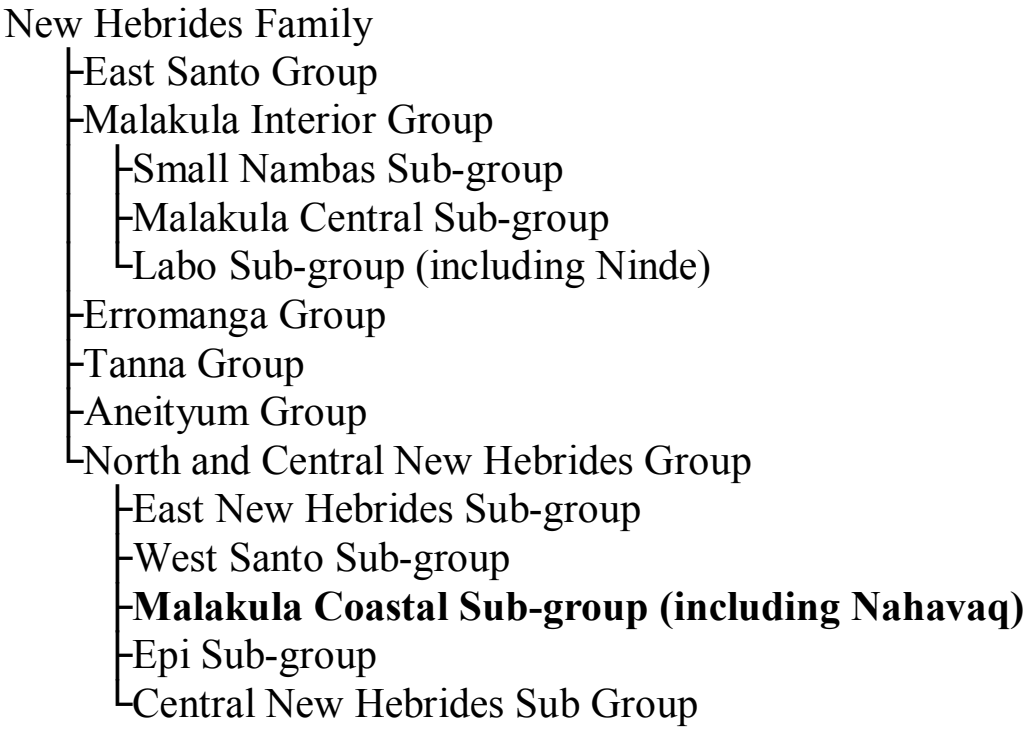

Lower level groupings of Malakula languages including Nahavaq have been rather speculative, partly because of the lack of description of so many languages. As mentioned above, Tryon grouped Nahavaq within the Malakula Coastal Sub-group of the North and Central New Hebrides Group. However, interestingly, one of Nahavaq's closest geographical neighbours, Ninde, was grouped within the Malakula Central Sub-group of the Malakula Interior Group, which is a sister group to North Central. This implies that Nahavaq is more closely related to languages in Ambae, Pentecost, Santo, Epi, Efate, and the Banks and Torres groups than it is to Ninde and other Malakula interior languages. Charpentier (1982) also comments on Ninde's phonological and grammatical differences from many coastal languages. But Lynch (2006; 2007) groups Nahavaq in a Western Linkage, which contains most of the languages of Tryon's Malakula Interior Group (including Ninde).

From conversations I have had with speakers of various languages in the South West Bay area, it is clear to me that Nahavaq is closely related to Na'ahai, ${ }^{5} \mathrm{Na} t i$, and Navwien. This is based on talking to people in South West Bay, some observations of speech, and the work of Crowley (1998b), Tryon (1976), and Charpentier (1982). It is likely that these form a low-level sub-group. Local people have told me that Nahavaq, Na'ahai, and Nāti are 'like a triangle,' meaning that any two may share features that the third does not have. It is not clear how Navwien fits into this picture, but Nahavaq speakers have told me that it is similar to Nahavaq. Tryon's lexicostatistical data supports a close relationship between Nahavaq and Na'ahai (70$71 \%$ cognate depending on which list) that is far closer than that between Nahavaq and Ninde (45-55\% cognate). However, it would appear that Nahavaq is more closely

\footnotetext{
${ }^{5}$ Note that the language that I spell Na'ahai is spelled in many sources as Naha'ai. I believe the latter was a typo that has been perpetuated through quotation. Nahavaq speakers refer to the language as [na?ahaj], [na?haj], or [nahaj].
} 
related to Ninde than Na'ahai, which scores only $42-47 \%$ cognates with Ninde. The full picture of the relationships will not be known until further work has been done on languages in the surrounding area.

Table 1: Lexicostatistical comparisons ${ }^{6}$
Nahavaq
\begin{tabular}{|c|c|c|}
\hline $82 \%$ & Nāti & Na'ahai \\
\hline $70-71 \%$ & $64 \%$ & Ninde
\end{tabular}

A case could be made for either or both of Nāti or Na'ahai being a dialect of Nahavaq. While Nāti and Nahavaq share a lot of close cognates (it is apparent from looking at Crowley's 1998b wordlist), there are some major differences: their pronoun paradigms are substantially different, Nāti has consonant mutation of verb stems (Crowley 1998b: 124-125) which Nahavaq lacks, and Nāti has a more complex vowel system with 7 vowels and length distinction where Nahavaq only has 5 vowels and no length distinction. It seems likely that Nāti and Nahavaq could be mutually intelligible with exposure as is the case for Nahavaq and Na'ahai described below. However, because Nāti is moribund, Nahavaq speakers do not generally have much exposure to it. In fact, Crowley (1998b: 105) claims that Nahavaq speakers do not understand Nāti when they hear it. And since there are no Nāti speakers who do not speak Nahavaq (Crowley 1998b: 103), the bilingual interaction which can be seen between Nahavaq and Na'ahai does not occur between Nāti and Nahavaq.

I have witnessed conversations between Nahavaq speakers and Na'ahai speakers where each speaks his or her own language and the other understands but responds in his or hers. Since the languages are closely related, this would appear to be mutual intelligibility. However, this kind of interaction depends on both parties having had enough exposure to the other's language. Nahavaq speakers from Luqmow (the southern-most Sinesip village) are able to understand Na'ahai speakers because as children they go to school with them. But children from more northern villages, who have not had much contact with Na'ahai speakers, cannot understand them. ${ }^{7}$ So while this is almost mutual intelligibility, it is not strictly so. Even with this degree of closeness, there is a good basis for considering them as two separate languages rather than as dialects of the same language. They are each associated with a separate nonoverlapping area, each language is associated with a distinct culture and a separate history. And finally, speakers of Nahavaq and $\mathrm{Na}$ 'ahai consider them separate languages.

\footnotetext{
${ }^{6}$ Numbers in this chart come from (Tryon 1976) and (Crowley 1998b: 105). Where two numbers are mentioned, it is because more than one word list was collected from some languages and these numbers represent the highest and lowest percentages of multiple list comparisons. It is likely that Crowley's numbers are higher than Tryon's would be for the same comparison because he was comparing an entire dictionary (rather than a single entry for each word) to Tryon's data and also presumably counting the Lembinwen and Mbenewur lists as a single language and counting a cognate wherever either of them provided one.

${ }^{7}$ Note that children from some of the northern Sinesip villages have had substantial contact with Ninde because they go to primary school in the Ninde-speaking village of Wintua. However, they do not acquire the receptive proficiency that southern children do with Na'ahai. This implies that two elements are needed: exposure and similarity of language.
} 


\subsection{Sociolinguistic overview}

Most Nahavaq speakers live inside the Sinesip area in one of the six villages. Up to 50 Nahavaq speakers live outside the community--either in major centres or working in other rural areas. And a similar number of non-native speakers live inside the Sinesip area.

\subsubsection{Language inventory}

For most children growing up in the Sinesip area, Nahavaq is the first language learned. Children begin to acquire Bislama, the national creole, around the time they start school and this usually corresponds to the time when they begin to be exposed to speakers of other languages. The language of education (above the kindergarten level, which now uses the vernacular language) is French or English. The school at Luqmow is a French language school, and the school at Wintua is an English language school. So generally speaking, most members of the Sinesip community use at least three languages. However, many also learn the local language of another area. It is common for women to marry outside their area and then learn the language of their husbands. And likewise, many women come into the Sinesip area speaking their own vernacular language and then learn Nahavaq as an additional language. Some people spend time with family from other language areas and acquire proficiency in those. It is not uncommon for a Nahavaq speaker to speak 5-6 languages (to various degrees of proficiency).

\subsubsection{Social structure}

Here I will give a very brief summary of Sinesip social structure. For a more detailed description with a traditional focus, see Deacon (1934).

Even though Sinesip people now live in villages with mixed nakamals, nakamals still play an important role in a person's identity. It is a larger family unit. Family relationships are very complex. Any Sinesip person is related to every other Sinesip person--as well as many people in surrounding area--with a kinship role. Some of the roles include predefined interpersonal relationships with taboos, rights to the other person's possessions, or an expectation to play practical jokes.

There are two kinds of chief now: custom chiefs who buy their status and pass through customary ceremonies, and paramount chiefs who are selected to represent each nakamal. Chiefs have limited social power but are important for resolving disputes.

Nuclear families live in households with an average size of 5-6 people. They generally have separate houses for cooking and sleeping, and sometimes also for eating or bathing. Children live with their parents until they are married, at which point daughters go to live with their husbands, and sons establish a new household, usually close to their parents' household.

Marriage is a complicated arrangement because of the complex kinship relationships. Men have always taken wives from outside their nakamal and often outside the Sinesip area, but these days it is also common for them to take wives from other islands. Wives are still bought, but the role of women is changing. Men and women tend to socialise separately. 
Christianity is a major organising force in daily life. It serves to socialise young people and organise community activity. There is also a good deal of conflict between denominations.

\subsubsection{Education}

Education is expensive for Ni-Vanuatu (the people of Vanuatu) due to school fees and the difficulty in acquiring money in a subsistence economy. Some children never go to school at all. In the past decades, no schooling was carried out in Nahavaq. Only recently have kindergartens begun teaching in the vernacular. Although the Vanuatu National Language Policy (see section 1.3.5) has a goal of vernacular instruction in the first two years of primary school, this is not practical at this point for Sinesip children because both schools in the area have pupils from different language backgrounds. Most commonly, pupils complete primary school (6 years) but do not move on to higher levels of education. Some people are educated at high school level or higher, and this generally involves spending those years outside the community.

\subsubsection{Occupation}

Almost everyone in the Sinesip area grows the bulk of their own food through subsistence horticulture. The staple crops include yams, taro, manioc, breadfruit, banana, and kumala. There is also a small cash economy and exports include cacao, kava, copra, and vanilla, while imports into the area include rice, sugar, flour, oil, fuel, matches, candles, fabric, clothes, soap, and luxury items. Other occupational activities besides horticulture include limited commercial fishing, education, health, religion, retail, and general wage-labour.

\subsubsection{The status of Nahavaq}

The most recent draft of the Vanuatu National Language Policy (Vanuatu National Language Council 2006) declares the official languages of Vanuatu to be Bislama, French, and English, with Bislama being the national language. However, the policy also has many goals of recognising, documenting, preserving, and promoting indigenous languages as well as integrating them into the education system and increasing vernacular literacy.

Nahavaq is currently used as the main language for personal interaction within the Sinesip area, but it is not used much in public domains. While literacy in general is low, it has been almost non-existent in the Nahavaq language. ${ }^{8}$

\subsubsection{Endangerment}

The number of Nahavaq speakers is currently on the rise, due largely to a high birthrate. But its future is far from secure. UNESCO (2003) has produced a helpful set of criteria by which to judge a language's vitality. The following sections give my scores ( 5 being safest) for Nahavaq for each of UNESCO's nine factors to consider in language vitality and a brief discussion of each:

\footnotetext{
${ }^{8}$ As part of this research project, I have made serious efforts at promoting Nahavaq literacy (with spelling reform, literacy materials, and training sessions). But only time will tell if these efforts have any effect on the overall trend.
} 


\subsubsection{Intergenerational Language Transmission: 5 (stable yet threatened)}

"The language is spoken in most contexts by all generations with unbroken intergenerational transmission, yet multilingualism in the native language and one or more dominant language(s) has usurped certain important communication contexts" (UNESCO 2003: 8). In most households, Nahavaq is the language most often used. A minority of households use Bislama as the main language, but even children growing up in those households learn Nahavaq from their peers. Even so, songs and skits learnt by children are rarely in Nahavaq these days, and Bislama is being acquired at a younger age than in the past. Today, most five-year-olds can understand almost any Bislama and carry on a simple conversation in it.

\subsubsection{Absolute Number of Speakers: approximately 700}

Dixon (1991: 231) classifies all languages with fewer than 1000 speakers as "severely at risk" of dying within the next century. He predicts that by 2100 at most a dozen or two of Vanuatu's (approximately) 105 languages will be spoken, the rest being replaced by Bislama (Dixon 1991: 250), and he mentions the move from subsistence to a cash economy as a serious threat to small local languages. If Dixon is correct, Nahavaq as a slightly-smaller-than-average Vanuatu language is unlikely to survive this century. However, Crowley (1995) suggests that Vanuatu's languages are a bit more secure than languages in some other parts of the world because of factors such as culture, economics, and bilingualism. Yet he also warns that "Linguistic ecologies are delicate things that can be easily disturbed...Urbanisation, immigration, emigration, and education can all interact within the space of a single generation to cut the lines of linguistic transmission" (1995: 341). Both Dixon (1991: 234) and Crowley (1995: 341) stress the importance of giving attention to languages with a small number of speakers before they get to the point of serious endangerment when it is often too late.

\subsubsection{Proportion of Speakers within the Total Population: 4 (Unsafe)}

"Nearly all speak the language"(UNESCO 2003: 9). There are three groups of people that may live in the Sinesip area without speaking Nahavaq. The first is church officials, religious leaders, medical workers, etc. who usually come from other parts of Vanuatu to do a specific job in the area. These people do not often stay for longer than a couple of years. The second group is people who belong to the area but have grown up outside the language community. These are the children of people who have found work in main centres or work as teachers, religious leaders, or medical workers in other areas. The third group is people from other areas who come to join Sinesip families. Most often these are women who marry Sinesip men. But they can also be relatives from other surrounding areas who come to live with their families in the Sinesip area for extended periods of time. The total percent of people who join the community as non-speakers of Nahavaq is estimated at 15-20\%. Most of these people learn Nahavaq and become proficient within a couple of years. ${ }^{9}$ However others develop some receptive knowledge of Nahavaq but never learn to speak it.

\footnotetext{
${ }^{9}$ Nahavaq is known in the area as being an easy language to learn. This is good for the language's vitality because it means that almost everyone in the community uses Nahavaq and the number of speakers in continually increasing. However, the large number of non-native Nahavaq speakers may be contributing to rapid language change (see Section 1.3.7).
} 


\subsubsection{Shifts in Domains of Language Use: 4 (Multilingual parity)}

"Two or more languages may be used in most social domains and for most functions; the ancestral language usually is rare in the public domain" (UNESCO 2003: 10). Most public or official speech is conducted in Bislama. This includes most religious interactions (including prayers), politics, festive events, and education beyond kindergarten. To some extent this is because there could be participants who don't speak Nahavaq. Sometimes a teacher, church leader, or politician comes from outside the community. However more often than not, all participants know Nahavaq, and young children and some older women do not know Bislama well. It would seem that using Bislama in these contexts has become a self-perpetuating habit. Many speakers feel incapable of public speaking in Nahavaq probably because they are not exposed to Nahavaq speech-making. But they feel comfortable speaking publicly in Bislama, so people continue to hear and produce Bislama in these contexts. There is, however, one public context in which Nahavaq is used-the local court.

\subsubsection{Response to New Domains and Media: 0 (Inactive)}

"The language is not used in any new domain." (UNESCO 2003: 11). The Sinesip community has not had the opportunity to create much new media such as television, film, radio, newspaper, internet, or any other such new domains. Such media are produced outside the community in Bislama, French, or English. The one recorded medium that is produced by the community is notices on notice boards, which are written in Bislama. Most domains introduced in the last 120 years (Christian ceremony, Western education, economics, etc.) are dominated by Bislama. The exceptions are locally-produced modern music (approximately 75\% Bislama, 25\% Nahavaq), kindergarten (which switched from Bislama to Nahavaq in the last 5 years), and telephone conversations which would depend on participants and topic, but may be in Bislama or Nahavaq or mixed.

\subsubsection{Materials for Language Education and Literacy: 1}

"A practical orthography is known to the community and some material is being written" (UNESCO 2003: 12). Prior to this project, Nahavaq had a score of 0 , with an orthography in existence but less than $5 \%$ of the adult community literate in it. With the revised orthography (Section 2.9) and my efforts at promoting it, the Nahavaq literacy rate has risen to an estimated $15 \%$, and a book of stories as well as translations of the Book of Matthew have been produced in Nahavaq. The degree to which further materials will be produced by the community is unknown.

\subsubsection{Governmental \& Institutional Language Attitudes and Policies including Official Status \& Use: 4 (Differentiated support)}

"Non-dominant languages are protected primarily as the language of the private domain. The use of the non-dominant language is prestigious" (UNESCO 2003: 1314). The Vanuatu National Language Policy (Vanuatu National Language Council 2006) aims to protect and promote vernacular languages, but mainly in the private domain: "to encourage the use of indigenous languages at home", "The use of indigenous languages should be encouraged at all times in indigenous community activities". However, there is also a goal of using vernacular languages as the language of instruction in early primary education. While these policies may be good for the vitality of Vanuatu's vernacular languages, at this point they are only policy without practice in the Sinesip community. 


\subsubsection{Community Members' Attitudes toward Their Own Language: 4}

"Most members support language maintenance" (UNESCO 2003: 14-15). Most people are in favour of language maintenance, but a few see Bislama or English as more beneficial and therefore see the promotion of Bislama or English as a priority over the maintenance of Nahavaq.

\subsubsection{Amount and Quality of Documentation: 3 (Fair)}

Prior to this project, Nahavaq had a score of 1 (inadequate), with only word lists, a sketch grammar, fragmentary texts, and no audio or video recordings (see section 1.4 for details of previous documentation). But after this project, the score has moved to 3 (fair): "There may be an adequate grammar, some dictionaries, and texts, but no everyday media; audio and video recordings may exist in varying quality or degree of annotation." (UNESCO 2003: 16).

\subsubsection{Variation within Nahavaq}

There is a small amount of linguistic variation within the Nahavaq-speaking community. Almost all of it relates to age and language change (see Section 2.7 for example). There also appears to be variation loosely based on how long an individual has spent outside the Sinesip area. This includes non-native speakers who arrive in the area later in life (with obvious results such as non-native phonology and simplified vocabulary). But also a number of speakers attend high school outside the area and may continue to work outside the area for a number of years before returning and starting a family. Such speakers are often characterised as having a large number of Bislama borrowings in their Nahavaq, and in some cases, phonological contrasts that were made by the speakers before they left the community may be lost. This latter group tends to be the better educated and wealthier members of the community, and therefore it is possible that some of the language change currently taking place in Nahavaq is being driven by the prestige associated with having lived outside the community.

There is some other variation (mainly the phonological identity of certain words, i.e. $/ \mathrm{nu}^{\mathrm{n}} \mathrm{gut} / \sim / \mathrm{ni}^{\mathrm{n}} \mathrm{gut} /$ 'banana') that I could not link to any social factors.

Nahavaq does not appear to have any geographically based variation. I have heard reports that the speech of Lembinwen is 'lighter' (i.e. more innovative) than the more conservative speech of Witavaq or Luqmow. However in practice I have not found that to be strictly the case. Age and time-spent-outside-community better explain such variation. The lack of geographical variation may be the result of the major shift from small isolated inland villages to large coastal villages of mixed nakamals, which with the help of depopulation, could have quickly eliminated existing variation through dialect levelling. But there are two things that make me suspect that there had previously been different dialects within the Nahavaq language. The first is the word list published in Ray (1893) that is discussed in Section 1.4. The second is that I have heard some reports of some speakers of one nakamal, Luhaq, speaking differently (imitators used raised and fronted vowels). But those speakers speak standard Nahavaq most of the time and insist that the other variety is a kind of play and do not want to demonstrate. So it remains unknown whether it is in fact a kind of 
play (it is laughed at by observers) or the remnants of a variety that has been stigmatised out of everyday use.

There is a lot of age-based change which seems to suggest change in progress. Phonological variation includes the loss of what was probably a phoneme, $/{ }^{n} \mathrm{~d}$ r/ (Section 2.1.2), the loss of distinction between bilabial and labiovelar consonants (Section 2.1.3.4), and the change of prenasalised stops word-finally into nasal consonants. Morphologically, the realis mood is no longer marked by younger speakers on verbs with non-singular subjects (though this may have a phonological motivation, see Section 2.7.3), there is variation in how initial consonants are reduplicated (Section 2.4.6.1), and reduced use of third order verbal prefixes (Section 4.4). Younger speakers also appear to have even more rigid accretion of $n \mathrm{~V}$ - nominal prefixes (Section 3.3.2). Syntactically, younger speakers may use more clause-initial modifiers which may have been borrowed from Bislama (Section 5.3.3). There also appears to be age-based variation in the ordering of malas 'yet' with relation to the second negative element (Section 4.7.4.4) and younger speakers are also reported to drop the first verbal negative markers more often (Section 4.3). But the difference most salient to the community is the use of lexical items borrowed from Bislama in the speech of younger speakers. The age-based variation is so extreme that sometimes younger people don't understand what an older person tells them, particularly if the older speaker uses a word such as mbulqun 'kava' that has a borrowed alternative, kava 'kava'.

\subsection{Previous work on Nahavaq}

While there are a small number of resources on the Sinesip language, none of them goes into much depth, and many of them were written before current methods of linguistic description. The earliest record of the language is a list of 48 words from the diary of Commodore Goodenough (1876: 360-361). The next is a short word list and seven sentences which were collected from a speaker of the "Lamangkau dialect, South West Bay, Malekula" (Ray 1893: 396-397). Ray identifies this as the same language as that in Goodenough (1876), and Lamagcaw is a place within the Sinesip area. However, there are many more substantial lexical differences between Ray's (1893) Lamagcaw dialect and modern Nahavaq than there are between Goodenough's list and modern Nahavaq. And many of those differences align it with one of the neighbouring languages based on Charpentier's (1982) atlas, but not consistently. So it seems plausible that Ray's Lamagcaw list is from an extinct dialect of Nahavaq or an extinct dialect of a related language such as Nāti or Na'ahai. The next published source on Nahavaq is a collection of bible extracts in Nahavaq (Boyd 1905). ${ }^{10}$ This was put together by the missionary Revered Robert Boyd, who arrived in the area in 1895. Unfortunately, even after its orthography is excused, there are many ungrammatical phrases, and I was told that Boyd made the translation with the help of a non-native speaker of Nahavaq in the Mewun area. Then based on these poor examples of Nahavaq, Ray (1926: 302-311) produced a 9-page grammatical sketch of Nahavaq. Naturally there are inaccuracies arising from the text on which the sketch was based. The next source published on Nahavaq is a collection of notes collected by the anthropologist, Bernard Deacon, and published after his death (Deacon 1934).

\footnotetext{
${ }^{10}$ I was also shown a Nahavaq primer published with an unknown date and a book of hymns in Nahavaq, Na'ahai, and Ninde which was produced some time around the 1950s. The publishers and dates of these publications are unknown.
} 
Because Deacon spent more time in the Sinesip area than any of the other areas he was investigating, there is a substantial amount of Nahavaq cultural vocabulary in the published notes as well as 11 texts with English translations. Gowers's (1976) botanical work contains a few Nahavaq words for tree species. Tryon's (1976) collection of word lists for the purpose of lexicostatistical analysis of the languages of the New Hebrides includes two lists of Nahavaq words taken from the villages of Lembinwen and Mbenewur. Each list contains around 300 words, and Tryon's analysis identified the two lists as constituting one language. Charpentier (1982) contains entries for 1721 elicited Nahavaq words as part of a survey of Southern Malakula languages. With the exception of Boyd and Deacon's work, these sources were produced by people who spent little if any time in the Nahavaq-speaking community.

\subsection{The current study}

The aim of this study is to fulfil a need for documentation and description of the Nahavaq language. This includes compiling a corpus of texts and a dictionary and writing a descriptive grammar (this thesis) and depositing all materials in archives.

There are some related outcomes specifically to benefit the Sinesip community: spelling reform, literacy materials, and literacy training.

The scope of this study is limited by the time period of three years. There are no doubt aspects of Nahavaq that I have not even noticed. There are several areas within this grammar where I was unable to come to a conclusion. And no doubt there are some mistakes due to my misinterpretation of data. But I have tried to be as thorough and accurate as possible.

\subsubsection{Methodology}

I collected data through field trips to the Sinesip area. I made three trips of three months each in the period 2006-2008. I spent most of the time in Lembinwen village but made a point of spending at least a week in the southern villages in each trip. I visited other villages in day trips. On arrival I was immediately adopted into a family and I had the privilege of participating in the daily life of the Sinesip people. In daily life and in linguistic elicitation session, I primarily used Bislama to interact with people, although in the final few months I used Nahavaq for simple interactions.

Both text analysis and elicitation were crucial to my work. Texts provide a picture of authentic language use which allows me to trust what has been said in elicitation and also exposes me to structures that never came up purely through elicitation. However, without elicitation, one cannot know how productive structures are and there would be a lot of gaps in the data simply due to low frequency and a limited corpus. While texts can provide many examples of grammatical constructions, ungrammatical constructions can only generally only be identified through elicitation, and sometimes one ungrammatical phrase is more telling than 100 grammatical phrases. In reality, I find it difficult to fully separate text analysis and grammatical elicitation. Most elicitation is inspired by the data in texts. And in transcribing or translating a text, I am often compelled to elicit further material to better understand the text I am dealing with. 


\subsubsection{Text analysis}

My primary method of text collection was to record speech and then transcribe and translate it with the help of native speakers. This included audio and video recordings. In the first field trip, I used a Sony Hi-MD Walkman MZ-NHF800 with Sony ECM-MS907 directional stereo microphone. Texts were recorded uncompressed at $44.1 \mathrm{~Hz}, 16$ bit and digitally transferred to computer. For the second and third field trips, after a Field Trip Grant from the Endangered Languages Documentation Programme, I was able to use a Fostex FR2-LE solid state field recorder (at a minimum of $44.1 \mathrm{~Hz}, 16 \mathrm{bit} / \mathrm{s}$ but often higher with texts and phonological elicitation) and a variety of microphones: a Voice Technologies VT700 head-mounted microphone, and Sennheiser me62 and me64 microphones. On the 2007 trip, I also collected video with the help of Giles McNeill and his Sony PD150P video camera.

Speakers produced texts on a voluntary basis. Everyone officially gave informed consent before being recorded.

I tried to gather as wide a range of texts as possible, i.e. a range of speakers and a range of texts types. And I tried to record in as natural a setting as possible. But to a large extent, text types were dictated by the speaker, and as a result, most of the texts are monologues, either descriptive or narrative.

\subsubsection{Elicitations}

While most of my elicitation was inspired by the structures I found through text analysis, early on I used a lot of tools to get me started. This includes already published materials that I could check, i.e. Tryon's (1976) wordlist, Charpentier's (1982) wordlist, some of Deacon's (1934) texts and some of his vocabulary. To help me in vocabulary elicitation, I used the wordlist from the Austronesian Basic Vocabulary Database (Greenhill et al. 2008), 'Indo-Pacific Coral Reef Field Guide' (Allen and Steene 1998), 'Birds of Vanuatu' (Bregulla 1991) to help me with vocabulary elicitation, and 'A New Bislama Dictionary' (Crowley 2003)(for some plant and animal names). To guide me in grammatical elicitation, I used Dahl's (1985: 198-205) TMA (Tense-Mood-Aspect) Questionnaire, the Anaphora Typology Questionnaire (Dimitriadis and Everaert 2002), and examples from the Lexical Valence Typology project (Nichols 2007). Descriptions of other Vanuatu languages also provided ideas of features to investigate in my elicitation session. I worked with a total of 41 speakers in elicitation sessions. In the first field trip, I made audio recordings of all elicitation sessions, including transcription and translation sessions. ${ }^{11}$ This was helpful especially early in my research because I could return to it when my knowledge had increased and check whether I had interpreted things correctly. However, in the second and third trips I did not record all elicitation sessions. I recorded those particularly focused on phonetics or phonology because an audio recording is a much more accurate record than my transcription. But for many morphological or syntactical elicitations in the second and third trips, I only wrote in a notebook without recording. ${ }^{12}$

\footnotetext{
${ }^{11}$ During the first field trip, elicitations that were not related to phonetics or phonology were usually recorded with digital compression on the Sony MZ-NHF800.

${ }^{12}$ I stopped recording all elicitation sessions because I found that I was accumulating hundreds of hours of recordings and not using them again. However, this is a decision that I now regret because there was
} 


\subsubsection{Archiving}

Archiving of materials is an important part of this project because one of the main aims is to document the Nahavaq language so that the materials will be available to future researchers and the language community. I am depositing materials with three archives, the Vanuatu Kaljoral Senta national photo, film \& sound archive; Pacific and Regional Archive for Digital Sources in Endangered Cultures (PARADISEC); and Hans Rausing Endangered Languages Project's Endangered Languages Archive (ELAR). Permission for archiving was obtained for all materials . In each archive, I am depositing audio and video recordings, scanned images of notebooks, relevant photos, and my produced materials: dictionary, grammar, transcribed texts, and community materials.

\subsubsection{Analysis and description}

In my analysis and description of Nahavaq, I try to avoid overly-formal theoretical frameworks. I follow the general practice for an "extended sketch grammar", which is to mainly describe surface structure and only go into more theoretical analysis where it is well-accepted by the linguistic community (phonemes and morphological paradigms) or where it makes the surface facts clearer (for example the idea of movement of constituents in Sections 6.1 and 6.3).

Terminology is a major challenge for the description of any language. On the one hand, it is good to use terminology that has been used to describe other languages so that they are comparable. But on the other hand, the phenomena that the terms describe in other languages may not align well with the phenomena in the language under discussion and using such terms could be inaccurate and give false impressions. I attempt to balance describing Nahavaq in its own terms with fitting in to discussion of other languages, particularly other Vanuatu languages.

Table 2 lists the main specialty software tools that I have used in my analysis and description of Nahavaq.

Table 2: Software tools

\begin{tabular}{ll}
\hline Software title & Purpose \\
\hline Sony SonicStage (v4.0) & $\begin{array}{l}\text { digitally transfer minidisc recordings to } \\
\text { computer }\end{array}$ \\
\hline $\begin{array}{l}\text { CoolEdit Pro (v1.2a), } \\
\text { Audacity (v1.2.6) }\end{array}$ & manipulate audio files \\
\hline Transcriber (v1.5.1) & $\begin{array}{l}\text { transcribe audio files (match text to time } \\
\text { codes) }\end{array}$ \\
\hline ELAN (v3.0) & $\begin{array}{l}\text { transfer Transcriber files to Toolbox and } \\
\text { annotate some video }\end{array}$ \\
\hline $\begin{array}{l}\text { Field Linguist's Toolbox } \\
\text { (v1.5.0) }\end{array}$ & $\begin{array}{l}\text { building dictionary, interlinearising text, } \\
\text { searching corpus }\end{array}$ \\
\hline Praat (v4.4.34) & acoustic phonetic analysis \\
\hline JplotFormants (v1.4) & plotting vowel formants \\
\hline
\end{tabular}

some information that I did not write in my notes because it did not seem important at the time, which I later wanted. 


\subsubsection{Corpus}

The corpus contains a total of 245 texts (Table 3). This includes 14.9 hours of audio texts (roughly $90 \%$ transcribed), including songs, narratives, conversations, instructions, a sermon, sports commentary, a kindergarten lesson, and informative monologues collected from 62 speakers ranging in age from four to late $80 \mathrm{~s}$.

Appendix 5 lists basic metadata of the audio texts. There are also some written texts without audio recordings, including translations of the four Gospels, ${ }^{13}$ nine Nahavaq texts included in Deacon (1934), and stories and hymns that were either written down by Nahavaq speakers or dictated to me by speakers. The total written corpus (including transcriptions of audio texts) totals 194,450 running words (Table 4). Metadata, transcripts, and media files associated with texts are included in the attached DVD-ROM.

Table 3: Texts in corpus

\begin{tabular}{lll}
\hline & Number of texts & Hours \\
\hline written texts & 36 & - \\
audio only texts & 74 & 7.3 hours \\
audio/video texts & 135 & 7.6 hours \\
\hline total: & 245 & 14.9 hours \\
\hline
\end{tabular}

Table 4: Corpus size

\begin{tabular}{ll}
\hline Text category & Running words \\
\hline Gospel translations & 105,936 \\
Deacon's (1934) Nahavaq texts & 1,663 \\
Written stories & 2,270 \\
Written song lyrics & 685 \\
Transcribed audio texts & 83,896 \\
\hline total: & 194,450 \\
\hline
\end{tabular}

\subsection{Brief typological overview}

Below are listed some very basic typological features of Nahavaq:

- $(\mathrm{C}) \mathrm{V}(\mathrm{C})$ syllable structure

-5 vowels, no vowel length

- no phonemic stress

- Major consonant series: nasals, voiceless plosives, prenasalised plosives, and fricatives. Major place of articulation: 'bilabial' (palatalised bilabial), 'labiovelar' (velarised bilabial), alveolar, velar, and glottal (Table 6 on page 17).

- SVO word order

- modifiers mainly follow the head

- two categories of nouns (directly possessed/indirectly possessed)

- pronouns distinguish inclusive and exclusive categories, and singular/dual/plural numbers.

— obligatory prefixes on verbs mark subject and mood

— objects marked through word order only

\footnotetext{
${ }^{13}$ The entire New Testament was translated by Massing Nambuas into Nahavaq in hand-written notebooks before his death in 2000. While all of these have been digitised, I have only looked closely at the Gospels because of time constraints, so it is only those that are included in my corpus for language description.
} 
— productive reduplication of verb roots

— serial verb-like constructions

\subsection{Organisation of the thesis}

The body of this thesis is organised into 5 chapters: Phonology, Noun Phrase, Verb Phrase, Clause structure, and Discourse. There is no specific section on morphology as it is discussed throughout all the chapters. Word classes are discussed in the chapters to which they are most relevant. The major classes are nouns (discussed in Section 3.1), verbs (discussed in Section 4.1), and prepositions (discussed in Section 5.3.2.3). Examples, tables, and figures are numbered consecutively throughout the thesis.

In addition to the appendices included in this thesis, there is some further material for the purpose of reference included on a DVD-ROM. This includes:

1. Sound files of all texts (in $22 \mathrm{kHz}, 16$-bit mono .wav files - higher quality sound files are available through archives)

2. Transcripts of texts (roughly $75 \%$ with translation, $25 \%$ interlinearised)

3. Draft Nahavaq dictionary in .pdf format

\subsubsection{Presentation of examples}

This grammar of Nahavaq is based on a corpus of texts as well as elicitations. Where possible and practical, I try to give illustrative examples from the spoken corpus, but I also use elicited examples where the corpus lacks a feature or where the elicited examples are particularly revealing. I try to avoid analysis based solely on translated texts, but I include examples from translated text to strengthen claims and when necessary to illustrate claims where it is not possible with the spontaneously produced texts. I have edited out disfluencies from examples except where they are relevant. References to examples throughout this thesis are given in the following formats in Table 5. Note that for video examples, reference is made to a related sound file. Some notes also have an associated sound file which is marked at the top of the page of the notes. Scanned copies of notes as well as all media materials are accessible through archives (Section 1.5.1.3), and sound files, transcripts, and metadata for texts are included in the DVD-ROM accompanying this thesis. Basic metadata of audio texts is also included in Appendix 5.

Table 5: Format for example references

\begin{tabular}{ll}
\hline Type of reference & Format \\
\hline Sound recording: & {$[$ text.line file.wav start end $]$} \\
& {$[07074.007$ 07074.wav 28.625 32.328] }
\end{tabular}

Notes: [yearNBnumber.page]

[07NB1.022]

Supplementary notes (loose pages): [s|year|number.page] [s0802.15]

Bible translations: [book.chapter:verse] [LUK.09:38] 


\section{Chapter 2: Phonology}

This chapter begins with an outline of consonant and vowel phonemes and their phonetic realisations (Sections 2.1-2.2). Of particular interest is the distinction between bilabial and labiovelar consonants (Section 2.1.3). Section 2.3 outlines phonotactic and syllable structure, which is primarily $(\mathrm{C}) \mathrm{V}(\mathrm{C})$. Section 2.4 deals with morphophonemic topics. Sections 2.5 discusses stress and tentatively argues against fixed word-level prominence. Section 2.6 is a brief look at intonation. Some patterns of phonological variation, many of which are recognisable as changes in progress, are discussed in Section 2.7. The concept of the phonological word in Nahavaq is discussed in Section 2.8, and 2.9 outlines the orthography used in the rest of the thesis.

I use broad phonetic transcriptions, only showing details that are necessary for the discussion. So while the realisation of $/ \mathrm{u} /$ is very fronted in some predictable contexts, I only represent it as [y] in discussion of vowel allophones and not in sections discussing other phenomena.

\subsection{Consonants}

Nahavaq has 21 consonants (Table 6) and possibly another, $/{ }^{n} \mathrm{dr} /$, which is nearly extinct (See section 2.1.2). There are five major places or articulation: bilabial, labiovelar, alveolar, velar, and glottal. And there are four major manners of articulation: voiceless stop, prenasalised stop, nasal, and fricative. There is a notable lack of a velar fricative which exists in many Malakula languages such as Port Sandwich (Crowley 2002a: 650), Naman (Crowley 2006b: 24), Tape (Crowley 2006d: 100), Nese (Crowley 2006c: 38), Neve'ei (Musgrave 2007: 6), V'ënen Taut (Fox 1979), Unua (Pearce n.d.: 1), and Neverver (Barbour, p.c.). However velar fricatives are also lacking in some other Malakula languages, including closely-related Nāti (Crowley 1998b: 106). Minimal pairs of all articulatorily similar consonants are given in Appendix 1. The relationship between bilabial and labiovelar consonants is discussed in depth in Section 2.1.3. Throughout this chapter, the term labial will be used to refer to bilabial and labiovelar consonants together. The terms labial, bilabial, and labiovelar do not include /w/, which is discussed separately in Section 2.3.2.

Table 6: Consonants

Voiceless stop
Prenasalised stop
Nasal
Fricative
Lateral
Trill/flap
Glide
Bilabial Labiovelar Alveolar Velar Glottal

\begin{tabular}{|c|c|c|c|c|}
\hline $\mathrm{p}^{\mathrm{j}}$ & $\mathrm{p}^{\mathrm{w}}$ & $\mathrm{t}$ & $\mathrm{k}$ & $?$ \\
\hline${ }^{\mathrm{m}} \mathrm{b}^{\mathrm{j}}$ & ${ }^{\mathrm{m}} \mathrm{b}^{\mathrm{w}}$ & ${ }^{\mathrm{n}} \mathrm{d}$ & ${ }^{\mathrm{j}} \mathrm{g}$ & \\
\hline $\mathrm{m}^{\mathrm{j}}$ & $\mathrm{m}^{\mathrm{w}}$ & $\mathrm{n}$ & $\mathrm{y}$ & \\
\hline$\beta^{\mathrm{j}}$ & $\beta^{\mathrm{w}}$ & $\mathrm{s}$ & & $\mathrm{h}$ \\
\hline & & $\mathrm{l}$ & & \\
\hline & \multicolumn{5}{|c|}{$\mathrm{r}$} & & \\
\hline & $\mathrm{j}$ &
\end{tabular}

The justification for treating prenasalised stops as single segments is that they can occur word-initially as in / ${ }^{\mathrm{n}} \mathrm{ginh}$-n/ 'nose-3SG' or word-finally /na- $\mathrm{Pa}^{\mathrm{m}} \mathrm{b}^{\mathrm{j} /}$ ' $\mathrm{NV}$-banyan tree', and Nahavaq's basic syllable structure, $(\mathrm{C}) \mathrm{V}(\mathrm{C})$, does not allow for consonant 
clusters in these positions (Section 2.3). I have chosen to use a superscripted nasal segment in the phonological representation of prenasalised stops because consonants from the 'voiceless stop' series can be voiced (Section 2.1.1.3), meaning that it is the prenasalisation that differentiates the two sets. In phonetic representations of prenasalised stops, the nasal segment will be superscripted. This is partly due to the fact that in prenasalised labial stops, the palatalisation or velarisation quality is present in the nasal phase as well as the stop phase (Section 2.1.3.1) so without superscripting the nasal character, $/ \mathrm{m}^{\mathrm{w}}$ / to be represented phonetically with the unwieldy sequence $\left[\mathrm{m}^{\mathrm{w}} \mathrm{b}^{\mathrm{w}}\right]$. Instead, I have chosen to represent such a realisation as $\left[{ }^{\mathrm{m}} \mathrm{b}^{\mathrm{w}}\right]$.

Superscripting the nasal character is also supported by Riehl's (2008) finding that prenasalised stops are phonetically different from nasal-plosive sequences in terms of timing.

\subsubsection{Major allophones}

This section outlines some notable allophones of Nahavaq's consonant phonemes, but it is not exhaustive.

\subsubsection{Glottal stop}

Looking at spectrograms of Nahavaq glottal stops, it is clear that medial glottal stops are only very rarely produced with full sustained closure of the vocal folds. Figure 5 shows an example of a complete realisation of a glottal stop.

Figure 5: Full glottal stop ${ }^{14}$

Image produced using Praat. /no-Pon/ [no?on] 'nV-basket' [07089.162 07089.wav 750.762 755.684].

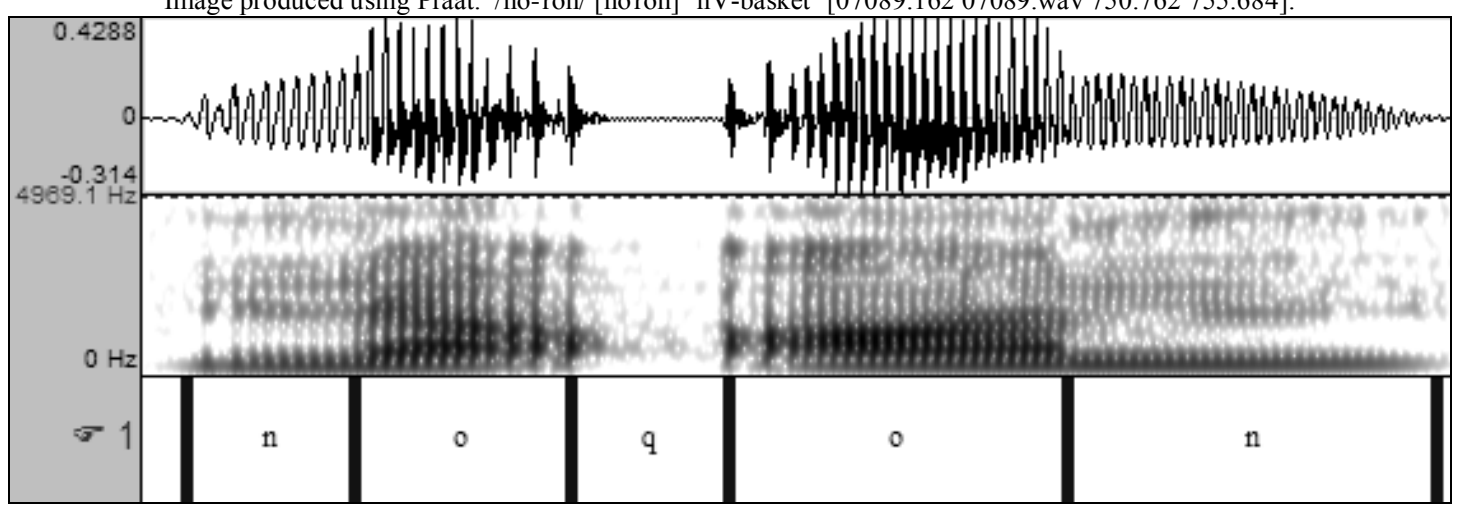

More often, intervocalic glottal stops are realised with disruption to the vibration of the vocal folds in the form of creaky voice. An intervocalic glottal stop may have a clear period of creaky voice between modally voiced vowels as in /na-?an/ [naaan] '1SG.R-eat' [08016.wav] (Figure 6). Or it may affect the entire preceding vowel as in /kese?er/ [keseer] '3SG.IRR-lost' [JS02.007 JS02.wav 21.987 26.003]. This is consistent with Ladefoged and Maddieson's (1996: 75) claim that cross-linguistically a period of creaky voice or stiff phonation is a more common realisation of a glottal stop than full glottal closure, especially intervocalically.

\footnotetext{
${ }^{14}$ The time-code references given in specrogram and pitch diagram figures is to the utterance from which they come, rather than the timeframe that is displayed.
} 
Figure 6: Glottal stop as creak

Image produced using Praat. /na-?an/ [naaan] '1SG.R-eat' [08016.wav].

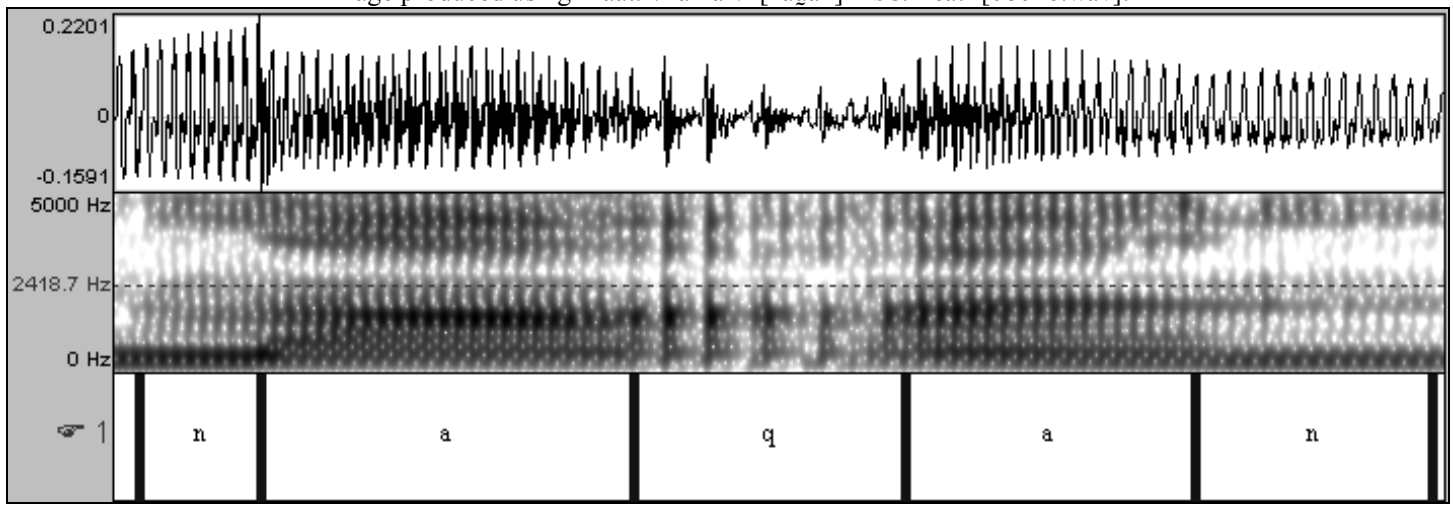

If a glottal stop occurs as the first element in a consonant cluster, it is often realised as creaky voice on the preceding vowel: /to?ta?/ [tota ?] '(personal name)' [07098.085 07098.wav 436.611 440.470], /i-to?sar/ [itosar] ‘3SG.R-remain' [JS02.003 JS02.wav 7.694 12.085], /ta? nin/ [tanin] 'thing DEM' [07089.028 07089.wav 165.732 173.717].

If it occurs as the second element of a consonant cluster, there can be a period of creaky voice on the following vowel as in $/ \mathrm{ni}^{\mathrm{n}} \mathrm{ge}-\mathrm{s}-\mathrm{Pan} /$ [ni $^{\mathrm{p}} \mathrm{gesaan}$ ] '1SG.R-NEG-eat' [07072.067 07072.wav 370.854 376.088]. Or there can be creaky voice on preceding segments if they are sonorant as in /ka-m ${ }^{\mathrm{j} a l} \mathrm{aah} /$ [kam ${ }_{\sim}^{\mathrm{j}}$ alah] '3SG.IRR-cold' [07113.028 07113.wav 229.156 231.984]. Creaky voice may occur on both segments preceding and following the glottal

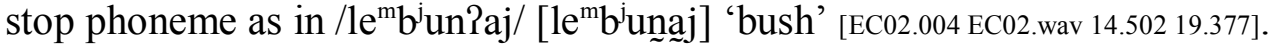

Only in initial and final position (adjacent to silence) are glottal stops regularly realised with a complete glottal closure, for example /i-to?/ [ito?] [08009.009 08009.wav 50.719 56.016], /Rej/ [?ej] '3SG' [EC02.118 EC02.wav 491.753 493.878]. However creaky voice is also possible in these positions, especially finally as in $/ \mathrm{ni}^{-}{ }^{\mathrm{m}} \mathrm{b}^{\mathrm{j}} \mathrm{ulu}-\mathrm{P} /\left[\mathrm{ni}^{\mathrm{m}} \mathrm{b}^{\mathrm{j}} \mathrm{ulu}\right]^{\text {' }} \mathrm{NI}-\mathrm{leg}-1 \mathrm{SG}$ ' [EC02.061 EC02.wav 243.923 245.266]. Non-phonemic glottal stops also occur initially before vowels (Section 2.4.1) as in /am ${ }^{\mathrm{w}} \mathrm{O}$ ?/ 'mother' [?am ${ }^{\mathrm{w}} \mathrm{O}$ ] [07074.048 07074.wav 212.411 217.319]. ${ }^{15}$

\subsubsection{Fricatives}

The labial fricatives $\left(/ \beta^{\mathrm{j}} /\right.$ and $\left./ \beta^{\mathrm{w}} /\right)$ are voiced in onset position. In coda position, labial fricatives do not contrast with the corresponding voiceless labial stops $\left(/ \mathrm{p}^{\mathrm{j} /}\right.$ and $/ \mathrm{p}^{\mathrm{w}} /$ ) (see Section 2.3.1) and a voiceless labial fricative $\left(\left[\phi^{\mathrm{j}}\right]\right.$ or $\left.\left[\phi^{\mathrm{w}}\right]\right)$ may be produced by some speakers. $/ \mathrm{s} /$ and $/ \mathrm{h} /$ are generally voiceless, but voiced realisations of $/ \mathrm{h} /$ are possible: /ke-mijeh/ [kemef] '3SG.IRR-cooked' [07112.016 07112.wav 58.936 63.859].

\footnotetext{
${ }^{15}$ It is very difficult to determine whether an initial glottal stop is phonemic or non-phonemic. If a word begins in a vowel, the final consonant of a preceding word may receive extra prominence as though the consonant were resyllabified as the onset of the vowel-initial word (Section 2.4.1) while glottal-stop initial consonants do not allow this. Where resyllabification happens, I know that a word begins with a vowel. But where resyllabification does not happen, I cannot be sure whether or not the word begins with a vowel because resyllabification is not obligatory. I have tested a number of words with possessive $t i$ - prefixes or relative clause marker with the same form. Both morphemes are realised as $t$ - before vowels (i.e. /t-a ${ }^{\mathrm{m}} \mathrm{b}^{\mathrm{w}}$ at/ 'POSS-foreigner') but as $t i$ - before glottal stops (i.e. /ti-?ar/ 'POSS3PL'). However, some lexical items could not be prefixed with either of these morphemes and remain ambiguous, and other words showed different patterns for different speakers, indicating that the distinction is not stable.
} 
Most often, $/ \mathrm{h} /$ is pronounced as a voiceless glottal fricative. But in coda position, it can be realised as friction at other points in the vocal tract. Following /i/, it can have a palatal fricative realisation: /ne- $\beta^{\mathrm{j} i \mathrm{ih}} /$ [ne $\left.\beta^{\mathrm{j}} \mathrm{iç}\right]{ }^{\mathrm{C}} \mathrm{NV}$-corn' [тв03.014 тв03.wav 70.194 77.585]. Following /u/, there can be labial friction (/ne-wuh/ [newuф] 'NV-rain' $[07098.102$ 07098.wav 528.465 530.965]) or friction in the back of the mouth anywhere from the velum (/ni- ${ }^{\mathrm{m}} \mathrm{b}^{\mathrm{w}} \mathrm{uh}^{\mathrm{m}} \mathrm{b}^{\mathrm{w}} \mathrm{uh} /$ [nim $^{\mathrm{m}} \mathrm{b}^{\mathrm{w}} \mathrm{ux}^{\mathrm{m}} \mathrm{b}^{\mathrm{w}} \mathrm{ux}$ ] 'NI-kind of fish' [07131.018 07131.wav 68.696 71.571]) to the pharynx (/ura?uh/ [ura?uh] '(place name)' [07087.021 07087.wav 98.493 102.602]). Following /o/, it can also have friction somewhere in the velar region: / ${ }^{\mathrm{n}}$ du-ko-koh/ [ ${ }^{\mathrm{n}}$ dukokox] '1IN.DU-DUP-be' [JS01.041 JS01.wav 221.869 230.150].

While there is a bit of inter-speaker variation in the front/backness and apical/laminalness of $/ \mathrm{s} /$ in general, it is common for the $/ \mathrm{s} /$ to be retracted adjacent to $/ \mathrm{u} /: / \mathrm{i}$-sum ${ }^{\mathrm{w}}$ $\mathrm{sum}^{\mathrm{w}} /$ [i $\mathrm{um}^{\mathrm{w}}{ }^{\mathrm{w}} \mathrm{um}^{\mathrm{w}}$ ] '3SG-DUP-sit' [KJ01.023 KJ01.wav 104.671 108.312], /sut/ [Sut] 'non-specific article' [JS02.011 JS02.wav 37.456 40.910], /u-s-mata?/ [u-S-mªta?] '2SG.R-NEG-fear' [07098.058 07098.wav 307.750311 .609$]$.

\subsubsection{Voiceless stops}

Intervocalic voiceless stops generally involve a period of voicelessness, and the voice onset time for a following vowel is about $14 \mathrm{~ms}$ for $/ \mathrm{p}^{\mathrm{w}} /, 12 \mathrm{~ms}$ for $/ \mathrm{p}^{\mathrm{j}} /, 10 \mathrm{~ms}$ for $/ \mathrm{t} /$, and $22 \mathrm{~ms}$ for $/ \mathrm{k} / .^{16}$ A sequence of a nasal consonant followed by a voiceless stop is usually phonetically different from prenasalised stop in that the former usually involves a period of voicelessness. For example, $/ \mathrm{nt} /$ in $/ \mathrm{li}-\beta^{\mathrm{w}} \mathrm{a}$ ?a-n-tes/ [li $\beta^{\mathrm{w}}$ a?antes] 'in-middle-3SG-sea' contrasts with $/{ }^{n} \mathrm{~d} /$ in $\left./ \operatorname{ande} \beta^{\mathrm{w}} \mathrm{er} / \mathrm{a}^{\mathrm{n}} \mathrm{de} \beta^{\mathrm{w}} \mathrm{er}\right]$ 'on the contrary' based on voicing. However, sometimes in rapid speech, voiceless stops can be

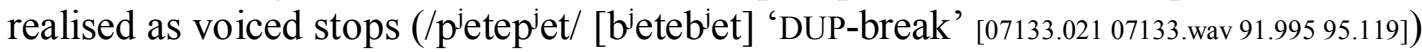
or occasionally even as voiced fricatives (/kakas/ [yayas] 'DUP-out' [07065.354 07065.wav $1275.8181280 .786])$.

Utterance finally, voiceless stops may be released but are often unreleased, for example /sut/ [sut?] 'NONSP' [AT01.016 AT01.wav 93.291 95.557]. For some speakers, a voiceless nasal release is common in this position: $/ \mathrm{m}^{\mathrm{j}} \mathrm{ilip} / \mathrm{p}^{\mathrm{j}} / \mathrm{m}^{\mathrm{j}} \mathrm{ilip} \mathrm{p}^{\mathrm{j} \mathrm{m}}$ ] '(village name)' [07064.006 07064.wav 39.056 46.681], /sut/ [sut ${ }^{\mathrm{n}}$ ] 'NONSP' [07064.074 07064.wav 286.342 291.419].

Voiceless alveolar stops frequently occur as the first element of an initial consonant cluster due to high vowel deletion (Section 2.4.3.2). In these settings, it is released into the second element. For example, in [07098.097 07098.wav 506.967 515.201], /t- ${ }^{\mathrm{m}} \mathrm{b}^{\mathrm{w}} \mathrm{ara}^{\mathrm{n}} \mathrm{gin} /$ 'REL-right' is produced without an audible alveolar release, but based on recordings, there seems to be a glottal plosive onset to the prenasalised stop [ ${ }^{\mathrm{m}} \mathrm{b}^{\mathrm{w}}$ ara $\left.{ }^{\mathrm{n}} \mathrm{gin}\right]$. It is not known whether or not there is an apico-alveolar gesture involved as well. Sequences of $/ \mathrm{tn} /$ as in /t-nu?un/ are generally articulated with a nasally-released alveolar plosive, i.e. [t'nu?un] 'REL-1IN.DU' [07089.089 07089.wav 428.268 433.908]. And sequences of $/ \mathrm{t} l /$ are produced as laterally released plosives: $/ \mathrm{t}-1 \mathrm{i} \beta^{\mathrm{w}} \mathrm{a}$ anm ${ }^{\mathrm{j}} \mathrm{ehep}^{\mathrm{j}} /$ [t $\mathrm{tli}^{\mathrm{l}}{ }^{\mathrm{w} a} \mathrm{a}$ anm ${ }^{\mathrm{j}} \mathrm{ehep}^{\mathrm{j}}$ ] 'REL-top' [07051.219 07051.wav 849.743 853.431]. Sequences of $/ \mathrm{tr} / \mathrm{are}$ produced with an alveolar plosive with a trilled release: /t-ro-koh/ [ $\left.{ }^{\mathrm{r}} \mathrm{okoh}\right]$ 'REL-3PLbe' [08009.177 08009.wav 987.458 991.923].

\footnotetext{
${ }^{16}$ These numbers are based on average measurements for four examples of each voiceless stop in an intervocalic position.
} 


\subsubsection{Prenasalised stops}

Word initially, the prenasalised phase of the prenasalised stop may not be present. For example, in [08009.075 08009.wav 432.086 438.430], / ${ }^{\mathrm{n}} \mathrm{du}-\beta^{\mathrm{j}} \mathrm{ej} /{ }^{\text {' } 1 \mathrm{IN} . D U-g o}$ ' is realised as [du$\left.\beta^{\mathrm{j}} \mathrm{ej}\right]$. However, most of the time, even when I cannot perceive the initial nasal phase, on close examination of a sound file, I find that there is a short nasal period before release.

Intervocalically, both the nasal phase and release phase of a prenasalised stop are generally present and clear: $/ \mathrm{a}^{\mathrm{m}} \mathrm{b}^{\mathrm{w}} \mathrm{at} /\left[\mathrm{a}^{\mathrm{m}} \mathrm{b}^{\mathrm{w}} \mathrm{at}\right.$ ] 'thumb' [07099.009 07099.wav 36.440 38.362].

In a coda position, the nasal phase is always audible, but the release may not be. Word-finally, prenasalised stops are often produced with only a nasal phase $\left(/ \mathrm{e}-\mathrm{ji}^{\mathrm{p}} \mathrm{g} /\right.$ [ejii] 'LOC-PROX' [07027.033 07027.wav 76.919 78.410]), ${ }^{17}$ or if they are released, they are devoiced and weak (/e-ji ${ }^{11} \mathrm{~g}$ [ [eji ${ }^{1} \mathrm{k}$ ] 'LOC-PROX' [KA01.002 KA01.wav 9.079 13.626]).

Prenasalised stops in word-internal coda positions are rare. In $/ \mathrm{i}-\mathrm{li}^{\mathrm{m}} \mathrm{b}^{\mathrm{j}} \mathrm{li}^{\mathrm{m}} \mathrm{b}^{\mathrm{j}} /{ }^{\mathrm{i}} 3 \mathrm{SG}$.R-

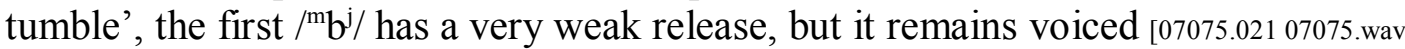
118.654 126.685]. Devoicing can be heard in $/{ }^{n} \mathrm{ge}-\mathrm{su}^{\mathrm{m}} \mathrm{b}^{\mathrm{w}}-\mathrm{su}^{\mathrm{m}} \mathrm{b}^{\mathrm{w}} /\left[\mathrm{gge}-\mathrm{su}^{\mathrm{m}} \mathrm{p}^{\mathrm{w}}-\mathrm{su}^{\mathrm{m}} \mathrm{p}^{\mathrm{w}}{ }^{\mathrm{w}}{ }^{\text {' }} 1 \mathrm{SG} . \mathrm{R}-\right.$ DUP-sit' [08009.033 08009.wav 190.024 196.392] where the $/{ }^{m} \mathrm{~b}^{\mathrm{w}} /$ precedes a voiceless consonant. Younger speakers do not have prenasalised stops in coda position. Where older speakers have a final prenasalised stop, younger speakers have the corresponding nasal (see Section 2.7.2).

\subsubsection{Bilabial trill}

Either of the prenasalised labial stops can have a trilled allophone before $/ \mathrm{u} /$. For example, there is a trilled allophone of $/{ }^{\mathrm{m}} \mathrm{b}^{\mathrm{w}} /$ in one instance of $/ \mathrm{ni}^{-}{ }^{\mathrm{m}} \mathrm{b}^{\mathrm{w}}$ uwes/ [nim ${ }^{\mathrm{B}}{ }^{\mathrm{w}}$ uwes] 'NV-pig' [08009.163 08009.wav 907.350 912.600] and a trilled allophone of $/{ }^{\mathrm{m}} \mathrm{b}^{\mathrm{j} /}$ in one instance of $/ \mathrm{ne}^{\mathrm{m}}{ }^{\mathrm{m}} \mathrm{b}^{\mathrm{j}} \mathrm{uy} /$ [ne $^{\mathrm{m}} \mathrm{B}^{\mathrm{j}} \mathrm{up}$ ] 'NV- mackerel' [07083.073 07083.wav 534.074 537.512]. Cross-linguistically, bilabial trills most often occur before high rounded vowels, and Maddieson (1989a) gives an aerodynamic explanation of this phenomenon, and Nahavaq fits the typical pattern for bilabial trill genesis.

Bilabial trills, though rare in the phonologies of the world's languages are common on Malakula. Unua (Dimock 2005), Neverver (Barbour, p.c.), Avava (Crowley 2006a: 30-32) and Uripiv (McKerras 2001: 1) have prenasalised bilabial trills as phonemes separate from prenasalised bilabial stops. Other languages are also reported to have bilabial trills, though with limited evidence, it would seem that they are allophones of prenasalised bilabial stops. These include Nitita and Viar (Crowley 2006a: 30) and three of Nahavaq's closest neighbours, Nati (Crowley 1998b: 107), Ninde (Maddieson 1989a: 92-94), and Na'ahai (Maddieson 1989a: 94-95).

My informal observation is that trilled allophones of labial prenasalised stops are produced more often and more distinctively by older speakers, but that some younger speakers also produce them. Bilabial trills may have been more prominent in the past as evidenced by the fact that both Goodenough (1876) and Deacon (1934) noticed them in Nahavaq. Goodenough transcribed < nalambrut $>$ 'cat' (/na-la ${ }^{\mathrm{m}} \mathrm{b}^{\mathrm{j} u t} /$ ' $^{\mathrm{N} V-r a t}$ ')

\footnotetext{
${ }^{17}$ While younger speakers have a phonological nasal in /e-jin/ 'LOC-PROX', the speaker who produced the example above produces [eji ${ }^{\mathrm{p}} \mathrm{k}$ ] in other instances [07018.005 07018.wav 14.566 16.660], so I speculate that for him the underlying form has a prenasalised stop and that a purely nasal variant is a possible realisation word-finally.
} 
and $<$ nambrr $>$ 'bamboo' (/na- ${ }^{\mathrm{m}} \mathrm{b}^{\mathrm{w}} \mathrm{u} /$ ' $^{\mathrm{NV}} \mathrm{N}$-bamboo') with $<$ mbr $>$ where modern Nahavaq could have a trill. He also writes <ambrr $>$ 'fire' (modern Nahavaq: /na$\mathrm{Pa}^{\mathrm{m}} \mathrm{b}^{\mathrm{j} /}$ ' $\mathrm{NV}$-fire') which suggests that either there was a word-final/u/ in Nahavaq in the nineteenth century (Clark 2005 reconstructs PNCV *kabu 'fire') or else, considering that no Malakula languages retained that final /u/ (Tryon 1976: 322-323), it is possible that Nahavaq used to allow a word-final bilabial trill just as in presentday Unua /no-yo ${ }^{\mathrm{m}} \mathrm{B} /$ 'fire' (Dimock 2005: 19), Avava /a: ${ }^{\mathrm{m}} \mathrm{B} /$ 'fire' (Crowley 2006a: 31), and Neverver [naya ${ }_{\mathrm{B}}^{\mathrm{m}}$ ] 'fire, firewood' (Barbour, p.c.). In the published version of Deacon's (1934) notes, several trill-able stops are transcribed as $<$ mbru $>$ :

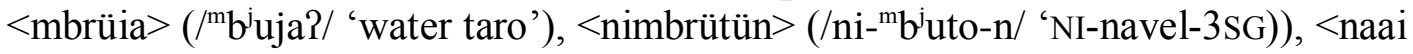
limbr $>$ (/na?aj $\operatorname{li}^{\mathrm{m}} \mathrm{b}^{\mathrm{w}} \mathrm{u} /$ 'croton'), but there is no sign of a trill in $<$ naamb $>/$ na- $\mathrm{Pa}^{\mathrm{m}} \mathrm{b}^{\mathrm{j}} /$ 'fire'.

In addition to trilled allophones of prenasalised labial consonants, I recorded one example of a trilled realisation of a voiceless bilabial stop before $/ \mathrm{u} /$ in fluent natural speech: /ndu-P-p ${ }^{j} \mathrm{ul} /$ [" ${ }^{\mathrm{n}} \mathrm{du} \mathrm{B}_{\mathrm{o}}^{\mathrm{j}} \mathrm{ul}$ ] '1IN.DU-IRR-turn' [07112.076 07112.wav 417.081 419.447]. A trilled allophone of a voiceless stop is also noted in Neverver (Barbour, p.c.) before $/ \mathrm{u} /$ and in Avava (Crowley 2006a: 28) before /ur/. However, I only noticed a single instance of this trill, and one Nahavaq informant told me that it did not sound as normal to her as the prenasalised trills. On the other hand, it may be a feature of older speakers as it is in Neverver.

\subsubsection{Alveolar trill}

The alveolar trill can be realised in a number of ways. The realisation depends a lot on the particular speaker and the rate of speech. Some realisations include a tap as in /i- ${ }^{\mathrm{p}}$ garumw/ [ $\mathrm{i}^{\mathrm{p}}$ garum $^{\mathrm{w}}$ ] ' 3 SG.R-grab' [EC02.103 EC02.wav 424.839 433.715], a trill as in /i- $\beta$ 'ar$p^{\mathrm{j} e t /}$ [i- $\beta^{\mathrm{j}}$ ar-p $\mathrm{p}^{\mathrm{j} e t]}$ '3SG.R-step-break' [07089.095 07089.wav 453.190 458.722], an approximant as in $/$ re-te $\beta^{\mathrm{j}}$ is/ [ Iete $\beta^{\mathrm{i}}$ is] '3PL-arrive' [LS01.063 LS01.wav 249.344 251.360], and an apical fricative as in /ni-si $\beta^{\mathrm{i}} \mathrm{ir} /$ [nisi $\left.\beta^{\mathrm{i}} \mathrm{iz}\right]$ 'NI-rainbow.lorikeet' [тв03.003 TB03.wav 15.655 19.077]. It is almost always voiced, but can be partially devoiced following a voiceless consonant as in $/ \mathrm{t}$ ra-kan/ [trakan] 'REL-3PL-sharp' [07081.029 07081.wav 132.967 135.904] or word-finally as in /nijar/ [nijar] 'NV-ironwood' [07076.013 07076.wav 54.199 56.887].

Young children often have trouble producing alveolar trills and may replace them with a $/ \mathrm{j} /$-like sound. Adults speaking to children often replace all $/ \mathrm{r} / \mathrm{s}$ with $/ \mathrm{j} / \mathrm{s}$. When children finally achieve a trilled articulation, they often over-trill, producing many more closures in the trill than an adult would.

\subsubsection{Possible /n $d \mathrm{t} /$}

There are some words that some older speakers pronounce with a prenasalised retroflex stop with a trilled release $\left[^{n}{ }^{n}\right]$. However, as with $/ r /$, the trill is not always successful, so it may be produced as $\left[{ }^{n} \mathrm{~d}^{\mathrm{z}}\right]$. Younger speakers pronounce these segments as $\left[{ }^{\mathrm{n}} \mathrm{d}\right]$. Some speakers who went to local schools in the 1950 s were instructed to pronounce certain words with a $\left[^{n} \mathrm{~d}^{\mathrm{l}}\right]$ trill, so they are conscious of the sound. But I only found three speakers who produced it spontaneously, and the 
youngest of those was born around 1930. ${ }^{18}$ None of those three speakers produced $\left[{ }^{n} \mathrm{~d}^{\mathrm{C}}\right]$ consistently in spontaneous speech.

It is difficult to tell whether $\left.{ }^{n}{ }^{n} \mathrm{~d}^{\mathrm{l}}\right]$ constituted an allophone of $/{ }^{\mathrm{n}} \mathrm{d} /$ or a separate phoneme. One older speaker was able to tell me that both $\left[{ }^{n} \mathrm{~d} l\right]$ or $\left[{ }^{\mathrm{n}} \mathrm{d}\right]$ were appropriate pronunciations in words like $\left.\left[\mathrm{ma}^{\mathrm{n}} \mathrm{d}\right]^{\mathrm{l}}\right] \sim\left[\mathrm{ma}^{\mathrm{n}} \mathrm{d}\right]$ 'bleed', but that for other words such as [lu $\left.{ }^{n} d\right]$ 'peel skin', a pronunciation with [ [ $d$ l'] was wrong. However, while his judgements generally aligned with the transcriptions of Charpentier (1982), he was not entirely consistent in his judgements. While I was unable to find any minimal pairs to prove separate phoneme status, Table 7 presents some $\left[{ }^{n} d^{\mathrm{l}}\right]$ and $\left[{ }^{\mathrm{n}} \mathrm{d}\right]$ pairs that my informant was relatively consistent about. It presents the segments in parallel distribution in syllable onset position before all vowels.

Table 7: $\left[{ }^{\mathrm{n}} \mathrm{d}{ }^{\mathrm{r}}\right]$ and $\left[{ }^{\mathrm{n}} \mathrm{d}\right]$ near-minimal pairs

These were produced by a male speaker $>80$ years old (see 08008 .wav).

\begin{tabular}{|c|c|c|c|}
\hline$\left[i-m^{j} a-{ }^{n} d a s\right]$ & '3SG-MV-torn' & {$\left[\mathrm{i}-{ }^{\mathrm{n}} \mathrm{dam}^{\mathrm{w}}\right]$} & '3SG-agree' \\
\hline$\left[n e-{ }^{n} d^{r} e j\right]$ & 'NV-blood' & {$\left[\mathrm{i}-{ }^{\mathrm{n}} \mathrm{den}\right]$} & '3sG-drown' \\
\hline$\left[i-{ }^{n} d{ }^{i} m^{j}-{ }^{n} d{ }^{r} i^{j}\right]$ & '3SG-think' & {$\left[\mathrm{i}^{\mathrm{n}} \mathrm{din}\right]$} & '3sG-follow' \\
\hline$[\mathrm{i}-\mathrm{n} d$ [is $]$ & '3SG-tear’ & {$\left[\mathrm{i}-{ }^{\mathrm{n}} \mathrm{dih}\right]$} & '3SG-scoot over' \\
\hline$\left[{ }^{n} \mathrm{~d}^{\mathrm{r}} \mathrm{oh}\right]$ & 'already' & {$\left[i-{ }^{n}\right.$ don $]$} & '3SG-empty' \\
\hline [i- " $\left.\mathrm{d}^{\mathrm{r}} \mathrm{us}\right]$ & '3sG-pull' & [naPam ${ }^{\mathrm{j}}$ nuy ${ }^{\mathrm{n}}$ dun] & 'smoke' \\
\hline
\end{tabular}

Some Malakula languages that have a prenasalised apical trill phoneme include: Avava (Crowley 2006a: 25), Neverver (Barbour, p.c.), and one of Nahavaq's closest linguistic neighbours, Nāti (Crowley 1998b). ${ }^{19}$ But there are also others that have such a segment as an allophone of a plain pre-nasalised stop. This includes Tape which has a trilled allophone before $/ \mathrm{u} /$ and $/ \mathrm{a} /$ and word-finally after /o/ and /o/ (Crowley 2006d: 101) and Neve'ei which has a trilled variant of the prenasalised alveolar stop word finally (Musgrave 2007: 7). While most Nahavaq speakers today do not have a prenasalised apical trill at all, it is clear that in the recent past, this sound was commonly used in Nahavaq, and it is probable that it was an independent phoneme which has since merged into $/{ }^{\mathrm{n}} \mathrm{d} /$.

\subsubsection{Labiovelar-bilabial distinction}

I use the terms labiovelar and bilabial because of the relationship of these segments to similarly labelled segments in Proto-Oceanic (Lynch 2002) and to similarly labelled segments in descriptions of other Vanuatu languages including Tape (Crowley 2006d: 100), Uripiv (McKerras 2001: 1), Avava (Crowley 2006a: 25), Neve'ei (Musgrave 2007: 6), Lolovoli (Hyslop 2001: 28), and Efate (Thieberger 2004: 78). The terms are not accurate descriptions of articulations in Nahavaq, nor do they capture the essence of the distinction between the two sets. In discussion of labiovelar consonants, $/ \mathrm{w} /$ is excluded as it is not functionally closely related to the labiovelar consonant series. To avoid presenting the labiovelar series as marked and the bilabial as unmarked, I will avoid the standard convention of putting a superscripted diacritic only on the

\footnotetext{
${ }^{18}$ Examples of [ [ $\mathrm{d}^{\mathrm{r}}$ ] within texts are: [i- $\left.{ }^{\mathrm{n}} \mathrm{d}^{\mathrm{r}} \mathrm{us}\right]$ '3SG.R-pull' [07076.041 07076.wav 159.955 165.237], and ["d'oh] 'already' [07117.572 07117.wav 1652.803 1655.240].

${ }_{19}$ Actually, in Crowley's (1998b) original analysis of Nāti, he analysed [ndr] as a sequence of three phonemes /ndr/. However in a footnote in a later publication (Crowley 2006a: 32), he rejects that analysis in favour of one that includes complex segments such as $/{ }^{\mathrm{n}} \mathrm{d}^{\mathrm{r}} /$.
} 
labiovelar series. Instead, labiovelar consonants will have a $w$ diacritic $\left(/ \mathrm{m}^{\mathrm{w}} / \mathrm{m}^{\mathrm{m}} \mathrm{b}^{\mathrm{w}} /\right.$ $/ \mathrm{p}^{\mathrm{w}} /$ and $\left./ \beta^{\mathrm{w}} /\right)$ and bilabial consonants will have a $j$ diacritic $\left(/ \mathrm{m}^{\mathrm{j}} / / \mathrm{m}^{\mathrm{j}} / / \mathrm{p}^{\mathrm{j}} /\right.$ and $\left./ \beta^{\mathrm{j}} /\right)$. Labial consonants without either of these diacritics $(/ \mathrm{m} / / \mathrm{m} \mathrm{b} / / \mathrm{p} /$ and $/ \beta /)$ will be used to represent segments that are ambiguous or for speakers who do not contrast the sets. Each series contains a nasal, a prenasalised stop, a voiceless stop, and a fricative. Nahavaq speakers describe the labiovelar series as 'heavy' in opposition to their 'light' (bilabial) counterparts.

The following sections describe the phonetic difference between the two sets of labial consonants, their distribution, matters of phonological markedness, and instability of labial consonants. Labial consonant harmony is discussed in Section 2.4.4.

\subsubsection{Phonetic difference}

The articulatory differences that I have visually observed between labiovelar and bilabial consonants are shown in Table 8 . I observed these differences when various speakers demonstrated minimal pairs for me, but they are not necessarily present in spontaneous speech.

Table 8: Labiovelar vs. bilabial--observable articulatory difference

\begin{tabular}{ll}
\hline Bilabial consonants & Labiovelar consonants \\
\hline - Corners of the mouth are held & - Corners of the mouth are not held \\
tight and back & back \\
— Lip position is spread & - Lip position is not spread and \\
& usually rounded in careful \\
& articulation \\
- Cheek muscles are tightened & Cheek muscles are relaxed and \\
& plosive consonants can sometimes \\
& be seen to puff out the cheeks \\
- The outsides of the lips are the & - The insides of the lips are the place \\
place of greatest constriction & of greatest constriction (exolabial) \\
(endolabial) & \\
-jaw position may be higher & - jaw position may be lower and/or \\
& protruding \\
\hline
\end{tabular}

Apart from these visual cues, there also seem to be differences in tongue position based on transitions between labial consonants and surrounding vowels and also vowel allophones conditioned by adjacent labial consonants. Labiovelar consonants followed by front vowels often have a prominent [w]-like off-glide. However, acoustic evidence below will show that while it may be salient in the off-glide, velarisation (or probably more accurately uvularisation or pharyngealisation) is present throughout the consonant. Labiovelar and bilabial consonants may have a backing or fronting effect on adjacent vowels. This is most noticeable with $/ \mathrm{u} /$ and $/ \mathrm{a} /$ which have noticeably fronted allophones when they occur adjacent to bilabial consonants. Many alveolar consonants have the same effect, and I propose that it is

\footnotetext{
${ }^{20}$ This distinction between the inside of the lips and the outside of the lips is comparable to the difference in compression-type rounding or protrusion-type rounding on vowels. This type of difference in lip posture is also transferred onto adjacent $/ \mathrm{u} /$ vowels, with $/ \mathrm{u} /$ adjacent to labiovelar consonants having lip protrusion and / $\mathrm{u} /$ adjacent to bilabial consonants having lip compression.
} 
due to a tongue body raised toward the palate in the production of these consonants (Section 2.2.1). This palatalisation is the reason I have chosen the superscript $j$ in the phonemic symbols for bilabial consonants. Like Nahavaq, Marshallese has two contrasting sets of labial consonants which are described as palatalised and velarised, however this distinction extends beyond labial consonants in Marshallese (Bender 1968: 16-17). In the case of Nahavaq, velarisation and palatalisation do not completely explain the contrast in the two sets of labial consonants because there is also a difference in lip posture. Interestingly, many of the same articulatory features have been noted in Ikwere (Niger-Congo) nonexplosive consonants, which are reflexes of earlier labiovelar stops (Clements and Osu 2002). These include loose pouting of the lips (as opposed to a firmly pressed "smirk" of the bilabial explosives), jaw lowering, some degree of tongue body retraction, and possibly also relaxation of the soft tissues of the lips, cheeks, and throat. Clements and Osu see all of these articulatory features contributing to the avoidance of positive oral pressure. However, Nahavaq also has similar articulatory features for a nasal and fricative consonant, both of which would presumably have very small pressure differences between oral cavity and atmosphere. So while similar articulatory features may be conspiring to make a distinction between explosive and nonexplosive consonants in Ikwere, there must be a different featural difference for Nahavaq. I propose that for Nahavaq the important difference is in the size of the front oral cavity between the lips and the point of constriction within the mouth. All of the articulatory features of labiovelar consonants can be seen as contributing to a maximally large front oral cavity. The tongue body is retracted, the lips are protruded, the jaw is lowered, and the cheeks are relaxed and may even be allowed to be pushed out in plosive consonants. The articulatory features of bilabial consonants can be seen as contributing to as small a front oral cavity as possible. The tongue body is fronted, the lips are pulled back and kept close to the teeth, the jaw is higher than for labiovelar consonants, and cheek muscles are taut, squeezing in at the sides. ${ }^{21}$

The acoustic result of the difference in size of oral cavity is a difference in the frequency of the second formant. Figure 7 shows spectrograms of the minimal pair, $/$ ne- $^{\mathrm{m}} \mathrm{b}^{\mathrm{j} e t}$ / 'NV-edible vine' and /ne- ${ }^{\mathrm{m}} \mathrm{b}^{\mathrm{w}} \mathrm{et} /{ }^{\prime} 1 \mathrm{sG}-\mathrm{lean}$ over'. For $/{ }^{\mathrm{m}} \mathrm{b}^{\mathrm{j}} /$ the second formant in the prenasal phase is around $1800 \mathrm{~Hz}$. For $/ \mathrm{m}^{\mathrm{m}} \mathrm{b}^{\mathrm{w}} /$ it is around $1435 \mathrm{~Hz}$. Note that this difference is present through the duration of the consonants and not simply in an off-glide. However, the off-glide from a labiovelar consonant to a front vowel is very pronounced and can also be seen in the spectrogram. Note that there is also a visible on-glide between the first vowel and $/{ }^{\mathrm{m}} \mathrm{b}^{\mathrm{w}} /$, though it is shorter in duration.

\footnotetext{
${ }^{21}$ Given this description of Nahavaq bilabial consonants as having an extremely small oral cavity, fronting of the tongue, and compressed rather than protruded lips, the linguo-labial shift that occurred in northern Malakula and Santo does not seem as surprising as it would if linguo-labial consonants had evolved from "normal" bilabial consonants. Pulling of the lips inward would further decrease the size of the front oral cavity. With a pulled-in upper lip and an advanced tongue body, it would not be difficult for the two to touch and for the contact to eventually become phonologically important.
} 
Figure 7: Spectrogram showing the difference between $/{ }^{\mathrm{m}} \mathrm{b}^{\mathrm{j}} /$ and $/{ }^{\mathrm{m}} \mathrm{b}^{\mathrm{w}} /$

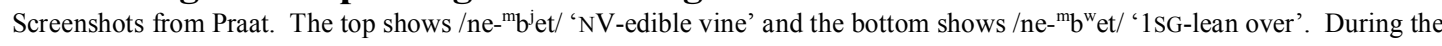
nasal phase of the prenasalised stops, there is a clear formant around $1800 \mathrm{~Hz}$ in the former and around $1435 \mathrm{~Hz}$ in the latter.

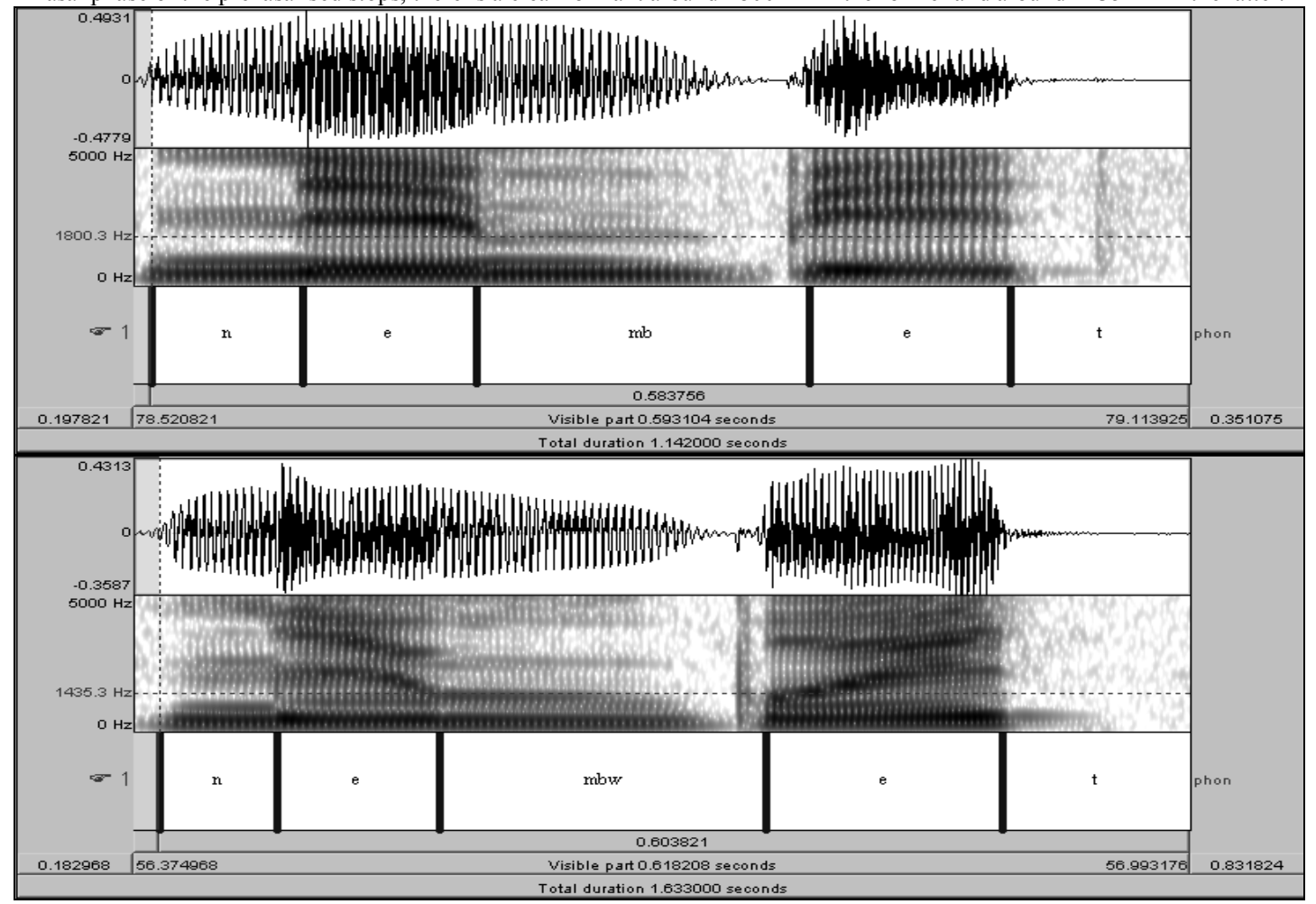

When the increasing of the oral cavity happens after oral closure for labiovelar plosives $\left(/ \mathrm{m}^{\mathrm{w}} /, / \mathrm{p}^{\mathrm{w}} /\right)$, there can be rarification of the air in the oral cavity, resulting in a nonexplosive allophone, which could possibly even have ingressive airflow, though probably not caused by movement of the glottis as in canonical implosive consonants. As mentioned above, many articulatory features of Nahavaq labiovelar consonants are similar to those of Ikwere nonexplosives. So it is not surprising that these can result in nonexplosive allophones in Nahavaq. While I did not make measurements of oral pressure or airflow, the waveform and intensity graph in Figure 8 show a very low amplitude release for the $/ \mathrm{p}^{\mathrm{w}} / \mathrm{segments}$ in an example of $/ \mathrm{p}^{\mathrm{w}} \mathrm{alap}{ }^{\mathrm{w}} \mathrm{al} /$ 'clean'.

Figure 8: Low-pressure $/ \mathrm{p}^{\mathrm{w} /}$

Image created with Praat. /pwalapwal/ 'clean' [07128.020 07128.wav 107.644 112.379]. The line superimposed over the spectrogram is intensity (40-80dB). Transcription in Figure in the new orthography (see Section 2.9).

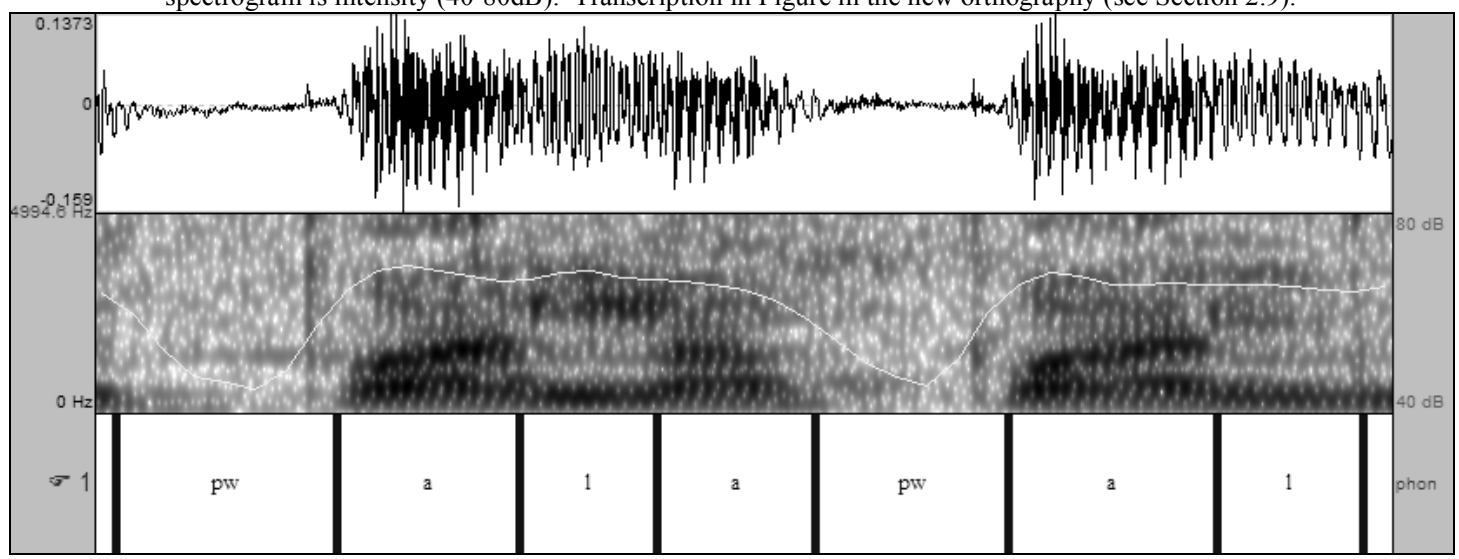




\subsubsection{Distribution}

Table 9 shows each pair of bilabial and labiovelar consonants contrasting in minimal pairs.

Table 9: Labiovelar-bilabial minimal pairs

\begin{tabular}{|c|c|}
\hline /i-m'il/ '3SG-wet' & /i-mwil/ '3SG-too short' \\
\hline 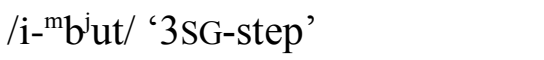 & /i- ' $\mathrm{b}^{\mathrm{w}} \mathrm{ut} /{ }^{\prime} 3 \mathrm{sG}-\mathrm{stop}$ crying' \\
\hline /i-p'en/'3SG-paint' & /i-p $\mathrm{p}^{\mathrm{w}} \mathrm{en} /$ '3SG-(sun)burn' \\
\hline /i- $\beta^{\mathrm{j}} \mathrm{ara} \beta^{\mathrm{j}}$ ar/ ' $3 \mathrm{SG}-$ push with leg' & $/ \mathrm{i}-\beta^{\mathrm{w}} \operatorname{ara} \beta^{\mathrm{w}}$ ar/ ' $3 \mathrm{sg}$-flow' \\
\hline
\end{tabular}

Bilabial and labiovelar consonants contrast before all vowels except for /o/. Table 10 shows $/{ }^{\mathrm{m}} \mathrm{b}^{\mathrm{w}} /$ and $/{ }^{\mathrm{m}} \mathrm{b}^{\mathrm{j}} /$ contrasting before all other vowels. The labial consonants that occur before /o/ are articulatorily more similar to labiovelar consonants than bilabial consonants, so I will treat them as the former.

Table 10: $/{ }^{\mathrm{m}} \mathrm{b}^{\mathrm{j}} / / /^{\mathrm{m}} \mathrm{b}^{\mathrm{w}} /$ distinction before different vowels.

\begin{tabular}{|c|c|}
\hline /i- ${ }^{\mathrm{m}} \mathrm{b}^{\mathrm{j}} \mathrm{ir}^{\mathrm{m}} \mathrm{b}^{\mathrm{j}} \mathrm{ir} /$ '3SG-weave' $^{-}$ & /i- ${ }^{\mathrm{m}} \mathrm{b}^{\mathrm{w}} \mathrm{ir}{ }^{\mathrm{m}} \mathrm{b}^{\mathrm{w}} \mathrm{ir} /$ '3SG-hang' \\
\hline /ne- ${ }^{\mathrm{m}} \mathrm{b}^{\mathrm{j} e t} /{ }^{\prime} \mathrm{NV}$-edible vine' & /ne- ${ }^{\mathrm{m}} \mathrm{b}^{\mathrm{w}} \mathrm{et} /$ '1SG-bend' \\
\hline /na- ${ }^{\mathrm{m}} \mathrm{b}^{\mathrm{j}} \mathrm{a} \mathrm{P} /{ }^{\prime} \mathrm{NV}$-banyan' & /na- ${ }^{\mathrm{m}} \mathrm{b}^{\mathrm{w}} \mathrm{a} 2 /$ 'NV-turtle' \\
\hline$\left(/{ }^{\mathrm{m}} \mathrm{b}^{\mathrm{j}} \mathrm{o} /\right.$ unattested $)$ & /no- ${ }^{\mathrm{m}} \mathrm{b}^{\mathrm{w}} \mathrm{on} /{ }^{\text {'NV}} \mathrm{N}$-smell' \\
\hline$/$ ne- $^{\mathrm{m}} \mathrm{b}^{\mathrm{j}} \mathrm{u}-\mathrm{n} /{ }^{\prime} \mathrm{NV}$-arse-3sG' & /ne-"'b ${ }^{w}$ un/ '1sG-full' \\
\hline
\end{tabular}

Bilabial and labiovelar consonants can also contrast word-finally (Table 11). Following /o/, only labiovelar consonants are attested word-finally. Following /u/, there is only one attested example of a bilabial consonant in $/ \mathrm{i}^{-}{ }^{\mathrm{m}} \mathrm{b}^{\mathrm{j}} \mathrm{um}^{\mathrm{j}} /$ ' $3 \mathrm{SG}$.R-creep'

Table 11: Word-final labial contrasts

\begin{tabular}{|c|c|}
\hline /ne-lipp/ '1sG-take & /ne-lip ${ }^{\mathrm{w} /}$ 'NV-bullet' \\
\hline /ne-semj/ 'NV-outrigger' & /ne-sem ${ }^{\mathrm{w}} /$ '1SG-chew' \\
\hline$/ i-P a^{m} b^{j} P a^{m} b^{j} /$ '3sG-flap wings' & $/ \mathrm{i}-2 \mathrm{a}^{\mathrm{m}} \mathrm{b}^{\mathrm{w}}-2 \mathrm{a}^{\mathrm{m}} \mathrm{b}^{\mathrm{w}} /$ '3SG-DUP-swollen' \\
\hline
\end{tabular}

\subsubsection{Split markedness}

While accounts of labiovelar and bilabial consonants in many other related languages treat the bilabial set as unmarked, there is good reason to consider the bilabial consonants marked in certain contexts in Nahavaq. ${ }^{22}$ It would seem that bilabial consonants are unmarked before front vowels, and labiovelar consonants are unmarked before non-front vowels. Evidence for this claim comes from frequency within the lexicon, borrowing, and change in progress.

Looking at the entries in my Nahavaq lexicon, it is clear that labiovelar consonants occur more frequently before back vowels (e.g. $/{ }^{\mathrm{m}} \mathrm{b}^{\mathrm{w}}$ oror/ 'deaf', $/ \beta^{\mathrm{w}} \mathrm{ul} /$ 'buy') and bilabial consonants occur more frequently before front vowels (eg. $/ \mathrm{m}^{\mathrm{j} i n} /$ 'drink', $/ \mathrm{p}^{\mathrm{j}} \mathrm{en} /$ 'race'). The same pattern holds for word-final labials following these vowels

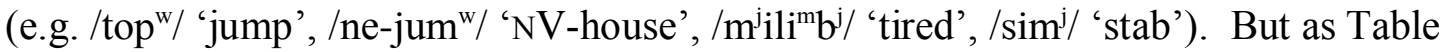
12 shows, with /a/ the pattern is less clear. Both before $/ \mathrm{a} /$ and in the context $\left\{\mathrm{a} \_\#\right.$,

\footnotetext{
${ }^{22}$ Even in articulation, there are some features of Nahavaq bilabial consonants that seem more marked than in labiovelar consonants. These include many of the features in Table 8 and the effects on adjacent vowels (see Section 2.2.1).
} 
labiovelar consonants are only slightly more frequent than bilabial consonants, but the pattern seen in borrowing is more convincing.

Table 12: Frequency of labial-V combination in lexicon

This table includes only the potion of the lexicon that has been specifically checked for the identity
of labial consonants. Related words were excluded when noticed. There are a total of 569 entries
distributed as in this table. Shaded squares represent apparently marked combinations.
\begin{tabular}{lcccccc} 
/i/ & /e/ & /a/ & /o/ & /u/ \\
\hline Labiovelar-V & 23 & 13 & 68 & 105 & 57 \\
Bilabial-V & 47 & 80 & 64 & 0 & 33 \\
\hline V-Labiovelar-\# & 1 & 1 & 10 & 35 & 6 \\
V-Bilabial-\# & 3 & 15 & 7 & 0 & 1 \\
\hline
\end{tabular}

When Nahavaq borrows words with labial consonants, there is a strong tendency for them to appear as bilabial consonants before front vowels and word-finally after front vowels (e.g. /pisnis/ 'business', /m $\mathrm{m}^{\mathrm{j}}$ eresin/ 'medicine', /sep'/ 'shave') and as labiovelar before non-front vowels and word-finally after non-front vowels (e.g. $/{ }^{m} b^{w} u r a s /$ 'brush', /telep ${ }^{\mathrm{w}}$ on/ 'telephone', /'b b atri/ 'battery', /jusumw/ ' use', /lamw/ 'lamp'). This suggests that labiovelar consonants are unmarked before $\{/ \mathrm{a} /, / \mathrm{o} /, / \mathrm{u} /\}$ and that bilabial consonants are unmarked before $\{/ \mathrm{e} /, / \mathrm{i} /\}$.

Table 13: Frequency of labial-V combination in borrowed words

\begin{tabular}{lccccc}
\multicolumn{5}{c}{ Shaded squares represent apparently marked combinations. } \\
& /i/ & /e/ & /a/ & /o/ & /u/ \\
\hline Labiovelar-V & 1 & 0 & 26 & 5 & 7 \\
Bilabial-V & 15 & 11 & 6 & 0 & 1 \\
\hline V-Labiovelar-\# & 0 & 0 & 3 & 1 & 1 \\
V-Bilabial-\# & 2 & 2 & 0 & 0 & 0 \\
\hline
\end{tabular}

The distinction between labiovelar and bilabial consonants is being lost. The difference between oldest speakers (most distinctions) and youngest speakers (no distinction) with a couple intermediate stages suggests a change in progress, with the distinction disappearing in certain contexts before others. Table 14 represents the progression of change. Neutralisation of labiovelar and bilabial consonants appears to first occur word-finally. Some speakers, who maintain the disction elsewhere, lose it word-finally, with all labial consonants after front vowels becoming bilabial and all labial consonants after non-front vowels becoming labiovelar ("First change" in Table 14). 
Table 14: Neutralisation of labial consonants over time

\begin{tabular}{|c|c|c|c|}
\hline Gloss & $\begin{array}{l}\text { Oldest } \quad \begin{array}{l}\text { First change } \\
(\text { age } \sim 35-95)(\text { age } \sim 25-60)\end{array}\end{array}$ & $\begin{array}{l}\text { Second change } \\
(\text { age } \sim 20-35)\end{array}$ & $\begin{array}{l}\text { eYoungest } \\
\text { (age } \sim 1-35)\end{array}$ \\
\hline $\mathrm{NV}$-outrigger & $/$ ne-sem $^{\mathrm{j}} / \quad$ /ne-sem $/$ & $/$ ne-sem $^{\mathrm{j}} /$ & /ne-sem/ [nesem $\left.{ }^{\mathrm{j}}\right]$ \\
\hline 1SG-chew & /ne-semw/ /ne-sem ${ }^{\mathrm{j}} /$ & /ne-sem ${ }^{\mathrm{j}} /$ & /ne-sem/ [nesem $\left.{ }^{\mathrm{j}}\right]$ \\
\hline 3sG-flap wings & $/ i-P a^{m} b^{j} P a^{m} b^{j} / / i-P a^{m} b^{w} P a^{m} b^{w} /$ & 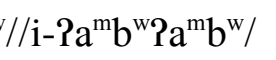 & $/ \mathrm{i}-2 \mathrm{a}^{\mathrm{m}} \mathrm{b}-\mathrm{Pa} \mathrm{a}^{\mathrm{m}} \mathrm{b} /\left[\mathrm{i} \mathrm{a}^{\mathrm{m}} \mathrm{b}^{\mathrm{w}} \mathrm{Pa}^{\mathrm{m}} \mathrm{b}\right.$ \\
\hline 3SG-swollen & $/ \mathrm{i}-\mathrm{Pa}^{\mathrm{m}} \mathrm{b}^{\mathrm{w}} / \quad / \mathrm{i}-\mathrm{Pa}^{\mathrm{m}} \mathrm{b}^{\mathrm{w}} /$ & $/ \mathrm{i}-9 \mathrm{a}^{\mathrm{m}} \mathrm{b}^{\mathrm{w}} /$ & $/ \mathrm{i}-\mathrm{Pa} \mathrm{a}^{\mathrm{m}} \mathrm{b} /\left[\mathrm{i} P \mathrm{a}^{\mathrm{m}} \mathrm{b}^{\mathrm{w}}\right]$ \\
\hline $\begin{array}{l}\text { SSG-short } \\
\text { grass }\end{array}$ & 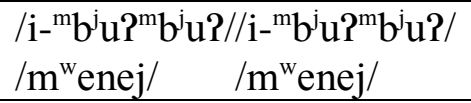 & $\begin{array}{l}/ \mathrm{i}^{\mathrm{m}} \mathrm{b}^{\mathrm{w}} \mathrm{uP}^{\mathrm{m}} \mathrm{b}^{\mathrm{w}} \mathrm{uP} / \\
/ \mathrm{m}^{\mathrm{j}} \text { enej/ }\end{array}$ & 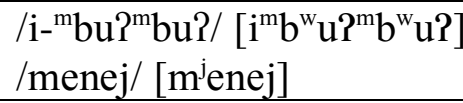 \\
\hline 3SG-wet & $/ \mathrm{i}-\mathrm{m}^{\mathrm{j}} \mathrm{il} / \mathrm{j}$ & $/ \mathrm{i}-\mathrm{m}^{\mathrm{j}} \mathrm{il} /$ & /i-mil/ [imil $\left.{ }^{\mathrm{j}} \mathrm{il}\right]$ \\
\hline 3SG-too short & /i-mw ${ }^{\mathrm{w}} \mathrm{il} /$ & /i-mw ${ }^{\mathrm{w}} \mathrm{il} /$ & /i-mil/ [im $\left.{ }^{\mathrm{j}} \mathrm{il}\right]$ \\
\hline 3sG-step & $/ \mathrm{i}^{\mathrm{m}} \mathrm{b}^{\mathrm{j}} \mathrm{ut} /$ & $/ \mathrm{i}-{ }^{\mathrm{m}} \mathrm{b}^{\mathrm{j}} \mathrm{ut} /$ & /i-mbut/ [i $\left.{ }^{\mathrm{m}} \mathrm{b}^{\mathrm{w}} \mathrm{ut}\right]$ \\
\hline 3SG-stop crying & $\mathrm{g} / \mathrm{i}-{ }^{\mathrm{m}} \mathrm{b}^{\mathrm{w}} \mathrm{ut} /$ & $/ \mathrm{i}^{\mathrm{m}} \mathrm{b}^{\mathrm{w}} \mathrm{ut} /$ & /i-mbut/ [i $\left.\mathrm{i}^{\mathrm{m}} \mathrm{w}^{\mathrm{w}} \mathrm{ut}\right]$ \\
\hline
\end{tabular}

The "Second change" in Table 14 sees the labial distinction neutralised in the direction of bilabial consonants adjacent to front vowels and labiovelar consonants adjacent to non-front vowels in most context, but still retaining some minimal pair distinctions. Finally, all distinction is lost but there may still be bilabial-like allophones adjacent to front vowels and labiovelar-like allophones adjacent to nonfront vowels, or at least this is how older speakers perceive the pronunciation of younger speakers. ${ }^{23}$ It is the conditioned neutralisation in "First change" and "Second change" that supports the case for split markedness with bilabial consonants being marked in non-front vowel environments and labiovelar consonants being marked in front vowel environments.

\subsubsection{Instability}

Nahavaq's labial distinction is unstable in three ways. First, there are a few words with labial consonants whose identity is not consistent even between the oldest speakers. These include the initial nasals in /marla ${ }^{\mathrm{m}} \mathrm{b}^{\mathrm{j}}$ / 'old man' and /mas/ 'laugh', which some speakers produce as bilabial and others as labiovelar. In addition, there are some pairs of bilabial consonants followed by a high back vowel $/ \mathrm{u} /$ which have a variant in the form of a labiovelar consonant followed by a high front vowel $/ \mathrm{i} /$. This pattern is discussed in Section 2.7.1. Finally, the distinction between bilabial and labiovelar consonants is being lost for younger speakers. Most speakers born before 1960 maintain the distinction in all of the places described in Section 2.1.3.2. Most speakers born after 1980 do not maintain a distinction anywhere. Others maintain the contrast only in certain contexts, for example, only in minimal pairs (as illustrated in Table 14 above) or only before front vowels.

Lynch (Lynch 2002: 336) suggests that labiovelars were unstable in POc times and well after the break-up of POc. However, at least some of Nahavaq's labiovelar consonants appear to be directly inherited from POc, so there must have been some level of stability at least for the lexical items in Table 15 to have survived with labiovelar consonants for thousands of years.

\footnotetext{
${ }^{23}$ The allophonic variation in /a/ and / $\mathrm{u} /$ which is conditioned by labial consonants (Section 2.2.1) is no longer present once the consonants no longer contrast.
} 
Table 15: Inherited labiovelars

Labiovelar consonants in these words appear to be directly inherited from POc. POc reconstructions are from (Lynch 2002).

\begin{tabular}{|c|c|c|c|}
\hline POc & gloss & SNS & gloss \\
\hline${ }^{*} \mathrm{~m}^{\mathrm{w}}$ aqane & 'male, woman's brother' & $/ \mathrm{m}^{\mathrm{w}}$ ene-n/ & 'woman's brother-3SG' \\
\hline$*^{\mathrm{w}} \mathrm{ata}$ & 'snake' & /na-mªt/ & 'NV-snake' \\
\hline * Rumwaq & 'house' & /ne-jumw / & 'NV-house' \\
\hline$*^{\mathrm{w}} \mathrm{atu}(\mathrm{k})$ & 'head, etc.' & $/ \mathrm{m}^{\mathrm{w}}$ ati-n/ & 'head-3SG' \\
\hline
\end{tabular}

Other Malakula languages show varying degrees of stability. The bilabial-labiovelar distinction in Tape seems to be quite stable (Crowley 2006d: 101-102). Other Malakula languages such as Vao (Maddieson 1989b), Nese (Crowley 2006c: 38), and V'ënen Taut (Fox 1979: 1) have undergone a shift from a bilabial-labiovelar distinction to a linguolabial-bilabial distinction. Interestingly, Unua (Pearce n.d.: 8-9) and Neve'ei (Musgrave 2007: 12) are currently undergoing the same kind of change as Nahavaq. Nahavaq speakers are not in regular contact with speakers of these languages, so it is surprising that, isolated from each other, they are undergoing the same change within approximately the same generation after retaining a labial distinction for thousands of years. I can only speculate that the change is influenced by Bislama, which does not have such a distinction and which is playing a larger role in young people's lives.

\subsection{Vowels}

This section describes vowel phonemes and allophones. High vowel deletion is discussed in Section 2.4.3, and vowel harmony/assimilation is discussed in Section 2.4.2. Phonetic diphthongs are analysed as a vowel and a glide and are discussed in Section 2.3.2.

Nahavaq has a simple five-vowel system with no length distinction. The vowels are shown contrasting in Table 16. Other languages of Malakula have more complex vowel systems involving length distinctions, schwa, and front rounded vowels, but Nahavaq has none of these.

Table 16: Five vowels contrasting in verb roots

\begin{tabular}{ll}
\hline i-sal// '3SG.R-hunt' \\
/i-sel// '3SG.R-hook' \\
/i-sil/ ' & '3SG.R-run and hide' \\
/i-sol// '3SG.R-salty' \\
/i-sul/ ' & '3SG.R-warm oneself' \\
\hline
\end{tabular}

The closely related language, Nāti, has long vowels (Crowley 1998b: 108). Many Nāti words that contain long vowels have $\mathrm{V} h \mathrm{~V}$ sequences in Nahavaq cognates. For example, the language name, Näti /nati/, in Nahavaq is pronounced /nahati/. And likewise, the language name Nahavaq /nahaßa?/ is pronounced /na:ßa?/ in Nāti. But there are also Nāti words with long vowels such as /ni-me:tu/ 'coconut' (Crowley 1998b: 133) which correspond to simple short vowels in Nahavaq such as in /ni-metu/ 'coconut'. For some Nahavaq speakers, intervocalic $/ \mathrm{h} /$ is dropped in some contexts resulting in phonetic long vowels (Section 2.7.3), but it does not happen widely or consistently enough to be considered part of general Nahavaq phonology. 
Schwas are known to exist in Naman (Crowley 2006b: 31-36), Tape (Crowley 2006d: 92-99), V'ënen Taut (Fox 1979: 1), and Ninde, which is one of Nahavaq's nearest neighbours. There are also front rounded vowels attested in Nāti (Crowley 1998b: 108), Port Sandwich (Crowley 2002a: 650), Uripiv (McKerras 2001: 2), Unua (Pearce n.d.: 2), and for older speakers of Neverver (Barbour, p.c.).

There is a front rounded [y] allophone of Nahavaq /u/, but for Nahavaq, this is conditioned by adjacent labial consonants rather than producing contrasts itself (Section 2.2.1).

\subsubsection{Vowel allophones}

There is some variation in frontness and backness of vowels depending on adjacent consonants. If a vowel occurs between two front consonants $\left(/{ }^{\mathrm{m}} \mathrm{b}^{\mathrm{j}} /, / \mathrm{m}^{\mathrm{j}} /, / \beta^{\mathrm{j}} /, / \mathrm{p}^{\mathrm{j}} /, /{ }^{\mathrm{n}} \mathrm{d} /\right.$, $/ \mathrm{n} /, / \mathrm{s} /, / \mathrm{t} /, / 1 /)$, it is more fronted than if it occurs between two back consonants $\left(/ \mathrm{m}^{\mathrm{w}} \mathrm{w} /\right.$, $\left./ \mathrm{m}^{\mathrm{w}} /, / \beta^{\mathrm{w}} /, / \mathrm{p}^{\mathrm{w}} /, / \mathrm{h} /, / \mathrm{R} /, / \mathrm{p} \mathrm{g} /, / \mathrm{y} /, / \mathrm{k} /\right)^{24} / \mathrm{r} /$ appears to be rather neutral in terms of fronting or backing of vowels, ${ }^{25}$ and the effects of $/ \mathrm{w} /$ and $/ \mathrm{j} /$ are not known. Figure 9 shows the formant values for vowels occurring before non-labial front and back consonants. The difference is particularly strong in the /u/ vowel, with no overlap between its front and back ellipses. Strangely, the /i/ vowel appears to be more advanced when adjacent to back consonants than front consonants. ${ }^{26}$

\footnotetext{
${ }^{24}$ A very similar pattern has been noted in Ponapean, which also groups bilabial consonants with alveolar consonants and labiovelar consonants with velars and also /r/ and /t/ (Rehg and Sohl 1981: 44). ${ }^{25}$ While / $\mathrm{r} /$ is produced in the alveolar region like other front consonants, there is likely to be a phonetic difference in the shape of the tongue with $/ \mathrm{r} /$ tending to have a more concave shape than $/ 1 /$, $/ \mathrm{n} /, / \mathrm{t} /$, and $/ \mathrm{s} /$. If it is the raising of the tongue body toward the palate in the articulation of front consonants that causes the fronting of vowels, the tongue shape of / $\mathrm{r} /$ could explain why it does not group with other alveolar consonants in the effect it has on vowels.

${ }^{26}$ Paul Warren (p.c.) suggest that the formants of the /i/ vowels may be influenced by the fact that all back conditioned $/ \mathrm{i} /$ vowels in this sample were followed by the velar nasal, while none of the front conditioned /i/ vowels was followed by a nasal.
} 


\section{Figure 9: Vowel formants influenced by consonants}

Formants of vowels between sets of front consonants and back consonants by a 50-year-old woman. 'iF' represents a /i/ vowel between front consonants, ' $\mathrm{iB}$ ' a /i/ vowel between back consonants, etc. Words elicited for front condition: /nalal/ 'trocchus

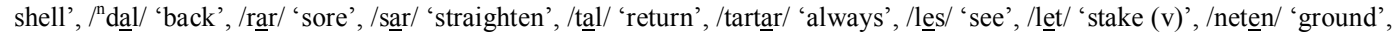
/lislis/ 'sore (eye)', /nilil/ 'kind of shell', /nilit/ 'fence', /nin dis/ 'dish', /sir/ 'scatter', /totot/ 'grandfather', /nisol/ 'salt', /nitortor/

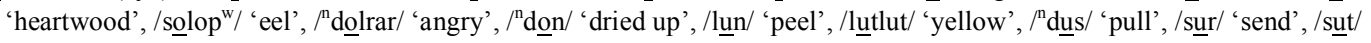

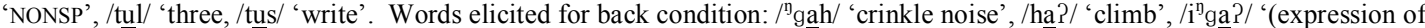

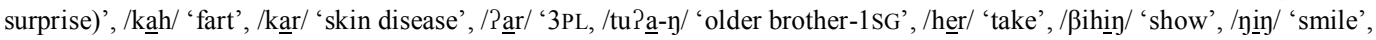
/nikin/ 'king', /" gor/ 'block', /Por/ 'today', /koh/ 'located', /tor/ 'burp' /hu?/ 'give', /hur/ 'near', /”gur/ 'cause', /kuk/ 'cook' Made with JPlotFormants.

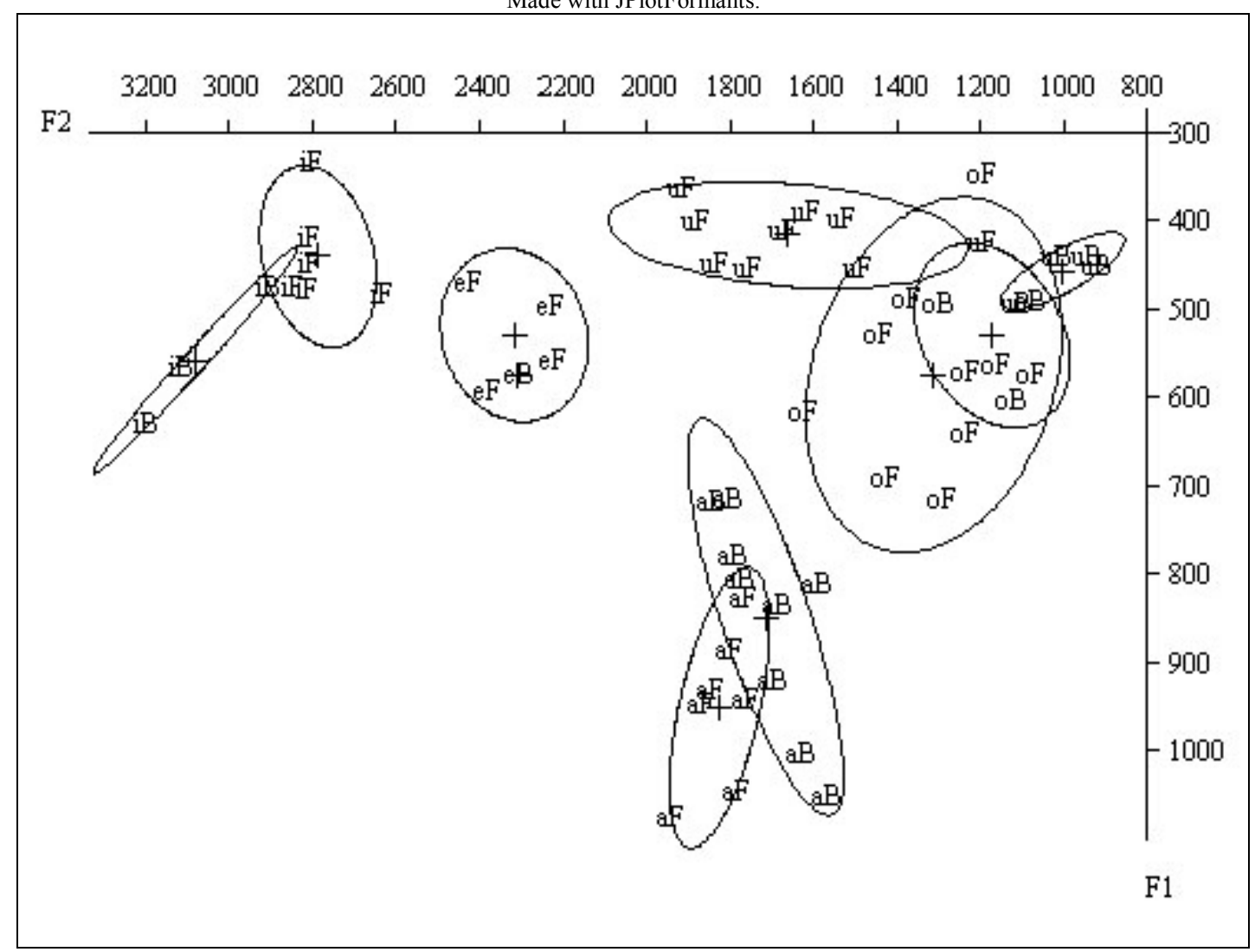

The same pattern can be seen with labial consonants (Figure 10). I present labial consonants separately from non-labial consonants because the effect of labial consonants on vowels is important for understanding some of the articulatory difference between bilabial and labiovelar consonants discussed in Section 2.1.3.1. Note that Figure 10 shows completely separated areas for the two labial conditions for $/ \mathrm{a} /$ and $/ \mathrm{u} /$, and this pattern is similar to what Figure 9 showed with non-labial consonants. Also of interest is the closeness in F1 and F2 between the $/ \mathrm{u} / \mathrm{after}$ and bilabial consonant and a /i/ after a labiovelar consonant. This may help to explain the variation in words like $/{ }^{\mathrm{m}} \mathrm{b}^{\mathrm{j}}$ ura?tew $/ \sim /{ }^{\mathrm{m}} \mathrm{b}^{\mathrm{w}}$ ira?tew/ 'hermit crab', $/ \mathrm{p}^{\mathrm{j}} \mathrm{uj} / \sim / \mathrm{p}^{\mathrm{w}} \mathrm{i} /$ ' pick fruit by twisting', which is discussed in Section 2.7.1. 


\section{Figure 10: Formants of vowels following labial consonants}

Formants of vowels following bilabial (1) and labiovelar (2) consonants by a 31-year-old man. Note that /o/ is not charted here because bilabial consonants do not occur before an /o/ vowel. Minimal pairs elicited: $/ \beta^{\mathrm{w}} \underline{\mathrm{i}} \mathrm{\beta}^{\mathrm{w}}$ is/ 'DUP-cut pieces', $/ \beta^{\mathrm{j}}$ is $\beta^{\mathrm{j}}$ is/ 'call to

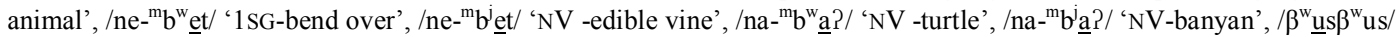
'squeeze coconut milk', $/ \beta^{\mathrm{j}} \underline{\mathrm{u}}-\beta^{\mathrm{j}} \mathrm{us} /$ 'DUP-pull', $/ \beta^{\mathrm{w}} \underline{\mathrm{ere}} \beta^{\mathrm{w}} \mathrm{er} /$ 'DUP-say', $/ \beta^{\mathrm{j}} \underline{\mathrm{ere}} \beta^{\mathrm{j}} \mathrm{er} /$ 'make fire', $/ \beta^{\mathrm{w}} \underline{\mathrm{el}} /$ ' 'come', $/ \beta^{\mathrm{j}} \underline{\mathrm{el}} /$ 'taboo',

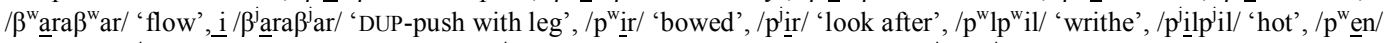

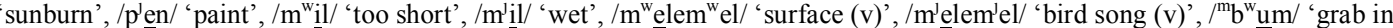

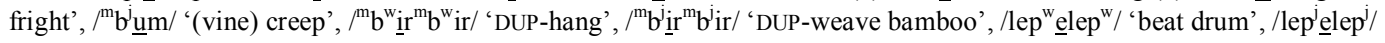
'splash'.

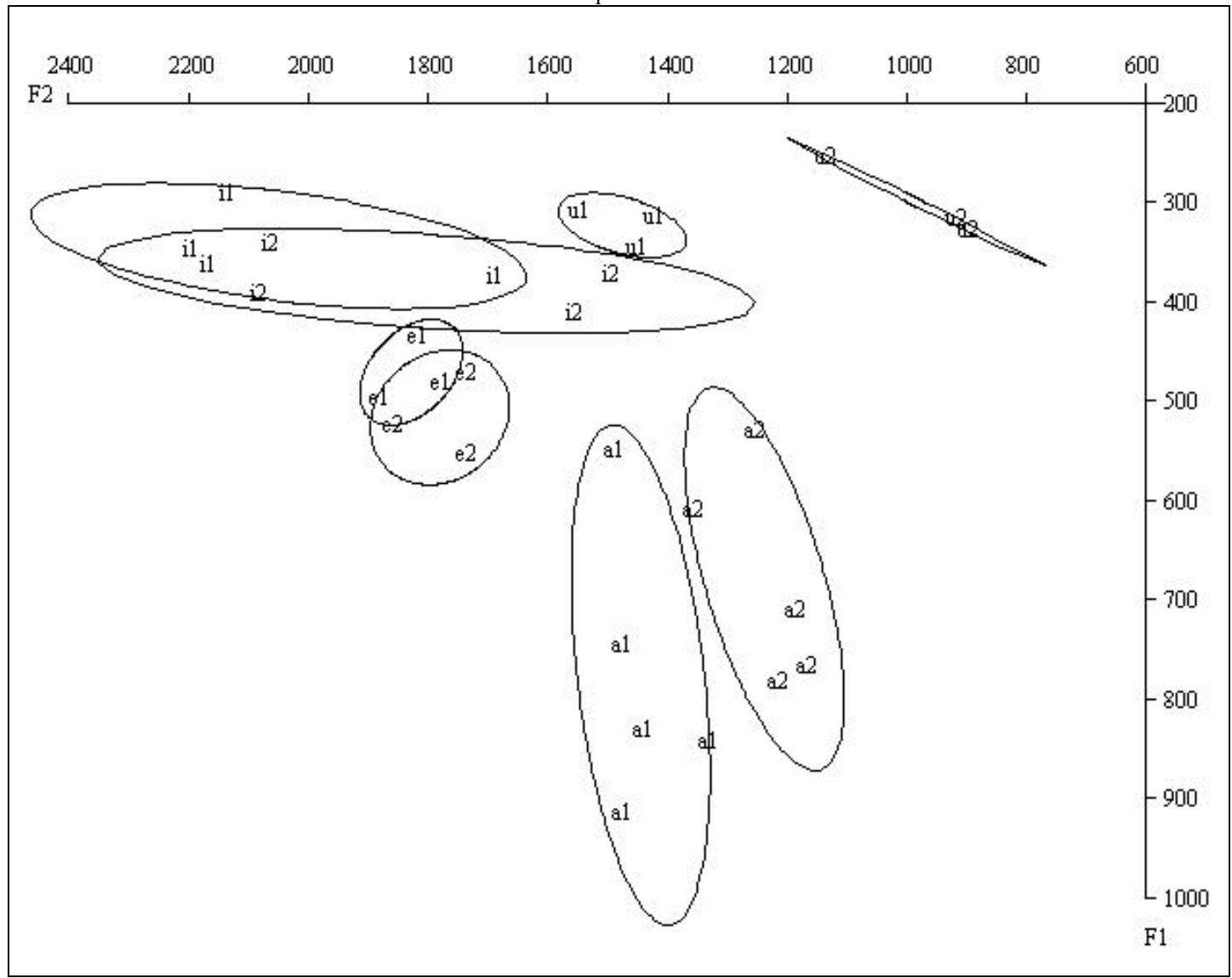

\subsection{Phonotactics and the syllable}

Nahavaq speakers generally have no trouble dividing words into syllables. However, some speakers divide a VCV sequence so that the intervocalic consonant is in both a coda position to the preceding vowel and onset to the following vowel. This is particularly common if the intervocalic consonant is a prenasalised stop, i.e. $/ \mathrm{ta}^{\mathrm{n}} \mathrm{gaw} /$ 'arrive' is divided as /tan.gaw/ [06NB6.033 060802.wav 1051.462 1067.680]. ${ }^{27}$ This may simply reflect the restriction on open syllables (Section 2.3.3) rather than being a sign of ambisyllabicity. In any case, I will analyse all VCV sequences as syllabified into V.CV, maximising the onset position. I have not come across any phonetic evidence that contradicts this analysis, and some sandhi phenomena support the syllabification of an intervocalic consonant with a following vowel (Section 2.4.1).

For non-borrowed words, Nahavaq syllables have the form $(\mathrm{C}) \mathrm{V}(\mathrm{C})$ as demonstrated in Table 17.

\footnotetext{
${ }^{27}$ This could be taken as support for an analysis of intervocalic prenasalised stops as two phonemes. However, other speakers do not divide in this same manner. Though I do not have a record of it, I also remember many times nasals being split into two syllables as in /ne-m'en/ 'nV-bird' split as /nem . $^{\mathrm{j}}$ en/ $^{\mathrm{j}}$
} 
Table 17: Examples of syllable types

V syllable: /e-tay/ [e.tay] 'LOC-DIST'

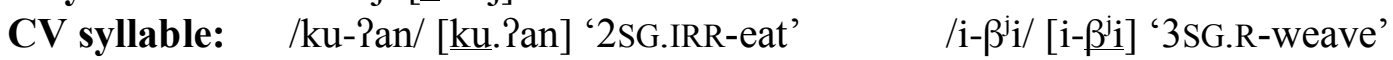

VC syllable: /i-s-lip'/ [is.lip'] '3SG.R-NEG-take'

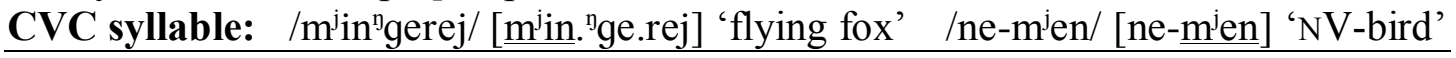

Only when a high vowel has been deleted (Section 2.4.3), can a consonant cluster onset occur in surface forms such as /ti-re-les/ [tre.les] 'REL-3PL-see'. Vowels never occur in sequence. Syllables without an onset consonant only occur word-initially and are restricted to a few grammatical classes (see Section 2.3.3).

\subsubsection{Coda restrictions}

Labial plosives $/ \mathrm{p}^{\mathrm{j} /}$ and $/ \mathrm{p}^{\mathrm{w}} /$ are not distinguished from their corresponding fricatives $/ \beta^{\mathrm{j}} /$ and $/ \beta^{\mathrm{w}} /$ in coda position. For example, $/ \mathrm{i}-\mathrm{lip}^{\mathrm{j} /}$ ' $3 \mathrm{SG}$-take' is pronounced as [ilip $\mathrm{p}^{\mathrm{j}}$ ], $\left[\mathrm{ili} \beta^{\mathrm{j}}\right]$, or [ili $\left.\phi^{\mathrm{j}}\right]$ and /i-rop ${ }^{\mathrm{w}} /$ '3SG-run' is pronounced as [irop $\left.{ }^{\mathrm{w}}\right]$, [iro $\left.\beta^{\mathrm{w}}\right]$, or [iro $\left.\phi^{\mathrm{w}}\right] .^{28}$ Some speakers always use the voiceless stop variant. Others always use a fricative variant. And some speakers systematically use a stop in these words, but when the following word begins with a vowel, the labial consonant is resyllabified as an onset fricative, for example /i-lip/ [i.lip'] '3SG-take' but /i-lip ${ }^{\mathrm{j}} \mathrm{en} /$ [i.li. $\beta^{\mathrm{j} e n]}$, '3SG-take ID'. A similar pattern of non-distinction of labial obstruents can be seen in Tape where the labial fricative and voiceless plosive are only differentiated in non-final position (Crowley 2006d: 102).

Prenasalised stops are being lost in coda position in Nahavaq. Word finally, there are many examples where older speakers have a prenasalised stop and younger speakers have the corresponding nasal instead (see Section 2.7.2). For example, / $\mathrm{kina}^{\mathrm{n}} \mathrm{g} /{ }^{\text {' }} 1 \mathrm{sG}$ ' is pronounced $\left[\mathrm{kina}^{\mathrm{n}} \mathrm{g}\right.$ ] by older speakers but [kinan] by younger speakers. But morpheme-internally I have not found any convincing cases of a prenasalised stop occurring in coda position before another consonant $\left(\mathrm{V}_{-} . \mathrm{CV}\right) .{ }^{29}$ Only in reduplicated roots are there many examples $\left(/ \mathrm{su}^{\mathrm{m}} \mathrm{b}^{\mathrm{w}}-\mathrm{su}^{\mathrm{m}} \mathrm{b}^{\mathrm{w}} /\right.$ 'DUP-sit', /li $\mathrm{i}^{\mathrm{m}} \mathrm{b}^{\mathrm{j}} \mathrm{i}^{\mathrm{m}} \mathrm{b}^{\mathrm{j}} /$ 'DUProll').

$/ \mathrm{k} /$ is very rare in a coda position. It is found in borrowed words such as /i-kuk/ '3SG.R-cook', which is borrowed from Bislama, and /i-makak/ '3SG.R-shine.through', which appears to be borrowed from $\mathrm{Na}$ 'ahai. It is also found in animal sound verbs such as /i-kik/ '3SG.R-chirp' and /i-kilkak/ '3SG.R-flying.fox.call'. Besides those restricted sets, Nahavaq does not have $/ \mathrm{k}$ / in coda position. Where neighbouring languages have $/ \mathrm{k} /$ in coda position, Nahavaq has / $/$.

\subsubsection{Glides}

Glides /w/ and / j/ fill an onset or coda position, just as any other consonants. The status of glides as consonants can be seen in their distribution. With the exception of

\footnotetext{
${ }^{28}$ In coda position, I have chosen to use the plosive symbols $/ \mathrm{p}^{\mathrm{j}} /$ and $/ \mathrm{p}^{\mathrm{w}} /$ to represent the sounds $\left[p^{\mathrm{j}}\right] \sim\left[\beta^{\mathrm{j}}\right] \sim\left[\phi^{\mathrm{j}}\right]$ and $\left[\mathrm{p}^{\mathrm{w}}\right] \sim\left[\beta^{\mathrm{w}}\right] \sim\left[\phi^{\mathrm{w}}\right]$ respectively because in my experience it seems to be the most common pattern.

${ }^{29}$ The closest candidates are /me ${ }^{\mathrm{m}} \mathrm{bkih} /$ 'turn over in one's sleep', which would appear to be bimorphemic based on the existence of /kih/ 'shift over', and /tamblas/ 'jump up in fright', which appears to be composed of $/ \mathrm{ta}^{\mathrm{m}} \mathrm{b}^{\mathrm{w}} \mathrm{ul} /$ 'stand up quickly' and -Vs 'transitive suffix' (Section 4.1.3), which then undergoes a process of high-vowel deletion as described in Section 2.4.3.
} 
/ij/ and /uw/, all combinations of VG and GV can occur (Table 18), ${ }^{30}$ but in nonborrowed words, there are no examples of VGC or CGV in a single syllable. It would appear that the glide is occupying the coda or onset of the syllable, making such forms impossible. While VGC or CGV patterns may exist in borrowed words (Section 2.3.5), they are unstable and tend to change to fit into $(\mathrm{C}) \mathrm{V}(\mathrm{C})$ syllable structure.

Table 18: Glide and vowel combinations

\begin{tabular}{|c|c|c|c|c|}
\hline \multicolumn{2}{|r|}{$\mathbf{w}$} & \multicolumn{3}{|c|}{$\mathbf{j}_{-}$} \\
\hline _a & /war/ & 'white haired' & /jar/ & 'finish' \\
\hline e & /wel/ & 'unravel' & /jes/ & 'touch' \\
\hline _i & /wijew/ & ‘worry' & /jip/ & ‘dive’' \\
\hline _o & /wowow/ & 'older brother' & /johjoh/ & 'strong' \\
\hline \multirow[t]{2}{*}{$=\mathrm{u}$} & $/ \mathrm{wu}^{\mathrm{n}} \mathrm{d} /$ & 'join’' & /juh/ & 'dig' \\
\hline & $\mathbf{w}$ & & $\mathbf{j}$ & \\
\hline$a_{-}$ & \multirow{5}{*}{$\begin{array}{l}\text { /law/ } \\
\text { /hew/ } \\
\text { /rißiw/ } \\
\text { /mbow/ }\end{array}$} & 'to sea' & /tataj/ & 'father' \\
\hline$e_{-}$ & & 'humid' & $/ \beta e j /$ & 'go’' \\
\hline i_ & & 'umbrella palm' & & \\
\hline o_ $_{-}$ & & ‘big’' & /Roj/ & 'scrape', \\
\hline$u_{-}$ & & & $/ \mathrm{m}^{\mathrm{w}} \mathrm{uj} /$ & 'earthquake' \\
\hline
\end{tabular}

\subsubsection{Initial and final vowels}

All canonical nominal and verbal roots begin with consonants. Only a restricted set of words begin with vowels. These include those beginning with a locational $e$ - such as /era?aj/ 'inland', /e $\beta^{\mathrm{j}} \mathrm{un} /$ 'under', /ejay/ 'there' or /etiy/ 'this' (Section 3.1.2.4.1, 6.4.1) and those beginning with personal $a$ - (Sections 3.1.2.4.2, 3.4.8.1 and 6.4.1) such as $/ \mathrm{a}^{\mathrm{m}} \mathrm{b}^{\mathrm{w}}$ at/ 'white person', /ajtip/ '(personal name)', and /asay/ 'that person'. There are also three verbal subject prefixes that begin with vowels: /i-/ '3SG.R', /a-/ '2PL', and /u-/ '2SG.R' (Section 4.2.1). Other words known to begin with vowels include $/ \mathrm{a}^{\mathrm{m}} \mathrm{b}^{\mathrm{j}} \mathrm{eh} /$ 'where', /a?/ 'tag question', /ija?/ 'who', /inuy/ '2sG pronoun', /utin/ 'here' and /utin/ 'there'. For many words it is difficult to tell whether they begin with a vowel or with a glottal stop since non-phonemic glottal stops are often inserted before initial vowels (Section 2.4.1). In non-borrowed words, only / $\mathrm{u} /$ and $/ \mathrm{i} /$ can occur word-finally

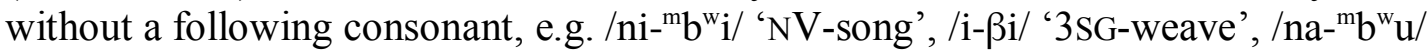
'NV-bamboo', /i-ru/ '3SG-two'.

\subsubsection{Consonant clusters}

Consonant clusters can occur where two $(\mathrm{C}) \mathrm{V}(\mathrm{C})$ syllables are joined, for example: /maliah/ 'cold', /surmeh/ 'clear throat', /nohyoh/ 'lazy'. The only restrictions I have found on these cross-syllabic consonant clusters include general restrictions on some coda consonants (Section 2.3.1), and a restriction on sequences of the same consonant (see degemination in Section 2.4.5). Also, some younger speakers are losing glottal stops from consonants clusters (see Section 2.7.3).

\footnotetext{
${ }^{30}$ One possible analysis would be that $/ \mathrm{ij} /$ and /uw/ actually do occur and that there are no words that end in an open syllable, but that what I have analysed as / $\mathrm{i}-\beta^{\mathrm{j}} \mathrm{i} /$ ' 3 sG-weave' and /i-ru/ '3sG-two' are actually $/ \mathrm{i}-\beta^{\mathrm{i}} \mathrm{ij} /$ and $/ \mathrm{i}$-ruw/. This would be consistent with the fact that $/ \mathrm{j} /$ and $/ \mathrm{w} /$ appear as glides between these words and a following vowel, i.e. /i- $\beta{ }^{\mathrm{i}} \mathrm{i}(\mathrm{j})$ ejay/ [i $\beta^{\mathrm{j}} \mathrm{ijejan]}$ ' $3 \mathrm{SG} . \mathrm{R}-w e a v e$ LOC-DIST', [i$\mathrm{ru}(\mathrm{w}) \mathrm{en}$ ] [iruwen] '3sG-two ID'. However, I find this analysis overly complex and unnecessary.
} 
In surface forms, there can be consonant clusters in onset position word-initially where a high vowel has been deleted (Section 2.4.3). For example, / ${ }^{\mathrm{m}} \mathrm{bi}$-lu-wej/ 'toin-water' is pronounced as either [ ${ }^{\mathrm{m}}$ biluwej] or [ $\left.{ }^{\mathrm{m}} \mathrm{bluwej}\right], / \mathrm{ti}^{-} \mathrm{ni}{ }^{\mathrm{n}} \mathrm{gi}{ }^{\mathrm{n}} \mathrm{d} /$ is pronounced as [tini $\left.{ }^{\mathrm{n}} \mathrm{gi}^{\mathrm{n}} \mathrm{d}\right]$ or [ tni $\left.^{\mathrm{n}} \mathrm{gi}^{\mathrm{n}} \mathrm{d}\right]$, and / ${ }^{\mathrm{m}}$ bura?tew/ 'hermit crab' is pronounced as [ ${ }^{\mathrm{m}} \mathrm{b}^{\mathrm{j}}$ ura?tew] or [ ${ }^{\mathrm{m}}$ bra?tew].

\subsubsection{Borrowed syllables}

Some borrowed words break the general syllable rules of Nahavaq. There are some words which contain consonant clusters in a syllable onset. The words in Table 19 were borrowed into Nahavaq from Bislama and have two variants: one with an onset cluster and one in which the cluster has been broken up by an epenthetic high vowel.

\section{Table 19: Borrowing consonant clusters}

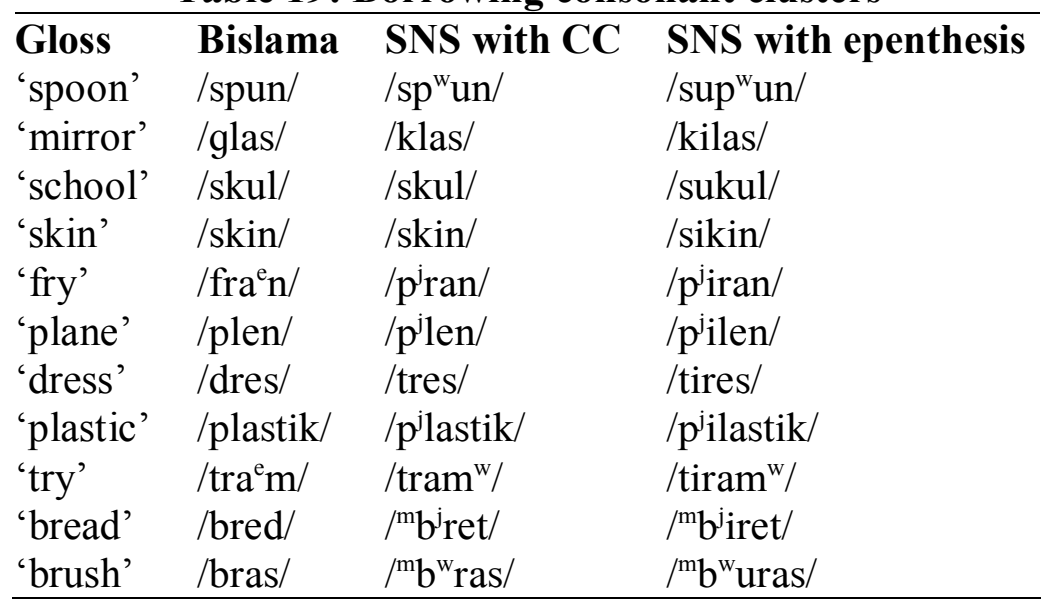

Interestingly, for those which are nouns, when they are prefixed with $n i$ - (Section 3.3.1.2), it is the form with the epenthetic high vowel which is used despite the fact that the $n i$-could allow the first consonant of the root to become a coda rather than part of a complex onset /nitires/*/ni.tres/*/nit.res/ 'NI-dress'. This seems contradictory to the obligatory nominal prefixing of monosyllabic nominal roots (Section 2.4.7). It also seems contradictory to the patterns of $v i$ - prefixation seen in Section 2.4.3.4. The best explanation for this pattern then is that the nominal roots that receive Nahavaq affixation are also fully transformed into Nahavaq phonology (with epenthetic vowels breaking up consonant clusters). The non-prefixed forms may be retaining borrowed phonology. ${ }^{31}$

Borrowed words which contain diphthongs may also change to fit Nahavaq's (C)V(C) syllable structure. Words like /tajm/ /tam/ 'when' and /trajm/ /tram/ /tiram/ 'try' delete the glide in the more nativised variant. In other words such as $/ \mathrm{rajs} / \sim / \mathrm{rajis} /$ 'rice', /pawn/ /pawun/ 'pound', /kawn/ /kawun/ 'account', /kwapw/ /kuwapw/ 'guava', the more common form is that in which the diphthong is split into two syllables separated by a glide. ${ }^{32}$

\footnotetext{
${ }^{31}$ There is one borrowed word that appears to have retained a complex onset in all situations: /stori/ /ni-stori/ 'story'.

${ }^{32}$ Where the borrowed diphthong exists in a single syllable, I have represented it as a vowel plus a glide rather than a sequence of two vowels, and I interpret the glide as part of a complex coda rather than part of the nucleus. This is partially supported by evidence from the language game, P-language, which transforms syllables from $\mathrm{C}_{1} \mathrm{~V}_{1} \mathrm{C}_{2}$ to $\mathrm{C}_{1} \mathrm{~V}_{1} \mathrm{pV}_{1} \mathrm{C}_{2}$. In [08005.wav 32.500 36.500], a Nahavaq
} 
Another exception to normal Nahavaq syllable structure occurs when borrowed words contain a word-final non-high vowel such as in $/ \mathrm{ka} \beta^{\mathrm{j} a}$ / 'kava', /erija/ 'area', and /ham ${ }^{\mathrm{w}}$-a/ 'hammer', which were borrowed from Bislama, and /nolo/ 'language', /koro/ 'saucepan', /nere ${ }^{\mathrm{m}} \mathrm{b}^{\mathrm{w}} \mathrm{e} /$ 'old living area', which were borrowed from Na'ahai. ${ }^{33}$ Some speakers (especially younger ones) may add a final $/ \mathrm{h} /$ to these words ([ham $\left.{ }^{\mathrm{w}} \mathrm{ah}\right]$ 'hammer'), and many speakers produce a $/ \mathrm{h} /$ when these words are followed by a vowel (e.g. [hamwah en] 'hammer ID'), as discussed in Section 2.4.1.

\subsection{Morphophonemic topics}

\subsubsection{Morpheme-boundary processes}

When the alveolar trill is preceded by the alveolar nasal $/ \mathrm{n} /$, there is a plosive burst in the transition, for example, /i-m'in-rar/ [imindrar] '3SG-recent-make' [07009.wav 138.030 140.546 07009.052]. This also applies across word boundaries as in /hala-n re-mjetur/ [halandrem ${ }^{\mathrm{j}}$ etur] 'brother-3SG 3PL-sleep' [TB01.012 TB01.wav 46.409 49.471].

When one word finishes in a consonant, and the next word begins with a vowel, the final consonant can become more prominent than it would be when not followed by a vowel. ${ }^{34}$ This may be a process of resyllabification where the final consonant becomes the onset for the next word. This phenomenon is particularly apparent with $/ \mathrm{h} /$ which is relatively weak in coda position (and being lost by younger speakersSection 2.7.3) and so strong in onset position that it can cause syllable prominence

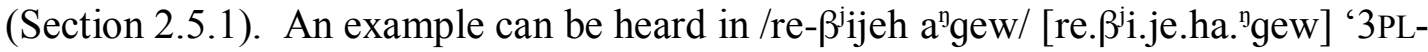
call Agcew' [07064.012 07064.wav 64.194 66.976]. Word-final labiovelar consonants can have a prominent off-glide when followed by a front vowel (see Section 2.1.3), and this can occur across morpheme boundaries or word boundaries as in $/ 1 \mathrm{i}-\mathrm{jum}^{\mathrm{w}}$ en/ [li.ju.mwen] ‘in-house ID’ [EC01.071 EC01.wav 361.017 366.282].

For some speakers who produce the labial segments $/ \mathrm{p}^{\mathrm{j}} / \sim \beta^{\mathrm{j}} /$ and $/ \mathrm{p}^{\mathrm{w}} / \sim / \beta^{\mathrm{w}} /$ (see section 2.3.1 on these underspecified segments) as voiceless stops $\left(/ \mathrm{p}^{\mathrm{j}} /\right.$ and $\left./ \mathrm{p}^{\mathrm{w}} /\right)$ in coda position, the same segment may be produced as a voiced fricative when a following morpheme begins with a vowel. For example, one speaker produced a stop utterance finally in /ro-rop w/ '3PL-run' [07076.007 07076.wav 28.231 34.137] and a voiced fricative intervocalically in /ku-ro $\beta^{\mathrm{w}}$ ewur/ '2SG.IRR-run Toman.Island' [07076.095 07076.wav 375.765 384.610]. The verbal roots /top $\mathrm{w} /$ 'jump' and / $\mathrm{rap}^{\mathrm{w} /}$ 'poison' can occur with final stops $\left[\right.$ top $\left.^{\mathrm{w}}\right]$ and $\left[\mathrm{rap}^{\mathrm{w}}\right]$, but when they occur with a transitive suffix (Section 4.1.3), the final consonant of the root appears as a fricative: [to $\beta^{\mathrm{w}}$ is] and [ra $\left.\beta^{\mathrm{w}} \mathrm{us}\right]$.

speaker produced the P-language form of /tajm/ 'when' as /tapajm/ rather than */tajpajm/, which may suggest that the $/ \mathrm{j} /$ element is part of the coda rather than the nucleus.

${ }^{33}$ It is difficult to be certain that these words were borrowed from Na'ahai. In the case of /koro/ 'saucepan', Nahavaq speakers told me that it was a Na'ahai word. I was surprised to find /nolo/ 'language' and $/$ nere $^{\mathrm{m}} \mathrm{b}^{\mathrm{w}} \mathrm{e} /$ 'old living area' (both of which are low frequency words which are not widely known among Nahavaq speakers) with word final non-high vowels when I did not find any other native words to have them. I asked $\mathrm{Na}$ 'ahai speakers if they had these words, and they confirmed that the form was apparently identical in Na'ahai. While Nahavaq and Na'ahai share many close cognates, words are not often identical between the two languages. So I suspect that these two words were borrowed from $\mathrm{Na}$ 'ahai.

${ }^{34}$ In this section, I refer to many things that happen at word boundaries. However, the phonological word in Nahavaq is not well-defined (Section 2.8). It is likely that with the exception of the nonphonemic glottal stop, most of the morphophonemic processes described in this section could apply at any morpheme boundary. 
When a word ends in a non-high vowel, which only occurs in borrowed words (Section 2.3.5) or when a $/ \mathrm{h} / \mathrm{h}$ has been lost from the speech of a younger speaker (Section 2.7.3), and the next word begins with a vowel, an $/ \mathrm{h} /$ segment can frequently be heard between them, for example, /holta et/ [holtahet] 'holder COMPL' [07051.043 07051.wav 332.497334 .359$]$. It is not clear whether there is an underlying final $/ \mathrm{h} /$ on some level or whether $/ \mathrm{h} /$ is the standard transition from a non-high vowel to another vowel. When high vowels are involved, a transition to another vowel is a glide, /w/ following $/ \mathrm{u} /$ or $/ \mathrm{j} /$ following $/ \mathrm{i} /$.

Words beginning with vowels may be realised with an initial non-phonemic glottal stop, for example, $/ \mathrm{a}^{\mathrm{m}} \mathrm{b}^{\mathrm{w}} \mathrm{at} / \mathrm{C}^{\mathrm{m}} \mathrm{b}^{\mathrm{w}} \mathrm{at}$ ' 'foreigner'. This makes it difficult to determine whether an initial glottal stop is phonemic or not. The best evidence comes from $t i$ prefixation (either the possessive $t i$ - described in Section 3.2.2.1, or the relative marker $t i$ - described in Section 3.4.7). For words with phonemic glottal stops like $/ 2 \mathrm{ej} /$ ' $3 \mathrm{SG}$ ', the prefix is realised as [ti], and the glottal stop remains: [ti?ej] 'POSS$3 \mathrm{SG}$ '. But if the glottal stop is non-phonemic as in $/ \mathrm{a}^{\mathrm{m}} \mathrm{b}^{\mathrm{w}} \mathrm{at} /$ 'foreigner', the prefix is realised as $[\mathrm{t}]$ and no glottal stop is present with prefixation: [ $\left.\mathrm{ta}^{\mathrm{m}} \mathrm{b}^{\mathrm{w}} \mathrm{at}\right]$ 'POSSforeigner'.

\subsubsection{Vowel harmony and assimilation}

This section describes three areas where vowel assimilation occurs. In most cases, both the trigger and the target are non-high vowels. The first two areas of assimilation concern prefixes, which exhibit regressive assimilation. A similar pattern is also found in /CVCe-/ reduplication (Section 2.4.6.2) and $/ \mathrm{nV}-/$ nominal prefixing (Section 2.4.7). The third area of vowel assimilation occurs across glottal consonants at both morpheme and word boundaries and exhibits both progressive and regressive assimilation.

\subsubsection{1. $m \mathrm{~V}$ -}

The vowel in the historical stative prefix (see Section 4.1.4) is lexically determined but shows a tendency toward vowel harmony, particularly for non-high vowels. Of the 116 words containing $m \mathrm{~V}$ - traces which are listed in Appendix 4, 69 have nonhigh vowels in the base. Of these, $96 \%$ (66 out of 69) have the same vowel in the prefix. For example, $/ \mathrm{m}^{\mathrm{j}}$ atar/ 'shrivelled', $/ \mathrm{m}^{\mathrm{j}} \mathrm{ewel} /$ 'unravelled', and $/ \mathrm{m}^{\mathrm{w}} \mathrm{op}^{\mathrm{w}} \mathrm{oj} /$ 'disassembled'. For roots containing high vowels, most contain either $/ \mathrm{a} / \mathrm{or} / \mathrm{e} / \mathrm{in}$ the prefix: / $\mathrm{m}^{\mathrm{w}}$ ahulhul/ 'hard-working', $/ \mathrm{m}^{\mathrm{j}} \mathrm{elim}^{\mathrm{j} / \text { ' }}$ soft'. But there is also a minority that have identical vowels in the prefix and in the base: /mundus/ 'decomposed', /mwisirsir/ 'crumbly'. Vowel assimilation in this prefix can also be seen in the reduplication of $/ \mathrm{m}^{\mathrm{j}} \mathrm{e}^{\mathrm{n}} \mathrm{des} /$ 'smooth', which has vowel raising in the reduplicand and also in the prefix: $/ \mathrm{m}^{\mathrm{j}} \mathrm{i}^{\mathrm{n}} \mathrm{dis}-\mathrm{des} /{ }^{36}$

\footnotetext{
${ }^{35}$ There are a few words for which I was not able to determine conclusively whether they started with a glottal stop or a vowel. This includes grammatical words like/(P)et/ 'but', and /ohoj/ 'simply', which cannot occur after either kind of $t i$-, and words like /(?)et/ 'COMPL', which seemed to behave differently for different speakers.

${ }^{36}$ Note that the labial nasal in $\mathrm{mV}$ - prefixes appears as bilabial in some words and labiovelar in others, and it is not predictable.
} 


\subsubsection{In verbal prefixes}

The /nde-/ 'next' verbal prefix (Section 4.4.1) as well as five verbal subject prefixes, /ne-/ '1 SG.R-' , /nde-/ '1IN.PL', /re-/ '3PL', /(ni) ${ }^{\mathrm{n}} \mathrm{ge}-/$ ' 1 SG.IRR-', and /ke-/ '3SG.IRR-' (Section 4.2.1), contain a vowel which undergoes the same assimilatory processes in each case. For each of these prefixes, if the first vowel in the base to which they attach contains $/ \mathrm{i} /, \mathrm{e} /$, or $/ \mathrm{u} /$, the vowel of the prefix will be $/ \mathrm{e} /$. But if the first vowel of the base is $/ \mathrm{a} /$ or $/ \mathrm{o} /$, the vowel in the prefix will be /a/ or /o/ respectively. ${ }^{37}$ For a minority of speakers, these prefixes may have an /o/ vowel when the first vowel of the base is $/ \mathrm{u} /$.

Table 20: Re- assimilating to vowel in base

\begin{tabular}{|c|c|c|}
\hline /a/ base: & re- '3SG' +/happw/'dance' & {$\left[\right.$ rahap $\left.^{\mathrm{w}}\right]$} \\
\hline /e/ base: & $r e-$ ' $3 \mathrm{SG}$ ' $+/ \mathrm{m}^{\mathrm{j}}$ etur/ 'sleep' & [rem etur] \\
\hline /i/ base: & $r e-' 3 \mathrm{SG}$ ' + $/ \mathrm{li} \mathrm{p}^{\mathrm{j} /}$ 'take' & {$\left[\right.$ relipp $\left.{ }^{j}\right]$} \\
\hline /o/ base: & $r e-$ ' $3 \mathrm{SG}$ ' + $/ \mathrm{rop}^{\mathrm{w}} /$ 'run' & {$\left[\right.$ rorop $\left.^{\mathrm{w}}\right]$} \\
\hline /u/ base: & $r e-{ }^{\prime} 3 \mathrm{sG}^{\prime}+/ \mathrm{su}^{\mathrm{m}} \mathrm{b}^{\mathrm{w}} /$ 'sit' & {$\left[\operatorname{resu}^{\mathrm{m}} \mathrm{b}^{\mathrm{w}}\right] \sim\left[\operatorname{ros}_{u^{\mathrm{m}}} \mathrm{b}^{\mathrm{w}}\right]$} \\
\hline
\end{tabular}

\subsubsection{Across glottals}

Assimilation of non-high vowels separated by a glottal consonant can happen across morpheme boundaries or word boundaries. ${ }^{38}$ I have found examples of both regressive and progressive vowel assimilation across glottals at morpheme boundaries. The only regressive example is /i-to? $\mathrm{a}^{\mathrm{m}} \mathrm{beh} /$ [ita? $\mathrm{a}^{\mathrm{m}} \mathrm{beh}$ ] ' $3 \mathrm{sg}-\mathrm{be}$ where' [MR01.086 MR01.wav 444.013 445.357]. Because I only have this single example, and I recall hearing it pronounced this way frequently in my time in South West Bay, I wonder if this may be a lexicalised sequence. Progressive assimilation is much more widespread: /a-her/ [ahar] '2PL-take' [07117.093 07117.wav 361.824 364.417], /wa-1-her/ [wa?har] '2DU-IRR-take' [07072.078 07072.wav 417.696 425.383], /wa-P-Poj/ [wa?aj] '2DU-IRR-scratch' [07072.078 07072.wav 417.696 425.383]. It is also widespread across word boundaries as in /naha $\beta^{\mathrm{j} a}$ ? en/ [naha $\left.\beta^{\mathrm{i} a} 9 a n\right]$ 'NV-what ID' [07117.573 07117.wav 1655.240 1657.630], /ru-koh en/ [rukohon] '3DU-be ID' [MR01.042 MR01.wav 286.161 289.801], /ru-koh ewur/ [rukohowur] '3DUbe Toman Island' [07064.005 07064.wav 32.275 39.056], and / $\beta^{\mathrm{j} i l a h}$ et/ [ $\beta^{\mathrm{j}}$ ilahat] 'Vila then' [07117.528 07117.wav 1557.315 1562.137]. However, I have also found examples of very similar sequences where the assimilation did not occur: /i-to? $\mathrm{a}^{\mathrm{m}} \mathrm{beh} /\left[\right.$ ito?a $\left.^{\mathrm{m}} \mathrm{beh}\right][07082.073$ 07082.wav 285.586 288.601], /ro-koh etin/ [rokohetin] '3PL-be ID' [07063.021 07063.wav 137.492 143.133].

\subsubsection{High vowel deletion}

High vowels can be deleted in the context $\mathrm{C}$ CV. In most cases that I have noticed (the exception being those in Section 2.4.3.4), this occurs word-initially creating a consonant cluster in onset position, which otherwise does not happen in Nahavaq. However, because all these examples can occur with the high vowel intact, I do not consider the consonant cluster to be the underlying form. Section 2.4.3.1 deals with

\footnotetext{
${ }^{37}$ Note that /e/ is occasionally produced before /a/ and /o/ roots, and is considered acceptable, but /a/ and /o/ realisations are much more common in these contexts. Because /e/ is acceptable in all contexts and because it is the standard realisation for these vowels in most contexts, I treat the vowels in these prefixes as being underlyingly /e/.

${ }^{38}$ I cannot say anything about assimilation within morphemes because I only have synchronic evidence and I cannot observe any processes happening within a single morpheme. However, in my dictionary, there are over 100 separate instances of $\mathrm{V}_{1} \mathrm{CV}_{1}$ where $\mathrm{V}_{1}$ represents a non-high vowel and $\mathrm{C}$ represents a glottal consonant, and there are no definite cases of two different non-high vowels occurring either side of a glottal consonant.
} 
high vowel deletion within morphemes. Sections 2.4.3.2 through 2.4.3.4 explain the pattern with three prefixes. A parallel can be drawn between these patterns of high vowel deletion and the high vowel epenthesis in borrowed words discussed in Section 2.3 .5

One other marginal example of high vowel deletion is that in rapid speech, an initial $i$ ' $3 \mathrm{SG}$ ' prefix can be so reduced as to be inaudible. However, there is a cline between a clear /i/ pronunciation and no audible vowel, and speakers consider the vowel to be present whether it is audible or not.

\subsubsection{Isolated lexical examples}

A cluster of two consonants can occur in onset position when a high vowel is deleted. For example $/{ }^{\mathrm{m}} \mathrm{b}^{\mathrm{j} u r a ? t e w / ~ ' h e r m i t ~ c r a b ' ~ m a y ~ b e ~ r e a l i s e d ~ a s ~[~}{ }^{\mathrm{m}} \mathrm{b}^{\mathrm{j} u r a ? t e w]}$ or [ ${ }^{\mathrm{m}} \mathrm{b}^{\mathrm{j}}$ ra?tew], and /silev'u-n/ 'under-3SG' may be realised as [sile $\beta^{\mathrm{j} u n]}$ [07074.004 07074.wav 15.062 20.812] or [sle $\beta^{j}$ un] [07116.061 07116.wav 302.246 306.668].

\subsubsection{2. $T(i)$ - prefixation}

There are two prefixes with the same $t(i)$ - form, a possessive marker (Section 3.2.2.1) and a relative marker (Section 3.4.7). Before many consonants, both of them can be realised as either [ti] or $[\mathrm{t}]$. Before $/ \mathrm{n} /, / \mathrm{r} /, / \mathrm{s} /$, and $/ 1 /$, the $[\mathrm{t}]$ realisation is particularly common:/ti-nu?un/ [tnu?un] 'POSS-1 IN.DU' [MR01.069 MR01.wav 382.434 385.263], /ti-re-me $\beta^{j}$ us/ [treme $\beta^{j}$ us] 'REL-3PL-white' [KO01.027 KO01.wav 82.085 84.132], /ti-sinesip/ [tsinesip] 'POSSSinesip' [07115.031 07115.wav 115.199 117.730], /ti-le $\beta^{\mathrm{w}}$ a?hat/ [tle $\beta^{\mathrm{w}}$ a?hat] 'POSS-morning' [07048.1046 07048.wav 2323.282 2325.562]. But it can also occur with others as in /ti-ke-m'elo?lo?/ [tkem'elo?lo?] 'REL-3SG.IRR-soft' [07095.062 07095.wav 485.025 490.353], $/ \mathrm{ti}-\beta^{\mathrm{j}} \mathrm{in}^{\mathrm{m}} \mathrm{b}^{\mathrm{w}} \mathrm{u}^{\mathrm{m}} \mathrm{b}^{\mathrm{w}}$ aRaw/ [ $\mathrm{t} \beta^{\mathrm{j}} \mathrm{in}^{\mathrm{m}} \mathrm{b}^{\mathrm{w}} \mathrm{u}^{\mathrm{m}} \mathrm{b}^{\mathrm{w}} \mathrm{a}$ aaw] 'REL-Vinmbwumbwaqaw' [07063.033 07063.wav 179.251 185.485], and /ti${ }^{\mathrm{m}} \mathrm{b}^{\mathrm{j}}$ enewur/ [ $\mathrm{t}^{\mathrm{m}} \mathrm{b}^{\mathrm{j}}$ enewur] 'POSS-Mbenewur' [07098.039 07098.wav 217.033 221.439]. However only the [ti] variant is possible before / $t /$ or / $/$ / [07NB1.085]. Before vowels, both prefixes are realised as $[\mathrm{t}] .^{39}$

\subsubsection{3. $M b$ - prefixation}

The $m b(i)$ - prefix (directional particle see Section 5.3.2.4) shows patterns very similar to those discussed in Section 2.4.3.2 for $t(i)$-. Before all consonants, it can be realised as [ $\left.{ }^{\mathrm{m}} \mathrm{b}^{\mathrm{j}} \mathrm{i}\right]$, but before many, it can also be realised as $\left[{ }^{\mathrm{m}} \mathrm{b}^{\mathrm{j}}\right]$. If the following sound is also a stop, the prefix stop is usually unreleased $\left[{ }^{\mathrm{m}} \mathrm{b}^{\mathrm{j}\urcorner}\right]$. A few examples (all from

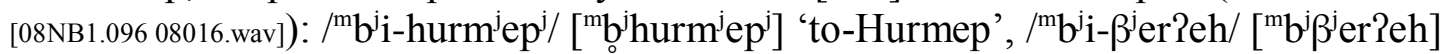

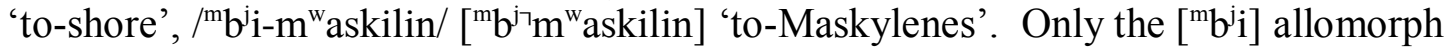
is possible before $/{ }^{\mathrm{m}} \mathrm{b}^{\mathrm{w}} /, / \mathrm{m}^{\mathrm{j}} \mathrm{j} /, / \mathrm{t} /, / \mathrm{k} /, / \mathrm{y} /$, and $/ \mathrm{n} /$ [08NB1.096].

\subsubsection{4. $V$ i- prefixation}

The copular/inchoative/directional prefix (Section 4.4.3) has two allomorphs: $\left[\beta^{\mathrm{j}} \mathrm{i}\right]$ and [p $\mathrm{p}^{\mathrm{j}}$. It differs from the $t(i)$ - and $m b(i)$ - prefixes discussed in the last two sections because it is always preceded by other verbal prefixes whereas $t(i)$ - and $m b(i)$ - are word-initial. When $v(i)$ - is immediately preceded and followed by consonants as in $/ \mathrm{ke}-\mathrm{s}-\beta^{\mathrm{j}} \mathrm{i}-\mathrm{m}^{\mathrm{w}}$ at/ '3SG.IRR-NEG-COP-snake', it is realised as [ $\left.\beta^{\mathrm{j}} \mathrm{i}\right]$ : [kes $\left.\beta^{\mathrm{j}} \mathrm{im}{ }^{\mathrm{w}} \mathrm{at}\right]$ [LS01.066

\footnotetext{
${ }^{39}$ Another possible analysis of $t(i)$ - prefixes it that the underlying form is /t-/ and that the high vowel is inserted to break up consonant clusters as in the case for borrowed word with consonant clusters (Section 2.3.5). I prefer the analysis of deletion rather than insertion because the /ti-/ form is more common in deliberate speech.
} 
LS01.wav 258.098 264.364]. But when it is preceded by a vowel as in $/ \mathrm{i}-\beta^{\mathrm{j}} \mathrm{i}-\mathrm{m}^{\mathrm{w}} \mathrm{at} /$, it can either be realised as a complete syllable [i. $\beta^{\mathrm{j}} \mathrm{i} . \mathrm{m}^{\mathrm{w}}$ at], or it can become the coda of the preceding syllable [ip ${ }^{\mathrm{j}} . \mathrm{m}^{\mathrm{w}}$ at] [LS01.065 LS01.wav 253.379 258.098]. Unlike with $t(i)$ - and $m b(i)$-, there do not appear to be any restrictions on the realisation of $\beta(i)-$ as $\left[\mathrm{p}^{\mathrm{j}}\right]$, presumably because it is not forming a complex onset. Before a root with initial $/ \mathrm{p}^{\mathrm{j}} /, / \mathrm{p}^{\mathrm{w}} /, / \beta^{\mathrm{j}} /$, or $/ \beta^{\mathrm{w}} /$, a copular prefix may completely disappear due to degemination (Section 2.4.5): $/$ ni- $\beta^{\mathrm{j} i}$ - $\beta^{\mathrm{j}}$ ene-n-yen/ $>/$ nip $^{\mathrm{j}}$. $\beta^{\mathrm{j}} \mathrm{e}$.nen.yen/ $>$ [ni. $\beta^{\mathrm{j} e}$.nen.yen] 'sister (literally: NI-COPsister-3SG-NOM)'.

\subsubsection{Labial harmony}

Most single morphemes that contain more than one labial consonant have either labiovelar or bilabial consonants (/m $\mathrm{m}^{\mathrm{w}} \mathrm{ap}$ w/ 'heal' /na- ${ }^{\mathrm{m}} \mathrm{b}^{\mathrm{w}} \mathrm{a}^{\mathrm{m}} \mathrm{b}^{\mathrm{w}} /{ }^{\text {' }} \mathrm{NV}$-liver', $/ \mathrm{m}^{\mathrm{j}} \mathrm{ev}{ }^{\mathrm{j}} \mathrm{us} /$

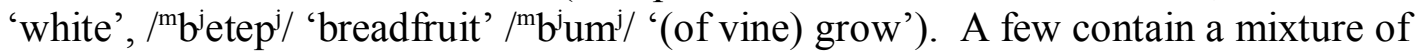
labiovelar and bilabial consonants, but in all such examples that I am aware of, there is always a non-labial consonant intervening. Examples include $/{ }^{m} b^{w}$ inp ${ }^{j} a^{n} d /$ 'young' and $/{ }^{\mathrm{m}} \mathrm{b}^{\mathrm{j}} \mathrm{us} \mathrm{s}^{\mathrm{m}} \mathrm{b}^{\mathrm{w}}$ ar/ 'swamp'. Across morpheme boundaries labiovelar and bilabial consonants may occur without intervening non-labial consonants. For examples, /i-

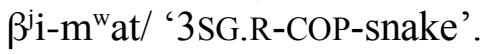

There is also a pattern of labial assimilation in directly possessed nouns. With the directly possessed nouns in Table 21, the last consonant in the nominal root is bilabial when the third person singular possessor suffix, /-n/ is attached, but it is labiovelar when the second person singular possessor suffix, $/-\mathrm{m}^{\mathrm{w}} /$ is attached.

Table 21: Directly possessed nouns with labial harmony

\begin{tabular}{|c|c|c|c|}
\hline Nahavaq & Gloss & Nahavaq & Gloss \\
\hline /tem ${ }^{\mathrm{j}} \mathrm{e}-\mathrm{n} /$ & 'father-3SG' & $/ \operatorname{tam}^{\mathrm{w}} \mathrm{a}-\mathrm{m}^{\mathrm{w}} /$ & 'father-2sG' \\
\hline /ne-he $\beta^{j}$ e-n/ & 'NV-what-3sG' & $/$ ne-he $\beta^{\mathrm{w}} \mathrm{e}-\mathrm{m}^{\mathrm{w}} /$ & 'NV-what-2sG' \\
\hline$/ \operatorname{tin} \beta^{\mathrm{j}} \mathrm{u}-\mathrm{n} /$ & 'wife-3SG' & $/ \operatorname{tin} \beta^{\mathrm{w}} \mathrm{u}-\mathrm{m}^{\mathrm{w}} /$ & 'wife-2sG' \\
\hline$/ \mathrm{e}^{\mathrm{m}} \mathrm{b}^{\mathrm{j}} \mathrm{u}-\mathrm{n} /$ & 'down.in-3SG' & $/ \mathrm{e}^{\mathrm{m}} \mathrm{b}^{\mathrm{w}} \mathrm{u}-\mathrm{m}^{\mathrm{w}} /$ & 'down.in-2sG' \\
\hline /mb $b^{\mathrm{j} u l u-n / ~}$ & 'leg-3SG' & $/{ }^{m} b^{w}$ ulu-m ${ }^{\mathrm{w}} /$ & 'leg-2sG' \\
\hline$/ m^{w} a P a j^{m} b^{j} u-n /$ & 'grandchild-3SG' & $/ \mathrm{m}^{\mathrm{w}} \mathrm{a} a \mathrm{j}^{\mathrm{m}} \mathrm{b}^{\mathrm{w}} \mathrm{u}-\mathrm{m}^{\mathrm{w}} /$ & ' 'grandchild-2sG' \\
\hline
\end{tabular}

Note that in $/{ }^{\mathrm{m}} \mathrm{b}^{\mathrm{j}} \mathrm{ulu}-\mathrm{n} /$ ' 'leg-3SG' and $/ \mathrm{mb}^{\mathrm{w}} \mathrm{ulu}-\mathrm{m}^{\mathrm{w}} /$ 'leg-2SG', the labial assimilation happen across an intervening /1/. There is also one example, $/ \mathrm{ne}^{-}{ }^{\mathrm{m}} \mathrm{b}^{\mathrm{j}} \mathrm{e}-\mathrm{n} /{ }^{~} \mathrm{NV}$-body$3 \mathrm{SG}$ ' vs. $/$ ne- $^{\mathrm{m}} \mathrm{b}^{\mathrm{j} e} \mathrm{e}-\mathrm{m}^{\mathrm{w}} /^{\mathrm{N} V} \mathrm{~V}$-body-2sG', which does not undergo labial harmony.

\subsubsection{Degemination}

In contexts where two of the same phoneme occur together due to morphological junction (and sometimes even word boundaries), degemination occurs. For example, /ke-s-sep'/ '3SG.IRR-NEG-fall' is realised as [kesepj]. [07126.010 07126.wav 25.314 29.330], /meten-nal/ 'hour (lt. eye-3SG-sun)' is realised as [metenal], and /ra-P-Pa ${ }^{\mathrm{m}} \mathrm{b}^{\mathrm{w}} \mathrm{i}$ ?/ '3PL-IRRplant' is realised as [ra?am ${ }^{w}$ ii?]. When labiovelar and bilabial sounds occur adjacently, they can also degeminate. For example, /i-top' ${ }^{\mathrm{w}}$-p'et/ '3SG.R-jump-break' is realised as [i-top et] [EC02.076 EC02.wav 300.685 304.623]. When a nasal consonant is followed by a homorganic prenasalised stop, it also degeminates in that the nasal closure is no longer than that of a prenasalised stop alone. For example, /i-kin ndur/ '3SG.R-dig through' is realised as [iki ${ }^{\mathrm{n}} \mathrm{dur}$ ] [07089.187 07089.wav 888.648 896.165], and /ro-rum ${ }^{\mathrm{w}}{ }^{\mathrm{m}} \mathrm{b} \mathrm{b}^{\mathrm{j} u n}$ / '3PLwhip-dead' is realised as [rory ${ }^{\mathrm{m}} \mathrm{b}^{\mathrm{j}} \mathrm{yn}$ ] [07090.124 07090.wav 436.968 440.452]. In the latter 
example, it is clear that it is the first sound $/ \mathrm{m}^{\mathrm{w}} /$ that is deleted because the preceding vowel is fronted by the influence of the bilabial consonant. The coda consonant which is either $/ \beta^{\mathrm{j}} /$ or $/ \mathrm{p}^{\mathrm{j}} /$ (Section 2.3.1) followed by $/ \beta /$ in the example $/ \mathrm{i}-1 i p^{\mathrm{j}} \beta^{\mathrm{j} e n e-n} /$ [3SG.R-take sister-3SG] “ [07064.272 07064.wav 934.689 938.907] can degeminate even across a word boundary. Finally, there is one example that I investigated which would have underlyingly different forms, but which would be homophonous with degemination: /hu-p ${ }^{\mathrm{w}}$ or/ 'hit.head-break' / hup ${ }^{\mathrm{w}}-\mathrm{p}^{\mathrm{w}}$ or/ 'blow-break'. I found that speakers would produce a long consonant in the latter [hup ${ }^{\mathrm{w}}$ :or] only if it was a matter of explicitly differentiating the two concepts.

\subsubsection{Reduplication}

There are two reduplicative verbal prefixes in Nahavaq. The first, which I will call $\mathrm{C} i$ - reduplication (Section 2.4.6.1), occurs on multisyllabic roots. The second has a number of lexically-specified allomorphs and occurs only on monosyllabic roots (Section 2.4.6.2). Their functions, which partially overlap, are discussed in Section 4.5.1. Note that while only verb roots reduplicate in a systematic way, reduplication can be seen in a few non-verbal words.

\subsubsection{Ci- reduplication}

Most polysyllabic verb roots can have only the initial consonant reduplicated with the addition of high front vowel/i/ (Table 22). This is a very productive morpheme and is even used in borrowed words such as $/$ ji-jusum ${ }^{\mathrm{w}} /$ 'DUP-use', /si-septem $/$ ' 'DUP-move', and /ti-tram/ 'DUP-try'.

\section{Table 22: $\mathrm{C} i$ - reduplication}

\begin{tabular}{ll}
\hline ti-taris/ & 'DUP-stand' \\
$/{ }^{n} \mathrm{gi}-{ }^{\mathrm{n}} \mathrm{gilew} /$ & 'DUP-look for' \\
$/ \mathrm{m}^{\mathrm{w}} \mathrm{i}-\mathrm{m}^{\mathrm{w}} \mathrm{i}{ }^{\mathrm{n}} \mathrm{dal} /$ & 'DUP-play' \\
$/ \beta^{\mathrm{j}} \mathrm{i}-\beta^{\mathrm{j}}$ ayas $/$ & 'DUP-speak' \\
$/ \mathrm{wi}-\mathrm{wijew} /$ & 'DUP-worry' \\
$/ \mathrm{Ri}-\mathrm{Ra}^{\mathrm{m}} \mathrm{b}^{\mathrm{w}} \mathrm{i} \mathrm{T} /$ & 'DUP-plant' \\
\hline
\end{tabular}

While some speakers maintain this pattern, some others have a variant whereby if the first syllable of the root contains $/ \mathrm{u} /$, then the vowel in the reduplicative prefix is also $/ \mathrm{u} /$ (Table 23). Some speakers (generally younger speakers) reduplicate the first vowel of the root along with the consonant, regardless of which vowel it is, so they essentially have $\mathrm{CV}$ - reduplication on multisyllabic roots:

Table 23: Synchronic evidence of change in $\mathrm{C} i$ - reduplication

\begin{tabular}{|c|c|c|c|}
\hline Most conservative & Innovative & Most innovative & Gloss \\
\hline /ji-jusumw / & /ju-jusumw/ & /ju-jusumw/ & 'DUP-use' \\
\hline /si-surej/ & /su-surej/ & /su-surej/ & 'DUP-sweep' \\
\hline$/$ hi-ha $\beta^{\mathrm{w}} \mathrm{ur} /$ & /hi-ha $\beta^{\mathrm{w}} \mathrm{ur} /$ & /ha-ha $\beta^{\mathrm{w}}$ ur/ & 'DUP-swear' \\
\hline /ri-rehej/ & /ri-rehej/ & /re-rehej/ & 'DUP-scrape off' \\
\hline /si-sowru/ & /si-sowru/ & /so-sowru/ & 'DUP-seven' \\
\hline
\end{tabular}

Since labiovelar and bilabial consonants do not contrast before /o/ (Section 2.1.3.2), another piece of support for the identifying labial consonant as labiovelar before /o/ 
comes from the fact that they reduplicate as labiovelar consonants in $\mathrm{C} i$ reduplication: $/ \beta^{\mathrm{w}} \mathrm{i}-\beta^{\mathrm{w}}$ onos/ 'DUP-enough'.

\subsubsection{Reduplication on monosyllabic roots}

There are four allomorphs of reduplication on monosyllabic verb roots. These are full-syllable, $\mathrm{CV}$-, $\mathrm{CVCe}$-, and $\mathrm{CVC} a$-, although the last one is marginal. Appendix 2 lists all the examples of reduplication on monosyllabic roots that I have found.

In full-syllable reduplication, an entire monosyllabic root is reduplicated (Table 24).

Table 24: Full-syllable reduplication

\begin{tabular}{ll}
\hline Reduplicated root & Gloss \\
\hline /sal-sal/ & 'DUP-hunt' \\
/ndin-"diy/ & 'DUP-follow' \\
/ha?-ha?/ & 'DUP-climb' \\
/Ras-Pas/ & 'DUP-bite' \\
/hu-hu/ & 'DUP-hit one's head' \\
\hline
\end{tabular}

In CV-reduplication, the initial CV- of a CVC verb root is reduplicated (Table 25). It may be that these forms once had full-syllable reduplication (for example */so?-so?/) and then subsequently simplified the resulting CC. This seems plausible since many of the bases in this set contain glottal consonants, which are not stable in consonant clusters (see Section 2.7.3). However, there are also a number of roots which contain glottal consonants but undergo full-syllable reduplication, so the difference is not fully justified.

Table 25: CV- reduplication

\begin{tabular}{ll}
\hline Reduplicated root & Gloss \\
\hline /tu-tus/ & 'DUP-write' \\
/ko-koh/ & 'DUP-be' \\
/ra-ra?/ & 'DUP-work' \\
$/$ Ro- $^{\text {mo }} \mathrm{b}^{\mathrm{w}} /$ & 'DUP-throw' \\
/so-so?/ & 'DUP-touch' \\
\hline
\end{tabular}

There are a number of forms that are ambiguous as to whether they are full-syllable reduplication or $\mathrm{CV}$ - reduplication because a CVC-CVC form would result in a consonant cluster which degeminates (see Section 2.4.5). Examples include /ra(r)-rar/

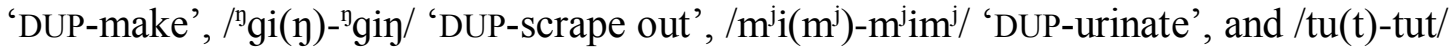
'DUP-transport fire'.

Many verbs of the form $\mathrm{CeC}$ that undergo full-syllable reduplication or $\mathrm{CV}$ reduplication have a high front vowel in the reduplicand (Table 26). But there are also some $\mathrm{CeC}$ roots that reduplicate exactly, such as /her-her/ 'DUP-take' and /Rep ${ }^{\mathrm{w}}$ Rep $\mathrm{w} /$ 'DUP-bend'. Similarly, a couple of $\mathrm{CoC}$ roots reduplicate with a raised back vowel in the reduplicand: $/{ }^{\mathrm{m}} \mathrm{b}^{\mathrm{w}} \mathrm{u}^{\mathrm{m}}{ }^{\mathrm{m}} \mathrm{b}^{\mathrm{w}} \mathrm{ow} /$ 'DUP-large' and $/ \beta^{\mathrm{w}} \mathrm{up}^{\mathrm{w}}-\beta^{\mathrm{w}} \mathrm{op}^{\mathrm{w}} /$ 'DUP-rain'. However, most CoC bases have the same vowel in the reduplicand (/tol-tol/ 'DUPcut'). 
Table 26: Vowel raising in reduplicand

\begin{tabular}{|c|c|c|c|}
\hline DUP-root & Gloss & DUP-root & Gloss \\
\hline /mis-mes/ & 'DUP-die' & $/$ tip $^{\mathrm{j}}-\mathrm{tep}^{\mathrm{j}} /$ & 'DUP-gust' \\
\hline$/{ }^{\mathrm{n}} \operatorname{din}-{ }^{\mathrm{n}} \operatorname{den} /$ & 'DUP-sink' & /jiw-jew/ & 'DUP-dissolve' \\
\hline$/{ }^{\mathrm{n}} \operatorname{dis}-{ }^{\mathrm{n}} \mathrm{des} /$ & ‘DUP-slip’ & /jis-jes/ & ‘DUP-touch’' \\
\hline$/ \operatorname{sip}^{\mathrm{j}}-\operatorname{sep}^{\mathrm{j}} /$ & 'DUP-fall' & /tis-tes/ & ‘DUP-slip' \\
\hline /tin-tey/ & 'DUP-cry' & $/{ }^{\mathrm{p}} \mathrm{gis}-{ }^{\mathrm{p}} \mathrm{ges} /$ & 'DUP-hairy' \\
\hline /ti?-te?/ & 'DUP-close' & /ndil-n del/ & 'DUP-coil' \\
\hline$/ \beta^{\mathrm{j}}$ is $-\beta^{\mathrm{j}} \mathrm{es} /$ & 'DUP-four' & /jin-jen/ & 'DUP-walk with legs apart' \\
\hline$/{ }^{n} \mathrm{gi}-{ }^{\mathrm{y}} \mathrm{gew} /$ & 'DUP-twist' & /ndi-ndej/ & 'DUP-dip' \\
\hline
\end{tabular}

In $\mathrm{CVCe}$ - reduplication, an entire monosyllabic root is reduplicated, but there is an additional vowel that intervenes between the two copies of the CVC syllable. The shape of this vowel is the same as the harmonising /e/ vowel discussed in Section 2.4 .2 , i.e. it is /e/ when the next vowel is $/ \mathrm{e} /, / \mathrm{i} /$, or $/ \mathrm{u} /$, but it assimilates to the following vowel in the case of $/ \mathrm{a} / \mathrm{or} / \mathrm{o} /$ (Table 27). It seems that the epenthetic vowel is a relic of a final $\mathrm{V}$ at an earlier stage. For example, /man/ 'agape' appears to be cognate with PNCV * maga (Clark 2005), and its reduplicated form /mayamay/ appears to be a derived of a CVCV- reduplication along the lines of*/mayamana/ with subsequent vowel loss. However, most monosyllabic Nahavaq roots seem to have lost a final vowel since PNCV, yet many of them do not reflect that final vowel the reduplication. ${ }^{40}$

Table 27: CVCe- reduplication

\begin{tabular}{ll}
\hline Reduplicated root & Gloss \\
\hline$/$ les-e-les/ & 'DUP-see' \\
$/$ wus-e-wus/ & 'DUP-brush away' \\
$/{ }^{\mathrm{m}} \mathrm{b}^{\mathrm{w}} \mathrm{il}-\mathrm{e}-{ }^{\mathrm{m}} \mathrm{b}^{\mathrm{w}} \mathrm{i} 1 /$ & 'DUP-hit' \\
$/ \beta^{\mathrm{w}}$ ar-a- $\beta^{\mathrm{w}}$ ar/ & 'DUP-flow' \\
$/$ loy-o-loy/ & 'DUP-walk' \\
\hline
\end{tabular}

The fourth allomorph, $\mathrm{CVC} a$-, is similar to the $\mathrm{CVCe}$ - pattern except that rather than being determined by the vowel of the root, the intervening vowel is always $/ \mathrm{a} /$. Roots that reduplicate as $\mathrm{C}_{1} a \mathrm{C}_{2}-a-\mathrm{C}_{1} a \mathrm{C}_{2}$ are ambiguous as to whether they should belong to the set of $\mathrm{CVCe}$ - or $\mathrm{CVC} a$-reduplication, but I have assigned them to the former because it seems to be a more common pattern. The only forms that I have found to have CVCa-reduplication are /ru-(w)a-ru/ 'DUP-two' and three forms of apparent reduplication (see Section 4.5.1.9): $/{ }^{\mathrm{m}} \mathrm{b}^{\mathrm{w}} \mathrm{una}^{\mathrm{m}} \mathrm{b}^{\mathrm{w}} \mathrm{un} /$ 'old, sour (v)', /ritarit/ '(intensifier)', and $/{ }^{\mathrm{m}} \mathrm{b}^{\mathrm{w}} \mathrm{ila} \mathrm{a}^{\mathrm{m}} \mathrm{b}^{\mathrm{w}} \mathrm{il} /{ }^{\prime} \operatorname{pool}(\mathrm{n})$ '.

While almost every monosyllabic verb root takes one of these reduplicative allomorphs, it is not predictable which one will be used based on the synchronic form of the verb root. Furthermore, a few roots have two reduplicated forms: $/ \mathrm{m}^{\mathrm{j}} \mathrm{e}\left(\mathrm{m}^{\mathrm{j}}\right)$ -

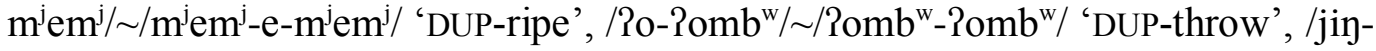

\footnotetext{
${ }^{40}$ There may be a pattern that those verbal roots which have a PNCV cognate ending in $a$ or $o$ tend to have synchronic $\mathrm{CVC} e$ - reduplication and those that have a cognate ending in $i, u$, or $e$ tend to have synchronic full-syllable reduplication. I would suggest that final $i, u$, or $e$ vowels were lost prior to a point at which reduplication patterns were fossilised, and then final $a$ and $o$ vowels were subsequently lost. This area requires more investigation.
} 
jey/ /jen-e-jey/ 'DUP-walk with legs apart', /rin-rey/ /rey-e-rey/ 'DUP-light/dawn', $/{ }^{\mathrm{n}} \mathrm{dem}^{\mathrm{w}}-\mathrm{e}-{ }^{\mathrm{n}} \mathrm{dem}^{\mathrm{w}} / \sim /{ }^{\mathrm{n}} \operatorname{dim}^{\mathrm{w}}{ }^{\mathrm{n}}{ }^{\mathrm{d}} \mathrm{dem}^{\mathrm{w}} /$ 'DUP-drip'.

In borrowed monosyllabic verb roots, full-syllable reduplication is common: /rit-rit/ 'DUP-read', /ku(k)-kuk/ 'DUP-cook'. There are a couple of instances of CVCe-

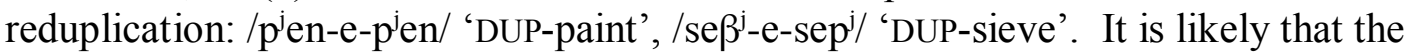

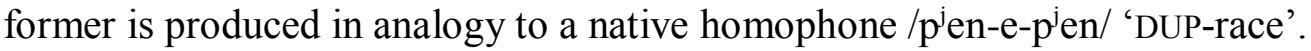

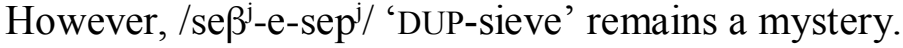

\subsubsection{Nominal prefix $(n \mathrm{~V}-)$}

There is a prefix of the form $/ \mathrm{nV}$-/ which occurs in most contexts on monosyllabic noun roots and some polysyllabic noun roots. Its grammatical function is discussed in Section 3.3.1.1. This section describes the phonological issues of which noun roots receive this prefix and what the form of the prefix is.

$/ \mathrm{nV}$-/ prefixes occur on all monosyllabic nominal roots with the exception of proper nouns, temporal nouns, and locational nouns (Sections 3.1.2.4-3.1.2.5). Examples include /na-lay/ 'NV-wind', /ne-he-n/ 'NV-jaw-3SG', and /ne-lin/ 'NV-behaviour'. Examples of monosyllabic temporal nouns and locational nouns that do not receive /nV-/ prefixes include /Ror/ 'today', /noh/ 'long ago', and /law/ 'sea'. /nV-/ prefixes also occur on polysyllabic roots beginning with liquids and glottals. Examples are given in Table 28. The exception is bird names which apparently begin with / $1 \mathrm{~V}-/$ prefixes (Section 3.1.2.4.2) such as /lim ${ }^{\mathrm{j}} \mathrm{eh} /$ 'wild duck', /lo?o $\mathrm{b}^{\mathrm{m}} \mathrm{ap} /$ 'Melanesian cuckoo shrike', and /li ' $\mathrm{b}^{\mathrm{w}}$ owar/ 'heron', and also the borrowed terms /loto/ 'car' and /lipus/ 'cat'. In the case of $/ \mathrm{li}^{\mathrm{m}} \mathrm{b}^{\mathrm{w}}$ owar/ 'heron', there is a variant, $/\left(\mathrm{ni}^{-}\right)^{\mathrm{m}} \mathrm{b}^{\mathrm{w}}$ owar/ indicating the prefix status of $/ \mathrm{lV}-/$.

Table 28: /nV-/ prefixes on multisyllabic words

\begin{tabular}{llll}
\hline /na-lambjut/ & 'NV-rat' & /ni-ruPumw/ & 'NV-crab' \\
/ni-lißwo-n/ & 'NV-tooth-3sG' & /ni-ruquh/ & 'NV-hill' \\
/no-loho-n/ & 'NV-testicle-3sG' & /ne-re?ey/ & 'NV-leaf' \\
& & /ne-revjuh/ & 'NV-bow' \\
\hline /nu-Pumwow/ 'NV-ironwood' & /na-haßja?/ & 'NV-what' \\
/no-Pojit/ & 'NV-octopus' & /na-halay/ & 'NV-taro' \\
/na-qaßwus/ & 'NV-cabbage' & $\begin{array}{l}\text { /nu-huhuh-n/ } \\
\text { /nu-wurjet/ }\end{array}$ & 'NV-breast-3SG' \\
& & 'NV-sago' \\
\hline
\end{tabular}

The vowel in the prefix is lexically determined, but there is a strong tendency for the vowel in the prefix to be identical to the first vowel of the root when it is a non-high vowel: /na-lay/ 'wind', /na-mwat/ 'snake', /na-way/ 'canoe', /ne-tel/ 'rope', /ne-hew/ 'garden', /ne-m ${ }^{\mathrm{j} e n} /$ 'bird', /no- $\beta^{\mathrm{w}} \mathrm{oh} /$ 'paddle', /no- ${ }^{\mathrm{m}} \mathrm{b}^{\mathrm{w}} \mathrm{ow} /$ ' 'eel', /no-toy/ 'mangrove'. There are exceptions such as /ni-nol/ 'wave', /ni-nal/ 'sun', /ni-nej/ 'native almond', and /nu-wes/ 'wild yam', but most monosyllabic roots containing non-high vowels fit this pattern. Some degree of productivity can been seen in the nominal prefixing of words recently borrowed from Bislama: /na-lamw/ 'lamp', /ne-tep'/ 'table', /no--Ros/ 'horse'. With roots containing high vowels, there is less of a pattern. The prefix may contain /a/ as in /na-hul/ ' $\mathrm{NV}$-dried coconut leaf' and /na- ${ }^{\mathrm{m}} \mathrm{b}^{\mathrm{w}} \mathrm{ir} /{ }^{\mathrm{N}} \mathrm{NV}$-gong rhythm', /e/ as in /ne-v'ul/ 'NV-moon' and /ne- ${ }^{\mathrm{n}} \mathrm{di} / \mathrm{'NV}$-bed', or /i/ as in /ni-luy/ 'NV-bundle' and /ni-lit/ 'NV-fence'. And a /nu-/ prefix occurs on some nominal roots which contain /u/ vowels as in /nu-wur/ 'NV-leaf' or /nu- ${ }^{\mathrm{g}} \mathrm{gut} /{ }^{\mathrm{N} V} \mathrm{~N}$-banana'. For some words, there is 
variation in the vowel of the nominal prefix. For example ' $\mathrm{NV}$-banana' is produced as /nu- ${ }^{\mathrm{g}} \mathrm{gut} / \mathrm{or} / \mathrm{ni}-{ }^{\mathrm{g}} \mathrm{gut} /$.

\subsubsection{Consonant mutation}

Alternation of the first consonant of a verb root is widespread in Northern and Central Vanuatu languages (Crowley 1991: 180-183). However, on Malakula, it is only attested in two languages: Aulua and Nāti. Nāti's system of alternation is opposite from all the others in that Nâti show a nasal mutation in the initial consonant in irrealis conditions, while all the other languages with initial consonant mutation on verb root show the nasal mutation in realis conditions (Crowley 1998b: 124-125). While Nahavaq does not exhibit either of these types of mutation, there are at least five pairs of a verb and a related element which reflect similar alternations (Table 29).

Table 29: Traces of consonant mutation

\begin{tabular}{ll}
\hline Non-nasal & Nasal mutation \\
\hline$/$ to?/ 'located (v)' & $/{ }^{\mathrm{n}} \mathrm{do} /$ ' 'remain (v2-result)' \\
/topha?/ 'climb (v)' & $/{ }^{\mathrm{n}} \mathrm{donha?/}$ 'uphill (v2-manner)' \\
/tur/ 'pierce (v)' & $/{ }^{\mathrm{n}} \mathrm{dur} /$ 'through (v2-manner)' \\
$/ \beta^{\mathrm{j} e j /}$ 'go (v)' & $/{ }^{\mathrm{m}} \mathrm{b}^{\mathrm{j}} \mathrm{ej} /$ 'thither (directional particle)' \\
$/ \beta^{\mathrm{w}} \mathrm{elen} /$ 'come (v)' & $/{ }^{\mathrm{m}} \mathrm{b}^{\mathrm{w}} \mathrm{elej} /$ 'hither (directional particle)' \\
\hline
\end{tabular}

Table 29 illustrates mutations of the form $/ \mathrm{t} />/{ }^{\mathrm{n}} \mathrm{d} /, / \beta^{\mathrm{j}} />/{ }^{\mathrm{m}} \mathrm{b}^{\mathrm{j}} /$, and $/ \beta^{\mathrm{w}} />/{ }^{\mathrm{m}} \mathrm{b}^{\mathrm{w}} /$, all of which are found in Nāti irrealis mutations (Crowley 1998b: 124). ${ }^{41}$ The forms with nasal mutation are either directional particle (Section 5.3.2.4) or the second verb in a serial verb-like construction (Section 4.6.1.2). Both of these types of words frequently occur immediately following an independent verb.

\subsection{Stress}

Nahavaq does not have lexical stress. ${ }^{42}$ I also find no convincing evidence of fixed word-stress. It seems that any prominence that exists can be explained by segmental phonology and/or prosody at a level higher than the word.

I have used three methods for investigating prominence in Nahavaq: my perception, speakers' perception and instinct, and acoustic analysis. I will discuss the findings of each in the following sections.

\subsubsection{Researcher perception}

I do not trust my perception of syllable prominence in any language besides English because the parameters for prominence are language-specific, and my perception is

\footnotetext{
${ }^{41}$ Note that Crowley (1998b: 124) analysed prenasalised stops as consonant clusters, i.e. $/{ }^{\mathrm{n}} \mathrm{d} / \mathrm{as} / \mathrm{nt} /$. He also analysed what are presumably labiovelar consonants as clusters, i.e. $/ \mathrm{m}^{\mathrm{w}} / \mathrm{as} / \mathrm{mpw} /$. He later (Crowley 2006a: 32) rejected that analysis in favour of a single phoneme solution. Note also that Nahavaq $/ \beta^{\mathrm{w}} />/ \mathrm{m}^{\mathrm{w}} /$ corresponds to what Crowley (1998b) presented as $/ \mathrm{w} />/ \mathrm{mpw} /$.

42 The closest thing I found to contrastive lexical stress was a 14-year-old female speaker who seemed to contrast ['nehen] 'name-3SG' and [ne'hen] 'chin-3SG' based on stress [06205.wav]. However, the word meaning 'name-3SG' is a recent reduction of [ne?ehen] or [ne?hen]. It is possible that that she still retained three vowels in total after deletion of the glottal stop as can be seen with deletion of $/ \mathrm{h} / \mathrm{in}$ words like /naha $\beta^{\mathrm{j} a q} /\left[\right.$ na: $\beta^{\mathrm{j}} \mathrm{a}$ ?] 'what' (Section 2.2). However, because I did not find other speakers who made the same distinction, I do not consider it part of general Nahavaq phonology.
} 
finely tuned to English, which relies heavily on pitch to mark stress. However, my perceptions are not to be completely disregarded.

I often perceive penultimate stress on Nahavaq words spoken in isolation. For

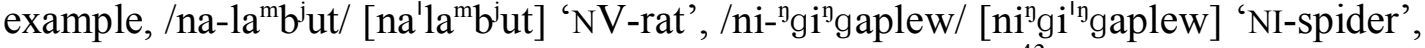
/ndo-loy/ ['ndolon] '1IN.PL-go', /ßene-n/ ['ßenen] 'sister-3SG' ${ }^{43}$ This is in line with the pattern of regular penultimate stress which is prevalent in Oceanic languages (Lynch 2000b). Most descriptions of Malakula languages which include a description of stress recognise a penultimate word-stress as standard (Fox 1979: 8; Crowley 1998b: 110; McKerras 2001: 2; Crowley 2002a: 651; Crowley 2006a: 36-37; Crowley 2006b: 39; Crowley 2006c: 42; Crowley 2006d: 104-107; Musgrave 2007: 21). There are however, Nahavaq words that I hear as having other stress patterns. For example, when the penultimate syllable contains a higher vowel than the final syllable, I often hear prominence on the final syllable: /ni-nal/ [ni'nal] ' $\mathrm{NV}$-sun', $/ \mathrm{i}-1 \mathrm{a}^{\mathrm{m}} \mathrm{b}^{\mathrm{w}} /\left[\mathrm{i}^{\prime} \mathrm{la}^{\mathrm{m}} \mathrm{b}^{\mathrm{w}}\right]$ '3SG-many', /ni-lii ${ }^{\mathrm{w}} \mathrm{o}-\mathrm{n} /\left[\right.$ [nili' $\left.\beta^{\mathrm{w}} \mathrm{on}\right]$ 'NI-tooth-3SG', $/ \mathrm{tu}^{\mathrm{m}} \mathrm{b}^{\mathrm{w}} \mathrm{i} \beta^{\mathrm{w}} \mathrm{am}^{\mathrm{w}} /\left[\mathrm{tu}^{\mathrm{m}} \mathrm{b}^{\mathrm{w}} \mathrm{i}^{\prime} \beta^{\mathrm{w}} \mathrm{am}^{\mathrm{w}}\right]$ 'fish-poison tree', / selsel $^{\mathrm{n}} \mathrm{gar} /$ [selsel ${ }^{1 \mathrm{~g}} \mathrm{gar}$ ] 'net fish'. I also often hear syllables that have a glottal onset as prominent: /i-mªl'?ah/ [im'al'?ah] '3SG-cold', /na-?aj/ [na'Paj] 'NV-wood', /ne-hew/ [ne'hew] 'NV-garden', /ku-hara ${ }^{\mathrm{n}} \mathrm{gas} /$ [ku'hara'gas] '2SG.IRRram'. ${ }^{44}$ However, when I listen to recordings of Nahavaq words in isolation, I frequently change my mind about which syllable sounds most prominent.

Words in isolation can present a problem when looking for prosodic patterns at word level because they constitute an utterance which has its own prosodic patterns (see Section 2.6 for Nahavaq intonation for words in isolation). In order to be sure that a pattern of prominence is associated with a word rather than with a higher level of prosody, one must look at words in a variety of contexts. I frequently encounter words in non-final contexts with what I perceive as having different prominence patterns than the penultimate prominence that I perceived on the word in isolation (1).
(1) A: / /ndu-loy/
B: / $/{ }^{\mathrm{n}} \mathrm{du}-{ }^{-}$lon $\quad{ }^{\mathrm{g}} \mathrm{gow} /$ 1 INC.DU-go 1INC.DU-go EMPH
A: 'Let's go.'
B: 'Yeah, let's go (now)!'

\subsubsection{Speaker perceptions}

If native speakers can identify prominence, they should be able to do so better than a non-native researcher. While speakers generally had no trouble diving words into syllables, even with training speakers could not confidently or consistently identify any one syllable as any stronger than others in the word. I tried a variety of techniques including asking speakers to clap, tap, yell, or whisper and then self-report any difference in 'strength', 'weight', 'length', 'size', etc. of syllables. But in general, speakers could not confidently or consistently identify any difference. I also attempted to model the pronunciation a multisyllabic word with exaggerated prominence (in terms of either length, pitch, loudness, or vowel quality) on different syllables, and asked speakers to state which variant sounded more natural. Generally,

\footnotetext{
${ }^{43}$ For audio recordings of Nahavaq words in isolation, see for example [06202.wav, 06204.wav, 08016.wav, 060101.wav].

${ }^{44}$ Elbert (1974: 13) also identifies stress on syllables beginning with /h/ in Puluwat (Micronesian). Further investigation would be needed to determine whether there is phonetically greater force in glottal onset syllables or whether it is a phonological perception of English-speakers.
} 
all variants where considered acceptable and only a few variations were ever considered less natural. Those considered less natural tended to have prominence on the final syllable of a three-syllable word, and such productions were described as sounding like a child whining.

I also investigated a high toned accent with an intensifying function to see if it was restricted to a single syllable of a multisyllabic word. But speakers could produce this tonic accent on many different syllables (Section 2.6). So again, this does not support the theory of fixed word-level prominence.

\subsubsection{Acoustic analysis}

Before I can make generalisation of patterns of syllable prominence within Nahavaq words, I need to be able to identify one syllable as more prominent than another for a single word (and even for a single instance of a single word, this can be difficult). Since my own perception and Nahavaq speaker's perceptions or instincts were not conclusive, I attempted to find syllable prominence through acoustic analysis.

While different languages use different cues to signal stress, it is generally found to be one or more of the following variables: pitch (F0), loudness (intensity), length (length), or vowel quality (F1 and F2). In some languages, one or the other of these may be the main factor in signalling stress. In others it can be a more complex combination of signals, or paterns such as a change in pitch rather than just a maximum F0. And there can be other factors as well, such as consonant allophones.

My initial investigation into prominence in Nahavaq looked at F0, intensity, and length of vowels of two syllable words of the form $\mathrm{CV}_{1}(\mathrm{C}) \mathrm{CV}_{1} \mathrm{C} .^{45} \mathrm{I}$ avoided glottal consonants and glides because of difficulties in segmentation. Words included: /ne-

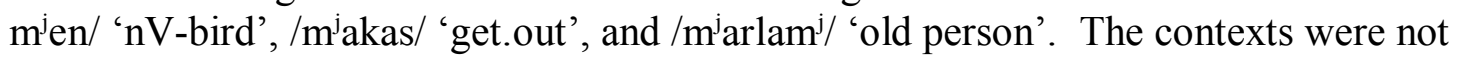
strictly controlled (they were extracted from texts in my recorded corpus), but all words occurred both utterance finally and medially. ${ }^{46}$

The results were not conclusive. For single instances, one measure of prominence (for example longer first vowel) often contradicted another (for example higher F0 of second vowel), and overall patterns did not show a convincing pattern. Figure 11 shows the results for 26 examples of /ne-m ${ }^{\mathrm{j}} \mathrm{en} /$ ' $\mathrm{NV}$-bird'. The final vowel was longer than the penultimate in most cases (which could be due to prosodic lengthening of final syllables), but with amplitude and fundamental frequency (F0), there were many cases of either syllable being more prominent than the other. It may be that there is some kind of complex interaction between some of these parameters, but my initial investigation did not uncover anything.

\footnotetext{
${ }^{45}$ For this investigation, I used words with identical vowels in both syllables so that I could compare vowel quality (F1 and F2). However, I had to completely ignore vowel quality in the end because of my later finding that front/backness of vowels is significantly influenced by surrounding consonants (Section 2.2.1), which I did not control for.

${ }^{46}$ I presented some results from this investigation at COOL7 (Noumea 2007), but I would like to one day do a more thorough investigation and publish the results.
} 
Figure 11: Prominence patterns for 26 examples of $/ \mathrm{ne}^{\mathrm{m}} \mathrm{m}$ en/ ' $\mathrm{NV}-\mathrm{bird}$ ' 47

\begin{tabular}{|c|c|c|c|c|}
\hline amplitude & 10 & 5 & 11 & $\begin{array}{l}\square \text { penultimate } \\
\text { prominence }\end{array}$ \\
\hline F0 & 9 & 4 & 13 & $\begin{array}{l}\square \text { within margin } \\
\text { of error }\end{array}$ \\
\hline length & 5 & & & $\begin{array}{l}\square \text { final } \\
\text { prominence }\end{array}$ \\
\hline
\end{tabular}

While there was no consistency for a word in varied contexts, there seemed to be some consistency for context regardless of the words involved. Generally, at the ends of utterances, there was a fall in pitch and intensity over the last two syllables. This is exemplified in Figure 12, where the two syllables of /ne-m'en/ 'NV-bird' make up the penultimate and final syllables of an utterance in one case and the antepenultimate and penultimate syllables in another case. In both cases, the final syllable of the utterance has a lower amplitude and lower F0 than the penultimate syllable. As a result, /ne$\mathrm{m}^{\mathrm{j} e n /}$ ' $\mathrm{NV}$-bird' seems to have more prominence on its first syllable in the first example and more prominence on its final syllable in the second example.

\section{Figure 12: Utterance final prominence patterns}

Images created with Praat. The dotted line shows F0 (Hz). The solid line shows intensity (dB). The top example is the final three syllables of an utterance meaning 'I want to tell a story about birds.' [TB03.001 TB03.wav 3.654 9.499]. The bottom example is an utterance meaning 'It's a bird.' [07080.018 07080.wav 64.688 68.970]. Note that the rise in intonation at the start could be attributed to the beginning of an utterance. Transcriptions in orthography outlined in Section 2.9 .

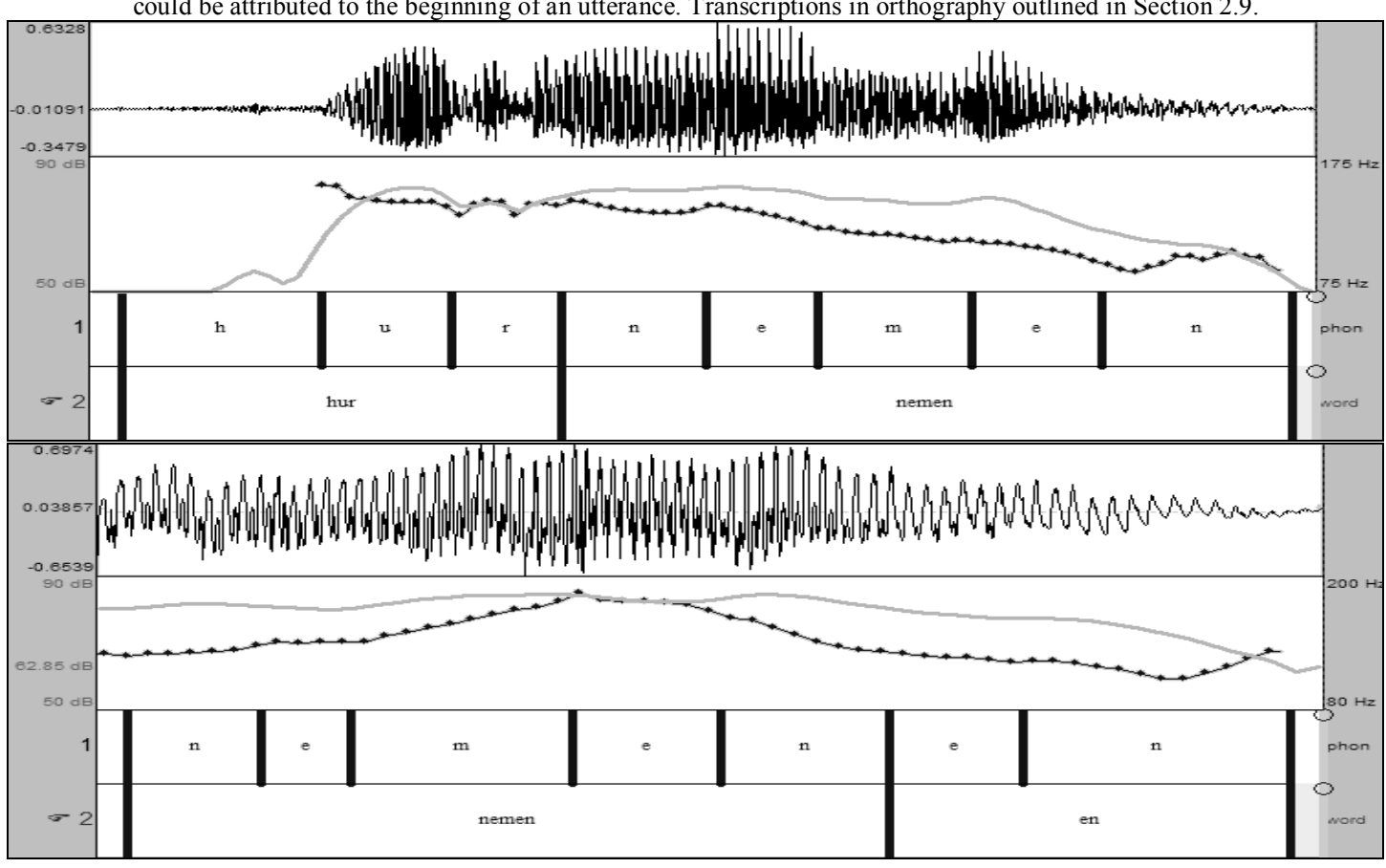

${ }^{47}$ The margin of error for this experiment was based on how readings could be different depending on what part of the sound wave was sampled. I measured this by dividing sound files twice to see how much difference was due to slight differences in segmenting sound files. Based on these differences, I considered any difference less than $0.0132 \mathrm{~s}$ (for length), $1.9 \mathrm{~Hz}$ (for F0), and $0.637 \mathrm{~dB}$ (for intensity) could simply have arisen based on where the sound file was segmented. Those measurements are what the "within margin of error" category in Figure 11 and Figure 13 are based on. Perhaps a better measurement for some of these variables may have been percent difference rather than absolute difference, but the latter is what was used. 
In a second experiment, I compared the vowels of the final two syllables at the ends of clauses regardless of the lexical makeup of those syllables. I measured amplitude, fundamental frequency and length of vowels in four different clause-final categories: at the end of an 'if' clause preceding a main clause, at the end of a 'when' clause preceding a main clause, at the end of quoted speech, and at the final closing of a narrative. Some results are displayed in Figure 13.

Figure 13: Prominence patterns at ends of clauses

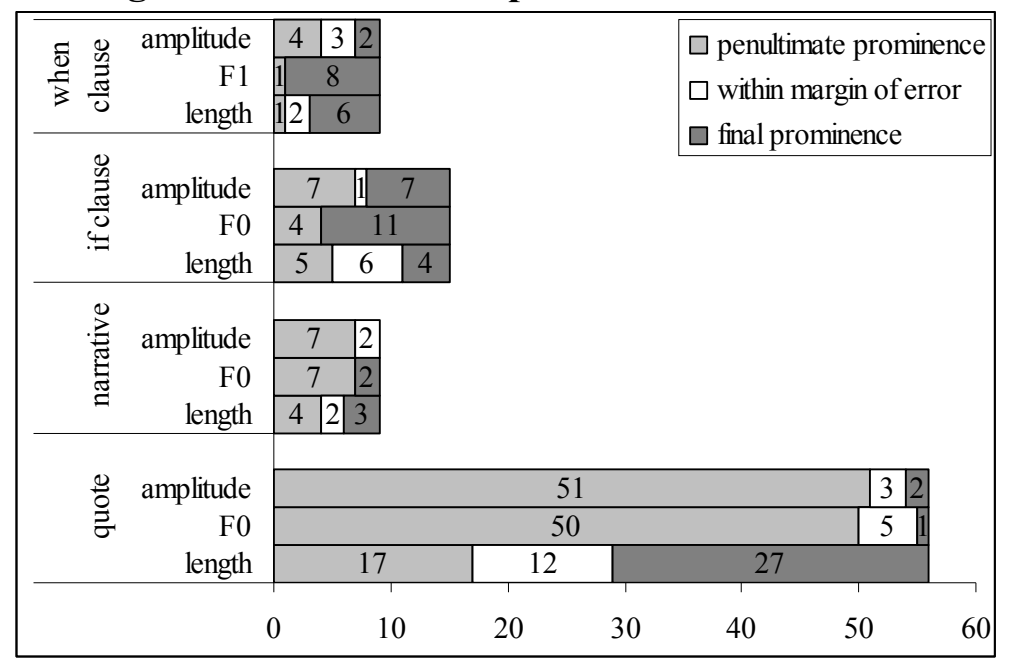

Vowels in utterance-final syllables generally tended to be longer than the vowel of the preceding syllable. Such final lengthening is not surprising and is common crosslinguistically. At the ends of narratives and quoted speech the penultimate vowel tended to have a higher fundamental frequency and amplitude than the final vowel, finally revealing the penultimate prominence that I perceived in words in isolation but failed to find consistently in words extracted from running texts. In the case of 'if' and 'when' clauses, the amplitude distribution was less consistent, but the final vowel often had a higher fundamental frequency than the penultimate, which is a general pattern for subordinate clause prosody (see Section 2.6).

\subsection{Intonation}

I have not done an exhaustive study of Nahavaq intonation. This section contains a few simple observations that I have made. The neutral intonation for a Nahavaq utterance has a gradual fall in pitch somewhere around the last two syllables (Figure 14).

Figure 14: Neutral intonation (falling)

Image created with Praat. /en ?ej ito? si? tej/ 'and he lived alone.' [08009.010 08009.wav 56.016 58.875]. Transcription in Figure in the new orthography (see Section 2.9). Note that the extreme fall in the second word is due to a glottal stop.

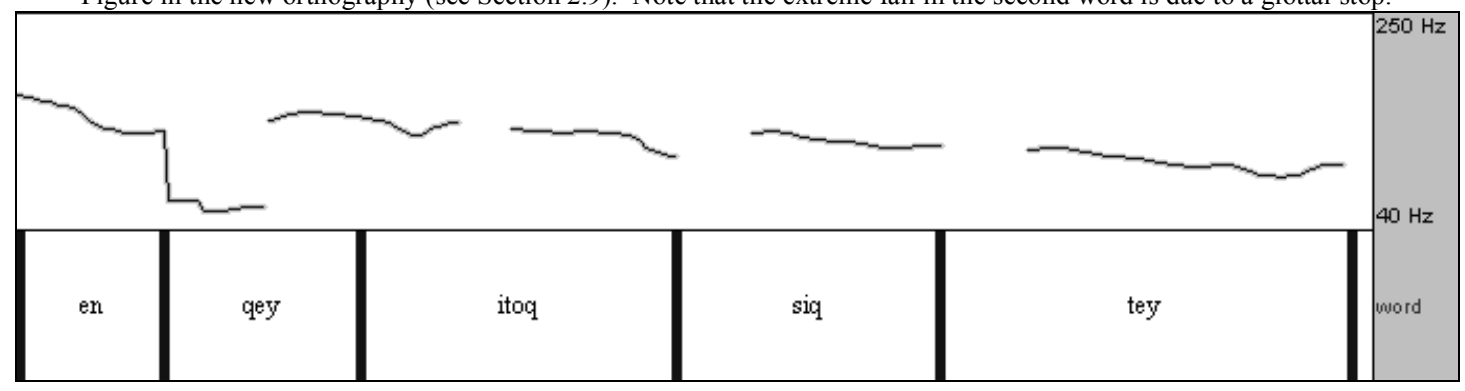


The same small fall can be seen at the ends of words in isolation (Figure 15). This relates to my (English) perception of penultimate prominence for words in isolation.

Figure 15: Word in isolation (falling)

Images created with Praat. Sound files from 08016.wav. Transcription in the new orthography (see Section 2.9) Top: /tu?ay/ 'older sibling' Bottom: /i-lutlut/ '3sG-yellow'

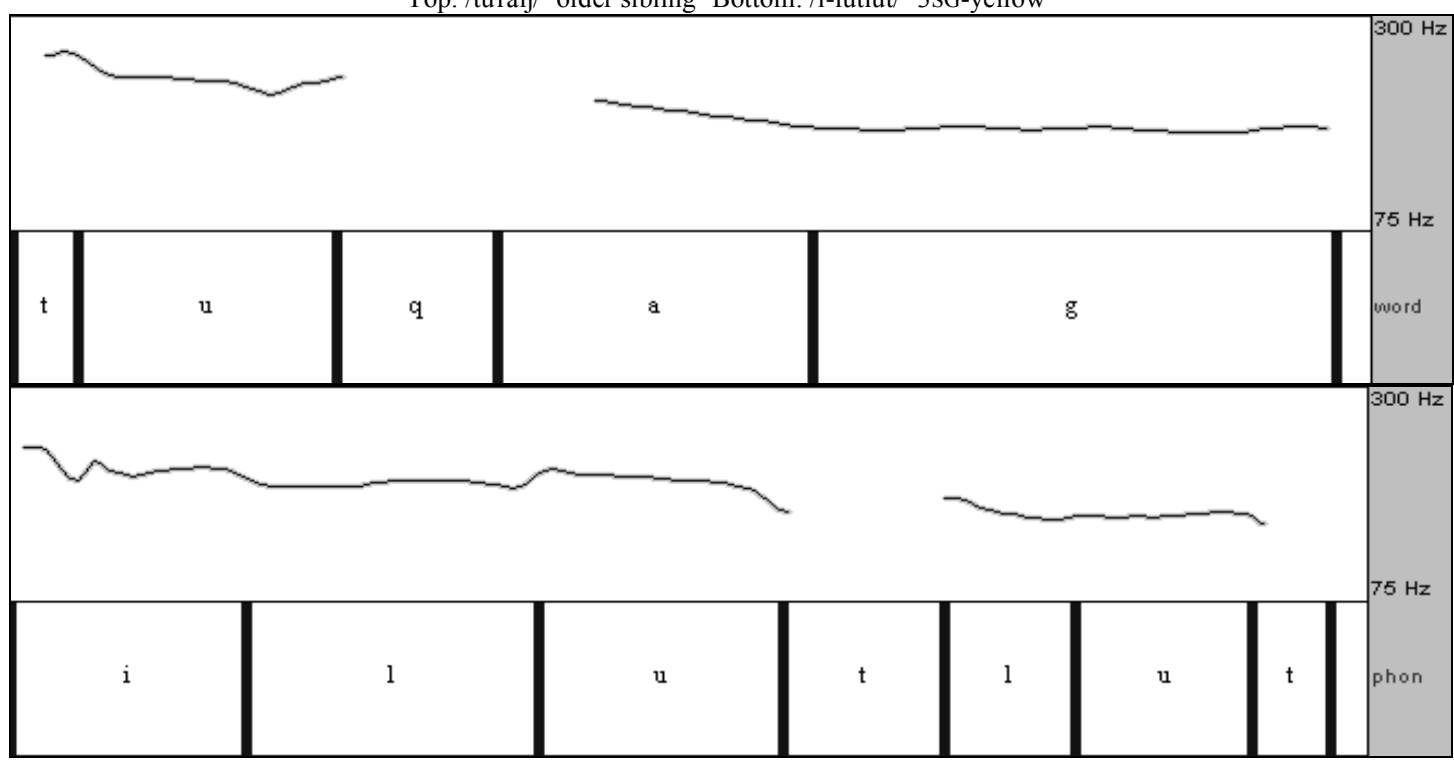

Figure 16 shows a subordinate clause before a main clause. There is a rise of the final syllable of the subordinate clause before a fall back to a middle frequency for the main clause. Again, the main clause shows a fall on the final syllable.

\section{Figure 16: Subordinate clause (rise)}

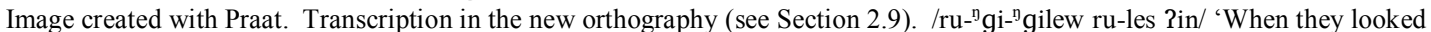
up, they saw him' [08009.119 08009.wav 704.745 710.417].

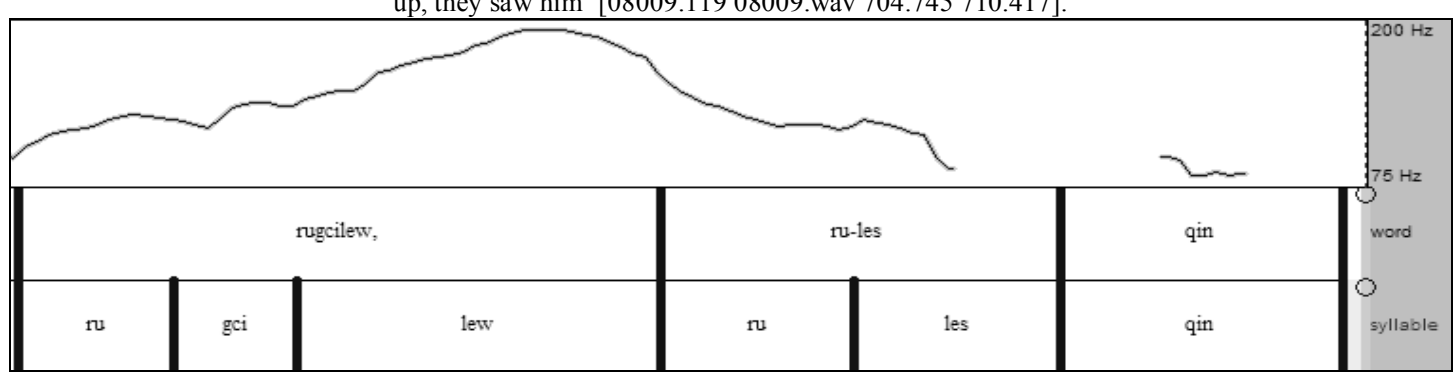

Yes/no questions, which only differ from declarative sentences in their intonation, show a marked rise and fall within the final syllable (Figure 17). 
Figure 17: Intonation of yes/no questions (rise fall)

Images created with Praat. Sound files from 08016.wav. Transcription in the new orthography (see Section 2.9)

Top: /lora, ne-wuh $\mathrm{i}-\beta^{\mathrm{w}} \mathrm{op}$ / / 'Laura, is it raining?' Bottom: /U-s-?an ve? mwalas/ 'Have you not eaten yet?'

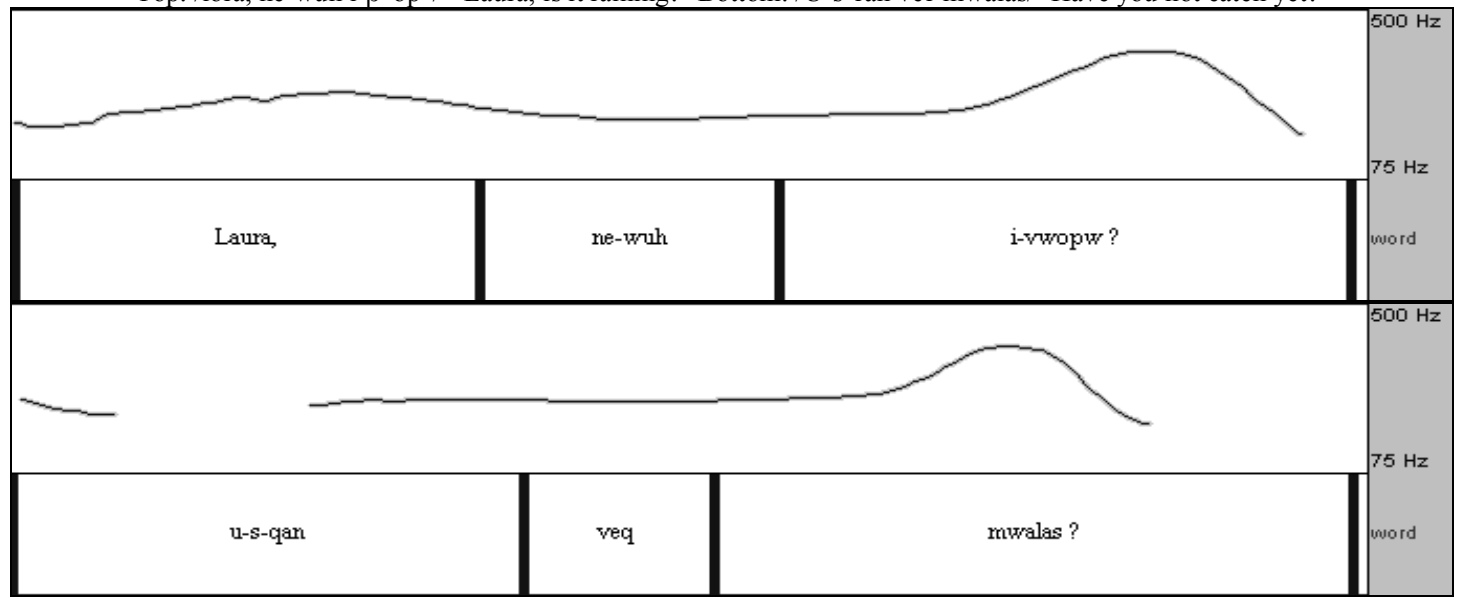

Content questions have a final fall in tone. They may have a slightly higher tone throughout than declarative sentences and may have a more extreme fall at the end.

\section{Figure 18: Content questions (high-fall)}

Image created with Praat. Transcription in the new orthography (see Section 2.9). First sentence: $/ \mathrm{u}^{-}{ }^{\mathrm{m}} \mathrm{b}^{\mathrm{w}} \mathrm{c}^{\mathrm{i}} \mathrm{l}^{\mathrm{m}} \mathrm{b}^{\mathrm{w}} \mathrm{il} \mathrm{m}^{\mathrm{j}}$ ete-n kinan 'gen haßja?/ 'Why are you hitting my eye?' [KJ01.027 KJ01.wav 125.829 130.204]. Second sentence: /ku-to-to? 'gen ija?/ 'Who will you stay with?' [07117.522 07117.wav 1549.534 1551.753]. Third sentence: /naha $\beta^{\mathrm{j} a}$ ? Ret ito? la?am/ 'What is on the fire?' [07065.255 07065.wav 936.727 938.993]

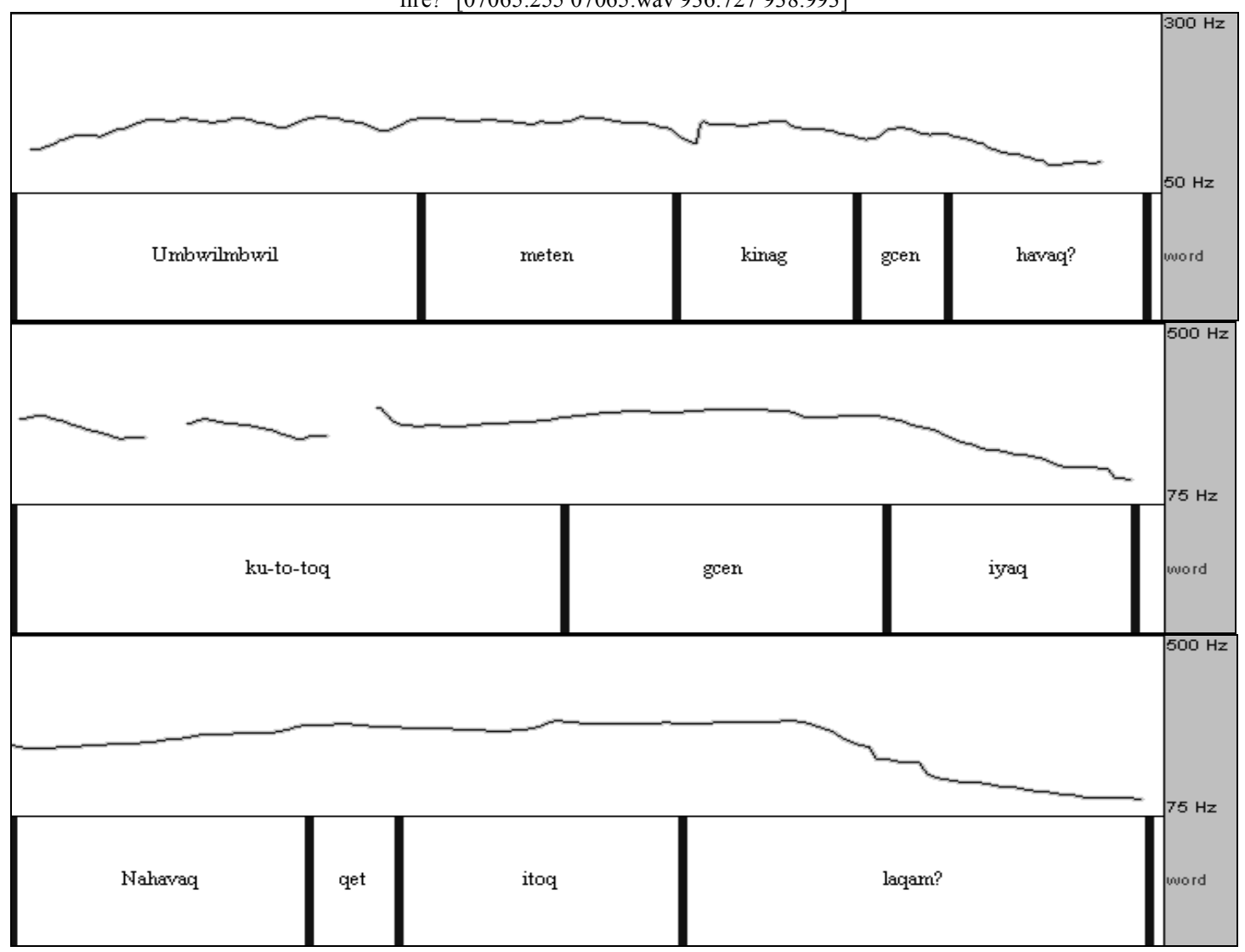

In a list of items, there is a rise in pitch at the end of all but the last item (Figure 19) 
Figure 19: List intonation (rises with final fall)

Image created with Praat. Transcription in the new orthography (see Section 2.9). This sentence lists seven people: 'Just me and Uncle Mbata, Maya, Manu, Edwin, Uncle Aiel, and Uncle Kalset' [07117.081-083 07117.wav 330.432 339.220]. A rising tone can be seen at the end of each item in the list, there is a fall at the end of the last item.

\begin{tabular}{|c|c|c|c|c|c|c|c|c|c|c|c|c|c|c|}
\hline 1 & & & 2 & & & 3 & 4 & 5 & & 6 & & & 3 & item \\
\hline \multirow{2}{*}{ 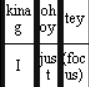 } & inet & рарар & Mbata & inet & am & Maya & Manu & Edwin & ${ }_{p}^{P a}$ & Aivel & inet & Pap & Kalset & |word \\
\hline & then & uncle & Mbata & then & (hesitation) & Maya, & Мanu, & Edwin & the & Aivel & then & uncl & Kalset & gloss \\
\hline
\end{tabular}

Directly quoted speech (discussed in Section 6.11) has a marked fall at the end of the

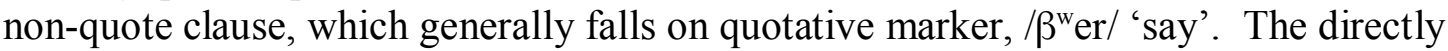
quoted speech then starts at a notably higher pitch than the low pitch of the quotative marker (Figure 20).

Figure 20: Quoted speech

'He talked alone to the stone, saying, "I have beaten you."' [07098.043-044 07098.wav 235.235 242.985] 'The bird said, "I don't have a wife."' [07072.056 07072.wav 311.730 317.433]. Transcriptions in orthography (Section 2.9).

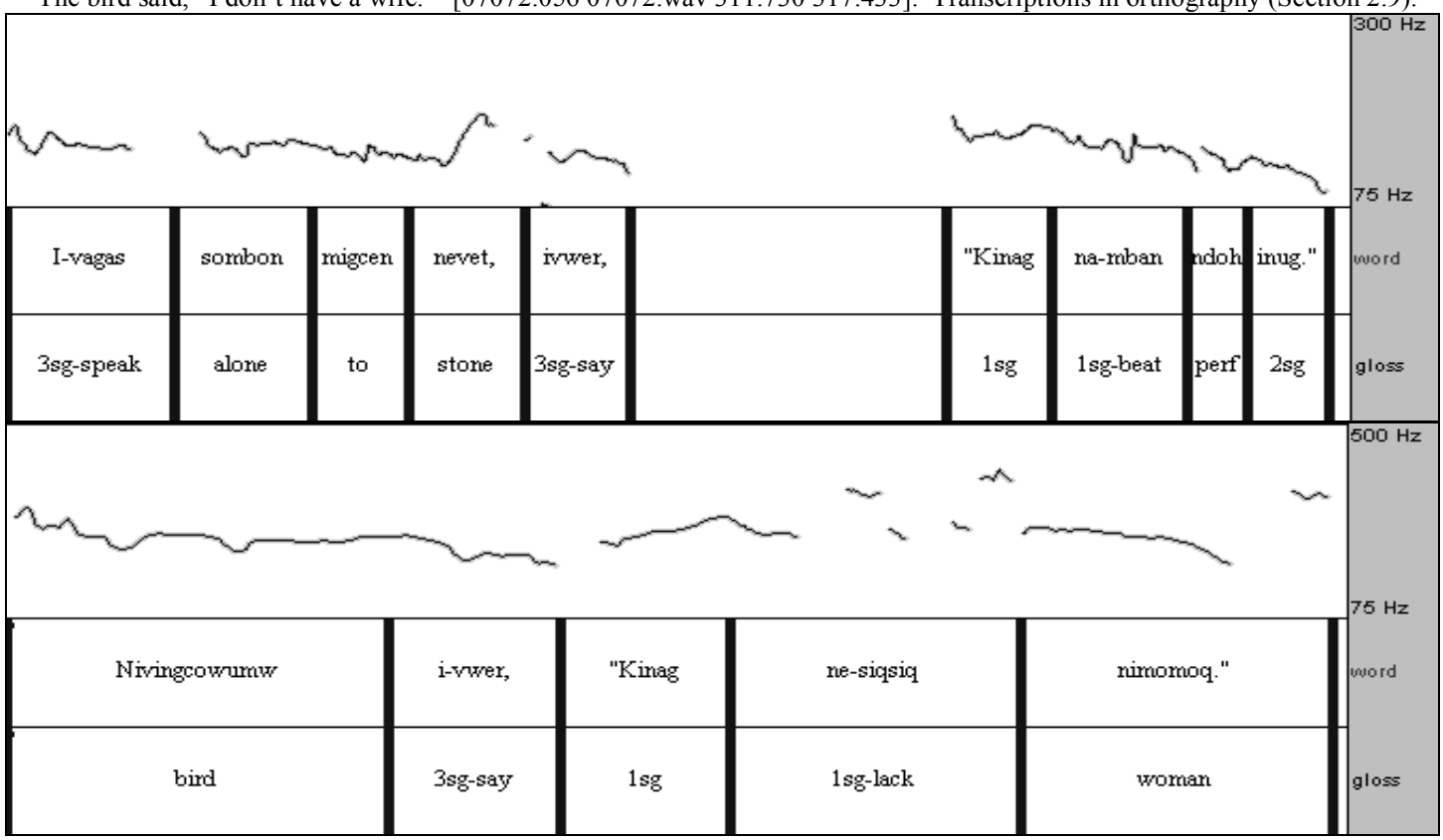

There is a pattern of intonation that serves an intensifying function. One of the syllables of the word to be intensified is lengthened and receives an extra high tone. Interestingly I found that almost any syllable of a multisyllabic word can carry this focus intonation. Figure 21 below shows this tonic accent falling on 4 out of 5

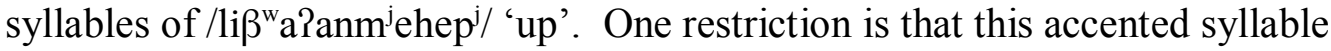
cannot be utterance-final, but it can be word-final if there is at least one syllable after it. The speaker who produced the utterances in Figure 21 said that the earlier the accent occurred in the word, the greater the intensifying effect was. 
Figure 21: Focus intonation on a 5-syllable word ${ }^{48}$

Image created with Praat. These were elicited from a 50-year-old female speaker within the context of /i-to? lij ${ }^{\mathrm{w}}{ }^{\mathrm{a}} \mathrm{Panm}^{\mathrm{j}} \mathrm{ehep}^{\mathrm{j} /}$ 'It is up high (lit. 3sG-located up)' (08016.wav 0.000 54.520). The final example is followed by $/{ }^{\mathrm{n}} \mathrm{gow} /$ 'emphatic' because tonic stress is not possible on the final syllable of an intonation phrase. Transcriptions in this figure are in the orthography discussed in Section 2.9.

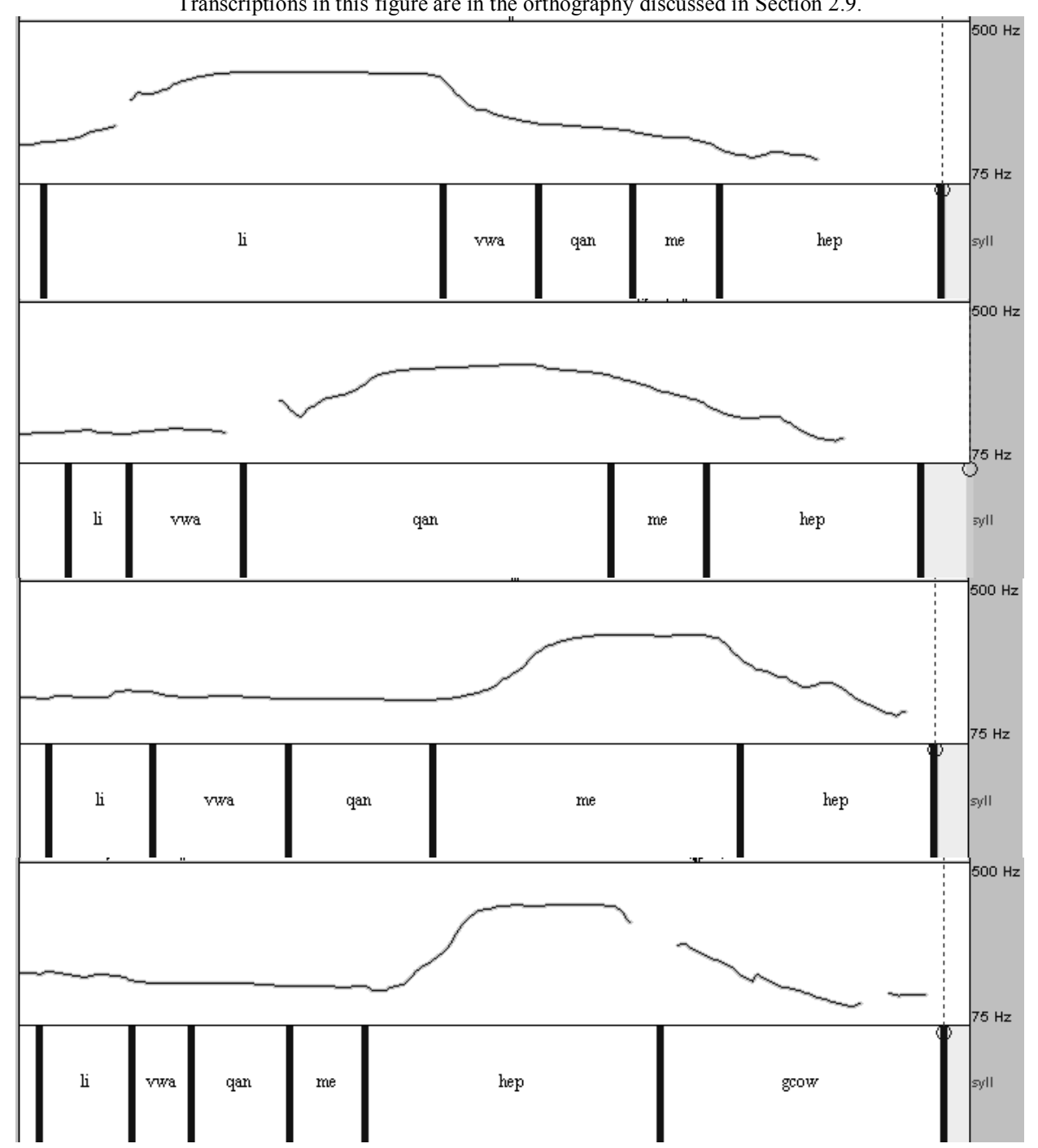

Certain words have intonation patterns associated with them. This includes interjections such as /opo/ '(mildly surprised)' (low-mid), /aka/ '(caution)' (mid-low), and $/ \mathrm{o} \beta \mathrm{j}$ eh/ '(shocked)' (low-high and lengthened) (Figure 22), and also the affirmative particle, $/{ }^{\mathrm{g}} \mathrm{gow} /$, which is discussed in Section 4.7.5.1. Figure 23 shows that the syllable preceding $/{ }^{\mathrm{n}} \mathrm{gow} /$ is lengthened and has a high pitch. There is a marked drop in pitch in the transition to $/{ }^{n} \mathrm{gow} /$.

\footnotetext{
${ }^{48}$ Note that when I produced the tonic stress on the second syllable, the speaker confirmed that it was grammatical, but repeated my utterance (without any correcting note that I was aware of) with tonic accent on the third syllable.
} 
Figure 22: /oßjeh/interjection

Image created with Praat. Transcription in the new orthography (see Section 2.9). The second syllable of the interjection /o $\beta^{\mathrm{j}} \mathrm{eh} /$ '(shocked) is protracted and high. The sentence shown means: 'The rat said, "Whoa! Thank you."' [07117.408 07117.wav $1285.6461288 .912]$.

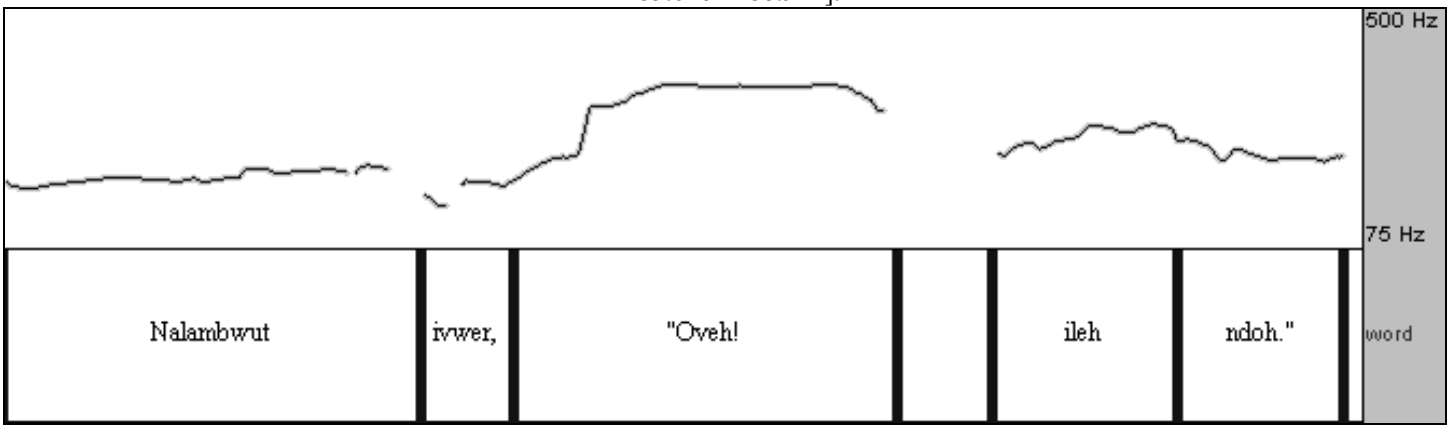

Figure 23: /ngow/intonation

Image created with Praat. Transcription in the new orthography (see Section 2.9). The top utterance is /i-leh " gow i-leh/ ' 3 SG.Rgood AFFIRM 3SG.R-good' [07126.039 07126.wav 105.128 107.628]. The second utterance is /ka-?anew "gow/ '3SG.IRR-plenty AFFIRM’ [07031.028 07031.wav 73.278 76.232].

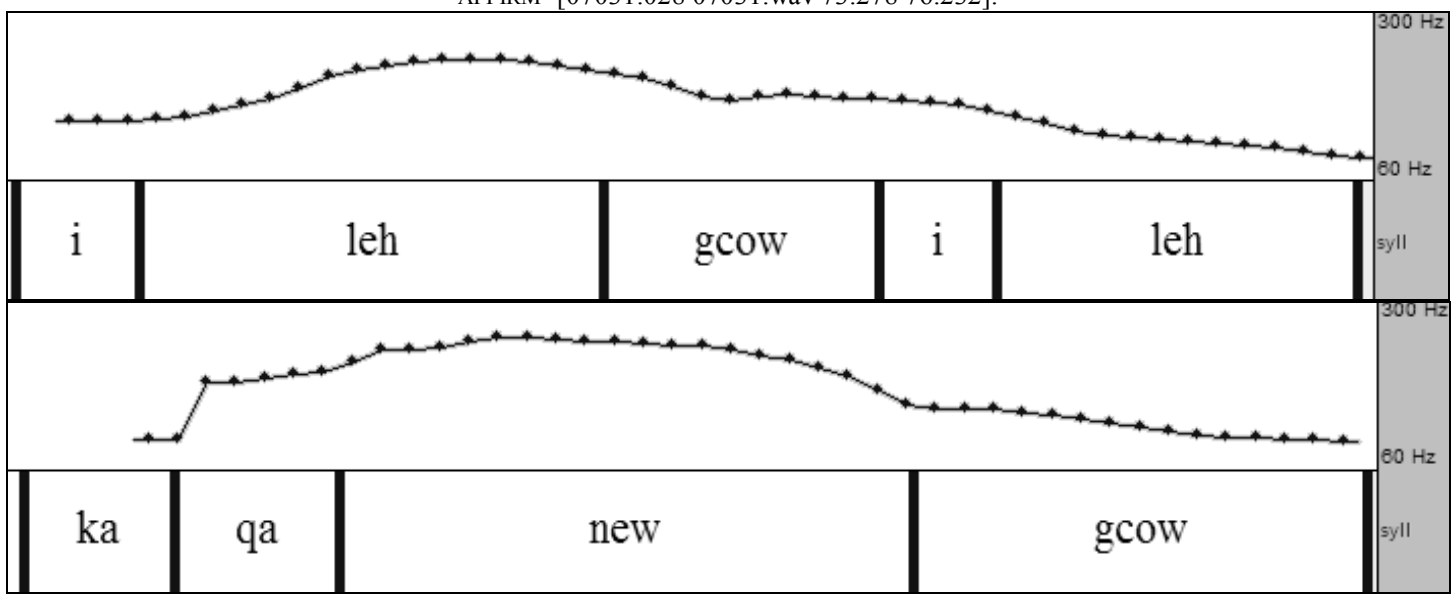

\subsection{Phonological variation}

Apart from single lexical items with variants (e.g. $/ \mathrm{p}^{\mathrm{w}}$ aras $/ \sim \mathrm{p}^{\mathrm{w}}$ aris/ 'strong', /ni${ }^{\mathrm{g}} \mathrm{gut} / \sim / \mathrm{nu}-{ }^{\mathrm{g}} \mathrm{gut} /{ }^{\mathrm{N} V} \mathrm{~N}$-banana'), there are a number of wider patterns of phonological variation that I have identified (Sections 2.7.1-2.7.6). Other phonological variation that has been discussed in other sections includes the $/{ }^{/ 2} \mathrm{~d} / \mathrm{segment}$ (Section 2.1.2) and the loss of the bilabial-labiovelar distinction (2.1.3.4).

\subsection{1. [BILABIAL] $\boldsymbol{u}$ - [LABIOVELAR] $\boldsymbol{i}$ alternation}

There are a number of words which have two alternates, one with a bilabial consonant followed by $/ \mathrm{u} /$, and the other with a labiovelar consonant followed $/ \mathrm{i} /$ :

\begin{tabular}{|c|c|c|}
\hline \multirow{5}{*}{$\begin{array}{l}\text { Bilabial variant } \\
\text { /mb }^{\mathrm{j} u r a ? t e w} / \\
\text { /mb }^{\mathrm{j}} \mathrm{b}^{\mathrm{j}} \mathrm{ur}^{\mathrm{j}} \mathrm{em}^{\mathrm{j} /} \\
\text { /mb }^{\mathrm{j}} \mathrm{ujsi} / \\
/ \mathrm{m}^{\mathrm{j}} \mathrm{uj} /\end{array}$} & \multicolumn{2}{|c|}{ Labiovelar variant Gloss } \\
\hline & /mbwira?tew/ & 'hermit crab' \\
\hline & $/{ }^{m} b^{w} \operatorname{ir} \beta^{j} e^{j} /$ & 'butterfly' \\
\hline & $/{ }^{m} b^{w i s i} /$ & 'throw stone at' \\
\hline & $/ \mathrm{m}^{\mathrm{w}} \mathrm{i} /$ & 'rumble' \\
\hline
\end{tabular}

Both variants are produced by younger and older speakers, so this variation is not a clear case of one form being a recent change. This variation is very likely motivated 
by the similarity between the /u/ vowel after a bilabial consonant and the /i/ vowel after a labiovelar consonant. The similarity can be seen in a plot of their first two formants (Figure 10).

\subsubsection{Loss of final prenasalised stops}

While some older speakers produce prenasalised stops word-finally (e.g. /na- $\mathrm{Pa}^{\mathrm{m}} \mathrm{b}^{\mathrm{j} /}$

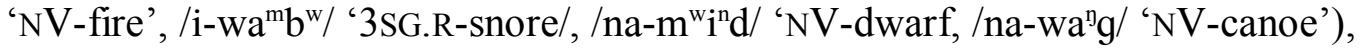
younger speakers (born after approximately 1950) have lost the plosive feature and have simple nasals in these positions (e.g. /na-Pam / ' $\mathrm{NV}$-fire', /i-wamw/ '3SG.R-snore/, /na-m' ${ }^{\mathrm{w}} \mathrm{in} /{ }^{\prime} \mathrm{NV}$-dwarf, /na-way/ 'NV-canoe'). As a result, some minimal pairs have become homophones for younger speakers (Table 31).

Table 31: Word-final prenasalised stops and nasals

\begin{tabular}{|c|c|}
\hline Older speakers & Younger speakers \\
\hline $\begin{array}{l}\text { no- } \mathrm{Po}^{\mathrm{n}} \mathrm{d} / \text { 'NV-basket' } \\
\text { /no-?o-n/ 'NV-face-3SG' }\end{array}$ & /no-?o(-)n/ 'NV-basket' ; 'NV-face-3sG' \\
\hline $\begin{array}{l}\text { /na-la"g/ 'NV-kind of tree } \\
\text { /na-lay/ 'NV-wind' }\end{array}$ & /na-lay/ 'NV-kind of tree' ; 'NV-wind' \\
\hline $\begin{array}{l}\text { /no- } \mathrm{oo}^{\mathrm{m}} \mathrm{b}^{\mathrm{w}} / \text { ' } 1 \mathrm{SG} . \mathrm{R}-\text { throw' } \\
\text { /no-?o-m } / \text { ' } \mathrm{NV} \text {-face-2SG' }\end{array}$ & /no-Po(-)mw ' 1 SG.R-throw' ; 'NV-face-2sG' \\
\hline
\end{tabular}

Other Malakula languages such as Unua (Pearce in preparation: 15) and Neverver (Barbour p.c.) are undergoing a similar change. As with the situation with the loss of the labial distinction discussed in Section 2.1.3.4, Nahavaq speakers do not have regular contact with speakers of Unua or Neverver, so it seems likely that the influence of Bislama, which does not have nasal-stop sequences word-finally, has brought about this change. ${ }^{49}$

\subsubsection{Glottal deletion}

There are two contexts in which $/ \mathrm{h} /$ is sometimes dropped by younger speakers: wordfinally and intervocalically. Some younger speakers appear to drop $/ \mathrm{h} /$ in all word final contexts. As a result, distinctions that older speakers make such as in /ne-wuh/ 'NV-rain' and /ne-wu/ 'NV-vein' are lost for younger speakers who would produce both words as $/ \mathrm{ne}-\mathrm{wu} /$. Another consequence of this is that words may end in nonhigh vowels (i.e. /i-leh/ '3SG.R-good' > /i-le/ '3SG.R-good'), which is not allowed by older speakers (Section 2.3.3). Intervocalic $/ \mathrm{h} /$ deletion between identical vowels is discussed in Section 2.2. Both of these changes I have only observed in adolescents and young adults, so it is unclear whether these constitute a change in progress or simply age grading.

More common than $/ \mathrm{h} /$-dropping is $/ \mathrm{l} /$-dropping in consonant clusters. This can occur if the glottal stop is the first element of a cluster as in $/ \mathrm{le} \beta^{\mathrm{w}} \mathrm{a}$ hhat/ $>/ \mathrm{le} \beta^{\mathrm{w}}$ ahat/ 'morning', $/{ }^{m} b^{j} a 2^{n} d e r />/{ }^{m} b^{j} a^{n} d e r / ~ ' u n t i l '$, or if it is the final element in a cluster as in $/ \mathrm{m}^{\mathrm{j} a l} \mathrm{lah} />/ \mathrm{m}^{\mathrm{j} a l a h} /$ 'cold'. Because the irrealis morpheme for non-singular subject in

\footnotetext{
${ }^{49}$ Bislama words which are derived from English words containing final nasal-stop sequences are generally borrowed with a final nasal, e.g. lamp $>$ /lam/ 'lamp', hand $>$ /han/ 'hand'.
} 
Nahavaq has the form / $/$ / and all verb roots begin with a consonant, irrealis marking forms a consonant cluster where the glottal stop is likely to be deleted, thereby losing the grammatical indication of irrealis mood. This has happened to an extent that most younger speakers (born after 1985) have no non-singular irrealis morpheme (Section 4.2.1).

\subsection{4. /w/ - /h/ alternation}

Some words such as /wupw/ /hupw/ 'blow', /wu'ndi-n/ /hundi-n/ 'piece-3SG' show a $/ \mathrm{wu} / \sim / \mathrm{hu} /$ alternation. I consider the $/ \mathrm{wu} /$ variant to be primary because some speakers have a minimal pair, /wupw/ 'blow'-/hupw/ 'wade'. But for those who produce /hupw/ 'blow', 'wade' and 'blow' are homophones.

\subsection{5. $/{ }^{\mathrm{m}} \mathrm{b}^{\mathrm{j}} />/ \mathrm{m}^{\mathrm{j} /}$}

There are two words that older speakers pronounce with an initial $/ \mathrm{m}^{\mathrm{j}} /$ while younger speaker use an initial $/ \mathrm{m}^{\mathrm{j}} /: /^{\mathrm{m}} \mathrm{b}^{\mathrm{j}} \mathrm{i}^{\mathrm{n}} \mathrm{ge}-\mathrm{n} / \sim / \mathrm{m}^{\mathrm{j}} \mathrm{i}^{\mathrm{p}} \mathrm{ge}-\mathrm{n} /{ }^{\text {'to- }} 3 \mathrm{SG}$ ' and $/{ }^{\mathrm{m}} \mathrm{b}^{\mathrm{j}} \mathrm{a}^{\mathrm{m}} \mathrm{b}^{\mathrm{j}} \mathrm{eh} / \sim / \mathrm{m}^{\mathrm{j}} \mathrm{a}^{\mathrm{m}} \mathrm{b}^{\mathrm{j}} \mathrm{eh} /$ 'whither'. The initial $/{ }^{\mathrm{m}} \mathrm{b}^{\mathrm{j}} /$ in both cases derives from the directional prefix (Section 5.3.2.4), but in these words, the prefix is no longer transparent to speakers, possibly in part due to the change of $/ \mathrm{m}^{\mathrm{j}} /$ to $/ \mathrm{m}^{\mathrm{j}} /$. Note that these are the only words where this change is known to have occurred.

\subsection{6. /ew/ > /ow/}

I have found a few words which have variations in a sequence /ew/ /ow/ such as in /hewhew/ [07028.016 07028.wav 57.034 59.612] /howhow/ [07122.024 07122.wav 65.404 69.435] 'medicinally steam', /ni-jew/ [07075.006 07075.wav 41.166 47.759] /ni-jow/ [song04.004 song04.wav 31.26539 .577 ] 'NV-tide'. I consider the /ew/ forms to be primary because speakers who produce the /ew/ forms in these words produce /ow/ in words such as /mbow/ 'big', but speakers who produce /ow/ in the above words don't seem to produce /ew/ sequences anywhere, so they have lost a contrast between /ew/ and /ow/ sequences.

\subsection{The phonological word}

Because I have been unable to find any convincing evidence of word stress (Section 2.5 ) and because I have not found any morphophonemic processes that consistently happen across some morpheme boundaries but not others, which could then be seen as the word boundaries, it is very difficult to define a phonological word in Nahavaq. My judgements of word boundaries are based on the pieces that speakers have broken utterances into when helping me to transcribe recorded texts. It is also worth noting how speakers break words when writing, but I do not know the extent to which such habits may have been influenced by teaching or by the influence of other languages. For example, I don't think I ever heard a speaker break a simple subject agreement prefix from a verb root when helping me to transcribe, i.e. I never hear something like /ro-loy/ '3PL-go' broken into /ro/ and /loy/, but in writing some speakers frequently write such words as /ro-loy/ as two separate written words. I suspect that this may come from analogy to English or Bislama literacy where the equivalents, $I$ went and oli go are spelt as two-word phrases. When different speakers verbally split phrases into words, there is rarely disagreement on the divisions.

\subsubsection{Serial verb-like constructions}

One of the main areas of confusion about word boundaries for Nahavaq speakers is in the nuclear-layer serial verb-like constructions discussed in Section 4.6.1.1. In these 
constructions, two verb-like roots occur adjacently with no prosodic separation. There is a tendency for Nahavaq speakers to present these as a single 'word' if the second verbal element is monosyllabic, i.e. /i-lip'-kas/ '3SG-take-out' but as separate 'words' if the second element is polysyllabic as in /i-lip ${ }^{j} \mathrm{ka}-\mathrm{kas} /$ '3SG-take DUP-out' or /i-Pom ${ }^{\mathrm{w}}$ gahal/ '3SG-hit-away'. This relates to the canonical disyllable discussed in the next section.

\subsubsection{Canonical disyllable}

There are many patterns which suggest that monosyllabic content word-forms in Nahavaq are avoided.

The first is the pattern described in Section 2.8.1, where the second element of a serial verb-like construction is seen as compounded to the first if it is monosyllabic but as an independent word if it is polysyllabic.

Another pattern can be seen in adverbs of manner (Sections 4.6.1.3.3 and 4.7.2) and adjectives (Section 4.1.5). In general, all of these words are derived from independent verbs. If the verb root is monosyllabic, a derived adjective or adverb is reduplicated. ${ }^{50}$ An example of this is the adverb of manner, /lehleh/ 'well' (from/leh/ 'good'). /i-rar lehleh/ '3SG-make well/ is well-formed, but*/i-rar leh/ is ungrammatical. Likewise, $/{ }^{\mathrm{n}} \mathrm{dip}^{\mathrm{wn}} \operatorname{dip}^{\mathrm{w} /}$ 'heavy (adj)' from / ${ }^{\mathrm{n}} \operatorname{dip}^{\mathrm{w} /}$ ' heavy (v)' can be seen in a reduplicated form /na-way ${ }^{\mathrm{n}} \operatorname{dip}^{\mathrm{wn}} \mathrm{dip}^{\mathrm{w}} /{ }^{\mathrm{N}} \mathrm{NV}$-canoe heavy', but not un-reduplicated: */na-way ${ }^{\mathrm{n}} \operatorname{dip}^{\mathrm{w}} /$.

Monosyllabic nominal roots almost always occur with an accreted article NVprefixed to them (Section 2.4.7). The only situations where they occur without this prefix are:

1. When having other prefixes such as the verbal derivation prefix, $/ \beta^{\mathrm{j}} \mathrm{i}$-/ (Section 4.4.34.1.9); the interrogative prefix, / $\mathrm{sep}^{\mathrm{j}-/}$ ' which' (Section 3.3.2); the possessive prefixes, $/ \mathrm{na}^{\mathrm{n}} \mathrm{gu}$-/ ' $1 \mathrm{SG}$ ' and $/ \mathrm{nam}^{\mathrm{w}} \mathrm{u}-/$ ' $2 \mathrm{SG}$ ' (Section 3.2.2.2); the personal prefix, /a-/ (Section 3.4.8.1); or the locational prefix /lV-/ (Section 5.3.2.2).

2. When incorporated into a verb (Section 4.1.9);

3. When forming part of a compound (Section 3.1.3.5);

4. For some speakers, when post-modified by an adjective (Section 3.4.8). Note that a case can be made for considering NOUN-ADJECTIVE constructions a single phonological word.

Finally, the numeral roots $1-5$ are monosyllabic and always occur with a verbal prefix (Section 4.1.6.1), for example, /i- $\beta^{\mathrm{j} e s /}$ '3SG.R-four'. Numerals 6-9 are bisyllabic and bimorphemic and the root for 10 is trisyllabic. Above 10, numerals are composed of multiple words. Unlike with 1-5, verbal prefixing is optional for 6-10 which are already polysyllabic. For example, /i-sowru/ /sowru/ '(3SG.R-)seven', /i-laya $\beta^{\mathrm{j} u l} / \sim$ /lana $\beta^{\mathrm{j} u l}$ / '(3SG.R-)ten'.

\footnotetext{
${ }^{50}$ There is one example of an un-reduplicated monosyllabic adjective: $/ \mathrm{m}^{\mathrm{j}} \mathrm{em} / \mathrm{j} /$ 'ripe'. However, it is not very productive and the two cases I have found where it can occur $\left(/ \mathrm{nu}^{\mathrm{p}} \mathrm{gut} \mathrm{m}^{\mathrm{j}} \mathrm{em}^{\mathrm{j} /}\right.$ 'ripe banana',

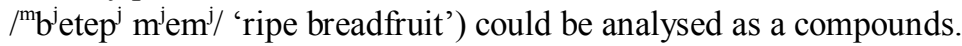


Since many nominal and verbal roots in Nahavaq are monosyllabic, ${ }^{51}$ many nominal and verbal word-forms are disyllabic when they occur in their most common forms $(n \mathrm{~V}$ - prefixation for nouns and monosyllabic subject prefixes for verbs).

Besides proper nouns, I am aware of two content words that are monosyllabic: /Ror/ 'today' and /law/ 'seaside'. The former is a temporal noun, and the latter a locational noun (both discussed in Section 5.3.2.1). Neither of these classes usually takes nominal or verbal affixation.

\subsection{Orthography}

Boyd, the Presbyterian missionary based at South West Bay from 1895 to 1928, developed a Nahavaq orthography, which resembles other Presbyterian mission orthographies in that it uses $<\mathrm{g}>$ for $/ \mathrm{y} /$ and $<\mathrm{gc}>$ for $/ \mathrm{g} g /$ (Table 32). His bible portions (Boyd 1905) and also the Nahavaq sections of a hymnbook (anon. 1918) use this orthography.

Table 32: Boyd's Nahavaq orthography

\begin{tabular}{|c|c|c|c|}
\hline $\begin{array}{l}/ \mathrm{p}^{\mathrm{j} /}<\mathrm{p}> \\
/ \mathrm{p}^{\mathrm{w}} /<\mathrm{p}> \\
\quad<\mathrm{pw}> \\
/ \mathrm{t} /<\mathrm{t}> \\
/ \mathrm{k} /<\mathrm{k}><\mathrm{c}> \\
/ \mathrm{p} / \varnothing \\
/ \mathrm{j} /<\mathrm{i}> \\
/ \mathrm{i} /<\mathrm{i}>\end{array}$ & {$\left[\begin{array}{rl}/{ }^{\mathrm{m}} \mathrm{b}^{\mathrm{j}} / & <\mathrm{mb}><\mathrm{b}><\mathrm{mp}> \\
/ \mathrm{m}^{\mathrm{m}} \mathrm{b}^{\mathrm{w}} /<\mathrm{mb}><\mathrm{b}><\mathrm{mp}><\mathrm{bw}> \\
& <\mathrm{mbw}> \\
/{ }^{\mathrm{n}} \mathrm{d} / & <\mathrm{d}><\mathrm{nd}><\mathrm{nt}> \\
/{ }^{\mathrm{n}} \mathrm{g} / & <\mathrm{g}><\mathrm{gc}><\mathrm{gk}><\mathrm{c}> \\
/ \mathrm{l} / & <\mathrm{l}> \\
/{ }^{\mathrm{n}} \mathrm{d} \mathrm{l} / & <\mathrm{nr}><\mathrm{ndr}> \\
/ \mathrm{o} / & <\mathrm{O}>\end{array}\right.$} & $\begin{aligned} / \mathrm{m}^{\mathrm{j}} / & <\mathrm{m}> \\
/ \mathrm{m}^{\mathrm{w}} / & <\mathrm{m}> \\
& <\mathrm{mw}> \\
/ \mathrm{n} / & <\mathrm{n}> \\
/ \mathrm{y} / & <\mathrm{g}> \\
/ \mathrm{r} / & <\mathrm{r}> \\
/ \mathrm{a} / & <\mathrm{a}> \\
/ \mathrm{u} / & <\mathrm{u}>\end{aligned}$ & $\begin{aligned} / / \mathrm{\beta}^{\mathrm{j}} / & <\mathrm{v}><\mathrm{f}> \\
\beta^{\mathrm{w}} / & <\mathrm{v}><\mathrm{f}><\mathrm{vw}> \\
& <\mathrm{W}> \\
/ \mathrm{s} / & <\mathrm{S}><\mathrm{sh}> \\
/ \mathrm{h} / & <\mathrm{h}>\emptyset \\
/ \mathrm{w} / & <\mathrm{w}><\mathrm{u}> \\
/ \mathrm{e} / & <\mathrm{e}>\end{aligned}$ \\
\hline
\end{tabular}

However, there are a number of problems with Boyd's orthography. First, glottal stops were not represented in any way in the orthography. This means that minimal pairs such as /i-hu/ and /i-hu?/ would be homographs, i.e. $<$ ihu $>$. Because the glottal stop signals the irrealis mood for non-singular subjects (see Section 4.2.1), this grammatical distinction could not be represented in Boyd's orthography, i.e. /ro-2-loy/ '3PL-IRR-go' and /ro-loy/ '3PL-go' would be homographs. The glides, /w/ and /j/ were written as $<\mathrm{u}>$ and $<\mathrm{i}>$ respectively $(<$ tilau $>/ \mathrm{t}$-i-lew/ 'REL-3SG.R-sacred', $<\mathrm{ei}>/ \mathrm{Rej} /$ ' $3 \mathrm{SG}$ '), or if they occurred adjacent to $/ \mathrm{u} /$ or $/ \mathrm{i} /$, they were generally omitted $(<$ lium $>$

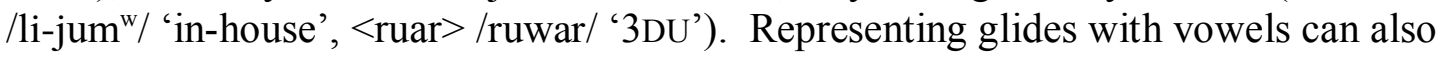
lead to confusion about how many syllables are present, i.e. the words /ndew/ 'remain' and /ndewu/ 'peaceful' would presumably both be spelt $<$ ndeu $>$. The omission of both glottal stops and glides causes further problems because when two orthographic vowels occur together, it could be either a glottal stop or a glide that occurs between them, i.e. <tuan> is used to represent both /tuwan/ 'INDEF' and /tu?a$\mathrm{n}$ / 'older sibling-3SG'. With prenasalised stops and labial fricatives, Boyd, who was not a proficient speaker of Nahavaq and would not have been thinking in terms of phonemes, clearly over-specified allophonic variation in his spelling system.

Despite its shortcomings, many of the older men and some older women alive today are literate to some degree in Boyd's orthography, but it seems that each writer has his

\footnotetext{
${ }^{51}$ My lexicon contains approximately 1000 verbal bases, of which roughly 500 are $\mathrm{CV}(\mathrm{C})$ in form. Of approximately 1000 nominal bases, roughly 300 are $\mathrm{CV}(\mathrm{C})$ in form. Many of the polysyllabic bases are polymorphemic as well.
} 
own idiosyncrasies in spelling, especially where the Boyd system is inadequate. It would seem that those schooled prior to the departure of the foreign missionaries in 1946 (Millar 1989: 508-509) and maybe for up to a decade after that were taught the orthography in local school. Future generations have largely failed to learn Boyd's orthography because of changes in the education system and possibly also because of the difficulties involved in learning an inconsistent spelling system.

As part of my project, I worked with the community to reform the Nahavaq orthography. Approximately 30 speakers from around the Nahavaq-speaking area met in 2006 and with my help chose the phoneme-grapheme correspondences presented in Table 33. It is similar to Boyd's orthography, but with the addition of the letter $<\mathrm{q}>$ representing the glottal stop $/ 2 /$. In addition, prenasalised stops are consistently represented as digraphs (or trigraphs in the case of the prenasalised labiovelar stop) and glides are represented by $w$ and $y$ rather than vowels. Labiovelar consonants are written with a $w$ following the grapheme for the corresponding bilabial grapheme.

Table 33: New Nahavaq orthography

\begin{tabular}{|cl|cl|ll|ll|}
\hline$/ \mathrm{p}^{\mathrm{j} /}$ & $<\mathrm{p}>$ & $/ \mathrm{m} \mathrm{b}^{\mathrm{j}} /$ & $<\mathrm{mb}>$ & $/ \mathrm{m}^{\mathrm{j}} /$ & $<\mathrm{m}>$ & $/ \mathrm{\beta}^{\mathrm{j}} /$ & $<\mathrm{v}>$ \\
$/ \mathrm{p}^{\mathrm{w}} /$ & $<\mathrm{p}(\mathrm{w})>$ & $/{ }^{\mathrm{m}} \mathrm{b}^{\mathrm{w}} /$ & $<\mathrm{mb}(\mathrm{w})>$ & $/ \mathrm{m}^{\mathrm{w}} /$ & $<\mathrm{m}(\mathrm{w})>$ & $/ \beta^{\mathrm{w}} /$ & $<\mathrm{v}(\mathrm{w})>$ \\
$/ \mathrm{t} /$ & $<\mathrm{t}>$ & $/{ }^{\mathrm{n}} \mathrm{d} /$ & $<\mathrm{nd}>$ & $/ \mathrm{n} /$ & $<\mathrm{n}>$ & $/ \mathrm{s} /$ & $<\mathrm{s}>$ \\
$/ \mathrm{k} /$ & $<\mathrm{k}>$ & $/{ }^{\mathrm{n}} \mathrm{g} /$ & $<\mathrm{gc}>$ & $/ \mathrm{n} /$ & $<\mathrm{g}>$ & $/ \mathrm{h} /$ & $<\mathrm{h}>$ \\
$/ \mathrm{P} /$ & $<\mathrm{q}>$ & $/ \mathrm{l} /$ & $<\mathrm{l}>$ & $/ \mathrm{r} /$ & $<\mathrm{r}>$ & $/ \mathrm{w} /$ & $<\mathrm{w}>$ \\
$\mathrm{j} /$ & $<\mathrm{y}>$ & $/ \mathrm{n} \mathrm{d} /$ & $<\mathrm{nd}>$ & & & & \\
\hline
\end{tabular}

However, the new orthography is not without its shortcomings. One issue is that a bilabial consonant followed by a $/ \mathrm{w} /($ i.e. $p+w=p w$ ) would be written exactly like a labiovelar consonant (i.e. $p w$ ). Luckily, I don't know of any intramorphemic sequences of a bilabial consonant followed by $/ \mathrm{w} /$. However, there is one example in my corpus of this sequence across a morpheme boundary: /i-p'-wej/ '3SG.R-COPWater' [AT01.010 AT01.wav 51.377 62.065], and it can alternatively be realised with a high vowel between the consonants: / $\mathrm{i}-\mathrm{v}^{\mathrm{j}} \mathrm{i}-\mathrm{w}$ ej/, so I do not see this problem as major. The other problem with any phoneme-based orthography is how to deal with variation and ongoing change. The new orthography presented in Table 33 represents $/{ }^{n} \mathrm{~d} / /$ as $/{ }^{n} \mathrm{~d} /$ because the change from $/{ }^{n} \mathrm{~d} / /$ to $/{ }^{\mathrm{n}} \mathrm{d} /$ is almost complete at this stage in time (see Section 2.1.2). The distinction between bilabial and labiovelar consonants is in the process of being lost, but it is not as advanced (see Section 2.1.3.4). The spelling committee chose to make distinctive graphemes for speakers who distinguish between the two sets (with the use of $w$ in labiovelar graphemes) but for those who do not distinguish between them, a spelling distinction would not be made. A similar approach was taken with word-final prenasalised stops which can be written with a digraph (noqond 'basket') or a nasal monograph (noqon 'basket') depending on the speaker. There is also some inter-speaker variation in the phonology of certain words (i.e. $/ \mathrm{v}^{\mathrm{j}}$ ewus/ / $\mathrm{v}^{\mathrm{w}}$ owus/ 'carry', /hupw $/ \sim /$ wup $^{\mathrm{w}} /$ 'blow') which can be similarly tolerated. Figure 24 shows an example of the new orthography. 
Figure 24: Example of orthography and phonemic representation

Humwan nuyih nimingcerey qey isumw tey ran naqay inoq qin nemen tuwan qar. $/$ hum $^{\mathrm{w}}$ an nujih nim ${ }^{\mathrm{j} i n^{\mathrm{y}}}{ }^{\mathrm{g}} \mathrm{gerej}$ ?ej isum ${ }^{\mathrm{w}}$ tej ran na?aj ino? ?in nem'en tuwan ?ar/

Mbonos tuwan, rusumw mbonombon tey qin nisivir ran naqay isiq, ${ }^{/ \mathrm{m}} \mathrm{b}^{\mathrm{w}}$ onos tuwan resum ${ }^{\mathrm{w}} \mathrm{m}^{\mathrm{w}}{ }^{\mathrm{w}} \mathrm{no}^{\mathrm{m}} \mathrm{b}^{\mathrm{w}}$ on tej ?in nisi $\beta^{\mathrm{j} i r}$ ran na?aj isi?/

en ruvagas ndap. En nimingcerey iles ut nisivir keviqis qey...

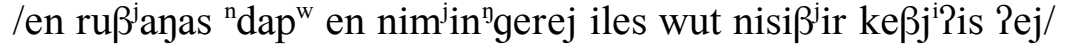

'Long ago, Flying Fox sat on trees like birds do. One time, he was sitting with Rainbow Lorikeet, and they were chatting. And Flying Fox saw that Rainbow Lorikeet would turn himself ...'

For the rest of this thesis, I will use the orthography in Table 33 except where pronunciation is relevant. I may not be consistent in the use of word-final prenasalised stops, the labiovelar-bilabial distinction, or other areas where variation exists. 


\section{Chapter 3: Noun phrase}

Noun phrases in Nahavaq are a clear category. Most noun phrases contain a noun head, although noun phrases without an overt head are also possible (Section 3.5). Noun phrases always have one of the following functions:

1. The subject of a verb

2. The object of a verb

3. The object of a preposition

4. The possessor of a noun (including associative possessor)

5. An adjunct to a clause (for temporal and locational noun heads only)

6. As a predicate in a verbless clause (Section 5.1.1)

Some of the most interesting features of the Nahavaq noun phrase include the many ways of expressing possession (Section 3.2) and the vestiges of POc definite article *na that can be seen in two synchronic morphemes (Section 3.3.1).

This chapter begins with an overview of different kinds of noun heads in Section 3.1. Then Section 3.2 describes the many constructions that are used in the expression of possession. Section 3.3 deals with elements which can occur before the head in the NP. Section 3.4 describes the elements which can occur after the head in the NP. Sometimes the modifying elements can occur without an overt head, and this phenomenon is described in Section 3.5. Finally, Section 3.6 describes coordination of NPs.

The ordering of elements within noun phrase is complicated. There is only one prefix allowed on a noun (Section 3.3), and the elements that can occur directly after a noun head are determined to an extent by whether the noun is directly or indirectly possessed. There is some flexibility in the ordering of elements after the noun head as discussed in Section 3.4.10. The order in Figure 25 is meant as a guide only.

Figure 25: Approximate ordering of a NP

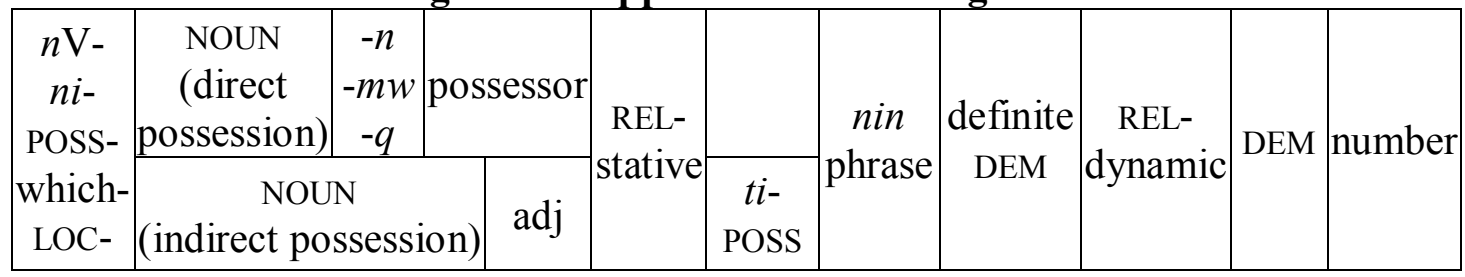

\subsection{Noun heads}

In the category of nominal heads, there is a major dichotomy between directly possessed nouns and indirectly possessed nouns. The former will be discussed in Section 3.1.1. All the other categories of nominal heads discussed in this section fall under the category of indirectly possessed nouns.

\subsubsection{Directly possessed nouns}

Directly possessed nouns are a closed class of nouns that generally fall into the category of inalienable possession (such as body parts or close kinship terms), and are 
obligatorily marked with a suffix for the possessor. Indirectly possessed nouns are an open class of nouns and refer to entities that are not necessarily possessed (ne-men 'bird', ni-nal 'sun'), things that could be considered alienable possessions (no-qond 'basket', ni-mbwuwes 'pig'), but also some things that semantically would be inalienable possessions (ni-sivul 'hair', avwutot 'grandfather').

Directly possessed nouns are obligatorily suffixed with $-q$ ' $1 \mathrm{SG}$ ', $-m w$ ' $2 \mathrm{SG}$ ', or $-n$ ' $3 \mathrm{SG}$ ' as in (2a-c). Note that the $-n$ ' $3 \mathrm{SG}$ ' suffix can be used as a default suffix followed by possessors of any person or number as in (2d). These same suffixes can be found on some prepositions (Section 5.3.2.3), and the modifier sombo- 'alone' (Section 3.4.9.3). The morphosyntax of possession of directly possessed nouns is discussed in Section 3.2.1. The remainder of this section outlines the particular noun heads that are members of the class of directly possessed nouns.
(2)
a. $\operatorname{vara}-q$
'my hand (hand-1SG)'
b. vara-mw
'your hand (hand-2SG)'
c. vara- $n$
'his/her hand (hand-3SG)'
d. vara-n kinag
'my hand (hand-3SG 1SG)'

Directly possessed nouns are a closed class with some consistent semantics to the group, but also idiosyncrasies. The pattern is that things that cannot exist without their relationship to a possessor tend to be directly possessed. Most body parts and products of the body fall into this category (Table 34 ).

Table 34: Directly possessed body parts and body products

\begin{tabular}{llll}
\hline gara- & 'chest' & ndilge- & 'ear' \\
livo- & 'tooth' & ndolo- & 'neck' \\
loho- & 'testicles' & ne-he- & 'jaw' \\
malambwugu- 'tongue' & $n e-h e v e-$ & 'what body part' \\
mbatavwa- & 'shoulder' & $n e-m b e-$ & 'body' \\
mbogo- & 'mouth' & $n e-m b u-$ & 'arse' \\
mbowu- & 'knee' & noqo- & 'face' \\
mbura- & 'thigh' & nuhuhu- & 'breast' \\
mbuto- & 'belly button' & pwanoqo- 'forehead' \\
mburogo- & 'gums' & siki- & 'skin'52 \\
mbwati- & 'head' & taqu- & 'back' \\
mbwulu- & 'leg' & vara- & 'arm' \\
mete- & 'eye' & veti- & 'belly' \\
morogco- & 'chest' & vwuqu- & 'vagina' \\
mwegce- & 'hip' & vwusi- & 'penis' \\
\hline gcoho- & 'leftovers/shit' & nombo-n & 'smell' \\
mbarha- & 'noise' & noqonli-n & 'egg' \\
mhuhu- & 'mucous' & tara- & 'shit' \\
nahu- $n$ & 'juice' & tuqla- & 'tracks' \\
\hline
\end{tabular}

\footnotetext{
${ }^{52}$ Note that $s i k i$ - 'skin' is borrowed from Bislama, and the final $n$ has be interpreted as a possessive suffix, so that there is a form siki-mw 'your skin (skin-2SG)'. This is evidence of some degree of productivity, so perhaps the class of directly possessed nouns is not completely 'closed'.
} 
However, as in other Malakula languages such as Naman (Crowley 2006b) and Tape (Crowley 2006d), most internal organs and some body products are indirectly possessed nouns (Table 35). ${ }^{53}$ There are also a few other body parts which are indirectly possessed, such as ni-vwilal 'rib', and na-qap 'armpit'.

Table 35: Indirectly possessed body parts and body products

\begin{tabular}{lll}
\hline na-qavwut & 'stomach' & na-mwambw 'liver' \\
ne-ndey & 'blood' & ni-vimim 'urine'
\end{tabular}

Kinship terms make up another semantic set of directly possessed nouns (Table 36). But there are also many kinship terms which are indirectly possessed (Table 37). For some relationships 'mother', 'father', and 'mother's brother', there are both possessed and indirectly possessed terms. ${ }^{54}$

Table 36: Directly possessed kinship terms

\begin{tabular}{llll}
\hline hala- & 'same-sex sibling' & teme- & 'father' \\
hine- & 'mother' & tesi- & 'younger same-sex sibling' \\
lawa- & 'nephew' & tinvu- & 'wife' \\
mituwa- & 'mother's brother' & tuqa- & 'older same-sex sibling' \\
mwaqaymbu- & 'grandchild' & vene- & 'man's sister' \\
mwene- & 'woman's brother' & vugo- & 'mother in law' \\
tambu- & 'father-in-law' & vwuti- & 'child' \\
ne-heve- & 'what relation' & & \\
\hline
\end{tabular}

Table 37: Indirectly possessed kinship terms

\begin{tabular}{llll}
\hline tatay & 'father' & avwu & grandparent \\
amoq & 'mother' & totot $\sim$ avwutot & grandfather \\
apap papap & 'uncle (including & kakapw & grandmother \\
& mother's brother)' & avwukapw & \\
avweyvwey & 'aunt' & aleq & son/brother-in-law \\
qayvwut & 'husband' & avwileq & daughter/sister-in- \\
& & & law \\
\hline
\end{tabular}

Another semantic set within directly possessed nouns is that of a part of a whole (Table 38). Because the possessors of these items are not human, they are not normally the speaker or addressee and therefore are only encountered with 3SG suffixes. Some speakers accept forms such as sumwara-q 'my tentacle (tentacle-1SG)' or $n a-q a r a-m w$ 'your root (NV-root-2SG)' in hypothetical situations where an animal or inanimate object is a speaker or addressee, but others consider such constructions ungrammatical. Because these words are generally only attested with 3SG endings, their membership to the class of directly possessed nouns is based on the fact that they can be directly followed by their possessor without any of the morphology associated with indirect possession. The directly possessed term siple- $n$ 'hair-3SG' is always possessed by mbwati-n 'head-3SG', and therefore it is considered a part-whole term

\footnotetext{
${ }^{53}$ In the case of internal organs, this could be because these parts are usually only perceived when the body is already dead, so the person or animal is no longer possessing them. But it is unclear how 'mucous' and 'shit' are semantically different from 'blood' and 'urine'. I put it down to idiosyncrasy. ${ }^{54}$ mituwa- 'mother's brother' is falling out of use in modern Nahavaq and being replaced by the directly possessed apap 'uncle', which has a wider reference (including father's sister's husband).
} 
rather than a body part term. Likewise, gcigcari-n 'finger/toe-3SG' is always possessed by vara-n 'hand-3SG' or mbuli-n 'leg-3SG' .

Table 38: Direct possession with parts of wholes

\begin{tabular}{|c|c|c|c|}
\hline mbulagca-n & 'shell' & malaga-n & 'scales' \\
\hline mbulu-n & 'seed' & $m b u s u-n$ & 'tail' \\
\hline naqambwu-n & 'stalk (of leaf)' & $m b w u m b o-n$ & 'feather' \\
\hline naqara-n & 'root' & nuququ-n & 'spur' \\
\hline$n a v w a-n$ & 'fruit' & sumwara-n & 'tentacles' \\
\hline$n d i v u-n$ & 'sprout' & hundi-n & 'half/piece' \\
\hline nelehe-n & 'bamboo joint' & livwaqa-n & 'middle' \\
\hline nibmwusvwu-n & 'coconut husk' & $m u s u-n$ & 'inside' \\
\hline nuquli-n & 'kernel' & mwahu-n & 'crest/end' \\
\hline sulu- $n$ & 'top' & nopo-n & 'lid' \\
\hline tagca-n & 'shell' & noqoni-n & 'inside' \\
\hline tivhu-n & 'flower' & sisegce-n & 'side of' \\
\hline vurogo-n & 'branch’' & tivsu- $n$ & 'side' \\
\hline noqolsi-n & 'skin/bark' & gcigcari-n & 'finger/toe' \\
\hline siple- $n$ & 'hair' & & \\
\hline
\end{tabular}

Finally, there are a few other directly possessed nouns which do not fit into the previous categories, but they still have a close association (Table 39). Naqapsu'penis wrapper' is a very personal piece of clothing and is directly possessed in other Malakula languages such as Tape (Crowley 2006d), Naman (Crowley 2006b), and Nāti (Crowley 1998b). Mwini- 'spirit' and neqhe- 'name' cannot semantically exist without a possessor, and the equivalent terms in other closely related languages are also directly possessed. Sara- 'place' refers to a place for something.

Table 39: Direct possession with other relationships

\begin{tabular}{llll}
\hline naqapsu- & 'penis wrapper' & $\begin{array}{l}\text { neqhe- } \\
\text { sara- }\end{array}$ & 'name' \\
mwini- & 'spirit' & 'place' \\
\hline
\end{tabular}

For some directly possessed nouns, there is an indirectly possessed alternative (Table 40). In the case of 'tongue' and 'hair', the indirectly possessed option may be suitable for reference to in-laws while the directly possessed option would be taboo (Section $6.9)$.

Table 40: Directly/Indirectly possessed alternatives

\begin{tabular}{lll}
\hline directly possessed & indirectly possessed & gloss \\
\hline malambugu- & malambug & 'tongue' \\
siple- & sivul & 'hair' \\
mbologco- & mboloq & 'bone' \\
tara- & ni-tar & 'excrement' \\
tuqla- & tuqal & 'tracks' \\
neqhe- & neqeh $\sim$ neheq & 'name' \\
\hline
\end{tabular}

There are also indirectly possessed forms of most directly possessed body part terms which are used exclusively in body part attribute constructions such as (3). These constructions are discussed in more detail in Section 3.4.8.1. Table 41 lists body parts 
that take part in these constructions (and two other directly possessed nouns which are not body parts: 'voice' and 'name').

(3) a-lipw-mbwu-mbow PERS-tooth-DUP-big

'big tooth / person with big teeth' [07NB4.023]

Table 41: Un-suffixed body part terms used in attributive constructions ${ }^{55}$

\begin{tabular}{|c|c|c|c|}
\hline & Direct possession form & Body attribute form & Gloss \\
\hline \multirow[t]{12}{*}{ a } & mbwati- & $a-m b w a t$ & 'head' \\
\hline & veti- & $a-v e t$ & 'belly' \\
\hline & mete- & $a-m e t$ & 'eye’' \\
\hline & no-qo- & $a-n o q$ & 'face' \\
\hline & mbogo- & $a-m b o g$ & 'mouth' \\
\hline & gcari- & $a-g c a r$ & 'finger' \\
\hline & ni-livo- & a-lipw & 'tooth' \\
\hline & ndolo- & a-ndol & 'neck/voice' \\
\hline & vara- & $a$-var & 'hand/arm’ \\
\hline & mbulu- & $a-m b u l$ & 'leg' \\
\hline & vwusi- & $a-w u s$ & 'penis' \\
\hline & vwuqu- & $a-v u q$ & 'vagina' \\
\hline \multirow[t]{4}{*}{ b } & gcinhu- & a-gcuh & 'nose' \\
\hline & ndilge- & $a-n d i l$ & 'ear' \\
\hline & ne-qhe- & a-heq & 'name' \\
\hline & nu-huhu- & $a$-sus & 'breast' \\
\hline \multirow[t]{10}{*}{$\mathrm{c}$} & ne-he- & $a-h e-n$ & 'jaw, cheek' \\
\hline & ne-mbe- & $a-m b e-n$ & 'body' \\
\hline & $n e-m b u-$ & $a-m b u-n$ & 'arse' \\
\hline & pwanqo- & a-pwanqo-n & 'forehead' \\
\hline & taqu- & $a-t a q u-n$ & 'back' \\
\hline & gara- & $a-g a r a-n$ & 'chest' \\
\hline & mbowu- & $a-m b o w u-n$ & 'knee' \\
\hline & mburogo- & $a-m b u r o g o-n$ & 'gums' \\
\hline & no-loho- & a-loh $\sim$ a-loho- $n$ & 'testicles' \\
\hline & mwegce- & $a-m w e g c e-n$ & 'hip' \\
\hline
\end{tabular}

Table 41a shows forms that lack the final syllable of the directly possessed form. Note that $n i$ - and $n \mathrm{~V}$ - prefixes are not present in the body attribute form which has the personal prefix $a$-. Table $41 \mathrm{~b}$ shows words in which there is a difference in the consonants. In the case of gcinhu- 'nose' and ndilge- 'ear', the loss of the final vowel leaves a consonant cluster which is simplified. In the case of gcinhu- $>$ gcuh 'nose', the remaining vowel also changes. In the case of 'name', the body attribute form may be more directly related to the indirectly possessed form ne-heq (Table 40). In the case of 'breast', the direct possession form has $/ \mathrm{h} /$ where the body part attribute form has $/ \mathrm{s} /$. While Nahavaq has experienced a lot of $\mathrm{s} \rightarrow \mathrm{h}$ change, other nearby languages

\footnotetext{
${ }^{55}$ Paamese also has two sets of related body-part nouns, one which takes direct possession suffixes (e.g. mee- 'tongue'), and the other with an $a$ - prefix and no suffix (e.g. amee 'tongue') (Crowley 1982: 110-111). And as with Nahavaq, these can refer to a body part or a person characterised by that body part.
} 
retain the $s$ in this word (Tryon 1976: 192-193). It is not clear whether $a$-sus might be a borrowing from another neighbouring language or the retention of an older form in this particular construction. For the constructions in Table $41 \mathrm{c}$, the body part attribute form appears to have the $-n$ ' $3 \mathrm{SG}$ ' possessor suffix. For citation forms such as $n e-h e-n$ 'jaw', ne-mbe-n 'body', and ne-mbu- $n$ 'arse', this may be phonologically motivated because if both the $n \mathrm{~V}$ - prefix and the final syllable are lost, the root is left without a syllable, so the final syllable with a 3 SG possessor suffix is retained.

\subsubsection{Indirectly possessed nouns}

Indirectly possessed nouns are an open class. All other common nouns besides those discussed in 3.1.1 are in the indirectly possessed category. These nouns do not need to be marked for possession, but they can be (see section 3.2.2). With the single exception of siki- 'skin (directly possessed)', all borrowed nouns are borrowed as indirectly possessed nouns. This includes several nouns such as (4a-c) which fit the semantic categories of direct possession outlines in Section 3.1.1.

(4) a. sistah t-inug 'your sister (sister POSS-2SG)'

b. kilas ti-kinag 'my glasses (glasses POSS-1SG)'

c. palawah nin na-qay 'tree's flower (flower ASS NV-tree)'

Section 3.2.2 discusses the possessive constructions that indirectly possessed nouns enter into. The following sections outline some subsets within the class of indirectly possessed nouns.

\subsubsection{Pronouns}

While many of the post nominal modifiers could be considered proforms when they occur without a lexical $\mathrm{N}$ head (section 3.5), the term pronoun in this description refers only to nominal proforms which cannot also act as nominal modifiers. ${ }^{56}$

\subsection{Personal pronouns}

Nahavaq distinguishes personal pronouns into three numbers and 4 persons:

Table 42: Personal pronouns

\begin{tabular}{|l|lll|}
\cline { 2 - 4 } \multicolumn{1}{c|}{} & Singular & Dual & Plural \\
\hline 1.EXCUSIVE & $\operatorname{kinag}(c) / \operatorname{nag}(c)$ & nuqumwem /mwem & kamem \\
$\mathbf{2}$ & & nuqun $(d)$ & nigcin $(d)$ \\
$\mathbf{3}$ & $\operatorname{inug}(c) / \operatorname{nug}(c)$ & nuqum & nigcim \\
\hline
\end{tabular}

Four of the pronouns in Table $42(\operatorname{kinag}(c)$, nuqumwem, $\operatorname{inug}(c), \operatorname{ruwar})$ can be abbreviated to the final syllable $(\operatorname{nag}(c), \operatorname{mwem}, \operatorname{nug}(c)$, war $) .{ }^{57}$ These abbreviations

\footnotetext{
${ }^{56} \mathrm{It}$ is debateable whether ( $\mathrm{ru}$ )war ' $3 \mathrm{DU}$ ' and qar '3PL' should be considered pronouns under this definition because of the existence of the homophonous number particles $(r u)$ war 'DU' and qar 'PL'. It could be argued that they are not separate words at all, but that they are simply number particles that can occur without a $\mathrm{N}$ head to form a single-word NP. However, I separate the number particles from the single-word occurrences of $(r u)$ war and qar (pronouns) simply because of the frequency of the latter and because they complete the personal pronoun paradigm (which matches in distribution with verbal subject prefixes).

${ }^{57}$ There is a perception among some speakers that the $\operatorname{nug}(c)$ ' $2 \mathrm{SG}$ ' and $\operatorname{nag}(c)$ ' $1 \mathrm{SG}$ ' forms are recent innovations while mwem '1EX.DU' and war '3DU' have been around longer and are better established.
} 
are almost nonexistent in Massing Nambuas's bible translations, so they may be a feature of spoken, informal or rapid speech. The abbreviation of ruwar to war is particularly common and applies to the personal pronoun as well as the homophonous dual number particle (Section 3.4.1).

Charpentier (1982) also lists a series of trial pronouns (Table 43). For first and second persons, Charpentier's trial pronouns look like a plural pronoun modified by a relative clause containing the quantifier $t u l$ 'three'. For the third person, there is a reduplicated quantifier $t u l-t u l$, which matches the pattern I had elicited across persons (Table 43). These appear to be compositional phrases rather than grammaticalised units. None of these phrases occur in my corpus, and plural pronouns are regularly used without modification when referring to a group of three as in (5).

Table 43: Charpentier's (1982) trial pronouns

Charpentier (1982) ${ }^{58} \quad$ My elicitations (2006)

nigcind $t$-i-tul '1IN.PL REL-3SG.R-three' nigcind nde-tul-tul '1 IN.PL 1IN.PL-DUP-three' kamem t-i-tul '1EX.PL REL-3SG.R-three' kamem mi-tul-tul '1EX.PL 1EX.PL-DUP-three' nigcim $t$ - $i$-tul '2PL REL-3SG.R-three' nigcim a-tul-tul '2PL 2PL-DUP-three' re-tul-tul '3PL-DUP-three' qar re-tul-tul '3PL 3PL-DUP-three'

(5) Qet i-her ohoy tey mwor ti-qey qar i-tul but 3SG.R-take simply FOC man POSS-3SG PL 3SG.R-three

Pita Jemis en Jon qar qet re-ndig taq. Yesu. Peter James and John PL PART 3PL-follow behind Jesus

'Then he did not let anyone else go on with him except Peter and James and his brother John.' [MRK.05:37]

\subsection{Qin (3SG, resumptive)}

(For the nominal coordinator qin 'with/and', see Section 3.6.3 and 5.3.2.3.12. For qin 'OBL/INSTR' see Section 5.3.2.3.11). Qin is a pronoun with 3SG reference. However, while qey ' $3 \mathrm{SG}$ ' occurs in a wide range of syntactic constructions, qin ' $3 \mathrm{SG}$ ' only occurs as an object of a transitive verb. In constructions like (6) qin and qey are interchangeable. Qin occurred in a narrative in Example (7). When I asked whether it could be replaced with qey in this context, my consultant said that qey was grammatical and it is conceivable that someone would use it in this context, but that qin is more natural because the speaker/addressees already know that the man was there. So there may be a difference in usage according to significance of the argument.

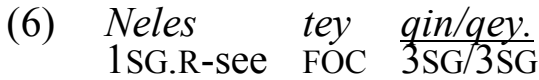

'I saw him.' [06NB06.003]

\footnotetext{
${ }^{58}$ Charpentier's (1982) transcription system has been modified in these examples to fit the orthography used in this grammar.
} 
(7) Ni-vilamnin i-les gin, I-vwer, 'Ay, u-log ambeh NI-girl DEM 3SG.R-see 3SG 3SG.R-say hey 2SG.R-go where mbweleg?'

to.FOC

'The girl saw him and said, "Hey! Where did you come from?"' [LS01.036 LS01.wav 152.728 156.650]

For some speakers, qin is acceptable in reflexive constructions as in (8), but for other speakers qin cannot be used in reflexive constructions and (8) would have a nonreflexive meaning.

$\begin{array}{ll}\text { (8) John i-les } & \text { qin. } \\ \text { John 3SG.R-see } & \text { 3SG }\end{array}$

'John saw him / ? John saw himself.' [07NB1.077, s0802.09]

Qin is also used as the resumptive pronoun in relative clauses (9) (3.4.7), qet-fronting (10) (6.1), and general noun phrase fronting (11) (6.3)

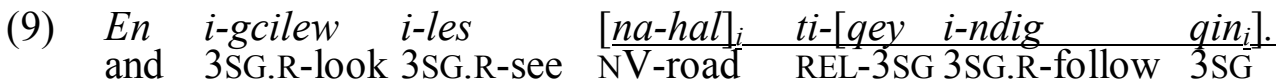
'And she looked and saw the road that she had followed.' [EC01.047 EC01.wav 224.150 230.102]

$\begin{array}{lllll}\text { (10) I-vwer, “Ay, } & {[\text { na-havaq }]_{i}} & \text { qet } & \text { wa-gcilew } & \text { qin } \\ \text { 3SG.R-say hey }\end{array}$ 'He said, "Hey, what is it that you two are looking for?" [07111.024 07111.wav 104.260 107.729]

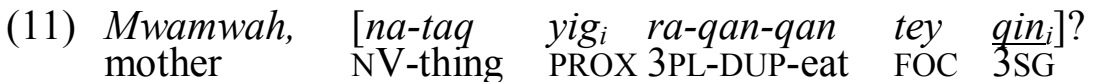
'Mama, is this thing generally eaten (i.e. is it good to eat)?' [07080.017 07080.wav $62.45564 .688]$

\subsection{Co-referential pronouns}

Reflexive constructions are formed using co-referential pronouns. There is no morphology specific to reflexives. Examples (12) and (13) show direct object pronouns which are co-indexed with the subject of the verb.

$\begin{array}{rll}\text { (12) Qet } & \text { Ni-vingcowum } & i \text {-qoyqoy } \\ \text { then NI-vingcowum } & \text { 3SG.R-scratch } & \text { 3SG }\end{array}$

'And Nivigcowum scratched himself.' [07072.075 07072.wav 404.180 407.711]

(13) En [ni-mwomwoq tag $]_{I}$ ru-pul war , ru-gcilew mb-eraqay. and NI-woman DEF.DIST3DU.R-turn 3DU 3DU.R-look to-inland

'And the two women turned themselves and looked inland.' [07072.116 07072.wav 689.447 696.134]

Co-referential pronouns are also used in other places besides direct object position. For example, (14) shows a co-referential pronoun as the possessor in a direct possession construction. In Example (15), it is the possessor in an indirect possession construction. In (16) and (17) the pronoun is the object of a preposition. 
(14) Qet ru-vwer ru-qoyqoy ni-taqu-n war.

then 3DU.R-say 3DU.R-scratch NI-back-3SG 3DU

'And they decided to scratch each other's backs.' [07117.240 07117.wav 824.334 835.052]

(15) John i-tu-seqer ni-sus ti-qey.

John 3SG.R-put-lose NI-shoe POSS-3SG

'John lost his shoes.' [07NB1.093]

(16)

$\begin{array}{llllll}\ldots \text { gcen } & \text { wut } & \text { re-q-vul-vul na-qanyen } & \text { sut } & \text { mbigce- } n & \text { qar: } \\ \text { for } & \text { that } & \text { 3PL-IRR-DUP-buy NV-food } & \text { NONSP } & \text { to-3SG } & \text { 3PL }\end{array}$

gcen wut ra-qan-qan

for that 3PL-DUP-eat

'.. in order to buy themselves something to eat.' [MRK.06:36]

(17) En re-vwere-vwer len qar sombo- $n$.

and 3PL-DUP-say in 3PL alone-3SG

'They started to argue among themselves.' [MAT.21:25]

There are two modifiers that can help to enforce a reflexive interpretation. The first is ndal 'back', which can occur in its PVM1 position (see Section 4.7.6.1) as in Example (18). However, when the co-referential pronoun is not the direct object of the verb, ndal may occur either in the PVM1 position of a preceding verb or in at least two other possible positions as illustrated by (19). Ndal was very common in elicitations of reflexive constructions, and often co-occurs with the focus marker, tey. However, while $n d a l$ may help to disambiguate between the two potential meanings in (20), it is never a required element in reflexive constructions. In fact, in the spoken corpus, there are no identified cases of $n d a l$ occurring with a reflexive interpretation. The other element is sombo-n 'alone-3SG', which is common in the Gospel translations, but not in the spoken corpus or in elicitations for reflexive constructions. ${ }^{59}$ Example (21) contains both $n d a l$ and sombo- $n$, and Example (22) contains only sombo- $n$.

$\begin{array}{lllll}\text { (18) Kinag } & \text { ne-les } & (\text { ndal }) & \text { (tey) } & \text { kinag. } \\ \text { 1SG } & \text { 1SG.R-see } & \text { back } & \text { FOC } & 1 \mathrm{SG}\end{array}$

'I saw myself.' [07NB1.077]

$\begin{array}{llllll}\text { (19) } & \text { Mary i-les } & \text { (ndal tey) } & \text { novol } & \text { taqu-n } & \text { (ndal tey) } \\ \text { Mary 3SG.R-see } & \text { back FOC } & \text { book } & \text { (ndal } \\ \text { behind-3SGback FOC } & \text { 3SG back }\end{array}$ tey).

FOC

'Mary saw a book behind her.' [07NB1.078]

(20) a. John i-les $\frac{q e y .}{3 S G}$
John 3SG.R-see

'John saw him/himself.' [07NB1.077]

\footnotetext{
${ }^{59}$ It is not clear whether this is a feature of formal Nahavaq or whether it is a calque from Bislama constructions such as hem $i$ luk hem wan (3SG PRED see 3SG one) 'he saw himself.' and hem i go hem wan. (3SG PRED go 3SG one) 'He went alone.'
} 


\section{b. John i-les
John 3SG.R-see
back 3SG \\ 'John saw himself.' [07NB1.077]}

$\begin{array}{lllll}\text { (21) I-temwin qey } & \text { ke-mbwil } & \text { ndal qey } & \text { sombo- } n \text { ? } \\ \text { 3SG.R-how 3SG } & \text { 3SG.IRR-kill } & \text { back 3SG } & \text { alone-3SG }\end{array}$

'Does this mean that he will kill himself?' [JON.08:22]

$\begin{array}{lllll}\text { (22) En i-leh } & \text { gcen wut nigce-vwer } & \text { mbigce-n } & \text { kinagc } \\ \text { And 3SG.R-good for that } & \text { 1SG.IRR-say to-3SG } & \text { 1SG }\end{array}$

sombo-n, nigce-vwer, 'Kinagc na-galgal mbutaqay.' alone-3SG 1SG.IRR-say 1SG 1SG.R-happy loud

'Then I will say to myself, "Lucky man!"” [LUK.12:19]

In some cases, there are two potential antecedents for a co-referential pronoun. The following examples are ambiguous in meaning:

(23) Mary i-vwer migce-n John hur amwoq ti-qey. Mary 3SG.R-say to-3SG John about mother POSS-3SG

'Mary talked to John about his/her mother.' [07NB1.093]

$\begin{array}{lllll}\text { (24) John tatay } & \text { ti-qey } & \text { i-rirog } & \text { ndal tey } & \text { qey. } \\ \text { John father } & \text { POSS-3SG } & \text { 3SG.R-like back FOC } & \text { 3SG }\end{array}$

'John's father likes himself/John.' [07NB1.093]

\subsection{Possessive pronouns}

The possessive pronouns nagcon 'mine' and namon 'yours' are clearly related to the 1SG and 2SG possessive prefixes nagcu- and namwu-, which are discussed in Section 3.2.2.2, and like the possessive prefixes, this paradigm is limited to $1 \mathrm{SG}$ and $2 \mathrm{SG}$ possessors. Equivalent possessive forms for other persons are formed using the possessive -yen suffix (Section 3.2.2.3).
(25) Inug ku-hapw len nagcon inet kinag gca-hapw 2SG 2SG.IRR-dance in mine and $1 \mathrm{SG}$ 1SG.IRR-dance
len namwon.
in yours

'You dance in mine, and I'll dance in yours.'[07064.094 07064.wav 363.218 366.671]

(26) En nagcon qar qet namwon qar, en namwon qar qet And mine PL PART yours PL and yours PL PART nagcon. mine

'All I have is yours, and all you have is mine.' [JON.17:10]

\subsubsection{Demonstrative pronouns}

The demonstratives in Table 44 act as nominal heads. They are discussed in detail in Section 6.4.1. 
Table 44: Demonstrative nominal heads

\begin{tabular}{llll}
\hline & Proximal & Distal & Neutral \\
\hline demonstrative pronoun & tiyig & tiyag & tinin \\
demonstrative place nominal & utig & utag & utin \\
demonstrative person nominal & asig & asag & asin \\
\hline
\end{tabular}

\subsubsection{Interrogative nouns (iyaq 'who' and na-havaq 'what')}

(For general description of interrogative constructions, see Section 5.2.2). The interrogative word for people is iyaq 'who'. It is not specified for number. Example (27) shows iyaq with singular referent and Example (28) with dual referent.

(27) Neqhe-n inugc i-ndam iyaq? name-3SG 2SG 3SG.R-name who

'What's your name?' [07117.001 07117.wav 42.594 45.032]

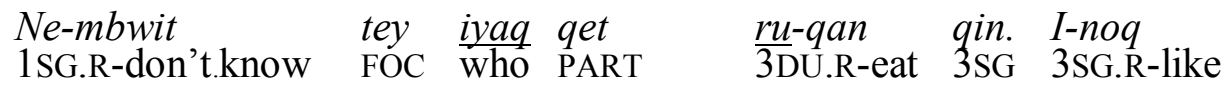

$\begin{array}{lllll}\text { Papap } & \text { Alis } & \text { qet } & \text { i-qan } & \text { qin. } \\ \text { uncle } & \text { Alis } & \text { PART } & \text { 3SG.R-eat } & \text { 3SG }\end{array}$

'I don't know. Who was it that ate it? Maybe it was Uncle Alis that ate it?' [07117.477 07117.wav 1458.792 1461.871]

For non-human directly-possessed nouns, the interrogative word is na-havaq 'what'.

(29) Nigca-qan
1SG.IRR-eat

'What will I eat?' [07082.030 07082.wav 123.642 128.049]

\subsubsection{Proper nouns}

This section describes some morphology that is commonly seen on proper nouns.

\subsection{Place names}

Some place names begin with what appears to be the locative prefix, $l \mathrm{~V}$ - (Section 5.3.2.2). Table 45a shows village names whose derivation has been fully interpreted, and it has been confirmed that the tree or geographical feature from which each name is composed is present at that location. Table $45 \mathrm{~b}$ lists additional place names which begin with $l \mathrm{~V}$ but whose full derivation is not clear. Note that some of these (Lawaq, Lambow) are located outside of the Nahavaq-speaking area, so they may be derived through another language. ${ }^{60}$

\footnotetext{
${ }^{60}$ However, for some villages outside the Nahavaq-speaking area, there is a Nahavaq name which is different from the local name of the village.
} 
Table 45: LV-prefix in place names

\begin{tabular}{l|ll}
\hline & Place name & Possible derivation \\
\hline $\mathrm{a}$ & Lemetu & $l \mathrm{~V}-+$ metu 'coconut' \\
& Lembinwen & $l \mathrm{~V}-+$ mbinwen 'sand' \\
& Luqumow & $l \mathrm{~V}-+($ nu- $)$ qumow 'kind of tree' \\
& Lamagcaw & $l \mathrm{~V}-+$ magcaw 'kind of grass' \\
& Lemuru & $l \mathrm{~V}-+$ muru 'landslide' \\
\hline $\mathrm{b}$ & Lesmbweq & \\
& Leqew-ran-nambag & \\
& Lembwil-Telis & \\
Lambwanin & \\
& Lenembul \\
\hline
\end{tabular}

Other prefixes which occur on place names are shown in Table 46.

Table 46: Other prefixes on place names

\begin{tabular}{|c|c|c|c|c|}
\hline$E$-prefix & $M b V$-prefix & $W i$-prefix & Vor- prefix & Loqor-prefix \\
\hline Ewur 'Toman Island' & $\begin{array}{l}\text { Mbenewur } \\
\text { (village) }\end{array}$ & $\begin{array}{l}\text { Witavwaq } \\
\text { (village) }\end{array}$ & Vorlesles & Loqorlagcalat \\
\hline Esip 'Vinmavis village' & mbwatnatam & Wihep & Vormburi & Loqormbarap \\
\hline Epmbwaqaymeqet & $\begin{array}{l}\text { Mbatmbag } \\
\text { (village) }\end{array}$ & Wivoq & Vormbimbarap & Loqornewey \\
\hline Evunet & $\begin{array}{l}\text { Mbwatmbug } \\
\text { (village) }\end{array}$ & Wiqamblu & Vortuqur & Loqormbwaqay \\
\hline \multirow{6}{*}{$\begin{array}{l}\text { Evungeymbwarambwar } \\
\text { Evunmbaqornalah } \\
\text { Ewut }\end{array}$} & & Wimbwu & & Loqorsem \\
\hline & & Wivwi & & Loqoru \\
\hline & & $\begin{array}{l}\text { Windu } \\
\text { (village) }\end{array}$ & & Loqoryet \\
\hline & & Wimburi & & Loqormbaq \\
\hline & & Wiwat (river) & & Loqorlambut \\
\hline & & $\begin{array}{l}\text { Wilemb } \\
\text { (river) }\end{array}$ & & Loqorvoq \\
\hline
\end{tabular}

The locative $e$ - prefix may be cognate with the South Efate locative affix $e$ (Thieberger 2004: 131-132). In Nahavaq, it can also be seen on some locational nouns and prepositions (Section 5.3.2.3) and locational demonstrative adverbs (Section 6.4.1). For some of the place names with $e$-prefixes, the full derivation is apparent, i.e. E-wur 'LOC-island' and E-sip 'LOC-go.ashore'. 61

Some of the place names in Table 46 appear to have the $m b \mathrm{~V}$ - prefix (Section 6.4.2). In particular Mbenewur can be analysed as $m b \mathrm{~V}-n \mathrm{~V}-w u r$ 'to-NV-island', and this village is located on the Malakula mainland just opposite a small offshore island. The other place names listed in the $m b \mathrm{~V}$ - column in Table 46 all begin with $m b a t-$, which may be related to mbwati- 'head' rather than the $m b \mathrm{~V}$ - prefix.

\footnotetext{
${ }^{61}$ Note that the Nahavaq name for Toman Island is Ewur, but in Na'ahai (the language spoken on Toman), the same is Wur.
} 
The wi- prefix in Table 46 means 'water' (the independent synchronic form is newey). Fully interpretable names include Wi-mburi 'water-small.brown.stones' and Wi-mbwu 'water-stink'.

The vor-prefix is likely related to the word no-vor 'world'. I was told that place names beginning with vor-specifically refer to a place of habitation rather than a region or landscape feature.

The loqor-prefix occurs on a number of place names, but its meaning is not clear. Deacon (1934: 61) claims that it is a term applied to satellite villages meaning 'a spot which is set apart'. It also appears to be cognate with Naman lokhor, which means a 'place of circumcision' (Crowley 2006b: 163). However, Nahavaq speakers that I spoke to did not know the meaning of loqor-.

\subsection{Person names}

These days in the Nahavaq-speaking area, some people's given names are Westerninspired while some are more traditional. There is a tendency for Western-inspired male names to end in -son (pronounced [son], [kon] or [bon]) or sometimes begin with son-. Western-inspired female names often end in -lin. A person's family name is usually the given name of one's father, paternal grandfather, or husband. However, there are some cases where people use the name of a male ancestor beyond the paternal grandfather.

Table 47: Western-inspired Nahavaq names ${ }^{62}$

\begin{tabular}{ll|ll}
\hline & Male & \multicolumn{2}{c}{ Female } \\
\hline Brianson & Sonpeti & Neslin & Merilin \\
Fredson & Sonkaltoa & Andrilin & Anilin \\
Alison & Sonsak & Votselin & Andilin \\
Makson & Sondrolog & Marklin & Marselin \\
Maksayson & & Moslin & Ndorlin \\
& & Polin & Noralin \\
& & Karlin & \\
Tom & Ron & Nesli & Nansi \\
Hokey & John & Jelian & Emili \\
Mickey & Sam & Natasha & Heta \\
Meldon & Taylor & Maddy & Louise \\
Mako & & Kelina & Krisel \\
& & Elling & \\
\hline
\end{tabular}

More traditional given names usually start with $\mathrm{Kal}$ - or $\mathrm{Ai}$ - for males and $\mathrm{Li}$ - for females. The Kal- of many names changes to Agcal-for address forms. This is likely the result of a personal prefix $a$ - (also discussed in Section 3.4.8.1 and 6.4.1). The origin of the $A i$ - prefix on names may be the personal prefix, $a$-, combined with the third person singular realis verbal subject prefix, $i$-. The $L i$ - prefix is not found elsewhere except for in a few animal names_limeh 'wild duck' limbowar 'heron', and limbir 'bitch'.

${ }^{62}$ Table 47 contains a mix of spelling conventions. 
Table 48: Traditional-style Nahavaq names

\begin{tabular}{lll}
\hline Kal- names (male) & Ai- names (male) & Li- names (female) \\
\hline Kalset & Aimbel & Lisulvere \\
Kalmar & Aindip & Likom \\
Kalo & Airog & Lisesmbwatmbuqmbuq \\
Kalmus & Aisoq & Lituqtapris \\
Kaltamwat & Aitip & Lituqurmeleg \\
Kalori & Aiel & Livwandalyep \\
Kalmuri & Ainder & Lipaw \\
Kalmbatik & Aimat & Lisig \\
Kalsig & Aimbog & Liteli \\
Kalminduwa & Aitip & Limasig \\
Kalmelu & Aitiplus & Liroqles \\
Kalmasig & Aimbuwas & Livagas \\
\hline
\end{tabular}

It is common to form affectionate nicknames with an $a$ - prefix for both males and females (Table 49). This usually involves abbreviation of the name root to a single syllable, most commonly the first syllable (Ketley $>$ Aket), but also sometimes the final syllable (Mbelinda $>$ Anda). However, the names are not always reduced to one syllable (Kalmboy $>$ Agcalmboy). Names beginning with kal- can either remain with $\mathrm{a} / \mathrm{k} /$ sound (Ketley $>$ Aket) or become prenasalised (Kalmar $>$ Agcalmar).

Table 49: $A$ - nicknames

[08NB1.035, 08NB1.074]

\begin{tabular}{llll}
\hline Name (male) & Nickname & Name (female) & Nickname \\
\hline John & Ason & Kori & Akor \\
Kalmboy & Agcalmboy & Linsa & Alin \\
Kalmar & Agcal(mar) & Karlin & Akar \\
Ketley & Aket & Mbelinda & Ambel $\sim$ Anda \\
Tom & Atom & Moslin & Amos \\
Ndik & Andik & Votselin & Avot \\
Mak & Amak & & \\
Sendry & Asen & & \\
Makson & Amak & & \\
\hline
\end{tabular}

There are some kinship titles that can precede given names as in Papap Aiel 'Uncle Aiel.' Other kinship terms that can act as titles include mama 'mother', amoq 'mother', tatay 'father', kakap 'grandmother', and totot 'grandfather'. When used as a title, the kinship terms with apparent reduplication are often un-reduplicated, i.e. Pap Aiel 'Uncle Aiel', Kap Jil 'Grandma Jill', Tot Pasta 'Grandfather Pastor'. In addition, given names are sometimes abbreviated when used in conjunction with a kinship title, and it is the first syllable or two of the given name that are dropped. For example, mama + Marino $>$ Mama-no, papap + Ambwata $>$ Pap-mbwata.

\subsubsection{Locational and temporal nouns}

Locational nouns such as law 'shore' in (30) and temporal nouns such as qor 'today' in (31) differ from other nouns because they can act as adjuncts to clauses. They are discussed in detail in Section 5.3.2.1. 
(30) U-rirog tey ku-vwahupw law?

2SG.R-like FOC 2SG.IRR-bathe shore

'You like to bathe in the sea?' [07117.057 07117.wav 271.248 274.998]

(31) Mahal yigc qet mi-lip len net qor. fish PROX COMPL 1EX.PL.R-take in net today

'This is the kind of fish we caught in the net today.' [07117.156 07117.wav 576.978 580.447]

\subsubsection{Derived nouns}

There are three patterns of nominalising affixation in Nahavaq: one which derives a noun from a verb (3.1.3.1), one which derives an instrument noun from a verb (3.1.3.2), and one that derives an ordinal noun from a numeral (3.1.3.3). In addition there are nominal roots which have the same form as related verbal roots. These are discussed in Section 3.1.3.4. However, they are not considered nominalisation because it is not clear in which direction the derivation may have taken place.

\subsubsection{1. $N i$-VERB-yen}

The simulfix involving the optional nominal prefix, $n i$ - (section 3.3.1) and the nominalising suffix, $-y e n$, is a productive means of deriving a noun from a verbal base. The $n i$ - prefix element of this simulfix is optional, but usually present. The -yen suffix is obligatory. Table 50 provides examples of nominalisation using this simulfix. For bases beginning in glottal consonants, the vowel in the ni- prefix may assimilate to the first vowel in the root (see Section 2.4.7). Note that words borrowed from Bislama such as kuk 'cook' and tagcyu 'thank you' undergo nominalisation with this simulfix, which demonstrates its productivity. 
Table 50: Nominalisation with ni-BASE-yen

\begin{tabular}{|c|c|c|c|}
\hline & Base & ni-base-yen & Gloss \\
\hline \multirow[t]{9}{*}{$\mathrm{a}$} & $r a q^{\prime}$ work (v)' & ni-raq-yen & 'work (n)' \\
\hline & galgal 'happy (v)' & ni-galgal-yen & 'happiness (n)' \\
\hline & mban 'win, beat, surpass (v)' & ni-mban-yen & 'victory/triumph (n)' \\
\hline & rog 'feel (v)' mereven 'sad (v)' & ni-rog-mereven-yen & 'sorrow (n)' \\
\hline & $k u k ' \operatorname{cook}(\mathrm{v}) '$ & $n i-k u k-y e n$ & 'cooking (n)' \\
\hline & $m e s$ 'die, dead (v)' & ni-mes-yen $\sim$ ni-mis-yen ${ }^{63}$ & 'death $(\mathrm{n})$ ' \\
\hline & mbon 'join (v)' & ni-mbon-yen & $\begin{array}{l}\text { 'union/unity/working } \\
\text { together (n)' }\end{array}$ \\
\hline & qambwiq 'plant (v)' & (ni-/na-)qambwiq-yen & 'planting (n)' \\
\hline & pwaras 'strong (v)' & ni-pwaras-yen & 'strength (n)' \\
\hline \multirow[t]{15}{*}{ b } & tagcyu 'thank (v)' & ni-tagcyu-yen & 'thanks (n)' \\
\hline & ndighur 'tell (v)' & ni-ndighur-yen & 'story (n)’' \\
\hline & hap 'dance (v)' & (ni-/na-)hap-yen & 'dance (n)' \\
\hline & hap-hap 'DUP-dance (v)' & (ni-/na-)hap-hap-yen & 'dance ceremony (n)' \\
\hline & ndip 'heavy (v)' & ni-ndip-yen & 'weight (n)' \\
\hline & meheq 'sick (v)' & ni-meheq-yen & 'disease/sickness (n)' \\
\hline & leq 'married (v)' & ni-leq-yen & 'wedding (n)' \\
\hline & mwindal 'play (v)' & ni-mwindal-yen & 'game (n)' \\
\hline & vagas 'speak (v)' & $n i$-vagas-yen & $' \operatorname{speech}(n) '$ \\
\hline & sug 'celebrate (v)' & ni-sug-yen & 'feast/celebration (n)' \\
\hline & tus 'draw, write (v)' & ni-tus-yen & 'drawing/writing (n)' \\
\hline & ndimndim 'think (v)' & (ni-)ndimndim-yen & 'thought (n)' \\
\hline & vinevin 'promise (v)' & ni-vinevin-yen & 'promise (n)' \\
\hline & viqis 'tell a lie, turn (v)' & ni-viqis-yen & 'lie (n)' \\
\hline & popow 'be surprised (v)' & ni-popow-yen & 'surprise (n)' \\
\hline \multirow[t]{6}{*}{$\mathrm{c}$} & vwutvwut 'act, stand for (v)' & $n i-v w u t-v w u t-y e n$ & 'sign, symbol (n)' \\
\hline & muwen'sweat (v)' & ni-muwen-yen & 'sweat (n)' \\
\hline & kambulugc 'make fist (v)' & ni-kambulugc-yen & 'fist (n)' \\
\hline & qan 'eat (v)' & $n a-q a n-y e n^{64}$ & 'food $(n)$ ' \\
\hline & qaqan 'have a meal (v)' & (ni-/na-)qaqan-yen & 'meal (n)' \\
\hline & mbonombon 'together (v)' & ni-mbonombon-yen & 'group, party (n)' \\
\hline
\end{tabular}

Crowley (1982: 83) identified four syntactic functions of nominalisation in Paamese, and three of these can be found in Nahavaq: (i.) an abstract noun denoting the actual action performed or the state experienced (Table 50a), (ii.) a particular instance of the action or state rather than the state or action itself (Table 50b), and (iii.) a concrete thing that is the entity directly affected by the activity expressed in the verb stem or the product of the activity (Table 50c). As in Paamese, many nominalisations in section a or b or Table 50 can either refer to an action or state in general as in (32) or a particular instance of that action or state as in (33).

\footnotetext{
${ }^{63} \mathrm{Ni}$-mis-yen $\sim$ ni-mes-yen 'death' has an irregular vowel change for some speakers.

${ }^{64}$ Note that na-qan-yen '(NV-eat-NOM) food' is such a frequent word, that I gloss it elsewhere as if it had a monomorphemic nominal base: na-qanyen ' $\mathrm{NV}$-food'.
} 
(32)

Qey sombo-n veq qet i-kuk taq yig. I-nitim 3SG alone-3SG NEG PART 3SG.R-cook thing PROX 3SG.R-need

morot nin raq-yen. man ASS work-NOM

'He didn't cook this thing alone. He needed workers.' [07058.133 07058.wav 524.211 526.930]

(33) Mwelgcil nin i-rar ndoh raq-yen ti-qey en magic DEM 3SG.R-make PERF work-NOM POSS-3SG ID

'The magic had done its work.' [07064.173 07064.wav 611.623 616.733]

There are also examples of $n i$-BASE-yen nominalisation where the base contains more than a single morpheme (Table 51). This includes VERB+MODIFIER (ni-vweleg-ndalyen 'return'), SUBJECT+VERB (ne-tes-wu-yen 'high tide'), and VERB+OBJECT (niroghur-wut-yen 'wisdom'). ${ }^{65}$

Table 51: $n i$-BASE-yen nominalisation of multi-morpheme bases

\begin{tabular}{|c|c|c|}
\hline Base & ni-base-yen & Gloss \\
\hline \multicolumn{3}{|c|}{ vagas 'speak (v)' + nderem 'reply (v)' } \\
\hline & ni-vagas-nderem-yen & 'response, answer (n)' \\
\hline \multicolumn{3}{|c|}{ ne-tes 'NV-sea (n)' + ndum 'crash (v)' } \\
\hline & ne-tes-ndum-yen & 'rough sea $(n)$ ' \\
\hline \multicolumn{3}{|c|}{$n e-t e s$ 'NV-sea (n)' + meh 'dry (v)' } \\
\hline & ne-tes-meh-yen & 'low tide (n)' \\
\hline \multicolumn{3}{|c|}{ ne-tes 'NV-sea (n)' + wu 'high tide (v)' } \\
\hline & ne-tes-wu-yen & 'high tide (n)' \\
\hline \multicolumn{3}{|c|}{ vwer 'say (v)' + gcor 'block (v)' } \\
\hline & $n i$-vwer-gcor-yen & 'law/rule (n)' \\
\hline \multicolumn{3}{|c|}{ roghur 'know (v)' + ne-wut 'NV-place (n)' = 'have knowledge' } \\
\hline & ni-roghur-(ne-)wut-yen & 'wisdom, knowledge (n)' \\
\hline \multicolumn{3}{|c|}{ vweleg 'come (v)' + ndal 'back (PMV1)' } \\
\hline & ni-vweleg-ndal-yen & 'return (n)' \\
\hline \multicolumn{3}{|c|}{ vene-ven 'DUP-shoot (v)' + men 'bird (n)' } \\
\hline & ni-vene-ven-men-yen & 'bird hunting (n)’ \\
\hline \multicolumn{3}{|c|}{ tavaraq 'stand up (v)' + ndal 'back (PVM1) } \\
\hline & ni-tavaraq-ndal-yen & 'resurrection (n)' \\
\hline \multicolumn{3}{|c|}{ koh 'be (v)' + siqsiq 'separately (PVM1) } \\
\hline & ni-koh-siqsiq-yen & 'separation (n)' \\
\hline \multicolumn{3}{|c|}{ koh 'be (v)' + tutu 'tight together (v2)' } \\
\hline & ni-koh-tutu-yen & 'group, meeting (n)' \\
\hline
\end{tabular}

One particular pattern of SUBJECT+VERB nominalisation is used to form nouns of quality from a stative verb with $n e-w u t$ ' $\mathrm{NV}$-place' as the subject (Table 52). A similar pattern can be seen in Avava (Crowley 2006a: 41).

\footnotetext{
${ }^{65}$ While all speakers seem to accept incorporated objects in these nominalisation structures as in $n i-$ vene-ven-men-yen '(NI-DUP-shot-bird-NOM) bird-hunting', speakers differ as to whether they accept non-incorporated objects which include $n i$ - or $n \mathrm{~V}$ - prefixes such as ?ni-vah-ni-mbunog-yen '(NI-bearNI-child-NOM) childbirth'
} 
Table 52: Nominalisation with Newut (STATIVE VERB)-yen

\begin{tabular}{lll}
\hline pilpil 'hot' & newut pilpil-yen & 'heat' \\
ponopon 'dirty black' & newut ponopon-yen & 'darkness/dark ages' \\
malqah 'cold' & newut malqah-yen & 'cold time/winter' \\
mehmeh 'dry' & newut mehmeh-yen & 'dryness/place for drying off' \\
har 'shine' & newut har-yen & 'light/open place' \\
reg 'light, dawn, early' & newut reg-yen & 'daylight/day' \\
\hline
\end{tabular}

The ni-BASE-yen construction also appears to be involved in the construction described in Section 3.2.1.3 where a noun is derived from a verb which is derived from a directly possessed noun as in (34).

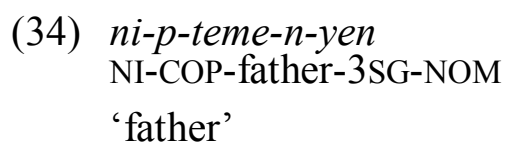

\subsubsection{Naqay-VERB}

A number of instruments are expressed with compounds of naqay 'wood, tree, stick' with a verb root. The naqay- nominalisations in Table 53a are clearly instruments that are commonly used to perform the action expressed by the verb root. The nominalisations in Table 53b are less clear, and for some of them, the verb root is not known. In some cases the verb root is reduplicated, while in others it is not. In the case of naqay-qoy-metu 'coconut scraper,' there is an object of the uninflected verb root as well.

Paamese has a similar construction with the form ai-ROOT. Crowley (1982: 83) interprets the $a i$ - morpheme as deriving from the Proto-Oceanic common noun marker $* a$ - plus POc $* i$-. However, Proto Oceanic appears to have formed instrumental nouns with a *ka[i]- prefix (from *kaiu 'tree') (Lynch et al. 2002: 70), so the 'wood, tree, stick' interpretation for Nahavaq's instrumental prefix would seem plausible. 
Table 53: Nominalisation with naqay

\begin{tabular}{lll}
\hline a qoy 'scrape (v)' + metu 'coconut & naqay-qoy-metu & 'coconut grater' \\
(n)' & & \\
tur 'pierce' & naqay-tur & 'fish-stringing stick' \\
let 'stake up' & naqay-let & 'garden stake' \\
gcalas 'hold hot stone with tongs' & naqay-gca-gcal & 'tongs' \\
turtur 'sew' & naqay-turtur & 'needle' \\
gcewus 'pick with stick' & naqay-gcewus & 'long forked pole' \\
sipwsipw 'bail' & naqay-sipwsipw & 'canoe bailer' \\
sigir 'prop open/anchor' & naqay-si-sigir & 'support' \\
suq 'stab' & naqay-susuq & 'fruit-picking pole' \\
ndi-nduwel 'swing' & naqay-(ndi-)nduwel 'swing' \\
surey 'sweep' & naqay-(su-)surey & 'broom' \\
tuglag 'rest one's head' & naqay-tuglag & 'pillow' \\
top 'run' pet 'break' ('cross') & naqay-toppet & 'bridge' \\
sel 'hook' & naqay-sel & 'hook', 'seahorse' \\
sumbw 'sit' & naqay-sumbw- & 'seat' \\
& sumbw & \\
sag 'hang' & naqay-sag & 'shelf/table' \\
siyesi 'punt' & naqay siyesi & 'canoe pole' \\
kisiq 'limp' & naqay kisiq & 'crutch' \\
\hline mes 'die/dead' & naqay-mes & 'knife' \\
mbuq-mbuq 'short' & naqay-mbuqa-mbuq 'club' \\
- & naqay nagcar & 'cat' \\
wun 'join' & naqay-wun-wun & 'female line' \\
- & naqay gcirgcir & 'kitten' \\
- & naqay humbwen & 'ridgepole' \\
- & naqay susugar & 'fruit-picking pole' \\
yep 'lost from' & naqay yep & 'driftwood' \\
vowus 'carry' & naqay-vi-vowus & 'coffin' \\
vurey 'spit' & naqay-vurey & 'magic spit leaves' \\
tarapwir 'lay down structure' & naqay tarapwir & 'baton' \\
\hline & & \\
& &
\end{tabular}

\subsubsection{Naqay-NUMERAL-yen}

Another construction which uses the $-y e n$ suffix is ordinal numbers. They are composed of naqay-NUMERAL-yen for numerals above one. ${ }^{66} 67$

Table 54: Ordinal numbers

\begin{tabular}{lll}
\hline$r u$ 'two' & naqay-ru-yen & 'second' \\
tul 'three' & naqay-tul-yen & 'third' \\
sow-ru 'six' & naqay-sow-ru-yen & 'sixth' \\
lagavul 'ten' & naqay-lagavul-yen & 'tenth' \\
morlalaq 'twenty' & naqay-morlalaq-yen & 'twentieth' \\
\hline
\end{tabular}

\footnotetext{
${ }^{66}$ It is not clear whether the naqay-prefix in ordinal constructions has the same origin as that in instrumental constructions (Section 3.1.3.2).

${ }^{67}$ I was unable to find a speaker who could form an ordinal construction for numerals that are composed of multiple units such as morlalaq i-siq no-qorond i-lagavul ndumwen i-lim '35 (twenty 3SG.R-one NV-??? 3SG.R-ten ??? 3sG.R-five)'.
} 
My analysis of ordinal numbers as nouns is based on two observations First, they contain what appears to be the nominalising suffix on numeral roots, which are themselves verbs. Second, while they occur both alone as an NP (35) or with an NP (36)-(38), it is difficult to make a case that they are nominal modifiers because they can occur either before the noun, (36) and (37), or after the noun that they would be modifying, (36) and (38). The two orders are interchangeable. Therefore, I consider ordinal numbers to be nouns. When they occur with another noun as in (36)-(38), the two noun phrases are in apposition.

(35) En naqay-tul-yen qey ke-lip ndal lis ni-momoq nin. and ORD-three-NOM 3SG 3SG.R-take back again NI-woman DEM 'And the third (brother) also took that woman.' [LuK.20:31]

(36) Re-metur ni-mbug naqay-ves-yen en. Re-metur ne-wut 3PL-sleep NV-day ORD-four-NOMI NDIC 3PL-sleep NV-place $\begin{array}{llll}i \text {-reg levahat len naqay-lim-yen } & \text { ni-mbug. } \\ \text { 3SG.R-light morning } & \text { in } & \text { ORD-five-NOM } & \text { NV-day }\end{array}$

'They slept on the fourth day. They slept until the morning dawned on the fifth day.' [TB03.049 TB03.wav 248.283 254.972] $\begin{array}{lllllll}\text { (37) En } & \text { ndal lis qey } & \text { i-sur } & \text { naqay-ru-yen } & \text { ni-morot } & \text { nin } \\ \text { and } & \text { back again 3SG } & \text { 3SG.R-send } & \text { ORD-two-NOM } & \text { NI-man } & \text { ASS }\end{array}$ ni-raq-yen ti-qey. NI-Work-NOM POSS-3SG

'And he sent a second slave of his.' [LUK.20:11]

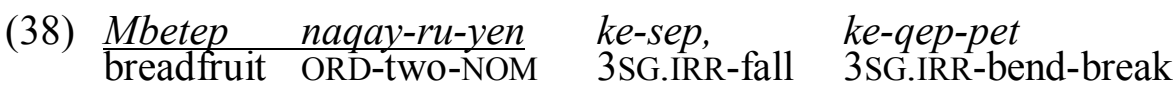
naqay-ru-yen. ORD-two-NOM

'When the second breadfruit falls, he will break the second leaf.' [07044.011-012 07044.wav 25.915 28.142]

\subsubsection{4. Ø-derivation (nouns and verbs)}

Table 55 shows pairs of related nominal roots and verbal roots which have the same form. It is not clear whether the nominal form was derived from the verbal form or visa versa. In many cases, the nominal form has a nominal prefix (Section 3.3.1). In some cases, either the noun or the verb is reduplicated while the other is not. A subset of the Ø-derivations (Table 55b) refer to a person with a physical condition or a person having that condition in the case of the noun, and the state of having that condition in the case of the verb. 
Table 55: Ø-derivation (nouns and verbs)

\begin{tabular}{|c|c|c|c|c|}
\hline & Nominal form & Gloss & Verbal form & Gloss \\
\hline \multirow[t]{12}{*}{ a. } & malqah & 'cold/flu' & malqah (v.i.) & 'be cold' \\
\hline & ni-hew-hew & $\begin{array}{l}\text { 'device for steam } \\
\text { infusion' }\end{array}$ & hewhew (v.t.) & $\begin{array}{l}\text { 'steam with an } \\
\text { infusion' }\end{array}$ \\
\hline & molol & 'dirt' & molol (v.i.) & ‘dirty’ \\
\hline & mbulmbul & 'glue' & mbulmbul & 'stick' \\
\hline & $n a-g a r$ & 'mucous/flu' & gar & 'have cold' \\
\hline & na-hul & 'coconut leaf' & hul (v.i.) & 'kindle fire' \\
\hline & $n i-l u$ & 'vomit' & $l u$ (v.i.) & 'to vomit' \\
\hline & ni-mbutembut & 'heel' & mbutembut (v.i.) & 'step' \\
\hline & na-qapqap & 'penis-wrapper' & qapqap & 'circumcise' \\
\hline & ni-qoyqoylop & 'local ice-cream' & qoyqoylop & $\begin{array}{l}\text { 'make local ice- } \\
\text { cream' }\end{array}$ \\
\hline & $n i-s k u l$ & 'church/school' & skul (v.i.) & $\begin{array}{l}\text { 'attend } \\
\text { church/school' }\end{array}$ \\
\hline & ni-pen & 'paint' & pen (v.t.) & 'to paint' \\
\hline \multirow[t]{4}{*}{ b. } & $n a-k a r$ & $\begin{array}{l}\text { 'skin disease/person } \\
\text { with skin disease' }\end{array}$ & kar & $\begin{array}{l}\text { 'have skin } \\
\text { disease' }\end{array}$ \\
\hline & $n a-m b w u r$ & $\begin{array}{l}\text { 'elephantiasis/person } \\
\text { with elephantiasis' }\end{array}$ & mbwur & $\begin{array}{l}\text { 'have } \\
\text { elephantiasis' }\end{array}$ \\
\hline & na-war & $\begin{array}{l}\text { 'white-haired- } \\
\text { ness/person with white } \\
\text { hair' }\end{array}$ & war & 'have white hair' \\
\hline & ni-mevus & $\begin{array}{l}\text { 'albino person/white } \\
\text { person'' }\end{array}$ & mevus & 'white' \\
\hline
\end{tabular}

\subsubsection{Compound nouns}

There are many compound nouns formed by a head noun plus some kind of modifier. Whether or not they constitute single phonological words or multiple phonological words is not clear. Speakers vary in how they divide them when writing. But when the second element contains only a single syllable (na-lag-rap ' $\mathrm{NV}$-wind+??? = hurricane', mete-n-hal 'eye-3SG+road = trailhead'), the compound is more often considered to be a single word, presumably to avoid single-syllable content words (See section 2.8.2). Because it is not clear whether many other compounds constitute single words or multiple words, there may be inconsistency in their orthographic representation.

The modifier in a nominal compound may be a verb (Table 56a), a noun (Table 56b), or an element with unidentified part of speech such as raqay which is clearly related to the locational noun eraqay, but which does not occur independently (Table 56c and many of the unidentified items in Table 56d). Compounds are particularly common in plant or animal names (Table 56d). There may be three lexical elements in a compound as in naqay-gcew-mbetep 'NV-stick + straddle + breadfruit = stick insect' or ne-ndiq-mbwat-mbwaqay 'NV-mat + head + yam = 'food scrap mat'. 
Table 56: Nominal compounds

\begin{tabular}{|c|c|c|}
\hline a. metu gcor & coconut+block & 'dry coconut' \\
\hline na-lag ndel & NV-wind+swirl & 'whirlwind' \\
\hline na-mbwu-huphup & NV-bamboo+DUP-blow & 'flute' \\
\hline na-lag-sip & $\mathrm{NV}$-wind+ashore & 'Northeast wind' \\
\hline ne-revuh mbaragcin & NV-bow+true & 'bow' \\
\hline temes ndigndig & devil+DUP-follow & 'custom story' \\
\hline ne-revuh yalyal & NV-bow+DUP-sing & 'musical bow' \\
\hline ne-wey mbumbu & NV-water+DUP-stink & 'pus' \\
\hline ni-nal-nden & $\mathrm{NV}$-sun+dive & 'kind of crab' \\
\hline mbwaqay-vew & yam+new & 'new yams' \\
\hline niyir turtur & $\mathrm{NV}$-needle+sew & 'needle' \\
\hline b. mbwat mbusus & head(?)+door & 'wall' \\
\hline$n i$-vwinduq metu & $\mathrm{NV}$-midrib+coconut & 'midrib of coconut leaf' \\
\hline na-hal temes & NV-road+devil & 'customary ways?' \\
\hline mbwunog morot & child+man & 'boy' \\
\hline vwutin mbwunog & child-3SG+child & 'child' \\
\hline na-mbaq rayis & NV-bag+rice & 'rice bag' \\
\hline ne-yumw-skul & NV-house+church & 'church house' \\
\hline na-mbaq-ne-revuh & NV-???- NV-bow & 'the wood of the bow?' \\
\hline mweney-mbwuwes & money+pig & 'price in pigs' \\
\hline mete-n-hal & eye-3SG+road & 'trailhead' \\
\hline mete-n-nal & eye-3SG+sun & 'hour' \\
\hline mete-n-lambut & eye-3sG+rat & 'ankle' \\
\hline ne-ndiq-mbwat-mbwaqay & $\mathrm{NV}-\mathrm{mat}+$ head+yam & 'food scrap mat' \\
\hline na-mwas-nal & $\mathrm{NV}$-spear+sun & 'shooting star' \\
\hline na-qayew mbwati-n & $\mathrm{NV}$-pudding+head-3SG & 'brain' \\
\hline ne-reqey met-en & NV-leaf+eye-3SG & 'centre leaf for pudding' \\
\hline ne-vet vulus & $\mathrm{NV}$-stone+oven & 'cooking stones' \\
\hline pwan-qo-n & $? ? ?+$ face-3SG & 'forehead' \\
\hline c. na-lag raqay & wind+inland & 'South wind' \\
\hline d. mahal lanlan & fish+??? & 'kind of fish' \\
\hline mahal yuyuh & fish + move(with hand) & 'kind of fish' \\
\hline mahal-kas & fish+??? & 'whale' \\
\hline mahal-pag & fish $+($ bloodshot?) & 'crayfish' \\
\hline mahal-tiq & fish+??? & 'kind of fish' \\
\hline malqes yar & fish+???+??? & 'kind of fish' \\
\hline mesin novor & trevally+deep reef & 'kind of fish' \\
\hline no-qoyit reverep & NV-octopus+??? & 'cuttlefish' \\
\hline nu-gcut morot & $\mathrm{NV}$-banana+man & 'k.o.banana' \\
\hline nu-wur mbalagcaw mbinwe & $\mathrm{NV}$-leaf+cup+sand & 'kind of flounder' \\
\hline na-qay-gcew-mbetep & $\mathrm{NV}$-stick+straddle+breadfruit & 'stick insect' \\
\hline na-qavwus ne-weg & NV-cabbage+ NV-??? & 'island cabbage' \\
\hline mweney ruqurq & grass $+? ? ?$ & 'sea grass' \\
\hline kilu nu-gcut & $\mathrm{NV}$-dog+ NV-banana & ‘earwig’ \\
\hline na-lambut magcar & NV-rat+??? & 'cat' \\
\hline na-lambut kikik & NV-rat+??? & 'European rat' \\
\hline na-halag mbwaqay & NV-taro+yam & 'kind of taro' \\
\hline
\end{tabular}


If the head noun normally contains a $\mathrm{NV}$ - prefix, the prefix is retained (na-qayew $m b$ wati- $n$ 'NV-pudding+head-3SG = brain'). If the modifier is a noun that normally contains a NV-prefix, it may be retained (na-mbaq-ne-revuh ' $\mathrm{NV}-? ? ?+\mathrm{NV}$-bow = bow string') or it may not (na-mwas-nal ' $\mathrm{NV}$-spear+sun = shooting star'). Both directly possessed and indirectly possessed nouns can be found as heads or modifiers. Interestingly, in some cases directly possessed nouns retain their $3 \mathrm{SG}$ possessor ending (vara-n mbaragcin 'arm-3SG+right $=$ right hand/arm'), but in other cases ( $m b$ wat mbusus 'head?+door $=$ wall'), they do not.

\subsection{Possession}

This section describes possessive constructions. Nahavaq has a major division in nouns between directly possessed and indirectly possessed nouns (for more detail on these groups, see Section 3.1.1). Both can enter into a number of possessive constructions. Table 57 list nine surface constructions that express possessive relationships.

Table 57: Surface structures of possession

\begin{tabular}{|c|c|c|c|}
\hline Form & $\begin{array}{c}\text { Directly } \\
\text { possessed } \\
\text { possessee }\end{array}$ & $\begin{array}{l}\text { Indirectly } \\
\text { possessed } \\
\text { possessee }\end{array}$ & Section \\
\hline N-suffix & $\mathrm{y}$ & $\mathrm{n}$ & 3.2 .1 .1 \\
\hline N-suffix POSSESSOR & $\mathrm{y}$ & $\mathrm{n}$ & 3.2.1.2 \\
\hline POSSESSOR N-suffix & $\mathrm{y}$ & $\mathrm{n}$ & 3.2.1.2 \\
\hline$n i-v i$-N-yen ti-POSSESSOR & $\mathrm{y}$ & $\mathrm{n}$ & 3.2.1.3 \\
\hline N $t i$-POSSESSOR & $?$ & $\mathrm{y}$ & 3.2.2.1 \\
\hline 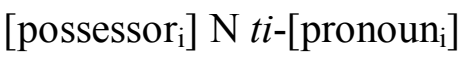 & $?$ & $\mathrm{y}$ & 3.2.2.1 \\
\hline prefix-N & $?$ & $\mathrm{y}$ & 3.2.2.2 \\
\hline POSSESSOR-yen $\mathrm{N}$ & $\mathrm{y}$ & $\mathrm{y}$ & 3.2.2.3 \\
\hline $\mathrm{N}$ nin POSSESSOR & $\mathrm{n}$ & $\mathrm{y}$ & 3.2.2.4 \\
\hline
\end{tabular}

\subsubsection{Possessive constructions with directly possessed nouns}

\subsubsection{Direct possession with possessor suffix}

Directly possessed nouns are obligatorily suffixed with either $-q$ for $1 \mathrm{SG},-m w$ for $2 \mathrm{SG}$, or $-n$ for $3 \mathrm{SG}(39) .{ }^{68}$ The $-n$ ' $3 \mathrm{SG}$ ' suffix can also function as a default suffix for any person or number of possessor as described in Section 3.2.1.2.

(39)
a. vara- $q$
'my hand (hand-1SG)'
b. vara-mw
'your hand (hand-2SG)'
c. vara-n
'his/her hand (hand-3SG)'

In some words there is change in the final vowel associated with the different suffixes. There are two common patterns of vowel variation. The first has /a/ as the final vowel in $1 \mathrm{SG}$ and $2 \mathrm{SG}$, but /e/ in 3SG (Table 58a-d). This alternation in the vowel can be seen further to the left as well in 'eye' and 'father'. The second pattern has $/ \mathrm{u} /$ as the final vowel in $1 \mathrm{SG}$ and $2 \mathrm{SG}$, but $/ \mathrm{i} /$ in $3 \mathrm{SG}$ e-g. Neither pattern can be considered productive as there are items that have consistent /a/, /e/, /u/, and /i/ as the final vowel

\footnotetext{
${ }^{68}$ From Deacon's (1934) transcriptions, it is clear that in the early $20^{\text {th }}$ century, $-g c$ was present as a $1 \mathrm{SG}$ direct possessive ending.
} 
in all cells of the paradigm (Table $58 \mathrm{~h}-\mathrm{k}$ ). There is also some alternation in labial consonants in direct possession paradigms as described in Section 2.4.4.

Table 58: Vowel variance with direct possession suffixes

\begin{tabular}{|c|c|c|c|}
\hline $1 \mathrm{SG}$ & 2SG & 3SG & Gloss \\
\hline a. $\quad$ mata- $q$ & $m \underline{a} \underline{a} \underline{a}-m w$ & mete- $n$ & 'my/your/her eye' \\
\hline b. * & $t \underline{t a m w a-}-m w$ & teme- $n$ & 'my/your/her father' \\
\hline c. * & hina-mw & hine- $n$ & 'my/your/her mother' \\
\hline d. $n$ dilg $\underline{a}-q$ & $n d i l g \underline{a}-m w$ & ndilge-n & 'my/your/her ear' \\
\hline e. $m b w u l \underline{u}-q$ & mbwulu- $-m w$ & mbuli- $n$ & 'my/your/her leg' \\
\hline f. $\quad v u t \underline{u}-q$ & vutu- $m w$ & vuti-n & 'my/your/her child' \\
\hline g. tesu-q & tesu-mw & tesi-n & 'my/your/her younger sibling' \\
\hline h. hala-q & hala-mw & hala-n & 'my/your/her brother' \\
\hline i. vene-q & vene-mw & vene- $n$ & 'my/your/his sister' \\
\hline j. $\quad$ nembwu-q & nembwu-mw & nembu-n & 'my/your/her arse' \\
\hline k. $\quad$ mwini-q & mwini-mw & mwini-n & 'my/your/her spirit' \\
\hline
\end{tabular}

Some sets are defective. For example, Table $58 \mathrm{~b}$ and Table $58 \mathrm{c}$ above do not have a related form attested for 'my mother' or 'my father'. Instead there are indirectly possessed options, amoq 'mother' and tatay 'father'. As discussed in Section 3.1.1, there is a subset of directly possessed nouns that always has non-human possessors. Therefore, these nouns are only ever encountered with a 3SG suffix.

\subsubsection{Direct possession with possessor NP}

Direct possession nouns are frequently suffixed with $-n$ ' $3 \mathrm{SG}$ ' and followed by a possessor noun phrase as in (40)-(42). This is common even for 1SG and 2SG possessors as in (42), which have the option of expressing the possessor in suffix form as described in Section 3.2.1.1. There does not seem to be any referential or pragmatic difference between forms such as (42) and (39a). ${ }^{69}$

(40) ni-vara-n mworot NI-hand-3SG man

'people's hands' [07113.017 07113.wav 101.965 106.496]

(41) vara- $n$ nigcin hand-3SG 1PL.INC

'our hands' [07117.726 07117.wav 1944.067 1948.208]

(42) ni-vara-n kinag

NI-hand-3SG 1SG

'my hand' [EC02.053 EC02.wav 228.248 230.811]

\footnotetext{
${ }^{69}$ A number of Vanuatu languages have constructions like this, where a directly possessed noun take a suffix identical to the 3 SG possession suffix and it is then followed by a noun or pronoun denoting the possessor. In some analyses, this suffix is labelled a 'construct suffix'. In others it is simply labelled

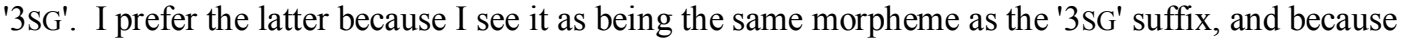
that is the gloss used in Crowley's recent descriptions of some of Nahavaq's closest linguistic neighbours: Nati (Crowley 1998b), Naman (Crowley 2006b), and Avava (Crowley 2006a).
} 
In these constructions, the possessor NP can be fronted to a position before the directly possessed noun as in (43)-(46) (See Section 6.2 on noun-phrase-fronting). This may have a discourse function of giving greater prominence to the possessor. However, (44) and (45) come from equivalent statements in the same narrative, and it is not clear why the possessor would be preposed in one but not the other. Example (46) shows a very complex possessor noun phrase fronted before hine-n 'mother-3SG'. The possessor noun phrase itself has an indirect possession construction with the possessor fronted (Section 3.2.2.1).

(43) En ni-mbunog ni-gcinhu-n i-ndun. And NI-boy NI-nose-3SG 3SG.R-shrink

'And the boy's nose shrunk.' [EC02.048 EC02.wav 217.512 219.059]

(44) Gcen ni-yar ni-mbwati-n i-vwariq. because NI-tree NI-head-3SG 3SG.R-small

'Because the trunk of the ironwood was small.' [07076.082 07076.wav 318.061 320.530]

(45) Gcen ni-mbwati-n ni-yar i-mbwow. because NI-head-3SG NI-tree 3SG.R-big

'Because the trunk of the ironwood was big.' [07076.018 07076.wav 74.480 77.887]

$\begin{array}{lllll}\text { En }\left[\left[\text { Saymon }_{i}\right.\right. & {[\text { ni-mwomwoq }} & \left.\left.\text { ti-qey }_{i}\right]\right]_{j} & \left.\text { hine- } n_{j}\right] & \text { i-meheq } \\ \text { And Simon } & \text { NI-woman } & \text { POSS-3SG } & \text { mother-3SG } & \text { 3SG.R-sick } \\ \text { ni-malqah. } & & & & \\ \text { NI-cold } & & & & \end{array}$

'Simon's mother-in-law was sick with a fever.' [MRK.01:30]

If the directly possessed noun has other modifiers besides the possessor, these occur after the possessor. This can lead to ambiguity as to which NP is being modified as in (47):

(47) gcinhu-n siv t-i-mbwow nose-3SG chief REL-3SG.R-big

'the big chief's nose / the chief's big nose' [07NB4.025]

Occasionally, directly possessed kinship nouns occur with the 3SG ending, but with $t i$ preceding the possessor, a construction normally reserved for indirect possession nouns (3.2.2). It is fairly common for children to do this with kinship terms, but adults do as well. Example (48) was produced by a 49 -year-old woman. ${ }^{70}$

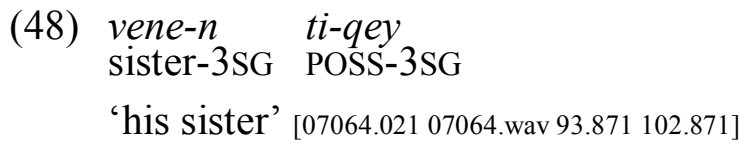

\subsubsection{Special -yen construction for close kinship terms}

Directly possessed close kinship terms can enter into a special possessive construction as in (49).

\footnotetext{
${ }^{70}$ There is no referential difference between vene-n ti-qey and vene-n qey, and I failed to find any pragmatic difference.
} 
(49) Ru-tagcaw eyum, ni-v-hine-n-yen ti-qey i-les 3DU-reach village NI-VERB-mother-3SG-NOM POSS-3SG 3SG.R-see

ne-yumw ti-qar en i-top.

NV-house POSS-3PL and 3SG.R-run

'When they arrived at the village, his mother saw their house and started running.' [EC01.065 EC01.wav 338.352342 .008 ]

The -yen in this construction in (49) is functionally different from the -yen possessive suffix discussed in 3.2.2.3 because it is attaching to the possessed noun rather than the possessor. However, it appears to fit the pattern of the nominalising suffix discussed in Section 3.1.3.1. It appears in combination with a $n i$ - prefix and attaches to a verb. A verb is derived from the noun by adding a $v i-/ p$ - prefix (see Section 4.4.3). So it appears that the directly possessed noun in (49), hine- $n$ 'mother-3SG', has been transformed into a verb and then back into a noun again, but it is now an indirectly possessed noun. In the corpus, these constructions nearly always have a possessor expressed with $t i$ - (Section 3.2.2.1). I was told that such constructions add an extra emotional interpretation to the relationship (intimacy, yearning, sorrow, cherishing, etc.). Other kinship nouns which can be used in this type of construction are teme'father', vene- 'sister', hala- 'sibling', mwene- 'brother', lawa- 'nephew', and mwaqaymbu- 'grandchild'.

\subsubsection{Possessive constructions with indirectly possessed nouns}

The following sections describe possessive constructions which are used with indirectly possessed nominal heads. However, some of them can be used with directly possessed nominal heads as well.

\subsubsection{Indirect possession with $\boldsymbol{t} i$ -}

(For the relative marker with the same form see 3.4.7). The most common construction for expressing possession of an indirectly possessed noun is shown in Examples (50)-(53). The directly possessed noun is followed by the possessor which is prefixed with $t i$ - 'POSS' (or $t$ - if the high vowel has been deleted as described in Section 2.4.3.2). The examples below show a range of types of possessors: a singular pronoun in (50), a non-singular pronoun in (51), and extended noun phrase in (52), and a proper noun in (53).

(50) ni-mbwuwes ti-kinag NI-pig POSS-1SG

'my pig' [07080.043 07080.wav 168.248 172.419]

(51) ne-yumw ti-qar

$\mathrm{NV}$-house POSS-3PL

'their house' [TB03.210 TB03.wav 1164.836 1169.632]

(52) ne-hew ti-mworot qar $\mathrm{NV}$-garden POSS-man PL

'the people's gardens' [TB03.168 TB03.wav 925.893 931.314] 
(53) ni-vilam t-Agcew

NI-girl POSS-Agcew

'Agcew's daughter' [07064.057 07064.wav 229.765 232.718]

Most post-nominal-modifiers (Section 3.4) of the head noun follow the $t i$-possession phrase. Example (54) shows an indefinite marker and a relative clause following the possessive construction.

(54) ni-mbunog ti-kinag tuwan ti-toq humwan NI-boy POSS-1SG INDEF REL-be first

'my first born child' [07117.027 07117.wav 141.200 149.309]

Adjectives (55) and nin phrases (56) may precede the $t i$-possession phrase.

(55) tatay vwariq ti kinag

father small POSS-1SG

'my small daddy (i.e. father's younger brother)' [07086.012 07086.wav 55.180 61.117]

(56) ni-morot nin ni-raq-yen ti-nugc sut NI-man ASS NI-work-NOM POSS-2SG NONSP

'a servant of yours' [LUK.15:19]

The possessor NP in the $t i$ - possession construction can be fronted as in (57) and (58). The $t i$ - prefix attaches to a co-referential pronoun following the directly possessed noun.

(57) $[\text { hala-mw }]_{\mathrm{i}}$ ni-mwomwoq ti-qey sibling-2SG NI-woman POSS-3SG

'your brother's wife' [MRK.06:18]

(58) Agcew $_{\mathrm{i}}$ ni-vilam ti-qey Agcew NI-girl POSS-3SG

'Agcew's daughter' [07064.070 07064.wav 271.545 277.498]

\subsubsection{Possessive prefix constructions: nagcu-namwu-nin-}

For singular possessors, possession may be expressed with the possessive prefixes nagcu- ' $1 \mathrm{SG}$ ' as in (59), namwu- ' $2 \mathrm{SG}$ ' as in (60), or nin- as in (61). ${ }^{71,72}$ These constructions are much less common in Nahavaq than $t i$ - possession (3.2.2.1) for singular possessors of indirectly possessed nouns. In fact nin- ' $3 \mathrm{SG}$ ' was not present at all in the corpus and only discovered through elicitation. For most speakers, when possessive prefixes are present, $n i$ - and $n V$ - nominal prefixes are not permitted (see Section 3.3.1). ${ }^{73}$

\footnotetext{
${ }^{71}$ I call these prefixes due to the fact that they can attach to monosyllabic nominal roots such as (59) and (61) which cannot stand alone.

${ }^{72}$ In Nāti (Crowley 1998b), similar prefixes are used in the default indirect possession constructions for 1SG and 2SG. South Efate (Thieberger 2006) and Sye (Crowley 1998a) each only has a 1SG possessive pronoun nakte and nagku respectively.

${ }^{73}$ The incompatibility between possessive prefixes and nominal prefixes may either be due to the single prefix pattern generally seen on nouns, or it may be the case that the possessive prefixes already contain the nominal prefixes: $n a-g c u-, n a-m w u-$, and $n i-n-$. But it is also possible that these possessive
} 
(59) nagcu-taq

1SG-thing

'my thing' [07072.043 07072.wav 252.441 256.894]

(60) namwu-tumbwel

2SG-arrow

'your arrow' [DK01.082 DK01.wav 416.910420 .691$]$

(61) nin-hew

3SG-garden

'his garden' [08NB1.034]

\subsubsection{Possessive -yen constructions}

(See Section 3.1.3.1 for the homophonous nominalising suffix -yen). Another possessive construction is formed by adding a suffix -yen to a pronominal possessor which precedes the possessed noun as in (62). If there is a noun phrase possessor, it appears before a co-referential pronoun which is suffixed with -yen and followed by the nominal head as in (63). Note that this possessive construction applies to both directly possessed (63) and indirectly possessed nouns (62).

(62) nigcin-yen marlam

1PL.INC-POSS old.man

'our old men' [07083.131 07083.wav 2010.274 2013.680]

(63) Vales tuwan mwomwoq $_{i}$ gey $_{i}$-yen ni-mbwunog i-log. time INDEF Woman 3SG-POSS NI-child 3SG.R-go

'And one time, the woman's child went.' [07082.010 07082.wav 43.005 47.427]

First and second person singular pronouns are an exception. The independent pronouns $\operatorname{kinag}(c)$ ' $1 \mathrm{SG}$ ' and $\operatorname{inug}(c)$ ' $2 \mathrm{SG}$ ' cannot be suffixed with $-y e n$. The equivalent forms, nagcuyen ' $1 \mathrm{SG}$ ' and namwuyen ' $2 \mathrm{SG}$ ', resemble the possessive prefixes discussed in Section 3.2.2.2. The possessive pronouns, nagcon '1SG' and namon ' $2 \mathrm{SG}$ ' (Section 3.1.2.1.4) may in fact have a similar origin to nagcuyen ' $1 \mathrm{SG}$ ' and namwuyen ' $2 \mathrm{SG}$ '.
a. *kinag-yen
1SG-POSS
novol i-mamal
1SG-POSS book 3SG.R-red
b. nagcuyen novol i-mamal
1SG.POSS book 3SG.R-red

'My book is red.'

prefixes have a similar origin to the 'general relational classifiers' in many Vanuatu languages. Notice the surface similarity between Nahavaq namwu-wey 'your water' and the general relational classifier construction in Lolovoli (Hyslop 2001: 181), no-mu wai 'GENERAL.CLASSIFIER-2SG.POSS water (your water to wash with)'. Also note that none of the languages with these type of personal pronoun possessors (Nahavaq, Nāti (Crowley 1998b), South Efate (Thieberger 2006) and Sye (Crowley 1998a)) have sets of possessive classifiers for indirect possession found in many other Vanuatu languages. 
(65)
a. *inug-yen novol i-qasen
2SG-POSS book 3SG.R-green
b. namwuyen novol i-qasen
2SG.POSS book 3SG.R-green
'Your book is green.'

These possessive -yen constructions can also occur without an overt nominal head (Section 3.5).

\subsubsection{Associative constructions (nin)}

(For discussion of the homophonous demonstrative nin see section 3.4.4). As seen in (66), the associative marker takes similar suffixes to direct possession nouns (but with a velar nasal rather than a glottal stop for the $1 \mathrm{SG}$ suffix). However, the $1 \mathrm{SG}$ and $2 \mathrm{SG}$ forms are rarely used and are not attested at all in the corpus. Instead the $3 \mathrm{SG}$ suffix is used followed by a noun phrase possessor as in (67). In the rest of this grammar, I treat $\operatorname{nin}$ as a single morpheme and gloss it as 'ASS'.

(66)

$$
\begin{aligned}
& \text { a. ne-ndey ni-n } \\
& \text { NV-blood ASS-3SG } \\
& \text { 'his blood' } \\
& \text { b. ne-ndey na-mw } \\
& \text { NV-blood ASS-2SG } \\
& \text { 'your blood' } \\
& \text { c. ne-ndey na-g } \\
& \text { NV-blood ASS-1SG } \\
& \text { 'my blood' }
\end{aligned}
$$

(67) ne-ndey nin kinag

$\mathrm{NV}$-blood ASS-3SG 1SG

'my blood' [JON.06:54]

Nin is used to express a relationship between two nouns. ${ }^{74}$ The ' $\mathrm{X} \operatorname{nin} \mathrm{Y}$ ' construction covers a range of relationships as shown in Examples (68)-(80) below. While not all of the meanings would fall under the concept of possession, some do, and for some body parts or products such as 'tongue' (68) and 'blood' (67), the nin construction is the only way to express possession. Note that with the exception of the ' $\mathrm{X}$ belonging to $\mathrm{Y}$ ' category, the

\section{$\mathrm{X}$ belonging to $\mathrm{Y}$ :}

(68) malambug nin kinag

tongue ASS $1 \mathrm{SG}$

'my tongue' [s0802.31]

\footnotetext{
${ }^{74} \mathrm{Nin}$ has many features in common with prepositions (Section 5.3.2.3). Like prepositions, it takes a nominal object but does not any verbal morphology. It also has direct possession morphology like many prepositions. However, unlike prepositional phrases which function as adjuncts to clauses, nin phrases function as nominal modifiers.
} 
(69) navwanevus nin kinag

heart ASS 1SG

'my heart' [Song07.002]

$\mathrm{X}$ which is part of $\mathrm{Y}$ :

(70) na-mbal nin na-mbaq

$\mathrm{NV}$-branch ASS NV-banyan

'branch of banyan tree' [07076.043 07076.wav 169.300 178.299]

$\mathbf{X}$ for the purpose of $\mathbf{Y}$ :

(71) ne-tel nin mbwuwes

NV-rope ASS pig

'pig rope (rope for pulling a pig)' [TВ01.039 TB01.wav 176.634 180.321]

(72) ni-mbwug nin ut ru-qambwiq

NI-day ASS COMPL 3PL-plant

'the day for planting' [07072.023 07072.wav 134.207 140.958]

$X$ produced by $Y$ or $X$ which originates from $Y$ :

(73) no-mol nin mworot

$\mathrm{NV}$-shadow ASS man

'a man's shadow' [KO01.009 KO01.wav 32.006 33.757]

(74) na-qamb nin ni-mbetep

$\mathrm{NV}$-firewood ASS NI-breadfruit

'wood of a breadfruit tree' [07072.066 07072.wav 360.650 370.854]

(75) mwor nin ut Mbenewur

man ASS place Mbenewur

'a man from Mbenewur' [07117.020 07117.wav 112.512 114.387]

(76) na-mbwaq nin ne-tes

$\mathrm{NV}$-turtle ASS NV-sea

'turtle from the sea (used to differentiate from na-mbaq 'banyan' for speakers who do not distinguish labiovelar and plain bilabial consonants).' [07117.564 07117.wav 1627.399 1629.139]

$\mathrm{X}$ which is composed of $\mathrm{Y}$ :

(77) ni-qinew nin ni-mworot

NI-crowd ASS NI-man

'the crowd of people' [LUK.01:10]

\section{$\mathrm{X}$ with the role of $\mathrm{Y}$ :}

(78) ni-mworot nin ni-log-humwan-yen

NI-man ASS NI-go-first-NOM

'leader/shepherd' [MRK.14:27] 
(79) ni-morot nin ni-vene-ven-mahal-yen

NI-man ASS NI-DUP-shoot-fish-NOM

'fisherman' [DK01.037 DK01.wav 296.359 300.540]

\section{$\mathrm{X}$ with the topic of $\mathrm{Y}$ :}

(80) Ni-stori nin Ni-vinmbwumbwaqaw NI-story ASS NI-Vinmbwumbwaqaw

'a story about Vinmbwumbwaqaw' [07063.001 07063.wav 34.446 41.055]

There is a degree of overlap between the above categories. For example, in (81) a 'church song' could mean a song belonging to the church ( $\mathrm{X}$ belonging to $\mathrm{Y}$ ), a song to be used in church services (X for the purpose of $Y$ ), a song produced by the church (X produced by $\mathrm{Y}$ or $\mathrm{X}$ which originates from $\mathrm{Y}$ ), or possibly even a song with a church topic (X with the topic of Y).

(81) ni-mbwi nin skul NI-song ASS church

'church song'

All of the nouns which are modified by nin constructions are indirectly possessed nouns. Some of them can also be modified with $t i$ - possession with a different meaning. For example with marhaw 'price' a nin construction (82) describes what the price is for, but a $t i$ - construction (83) describes who the money goes to. With $n i$ ndighur-yen 'story', a nin construction (84) describes the subject of the story, but a $t i$ construction (85) describes who makes the story.

(82) ni-marhaw nin ni-vilam t-nuqun

NI-price ASS NI-girl POSS-1INC.DU

'the bride-price of our daughters' [LS01.095 LS01.wav 394.996 400.151]

(83) ni-marhaw ti-qar

NI-price POSS-3PL

'their pay' [LUK.10:07]

(84) ni-ndighur-yen nin ni-mbwunog tuwan NI-tell.story-NOM ASS NI-child INDEF

'story about a child'

(85) ni-ndighur-yen ti-kinag

NI-tell.story-NOM POSS-1SG

'my story (that I tell)'

It is possible to have a nin construction with no overt object if the object has had previous mention or is understood as in (86). 
(86) En ni-vwuti-n mbwunog nin ni-mete-n i-ndun And NI-child-3SG boy DEM NI-eye-3SG 3SG.R-shrink

$\begin{array}{ll}i \text {-ndun } & \text { mbe-len } \\ \text { 3SG.R-shrink } & \text { toward-inside } \\ \text { NV-gut } & \text { ASS }\end{array}$

'And the boy's eye shrank down into his guts.' [EC02.040 EC02.wav 197.018 200.611]

\subsection{Pre-nominal modifiers}

There are four classes of elements which can be prefixed to noun roots:

1. Possessive prefixes (Section 3.2.2.2)

2. Locative prefixes (Section 5.3.2.2)

3. Nominal prefixes (the remnants of a historical article) (Section 3.3.1)

4. Sep- 'which' (Section 3.3.2)

None of these prefixes can co-occur.

\subsubsection{Historical articles}

Many nouns in Nahavaq begin with $n \mathrm{~V}$-. This is derived from a historical article of Proto Oceanic, *na-. In Nahavaq, there are two separate but related morphemes, $n V$ and $n i$-. Because there is some crossover in form, the distinction between them is made on the basis of usage, with $n \mathrm{~V}$ - being obligatory in most constructions and $n i$ being optional in most constructions.

While most nouns can have either the $n i$ - or $n \mathrm{~V}$ - prefix, there is a set of nouns that never take these prefixes. This set includes:

1. All locational and temporal nouns (Section 5.3.2.1)

2. Most kinship terms (including $a v w u$ 'grandparent', aleq 'son/brother-in-law', avileq 'daughter/sister-in-law', hala- 'brother', kakap 'grandmother', totot 'grandfather', wowow 'eldest brother', mwene- 'brother', vene- 'sister', hala'sibling', etc.). Exceptions include (ni-)vuti- 'child' and (ni-)hine- 'mother'. 76

3. Some other nouns referring to people: ambwat 'white man', mises 'white woman', miliwun 'chief'.

4. Proper nouns

5. Pronouns (although the first syllable of nuqumwem '1EX.DU', nuqund '1IN.DU', nuqum '2DU', nigcind '1IN.PL', and nigcim '2PL' may have come from the historical article)

\subsubsection{1. $n \mathrm{~V}-$}

This prefix can take the form $n a-, n e-, n i-, n o-$ or $n u-$. As explained in Section 2.4.7, it occurs on monosyllabic roots and also polysyllabic roots beginning with glottals and liquids. The vowel of the prefix is not fully predictable, but in most cases, it is

\footnotetext{
${ }^{75}$ It would be possible to see (86) as having the object of nin, ni-vwuti-n mbwunog nin 'the boy' fronted to the start of the clause, however, the same NP also seems to serve as the possessor of ni-mete$n$ 'ni-eye-3SG', and in that case has been fronted to the start of the NP, leaving the nin without an overt grammatical object.

${ }^{76}$ There is some variation between speakers as to whether the 'sister', 'brother', 'sibling', 'father', and 'mother' terms may take ni- prefixes.
} 
identical to the first vowel in the root. Its allomorphy is described in detail in Section 2.4.7. Table 59 presents some examples of $n \mathrm{~V}$ - prefixation.

Table 59: Examples of $\boldsymbol{n V}$-prefixation

\begin{tabular}{|c|c|c|c|c|c|}
\hline$\overline{\text { na-hal }}$ & 'road' & $n a-q a y$ & 'tree' & ne-wey & 'water' \\
\hline na-havaq & 'what' & na-wag & ‘canoe' & ne-yumw & 'house' \\
\hline na-lambwut & 'rat' & ne-hew & 'garden' & ni-gey & 'kind of nut' \\
\hline na-mwat & 'snake' & ne-men & 'bird' & $n i-n a l$ & 'sun’' \\
\hline na-muy & 'earthquake' & ne-ndey & 'blood' & no-qoyit & 'octopus' \\
\hline$n a-m b w a q$ & 'turtle' & ne-ndiq & 'bed' & nu-huvweq & 'steam' \\
\hline
\end{tabular}

There are a few cases where different vowels in the prefix distinguish different meanings for homophonous roots (87). The vowel in the prefix can also be a source of variation as in the examples in (88).

(87) a. ni-pwil 'crooked shin'

b. na-pwil 'shin'

c. ni-mbur 'fungus'

e. ne-mbur 'limestone'

f. ne-mbwug 'manggru fish'

g. ni-mbwug 'day'

h. na-mbwug 'special event five days after death'

(88) a. ni-gcut nu-gcut 'banana'

b. $n u$-wes $\sim n i$-wes 'wild yam'

The $n \mathrm{~V}$ - prefix is somewhat productive as evidenced by borrowings from Bislama that have obligatory prefixes attached to them (89). However, most one-syllable nouns borrowed from Bislama are not obligatorily prefixed (see 3.3.1.2).

(89) a. no-qos 'horse'

b. ne-tep 'table'

c. ni-mbwut 'boat'

d. ni-ndis 'dish'

For nouns that take the $n \mathrm{~V}$ - prefix, the prefix is obligatory in most situations. The exceptions are constructions with the possessive prefixes (see 3.2.2.2) (90), the sepprefix (3.3.2) (91), locational $l V$ - prefix (see 5.3.2.2) (92), some compound constructions (93) (3.1.3.5), incorporated objects (4.1.9) (94), and the vi- prefix which derives a verb from a nominal root (4.4.3) (95).

(90) a. nagcu-wag '1SG.POSS-canoe'

b. namu-yum '2SG.POSS-house'

(91) sep-men 'which-bird'

(92) a. li-yum 'LOC-house'

b. lu-wey 'LOC-water'

(93) a. ruqum-mbwaq 'crab-turtle = sargassum crab'

b. na-mwas-nal 'NV-spear-sun = shooting star' 
(94) a. i-vene-ven-men '3SG.R-DUP-shoot-bird'

b. i-tuq-tuq-gcey '3SG.R-DUP-hammer-nut'

(95) a. i-vi-mwat '3SG.R-COP-snake'

b. i-vi-mwat '3SG.R-COP-snake'

\subsubsection{1. $N a-/ a$ - prefixed nouns}

There is a small class of nouns that has a more complex situation of $n \mathrm{~V}$-prefixation. The nouns in Table 60 all have the form $n a \mathrm{CVC}$ in their citation form, and all speakers accept the CVC form (root form 1) in the situations where $n \mathrm{~V}$ - prefixes can be omitted (as explained in Section 3.3.1.1). But for these words, some speakers also accept an $a \mathrm{CVC}$ form in these cases as in (96c). It seems to be more conservative speakers who retain the $a \mathrm{CVC}$ variant of these words.

$$
\begin{aligned}
& \text { a. } \text { I-qil-qil na-qupw. } \\
& \text { 3SG.R-DUP-dig NV-ghost.crab } \\
& \text { b. I-qil-qil-qupw. } \\
& \text { 3SG.R-DUP-dig-ghost.crab } \\
& \text { c. } \text { I-qil-qil-aqupw. } \\
& \text { 3SG.R-DUP-dig-ghost.crab } \\
& \text { 'She was digging for ghost crabs.' [08NB1.089] }
\end{aligned}
$$

Table 60: $\mathrm{Na}-/ \mathrm{a}$ - prefixed nouns

\begin{tabular}{llll} 
Forms marked with '?' were judged ungrammatical by one speaker who accepted all of the other $a \mathrm{CVC}$ forms \\
\hline Gloss & Citation form & Root form 1 & Root form 2 \\
\hline 'ghost crab' & naqupw & $-q u p w$ & aqupw \\
'juice-3SG' & nahu-n & $-h u-n$ & ahu-n \\
'louse' & naqut & $-q u t$ & aqut \\
'orange' & namwul & - mwul & amwul \\
'yam insect' & nambwuq & $-m b w u q$ & ambwuq \\
'dry coconut leaves' & nahul & - hul & nahul \\
'mushroom' & nambwur & - mbwur & ?mbwur \\
'necklace' & nahumw & $-h u m w$ & ?ahumw \\
'gong rhythm' & nambwir & - mbwir & ?ambwir \\
\hline
\end{tabular}

There are several possible origins of this $a$. The first is that it is related to the Nahavaq personal prefix, $a$ - (Section 3.4.8.1). However, the nouns in Table 60 seem to be an unlikely semantic group to take a personal prefix. Another is that it derives from the Proto Oceanic article, $* a$ (Lynch et al. 2002). There are a few Malakula languages including Aveteian, Ajiauleian (Charpentier 1982), and Avava (Crowley 2006a) that have an $a$ - prefix on nouns where other Malakula languages (including Nahavaq) have a $n a$-like prefix, so it seems possible that Nahavaq could have borrowed or kept such forms somehow. Another possibility is a phonological origin. The words in Table 60 share a phonological similarity: the CVC portion is either [glottal]- $u$-C or [velarised bilabial]-[high vowel]-C. ${ }^{77}$ However, there are other roots that fit this description that don't show this pattern (e.g. na-qur 'goatfish': *aqur).

\footnotetext{
${ }^{77}$ It seems unlikely that a [glottal]- $u$-C root would motivate the addition of an $a$ - vowel, but if these roots were regularly prefixed by * $n a$ - (from which synchronic $n \mathrm{~V}$ - prefixes derive), it seems more plausible that the glottal consonant might somehow motivate a reinterpretation of the vowel in the
} 


\subsubsection{2. $N i-$}

$\mathrm{Ni}$ - differs from $n \mathrm{~V}$ - (3.3.1.1) in that it is optional rather than obligatory, and that its form does not vary. $\mathrm{Ni}$ - occurs optionally before most noun roots of more than one syllable. Some examples are listed in (97).

(97) a. (ni-)morot 'man'

b. (ni-)mbwilambwil 'pool'

c. (ni-)taqu-n 'back-3SG'

d. (ni-)gcalat 'nettle tree'

e. (ni-)gcigcaplew 'spider'

f. (ni-)hini-n 'gut-3SG'

The $n i$ - prefix is highly productive, and it is applied to borrowed nouns (98). Interestingly, many borrowed words that in Bislama have one-syllable and begin with a consonant cluster are borrowed in two formats into Nahavaq (99). They are borrowed and used in a monosyllabic form without any prefix and also in a disyllabic form (with epenthetic vowel) that is optionally prefixed. The borrowed monosyllbic forms are exceptional in that they can have consonant clusters unlike native Nahavaq words (Section 2.3), and besides these words, there is a notable lack of monosyllabic content words in Nahavaq (Section 2.8.2). It is surprising that the borrowed monosyllabic roots in (99) cannot be prefixed with $n i$ - as this would resolve both of these exceptions: the consonant clusters could be broken by resyllabification (niCCVC > niC.CVC) and there would be no monosyllabic content words. However the fact remains that such forms (*ni-skul 'school', *ni-tres 'dress', *ni-spun 'spoon', and *ni-mbet 'bread') are ungrammatical. It would seem that the two different forms of these borrowed words may reflect different kinds of borrowing: one with non-native phonotactics and without native phonology, and the other with native phonology and phonotactics.

(98) a. (ni)mbwuluk'cow'

b. (ni)pistas 'peanut'

(99) a. skul / *ni-skul / sukul / ni-sukul 'school'

b. tres / *ni-tres / teres / ni-teres 'dress'

c. spun / *ni-spun / supun / ni-supun 'spoon'

d. mbret / *ni-mbet / mbiret / ni-mbiret 'bread'

\subsection{Usage of $n i-$}

As with $n \mathrm{~V}$ - (Section 3.3.1.1), there are certain situations where $n i$ - cannot be used, such as possessive prefixes (100), the sep- prefix (101), the prepositional prefix (102), some compounds (103), object incorporation (104), and the vi-prefix (Section 4.4.3) (105).

(100) nagcu-mahal '1SG-fish'

(101) sep-mahal 'which-fish'

(102) lo-mbogo-n 'LOC-mouth-3SG'

(103) mbwunog-mworot 'child-man'

prefix as part of the root. It is also notable that vowel assimilation, which is common across glottal consonants (Section 2.4.2.3), has not happened in these words. 
(104) $i$-vene-ven-mahal '3SG.R-DUP-shoot-fish'

(105) i-p-mworot '3SG.R-COP-man'

In all other situations $n i$ - is fully optional. Despite my best efforts, I was not able to find any semantic principle governing the use of $n i-$. The prefixed form is preferred in citation forms and formal writing. For example, in Massing Nambuas's Bible translation, $n i$ - is present in almost all places where it could be used. But in natural speech, all speakers use $n i$ - variably. I ran a small experiment to see if speakers could accurately predict which nouns in a text would have $n i$ - prefixes. Their answers suggested that $n i$ - use is not predictable even when embedded in the context of a narrative text.

In some cases, the use of ni- may be influenced by possible confusion with other words. Although it is not obligatory, ni-yipyep 'mangrove variety' is often preferred with the $n i$ - prefix, and this could be influenced by the fact that -yipyep is a verb with a different meaning, so using the prefix on the noun makes it clear what meaning is intended (106). One speaker considered (107b) to require the prefix because of possible confusion with a verb form with a different meaning $(107 \mathrm{c})$. However, the same root with a different direct-possession suffix did not have that problem and the prefix was considered optional (107a). However, other speakers consider mata- $q$ 'eye-1SG' to be acceptable too.

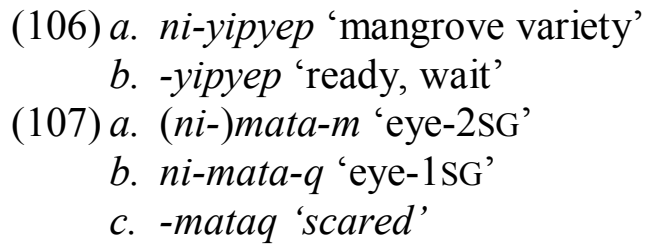

\subsubsection{Sep- which}

Sep- is prefixed to nouns to mean 'which x' or 'what x' (108)-(109). Although (110) was produced in natural speech (by an 18 year-old speaker), it is considered ungrammatical by many speakers. For older speakers, sep- cannot co-occur with $n i$ or $n V-(111)$.

(108) Qay, sep-mbwunog etig?

hey which-child ID.PROX

'Hey, what boy is that?' [MR01.079 MR01.wav 416.950420 .466 ]

(109) Tey sep-mahal etig?

FOC which-fish ID.PROX

'But what fish is this?' [07117.234 07117.wav 797.912 799.709]

(110) Sep-ne-men eg? U-les tey i-noq ne-men which-NV-bird ID.PROX 2SG.R-see FOC 3SG.R-like NV-bird

t-i-toq hur ne-tes, aq? REL-3SG.R-be near NV-sea huh

'What kind of birds are these? Do you see it is like these are seabirds, huh?' [07117.807 07117.wav 2134.616 2138.820] 
(111)a. *sep-ni-mbwaqay

which-NI-yam

b. sep-mbwaqay

which-yam

'which yam'

c. *sep-ne-yumw

which-NV-house

d. sep-yumw

which-house

'which house'

\subsection{Post-nominal modifiers}

There are a variety of modifiers that occur after the noun head. This includes many of the possessive constructions discussed in Section 3.2 above. Other post-nominal modifiers include quantifiers (3.4.1), number particles (3.4.2), indefinite articles (3.4.3), demonstrative determiners (3.4.4), relative clauses (3.4.7), adjectives (3.4.8), and a set of modifiers described in Section 3.4.9 that can modify verb phrases as well as noun phrases. The ordering of these post-nominal modifiers is discussed in Section 3.4.10.

\subsubsection{Quantifiers}

Quantifiers are a subset of stative verbs that can modify nouns. The set of quantifiers is discussed in Section 4.1.6, and includes the numerals 1-10, lambw 'many', ris 'few', and vih 'how many'. Quantifiers occur most often with 3SG verbal prefixes and may have either realis or irrealis mood marking. Examples (112)-(114) show quantifiers modifying nouns. If the noun phrase is definite, there may additionally be a $t$ - prefix on the quantifier as in (115). If definiteness is marked elsewhere in the noun phrase, the $t$ - prefix is optional (116a-b), but if not, it is obligatory (116c-d). ${ }^{78}$

(112) Steward i-kambwur mweney $i$-vih? steward 3SG.R-pack money 3SG.R-how.many

'How much money did Steward have?' [07048.1337 07048.wav 3783.805 3785.455]

(113) Qet na-qay yig, morot i-lam ra-mataq qin. but NV-wood PROX man 3SG.R-many 3PL.R-fear 3SG

'But many people are scared of this tree.' [07127.006 07127.wav 17.088 19.354]

(114) War ru-veqen ni-mbwunog i-tul. 3DU 3DU-have NI-child 3SG.R-three

'The two of them have three children.' [07117.025 07117.wav 131.200 135.059]

(115) Ne-viyal ni-p-hala-n-yen ti-kinag t-i-tul. 1SG.R-search.for NI-COP-sibling-3SG-NOM POSS-1SG REL-3SG.R-three

'I'm looking for my three brothers.' [07089.120 07089.wav 564.959 571.267]

\footnotetext{
${ }^{78}$ While I gloss the $t$ - prefix on quantifiers as 'REL' (relative clause marker), its function in this case (and probably in all relative clauses) is to mark definiteness.
} 
(116) a. $\begin{array}{lll}\text { Morot } \\ \text { man }\end{array} \frac{t-i \text {-ves }}{\text { REL-3SG.R-four }} \quad \frac{\text { tinin }}{\mathrm{DEF}} \begin{aligned} & \text { ro-log } \\ & \text { 3PL-go }\end{aligned}$ lembunqay.

'The four men walked in the bush.' [08NB1.20]

b. Morot i-ves tinin ro-log lembunqay. man 3SG.R-four DEF 3PL-go bush

'The four men walked in the bush.' [08NB1.20]

c. Morot t-i-ves nin ro-log lembunqay.

man REL-3SG.R-four DEM 3PL-go bush

'The four men walked in the bush.' [08NB1.20]

d. *Morot i-ves nin ro-log lembunqay.

man 3SG.R-four DEM 3PL-go bush

'The four men walked in the bush.' [08NB1.20]

\subsubsection{Number particles}

The number particles are ( $r u$ )war 'DU' and qar 'PL', which have the same form as the 3DU and 3PL personal pronouns (Section 3.1.2.1.1). There is no singular number particle.

(117) En ru-vwur-vwur ni-vuti-n mbwuwes nin war. and 3DU.R-DUP-hold NI-child-3SG pig DEM DU

'And they caught the two piglets.' [07010.011 07010.wav 26.995 29.102]

(118) Qet ni-mwomwoq tinin ruwar ru-logo-log gcen then NI-woman DEF DU 3DU.R-DUP-go because ru-gci-gcilew na-qanyen. 3DU.R-DUP-look.for $\mathrm{NV}$-food

'And the two women were walking and looking for food.' [LS01.011 LS01.wav 46.320 51.351]

(119) Na-laykem vwovwoh ni-ruqum yig qar. 1SG.R-like very NV-crab PROX PL

'I really like these crabs.' [07117.107 07117.wav 403.091 404.888]

Because the number particles are not distinct from third person pronouns, there can be ambiguity when one of these forms occurs after a directly possessed noun as in (120).

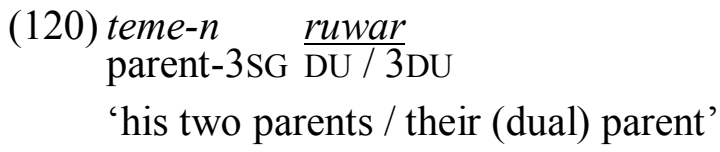

Because number particles occur at the far right of the noun phrase (Section 3.4.10), ambiguity can also arise when there is more than one noun within a noun phrase as in (121). In this case the number particle could be modifying the head of the whole NP or it could be modifying the nominal head which acts as a direct object in the relative clause.

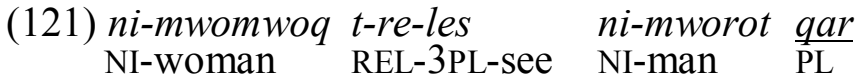

'the women who saw the man / men' 
Numbers (Section 3.4.1) and number particles can co-occur:
(122) I-her
I-her
3SG.R-take
ni-vilam
NI-girl
$\frac{t-i-r u}{\text { REL-3SG.R-two }}$
$\operatorname{nin}_{\mathrm{DEM}} \frac{\text { war, }}{\mathrm{DU}}$
'He took the two girls.' [LS01.141 LS01.wav 615.774 620.806]

\subsubsection{Indefinite articles}

\subsubsection{Sut non-specific}

Sut indicates that a noun phrase is non specific. In (123)-(125) sut has a partitive meaning. In (126), it has a non-partitive meaning. Sut can be used in singular (123) or non-singular noun phrases (124).

$\begin{array}{cllll}\text { (123) Gcen } & \text { konoq } & \text { qar } & \text { sut } & \text { ka-gcal-pet } \\ \text { because } & \text { if } & \text { 3PL } & \text { NONSP } & \text { 3SG.IRR-hang-break then }\end{array}$

Ni-vinmbwumbwaqaw ka-qan qin.

NI-Vinmbwumbwaqaw 3SG.IRR-eat 3SG

'Because if one of them fell, Vinmbwumbwaqaw would eat him.' [07076.051 07076.wav 205.107 209.388]

(124) Qar sut remes hur na-hal gcen wut re-vutol. 3PL NONSP 3PL-die near NV-road because COMPL 3PL-hungry

'Some of them will faint along the road because they are hungry.' [MAT.15:32]

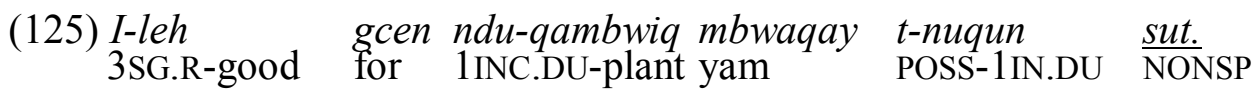

'We should plant some of our yams.' [MR01.069 MR01.wav 382.434 385.263]

(126) Ndu-q-her na-qanyen sut migce-n. 1 IN.DU-IRR-take NV-food NONSP to-3SG

'Let's take some food to her.' [07074.045 07074.wav 199.173 203.721]

\subsubsection{Tuwan indefinite}

Tuwan is used for specific, indefinite NPs. Like sut '(non-specific)', tuwan '(indefinite)' can be used with singular (127) or plural noun phrases (129) with a partitive (128) or non-partitive interpretation (127), (129).

$\begin{array}{llll}\text { (127) } \text { Mur-les } & \text { gcow } & \text { mbwumbwo-n } & \text { ne-men tuwan. } \\ \text { 1EX.DU R-see } & \text { EMPH } & \text { feather-3SG } & \text { NV-bird INDEF }\end{array}$

'We saw a feather.' [07072.051 07072.wav 286.080 288.940]

$\begin{array}{rlrl}\text { (128) En } & \text { Ni-vinmbwumbwaqaw i-sur } & \text { ni-vuti-n } & \text { tuwan. } \\ \text { and } & \text { NI-Vinmbwumbwaqaw 3SG.R-send NI-child-3SG } & \text { INDEF }\end{array}$

‘And Vinmbumbaqaw sent one of her children.' [EC02.020 EC02.wav 94.982 98.825] 
(129) Valestuwan etin qet vuti-n mbwunog tuwan qar time INDEF ID PART child-3SG child INDEF PL

re-min-mwindal tey i-noq nin.

3PL-recent-play FOC 3SG.R-like DEM

'One time some children were just playing like this.' [MF01.003 MF01.wav 6.981 11.184]

\subsubsection{Demonstrative determiners}

The larger class of demonstratives is discussed in Section 6.4.1, including their deictic reference. This section is concerned only with the syntax of the demonstrative determiners (Table 61) that modify nouns.

Table 61: Demonstrative determiners

\begin{tabular}{llll}
\hline & Proximal & Distal & Neutral \\
\hline With $\boldsymbol{t i}$ - & $\operatorname{tiyig}(c) \sim \operatorname{tig}(c)$ & $\operatorname{tiyag}(c) \sim \operatorname{tag}(c)$ & $\operatorname{tinin} \sim \operatorname{tin}$ \\
Without $\boldsymbol{t i -}-$ & $\operatorname{yig}(c)$ & - & $\operatorname{nin}$ \\
\hline
\end{tabular}

Each of the $t i$ - terms in Table 61 has a full disyllabic form and a reduced monosyllabic form. While the proximal and distal demonstratives have spatial reference (130)-(133), the neutral demonstratives do not and function primarily to mark a noun phrase as definite (134)-(135). Example (136) explicitly demonstrates the definite interpretation of tin 'definite' by contrasting it with tuwan 'indefinite' in the first reference to the same child.

(130) Na-qay tiyig neqhe-n qet ni-marmbugmbug. $\mathrm{NV}$-tree DEF.PROX name-3SG COMPL NI-marmbugmbug

'This tree's name is Marmbugmbug.' [07025.002 07025.wav 4.045 6.405]

(131) Nigce-gciyew ne-yumw tig.

1SG.IRR-destroy NV-house DEF.PROX

'I will destroy this building.' [JON.02:19]

(132) Qet ku-lip $\quad k u$-log $\quad k u$-tu len no-qond tiyag. then 2SG.IRR-take 2SG.IRR-go 2SG.IRR-put in NV-basket DEF.DIST

'Then take it and go put it in that basket.' [07089.040 07089.wav 237.344 239.860]

(133) Nde-q-ndum tey len ne-hew tag. 1IN.PL-IRR-do.down FOC in NV-garden DEF.DIST

'Let's just fly down to that garden.' [TB03.056 TB03.wav 288.333 293.083]

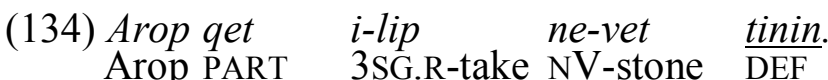

'Arop was the one who took the stone.' [07083.081 07083.wav 566.574 574.464]

(135) Ni-vilamb tin i-log gcen ke-qil-qil aqupw. NI-girl DEF 3SG.R-go because 3SG.IRR-DUP-dig ghost.crab 'She dug crabs all the way to Undumwat, she would go digging crabs.' [07074.009 07074.wav 40.609 45.671] 
(136) En i-veqen ni-mbwunog ni-morot tuwan. En mbwunog and 3SG.R-have NI-child NI-man INDEF and child morot tin i-vwariq. I-hip ne-revuh migce-n. man $\overline{\mathrm{DEF}}$ 3SG.R-small 3SG.R-carve NV-bow to-3SG 'And she had a son. And the boy was small. She carved him a bow.' [07080.003-004 07080.wav 10.086 18.383]

The proximal and neutral categories also have a form without $t i-$. Example (137) shows the proximal form and (138) the spatially neutral form, which marks definiteness.

(137) Na-halag yig re-viyeh neqhe-n qet na-halag mbwaqay. NV-taro PROX 3PL-call name-3SG COMPL NV-taro yam

'This taro is called Yam Taro.' [07120.002 07120.wav 5.547 10.031]

(138) Stori nin i-yar en. story DEM 3SG.R-finish ID

'The story ends here.' [07009.081 07009.wav 224.918 226.590]

In many cases, various forms for one category can be used interchangeably as in (139)-(140). However, in some constructions, the $t i$ - form is required. In (141) only a $t i$ - demonstrative is grammatical before a relative clause. In (142) at least one of the quantifier or the demonstrative must have $t(i)$-. While I have not figured out the exact nature of $t i$ - in these cases, it would appear to be some kind of syntactic definiteness particle, most likely related to the relative marker (Section 3.4.7). There could also be a relationship to the $t i$ - prefix used in indirect possession constructions (Section 3.2.2.1).

(139) Ne-vet t-i-metemet $\quad$ tinin/tin/nin $\quad i$-mbow. $\mathrm{NV}$-stone REL-3SG.R-black $\frac{\text { DEF }}{3 \text { SG.R-big }}$

'The black stone is big.' [s0802.49]

$\begin{array}{lll}\text { (140) Arop qet i-lip } & \text { ne-vet } & \text { tinin/tin/nin. } \\ \text { Arop PART 3SG.R-take NV-stone } & \text { DEF }\end{array}$

'Arop was the one who took the stone.' [s0802.47]

(141) Ne-vet $\quad$ tinin/tin/*nin $t$-i-metemet $\quad i$-mbow. NV-stone DEF REL-3SG.R-black 3SG.R-big

'The black stone is big.' [s0802.49] 


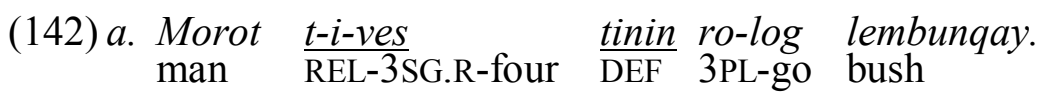

'The four men walked in the bush.' [08NB1.20]

b. Morot i-ves tinin ro-log lembunqay. man 3SG.R-four DEF 3PL-go bush

'The four men walked in the bush.' [08NB1.20]

c. Morot t-i-ves nin ro-log lembunqay.

man REL-3SG.R-four DEM 3PL-go bush

'The four men walked in the bush.' [08NB1.20]

d. *Morot i-ves nin ro-log lembunqay.

man 3SG.R-four DEM 3PL-go bush

'The four men walked in the bush.' [08NB1.20]

\subsubsection{Havaq 'what'}

Havaq 'what' is clearly related to the noun na-havaq 'what', but havaq functions as a post nominal modifier meaning 'what $\mathrm{X}$ ' or 'what kind of $\mathrm{X}$ '.

(143) Qet u-yar len yiyah havaq?

but 2SG.R-finish in year what

'But what year did you finish in?' [07117.036 07117.wav 195.095 201.830]

$\begin{array}{llllll}\text { (144) En } & \text { ni-po-pow-yen havaq qet } & k \text {-vihigc } & \text { mbigce-n } & \text { qar? } \\ \text { and } & \text { NI-Surprise-NOM which } & \text { COMPL } & \text { 2SG.IRR-show to-3SG } & \text { 3PL }\end{array}$ 'What miracle will you perform?' [JON.06:30]

\subsubsection{Timbeh 'which'}

In contrast to havaq 'what', timbeh 'which' refers to a fixed set of options. It bears a resemblance to ambeh 'where'. And like many post-nominal modifiers, it begins with $/ \mathrm{t} /$, which may be related to definiteness.

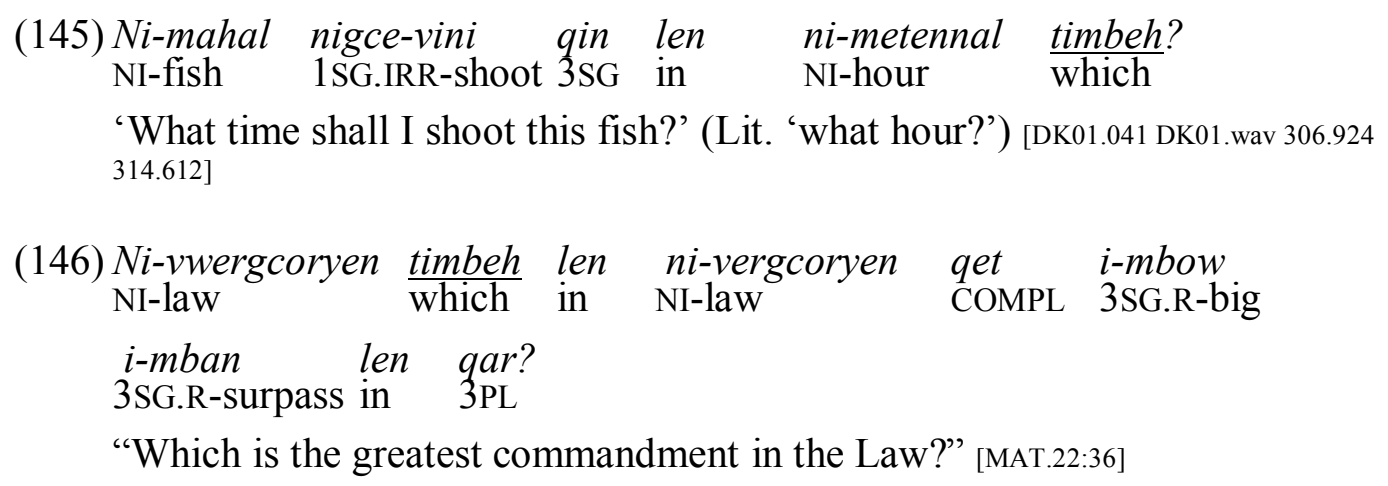

\subsubsection{Relative clauses}

Relative clauses are usually marked with the relative marker, $t i-$, which has two allomorphs, $t i$ - and $t$ - (see Section 2.4.3.2 on allomorphy of $t i$-). ${ }^{79}$ In some cases, $t i$ - is optional, and I have been unable to discern what determines whether or not it is required. Throughout this section, I will mark obligatory relative markers in bold as in (147) and optional relative markers with parenthesis as in (148). ${ }^{80}$ Note that of all

\footnotetext{
${ }^{79}$ Note that the possessive marker $t i$ - (Section 3.2.2.1) has the same two allomorphs.

${ }^{80}$ All information on obligatory/optional relative markers comes from [s0802.51-55].
} 
the examples in this section, only (148) was actually produced without the relative marker. ${ }^{81}$

(147)En i-les hala-n i-mbwit tey taq ti-[ke-rar $\left.\varnothing_{i}\right]$. and 3SG.R-see sibling-3SG 3SG.R-unable FOC thing REL-3SG.IRR-make

'He saw that his brother didn't know what was causing it.' [АТ01.013 AT01.wav $70.32074 .285]$

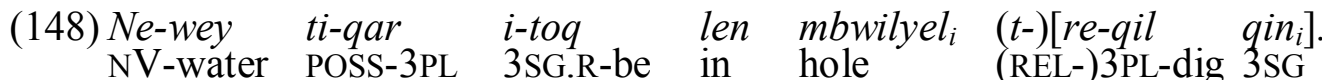
'Their water is underground in a hole that they dug.' [EC01.005 EC01.wav 17.680 20.852]

The relative clause follows the noun that is being modified, and within the relative clause, the co-referential argument may have a range of roles. Below are examples of the relativised noun functioning as the subject (149)-(156) or object of a verb (157)(163), the object of a preposition (164)-(166), or a possessor (167)-(169) within the relative clause.

When the modified noun functions as the subject of a verb in the relative clause, there is no overt NP in that subject position. In these cases, the relative marker is followed directly by the subject/mood prefix, which agrees in person and number with the modified noun.

(149)Ey, nigcim $(t-)\left[a_{\mathrm{i}}\right.$-mewur qorigc etin] a-s-rogndew veq, hey 2PL (REL-)2PL-live now ID 2PL-NEG-believe NEG

a-liley.

2PL-crazy

'Hey, you people who are living now don't believe and you are crazy.' [LUK.09:41]

(150) A-log en a-les qey tinin $(t-)\left[k e_{\mathrm{i}}-l e q\right]$. 2PL-go and 2PL-see 3SG DEF (REL-)3SG.IRR-married

'Come see the one who is going to be married.' [MAT.25:06]

(151) Qet tartar mwas ku-lip $\quad n a-q a y_{\mathrm{i}} \quad \boldsymbol{t}$-[ru $\mathrm{i}_{\mathrm{i}}$-vaqayndag]. but always must 2SG.IRR-take NV-wood REL-3DU.R-same

'But you must always use two of the same kind of wood.' [07095.039 07095.wav $247.231249 .794]$

While Nahavaq has a class of adjectives that can modify noun heads as described in Section 3.4.8, it is far more common for attributes to be expressed through a relative clause as in (152)-(153). Relative clauses with adjective/attribute verbs do not differ syntactically from those with intransitive dynamic verbs as in (154)-(156). However, there is a tendency for adjective/attribute relative clauses to occur closer to the noun than dynamic relative clauses (see Section 3.4.10).

\footnotetext{
${ }^{81}$ This does not necessarily mean that relative clauses without $t i$ - are rare. My lack of examples of this sort may be because of the fact that examples containing $t i$ - would be more salient to me.
} 
(152) En i-rar ne-revuh mbaragcin migce-n ni-mbunog and 3SG.R-work bow true to-3SG NI-child

$\boldsymbol{t}$ - $\left[i_{\mathrm{i}}\right.$-vwariq $] \quad$ yig.

REL-3SG.R-small PROX

'And she made a bow for the little boy.' [EC01.027 EC01.wav 131.693 139.100]

(153) En hine-n ruwar i-vwer, 'Na-qanyen $\mathrm{i}_{\mathrm{i}} t$-[ $i_{\mathrm{i}}$-leh $]$ and mother-3SG 3DU 3SG.R-say NV-food REL-3SG.R-good etin. ${ }^{82}$

ID

"And their mother said, "This is good food."” [LS01.017 LS01.wav 71.391 73.954]

(154) I-rar i-noq nin ra-n na-taq $\mathrm{t}$-[re $\mathrm{i}_{\mathrm{i}}$-mewur $] \quad$ qar. 3SG.R-work3SG.R-like DEM INSTR-3SG NV-thing REL-3PL.R-live 3PL

'He did the same with many other living things.' [EC01.037 EC01.wav 172.462 176.400]

(155)I-vwer, “Aley, a-log mbweleg a-mi-mis mete-n 3SG.R-say okay 2PL-go to.FOC 2PL-DUP-piss eye-3SG

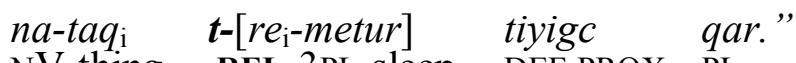
NV-thing REL-3PL-sleep DEF.PROX PL

'He said, "Okay, go and piss in the eyes of those sleeping things there.", [EC02.130 EC02.wav 540.577 544.561]

(156) En ni-leh-yen migce-n qar $\mathrm{r}_{\mathrm{i}}$ tinin $(t-)\left[\mathrm{re}_{\mathrm{i}}\right.$-teg $]$ en $q a r_{\mathrm{j}}$ and NI-good-NOM to-3SG 3PL DEF (REL-)3PL-cry and PL

$(t-)\left[r o_{\mathrm{j}}-r o g \quad i-h e t\right]$. REL-3PL-feel 3SG.R-bad

'Goodness to those who cry and those who feel bad.' [MAT.05:04]

When the modified noun has the function of object of a verb in the relative clause, the resumptive pronoun qin can occur inside the relative clause as in (157)-(160).

However, qin can also not be present as in (161)-(163). ${ }^{83}$

(157) Ni-story $(t-)\left[\right.$ ne-vwer $\quad$ nigce-vwer $\quad$ qin $\left.{ }_{i}\right]$ i-makas $\quad$ ndilqin NI-story (REL-)1SG.R-intend 1SG.IRR-say 3SG 3SG.R-come.out from

ni-mworot nin ut Raqhaw Vwariq tuwan.

NI-man ASS place Raqhaw Vwariq INDEF

'The story that I want to tell comes from some people of Raqhaw Vwariq.' [DK01.001 DK01.wav 157.715 163.184]

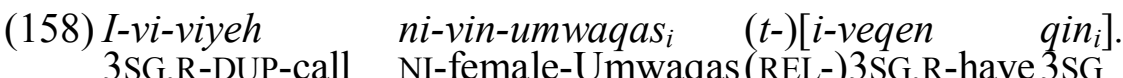

'He sang out to the woman from Umwaqas that he had married.' [DK01.104 DK01.wav 490.095 494.454]

\footnotetext{
${ }^{82}$ Removal of the relative marker in Example (153) would transform the outer clause from an identificational clause ('It is good food') to a verbal clause ('the food is good') [s0802.52]

${ }^{83}$ Elicitation revealed that in (161)-(163) use of the resumptive pronoun is possible. Unfortunately I did not investigate whether it could be omitted in (157)-(160).
} 
(159) Ni-mbwulqun i-ru gin en, tuwan ni-mwbulqun NI-kava 3SG.R-two 3SG ID INDEF NI-kava

$(t-)\left[\right.$ re-min-min $\left.q i n_{i}\right] \ldots$ (REL-)3PL-DUP-drink3SG

'There are two kinds of kava: the one they drink...' [07046.003 07046.wav 10.518 13.158]

(160) Qay, ni-mahal ${ }_{i} \quad \boldsymbol{t}$-[a-vwer qin $]$ i-s-vweleg veq. Hey NI-fish REL-2PL-say 3SG 3SG.R-NEG-come NEG

'Hey, that fish that you talked about isn't coming' [DK01.070 DK01.wav 389.410 391.597]

(161) Na-taq $\quad\left(t\right.$-)[ne-sum-sum-gcor $\left.\varnothing_{\mathrm{i}}\right] \quad$ ti-qor qet ni-temes en. NV-thing (REL-)1SG.R-DUP-sit-guard POSS-today COMPL NI-devil ID

'The thing that I sat guarding today, it's a devil.' [KJ01.040 KJ01.wav 189.051 201.098]

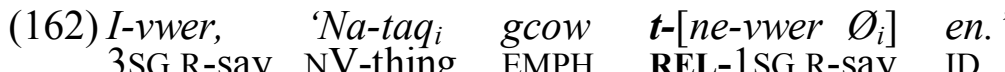

"She said, "That's exactly what I said."” [07073.051 07073.wav 226.616 230.498]

(163) En ra-qan-qan na-qanyen tinin $(t-)\left[\right.$ ni-vilam $_{j} \quad t$-[ $i_{j}$-vwariq $]$ and 3PL-DUP-eat NV-food DEF (REL-)NI-girl REL-3SG.R-small i-tigtig $\left.\varnothing_{i}\right]$. 3SG.R-roast

'And they ate the food that the younger girl had roasted.' [07072.072 07072.wav 392.523 396.805]

The relativised nouns in (164)-(165) act as the object of the preposition $r a-n$ in the relative clause. $R a-n$ takes different endings for first, second, or third person singular objects (see Section 5.3.2.3), so it could be argued that the NP is overtly realised in the form of the object suffix. However, in the similar example, (166), the preposition, len, is not known to take object suffixes.

(164) En i-gcilew i-les $\quad$ ni-mbwasar tinin $t$ - $\left[i \text {-toq } \quad r a-n_{i}\right]^{84}$ and 3SG.R-look 3SG.R-see NI-village DEF REL-3SG.R-be on-3SG

'And she saw the village she lived in.' [EC01.051 EC01.wav 244.778 249.653]

(165)En ni-marlam $_{i} t$-[re-vwer Aimbel $\left.r a-n_{i}\right]$ qey qet $i$-vurvur and NI-old.man REL-3PL-say Aimbel on-3SG 3SG PART 3SG.R-hold ni-nal Mbenewur. ${ }^{85}$ $\mathrm{NV}$-sun Benaur

'And the man they called Aimbel, he caught the sun at Mbenewur.' [07098.111 07098.wav 578.826 586.982]

\footnotetext{
${ }^{84}$ Removal of the relative marker in (164) would remove the relative interpretation, so it would become: 'She saw the village and she lived in it.' [s0802.54]

${ }^{85}$ Removal of the relative marker in (165) would remove the relative interpretation, so it would become: 'And they called him Aimbel, and he caught the sun.' [s0802.54]
} 
(166) Ni-morot tinin re-sisiq na-taq $\quad t$-[re-vutuq ne-wey len $\left.\varnothing_{i}\right]$. NI-man DEF 3PL.R-lack NV-thing REL-3PL-fetch NV-water in 'These people didn't have anything to fetch the water in.' [EC01.007 EC01.wav 26.867 37.087]

Example (167) shows the relativised noun in the role of direct possessor in the relative clause. Note that the relative clause is a verbless clause (Section 5.1.1).

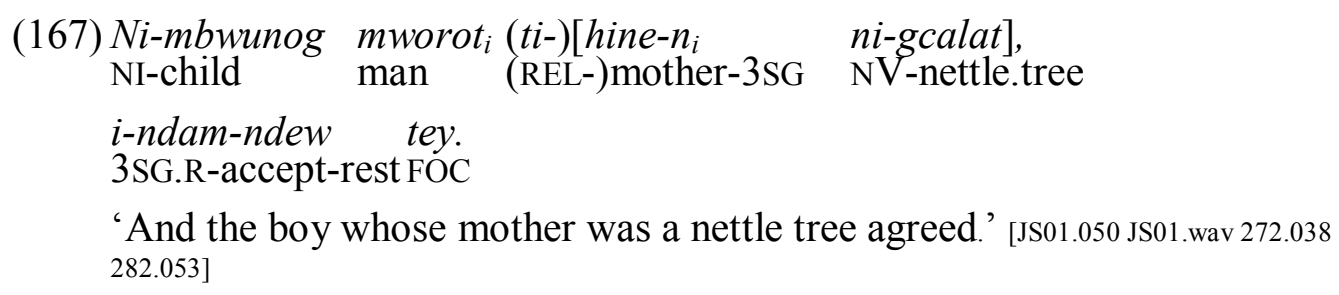

Example (168) shows the relativised noun in the role of indirect possessor in the relative clause. In this case the possessor is overtly realised as the full $3 \mathrm{SG}$ pronoun, qey.
(168) Waq-log wa-q-les ni-marlam (ti-) $_{\text {ne-yum }} \quad$ ti-qey $_{i}$ 2DU.IRR-go 2DU-IRR-see NI-old.man REL-NV-house POSS-3SG i-toq mbogo-n na-hal]. 3SG.R-be mouth-3SG NV-road

'Go see the old man whose house is at the trailhead.' [LS01.077 LS01.wav 305.602 $319.460]$

In example (169) the relativised noun is the object of an associative nin construction in the relative clause:
(169) En inugcku-s-huq veq na-taq $q_{i} \quad t$-[i-leh $] \quad t$-inugc and 2SG 2SG.IRR-NEG-put NEG NV-thing REL-3SG.R-good POSS-2sg (ti-)[ni-marhaw nin $\varnothing_{i} \quad i$-mbwow] mbigce-n ni-mbwuwes ka-qan (REL-)NI-price ASS 3SG.R-big to-3SG NI-pig 3SG.IRR-eat qin. 3SG
'Don't give your nice expensive things to a pig to eat.' [MAT.07:06]

There are two patterns by which relative clauses can be combined. The first is when one relative clause modifies a noun within another relative clause as in (170). The second is when two relative clauses modify a single noun. This is the case in (171) where the two relative clauses are coordinated and have only a single relative marker.

(170) En len ni-mbugtin qet Yesu i-rop mar-meheq and in NI-day DEF COMPL Jesus 3SG.R-help man-sick

i-lamb (t-)[re -veqen $\quad$ ni-meheq-yen $_{j}(t-)\left[r\right.$ - $_{i}$-vi-sensiley $\left.] \quad q a r\right]$. 3SG.R-many (REL-)3PL-have NI-sick-NOM (REL-)3PL-be-different PL

'At that time, Jesus helped many sick people who had all different kinds of disease.' [LUK.07:21] 

(171) I-vwer 'Awaq, ne-mbwit gcow ni-mbwunog $\boldsymbol{t}_{i} \boldsymbol{t}$-[ $i_{i}$-tevis 3SG.R-say no 1SG.R-unable EMPH NI-child REL-3SG.R-appear
eyig qet $i_{i}$-qan ni-puhog ti-inug].'
PROX then 3SG.R-eat NI-roasted.yam POSS-2SG

'She said, "No, I don't know what child came here and ate your roast yam.", [07082.031 07082.wav 128.049 133.612]

\subsubsection{Adjectives}

Nahavaq adjectives are a subset of verbs, and the class is described in Section 4.1.5. What makes adjectives different from any other kind of verbs is that they can modify noun heads simply by following them without any verbal morphology as in the constructions in (172) below. However, these attributive constructions are rarely used in Nahavaq. Attributes are more commonly expressed through a relative clause with full verbal morphology (Section 3.4.7) as in (173). My data on attributive constructions such as those in (172) comes entirely from elicitation.

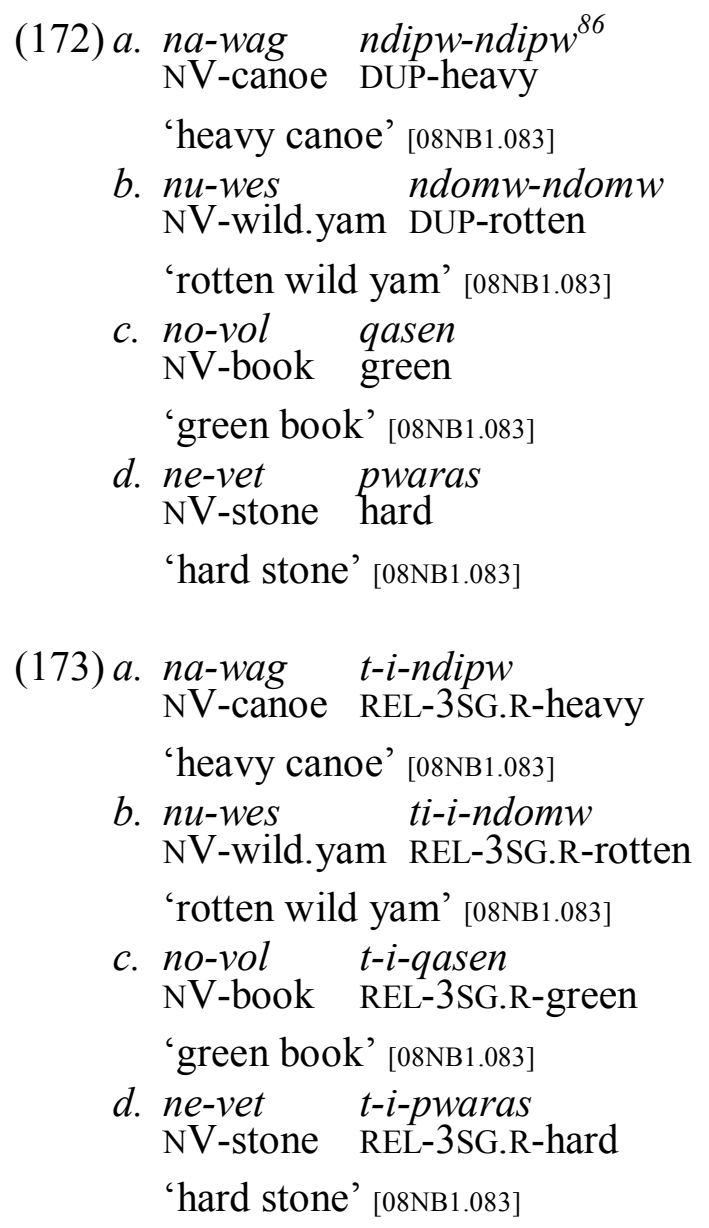

Only a single adjective can modify a noun (174). If a noun has more than one attribute, additional ones can be expressed through relative clauses (174e-f).

${ }^{86}$ Reduplication in adjectives roots such as that is (172a-b) is discussed in Section 4.1.5. 
(174)a. na-qaymes mbarap

$\mathrm{NV}$-knife long

'long knife'

b. na-qaymes tigteg

$\mathrm{NV}$-knife rusty

'rusty knife'

c. *na-aqymes mbarap tigteg

$\mathrm{NV}$-knife long rusty

d. *na-qaymes tigteg mbarap

$\mathrm{NV-knife}$ rusty long

e. na-qaymes mbarap t-i-tigteg

NV-knife long REL-3SG.R-rusty

'rusty long knife'

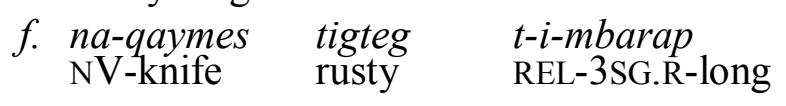

'long rusty knife'

Modifiers such as $t i$ - possession (175a), relative clauses (175b), articles (175c), and the interrogative modifier (175d) cannot occur between the head noun and an attributive adjective.

$\begin{array}{cll}\text { (175)a. }{ }^{*} \text { na-qaymes } & \text { ti-kinag } & \text { mbarap } \\ \text { NV-knife } & \text { POSS-1SG } & \text { long } \\ \text { b. *na-qaymes } & \text { ti-leh } & \\ \text { NV-knife } & \text { REL-3SG.R-good long } \\ \text { c. *na-qaymes } & \text { sut } & \text { mbarap } \\ \text { NV-knife } & \text { NONSP } & \text { long } \\ \text { c. *na-qaymes } & \text { havaq } & \text { mbarap } \\ \text { NV-knife } & \text { which } & \text { long } \\ \text { [08NB1.076] } & & \end{array}$

For some speakers, nouns which are normally prefixed with $n \mathrm{~V}$ - may occur without the prefix when modified by an adjective as in (176). ${ }^{87}$

\footnotetext{
${ }^{87}$ Most younger speakers reject the constructions in (176). However, some older speakers do as well. It is not clear whether this is a conservative feature or a feature of $\mathrm{Na}$ 'ahai that has crept into some people's Nahavaq (as was suggested by one speaker).
} 


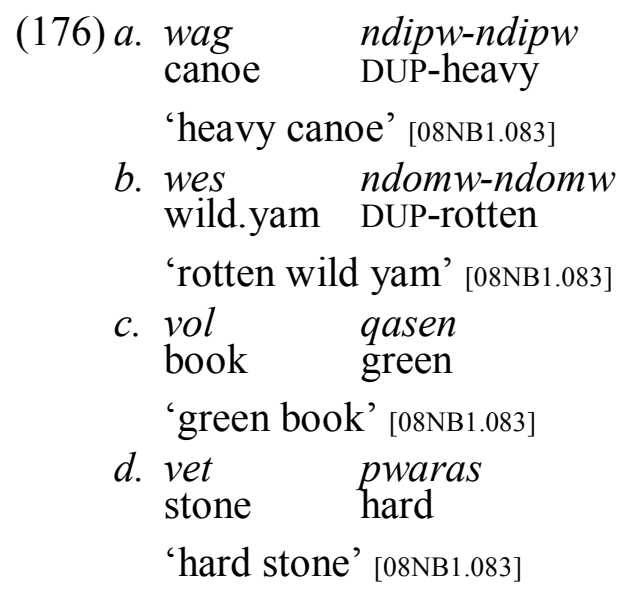

\subsubsection{Body part attribute constructions}

Directly possessed nouns cannot be modified by an attributive adjective. But there is an interesting construction that allows attributive modification of body parts which would normally be directly possessed (177).

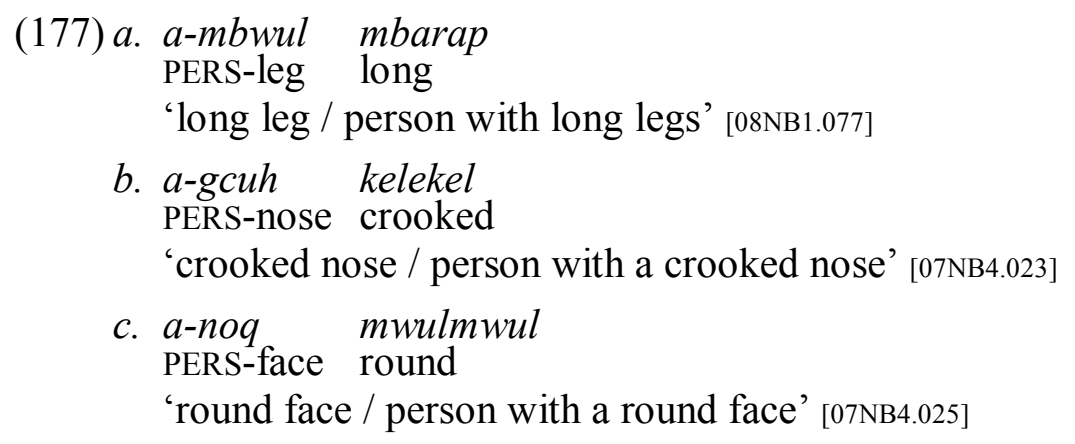

The constructions in (177) use a form of the body part root that is only found in these constructions. For example, in any other construction 'nose' takes the form gcinhuwith a possessor suffix, but in body part attribute constructions, it prefixed with a personal prefix and unsuffixed: $a$-gcuh. The forms of the body part root in these constructions are discussed in Section 3.1.1.

The construction in (177) uses the male personal prefix and can refer either to a body part or to a person who is characterised by that body part. These constructions can also use the female personal prefix as in (178). In these cases, the reference can only be a female person.

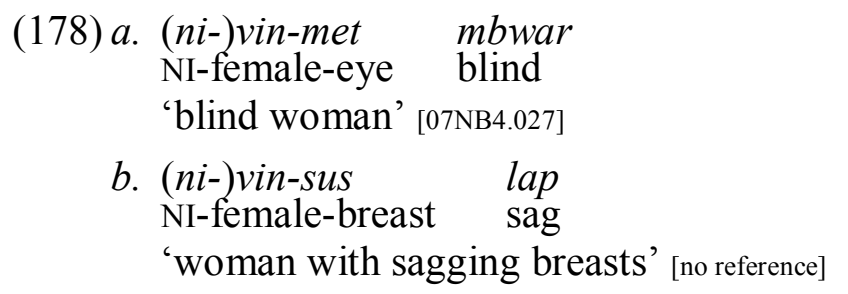

\subsubsection{Nominal modification by verbal modifiers}

There are a number of elements which most often occur as post verbal modifiers (Sections 4.7-4.8), but may also modify nouns. 


\subsubsection{Mbwaq 'sorry'}

Mbwaq 'sorry' as a verbal modifier expresses regret. In the examples below where mbwaq modifies a noun, the meaning seems to be 'poor X'. Example (181) is particularly interesting because $m b w a q$ occurs between a directly possessed head and its possessor.

(179) Gce-vwer hur ndal lis na-qay mbwaq ti-i-vwariq, 1SG.IRR-say about back again NV-wood sorry REL-3SG.R-small ni-gcohgcoh tiyig. NI-rubbish DEF.PROX

'I just want to talk about this small unfortunate weed.' [07030.001 07030.wav 9.654 14.904]

(180) Mbwunog mbwaq yig ru-teg gcen-havaq? child sorry PROX 3DU.R-cry for-what

'Why are these two poor kids crying?' [KO03.039 KO03.wav 129.859 133.578]

$\begin{array}{llll}\text { (181) } R \text { Ru-les } & \text { ni-vara-n mbwaq } & \text { hine-n } & \text { ruwar. } \\ \text { 3DU.R-see } & \text { NI-arm-3SG Sorry } & \text { mother-3SG } & \text { 3DU }\end{array}$

'And they saw their mother's poor (dist

'And they saw their mother's poor (dismembered) wing.' [KO03.022 KO03.wav $79.32683 .575]$

\subsubsection{Ndalis 'again (another)'}

Ndalis is a compound modifier composed of two morphemes: ndal 'back' and lis 'again'. In verbal modification, these two elements can occur separately or as a compound meaning 'again' (Section 4.8.2). In nominal modification, lis and ndalis are possible, both meaning 'additional' (182a-b). But ndal 'back' cannot function as a nominal modifier in this context (182c). Examples (183)-(185) show usage of ndalis as a nominal modifier from the corpus. Note that it can occur in a specific (183), (184) or non-specific phrase (182), (185). Also notable is the variation in ordering between ndalis 'again' and tuwan 'DEF' that can be seen in (183), (184).

$$
\begin{array}{llll}
\text { a. Ku-lip } & \text { no-vol } & \text { ndalis } & \text { sut } \\
\text { 2SG.IRR-take } & \text { NV-book } & \text { again } & \text { NONSP }
\end{array}
$$
b. Ku-lip no-vol lis 2SG.IRR-take NV-book another
sut
NONSP

c. ${ }^{*}$ Ku-lip

no-vol

$\underline{n d a l}$

'Take another book.' [s0801.55]

(183) $E$
and
ro- $\log$
mba-ra-n ni-mbwasar
tuwan ndalis
INDEF
again
qar.
'And they will go to other towns.' [MAT.23:34] 
(184)Len ne-wut-reg-yen ndalis tuwan, ru-metur ne-wut in NV-place-light-NOM again INDEF 3DU.R-sleep NV-place

i-reg, 3SG.R-light

'On another day, they were sleeping and the dawn broke,' [EC01.041 EC01.wav 194.821 199.384]

(185)En i-leh tey gcen wut a-vowus mwin lis hur and 3SG.R-good FOC for that 2PL-carry first again about $\begin{array}{lll}\text { mayil } & k e-s i q & \text { ndalis. } \\ \text { mile } & \text { 3SG.IRR-one } & \end{array}$

'It is good if you carry it for another mile.' [МАТ.05:41]

\subsubsection{Sombo-n 'alone-3SG'}

Sombo- $n$ 'alone-3SG' is only attested in the corpus with a $3 \mathrm{SG}$ suffix. However, elicitation revealed that $1 \mathrm{SG}$ and $2 \mathrm{SG}$ forms also exist: sombo- $q$ 'alone-1SG', sombo$m w$ 'alone-2SG'. In all instances in the corpus of sombo- $n$ as a nominal modifier, it modifies a noun which acts as the subject of a verb. It has a meaning of 'only X' or 'X acted alone' (186)-(189). Sombo-n 'alone' has a similar function when it occurs as a verbal modifier (Section 4.7.6.2).

(186) Morot sombwo-n tey ra-qan solop nin qar. man alone-3SG FOC 3PL.IRR-eat eel DEM 3PL

'Only men ate those eels.' [KJ01.013 KJ01.wav 54.389 60.499]

(187)Qet Atuwa sombo-n tey qet ke-sur-kas ni-samb-yen but God alone-3SG FOC COMPL 3SG.IRR-send-out NI-sin-NOM

nin ni-morot qar.

ASS NI-man PL

'God is the only one who can forgive sins!' [MRK.02:07]

(188) T-i-mbow tey sombo-n qet i-lip tartar REL-3SG.R-big FOC alone-3SG COMPL 3SG.R-take always

Nivingcowumw.

Nivingcowumw

'The older girl would always take Nivigcowum by herself.' [07072.061 07072.wav 334.902 340.730]

(189) Kinag no-rog kinag sombo-n gce-lese-les. $1 \mathrm{SG}$ 1SG.R-want 1SG alone-3SG 1SG.IRR-DUP-see

'I want to look at it by myself.' [07048.0410 07048.wav 756.461757 .451 ]

\subsubsection{Mbot 'all over'}

While mbot as a post verbal modifier means 'all over' (Section 4.7.2.4), as a nominal modifier it means 'any X' or 'all kinds of X' (190)-(191).

(190) Qet ni-mahal mbot ro-s-topw veq mbelen. then NI-fish all.over 3PL-NEG-run NEG into

'But not all fish swim into it (only mackerel).' [07083.069 07083.wav 519.746 524.996] 
(191) Gcen ut ni-vuti-n i-log i-vene-ven ndap because that NI-child-3SG 3SG.R-go 3SG.R-DUP-shoot plenty

na-taq mbot.

$\mathrm{NV}$-thing all.over

'Because the child went hunting for all kinds of things.' [07082.014 07082.wav 60.319 65.013]

\subsubsection{Mwin-(lis) 'other'}

The verbal modifier, mwin 'first' has a number of functions, including marking that something will happen soon or specifying a clause as imperative (Section 4.7.5.4). As a noun phrase modifier, mwin means 'other' (192)- (194), and it can be compounded with lis, which also means 'other' (192)-(193).

$\begin{array}{llllllll}\text { (192) Ni-morot } & \text { i-lamb } & \text { liglig } & \text { ni-morot } & \text { nin } & \text { takis } & \text { qar en } \\ \text { NI-man } & \text { 3SG.R-many } & \text { INTENS NI-man } & \text { ASS tax } & \text { PL } & \text { and } \\ \text { ni-morot } & \text { tuwan } & \text { qar } & \text { mwin-lis. } & & & & \\ \text { NI-man } & \text { INDEF } & \text { PL } & \text { other-other } & & & \end{array}$

'There were a large number of tax collectors and other people' [LUK.05:29]

(193) na-havaq mwin-lis qet i-qasen len kinda $\mathrm{NV}$-what other-other PART 3SG.R-green in kindergarten

'What else is green inside the kindergarten?' [07048.2007 07048.wav 5019.333 5020.997]

(194) Qet ni-mahal havaq mwin qet a-her qin? then NI-fish what first PART 2PL-take 3SG

'So what other kinds of fish did you guys get?' [07117.093-07117.wav 361.824 364.417]

\subsubsection{Mwah}

When $m$ wah functions as a post nominal modifier, it means 'all X' or 'every $\mathrm{X}$ '.

(195) Na-qay mwah t-i-lamb tinin ti-ke-s-veqen veq na-vwan $\mathrm{NV}$-tree all REL-3SG-manyDEF REL-3SG.IRR-NEG-have NEG NV-fruit ra-tar-pet qin, en ro-qom qin mbe-len na-qam. 3PL-cut-break 3SG and 3PL-throw 3SG to-in NV-fire

'Every tree that does not bear good fruit will be cut down and thrown in the fire.' [LUK.03:09]

(196) Kamem mwah tey ti-i-lam mi-koh eraqay. 1EX.PL all FOC REL-3SG.R-many 1EX.PL.R-be up

'All of us were inland.' [07086.036 07086.wav 151.177 155.177]

\subsubsection{Ohoy (tey/ndoh)}

Ohoy (tey) is frequently used to modify nouns with a meaning of 'simply / exclusively'. 
(197) Ni-morot ohoy tey nin takis qar ra-rar ko-noq nin NI-man simply FOC of tax PL 3PL-make 3SG.IRR-like DEM qin.

'Even the tax collectors do that!' [MAT.05:46]

(198) Ut tatay ti-kinag i-mes i-noq nin, qet nuqumem when father POSS-1SG 3SG.R-die 3SG.R-like DEM then 1IN.DU $\begin{array}{lll}\text { ohoy } & \text { tey } & \text { mur-koh. } \\ \text { simply } & \text { FOC } & \text { 1EX.DU.R-be }\end{array}$

'When my father died like that, only the two of us remained.' [07117.012-013 07117.wav 87.190 91.956]

(199) Na-taq ohoy tey i-siq i-toq-sar. NV-thing simply FOC 3SG.R-one 3SG.R-be-remain

'Simply one thing is left.' [07064.238 07064.wav 815.425 817.331]

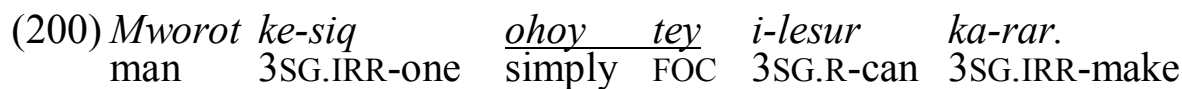

'This can be done by a single person.' [07083.117 07083.wav 1706.303 1711.006]

(201) Ne-mbu-n $\quad$ ohoy-ndoh i-toq-sar $\quad$ en. $\mathrm{NV}$-arse-3SG only 3SG.R-be-remain ID

'Only the end is left.' [07112.198 07112.wav 1150.575 1153.388]

(202) Ni-mbwulu-n ohoy-ndoh i-pwos ni-mbusus. NI-leg-3SG only 3SG.R-slap NI-door

His leg slapped the door.' [07011.074 07011.wav 216.052 221.191]

$\begin{array}{ll}\text { (203) Ne-vet } & \text { ohoy-ndoh } \\ \text { NV-stone } & \text { only-sar. } \\ \text { ong.R-be-remain }\end{array}$

'Only stones remained.' [07009.079 07009.wav 219.809 222.106]

Examples (201)-(203) all contain ohoy-ndoh as a possessor. The meaning has something to do with exclusivity, but it is not clear how the meaning of ohoy-ndoh differs from ohoy tey.

\subsubsection{Morsu}

As a verbal modifier, morsu means 'unrestricted' (Section 4.7.2.5). When used as a nominal modifier, it has a similar function. There is no restriction on the types of animals that the boy shoots in (204). There is no restriction on which villages the people are to visit in (205). And in (206), the things washed up everywhere (no restriction on the place). 
(204) En ni-vuti-n mbunog ke-vini ni-mahal qaw ke-vini and NI-child-3SG child 3SG.IRR-shoot NI-fish or 3SG.IRR-shoot ne-tew qaw ke-vini na-taq morsu qar. NV-chicken or 3SG.IRR-shoot NV-thing every PL

'And the boy would shoot fish or he would shoot chickens or he would shoot anything.' [KO02.002 KO02.wav 11.685 19.872]

(205) 'Ku-log hur na-hal morsu en ni-mbwasar qar,' 2SG.IRR-go along NV-road every and NI-village PL

'Go along the all the roads and the villages.' [LUK.14:23]

(206) I-her i-mbu-mburaq mba-law gcen ra-hal ohoy tey 3SG.R-take 3SG.R-DUP-throw to-shore for 3PL-float simply FOC re-q-p-sig $\quad$ mbey ne-wut morsu. 3PL-IRR-become-ashore to NV-place every

'And he took them and threw them into the sea so that they just float and wash up everywhere.' [07027.043 07027.wav 97.387 99.981]

\subsubsection{Ordering of post-nominal modifiers}

Ordering of elements within the noun phrase is complex because of scope issues. In particular, sut 'NONSP' and tuwan 'INDEF' can occur in a range of different positions depending on their scope. For example, in (207a) tuwan 'INDEF' has scope over qar 'PL', but in (207b), qar 'PL' has scope over tuwan 'INDEF'.

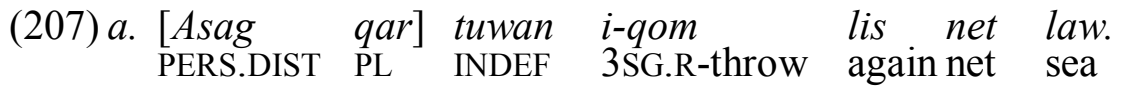

'One of those guys put a net in the sea again.' [07117.493 07117.wav 1493.257 1496.117]

b. [Marlam tuwan] qar repir nimbuwes.

old.man INDEF PL 3PL-raise NI-pig

'Some old men were raising pigs.' [07111.082 07111.wav 312.642 317.267]

However, there is at least a tendency for modifiers to occur in the order shown in Figure 26.

\section{Figure 26: Ordering of post-nominal modifiers}

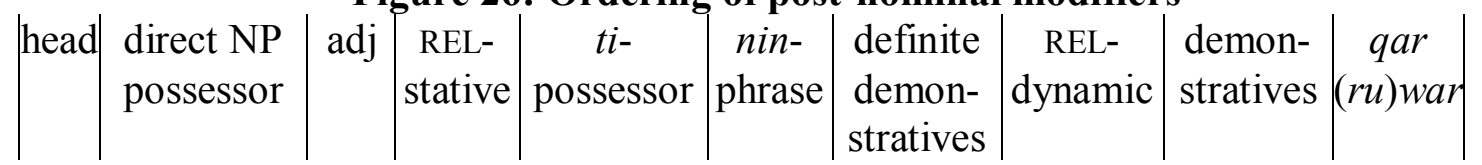

Stative relative clauses tend to occur before $t i$ - indirect possession as in (208), while dynamic relative clauses tend to occur after $t i$ - indirect possession as in (209).

$$
\begin{aligned}
& \text { (208) } \begin{array}{l}
n i-\text { mbunog } \\
\text { NI-child }
\end{array} \\
& \text { 'my small child' } \frac{t \text {-vwariq }}{\text { REL-3SG.R-small }} \frac{t i-\text { kinagc }}{\text { POSS-1SG }}
\end{aligned}
$$


(209) naqay-sag ti-qar $\quad$ t-ra-qa-qan $\quad r a-n$ table POSS-3PL REL-3PL-DUP-eat on-3SG

'their dining table' [MRK.07:28]

The positions of determiners are complicated. Definite demonstratives such as tinin 'DEF' in Example (210) can occur both before and after a relative clause.

Demonstratives that do not begin in /ti/ can occur after a relative clause as in (211).

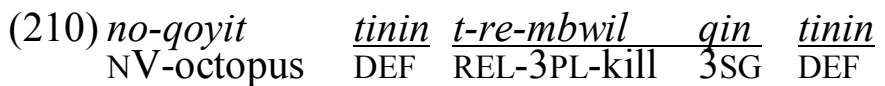

'the octopus that they killed' [07074.100 07074.wav 438.102 441.930]

(211) $n$ i-vilamb
NI-girl $\frac{\text { t-ru-leh }}{\text { REL-3DU-good }} \stackrel{\text { vig war }}{\text { PROX du }}$

C REL-3DU-goOd PROX du

'these two good girls' [LS01.125 LS01.wav 532.082 537.270]

\subsection{Headless noun phrases}

Many post-nominal modifiers may stand alone in a noun phrase without an overt head. $\begin{array}{ll}\text { (212) Antony } i \text {-vini } & \text { tuwan } \\ \text { antony } & \text { 3SG.R-shoot } \\ \text { INDEF } & \text { there }\end{array}$

'Antony shot one over there.' [07117.475 07117.wav 1453.511 1455.620]

In example (212), there is no overtly realised nominal head that tuwan is modifying. This could be analysed as an empty head [NP Ø tuwan]. Another possible interpretation of these elements would be that they are separate pronouns which are related to the post-nominal modifiers. However, I find it much simpler to analyse these forms as single items rather than sets of homophones that have two functions.

Not every element which may modify a noun can occur in a headless noun phrase construction. The verb/noun modifiers discussed in Section 3.4.9 can stand as a noun phrase without an overt head. Possessive post-nominal modifiers do not occur in these kinds of constructions either, but possessive pre-modifiers of the form POSSESSOR-yen (Section 3.2.2.3) can occur without the nominal head.

(213) Nagcu-yen en! 1 SG-POSS ID

'It's mine!' [07063.371 07063.wav 1234.913 1239.694]

(214) Na-taq ti-kinagc qar qet namu-yen en qar. NV-thing POSS-1SG PL PART 2SG-POSS ID PL

'All my things are yours.' [LUK.15:31]

(215) Kamem-yen i-yar _en. 1PL.INC-POSS 3SG.R-finish ID

'Ours is finished.' [тв03.095 TB03.wav 470.041 471.619] 
(216) Qey ke-s-veqen veq ni-rirog-yen ka-mban ra-n. 3SG 3SG.IRR-NEG-have NEG NI-like-NOM 3SG.IRR-beat on-3SG

Yesu qey-yen,

Jesus 3SG-POSS

'His love is not as big as Jesus's.' [JON.15:13]

While the demonstratives tinin 'DEF', tiyig 'DEF.PROX', and tiyag 'DEF.DIST' all occur in headless noun phrases, the demonstratives nin 'DEM' and yig 'PROX' do not. This may relate to some kind of definite function of /ti/ as discussed in Section 3.4.4.

(217) Gce-lip tiyig gce-tu eyig.

1SG.IRR-take DEF.PROX 1SG.IRR-put here

'I take this and put it here.' [07107.007 07107.wav 18.989 20.676]

(218) Tinin i-minim u-mwas ku-teqes-kas bobinkes $t$-inug. DEF 3SG.R-mean 2SG.R-must 2SG.IRR-pull-out bobbin case POSS-2SG 'This means that you have to take out your bobbin case.'[07051.301 07051.wav 1161.299 1165.127]

(219) Ku-rivi tiyag.

2SG.IRR-pull DEF.DIST

'Pull that one.' [nendiq.526 nendiq.wav 1594.099 1595.419]

The following are examples of headless noun phrases with sut 'NONSP', tuwan 'INDEF', and timbeh 'which'.

(220) A-les sut et a-lip mbweleg. 2PL-see NONSP then 2PL-take to.FOC

'If you see one, give it to me.' [07076.034 07076.wav 133.832 138.019]

(221) Tuwan ke-luwe-lu, tuwan ke-s-luwe-lu veq. INDEF 3SG.IRR-DUP-vomit INDEF 3SG.IRR-NEG-DUP-vomit NEG 'Some overflow; some don't.' [07112.058-059 07112.wav 327.456 331.972]

(222) inug u-rirog timbeh?

'Which one do you like?' [07048.1692 07048.wav 4417.381 4420.579]

Examples (223) and (224) have headless noun phrases with stative relative clauses.

(223) Ambwat ke-her yig war ko-noq yig. thumb 3SG.IRR-take REL-3SG.R-two this DU 3SG.IRR-like this 'The thumb takes these two like this.' [07106.006 07106.wav 25.942 29.036] 

(224) $T$-i-mbow $\quad i-h a q \quad r a-n \quad n a-q a y$ en $t-i-v$ wariq REL-3SG.R-big 3SG.R-climb on-3SG NV-tree and REL-3SG.R-small
i-toq tey leten.
3SG.R-be just down

'The older boy climbed the tree and the younger just stayed on the ground.' [AT01.006 AT01.wav 28.002 32.939]

\subsection{Coordination of noun phrases}

Noun phrases can be coordinated in a number of ways. They can simply be juxtaposed without any coordinator (Section 3.6.1), or there are a variety of words that can coordinate noun phrases. Two of these coordinators (en 'and' and inet 'then') can also be used in the coordination of clauses as discussed in Section 5.5.

\subsubsection{Juxtaposed NPs}

Coordinated NPs can be simply juxtaposed without any coordinator as in (225).

$$
\begin{aligned}
& \begin{array}{llllll}
\text { (225) Ut } & k u \text {-lip } & \text { na-qay } & \text { tuwan } & \text { ka-pwaras } \\
\text { COMPL } & \text { 2SG.IRR-take } & \text { NV-wood } & \text { INDEF } & \text { 3SG.IRR-hard } & \text { INDEF }
\end{array} \\
& \text { ke-meloqlog et vanmbug tuwan i-s-lesur veq } \\
& \text { 3SG.IRR-soft then occasion INDEF 3SG.R-NEG-can NEG } \\
& \text { ke-viyag, } a q \text { ? } \\
& \text { 3SG.IRR-light TAG }
\end{aligned}
$$

'If you use one piece of hard wood and one piece of soft wood, sometimes it won't light, eh?' [07095.040-041 07095.wav 249.794 257.793]

\subsubsection{Inclusory constructions with personal pronouns}

With non-singular personal pronouns, a member of the group may be specified after the pronoun as in (226). In a related way, (ru)war '3DU' or qar '3PL' may be used to coordinate noun phrases as exemplified in (227).

(226) Nuqum Giles wa-got ni-mbuluk. 2DU Giles 2DU-not.want NI-cattle

You and Giles don't want beef. [07NB1.067]

(227) No-qoyit war
NV-octopus 'The octopus and the rat, yes.' [07117.368 07117.wav 1184.856 1186.376]

It is also common for third person pronouns to be used in this way with the addition of qin (which has a 'with' function when occurring as an adjunct as described in Section 5.3.2.3.11) (228)-(230). Note that when more than two noun phrases are coordinated in this way, the pronoun occurs only after the first item (230a-b).

(228) George war qin Brian ru-yar ndoh war-yen. George 3DU with Brian 3DU-finish PERF 3DU-POSS

'George and Brian have already finished theirs.' [07048.0597 07048.wav 1108.814 1111.986] 
(229) Mworot tuwan war qin momoq ti-qey ru-koh. man INDEF 3DU with woman POSS-3SG 3DU.R-be

'There was a man and his wife.' [07009.003 07009.wav 7.135 12.025]

(230)a. Giles qar qin Hokey Brian Giles 3PL with Hokey Brian

'Giles, Hokey, and Brian' [07NB1.083]

b. *Giles gar qin Hokey gar qin Brian Giles 3PL with Hokey 3PL with Brian

\subsubsection{Mbon qin}

Mbon qin can occur as a coordinator between two noun phrases as in (231). However, it more often occurs in an adjunct position with a 'with' function as in (232). Mbon appears to be cognate with mbonombon 'together'.

$\begin{array}{lll}\text { (231) Ro-topw mbey re-lip ne-revuh mbaragcin mbon qin } & \begin{array}{l}\text { mumbwel. } \\ \text { 3PL-jump to 3PL-take NV-bow }\end{array} \text { straight }\end{array}$

'They went and got a bow and arrows.' [EC02.083 EC02.wav 330.311 333.828]

$\begin{array}{cllll}\text { (232) Re-mbulug qey } & \text { mbwon qin } & \text { ni-morot } & t \text {-ra-samb } & \text { qar. } \\ \text { 3PL-count 3SG } & \text { with } & \text { NI-man } & \text { REL-3PL-evil } & \text { PL }\end{array}$

'He was counted with the criminals.' [MRK.15:28]

\subsubsection{Luqur 'with'}

Luqur or luqur qin 'with' can be used as a coordinator as in (233)-(235). When more than one NP is coordinated, luqur may or may not be used multiple times (235).

(233) Mworot nin luqur mwomwoq ti-qey ni-vuti-n qar man DEF with woman POSS-3SG NI-child-3SG PL

re-mewur ro-koh.

3PL-live 3PL-be

'The man and his wife and their child lived on.' [07009.080 07009.wav 222.106 224.918]

(234) Qet re-lip tatay ti-kinag luqurqin olfala tuwan ra-n then 3PL-take father POSS-1SG with 3SG old.man INDEF on-3SG ut Ewur. place Toman

'And they took my father and an old man to Toman Island.' [07086.045 07086.wav 182.373 188.154]

(235) a. Giles luqur Hokey luqur Brian

Giles with Hokey with Brian

'Giles, Hokey, and Brian' [07NB01.083]

b. Giles luqur Hokey Brian

Giles with Hokey Brian

'Giles, Hokey, and Brian’ [07NB01.083]

Like mbon qin 'with', luqur 'with' occurs frequently in an adjunct position as in (236)-(237). 
(236) En Paylat i-log mbi-vusar luqurqar. and Pilate 3SG.R-go to-outside with 3PL

'So Pilate went outside to them.' [JON.18:29]

$\begin{array}{cllll}\text { (237) Ne-vwer } & \text { ku-sarlis } & \text { veq } & \text { niqismbwet ti-nugc } & \text { luqur } \\ \text { 1SG.R-say } & \text { 2SG.IRR-exchange } & \text { NEG } & \text { grass.skirt POSS-2SG } & \text { with }\end{array}$ ni-vilam sut. NI-girl NONSP

'I said don't trade your skirt with another girl.' [07064.164 07064.wav 585.452 589.670]

\subsubsection{En' 'and'}

$E n$ 'and' is used to coordinate noun phrases as in (238)-(239), and it may be repeated as in (239).

(238) Marlam tuwan en momoq tuwan vinmarlam ti-qey ru-koh. old.man INDEF and woman INDEF old.woman POSS-3SG 3DU.R-be

'There was an old man and a woman, his wife.' [07010.002-003 07010.wav 6.653 12.543]

(239) En hala-n qar qet Jemis, en Josis, en Saymon, and sibling-3SG PL PART James and Joseph and Simon

en Judas?

and Judas

'And aren’t James, Joseph, Simon, and Judas his brothers?' [MAT.13:55]

\subsubsection{Inet 'then'}

Inet 'then' is used as a coordinator when an additional noun phrase is added as an afterthought as in (240) or in an extended list as in (241).

(240)En ni-story tiyig hur Nivutin Mbeqey en and NI-story DEF.PROX about Nivutin Mbeqey and Ni-vinmbumbaqaw inet Ambwatmalqun en ni-vuti-n qar. NI-Vinmbwumbwaqaw then Ambwatmalqun and NI-child-3SG PL 'And this story is about Nivutin Mbeqey and Vinmbwumbwaqaw, Ambwatmalqun and their children.' [EC02.001-002 EC02.wav 1.156 9.907]

(241)Kinag ohoy tey inet papap mbwata inet Maya, Manu, 1SG simply FOC then uncle Ambwata then Maya Manu

Edwin, pap Aiel, inet pap Kalset.

Edwin uncle Aiel then uncle Kalset

'It was just me and Uncle Ambwata and Maya, Manu, Edwin, Uncle Aiel, and Uncle Kalset.' [07117.081-083 07117.wav 330.432 339.220] 


\section{Chapter 4: Verb Phrase}

The minimal verb phrase in Nahavaq consists of a subject/mood agreement prefix and a verb root. If there is a direct object, it occurs to the right of the verb, and I define the verb phrase as everything that occurs between the subject/mood subject agreement prefix and the direct object. The consituents in the verb phrase are strictly ordered as in Figure 27.

\begin{tabular}{|c|c|c|c|c|c|c|c|c|c|c|}
\hline & \multicolumn{10}{|c|}{ Figure 27: Verb phrase constituent ordering } \\
\hline $\begin{array}{l}\text { subj/ } \\
\text { mood- }\end{array}$ & & $\begin{array}{l}\text { third } \\
\text { order }\end{array}$ & $\mathrm{C} i-$ & *ma- & DUP- & ROOT & PVM1 & NEG & PVM2 & D.O. \\
\hline$\S 4.2$ & $\S 4.3$ & $\S 4.4$ & $\S 4.5$ & $\S 4.1 .4$ & $\S 4.5$ & $\S 4.1$ & $\S 4.7$ & $\S 4.3$ & $\S 4.8$ & $\$ 4.9$ \\
\hline
\end{tabular}

The elements which occur before the verb root in Figure 27 behave as prefixes, with many of them phonologically dependent on the base to which they attach. Nearly all of the elements which follow the verb root are separate phonological words. The only exceptions are where there is object incorporation (Section 4.1.9) or nuclear-layer serial verb constructions (Section 4.6.1.1).

This chapter will begin with a summary of different types of verb heads (4.1). The next four sections describe verbal prefixes: subject/mood agreement prefixes (4.2), disjunctive verbal negation (which is disjunctive)(4.3), a group of prefixes termed 'third order prefixes', and reduplication (4.5). Section 4.6 dicusses the concept of Serial Verb Constructions (SVCs) in Nahavaq. Then Sections 4.7 and 4.8 describe two major groups of post verbal modifiers, and finally Section 4.9 discusses direct objects.

\subsection{Verb heads}

I define Nahavaq verbs as heads that can take subject/mood prefixes.

\subsubsection{Transitivity}

Nahavaq verbs can be intransitive, transitive or ambitransitive. Because transitive verbs such as qom 'throw' in (242) can occur with a non-overt object, it is difficult to distinguish between intransitive verbs and transitive verbs with a non-overt object. I therefore classify all verbs which can take direct objects as transitive.

$$
\begin{aligned}
& \text { (242) Na-taq nin i-het. Ku-qom. Merey en. } \\
& \text { NV-thing DEM 3SG.R-bad 2SG.IRR-throw lizard ID }
\end{aligned}
$$

Transitive verbs include stative (veqen 'have', rirog 'like', noq 'be like', sinkon 'be angry at') and dynamic verbs (qas 'bite', qombw 'throw', vowus 'carry', mbwil 'hit', etc.).

Intransitive verbs never have direct objects. These include dynamic verbs (log 'go/walk', metur 'sleep', kaptoh 'cough', teg 'cry', taris 'stand up', etc.) and stative verbs (gotsul 'lazy', het 'bad', hew 'humid', pon 'constipated', etc.). Two major 
subsets of stative verbs are discussed in later sections. Adjectives (described in Section 4.1.5) are stative verbs which can also function as nominal modifiers. Quantifiers (described in Section 4.1.6) are another subset of stative verbs. They have a limited range of verbal prefixes and can also modify nouns.

Ambitransitive verbs can be used in both transitive structures and unaccusative intransitive structures. An example of an ambitransitive verb is seven 'open'. In (243), it is used with an agentive subject and patient object. In (244), it is used with a patient subject. Other verbs of this type include (limblimb 'roll', luqluq 'hide', mband 'exceed/win', nden 'sink/submerge', sig 'go ashore/drive ashore', sisiq 'lack/not exist', tiqteq 'close', yar 'finish', and kurkur 'move').

(243) A-si-seven no-qond ke-leh. 2PL-DUP-open NV-basket 3SG.IRR-good.

'Open the basket properly.' [EC02.035 EC02.wav 174.690 181.283]

(244) En i-ven-tut ra-n ne-vet, ne-vet i-si-seven. and 3SG.R-shoot-stick on-3SG NV-stone $\mathrm{NV}$-stone 3SG.R-DUP-open 'He pierced the stone, and the stone opened up.' [EC01.043 EC01.wav 201.184 208.931]

In addition, there are a few verbs such as ndilgcus 'stop up' in (245) that exhibit object/oblique alternation as described in Section 5.3.2.3.12.

$$
\begin{aligned}
& \begin{array}{llll}
\text { (245)a. Ke-ndilgcus } & \begin{array}{l}
\text { no-pon } \\
\text { 3SG.IRR-stop.up }
\end{array} & \text { qin } & \text { ne-reqey. } \\
\text { NV-oping } & \text { OBL } & \text { NV-leaf }
\end{array} \\
& \text { b. Ke-ndilgcus ne-reqey qin no-pon. } \\
& \text { 3SG.IRR-stop.up NV-leaf OBL NV-opening } \\
& \text { 'He would stop up the opening with leaves.' [08NB1.102] }
\end{aligned}
$$

There is no specific productive valency-changing verbal morphology in Nahavaq, but there are vestiges of a transitive suffix (Section 4.1.3) and a stative prefix *ma-, which may have had a detransitivising function (Section 4.1.4). ${ }^{88}$

\subsubsection{Directional verbs}

Nahavaq verbs associated with motion can be split into two categories according to how the destination or direction is expressed (Table 62).

\footnotetext{
${ }^{88}$ Some transitive verbs that have been borrowed from Bislama retain the Bislama transitivising suffix -em. These include salem 'sell', sekem 'check', traym 'try' septem 'move', minim 'mean', and yusum 'use'. There is no evidence to suggest that these function as anything but single-morpheme verbal roots in Nahavaq.
} 
Table 62: Directional verbs and non-directional verbs of motion

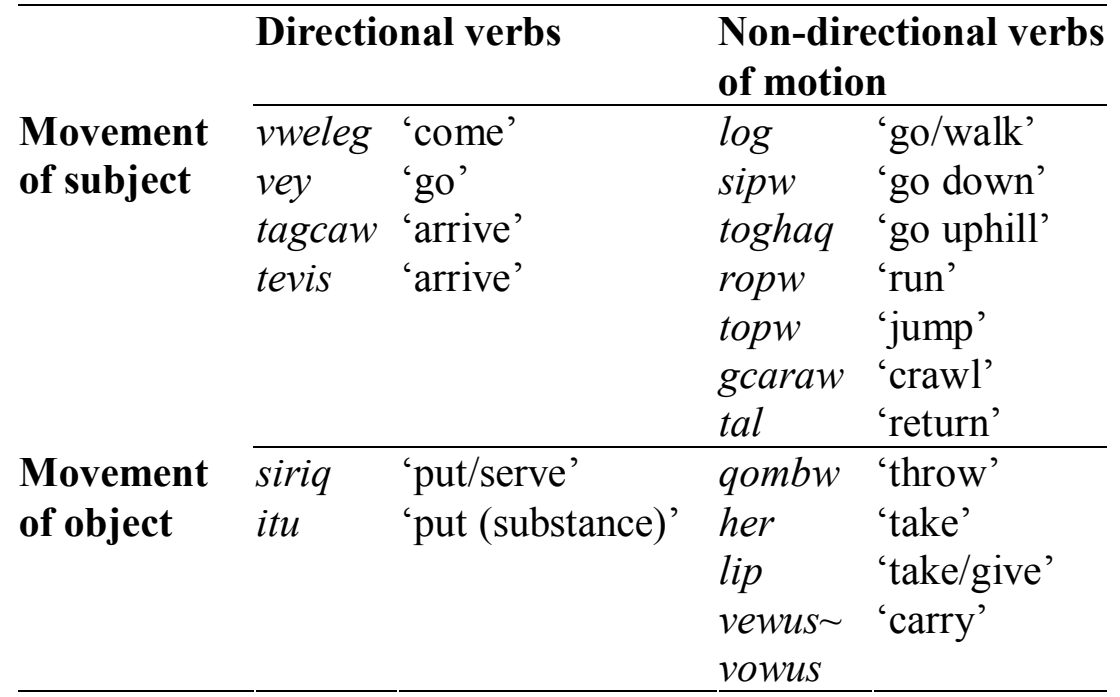

When a locative follows a directional verb, it refers to a goal/destination (246). When a locative follows a non-directional verb of motion, it refers to an origin (247a). For such verbs, goal/destination can be specified with a directional particle (Section 5.3.2.4) as in Example (247b).

(246) Directional verb

a. A-vey ambeh?

2PL-go where

'Where are you guys going?' [MAHR.038 MAHR01.wav 402.040 405.462]

b. Ne-tes i-vweleg len na-wagc t-ruwar. $\mathrm{NV}$-sea 3SG.R-come in NV-canoe POSS-3DU

'Sea water came into their boat,' [07117.376 07117.wav 1202.836 1205.711]

c. I-tevis Lavor Mbimbarap.

3SG.R-arrive Lavor Mbimbarap

'He reached Lavor Mbimbarap,' [07080.061 07080.wav 239.687 242.109]

d. I-haq i-tagcaw livwaqan.mehep.

3SG.R-climb 3SG.R-arrive up

'She climbed until she reached the top,' [EC02.119 EC02.wav 493.878 499.285]

(247) Non-directional verb of motion

a. War-log ambeh?

2DU-go where

'Where did you two come from?' [LS01.074 LS01.wav 295.063 295.836]

b. I-sipw $\quad$ Mbwilmbwar mbweleg law.

3SG.R-go.down mbwilmbwar to.FOC shore

'He came down to the beach from Mbwilmbwar.' [07074.030 07074.wav 135.955 141.079] 
c. Na-tal Qamel en.

1SG.R-return Qamel ID

'I have come back from Qamel."“ [07063.192 07063.wav 650.990 653.772]

(248) Non-directional verb of motion + directional particle
a. Ndo-q-log mb-ambeh?
$1 \mathrm{IN} . \mathrm{PL}-\mathrm{IRR}$-go
to-where

'And they said, "Where are we going?"‘ [07072.081 07072.wav 442.113 443.616]

b. Salambow i-sipw mbweleg leten.

Salambow 3SG.R-go to.FOC LOC.down

'Salambow went down.' [MAHR.086 MAHR01.wav 613.753 615.893]

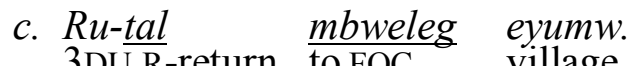

3DU.R-return to.FOC village

‘The two came home,' [07072.071 07072.wav 388.038 392.523]

Examples (249)-(251) show the same distinction with transitive verbs where the object moves along a path. Example (249) shows transitive directional verbs with a locative adjunct indicating the goal or destination. Example (250) shows transitive non-directional verbs of motion which have a locative adjunct indicating the origin. Examples (251) show such verbs with a directional particle before the locative adjunct indicating goal or destination.

\section{(249) Transitive directional verbs}

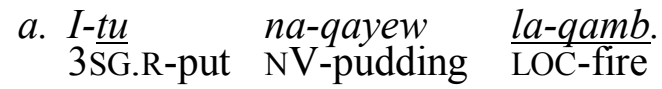

'He put the pudding in the fire.' [07075.016 07075.wav 91.840 96.717 ELANParticipant Emile]

$\begin{array}{lll}\text { bu-siriq } & \text { ra-n } & \text { kinag. } \\ \text { 2SG.IRR-put } & \text { on-3SG } 1 \mathrm{SG}\end{array}$

'Put it on me.' [07098.065 07098.wav 342.188 345.594]

(250) Transitive verbs of motion + locative origin

$\begin{array}{lll}\text { a. Ku-her } & \text { ni-mbwisnep metelqam. } \\ 2 \mathrm{SG} \text {.IRR-take NI-ashes } & \text { fireplace }\end{array}$

'Take some ashes from the fireplace.' [07098.064 07098.wav 335.860 342.188]

b. Ro-qombw kinag len skul.

3PL-throw $1 \mathrm{SG}$ in school

'But they threw me out of school.' [07117.034 07117.wav 181.556 184.884]

c. Re-vwer re-vowus-kas len ni-vulus. 3PL-intend 3PL-carry-out in NI-oven

'They intended to carry it out of the oven.' [KJ01.050 KJ01.wav 262.234268 .321 ] 
d. U-lip
2SG.R-take money $\frac{\text { ambeh }}{\text { where }}$ then
2SG.R-buy donut

'Where did you get the money to buy the donuts?' [07048.1266 07048.wav 3682.199 3685.609]

(251) Transitive verbs of motion + directional particle + locative destination
a. Mwene- $n$
i-vowus
ni-hinenmbwilqey
ti-qey
brother-3SG
3SG.R-carry
NI-tamtam
poss-3SG to-shore

'Her brother carried his big tam-tam drum ashore,' [07064.271 07064.wav 930.329 934.689]

Re-her
3PL-take to-in $\frac{\text { len }}{\text { pwayp. }}$ pipe

'They put it in the pipe,' [RF-MF01.052 RF-MF01.WAV 238.188 246.923]

$\begin{array}{llll}\text { c. Tatay } & i \text {-vwer } & n d u \text {-lip } & \text { mor yig } \\ \text { father } & \text { 3SG.R-say } & \text { 1IN.DU-take } & \text { man } \\ \text { PROX } & \text { to-home }\end{array}$

'Father said we should take this man home.' [08009.140 08009.wav 798.195 802.367]

\subsubsection{Vestigial transitive suffixes}

There are 27 verbs listed in Table 63 that show evidence of a former transitive suffix. The only cases where these suffixes have a clearly transitive function are in the verbs teg(-is) 'cry/cry for' (252) and pil(-is) 'hot/heat' (253). However, the suffixed verbs in Table 63 are all transitive and have cognates without the apparent suffix.

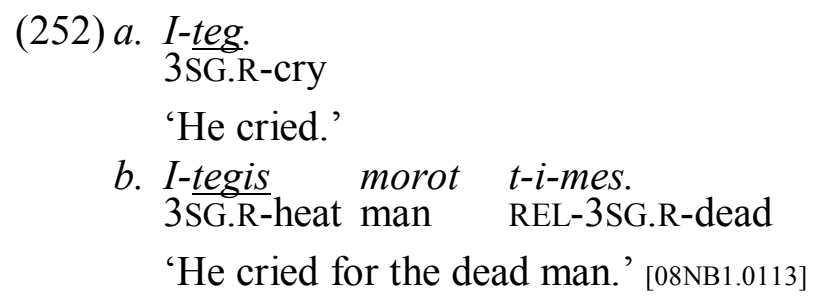

(253) a. I-pilpil.

3SG.R-hot

'It is hot.'

b. I-pilis asin.

3SG.R-heat PERS

'It heated the guy.' [08NB1.026]

The suffixes in Table 63 have the form -Vs (qinis 'pinch', teqes 'yank', gcalas 'hold with tong', qoros 'cut', ravwus 'poison'), -i (vini 'shoot', suli 'pry out'), or -ey (terey 'cut'). 
Table 63: Vestigial transitive suffixes

\begin{tabular}{|c|c|c|c|c|c|}
\hline $\begin{array}{l}\text { Indep. } \\
\text { suffixed } \\
\text { verb }\end{array}$ & Gloss & $\begin{array}{l}\text { Defic- } \\
\text { ient V1 }\end{array}$ & Gloss & Indep. verb & Gloss \\
\hline terey & 'cut' & tar & 'cut' & tartar & 'cut pieces off' \\
\hline veres & 'push with leg' & var & 'step on' & varavar & 'push with leg' \\
\hline ravwus & 'poison (v.t.)' & rap & 'poison' & rirap & 'be a poisoner' \\
\hline qoros & 'cut' & qor & 'cut' & qorqor & 'cut' \\
\hline pilis & 'heat' & pil & 'heat' & pilpil & 'be hot (v.i.)' \\
\hline qinis & 'pinch' & qin & 'pinch' & qinqin & 'pinch' \\
\hline vini & 'shoot' & ven & 'shoot' & veneven & 'shoot' \\
\hline gcalas & 'hold with tongs' & gcal & $\begin{array}{l}\text { 'hold with } \\
\text { tongs' }\end{array}$ & gcagcal & 'hold with tongs' \\
\hline qambus & 'cover' & $q a m b$ & 'cover' & & \\
\hline mwalis & 'debark' & mwal & 'debark' & & \\
\hline tinis & 'scorch' & tin & 'scorch' & & \\
\hline gcaris & 'scrape straight' & gcar & $\begin{array}{l}\text { 'scrape } \\
\text { straight' }\end{array}$ & & \\
\hline teqes & 'yank' & teq & 'yank' & & \\
\hline vowus & 'carry' & vow & 'carry' & & \\
\hline rivi & 'pull' & $r a p$ & 'pull' & & \\
\hline karas & 'irritate/scratch' & kar & 'itch' & & \\
\hline vulus & 'rotate' & $v u l$ & 'rotate' & & \\
\hline gcamwus & 'chase' & gcam & 'chase' & & \\
\hline pilis & 'heat' & & & pilpil & 'hot (v.i.)' \\
\hline goros & 'scrape with teeth' & & & gorogor & 'scrape with teeth' \\
\hline gcewus & $\begin{array}{l}\text { 'pick with turning } \\
\text { motion' }\end{array}$ & & & gcegcew & $\begin{array}{l}\text { 'pick with turning } \\
\text { motion (v.t. pl object) }\end{array}$ \\
\hline sili & 'pry out' & & & silsil & 'pry out' \\
\hline hevi & 'separate' & & & hephep & 'separate' \\
\hline huli & 'illuminate' & & & hulhul & 'use torch (v.i.)' \\
\hline tovwis & 'fly across' & & & topw & 'fly/jump (v.i.)' \\
\hline tegis & 'cry for' & & & teg & 'cry (v.i.)' \\
\hline suqus & 'poke with stick' & & & suq & 'poke with stick (v.t.)' \\
\hline
\end{tabular}

Note that while the un-suffixed cognates may undergo monosyllabic reduplication (254) as described in Section 2.4.6.2, the suffixed forms are all polysyllabic and can only be reduplicated with $\mathrm{C} i$ - reduplication (255) as described in Section 2.4.6.1.

(254) Ru-rog mi nivuti-n mbwunog i-tig-teg len ni-vetevet 3DU-hear FOC child-3SG child 3SG.R-DUP-cry in NI-yam.bed

'They heard a boy crying in the yam bed.' [MR01.078 MR01.wav 413.497416 .950 ]

(255) Mbwunog i-ti-tegis loli.

child 3SG.r-DUP-cry lolly

'The child cried for lollies.' [08NB1.013]

\subsubsection{Vestigial *ma- prefix}

There are at least 116 Nahavaq words (Appendix 4) that appear to have reflexes of a historical prefix descended from the POc stative verb derivative, *ma- (Evans and 
Ross 2001). The form of these vestigial prefixes is discussed in Section 2.4.2.1. For a few of these words, there is evidence from synchronic pairs such as the transitive wel 'untie' in (256a) and the stative mwewel 'unravelled' (256b).

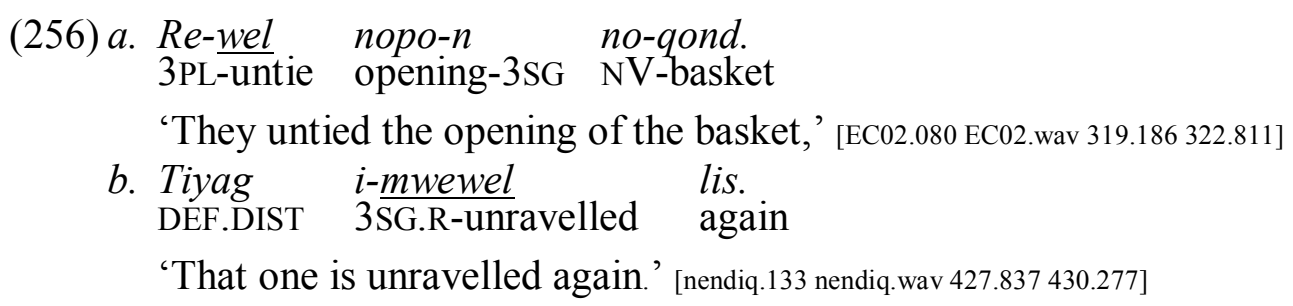

Others, such as mwakas 'get out' (257) are known from other kinds of un-prefixed cognates such as the V2 (second element of a nuclear-SVC, Section 4.6.1) kas 'out' (258).

(257) Ni-vilamb tinin ru-mwakas. NI-girl DEF 3du-get.out

'The two girls got out,' [07073.069 07073.wav 294.033 299.852]

$\begin{array}{ll}\text { (258) I-lip-kas } & \text { na-qaymes. } \\ \text { 3SG.R-take-get.out } & \text { NV-knife }\end{array}$

'He took out the knife,' [07089.169 07089.wav 785.336 790.008]

Some are known from reduplication patterns. Nahavaq reduplication occurs to the left of the base (prefixing). *ma-prefixed words often show reduplicative patterns where the reduplication is prefixed closer to the verbal root than the *ma-prefix: mendep 'overripe' > mendepndep 'DUP.overripe', membiqis 'turn in one's sleep' > membimbiqis 'DUP.turn in one's sleep'.

Interestingly, some $* m a$ - prefixed verbs show two different reduplication patterns with different meanings, and different positions. Monosyllabic reduplication can be prefixed to the root closer than the *ma- prefix. In the case of $(259 \mathrm{~b})$, this means that the object is torn in many places, i.e. tattered. However, $\mathrm{C} i$ - reduplication can occur to the left of the *ma-prefix. In the case of (259c), this gives a 'characteristic' interpretation. The two reduplicative prefixes can also co-occur on either side of the *ma- prefix, with both meanings combined as in (259d). Other *ma-prefixed verbs that are known to behave in this way include mambwit 'bent' and mandur 'have hole'. 
(259) a. I-ma-ndas.

3SG.R-MV-torn

'It is torn.' [s0804.11]

b. I-ma-ndas-ndas.

3SG.R-MV-DUP-torn

'It is tattered.' [s0804.11]

c. I-mi-ma-ndas.

3SG.R-DUP-MV-torn

'It always tears/tears easily.' [s0804.11]

d. I-mi-ma-ndas-ndas.

3SG.R-DUP-MV-DUP-torn

'It always tatters/tatters easily.' [s0804.11]

\subsubsection{Adjectives}

Adjectives are a subset of stative verbs that can directly modify nouns without the subject/mood prefixes that verbs usually have. Qasen 'green' in (260a) is an example of this direct attributive construction, which is described in more detail in Section 3.4.8. Such constructions are relatively rare compared to constructions such as (260b) which use the adjective (or any other verb) with a subject/mood prefix inside a relative clause (Section 3.4.7).

$$
\begin{aligned}
& \begin{array}{lll}
\text { (260)a. I-toq len no-qond } & \text { qasen. } \\
\text { 3SG.R-be in NV-basket green }
\end{array} \\
& \begin{array}{llll}
\text { b. I-toq } & \text { len no-qond } & \text { t-i-qasen. } \\
\text { 3SG.R-be in NV-basket } & \text { REL-3SG.R-green }
\end{array} \\
& \text { 'It is in the green bag.' [08NB1.051] }
\end{aligned}
$$

Through elicitations, I have found 87 stative verbs describing attributes which can directly modify nouns as in (260a). These are listed in Appendix 3. It is not the case that all stative verbs describing attributes can be used in this manner. Some that cannot include mbahal 'poor', gotsul 'lazy', het 'bad', hew 'humid', pon 'constipated', kon 'burnt', meh 'cooked', remw 'skinny', and sol 'salty'.

\subsubsection{Quantifiers}

Quantifiers are a subset of stative verbs that may occur as predicates as in (261)-(263), or as nominal modifiers as in (264)-(266). The class of quantifiers includes the numerals 1-19 (see Section 4.1.6.1) (261)-(262), lamb 'many' (264), ris 'few', and vih 'how many' (263). In addition mbow 'large' can be used as a quantifier as in (265)(266). 3SG.R-how OBL NI-eye-3SG-sun 3SG.R-NEG-ten NEG NI-plus

$\frac{i-r u}{3 \text { SG }}$ len newutregyen?

3SG.R-two in day

'A day has twelve hours, hasn't it?' [JON.11:09] 
(262) Mbetep i-lagavul. A-gcilew. breadfruit 3SG.R-ten 2PL-lookfor

'There are ten breadfruit. Look for them!' [07044.020 07044.wav 51.109 52.952]

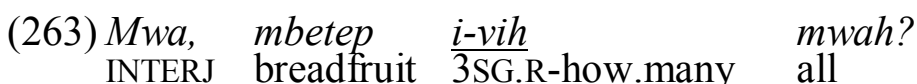

'Hey, how many breadfruit were there all together?' [07044.016 07044.wav 37.750 40.906]

(264) [Provet ka-lamb] en [Kig ka-lamb] re-rirog wut prophet 3SG.IRR-many and king 3SG.IRR-many 3PL-like COMPL $\begin{array}{llllll}\text { re-les } & \text { na-taq } & \text { yigc qar } & \text { ti-nigcim } & \text { a-les } & \text { qin. } \\ \text { 3PL-see NV-thing } & \text { PROX PL } & \text { REL-2PL } & \text { 2PL-See } & \text { 3SG }\end{array}$

'Many prophets and many kings wanted to see these things that you have seen.' [LUK.10:24]

(265) I-min [ne-wey $\quad i-m b w o w]$.

3SG.R-drink NV-water 3SG.R-much

'He drank a lot of water.' [07NB1.021] $\begin{array}{cllllll}\text { (266) En } & \text { [ni-morot } & \text { i-mbwow }] & \text { ro-log } & \text { hur } & \text { na-hal } & \text { tinin. } \\ \text { and } & \text { NI-man } & \text { 3SG.R-many } & \text { 3PL-go } & \text { along } & \text { NV-road } & \text { DEF }\end{array}$

'A many men walk along this road.' [MAT.07:13]

While quantifiers usually occur with third person singular subject marking regardless of the person or number of the subject (see section 4.2.2.3 for realis and irrealis mood marking on quantifiers), they can also occur with non-singular third person subject prefixes as in (267) and (268), which are variants on (263) and (264) above.

(267) Mbetep re-vih $\begin{aligned} & \text { mwah?' } \\ & \text { breadfruit }\end{aligned}$ 3PL-how.many all
'How many breadfruit were there all together?' [s0801.31]

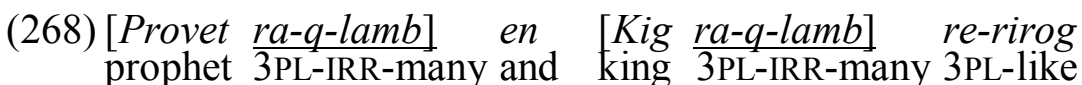
'Many prophets and many kings wanted ...' [s0801.31]

\subsubsection{Numerals}

(For ordinal numerals, see Section 3.1.3.3. For iterative numerals, see Section 5.6.4). Nahavaq has a base-twenty number system with sub-bases of five and ten. Numbers 6-9 resemble numbers 1-4, with the addition of a sow-prefix. Nine shows a mutation in the base from ves 'four' to sow-vey. Note that in counting, number 1-5 use a 3SG.R prefix $i$-, while on 6-10 it is optional. This difference may be related to the number of syllables and Nahavaq's tendency to avoid monosyllabic content words (Section 2.8.2). 


\section{Table 64: Numbers 1-10}

$\begin{array}{lll}i \text {-siq } & \text { 'one' } & (i \text {-)sow-siq 'six' } \\ i \text {-ru } & \text { 'two' } & (i \text {-)sow-ru 'seven' } \\ i \text {-tul } & \text { 'three' } & (i \text {-)sow-tul 'eight' } \\ i \text {-ves } & \text { 'four' } & (i \text {-)sow-vey 'nine' } \\ i \text {-lim } & \text { 'five' } & (i-) \text { lagavul 'ten' }\end{array}$

To some extent, native Nahavaq numerals are being replaced with Bislama numerals. For most adult speakers, numbers 1-10 are usually produced with native Nahavaq words. Numbers above ten are usually produced with Bislama numerals as in (269). I observed young children using Bislama terms for numbers above five, but it is unknown whether this is a pattern that will continue as they grow older, or whether it is a temporary effect of early schooling.
(269) I-gcur 3SG.R-make $\quad$ norig en Gcigcaplew
$\begin{array}{lll}\text { twenti-tri } & \text { inet Mbuwar nayntin. } \\ \text { twenty-three then } & \text { gull nineteen }\end{array}$
'It means that now Team Spider has twenty-three (points) and Team Gull nineteen.' [07069.076 07069.wav 265.219 269.828]

Numbers 11-19 are constructed using lagavul 'ten' + (ni-)ndumwen, and the numbers $1-9 .{ }^{89}(\mathrm{Ni}-)$ ndumwen has a function of addition but no use elsewhere in the language. Twenty has a unique lexical item, ni-morlalaq. ${ }^{90}$ It can additionally be followed by $i$ siq to denote that there is one set of 20 .

\section{Table 65: Numbers 11-20}

\begin{tabular}{|c|c|}
\hline 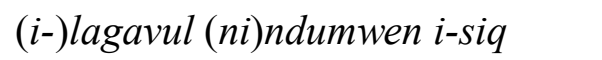 & ' 1 \\
\hline (i-)lagavul (ni)ndumwen i-ru & ' $12{ }^{\prime}$ \\
\hline (i-)lagavul (ni)ndumwen i-tul & \\
\hline (i-)lagavul (ni)ndumv & \\
\hline (i-)lagavul (ni)ndumwen i-lim & ' 1 \\
\hline (i-)lagavul (ni)ndumwen i-sow-siq & \\
\hline agavul (ni)ndumwen i-sow-ru & ‘ \\
\hline agavul (ni)ndumwen i-sow-tul & \\
\hline & \\
\hline norlalac & \\
\hline
\end{tabular}

\footnotetext{
${ }^{89}$ (ni-)ndumwen has apparent cognates in Unua rromen (Pearce, p.c.), Nāti nentumön (Crowley 1998b), Nese rrom (Crowley 2006c), Lolovoli domwagi (Hyslop 2001), Araki comana (François 2002), V'ənen Taut dëman 'seven' (Fox 1979), Avava ndruman (Crowley 2006a), Tape dëmon (Crowley 2006d), Naman daman (Crowley 2006b), and Neve'ei nendremwen (Musgrave 2007). In all of these languages these words are used in a similar way to Nahavaq for constructing numbers 11-19. The Avava and Neve'ei terms are also the terms for 'his body' in those languages. This is not the case now for Nahavaq, where the word for 'his body' is nembe- $n$. Mewun also has cognate form, dumane, but it is used with a '5+' function like Nahavaq sow- (Leina Isno, p.c.).

${ }^{90}$ On the surface, ni-morlalaq seems to be composed of mor 'person' and lalaq 'quiet/still'. The reference to person makes sense, as 20 is the total number of digits (fingers and toes) on the human body.
} 
Numbers 21-39 are composed by combining ni-morlalaq $i$-siq ' $20 \times 1$ ' with the names for 1-19, using noqorond as the addition function. ${ }^{91}$

Table 66: Numbers 21-40

ni-morlalaq $i$-siq no-qorond $i$-siq

ni-morlalaq $i$-siq no-qorond $i$-ru

$(20 \times 1)+1=21$

ni-morlalaq i-siq no-qorond $i$-tul

$(20 \times 1)+2=22$

$(20 \times 1)+3=23$

$n i$-morlalaq $i$-siq no-qorond $i$-ves

$(20 \times 1)+4=24$

ni-morlalaq $i$-siq no-qorond $i$-lim

$(20 \times 1)+5=25$

ni-morlalaq $i$-siq no-qorond $i$-sow-siq

$(20 \times 1)+5+1=26$

ni-morlalaq $i$-siq no-qorond $i$-sow-ru

$(20 \times 1)+5+2=27$

ni-morlalaq $i$-siq no-qorond $i$-sow-tul

$(20 \times 1)+5+3=28$

ni-morlalaq i-siq no-qorond i-sow-vey

$(20 \times 1)+5+4=29$

ni-morlalaq i-siq no-qorond i-lagavul

$(20 \times 1)+10=30$

ni-morlalaq i-siq no-qorond i-lagavul (ni)ndumwen $i$-siq

ni-morlalaq i-siq no-qorond i-lagavul (ni)ndumwen i-ru

$(20 \times 1)+10+1=31$

$(20 \times 1)+10+2=32$

ni-morlalaq i-siq no-qorond i-lagavul (ni)ndumwen i-tul

$(20 \times 1)+10+3=33$

ni-morlalaq $i$-siq no-qorond i-lagavul (ni)ndumwen i-ves

$(20 \times 1)+10+4=34$

ni-morlalaq i-siq no-qorond i-lagavul (ni)ndumwen i-lim

$(20 \times 1)+10+5=35$

ni-morlalaq $i$-siq no-qorond i-lagavul (ni)ndumwen i-sow-siq

ni-morlalaq i-siq no-qorond i-lagavul (ni)ndumwen i-sow-ru

ni-morlalaq i-siq no-qorond i-lagavul (ni)ndumwen i-sow-tul

ni-morlalaq i-siq no-qorond i-lagavul (ni)ndumwen i-sow-vey

$(20 \times 1)+10+5+1=36$

$(20 \times 1)+10+5+2=37$

$(20 \times 1)+10+5+3=38$

ni-morlalaq i-ru

$(20 \times 1)+10+5+9=39$

$(20 \times 2)=40$

Beyond 40, the pattern continues but with the multiplier increasing.

Table 67: Numerals 50-200 by tens

ni-morlalaq iru no-qorond ilagavul

ni-morlalaq i-tul

ni-morlalaq i-tul no-qorond i-lagavul

ni-morlalaq $i$-ves

ni-morlalaq i-ves no-qorond i-lagavul

ni-morlalaq i-lim

ni-morlalaq i-lim no-qorond i-lagavul

ni-morlalaq $i$-sow-siq

ni-morlalaq i-sow-siq no-qorond i-lagavul

ni-morlalaq i-sow-ru

ni-morlalaq i-sow-ru no-qorond i-lagavul

ni-morlalaq $i$-sow-tul

ni-morlalaq i-sow-tul no-qorond i-lagavul

ni-morlalaq $i$-sow-vey

ni-morlalaq i-sow-vey no-qorond i-lagavul

ni-morlalaq i-lagavul

$$
\begin{aligned}
& '(20 \times 2)+10=50, \\
& '(20 \times 3)=60, \\
& '(20 \times 3)+10=70, \\
& '(20 \times 4)=80, \\
& '(20 \times 4)+10=90, \\
& '(20 \times 5)=100 ' \\
& '(20 \times 5)+10=110, \\
& '(20 \times(5+1))=120, \\
& '(20 \times(5+1))+10=130, \\
& '(20 \times(5+2))=140 \\
& '(20 \times(5+2))+10=150, \\
& '(20 \times(5+3))=160 \\
& '(20 \times(5+3))+10=170, \\
& '(20 \times(5+4))=180 \\
& '(20 \times(5+4))+10=190, \\
& '(20 \times 10)=200
\end{aligned}
$$

Beyond 200, I was not able to find definite answers on how numbers were formed. Massing Nambuas's translations yielded (270), which would have a literal translation

\footnotetext{
${ }^{91}$ No-qorond does not occur elsewhere in the language, and the most closely-related languages to Nahavaq which have so far been described all use base-10 systems which don't use separate additive terms for 21-39 from those used in making number 11-19.
} 
like ' 100 three times' for 300 (base-10-style), and he also produced (271), which has 400 represented as '200 twice' (base-20/10-style). However, he also used the expected base-20 representation for ' 276 ' in (272). It is likely that in (270) and (271) he was creating a more decimal-like system. One reason for this could be the potential bracketing confusion between 300 and 205 expressed in base-20 (273). I suspect that this is the reason for the two different words with an addition function: no-qorond and (ni-)ndumwen. The former is only used to separate the 20's units from the 1's units. And the distinction may have been very important in distinguishing (273) meaning ' 205 ' from (274) meaning ' 300 '. The expected base-20 representation for ' 400 ' would be either ni-morlalaq ni-morlalaq ' $20 \times 20$ ' as I heard in some elicitations, or a unique word for '400' just as many base-10 systems use a unique word for ' 100 '.

(270) ni-morlalaq i-lim i-vaq-tul vatu NI-twenty 3SG.R-five 3SG.R-ITERATIVE-three vatu(curency)

'three hundred coins' [JON.12:05]

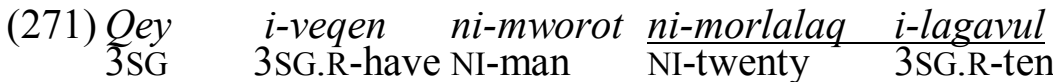

i-vaq-ru.

3SG.R-ITERATIVE-two

'He had four hundred men.' [ACT 5:36]

(272) ni-morlalaq i-lagavul ni-ndumwen i-tul no-qoron NI-twenty 3SG.R-ten NI-plus 3SG.R-three NV-plus

i-lagavul ni-ndumwen i-sow-siq

3SG.R-ten NI-plus 3SG.R-5+-one

' $(20 \times(10+3)+10+5+1=276$ ' [ACT.27:37]

(273)(?)ni-morlalaq i-lagavul ni-ndumwen i-lim NI-twenty 3SG.R-ten NI-plus 3SG.R-five

' $20 \times(10+5)=300$ ' or ' $(20 \times 10)+5=205$ '

(274)(?)ni-morlalaq i-lagavul no-qoron i-lim NI-twenty 3SG.R-ten NI-plus 3SG.R-five

$' 20 \times(10+5)=300$ '

The numerals 1-10 function as quantifiers as discussed in Section 4.1.6. In contrast, morlalaq 'twenty' is a noun. As can be seen in the previous examples, (270)-(274), morlalaq takes the optional ni- nominal prefix (Section 3.3.1.2). As shown in (275), a quantity of twenty items is expressed as 'a twenty of items' using the associative marker nin (Section 3.2.2.4) while the multiplier quantifier lim 'five' occurs after the associative construction.

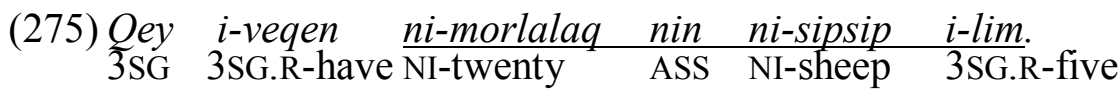

'He had a hundred sheep (He has five 20-units of sheep).' [LUK.15:04] 


\subsection{7. 'Be' verb roots}

There are two verbs which mean 'exist', 'be located', or 'stay'. These are toq and $k o h$, both of which are glossed simply as 'be'. Toq 'be' is used exclusively for singular subjects, while koh 'be' is used in equivalent constructions for plural subjects. Example (276) demonstrates the use of both 'be' verbs.

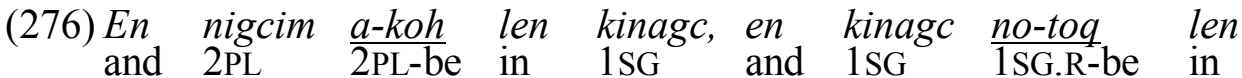
nigcim. 2PL

'Be in me, and I will be in you.' [JON.15:04]

Examples (277)-(280) show toq 'be' with a range of singular subjects and both realis and irrealis mood.

(277) Ni-marlam tinin i-vwer 'ni-vinmarlam, u-toq tey lum?' NI-old.man DEF 3SG.R-say NI-old.woman 2SG.R-be FOC home 'The old man said, “Old woman, are you home?”“ [07074.062 07074.wav 271.871 277.221]

(278) I-vwer, 'Awaq, inug ku-to-toq.' En i-vwer, 'Mwamwah 3SG.R-say no 2SG 2SG.IRR-DUP-be and 3SG.R-say mother ti-nugc i-toq ambeh?' POSS-you 3SG.R-be where

'He said, "No. You stay." And he said, "Where is your mother?"، [07082.073 07082.wav 285.586 288.601]

(279) En i-vwer, 'Aley,gco-toq-sar tey eyig. A-log.' and 3SG.R-say okay 1SG.IRR-be-remain FOC PROX 2PL-go

'And she said, "Okay, I will just stay here. You guys go."” [MAHR.044 MAHR01.wav $423.107428 .256]$

(280) Na-hapw-hapw-yen tuwan ko-toq ut tuwan, aley war 1SG.R-DUP-dance-NOM INDEF 3SG.IRR-be place INDEF then 3DU ru-vey.

3DU.R-go

'If there was going to be a dance some place, then they would go.' [07010.018 07010.wav 44.88049 .568 ]

Examples (281)-(287) show koh used with a range of non-singular subjects and with both realis and irrealis moods.

(281) $M$ Mu-koh luqur amwoq ti-nuqumem. 1EX.DU-be with mother POSS-1IN.DU

‘We lived with our mother.' [07117.014 07117.wav 91.956 94.269]

(282) Kamem mwah tey ti-i-lam mi-koh eraqay. 1EX.PL all FOC REL-3SG.R-many 1EX.PL-be up

'We were all inland.' [07086.036 07086.wav 151.177 155.177] 
(283) Awaq, i-leh gcen nuqun ndutey ndu-q-koh eyig. no 3SG.R-good for 1IN.DU both 1INC.DU-IRR-be PROX

'No it is better if we both stay here.' [KO01.034 KO01.wav 98.523 100.914]

(284) No-roqvun, i-leh gcen wut nigcind ndo-q-koh-sar NV-lord 3SG.R-good because that 1IN.PL 1IN.PL-IRR-be-remain tey eyigc.

FOC PROX

'Lord, how good it is that we are here!' [MAT.17:04]

(285) Wa-q-koh taq, kinagnigco-toq humwan. 2DU-IRR-be behind 1SG 1SG.IRR-be before

'Stay behind, and I will sit in front.' [07073.061 07073.wav 261.654 265.358]

(286)Mor tuwan war qin mwomwoq ti-qey ru-koh. man INDEF du with woman POSS-3SG 3DU.R-be

'There was a man and his wife,' [07009.003 07009.wav 7.135 12.025]

(287) Ne-revuh tinin [t-ro-koh lum] qet re-her ka-kas ehun. NV-gun DEF REL-3PL-be home PART 3PL-take DUP-out away

'The guns that were in the houses were taken out and taken.' [07086.040 07086.wav $168.162171 .318]$

Koh 'be' may also occur with 3SG subject marking when the subject is a mass noun (288), a general category (289)-(290), or a group of items (291).

(288) Ut t-i-metemet yig ko-koh sam ra-n ni-vara-n morot. place 3SG.R-black PROX 3SG.IRR-be beware on-3SG NI-arm-3SG man qet ke-rehey ko-noq yig. then 3SG.IRR-scrape 3SG.IRR-like PROX

'So that the black stuff doesn't get on one's hands, they scrape it like this.' [07113.017 07113.wav 101.965 106.496]

(289) A-roghur tey morot i-vih len ne-hew? 2PL-know FOC man 3SG.R-how.many 3SG.R-be in NV-garden 'Do you guys know how many people were in the garden?' [07048.1107 07048.wav 3385.601 3387.681]

(290) Ni-maqap i-lam $\quad$ i-koh $\quad r a-n$. NI-sore 3SG.R-many 3 SSG.R-be on-3SG

'There are a lot of sores on it,' [07021.010 07021.wav 38.983 40.812]

(291) Ne-reqey t-inugc $\quad$-koh eyig. NV-leaf POSS-2SG 3SG.R-be PROX

'Your leaves are here.' [07048.0396 07048.wav 727.395 728.855]

\subsubsection{Nouns as verbal heads}

Nouns can function as verbal heads either without any derivational morphology as in (292a), or with the copular prefix vi-/p- (Section 4.4.3) as in (292b). However, neither of these constructions occurs frequently in the corpus because concepts of 'be a 
NOUN' are more commonly expressed through non-verbal clauses (Section 5.1.1.2) as in $(292 \mathrm{c})$.

$$
\begin{aligned}
\text { (292) a. John i-dokita. } \\
\text { John 3SG.R-doctor } \\
\text { b. John i-p-dokita. } \\
\text { John 3SG.R-COP-doctor } \\
\text { c. John ni-dokita tuwan. } \\
\text { John NI-doctor INDEF } \\
\text { 'John is a doctor.' [08NB1.093] }
\end{aligned}
$$

\subsubsection{Object incorporation}

Nahavaq has a productive pattern of object incorporation. In (293), men 'bird' is an incorporated object. Unlike non-incorporated objects such as in (294), incorporated objects occur directly after the verb root before any verbal modifiers. Also, monosyllabic nominal roots such as men 'bird' in (294) are usually prefixed with $n \mathrm{~V}$ (Section 3.3.1.1). When acting as incorporated objects, they are never prefixed. Verbs with incorporated objects are always reduplicated (see Table 68 for some examples).

$$
\begin{aligned}
& \text { (293) Wa-s-vene-ven-men } \\
& \text { 2DU.R-NEG-DUP-shoot-bird alwar veq mbey siley. } \\
& \text { 'You mustn't go bird hunting so far away!' [07011.011 07011.wav } 31.728 \text { 34.197] }
\end{aligned}
$$

$$
\begin{aligned}
& \text { (294) I-vene-ven ndap } \\
& \text { 3SG.R-DUP-shoot plenty }
\end{aligned}
$$

'He went hunting for birds in the bush.' [07082.015 07082.wav 65.013 69.942]

Semantically, the incorporated objects have general reference and the verb phrase refers to an activity. Table 68 lists further examples of object incorporation.

Table 68: Examples of object incorporation

\begin{tabular}{llll}
\hline Verb & Noun & Object incorporation & Meaning \\
\hline tuq 'knock' & ni-gey 'nut' & tuq-tuq-gey & 'nut cracking' \\
tuq 'knock' & ne-vet 'stone' & tuq-tuq-vet & 'stone knocking' \\
ven 'shoot' & ne-men 'bird' & vene-ven-men & 'bird hunting' \\
ven 'shoot' & (ni-)mahal 'fish' & vene-ven-mahal & 'fish shooting' \\
ndig 'follow' & ne-tes 'sea' & ndig-ndig-tes & 'following the sea' \\
mbwil 'hit' & (ni-)morot 'man' & mbwil-mbwil-morot & 'fighting' \\
\hline
\end{tabular}

\subsection{Subject $/$ mood prefix}

The person and number of a verb's subject as well as realis or irrealis mood are obligatorily marked with a prefix on an independent verb. The forms of the prefixes are discussed in Section 4.2.1, and the various functions of the mood distinction are discussed in Section 4.2.2. Note that while these subject agreement prefixes are obligatory, subject noun phrases are optional. When a subject noun phrase is present, it occurs to the left of the verb phrase as in (295). However, it is quite common for a verb phrase to occur without any overt noun phrase subject as in (296), but the person and number of the subject is indicated by the subject agreement prefix. 
$\begin{array}{lll}\text { (295) } \frac{\text { Kinag }}{1 \mathrm{SG}} & \text { ne-sisiq } & \text { ni-momoq. } \\ \text { 1SG.R-lack } & \text { NI-woman }\end{array}$

'I haven't got a wife.' [JS01.038 JS01.wav 208.604 215.464]

(296) Ne-les ni-mbunog tuwan eyag.

1SG.R-see NI-child INDEF DIST

'I saw a boy over there.' [JS01.048 JS01.wav 263.632 269.584]

\subsubsection{Person/mood prefixes}

Verbs are prefixed with an element that agrees with the subject of the verb and specifies the mood as being either realis or irrealis. ${ }^{92}$ For singular subjects, the realis and irrealis mood are expressed along with person and number in a portmanteau prefix. The prefixes in Table 69 and Table 70 below which contain an ' $e$ ' vowel undergo vowel harmony as discussed in Section 2.4.2.2.

Table 69: Singular subject/mood prefixes

\begin{tabular}{lll}
\hline & Realis & Irrealis \\
\hline First person singular & $n e-$ & $(n i) g c e-$ \\
Second person singular & $u-$ & $k u-$ \\
Third person singular & $i-$ & $k e-$ \\
\hline
\end{tabular}

Note that the irrealis forms bear a similarity to the realis forms, but with a velar element appearing at the start. The first person singular irrealis prefix has two forms, gce- and nigce-. The /ni/ portion of nigce- resembles the nominal prefix $n i$ - in form and optionality, but not in function because verbs prefixed with nigce- do not function as nouns. The longer form, nigce- is used more frequently in the bible translations, and therefore may be a feature of a formal register.

Non-singular subjects are marked with the prefixes in Table 70.

Table 70: Non-singular subject prefixes

\begin{tabular}{lll}
\hline & DU & PL \\
\hline First person exclusive & $m u-\sim m u r-$ & $m i-$ \\
First person inclusive & $n d u-\sim n d u r-$ & $n d e-$ \\
Second person & $w a-\sim$ war- & $a-$ \\
Third person & $r u-\sim u r-$ & $r e-$ \\
\hline
\end{tabular}

Note that for each person, the dual and plural forms share a common element: $/ \mathrm{m} /$ for first person exclusive, $/{ }^{n} \mathrm{~d} /$ for first person inclusive, $/ \mathrm{r} /$ for third person, and in the case of second person, they share a lack a of strong consonant and they share the vowel quality /a/. Also note that with the exception of second person, the first consonant in non-singular suffixes aligns with the final consonant in the corresponding independent pronoun.

\footnotetext{
${ }^{92}$ Note that there are a couple of exceptions. Quantifiers (Section 4.1.6) occur most often with a 3SG prefix rather than one that agrees with the subject. And 3PL subjects may occur with a $3 \mathrm{SG}$ prefix in some instances with the verb koh 'be' (Section 4.1.7).
} 
Table 71: Comparison of non-singular pronouns and subject prefixes.

\section{Independent pronoun Subject prefix}

\begin{tabular}{|c|c|c|}
\hline \multirow{2}{*}{\multicolumn{2}{|c|}{$\begin{array}{l}\text { First person exclusive dual }(\mathrm{nuqu}) \mathrm{mwem} \\
\text { First person exclusive plural } \mathrm{kamem}\end{array}$}} & $\underline{m} u(r)-$ \\
\hline & & $\underline{m i-}$ \\
\hline First person inclusive & $\operatorname{nuqun(d)}$ & $\underline{n d} u(r)-$ \\
\hline First person inclusive & $\operatorname{nigcin}(d)$ & $\underline{n d e-}$ \\
\hline Second person dual & nuqum & $w a(r)-$ \\
\hline Second person plural & nigcim & $a$ \\
\hline Third person dual & (ru)war & $\underline{r} u(r)-$ \\
\hline Third person plural & qar & $\underline{r e}-$ \\
\hline
\end{tabular}

Note also that all dual forms have a $/ \mathrm{u} /$-like element and an optional $/ \mathrm{r} /$. These sounds bear a resemblance to $r u$ 'two' which is a likely origin of the dual forms. The variants of dual prefixes ending in $/ \mathrm{r} /$ are now archaic. Only a few older speakers still produce them. Based on their prevalence in Deacon's (1934) transcriptions, it is likely that they were much more common 80 years ago.

For verbs with singular subject, the subject prefix also specifies the mood of the verb phrase as realis or irrealis (Table 69 above). For non-singular subjects, irrealis mood is marked with a glottal stop $q$ - after the subject prefix as in (297). However, younger speakers no longer use this morpheme, probably due to phonological reasons (Section 2.7.3). As a result, these younger speakers no longer make a grammatical mood distinction for verbs with non-singular subjects.

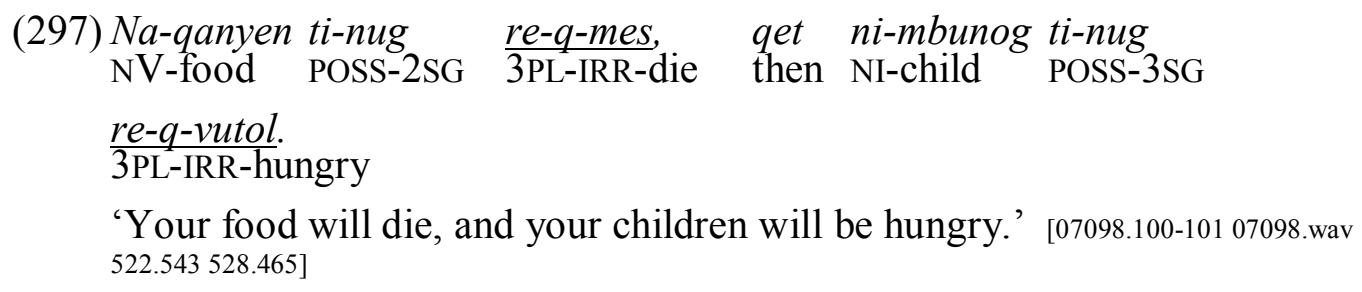

\subsubsection{Functions of realis and irrealis mood}

Every verb with a singular subject in Nahavaq must be specified as either realis or irrealis. For non-singular subjects in modern Nahavaq the realis/irrealis distinction is non-existent for younger speakers and even for older speakers who use the $q$-irrealis marker, it is difficult to know whether they do so consistently because of the nonsalience of the glottal stop in this position. Therefore, in the following discussion about the usage of realis and irrealis, I will limit examples to verbs with singular subjects (and therefore unambiguous mood marking).

\subsubsection{Realis}

Realis mood marking is used for events or states which are real. To qualify as real, events or states must be set in the past (298) or the present (299). ${ }^{93}$

\footnotetext{
${ }^{93}$ Fictional narratives can also be encoded mainly in realis mood. Even though the events are not real in the actual world, they are real within the story. And events which are not within that fictional reality are encoded with irrealis mood.
} 
(298) I-rirog ni-vilam tuwan qet ni-vilam nin i-toq Milip. 3SG.R-like NI-girl INDEF then NI-girl DEM 3SG.R-be milip

'He fancied a certain girl, but the girl lived in Milip.' [07064.006 07064.wav 39.056 46.681]

(299)Aley, qorigen qet ne-yipyep gcen gce-teqes kas okay now ID PART 1SG.R-ready for 1SG.IRR-pull out

na-qayew la-qambw en.

$\mathrm{NV}$-pudding in-fire ID

'Okay, now I am ready to take the pudding out of the fire.' [07093.001 07093.wav $3.1966 .805]$

Realis is also used in conjunction with negated verbs when a state or event actually did not occur.

$\begin{array}{llll}\text { (300) } \frac{I-s-k a m}{3 \text { SG.R-NEG-hold }} & \text { veq } & \text { no-qon } & \text { sut. } \\ \text { NEG } & \text { NV-basket NONS }\end{array}$

'He wasn't carrying a basket.' [07063.046 07063.wav 224.329 228.001]

$\begin{array}{llll}\text { (301) I-toq-sar } & \text { li-yumw. } & \text { Ne-s-lip } & \text { veq. } \\ \text { 3SG.R-be-remain LOC-house } & \text { 1SG.R-NEG-take } & \text { NEG }\end{array}$

'It's still in the house. I didn't bring it.' [07112.140 07112.wav 841.187 843.546]

\subsubsection{Irrealis}

Irrealis mood marking is used for a range of functions, but they all have a common characteristic of being not actual or not specific.

\subsection{Future}

One function of irrealis mood marking is for future events or states (302)-(305).

(302) Usut ndoh, gco-log gce-gcilew gin.

Some.time PERF 1SG.IRR-go 1SG.IRR-look.for 3SG

'Some time I'll go and look for it.' [07117.128-129 07117.wav 477.474 481.321]

$\begin{array}{llll}\text { (303) Qet } & \text { gce-s-vwer } & \text { veq } & \text { migce-n inug. } \\ \text { but } & \text { ISG.IRR-NEG-say NEG to-3SG 2SG }\end{array}$

'But I won't tell you.' [07098.098 07098.wav 515.201 517.309]

(304)Ku-vagas mwin mbwutaqaygcen taq yig ke-lip inug. 2SG.IRR-talk first loud for thing PROX 3SG.IRR-take 2SG

'You should speak up so that this thing will record you.' [07117.505 07117.wav $1518.5471520 .500]$

(305) Mor t-i-ru qor t-i-tul tinin ni-vagas-yen ti-qar Man REL-3SG.R-two or REL-3SG.R-three DEF NI-speak-NOM POSS-3PL

ke-veqen ni-paras-yen.

3SG.IRR-have NI-strong-NOM

'Two or three people, their message will have strength.' [MAT.18:16]

Irrealis marking is also used for states or events that are set in the past relative to the time of utterance, but in the future relative to other reference events. This kind of 
past-future temporal setting receives irrealis mood marking regardless of whether or not the event or state actually took place. In the case of (306), the climbing did eventually take place, but in the case of (307) the old man did not live on, and in the case of (308), none of the divers was bitten by a shark.

$\begin{array}{lll}\text { (306) I-yal-yal gcot gcen } & \text { ko-toghaq mbe-yumw en. } \\ \text { 3SG.R-DUP-sing } & \text { last.time for } & \text { 3SG.IRR-climb to-house ID }\end{array}$

'He sang for the last time before he would climb up to his house.' [07063.348 07063.wav 1165.288 1168.616]

(307) Nde-vwer tey ni-marlam yig ke-mewur, qet i-mes en. 1IN.PL-say FOC NI-old.man PROX 3SG.IRR-live but 3SG.R-die ID

'We thought he would live, but he has died.' [тв03.204 TB03.wav 1133.055 1142.383]

(308) Qet a-yipyip a-s-mataq veq konoq ka-qas nigcim sut. but 2PL-dive 2PL-NEG-fear NEG if 3SG.IRR-bite 2PL NONSP

'But when you were diving, weren't you scared that it (the shark) would bite one of you?' [07117.087 07117.wav 351.341 353.825]

\subsection{Imperative}

Imperatives, which are described in Section 5.2.3 use irrealis mood.

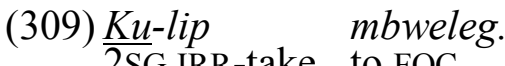

2SG.IRR-take to.FOC

'Bring it here.' [TB01.106 TB01.wav 396.650 398.025]

\subsection{Hypothetical}

In hypothetical conditionals, both clauses usually have irrealis mood marking (310). However, in (311) and (312) the clause describing a consequence has realis mood. It is not clear whether these conditionals are semantically different from (310).

Example (313) shows a counterfactual conditional using irrealis mood marking on both clauses.

(310) Na-qay yig konoq mworot ke-terey qin talay qet talay $\mathrm{NV}$-wood PROX if man 3SG.IRR-cut INSTRaxe PART axe

ko-topw ndal vwovwoh ra-n.

3SG.IRR-jump back necessary on-3SG

'If you cut it with an axe, your axe will bounce back.' [07124.007 07124.wav 17.562 20.031]

(311) Konoq ke-tip ra-n ni-ruquh, qet $i$-s-pwaras veq. if 3SG.IRR-grow on-3SG NI-hill PART 3SG.R-NEG-strongNEG

'If it grows on a hilltop, it isn't strong.' [07124.004 07124.wav 10.250 12.640]

(312)Konoq mi ko-toq sombwo-n, na-qay yig i-pwaras. if FOCUS 3SG.IRR-be alone-3SG NV-wood PROX 3 SG.R-strong 'If it grows alone, the tree is strong.' [07124.006 07124.wav 15.328 17.562] 
(313) Konoq wut inugcku-toq tey eyigc, qet if that 2SG 2SG.IRR-be FOC PROX then $\begin{array}{llll}n i-v-m a r-h a l a-n-y e n & \text { ti-kinagc } & \text { ke-s-mes } & \text { veq. } \\ \text { NI-be-man-brother-3SG-NOM } & \text { POSS-1SG } & \text { 3SG.IRR-NEG-die NEG }\end{array}$ 'If you had been here, my brother would not have died!' [JON.11:32]

\subsection{Repetition: non-specific event}

While the previously discussed functions of irrealis mood marking relate to non-actual events, in the case of repetition, irrealis mood is used on verbs that represent events that actually happened. However, the reference is to the general trend rather than to a specific instance of the event. Example (314) shows a repeated event within a narrative. The first clause uses realis mood like the bulk of a narration and establishes that the girl threw things. The subsequent clauses describe a repeated sequence (going, taking, throwing) and use irrealis mood marking. This function of irrealis mood is common in narrative texts.

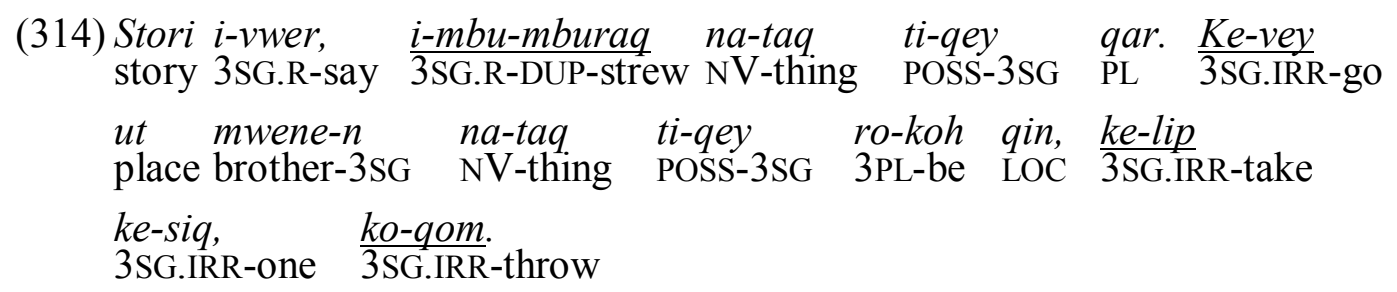

'The story says she went and threw all his things. She would go to the place where all her brother's things were, and she would take one and throw it.' [07064.218-220 07064.wav 756.029 766.935]

\subsubsection{Mood with quantifiers}

Quantifiers (section 4.1.6) can occur with either realis or irrealis mood marking. Noun phrases that occur as core arguments of realis-marked verbs occur with realis marking, and noun phrases that occur as core arguments of irrealis-marked verbs occur with irrealis marking. ${ }^{94}$ For example in (315) $i$-siq '3SG.R-one' modifies the subject of the verb toq 'be'. In (316) $i$-siq '3SG.R-one' stands alone as the direct object of sur 'send'. Example (317) shows ke-siq '3SG.IRR-one' modifying the subject of an irrealis-marked verb and also in the direct object position of another irrealis-marked verb.

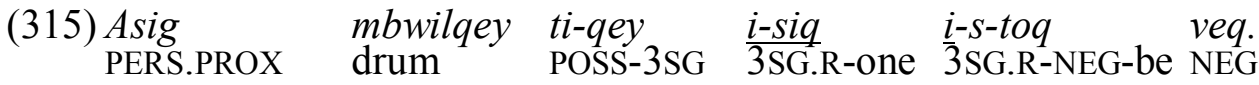

'One of his drums is missing.' [07064.214 07064.wav 739.669 743.013]

$\begin{array}{llll}\text { (316) } \frac{I}{\text {-sur }} \text { ndal lis } & \text { i-siq, } & \text { i-vwer, } & \text { "Ku-haq." } \\ \text { 3SG.R-send back again } & \text { 3SG.R-one } & \text { 3SG.R-say } & \text { 2SG.IRR-climb }\end{array}$

'She sent another one, she said, "Climb!"” [EC02.105 EC02.wav 436.418 439.120]

\footnotetext{
94 This includes verbs with irrealis meaning regardless of whether the speaker actually marks mood on the verb itself (in the case of non-singular subjects). See Example (318).
} 
(317) Mbetep ke-siq ke-sep, ke-qep-pet ke-siq. breadfruit 3SG.IRR-one 3SG.IRR-fall 3SG.IRR-bend-break 3SG.IRR-one 'When one breadfruit falls, he will break off one [leaf].' [07044.009-010 07044.wav 23.494 25.915]

For speakers who do not make the realis/irrealis distinction on verbs with nonsingular subjects, the irrealis/realis distinction can still be marked on quantifiers of arguments of verbs, giving the entire proposition a realis or irrealis meaning (318). ${ }^{95}$
$\begin{array}{llll}\text { (318) a. } \begin{array}{l}\text { Morot } \\ \text { man }\end{array} & \text { i-ves } & \text { tinin ro-log lembunqay. } \\ \text { 3SG.R-four DEF 3PL-go bush }\end{array}$
'The four men walked in the bush.' [08NB1.020]
b. Morot ke-ves tinin ro-log lembunqay.
man 3SG.IRR-four DEF 3PL-go bush

'The four men will walk in the bush.' [08NB1.020]

When quantifiers are used predicatively, they follow the patterns for realis/irrealis mood marking outlined in Sections 4.2.2.1-4.2.2.2. For example, in (319) the realis number predicate is actual and set in the past. In (320) the number predicate is a hope for the future, and in (321), quantifiers are used as predicates in both parts of a conditional proposition.

(319) Ambwat ro-koh Ewur. Ambwat i-lim. Oar i-lim. Ambwat 3PL-live Toman Ambwat 3SG.R-five 3PL $3 \mathrm{SG} . \mathrm{R}-$ five 'The Ambwat brothers lived on Toman Island. There were five Ambwats. There were five of them.' [07076.001-002 07076.wav 6.057 12.652]

$\begin{array}{lllll}\text { (320) En gcen wut qar mwah } & \text { ke-siq } & \text { ohoy tey. } \\ \text { And for that 3PL all } & \text { 3SG.IRR-one } & \text { simply } & \text { FOC }\end{array}$ '(I pray) that they may all be one.' [JON.17:21]

(321) Nigcind konoq ke-ves qet nu-quli-n na-taq nin 1IN.PL if 3SG.IRR-four COMPL NV-kernel-3SG NV-thing DEM ke-ves tey. 3SG.IRR-four FOC

'If there are four of us, there will be four kernels inside.' [07019.026-027 07019.wav 72.176 75.879]

\subsection{Negation of $V P$}

Verbal negation in Nahavaq is disjunctive. Disjunctive verbal negation is very common in Malakula languages and other parts of Vanuatu. In Nahavaq, the first negative element, $s^{-}$, occurs after the subject/mood prefix and before the verb root and whatever may be prefixed closer to the root (Sections 4.4-4.5). This first negative element occurs exclusively on verbs. The second negative element, veq, can negate a range of phrase types (see section 5.3.1), but when it negates a verb phrase it comes in a position between the verb and any direct object. There are a range of modifiers

\footnotetext{
${ }^{95}$ Pearce (p.c.) found that in the context of irrealis verb phrases in Unua, irrealis-marked quantifiers were used with non-specific noun phrases while realis-marked quantifiers were used with specific noun phrases. This does not appear to be the case in Nahavaq, as (318) shows both realis and irrealis marking on a specific noun phrase.
} 
which can occur between the verb root and this second negative element (Section 4.7) and also between the second negative element and any direct objects (Section 4.8). Example (322) is a typical example of verbal negation:

$\begin{array}{lllll}\text { (322) } \text { A-s-qan-qan veq } & \text { ne-hew } & \text { ko-noq } & \text { nin. } \\ \text { 2PL-NEG-DUP-eat NEG NV-garden } & \text { 3SG.IRR-like } & \text { DEM }\end{array}$

'Don't eat the gardens like that (like we did)' [тв03.173 TB03.wav 944.220 946.236]

When the base to which negative prefix, $s$-, is attached begins with /s/, the resulting cluster degeminates and is phonologically indistinguishable from the same base without a negative prefix.

$$
\begin{array}{ll}
\text { (323) } I \text {-s-sep } & \text { veq } \\
\text { 3SG.R-NEG-fall } & \text { NEG } \\
\text { 'It didn't fall.' } &
\end{array}
$$

Occasionally, speakers produce negative verb phrases without the $s$ - prefix, but there is no difference in propositional meaning or scope. Omission of the $s$ - prefix is common in child language, but even some older speakers omit it occasionally. All four examples from the spoken corpus were produced by one 65 year-old woman, who produces the $s$ - prefix most of the time, but not always. Example (324) is taken from her speech. ${ }^{96}$

$\begin{array}{rll}\text { (324) Qet } & \text { na-qayew } & \text { ke-luwe-lu } \\ \text { then NV-pudding } & \text { 3SG.IRR-DUP-vomit } & \text { veq. } \\ \text { NEG }\end{array}$

'Then the pudding won't overflow.' [07112.050 07112.wav 300.331 302.893]

\subsection{Third order prefixes}

Following the first negative element but before the verb root and any reduplicative prefixes on it, there is a position where four prefixes can occur: nde- 'next', min'recent', $v i-/ p$ - 'go/copular', and vwa- 'come'. 97 I follow Fox (1979) and Crowley (2006b) in naming this group after its position within the verb complex - third order prefixes. Nde- 'next' and min- 'recent' can be seen as counterparts which cannot cooccur. They occur before $v i$ - 'go' and $v w a$ - 'come' which also cannot co-occur with each other.

\subsubsection{Nde- 'next'}

For discussion of vowel harmony in the nde- 'next' prefix, see Section 2.4.2.2. Nde'next' marks an event as happening directly after another event (325)-(326) or in the immediate future (327).

\footnotetext{
${ }^{96}$ Other speakers recognise this as not 'proper Nahavaq', but they also say that it happens sometimes in everyday speech.

${ }^{97}$ For description of the allomorphy of $v i-/ p$ - 'go', see Section 2.4.3.4.
} 

(325) Waq-vweleg nde-q-sug mbwonombwon mwah en 2DU.IRR-come 1PL.INCL-IRR-roast together all and wa-q-nda-tal. 2DU-IRR-next-return

'The two of you come and we will all roast together. And then the two of you can go back.' [DK01.015-016 DK01.wav 217.605 226.137]

(326) Ni-vuti-n nigcim etig, tinin t-i-mbwar ndoh le-veti-n NI-child-3SG 2PL ID.PROX DEF REL-3SG.R-blind PERF LOC-belly-3SG hine-n ra-nda-vah qin? mother-3SG3PL-next-give.birth 3SG

'Is this your son here, who was blind before he was born?' [JON.09:19]

(327) En gce-nde-gcilew ndal lis ni-hine-n gcen gce-rar and 1SG.IRR-next-look.for back again NI-mother-3SGfor 1SG.IRR-make qin qet gce-tumbwatin gce-hip ni-vuti-n en. 3SG then 1SG.IRR-start 1SG.IRR-carve NI-child-3SG ID

'And soon I will look for the mother too and make it, but first I will start carving the "child of wood".' [07095.011 07095.wav 43.678 49.866]

\subsection{2. $M i n$ - 'recent'}

The counterpart of nde- 'next' is min- 'recent'. Min- 'recent' can indicate the temporal relationship between two events. In example (328), two events happen simultaneously, but the one marked with min- started first. In examples (329) and (330), the event marked with min- is interrupted by another event. In (331) the event marked by min- comes to its natural end, which is the other event.

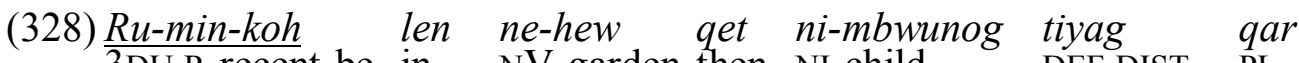
3DU.R-recent-be in NV-garden then NI-child DEF.DIST PL ra-tal. 3PL-return

'They were in the garden when the boys returned (to a different location).' [MR01.071 MR01.wav 390.451 395.357 MR01.wav 385.263 390.451]

(329) En qar re-min-rar ni-leq-yen nin, qet Noa qar ro-log and 3PL 3PL-recent-make NI-marry-NOM DEM then Noah3PL 3PL-go mbe-len na-wagc. to-in $\quad \mathrm{NV}$-canoe

'They were having weddings up till the time Noah and the others went into the boat.' [МАT.24:38]

(330) Wut qey i-min-tutamwat tey gcor qar, en Atuwa qey when 3SG 3SG.R-recent-pray FOC cover3PL and god 3SG i-lip qey mbe-len na-mwap. 3SG.R-take 3SG to-in NV-sky

'As he was praying over them, God took him into heaven.' [LUK.24:51] 
(331) Mahal ke-min-popom, tey ke-mes. fish 3SG.IRR-recent-twitch FOC 3SG.IRR-die

'And the fish would just twitch until it died.' [07063.054 07063.wav 243.346 245.252]

Min 'before' can place an event in the recent past relative to the time of utterance:

$\begin{array}{llll}\text { (332) Tinin na-taq } & \text { ti-Ambwat en } & \text { qey } & \text { i-min-vweleg. } \\ \text { DEF NV-thing } & \text { POSS-foreignerID } & \text { 3SG } & \text { 3SG.R-recent-come }\end{array}$

'They are white man's things, and they've only come recently,' [07095.006 07095.wav 23.91128 .490$]$

(333) Kinagc mu-min-leq tey qin ni-momoq ti-kinagc etin, qet $1 \mathrm{SG}$ 1EX.PL- recent-marry FOC with NI-woman POSS-1SG ID and

kinagc nigce-s-vwel veq.

$1 \mathrm{SG}$ 1SG.IRR-NEG-come NEG

'I have just got married, so I won't come.' [LUK.14:20]

(334) Momoq ti-kinag i-toq li-yumw, veti-n i-min-rar woman POSS-1SG 3SG.R-be LOC-house belly-3SG 3SG.R-recent-sore

en.

ID

'My wife is in the house and her belly has just started to be sore (before childbirth),", [07009.052 07009.wav 140.546 143.499]

\subsubsection{Vi- 'go/inchoative/copular'}

(For a description of $v i-/ p$ - allomorphy, see Section 2.4.3.4. For a discussion of the deictic reference of $v i-/ p$-, see section 6.4.3.)

There are a number of functions that are served by a $v i$-/p-prefix, and it is difficult to determine whether they may include more than one homophonous morpheme.

Figure 28: The spectrum of meanings for vi-/p-

$\begin{gathered}\frac{\text { Meaning 1: }}{\text { spatial }}(\text { go VERB }) \\ \text { (become VERB) }\end{gathered}>\begin{gathered}\frac{\text { Meaning 2: }}{\text { inchoative }} \\ (\text { become NOUN) }\end{gathered}>\begin{gathered}\frac{\text { Meaning 3: }}{\text { inchoative }} \\ (\text { be NOular } \\ \text { (be NOUN) }\end{gathered}$

There is semantic similarity between each of the meanings in Figure 28. However there are two likely but different origins of these prefixes. The first is that $v i$ - 'go' and its counterpart $v w a$ - 'come' derived from the independent verbs vey 'go' and vwel( eg) 'come' (or previous forms of those). And the other meanings arose as extensions of 'go'. Another possible origin of vi- (at least the fourth meaning) is from a Proto Central Vanuatu copula *vei (Ross Clark, cited in Lynch 2006: 3). If this was the origin of the copular $v i-/ p$-, it has evolved into a different structure than those used in some other Malakula languages. In Avava (335), the complement of the copula occurs in the same position that a direct object would, i.e. after the second negative element. However, in Nahavaq, the complement of the copula occurs before the second negative element (336). ${ }^{98}$

\footnotetext{
${ }^{98}$ This is the position that incorporated objects occur as described in Section 4.1.9.
} 
(335) Avava (Crowley 2006a: 108)

Bwisian sa-vi-mu mitile.

story 3SG.R.NEG-COP-NEG tale

'This story is not (just) a tale.'

\section{(336) Nahavaq}

$\begin{array}{lll}\text { hine- } n & k e-s-v i-m w a t & v e q \\ \text { mother-3SG } & \text { 3SG.IRR-NEG-COP-snake } & \text { NEG }\end{array}$

'Their mother can't be a snake."‘ [LS01.066 LS01.wav 258.098 264.364]

One explanation for the evolution of Nahavaq's $v i-/ p$ - prefixes is that a spatial prefix, $v i$ - and a copular verb $v i$ arose from different sources, and then because of phonological and semantic similarities (through extension of meaning of one or the other), they were reinterpreted as a single morpheme that occurs as a verbal prefix with a range of meanings. I will treat these prefixes as though they are a single morpheme with four meanings, which I will gloss 'go', 'change', 'become', and 'COP'.

(337)-(338) provide examples of the spatial 'go' meaning of $v i-/ p$-.

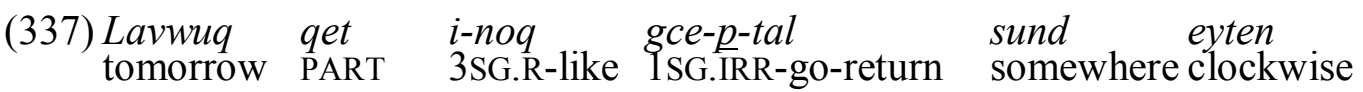 mwindey eyag.
further DIST

'Tomorrow I might go back to some place even further around (to the North) there.' [07063.196 07063.wav 662.111 666.111]

$\begin{array}{ll}\text { (338) I-p-toq } & \text { eyag. } \\ \text { 3SG.R-go-be } & \text { DIST }\end{array}$

'He went and stayed over there.' 99

In the following examples, $v i$ - is glossed as 'become' and indicates a change in state.

(339) Vindasin tag i-vi-mambuqmbuq ohoy tey. sow DEF.DIST 3SG.R-change-slack simply FOC

'The sow became slack.' [LS01.139 LS01.wav 605.915 611.071]

(340) Taq-tag i-p-meh. thing- DEF.DIST 3SG.R-change-cooked

'The thing became cooked,' [07065.216 07065.wav 809.940 813.440]

This change-of-state function is also represented in examples (341) when $v i$ - is prefixed to a temporal noun and in (342) where it is prefixed to a canonical noun. ${ }^{100}$

\footnotetext{
${ }^{99}$ Example (338) comes from notes from an unrecorded discussion based on [07065.103 07065.wav 435.805 438.649].

${ }^{100}$ Similar constructions are found in Nāti with a meaning of 'become a NOUN.' (Crowley 1998b: 129)
} 
(341)En wut ne-wut i-vi-larap, en ni-morot qar and when NV-place 3SG.R-become-afternoon and NI-man PL re-her ni-morot t-re-meheq qar en t-re-veqen ni-temes 3PL-take NI-man REL-3PL-sick PL and REL-3PL-have NI-devil len qar:

'When evening came, people brought to Jesus many who had demons in them.' [MAT.08:16]

(342) Kamem mi-s-rirog veq wut mor nin qey ke-p-kig 1EX.PL 1EX.PL-NEG-like NEG that man DEM 3SG 3SG.IRR-be-king ra-n kamem. on-3SG 1EX.PL

'We don't want this man to become our king.' [LUK.19:14]

The final semantic function of $v i-/ p$ - is copular and does not involve any change.

(343) I-toq embu-n ne-ten, amwoq i-p-mwat. 3SG.R-be under-3SG NV-ground mother 3SG.R-be-snake

'She is under the ground. Our mother is a snake.' [LS01.065 LS01.wav 253.379 258.098]

$\begin{array}{cllll}\text { (344) Morot } & \text { t-i-leh } & \text { ti-nog } & \text { yig qin } & \text { hine-n } \\ \text { man } & \text { REL-3SG.R-good } & \text { REL-3SG.R-like } & \text { PROX 3SG } & \text { mother-3SG }\end{array}$ ke-s-vi-mwat veq. 3SG.IRR-NEG-COP-snakeNEG

'With people as good as this, their mother can't be a snake.' [LS01.066 LS01.wav 258.098 264.364]

(345) Ruwar ru-p-morot nin ni-selselgcar-yen. 3DU 3DU-COP-man ASS NI-fishing-NOM

'They were fishermen.' [MRK.01:16]

The nominal prefixes, $n i$ - and $n \mathrm{~V}$ - cannot co-occur with $v i$-. This is one of the few contexts in which the otherwise obligatory $n \mathrm{~V}$ - prefix (see section 3.3.1.1) is not present, as can be seen in (343) and (344).

\subsubsection{Vwa- 'come'}

$V w a$ - is glossed as 'come' and indicates that an event includes movement toward a deictic centre (see Section 6.4.3 for more detail on the semantics).

(346)No-top mbe-len ne-wey en na-vwa-tagcaw eyig. 1SG.R-run to-in $\mathrm{NV}$-water and 1SG.R-come-arrive PROX

'I fell into the water and ended up in here.' [EC01.018 EC01.wav 83.989 87.739]

(347) Ra-tal mbweleg ra-vwa-metur. 3PL-return to.FOC 3PL-come-sleep

'They went back and went to sleep.' [тв03.069 тв03.wav 344.756 350.850] 

(348) Ku-s-mataq veq. Ku-vweleg ku-vwa-vwer ni-marhaw nin 2SG.IRR-NEG-fear NEG 2SG.IRR-come 2SG.IRR-come-say NI-price ASS ni-vilam ti-nuqun. NI-girl POSS-1IN.DU

'Don't be scared. Come say the price of our daughters.' [LS01.095 LS01.wav 394.996 400.151]

(349) Konoq ke-s-viyag veq qet mbwunog sut ke-vweleg if 3SG.IRR-NEG-light NEG then child NONSP 3SG.IRR-come

ka-vwa-traem.

3SG.IRR-come-try

'If it won't light, some boy could come try.' [07095.048 07095.wav 299.153 302.278]
(350) Amwoq, ku-top mbweleg, ku-vwa-les taq tuwan mother 2SG.IRR-run to.FOC 2SG.IRR-come-see thing INDEF
etig.
ID.PROX

'Mother, come here and look at this.' [EC01.045 EC01.wav 214.994 220.775]

\subsection{Reduplication}

There are two reduplicative verbal prefixes in Nahavaq, which I will refer to as monosyllabic reduplication and $\mathrm{C} i$ - reduplication. The former occurs only on monosyllabic verb roots and its form is not predictable (it may be $\mathrm{CVC}-\mathrm{CV}-, \mathrm{CVCe}$-, or CVC $a-)$ (351). ${ }^{101}$ The latter occurs mainly on polysyllabic bases, and its form is predictable (a copy of the first consonant of the base, plus /i/) (352). ${ }^{102}$ The allomorphy of both reduplicative prefixes is discussed in Section 2.4.6.

\section{(351) I- $\log$ - $\log$ lembunqay.} 3SG.R-DUP-go bush

'He was walking in the bush.' [EC02.004 EC02.wav 14.502 19.377]

(352) $R u$-vi-vagas mbey. 3DU.R-DUP-talk to

'The two of them talked on.' [KA02.015 KA02.wav 83.122 92.618]

These two morphemes overlap in function in most cases, but in a few situations (Sections 4.5.2 and 4.1.4), they can have different functions.

\subsubsection{The functions of verbal reduplication}

The reduplicative prefixes have a range of functions. The functions described in Sections 4.5.1.1-4.5.1.5 are productive and all related to pluractionality. Sections 4.5.1.7-4.5.1.9 describe the unproductive elements of verbal reduplication. Whenever possible, examples of both of the reduplicative morphemes are given for each function.

\footnotetext{
${ }^{101}$ Appendix 2 lists 298 cases of reduplication of monosyllabic verb roots.

${ }^{102}$ Note that there is variation between speakers in the vowel in $\mathrm{C} i$-reduplication. For conservative speakers, it is $/ \mathrm{i} /$. For some speakers it is $/ \mathrm{i} /$ or $/ \mathrm{u} /$, and for many younger speakers, it is a copy of the first $\mathrm{V}$ of the base (see Section 2.4.6.1).
} 


\subsubsection{Multiple objects}

Reduplicative verbal prefixes can denote multiple objects of the verb, as can be seen in the pair of elicited sentences in (353) and (354). Another example of this function is given in (355).

(353) Qey $\quad$ i-tus $\quad$ leta.

'He is writing a letter.' [06NB6.01]

$\begin{array}{ll}\text { Qey } & \text { i-tu-tus } \\ \text { 3SG } & \text { 3SG.R-DUP-write letter } \\ \text { 'He is writing letters' }\end{array}$

(355)a. Gce-(vul-)vul nuqum.

1SG.IRR-DUP-buy 2DU

'I will buy both of you.' [s0801.22], [LS01.060 LS01.wav 234.824 238.746]

b. *Gce-vul-vul inug.

1SG.IRR-DUP-buy 2SG [s0801.22]

\subsubsection{Multiple subject}

For some intransitive verbs, reduplication is required for non-singular subjects.

Example (356) provides parallel structures for a singular and dual subjects of $m b o w$ 'big', with the latter reduplicated. (357) shows a similar pattern for mes 'die'.

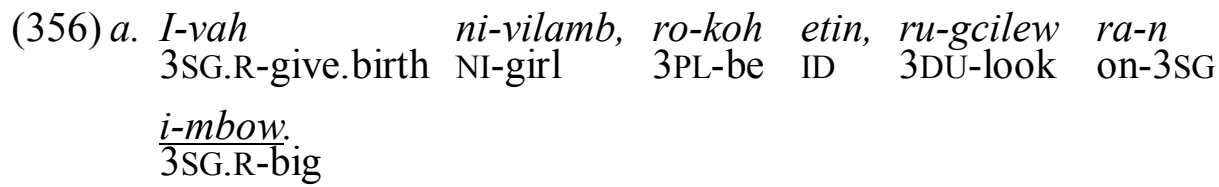

'She gave birth to a girl, and they stayed, and they looked after her until she was big,' [08009.097 08009.wav 582.963 587.400]

b. En i-s-mbarap veq i-vah ndalis ni-vilamb and 3SG.R-NEG-long NEG 3SG.R-give.birth again NI-girl i-siq. I-gcilew ra-n ni-vilamb nin war ru-mbu-mbow. 3SG.R-one 3SG.R-look on-3SG NI-girl DEM DU 3DU.R-DUP-big

'And it was not long before she gave birth to another girl. She looked after the two girls until they were big.' [08009.098-099 08009.wav 587.400 596.546]

(357) $\mathrm{Wa-mis-mes}$.

2DU.R-DUP-dead

'You two will die.' [07065.390 07065.wav 1397.437 1401.344]

\subsubsection{Duration}

Reduplication can represent a number of patterns of duration, and there is semantic overlap between the following categories. In each of the Examples (358)-(360), the reduplicated verb root describes a durative event.

$\begin{array}{cll}\text { (358) Na-havaq qet } & \text { wa-vwere-vwer? } \\ \text { NV-what } & \text { COMPL }\end{array}$

'What are you two talking about?' [07072.050 07072.wav 281.502 286.080] 
(359) Na-havaq qet i-tig-teg etin?

$\mathrm{NV}$-what COMPL 3SG.R-DUP-cry ID

'What is crying there?' [MR01.080 MR01.wav 420.466 424.075]

(360) I-ki-kaptoh hur hawah i-siq. 3SG.R-DUP-cough for hour 3SG.R-one

'He coughed for an hour.' [06NB6.07]

When an unfinished process is described, it can include reduplication. For example in (361), the writing is unfinished at the time of speaking. In (362) the circling of the fish started before the man saw them and continued afterward. In (363) vagas 'speak' describes what the speaker is doing at the time of speaking.

(361) $\frac{\text { I-tu-tus }}{3 \text { SG.R-DUP-write }}$ FOC $\quad$ gceyip.

'He is still writing it.' [06NB6.13]

(362) En i-les ne-mbug, ne-mbug ro-rop re-ndi-ndilvus and 3SG.R-see NV-mackerel NV-mackerel 3PL-run 3PL-DUP-circle naqhaw.

reef

'And he saw mackerel, and they were circling the reef.' [07083.007-009 07083.wav 37.153 43.420]

(363) Qet kinagc eg. Ne-vi-vagas mbigce-n inugc en, qet but $1 \mathrm{SG}$ ID.PROX $1 \mathrm{SG}$.R-DUP-speak to-3SG $2 \mathrm{SG}$ ID then kinagc etig.

$1 \mathrm{SG} \quad$ ID.PROX

'It is I. I am speaking to you, and it is I.' [JON.04:26]

\subsubsection{Habit or typical behaviour}

Habitual actions or typical behaviour can be marked with reduplication as in the following examples.

(364) En vene-n ti-qey .. ru-ko-koh qin ni-vilam nin i-rirog and sister-3SG POSS-3SG 3DU-DUP-be with NI-girl DEM 3SG.R-like vwovwoh qin.

'And his sister often stayed with the girl because the two of them were very good friends.' [07064.021 07064.wav 93.871 102.871]

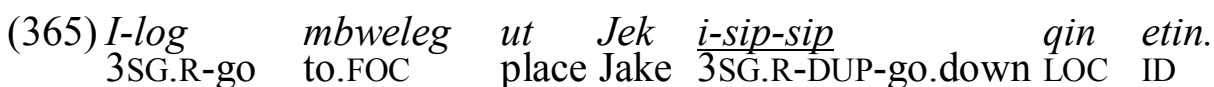
'He got to the place where Jake (typically) goes down.' [07063.058 07063.wav 249.408256.111] 
(366)En na-taq yigc qar re-vweleg-mevus ran wut Betani, en And NV-thing PROX PL 3PL-come-white on-3SG place Bethany and ra-n tispsu-n ne-wey Jordan wut Jon qey i-li-lumus on-3SG side-3SG NV-water Jordan place John 3SG 3SG.R-DUP-wash ni-morot qar qin. NI-man PL LOC

'All this happened in Bethany on the east side of the River Jordan, where John was (habitually) baptizing.' [JON.01:28]

In Examples (367)-(371) the subject of the reduplicated verb is the indefinite third person plural. The interpretation here is that these acts are typically done or typically not done in the case of the negative constructions in (367) and (368). This kind of unspecified subject is discussed in Section 6.8.1.

(367) Qet gcen qorig $\frac{r e-s-h e r-h e r}{3}$ veq lis no-qonli-n na-mbwaq. but for now 3PL-NEG-DUP-take NEG again NV-egg-3SG NV-turtle 'But now turtle eggs can’t be taken anymore.' [07117.778 07117.wav 2066.558 2070.074]

(368) Ni-mbulqun i-ru qin en, tuwan ni-mbulqun NI-kava 3SG.R-two PREP ID INDEF NI-kava

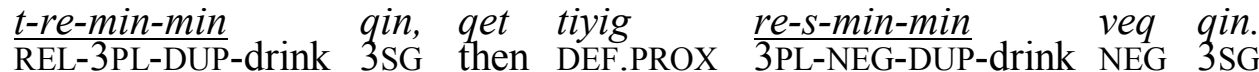
'There are two kinds of kava: one they drink, but this one they don't drink.' [07046.003-004 07046.wav 10.518 15.205]

(369) I-les ni-saranut re-vi-vutuq ne-wey qin en 3SG.R-see NI-place where 3PL-DUP-fetch NV-water LOC and i-gcilew i-les ni-mbwasar tinin ti-i-toq ra-n. 3SG.R-look 3SG.R-see NI-village DEF REL-3SG.R-be on-3SG

'She saw the place where water was fetched from and she saw the village she lived in.' [EC01.051 EC01.wav 244.778 249.653]

(370)Konoq ut mbwarmbwar, ne-vwer ndoh re-mi-milim qin if that triggerfish 1SG.R-say PERF 3PL-DUP-tired PREP mbwarmbwar. triggerfish

'But triggerfish, I thought people got sick from those.' [07117.102 07117.wav 385.918 389.011]

$\begin{array}{clllll}\text { (371) } \begin{array}{l}\text { Qet } \\ \text { but }\end{array} & \begin{array}{l}\text { klorioftasi } \\ \text { glory-of-the-sea }\end{array} & \text { qet } & \text { COMPL-vwer } & \text { re-si-salem } & \text { 2PL-say } \\ \text { 3PL-DUP-sell } & \text { 3SG }\end{array}$

'But "Glory of the Sea" shells, they say they can be sold.' [07117.746 07117.wav 1998.034 2001.925]

\subsubsection{Reduplication with numbers}

Monosyllabic number roots 1-5 can be reduplicated, and this gives a meaning of a number of people or objects grouped together. 
Table 72: Reduplicated number

\begin{tabular}{|c|c|c|}
\hline Number & $\underline{\text { Reduplicated form }}$ & Meaning of reduplicated form \\
\hline$i-s i q$ & $i$-si-siq i-siq-siq & 'singly, one-by-one, alone, separately' 103 \\
\hline$i-r u$ & $i-r u w a-r u$ & 'in groups/a group of two' \\
\hline$i$-tul & $i-t u l-t u l$ & 'in groups/a group of three' \\
\hline$i$-ves & $i$-vis-ves & 'in groups/a group of four' \\
\hline i-lim & i-lim-lim & 'in groups/a group of five' \\
\hline
\end{tabular}

There are a number of features that make reduplicated number roots more like canonical verbs than un-reduplicated number roots. Whereas non-reduplicated numbers and other quantifiers can only occur with third person singular prefixes, reduplicated number roots can occur with the whole range of verbal prefixes (372)(374). Example (373) contains a reduplicated root for 'two' as a main verb that has verb-like semantics along the lines of 'working together'. Reduplicated verb roots can also occur as the second element in simultaneous nuclear-layer SVC constructions (Section 4.6.1.3.2) as in (374).

(372) Ambwat ro-koh Ewur re-lim-lim. Ambwat 3PL-be Toman 3PL-RED-five

'The five Ambwat brothers lived together on Toman island' (TB01.003 TB01.wav 12.407 16.657)
(373) Mu-ruwa-ru hur na-taq yig, na-taq yig mworot 1DU.EXC-RED-two aboutNV-thing PROX NV-thing PROX man $i$-siq ohoy tey qet i-lesur ka-rar. 3SG.R-one simply FOC PART 3SG.R-can 3SG.IRR-make

'We are both doing this thing that a single man could make.' (07083.140 07083.wav 2125.175 2130.410)
(374) $R$-log siq-siq gcen ru-vwere-vwer migce-n 3DU-go RED-one because 3DU-RED-say to-3SG
'They went separately to ask their mothers.' (JS01.043 JS01.wav 234.932 242.792)

\subsubsection{Reduplication with object incorporation}

When an object is incorporated into a verb, the verb root is reduplicated (see section 4.1.9).

\subsubsection{Unpredictable Derivation}

While the functions of reduplication in Sections 4.5.1.1-4.5.1.6 are highly productive, some words containing reduplicated prefixes are unproductive and unpredictable. Table 73 contains reduplicated forms that appear to have been derived from unreduplicated roots, but there have a different meaning.

${ }^{103}$ Note that there is a homophone sisiq siqsiq 'to lack, not exist'. 
Table 73: Unpredictable derivation

${ }^{\dagger}$ These roots can also reduplicate with predictable meaning.

\begin{tabular}{llll}
\multicolumn{3}{c}{ In the case of qan 'eat' the predictable meaning has a different reduplicated form: qan-qan. } \\
\hline qan 'eat' & qa-qan 'have a meal' & teg ' 'cry' & tig-teg 'rust' \\
mes 'die' & mis-mes 'faint' & $k o n$ 'burnt' & kon-kon 'bitter' \\
meh 'cooked' & meh-meh 'dry' & les ${ }^{\dagger}$ 'see' & lese-les 'look after' \\
rog 'hear' & rogo-rog 'be careful' & pwal' 'bald' & pwala-pwal 'clean' \\
kan 'sharp' & kana-kan 'rocky' & & \\
\hline
\end{tabular}

\subsubsection{No difference in meaning}

Some verbal roots frequently occur with both reduplicated form and un-reduplicated form, but with no apparent difference in meaning (375)-(376). Verbal roots which fit this category include (gci-)gcilew 'look for', (vi-)viyeh 'call'

(375) Qet Yesu qey i-viyeh qar mbweleg gcen qey.

So.R-call 3PL to.FOC

'But Jesus called the children to him.' [LUK.18:16]

$\begin{array}{rlllll}\text { (376) En } & \text { Yesu } & \text { i-vi-viyeh } & \text { qar } & \text { mbweleg } & \text { gcen qey. } \\ \text { and } & \text { Jesus } & \text { 3SG.R-DUP-call } & \text { 3PL } & \text { to.FOC } & \text { to }\end{array}$

'So Jesus called them to him.' [MRK.03:23]

There is another set of verb roots for which reduplication does not make any apparent difference, but for the following words, the reduplicated form is much more common than the un-reduplicated form (which is known but very rare): (mil-)mil 'wet', (si-)seven 'open', (vi)vaqayndag 'same'.

\subsubsection{Apparent reduplication}

Some verbal roots only occur in a reduplicated form. The words in Table 74 do not have any un-reduplicated counterpart with a clearly related meaning.

Table 74: Apparent reduplication

\begin{tabular}{ll}
\hline Gloss & Apparent reduplication \\
\hline 'ready, wait' & yipyep \\
'make fire by rubbing' & verever \\
'argue' & titewul \\
'shy/ashamed' & mimaqan \\
\hline
\end{tabular}

There are a number of adjectives that are always reduplicated when occurring independently (377a-b), but when modified by an intensifier, they are not reduplicated (377c). Table 75 list adjectives of this type. Note that many of these intensifiers are specific to a single verb (Section 4.7.3.2), and that with the exception of $i$-kas mbwatmeqet 'very sweet', all of them are reduplicated. 
(377) a. I-mwulmwul.

3SG.R-round

'It is round.'

b. *I-mwul.

3SG.R-round

c. I-mwul ndindeleq.

3SG.R-round INTENS

'It is very round.'

Table 75: Reduplicated adjectives with un-reduplicated variant

Note that these forms are all given with the 3SG.R prefix, but not glossed as such.

\begin{tabular}{llll}
\hline i-mbuqmbuq & 'short' & i-mbuq mwinmwin & 'very short' \\
i-pilpil & 'hot' & i-pil haphap & 'very hot' \\
i-mamal & 'red' & i-mal ndisndis & 'very red' \\
i-metemet & 'black' & $i$-met punpun/rugrug & 'very black' \\
i-mwulmwul & 'round' & $i$-mwul ndindeleq & 'very round' \\
imeloqloq & 'soft' & $i$-meloq ndindi & 'very soft' \\
i-kaskas & 'sweet' & $i$-kas mbwatmeqet & 'very sweet' \\
\hline
\end{tabular}

\subsubsection{Double reduplication}

It is possible for a monosyllabic root to undergo reduplication twice. The first process of reduplication results in one of the allomorphs of the reduplicative prefix on monosyllabic verb root. Then for the second process of reduplication, the verb already has more that one syllable and the $\mathrm{C} i$ - reduplication occurs. This can result in forms such as those in Table 76 and Example (378).

Table 76: Double reduplication

\begin{tabular}{lll}
\hline Root & CVC- root & Ci-CVC- root \\
\hline tus 'write' & $\begin{array}{l}\text { tu-tus 'write a lot' } \\
\text { tig-teg 'cry for a long }\end{array}$ & $\begin{array}{l}\text { ti-tu-tus 'habitually write a lot' } \\
\text { ti-tig-teg 'habitually cry for long } \\
\text { periods of time.' }\end{array}$ \\
time' & $\begin{array}{l}\text { mwas 'laugh' } \\
\text { mwasa-mwas 'laughing' }\end{array}$ & $\begin{array}{l}\text { mwi-mwasa-mwas 'habitually laugh for } \\
\text { long periods of time' } \\
\text { topw 'jump' }\end{array}$ \\
\hline
\end{tabular}

(378) Qey i-ti-tu-tus leta.

3SG 3SG.R-DUP-DUP-write letter

'He used to write letters/He was a letter-writer.' [06NB6.01]

When double reduplication occurs, the reduplicand closest to the root serves one of the functions described in Sections 4.5.1.1-4.5.1.3: plurality of object or duration. The $\mathrm{C} i$ - reduplicand in these constructions always specifies habit or typical behaviour (section 4.5.1.4). A similar pattern can be seen in different patterns of reduplication on * $m a$ - prefixed verbs (Section 4.1.4).

\subsection{Serial Verb Constructions}

There are many different definitions of SVCs (serial verb constructions), and there are many different kinds of constructions which have been identified as SVCs. My discussion of SVCs in Nahavaq draws on ideas from Crowley (2002b), Aikhenvald 
and Dixon (2006), and Muysken and Veenstra (2005). The general definition of SVC that I will use requires:

1. Two verbs (or verb-like elements. See below)

2. A single predicate describing a single event

3. No signs of subordination or coordination

There are many Nahavaq constructions that could fit these criteria, including (379)(384) below. Each of these examples contains two verb roots that can occur independently, and each pair together describes a single event. None of the examples have any morphosyntactic sign of subordination or coordination between the verb roots. $^{104}$

(379) I-ndus mbarap na-taq. 3SG.R-pull long NV-thing

'He stretched the thing out.' [s0804.15]

(380) Ndo-q-topw sigcew mbe-yumw en. 1 IN.PL-IRR-fly cross to-house ID

'We will fly across to home.' [тв03.185 тв03.wav 1005.725 1011.397]

(381) $\begin{array}{ll}\text { I- } \log & \text { simbow. } \\ \text { 3SG.R-walk } & \text { kneel }\end{array}$

'He walked on his knees.' [s0804.26]

(382) I-vweleg i-her mwarlamb ti-kamem tuwan qar. 3SG.R-come 3SG.R-take old.man POSS-1EX.PL INDEF PL

'It came and took some of our old people' [07116.092 07116.wav 449.458 452.067]

(383) Ndur-vi-vagas $\quad$ i-mbarap.

1INC.DU-DUP-talk 3SG.R-long

'We have been talking for a long time.' [JS01.033 JS01.wav 178.214 187.698]

(384) Ra-qambwiq mwah ni-mbwaqay i-yar. 3PL-plant all NI-yam 3SG.R-finish

'The yams had all been planted.' [07072.026 07072.wav 158.112 164.921]

A major distinction can be made in Nahavaq between cases where a subject/mood prefix occurs only on the first verb root (379)-(381), and cases where each verb root has a subject/mood prefix (382)-(384). This difference corresponds to categories of nuclear-layer and serial-layer SVCs that are well-attested in Oceanic languages (Crowley 2002b: 42-43). Structures resembling core-layer SVCs are discussed in Section 5.6. The rest of this section deals with nuclear-layer SVCs.

\footnotetext{
${ }^{104}$ Under Muysken and Veenstra's (2005) definition of SVCs, (383) and (384) would not qualify as SVCs because the two verbs in each have formally different grammatical subjects. In each of these constructions the second verb always has a 3SG subject. Aikhenvald's (2006) definition of SVC does not require the two verbs to share a single grammatical subject, and she considers such constructions to be a specific variety of SVCs: 'event-argument' SVCs. Crowley (2002b: 41-42) uses the term 'ambient serialisation' for such constructions.
} 


\subsubsection{Nuclear-layer SVCs}

\subsubsection{Phonological words and nuclear-layer SVCs}

In writing and dictation, there is a tendency for Nahavaq speakers to treat a V1-V2 combination as a single word when the V2 is monosyllabic as in (385), but as two words if the V2 is polysyllabic as in (386) and (379)-(381) above. Nuclear-layer SVCs are transcribed along these lines in this thesis.

$$
\begin{aligned}
& \text { (385) Inet i-lip-kas } \\
& \text { then 3SG.R-take-get.out } \begin{array}{l}
\text { ni-mahal. } \\
\text { Nish }
\end{array} \\
& \text { 'And then he took off the fish,' [07063.245 07063.wav 815.572 818.040] }
\end{aligned}
$$

$$
\begin{aligned}
& \begin{array}{llll}
\text { (386) } \begin{array}{ll}
\text { Ra-gcal } \\
\text { 3PL-tong }
\end{array} & \text { ka-kas } & \text { ne-vet } & \text { en. } \\
\text { DUPet.out } & \text { NV-stone } & \text { ID }
\end{array} \\
& \text { 'They take out the stones.' [07092.004 07092.wav } 13.389 \text { 16.717] }
\end{aligned}
$$

\subsubsection{Verb status}

A major challenge to the classification of nuclear-layer SVCs in Nahavaq is the status of the verb-like elements. The construction in (387a) involves two elements, qombw 'throw' and por 'split' that both function as independent verbs (387b-c). Example (388a) is structurally and semantically parallel to (387a), but neither var 'step on' nor pet 'break' functions synchronically as an independent verb root (388b-c). Therefore, (387a) would satisfy all definitions of SVCs, but (388a), which has the same structure, would not be an SVC by most definitions, which require the verbs to be able to function independently.

$$
\begin{aligned}
& \text { (387) a. } \text { I-qombw-por } \quad \text { metu. } \\
& \text { 3SG.R-throw-split coconut } \\
& \text { 'He split the coconut by throwing it.' [s0804.20] } \\
& \text { b. I-qombw metu. } \\
& \text { 3SG.R-throw coconut } \\
& \text { 'He threw the coconut.' [s0804.22] } \\
& \text { c. I-por } \quad \text { metu } \\
& \text { 3SG.R-split coconut } \\
& \text { 'He split the coconut.' [s0804.20] }
\end{aligned}
$$

$\begin{array}{lll}\text { (388) a. I-var-pet } & \text { malaytet } & \text { nin. } \\ \text { 3SG.R-step.on-break } & \text { paving.stone } & \text { DEM }\end{array}$

'He broke the paving stone by stepping on it.' [07089.wav 555.694 559.162]
b. *I-var...
3SG.R-step.on [s0804.31]
c. ${ }^{*} I-$ pet $\ldots$
3SG.R-break [07NB4.09]
$\begin{array}{ll}\text { d. I-varavar } & n e-t u \text {. } \\ \text { 3SG.R-push.with.leg } & \text { NV-shell }\end{array}$

'He pushed the shells with his leg.' [s0804.31]

While var 'step on' and pet 'break' are not independent verb roots, their verb-like nature is apparent from related forms. In the case of var 'step.on', there is a related form with apparent reduplication, varavar 'push with leg', which can function as an 
independent verb (388d). Pet 'break' may be related to the term mepes 'breakable', for which one speaker had a variant mepet 'breakable'. Another speaker claimed that a construction I tried to make with pet as in independent verb sounded archaic. There are a number of verb-like elements that are used in SVC-like constructions that are not used synchronically as independent verbs.

Table 77 lists V1s (the first element of a nuclear-layer SVC) that do not function synchronically as independent verbs. Note that all of these forms are monosyllabic. For many of them, there are related independent verb forms, either with vestigial transitive suffixes (Section 4.1.3) or in a reduplicated form.

Table 77: Dependent V1s

\begin{tabular}{|c|c|c|c|c|c|}
\hline $\begin{array}{l}\text { Depend- } \\
\text { ent V1 }\end{array}$ & Gloss & $\begin{array}{l}\text { Indep. } \\
\text { suffixed } \\
\text { verb }\end{array}$ & Gloss & $\begin{array}{l}\text { Indep. } \\
\text { redup. } \\
\text { verb }\end{array}$ & Gloss \\
\hline tar & 'cut' & terey & 'cut' & tartar & 'cut pieces off' \\
\hline var & 'step on' & veres & 'push with leg' & varavar & 'push with leg' \\
\hline rap & 'poison' & ravwus & 'poison (v.t.)' & rirap & 'be a poisoner' \\
\hline qor & 'cut' & qoros & 'cut' & qorqor & 'cut' \\
\hline pil & 'heat' & pilis & 'heat' & pilpil & 'be hot' \\
\hline qin & 'pinch' & qinis & 'pinch' & qinqin & 'pinch' \\
\hline ven & 'shoot' & vini & 'shoot' & veneven & 'shoot' \\
\hline gcal & $\begin{array}{l}\text { 'hold with } \\
\text { tongs' }\end{array}$ & gcalas & $\begin{array}{l}\text { 'hold with } \\
\text { tongs' }\end{array}$ & gcagcal & $\begin{array}{l}\text { 'hold with } \\
\text { tongs' }\end{array}$ \\
\hline qamb & 'cover' & qambus & 'cover' & & \\
\hline mwal & 'debark' & mwalis & 'debark' & & \\
\hline $\operatorname{tin}$ & 'scorch' & tinis & 'scorch' & & \\
\hline gcar & $\begin{array}{l}\text { 'scrape } \\
\text { straight' }\end{array}$ & gcaris & $\begin{array}{l}\text { 'scrape } \\
\text { straight' }\end{array}$ & & \\
\hline teq & 'yank' & teqes & 'yank' & & \\
\hline vow & 'carry' & vowus & ‘carry' & & \\
\hline rap & 'pull’' & rivi & 'pull’' & & \\
\hline kar & 'itch' & karas & 'irritate/scratch' & & \\
\hline$v u l$ & 'rotate' & vulus & 'rotate' & & \\
\hline gcam & 'chase' & gcamwus & 'chase' & & \\
\hline kat & \multicolumn{5}{|c|}{ "touch with hands" } \\
\hline wur & \multicolumn{5}{|c|}{ 'beat with a stick' } \\
\hline gcar & \multicolumn{5}{|c|}{ 'grab' } \\
\hline taq & \multicolumn{5}{|c|}{ 'touch with fingertips' } \\
\hline
\end{tabular}

In some cases, the independent forms may function as V1s (389), while in others they may not (390).

(389) I-gcam-kas/i-gcamus-kas na-taq tuwan 3SG.R-chase-get.out/3SG.R-chase-get.out NV-thing INDEF

'He chased something out.' [08NB1.025] 
(390) I-qin-mbun/*i-qinis-mbun morot.

3SG.R-pinch-dead/3SG.R-pinch-dead man

'He pinched the man to death.' [08NB1.026]

Table 78 lists V2s (the second element of a nuclear-layer SVC) that do not function synchronically as independent verbs. For many of these, there is a related independent verb form. For some of these it is a verb with a vestigial $m \mathrm{~V}$ - prefix (Section 4.1.4). For some there seems to be a nasal mutation for the V2 form.

Table 78: Dependent V2s

\begin{tabular}{|c|c|c|c|}
\hline $\mathrm{V} 2$ & Gloss & Indep. verb & Gloss \\
\hline$\overline{m b u r}$ & 'nick' & membur & 'nicked' \\
\hline pet & 'break’ & mepesepes & 'breakable' \\
\hline koy & $\begin{array}{l}\text { 'slip but not fall } \\
\text { down' }\end{array}$ & mokoyokoy & ‘slippery’ \\
\hline piq & 'splash over edge & mepiq & ‘sway’ \\
\hline kas & 'out' & makas & 'get out' \\
\hline lur & 'come out easily' & mwalus & 'come out easily' \\
\hline ndew & 'rest' & mendew & 'stop (of weather)' \\
\hline ndin & 'stuck in' & mendin & 'stuck in' \\
\hline$n d e r$ & shake" & ndernder & shake" \\
\hline ndoghaq & "uphill"' & toghaq & "climb (hill)" \\
\hline ndur & 'through' & tur & 'pierce' \\
\hline ndoq & 'stay in place' & toq & 'be' \\
\hline gces & "grab" & & \\
\hline mbun & 'dead' & & \\
\hline kom & 'fall down' & & \\
\hline
\end{tabular}

Apart from lacking status as independent verbs, the V1 and V2 elements in Table 77 and Table 78 function just like any other V1s and V2s. Many of them are used very productively in the formation of nuclear-layer SVCs. This leaves three possible analyses to account for structures such as (388a). The first is that while (387a) may be considered an SVC, (388a) must not because it does not have two verbs. ${ }^{105}$ If we are to assume that (388a) is an SVC, then either the definition of a 'verb' has to change to accommodate the items in Table 77 and Table 78, or the definition of 'SVC' has to change to include 'verb-like elements' rather than only verbs. I will opt for the latter.

\subsubsection{Classes of nuclear-layer SVCs}

The following sections will outline some of the different kinds of events that are represented by SVCs in Nahavaq. They are arranged here in terms of the relationship between the first verbal element (V1) and the second verbal element (V2).

\footnotetext{
${ }^{105}$ To claim that $v a r$ 'step on' and pet 'break' are not verbs is slightly problematic because according to my definition of a 'verb' (something that takes a subject/mood prefix), there is some kind of verb in (388a).
} 


\subsubsection{1. $V 1$ results in $\mathrm{V} 2$}

In this category, the event represented by V1 causes the event or state represented by V2. This includes Aikhenvald's categories of cause-effect SVCs and resultative SVCs (Aikhenvald 2006: 14-20).

Structures such as (391) below have a transitive V1 and an intransitive V2, whose logical subject is the object of V1 and also the syntactic object of the SVC. Table 79 lists a few more examples of this type. Note that throughout this section, SVCs are shown on line 'a' of numbered examples, while lines ' $b$ ' and 'c' demonstrate the V1 and V2 independently. And to the right of examples, the argument structure is represented with X representing the subject of the SVC, Y representing the object of the SVC, and Z representing other arguments.

$$
\begin{aligned}
& \text { (391)a. I-ndus mbarap na-taq. } \\
& \text { 3SG.R-pull long } \mathrm{NV} \text {-thing } \\
& \text { 'He stretched the thing out.' } \\
& \text { b. I-ndus na-taq. } \\
& \text { 3SG.R-pull NV-thing } \\
& \text { 'He pulled the thing.' } \\
& \text { c. Na-tatq i-mbarap. } \\
& \mathrm{NV} \text {-thing 3SG.R-long }
\end{aligned}
$$

\begin{tabular}{|c|c|c|}
\hline V1 (v.t.) & V2 (v.i. stative) & SVC \\
\hline qin 'pinch' & pet 'break (broken)' & pin-pet 'pinch off' \\
\hline gcig 'scrap to the side' & pwalapwal 'clean' & gcig pwalapwal 'scrape clean' \\
\hline$h i$ 'rub between hands' & mevuyvuy 'crumbled' & $\begin{array}{l}\text { hi mevuyvuy 'crumble by rubbing } \\
\text { between hands' }\end{array}$ \\
\hline hip 'carve' & posopos 'flat' & hip posopos 'carve flat' \\
\hline vivih 'call' & mbonombon 'together' & $\begin{array}{l}\text { viviyeh mbonombon 'call (a group) } \\
\text { together' }\end{array}$ \\
\hline rar 'make' & meleleq 'tasteless' & rar-meleqleq 'make tasteless (food)' \\
\hline V1 (v.t.) & V2 (v.i. dynamic) & SVC \\
\hline mbwal 'light (fire)' & ndugndug 'smoke' & $\begin{array}{l}\text { mbwal ndugndug 'light a smoky } \\
\text { (fire)' }\end{array}$ \\
\hline $\begin{array}{l}\text { tar 'cut' } \\
\text { mbwil 'hit', }\end{array}$ & $\begin{array}{l}\text { man 'bleed' } \\
\text { nduwel 'swing', }\end{array}$ & $\begin{array}{l}\text { tar-man 'cut and draw blood' } \\
\text { mbwil nduwel 'hit causing it to } \\
\text { swing' }\end{array}$ \\
\hline
\end{tabular}

Table 79: X V1 Y causes Y V2

Example (392a) is semantically similar to (391a). They both describe an action that results in a change of state for a patient. However, the V2 in (392a) is transitive, having the same subject and object as the V1. 
(392) a. I-ndus-ndis $\quad$ no-vol. 3SG.R-pull-tear NV-book

'He pulled the book thereby tearing it.'

b. I-ndus no-vol. 3SG.R-pull NV-book

[X V1 Y]

'He pulled the book.'

c. I-ndis $\begin{aligned} & \text { no-vol. } \\ & \text { 3. }\end{aligned}$

[X V2 Y]

'He tore the book.'

Structures such as (393a) are semantically similar to (391a), but in this case, both V1 and V2 are intransitive and have different logical subjects. The logical subject of V2 is the object of the SVC. It could however be argued that 'thatch' is also a logical argument of V1, i.e. 'The fire smoked onto the thatch', but the V1 in its independent form cannot take an object.

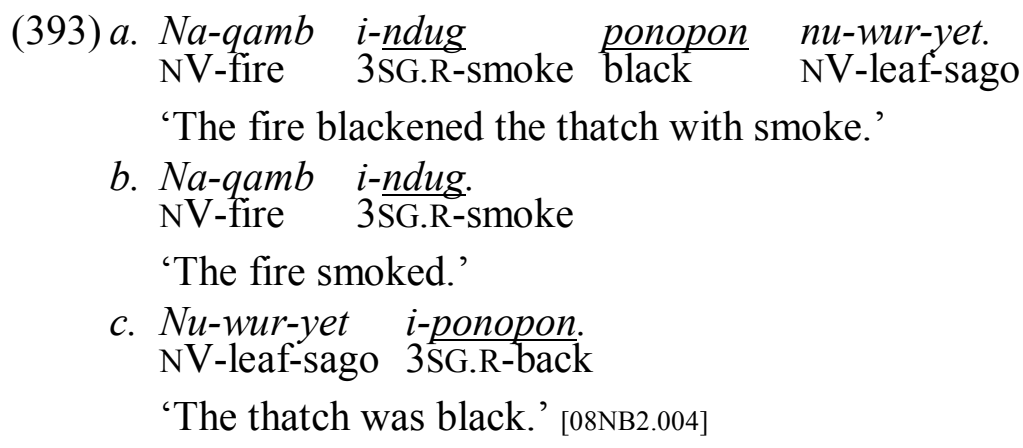

[X V1 V2 Y]

[X V1]

[Y V2]

Nuclear-layer SVCs in Nahavaq only have a single syntactic object. When the V1 and V2 involve more than two arguments, the SVC will always have the subject of V1 as its subject, but the object of the SVC is more flexible. In both (394) and (395), the object of the V1 acts as the subject of the V2. Yet in (394) the object of V1 acts as the object of the SVC, while in (395) the object of V2 acts as the object of the SVC.

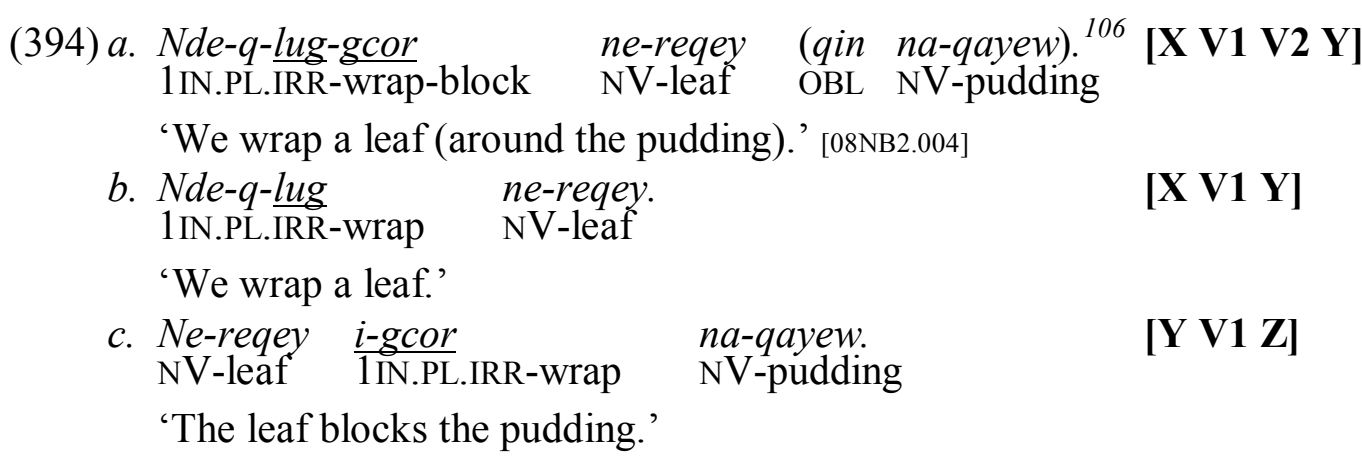

\footnotetext{
${ }^{106}$ Note that gcor 'block' can also function in a different kind of construction, as can be seen in the following sentences:

(i) I-tu gcor ni-lit qin ni-mbwuwes '(3SG.R-put block NI-fence OBL NI-pig) He fenced the pigs in.'

(ii) I-tu ni-lit gcor ni-mbwuwes '(3SG.R-put NI-fence block OBL NI-pig) He fenced the pigs in.' Because gcor 'block' is the only verb-like element that I have found occurring in the (ii) construction, I would not call (ii) an SVC and prefer to consider gcor 'block' in this construction a (marginal) preposition of verbal origin.
} 

(395)a. I-qombw soq ni-kilu (qin ne-vet). 3 SG.R-throw touch NI-dog OBL NV-stone
'He threw (a stone) at the dog (and hit it).' [08NB2.004]
$\begin{array}{ll}\text { b. I-qombw } & \text { ne-vet. } \\ \text { 3SG.R-throw } & \mathrm{NV} \text {-stone }\end{array}$
[X V1 Z]
'He threw a stone.'
$\begin{array}{lll}\text { c. Ne-vet } & i \text {-soq } & \text { ni-kilu. } \\ \text { NV-stone } & \text { 3SG.R-touch } & \text { NI-dog }\end{array}$
[Z V2 Y]
'The stone touched the dog.'

\subsection{Reduplication on cause-effect SVCs}

With the nuclear-layer SVCs that describe an event (V1) which results in another event/state (V2), the two verbal elements can be reduplicated separately with different effect. Very commonly, a reduplicated V2 indicates a plural object as in (396a). A reduplicated V1 can involve a number of other functions of reduplication as described in Section 4.5.1. In (396b), the reduplication can have a habitual or durative function. It is also possible for both V1 and V2 to be reduplicated as in (396c). ${ }^{107}$

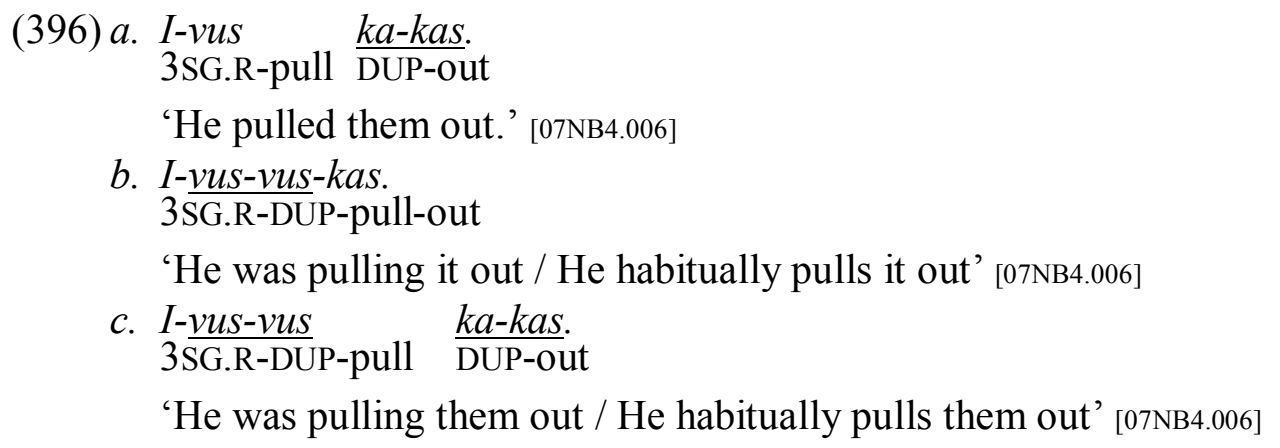

\subsection{Simultaneous events}

In this class of SVCs, two events happen simultaneously. The subject of the V1 and V2 are the same. In many cases, such as (397), V1 and V2 are both intransitive and the entire SVC is intransitive. However, if either or both of V1 and V2 are transitive as in (398), the resulting SVC is transitive. Further examples of this type of SVC are listed in Table $80 .^{108}$

$$
\begin{aligned}
& \text { (397)a. I-long } \frac{\text { simbow. }}{\text { 3SG.R-walk }} \\
& \text { 'He walked on his knees.' } \\
& \text { b. I-long. } \\
& \text { 'He walked.' } \\
& \text { c. I-simbow. } \\
& \text { 3SG.R-kneel } \\
& \text { 'He knelt.' }
\end{aligned}
$$

[ X V V1 V2]

[ X V1 V2 Y]

[ X V1 V2 Y]

\footnotetext{
${ }^{107}$ Mwotlap makes a similar distinction in the function of reduplication on V1 and V2 (François 2006: 228)

${ }^{108}$ François (2006: 233) uses the term 'concurrent serialization' to describe similar structures in Mwotlap.
} 
(398) a. I-mbwil $\frac{\text { sinkon }}{\text { 3SG.R-hit }} \quad \begin{aligned} & \text { morot. } \\ & \text { angry }\end{aligned}$

[ X V1 V2 Y]

'He hit the man in anger.'

b. I-mbwil morot.

3SG.R-hit man

[ X V1 V2 Y]

'He hit the man.'

c. I-sinkon morot.

[ X V1 V2 Y]

'He was angry at the man.'

Table 80: Simultaneous V1 and V2

\begin{tabular}{|c|c|c|}
\hline V1 & $\mathbf{V 2}$ & SVC \\
\hline ropw'run (v.i.)' & sipw'go down (v.i.)' & rop-sipw 'run down' \\
\hline log 'walk (v.i.)' & kisiq 'limp (v.i.)’ & log kisiq 'walk with limp' \\
\hline gcar 'swim (v.i.)' & $n d a-n d a n$ 'DUP-look up (v.i.)' & gcar-ndan 'swim on one's back' \\
\hline metur 'sleep (v.i.)' & mete-met 'DUP-wake up (v.i.)' & metur mete-met 'sleep lightly' \\
\hline $\log$ 'walk (v.i.)' & samw' lose the way (v.i.)' & $\log$-samw 'walk aimlessly' \\
\hline sumbw 'sit (v.i.)' & mbwit 'lean over (v.i.)' & sumbw-mbwit 'sit leaning over' \\
\hline qan 'eat (v.t.)' & mbonombon 'together (v.i.)' & $\begin{array}{l}\text { qan mbonombon'eat }(\mathrm{Y}) \\
\text { together' }\end{array}$ \\
\hline log 'walk (v.i.)' & sigesig 'hop (v.i.)' & log sigesig 'hop along' \\
\hline sumbw'sit (v.i.)' & ndil-ndilrog 'DUP-listen' & sumbw ndil-ndilrog 'sit listening' \\
\hline $\log$ 'walk (v.i.)' & siq-siq 'DUP-one (v.i.)' & log siqsiq 'go alone' \\
\hline$r a q$ 'work (v.i.)' & sinmbwug 'forget (v.t.)' & $\begin{array}{l}\text { raq sinmbwug 'work without } \\
\text { thinking (about Y) (v.t.)' }\end{array}$ \\
\hline
\end{tabular}

\subsection{Manner}

A third major type of nuclear-layer SVC in Nahavaq is where the V2 describes the manner in which the event described by V1 was performed as in (399)-(400). While in Table 80 above, many of the V2s could be seen as describing the manner in which the V1 event is performed, the V2s can be seen as having the same subject as the overall SVC as shown in (397c) and (398c). This is not the case for (399)-(400). In (400), the leh-leh 'DUP-good' cannot be seen as describing the subject (2SG, the addressee) or the object (1SG, the speaker). Instead, it is describing the quality of the holding act. Aikhenvald (2006) labels this kind of construction as event-argument SVCs.

$\begin{array}{ccllllll}\text { (399) Kinag } & \text { no-qoros } & \text { leh-leh } & \text { namwon, } & \text { en } & \text { inug } & \text { u-qoros } & \text { liley } \\ \text { 1SG } & \text { 1SG.R-cut } & \text { DUP-good } & \text { POSS.2SG } & \text { and } & \text { 2SG } & \text { 2SG.R-cut } & \text { crazy }\end{array}$ nagcon.

POSS.1SG

'I cut your (hair) well, and you cut mine crazily.' [netewmalaw.001]

$\begin{array}{lll}\text { (400) } K u \text {-vwur } \\ \text { 2SG.IRR-hold } & \frac{\text { leh-leh }}{\text { DUP-good }} \text { kinag! } \\ \text { SSG }\end{array}$

'Hold me well (tightly)!' [07048.1896 07048.wav 4789.771 4791.383] 


\subsubsection{Former V2s}

Table 81 lists a number of Post-verbal-modifers-1 (PVM1s - Section 4.7) that bear a resemblance to V2s in nuclear-layer SVCs. These PVM1s describe result and manner, as do the SVCs described in Sections 4.6.1.3.1 and 4.6.1.3.3. The also closely follow a verb root as do the V2s of nuclear-layer SVCs. However, the items in Table 81 are classed as PVM1s because they do not occur as independent verbs nor bear any resemblance to an independent verb. It is possible that they may have once been verbs that occurred frequently as V2s and have since grammaticalised into modifiers.

Table 81: PVM1s that resemble V2s

\begin{tabular}{ll}
\hline Describing result & Describing manner \\
\hline sar 'remain' & ndag 'carefully' \\
pis 'fail' & lalaq 'quietly' \\
pileh 'mess up' & mbwutaqay 'loudly' \\
& gargar 'quickly' \\
& mbot 'all over the place' \\
& kos 'correctly' \\
\hline
\end{tabular}

\subsection{Post-verbal-modifier-1}

There are a number of elements that modify a verb, which occur in a position between the verb head and the second negative element. This position was established through elicitations. Based on their position, these elements will collectively be called Post Verbal Modifiers-1 (PVM1s). They have a range of semantic functions, but Table 82 arranges PVM1s into semantic groups.

Table 82: Semantic grouping of PVM1s

\begin{tabular}{|c|c|c|}
\hline Result (Section 4.7.1) & Manner (Section 4.7.2) & Degree (Section 4.7.3) \\
\hline sar 'remain' & lalaq 'quietly' & liglig 'a lot' \\
\hline pis 'unfinished' & gargar 'quickly' & taqtaq 'a little' \\
\hline pileh 'mess up' & ndag 'carefully' & (intensifiers) \\
\hline & mbot 'all over' & \\
\hline & mbwutaqay 'loudly' & \\
\hline & kos 'correctly/directly' & \\
\hline Aspect (Section 4.7.4) & Mood (Section 4.7.5) & \\
\hline mwah 'all' & gcow'emphatic' & \\
\hline tartar 'always' & mbwaq 'sorry' & \\
\hline gcot 'for the last time' & ohoy 'simply' & \\
\hline malas 'yet' & mwin 'first' & \\
\hline mbaqsiq 'ahead' & mbeq 'maybe' & \\
\hline & sam 'beware' & \\
\hline
\end{tabular}

While ordering within this group of modifiers is complex and in some cases flexible, there is a tendency for PVM1s to occur in the order shown in Figure 29.

Figure 29: Ordering of PVM1s

\begin{tabular}{l|l|l|l|l|}
\hline VERB \\
ROOT
\end{tabular} result $\mid$ manner $\mid$ degree $\mid$ aspect $\mid \operatorname{mood}$ NEG




\subsubsection{Result PVM1}

\subsubsection{Sar 'remain'}

Sar 'remain' is frequently used with verbs of location (401)-(402), or posture (403), to indicate that the subject remains in place. In (404), where sar is used with the verb $t u$ 'put', it indicates that the object remains after being put somewhere. In (405) sar seems to have an aspectual extension, indicating that an action continues.

$\begin{array}{lllll}\text { (401) } \begin{array}{l}\text { I-toq } \\ \text { 3SG.R-be }\end{array} & \text { sar } & \text { liyumw } & \text { ne-s-lip } & \text { veq. } \\ \text { remain } & \text { LOC.house } & \text { 1SG.R-NEG-take } & \text { NEG }\end{array}$

'It's still in the house. I didn't bring it.' [07112.140]

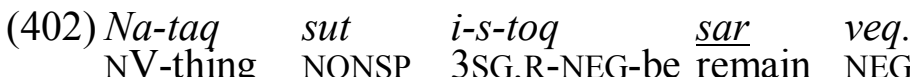

'Nothing was left.' [TB03.081 415.764 420.014]

$\begin{array}{llll}\text { (403) Ni-wundi-n } & \text { mbwaqay } & i \text {-sum } & \text { sar. } \\ \text { NI-portion-3SG } & \text { yam } & \text { 3SG.R-sit } & \text { remain }\end{array}$

'A potion of the yams were still sitting there.' [07072.024 07072.wav 140.958 147.567]

(404) U-vowus Lily qor qet $u$-tu
2SG.R-carryLily today then

'When you took Lily today, where did you leave her?' [07117.278 07117.wav 933.594 938.484]

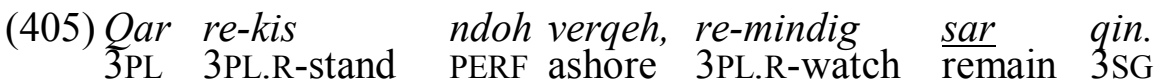

'They stood on the shore and kept watching him' [DK01.067]

\subsubsection{Pis 'fail'}

Pis 'fail' indicates that despite effort, an intended result did not occur.

(406) Kinag ne-viyal pis mwamwah ti-kinag.

1SG 1SG.R-search.for fail mother POSS-1SG

'I couldn't find my mother.' [MR01.085 MR01.wav 437.591 444.013]

$\begin{array}{lll}\text { (407) Na-qayew } & \text { i-meh } & \text { pis. } \\ \text { NV-pudding } & \text { 3SG.R-cook } & \text { fail }\end{array}$

'The pudding is not cooking (despite my efforts).' [07112.102 07112.wav 553.801 555.957]

(408) Ndu-vaqur pis ndu-gcur ke-viyag en. 1IN.DU-try fail 1IN.DU-make 3SG.IRR-light (fire) ID

'We try but fail to make it ignite.' [07095.053 07095.wav 348.155 350.811]

\subsubsection{Pileh 'mess up'}

Pileh 'mess up' is used to indicate that the result of an action is different from the intended result. Its usage is interesting. In the corpus, it was not used in any verb phrases with direct objects. Instead, $r a-n$ 'on-3SG' is used to mark arguments which would otherwise be the direct object. Also notable is the fact that it occurs with 
dependent verbs such as var 'step' (410) and ven 'shoot' (411) which normally occur as the first verb in a nuclear-layer SVC (Section 4.6.1.2). While pileh constructions are not considered SVCs under the definition used in Section 4.6.1.3, there is certainly a similarity to some constructions which are considered SVCs.

(409) Konoq ut ku-vwur pileh ra-n qet ke-nden kos if COMPL 2SG.IRR-hold mess.up on-3SG then 3SG.IRR-sink direct tey ka-vaq-siq.

FOC 3SG.IRR-time-one

'If you hold it wrong, then it will just sink right away.' [07117.589 07117.wav 1681.937 $1685.015]$

$\begin{array}{lllll}\text { (410) I-var } & \text { pileh } \\ \text { 3SG.R-step } & \text { mess.up then } & \text { 3SG.R-fall } & \text { mbe-len } & \text { ni-mwilyel nin, i-toq } \\ \text { 3SI-hole } & \text { DEM 3SG.R-be }\end{array}$ sar. remain

'He mis-stepped and fell into the hole, and he stayed there.' [07089.050 07089.wav $276.206280 .316]$

(411) I-vini ne-men, i-ven pileh ra-n ne-men, ne-men 3SG.R-shoot NV-bird 3SG.R-shoot mess.up on-3SG NV-bird NV-bird i-topw. 3SG.R-run

'He shot at the bird, but he missed the bird, and the bird flew away.' [EC02.085 EC02.wav 337.422 340.969]

\subsubsection{Manner PVM1}

While nuclear-layer SVCs can use a stative verb to describe the manner in which an action is performed (Section 4.6.1.3.3), this section describe words that function similarly, but show no signs of verb-hood.

\subsubsection{Lalaq 'quietly'}

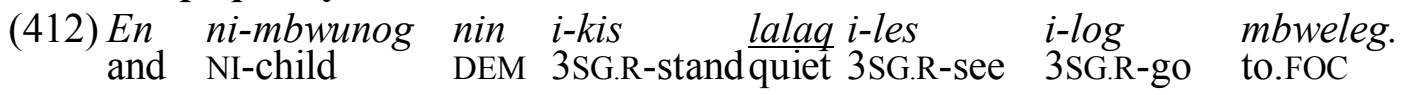

'And the boy hid and saw her coming.' [07064.156]

(413) Ku-sum lalaq eyig.

2SG.IRR-sit quiet PROX

'Be quiet! (lit. Sit there quietly!)' [07117.485]

\subsubsection{Gargar 'quickly'}

(414) Qet qey i-s-vey gargar veq qet kinag no-log mb-eyag but 3SG 3SG.R-NEG-go quick NEG then $1 \mathrm{SG}$ 1SG.R-go to-DIST ne-suqus mbetep-tambwat.

1SG.R-stick pawpaw

'But he didn't go quickly, so I went there and got a pawpaw' [07117.299 07117.wav 1010.450 1014.638] 
$\begin{array}{ll}\text { (415) } K u \text {-lip-kas } & \text { gargar! } \\ \text { 2sg.irr-take-get.out } & \text { quick }\end{array}$

'Take it out quickly!' [07065.268 07065.wav 982.728 986.447]

\subsubsection{Ndag 'carefully'}

Ndag 'carefully' indicates that an action was performed carefully, slowly, or deliberately.

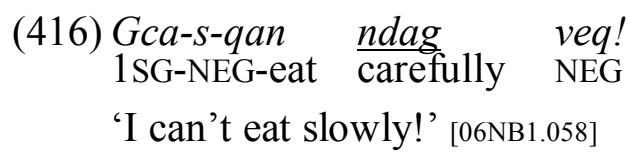

$\begin{array}{lllllll}\text { (417) Na-taq } & \text { yig } & \text { ra-qambwiq } & \text { ndag } & \text { tey } & \text { qin } & \text { en. } \\ \text { NV-thing } & \text { PROX } & \text { 3PL-plant } & \text { carefully } & \text { FOC } & \text { 3SG } & \text { ID }\end{array}$

'This thing was deliberately planted.' [07131.015 07131.wav 57.680 61.571]

\subsubsection{Mbot 'all over'}

Mbot 'all over' is used to indicate that an event is performed carelessly, indiscriminately, or all over the place. Mbot can also modify nouns with a meaning of 'all kinds of X' (Section 3.4.9.4).

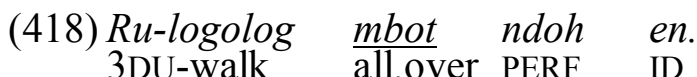

'They walked all over the place.' [07073.021 07073.wav 73.937 77.499]

(419) Valestuwan u-gcur ni-tred i-ropw mbot. time INDEF 2SG.R-make NI-thread 3SG.R-run all.over 'Sometimes you make the thread run all over the place.' [07051.223 07051.wav 859.915 862.152]

(420) Ra-mwas kinag gcen na-raq taq yig, taq tuwan 3PL-laugh 1SG because 1SG.R-make thing PROX thing INDEF ra-s-ra-rar $\quad \frac{\mathrm{mbot}}{\mathrm{veq}}$ qin. 3PL-NEG-DUP-make all.over NEG 3SG

'They will laugh at me because I did this thing. And it's a thing that is not done indiscriminately.' [07064.182 07064.wav 644.265 648.155]

\subsubsection{Morsu 'unrestricted'}

Morsu 'unrestricted' modifies a verb phrase to indicate that something happens without restrictions (421)-(422). It can also modify a noun phrase with a meaning of 'any X' or 'every X' (Section 3.4.9.8).

$\begin{array}{lll}\text { (421) } I-s-k o-k o h & \text { morsu } & \text { veq } \\ \text { 3SG.R-NEG-DUP-be } & \text { unrestricted } & \text { NEG ID }\end{array}$ 'It is not found just anywhere.' [07127.005 07127.wav 13.995 17.088]

$\begin{array}{ccc}\text { (422) Qet } & \text { re-vey } & \text { morsu } \\ \text { but } & \text { 3PL-go } & \text { teyrestricted } \\ \text { FOC }\end{array}$

'But can just anybody go?' [07132.010 07132.wav 54.208 60.458] 


\subsubsection{Mbwutaqay 'loudly'}

Mbwutaqay 'loud' may refer to a sound produced loudly as in (423)-(426). It can also be used as a general intensifier as described in Section 4.7.3.1.3.

$\begin{array}{cllll}\text { (423) Ku-vagas } & \text { mwin } & \text { mbwutaqay } & \text { gcen taq yig ke-lip } & \text { inug. } \\ \text { 2SG.IRR-talk first } & \text { loud } & \text { for thing PROX 3SG.IRR-take } & \text { 2SG }\end{array}$ 'You should speak up so that this thing will record you.' [07117.505 07117.wav 1518.547 1520.500]

$\begin{array}{cclll}\text { (424) I-vwer, } & \text { 'Ey } & \text { waq-S-vagas } & \text { mbwutaqay } & \text { veq!' } \\ \text { 3SG.R-say } & \text { hey } & \text { 2DU.IRR-NEG-talk } & \text { loud } & \text { NEG }\end{array}$

'He said, "Hey! Don’t talk so loud”" [KO01.013 KO01.wav 43.273 45.757]

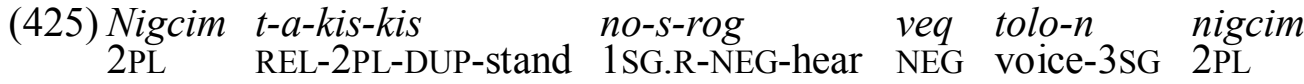

a-yal mbwutaqay.

2PL-sing loud

'You guys who are standing, I don't hear your voices, sing loud!' [07048.1612 07048.wav 4258.112 4261.115] (426) A-vos pwaq-pwaq mbwutaqay.
2PL-slap DUP-explode loud

'Clap loud!' [07048.2316 07048.wav 5551.258 5552.818]

\subsubsection{Kos 'directly/correctly'}

Kos 'directly/correctly' can indicate that a movement is made directly toward a goal as in (427). In (428) it indicates that one event (sleeping) directly follows another (arriving). Example (429) occurred in the context of many people guessing the name of a tree. In this case, kos indicates that saying of a name was successful or correct.

(427) I-sil kos tey mbe-len nu-qumbwen en. 3 SG.R-hide direct FOC to-in NV-fish.trap ID

'It dives right into the fish trap.' [nihumbwen2.045 nihumbwen.wav 525.288 529.788]

(428) Ra-tagcaw ra-n Newur, en re-metur kos tey gcen gcow 3PL-arrive on-3SG Tenstickand 3PL-sleep direct FOC because EMPH wut re-mbwun liglig.

COMPL 3PL-full INTENS

'They arrived at Tenstick Island and went straight to sleep because they were so full.' [TB03.030 TB03.wav 148.061 157.904]

(429) En i-yar mbwaq i-vwer kos neqhe-n. and 3SG.R-finish sorry 3SG.R-say correct name-3SG

'And that was the end. He successfully said the name,' [07065.238 07065.wav 879.990 883.194]

\subsubsection{Degree PVM1}

\subsection{Taqtaq 'a little'}

When taqtaq modifies stative verbs, it means 'a little bit' (430)-(431). When it modifies dynamic verbs, it can mean 'a short distance' (432) or 'for a little while' (433). 
(430) Na-vwan i-mbwow taqtaq tey.

$\mathrm{NV}$ - fruit 3SG.R-big a.little FOC

'The fruit is pretty big,' [07019.007 07019.wav 19.173 21.111]

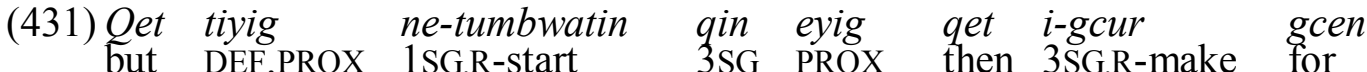
i-pwaras taqtaq.

3SG.R-hard a.little

'But I started [weaving] this one here and that makes it a bit difficult.' [nihumbwen2.004 nihumbwen.wav 14.943 19.131]

(432) Qey i-vwer mbigce-n Saymon gcen wut ke-susul taqtaq 3SG 3SG.R-say to-3SG Simon for that 3SG.IRR-push a.little na-wagc mbi-livwaqa-n-tes ndilqin wut verqeh. $\mathrm{NV}$-canoe to-middle-3SG-sea away place shore

'[He] asked him to push off a little from the shore.' [LUK.05:03]

(433) En ko-toq taqtaq ke-puy kas na-vwa-n ke-siq. and 3SG.IRR-be a.little 3SG.IRR-pick out NV-fruit-3SG 3SG.IRR-one 'And he would stay a short time, and then he would pick off another nut.' [EC02.016 EC02.wav 75.937 80.280]

\subsection{Liglig 'very/too much'}

Liglig 'very' functions as an intensifier of stative verbs (434). With dynamic verbs such as in (435) and (436), it can have a meaning of 'too much'.

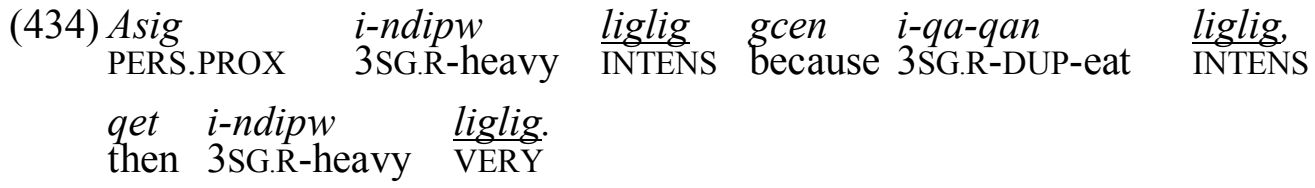

'The guy was very heavy because he had eaten so much and so he was very heavy,' [TB03.123 TB03.wav 602.302 610.911]

(435) Ku-s-logolog liglig veq.

2SG.IRR-walk INTENS NEG

“"Don't wander too far."“ [07074.010 07074.wav 45.671 51.187]

(436) Konoq ku-terey liglig ni-livwaqa-n qet na-qayew if 2SG.IRR-cut INTENS NI-middle-3SG then NV-pudding ko-topw. na-qayew ti-i-met ko-topw. 3SG.IRR-jump NV-pudding REL-3SG.R-raw 3SG.IRR-jump

'If you cut the middle too much, the raw pudding will jump out.' [07112.161]

\subsection{Mbwutaqay 'very'}

When modifying a stative verb, mbwutaqay has the approximate meaning of 'very', (437)-(438). With active verbs, it seems to mean 'intensely' in (439). It can also be used to describe an act performed 'loudly' as described in Section 4.7.2.6. 
(437) Re-les ni-gcigcaplew i-vwariq mbwutaqay. 3PL-see NI-spider.web 3SG.R-small INTENS

'They thought the spider web was very small.' [07076.050 07076.wav 201.467 205.107]

(438)Re-metur ro-rog i-leh mbwutaqay gcen re-sep ra-n 3PL-sleep 3PL-feel 3SG.R-goodINTENS because 3PL-find on-3SG na-qanyen ti-re-leh qar. NV-food REL-3PL-good PL

'They slept and they felt very good because they found good food.' [тв03.037 TB03.wav 189.528 193.481]

(439) En ni-morot qar re-mi-mindig mbutaqay Yesu. and NI-man PL 3P-DUP-watch INTENS Jesus

'And people were watching Jesus closely.' [LUK.14:01]

\subsection{Vovoh 'very'}

Vovoh 'very' acts as an intensifier in (440)-(442).

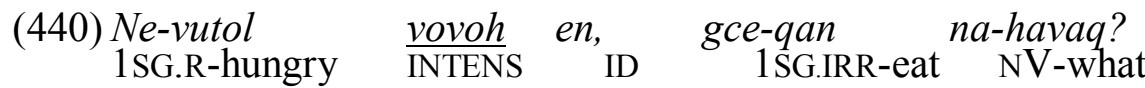

'I'm very hungry. What will I eat?' [07082.030 07082.wav 123.642 128.049]

$\begin{array}{cll}\text { (441) I-veqen } & \text { mbwunog } & \text { i-lam } \\ \text { 3SG.R-have child } & \text { 3SG.R-many } & \text { vovoh. } \\ \text { INTENS }\end{array}$

'She had many, many children.' [07087.002 07087.wav 7.016 13.625]

(442) Kinag ne-rirog vovoh no-qonli-n na-mbwaq. $1 \mathrm{SG}$ 1SG.R-like INTENS NV-egg-3SG NV-turtle

'I really like turtle eggs.' [07117.786 07117.wav 2086.168 2088.715]

Note that there is another function of vovoh which is falling out of use and being replaced by mwas (Section 5.3.3). It is to express necessity as in (443).

$\begin{array}{llll}\text { (443) Nigca-rar vovoh } & \text { tey } & \text { na-taq } & \text { sut. } \\ \text { 1SG.IRR-make must } & \text { FOC } & \text { NV-thing } & \text { NONSP }\end{array}$

'I must do something.' [07064.184 07064.wav 653.030 655.265]

\subsubsection{Verb-specific intensifiers}

While intensifiers such as liglig, mbwutaqay, and vovoh (Sections 4.7.3.1.2-4.7.3.1.4) productively modify a range of verbs, there are a number of intensifiers that can only modify a particular verb head. These are listed in Table 83. With the exception of mag lam 'wide open', all of these intensifiers involve apparent reduplication. For a few of the verbs which themselves involve apparent reduplication, the verb may appear un-reduplicated if it is modified by one of these intensifiers (see Section 4.5.1.9). Speakers were unable to identify any independent meaning for most of the intensifiers. However, some of the intensifiers in Table 83 seem to have synchronic cognates which perhaps reveal something of their origin. For example mwinmwin 'INTENS', which is used to modify mbuqmbuq 'short', is likely related to na-mwin(d) 'NV-dwarf', and the phrase may have once more literally meant 'short like a dwarf'. Likewise, vetevet 'INTENS', which modifies pwaras 'strong', appears to be related to 
ne-vet 'stone', and the phrase may once have meant 'hard as stone'. However, for many of these intensifiers, I was not able to find any convincing cognates. And others are a bit more dubious: mevus pwaqpwaq = 'white like an explosion?'.

Table 83: Verb-specific intensifiers

\begin{tabular}{lll}
\hline Verb & Intensifier & Possible cognate \\
\hline pwaras 'strong' & vetevet & ne-vet 'stone' \\
vwariq 'small' & kikeley & \\
mbow 'big' & lambalamb & lamb 'many' \\
qasen 'green' & mbwitambwit & \\
leh 'good' & ndegndeg & \\
mevus 'white' & pwapwaq & ? pwaq 'explode' \\
lamb 'many' & gcohgcoh & gcohgcoh 'rubbish' \\
mag 'agape/open' & lam & ? lamb 'many' \\
malqah 'cold' & mbwumbwuley & \\
pilpil 'hot' & (pil) haphap & \\
vop 'rain' & magamag & mag 'agape' \\
mamal 'red' & (mal) ndisndis & \\
mbuqmbuq'short' & (mbuq) mwinmwin & na-mwind 'dwarf' \\
meloqloq 'soft' & (meloq) ndindi & \\
metemet 'black' & (met) punpun & \\
metemet 'black' & (met) rugrug & \\
mbarap 'long' & qay(was)was & \\
remw 'skinny' & kuskus & ? kus 'graze' \\
wu 'high tide' & mbwu & ? mbwu 'stink' \\
mbwu 'stink' & kinkin & \\
kul 'weak' & mboqmboq & $?$ mbomboq 'squeamish' \\
mbwun 'full' & yohyoh & yohyoh 'strong' \\
ndamwat 'calm, peaceful' yaryar & (mwul ndindeleq & \\
mwulmwul 'round' & (mwish' \\
\hline
\end{tabular}

\subsubsection{Aspect PVM1s}

\subsubsection{Mwah 'all'}

Mwah, which is glossed as 'all', has a meaning of completeness, but mwah has many different functions. It can mean that a process is completed (444) or that a patient is completely affected (445).

(444) Taq nin ut i-yal-yal mwah, i-vwer... thing DEM when 3SG.R-DUP-sing all 3SG.R-say

'When he finished singing it, he said ...' [тВ01.038-039 TВ01.wav 174.790 180.321]

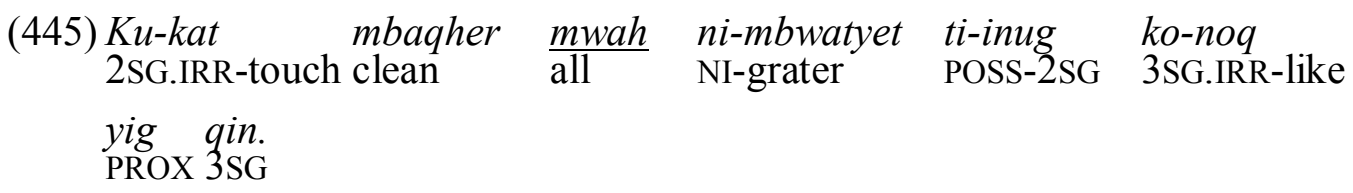

'Clean up your pudding grater just like this.' [07091.011 07091.wav 73.571 76.055]

Mwah can also be used to specify that all members of a plural argument are included. This can apply to the subject as in (446) where the meaning is that all of the 
addressees drink rather than that the implied object (wine) be completely drunk. ${ }^{109}$ This function of mwah can also apply to objects (447), or even to oblique arguments as in example (448). It is interesting that in these examples mwah occurs in the PVM1 position rather in a post-nominal modifier modifying the argument in question. ${ }^{110}$ Mwah can occur as a post-nominal modifier with a very similar meaning (see section 3.4.9.6).

$\begin{array}{llllll}\text { (446) I-huq } & \text { ndal } & \text { lis } & \text { mbigce-n } & \text { qar, en } i \text {-vwer, en } \\ \text { 3SG.R-give back } & \text { again to-3SG } & \text { PL and 3SG.R-say and } \\ \text { a-min } & \frac{m w a h}{\text { all }} & \text { tey len.' } & & \end{array}$

'[He] gave it to them again and said, "Drink it [wine], all of you."' [MAT.26:27]

$\begin{array}{lllll}\text { (447) } \begin{array}{ll}\text { Ra-vanaq } \\ \text { 3PL-steal }\end{array} & \frac{\text { mwah }}{\text { all }} & \text { na-taq } & \text { ti-qey } & \text { qar } \\ \text { NV-thing } & \text { POSS-3SG } & \text { PL }\end{array}$

'They stole all his things.' [LUK.10:30]
(448) ... ni-morot ke-siq ke-mes mwah mbigce-n ni-morot qar, NI-man 3SG.IRR-one 3SG-die all for-3SG NI-man PL

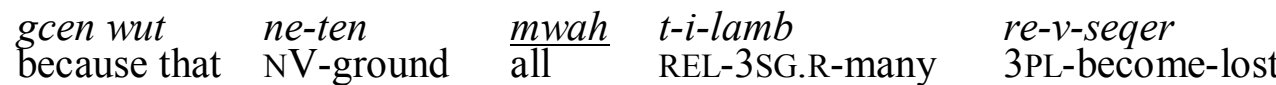
veq.
NEG

'... One man will die for all the men so that all the countries will not be lost.' [JON.11:50]

The multiple function of mwah means that occurrences such as (449) can be ambiguous. Here there are two interpretations. The first is that the patient is completely affected ('completely ruined'). The second is that every member in the plural object is included ('all the gardens').
(449) Na-taq $\mathrm{NV}$-thing
tuwan i-gciyew $\underline{\text { mwah }}$
ne-hew
qar.

'Something completely ruined the gardens/ruined all the gardens.' [тв03.093 TB03.wav 465.007 467.635], [s0801.52]

\subsubsection{Tartar 'always'}

Tartar means 'always' or 'often' (450)-(451). When it occurs in a negated verb phrase, it means 'not often' (450). Tartar 'always' also functions outside the noun phrase as a temporal noun (Section 5.3.2.1).

\footnotetext{
${ }^{109}$ The construction in (446) was confirmed to be ambiguous. While it is translated with the intended meaning, the same sentence could also mean 'drink all of it.' [s0801.51]

${ }^{110}$ One possible interpretation of examples such as (446) where the object is not overtly realised is that mwah is in fact occurring as post-nominal modifier on a non-overt head rather than in PVM1 position. However this interpretation is not viable for examples (447) and (448).
} 
(450) Tiyig ra-s-qan tartar veq tiyig mi ra-qan tartar DEF.PROX 3PL-NEG-eat often NEG DEF.PROX FOCUS 3PL-eat often qorig en. now ID

'That one isn't often eaten. But this one is eaten all the time now.' [07120.044 07120.wav 124.610 126.922]

(451) Ti-i-mbwow tey sombwo-n qet i-lip tartar nivingcowum REL-3SG.R-big FOC alone-3SG PART 3SG.R-take always Nivingcowum 'The older girl would always take Nivingcowum by herself.' [07072.061 07072.wav 334.902 340.730]

\subsubsection{Gcot 'for the last time'}

Gcot indicates that something which has happened before happens again for the last time. All examples of gcot in the corpus occur in PVM1 position.

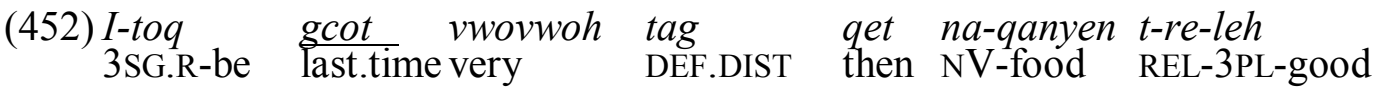
vwovwoh qet ro-koh len. very PART 3PL-be in

'That is the very last one and there is very good food in it.' [ТВ03.078 TB03.wav 396.580 402.064]

(453) I-yal-yal gcot gcen ko-toghaq mbe-yum en.
3SG.R-DUP-sing last.time for 3SG.IRR-climb to-house ID

'He sang for the last time before climbing the hill to his house.' [07063.348 07063.wav 1165.288 1168.616]

(454) I-hupw gcot ni-tavu morot re-gci-gcilew mbey. 3SG.R-blow last.time NI-conch man 3PL.R-DUP-look to

'He blew one more time on the conch, and people looked at them.' [LS01.122 LS01.wav 518.004 525.301]

\subsubsection{Malas 'never/yet'}

Malas 'never, yet' only occurs in negative constructions. Interestingly, it sometimes occurs before the negative marker, veq, (455)-(456), and sometimes after it (457)(458). While the former is more common in the spoken corpus, the latter is much more common in Massing Nambuas's bible translations. There is no difference in meaning between the two orderings. It appears to be a syntactic change in progress.

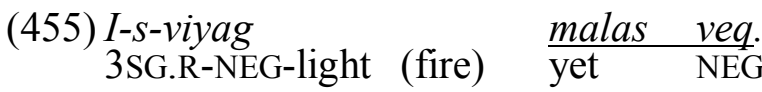

'It [fire] hasn't lit yet.' [07095.037 07095.wav 240.075 242.950]

(456) Wut ra-s-tagcaw malas veq en i-yal-yal ndal lis. when 3PL.R-NEG-arrive yet NEG and 3SG.R-DUP-sing back again 'And when they had not yet arrived, he sang again.' [тв01.034 Tв01.wav 139.381 143.053] 
$\begin{array}{ll}\text { (457) Inug usqan veq malas? } & \text { 2SG } \\ \text { 2SG.R-NEG-eat NEG yet }\end{array}$

'Have you never eaten it?' [07117.621 07117.wav 1740.543 1741.981] \begin{tabular}{clllll} 
(458) Yesu qey & i-s-vweleg \\
Jesus 3SG & 3SG.R-NEG-come & malas & ra-n & ni-mbwasar & en. \\
\cline { 2 - 4 } & yet & on-3SG & NI-village & ID
\end{tabular}

'Jesus had not yet arrived in the village' [JON.11:30]

In example (459), malas occurs with a negated noun phrase in a verbless clause. In this case it could be seen as a predicate modifier rather than a verbal modifier.

(459) Ni-mbug veq malas en.
NI-day

'It's not yet time' [MAT.08:29]

\subsubsection{Mbaqsiq 'ahead/beforehand'}

Mbaqsiq 'ahead of time' indicates that an event or state occurs in advance of another event.

(460)Aley ku-rar yipyep mbaqsiqnamu-tumbwel ke-leh okay 2SG.IRR-make ready ahead your-arrow 3SG.IRR-good gcen ku-vini. for 2SG.IRR-shoot

'Okay, get your arrow ready (in advance) so that you can shoot it.' [DK01.082 DK01.wav 416.910420 .691$]$

(461)Mi-roghur hur ni-mbunog ti-kamem wut qey i-mbwar. 1EX.PL-know about NI-boy POSS-1EX.PL that 3SG 3SG.R-blind mbwasiq len ni-veti-n hine-n en ra-nda-vah gin. ahead in NI-belly-3SG mother-3SGand 3PL-next-give.birth 3SG 'We know about our son that he was blind beforehand in his mother's belly, and was born after that.' [JON.09:20]

When modifying vwer 'say', mbaqsiq 'ahead' can express prediction or warning (462)-(464). $\begin{array}{rlllll}\text { (462) 'En } & \text { re-vweleg } & \text { qin kinag } & \text { en.' } & \text { I-roghur } & \text { mbaqsiq. } \\ \text { and } & \text { 3PL-come } & \text { PREP } & \text { lSG } & \text { ID } & \text { 3SG.R-know ahead }\end{array}$

“"They are coming for me." She predicted it.' [тВ01.053-054 ТВ01.wav 246.511 250.433]

(463) Gce-vwer mbaqsiq na-taq tuwan migce-n inug. 1SG.IRR-say ahead NV-thing INDEF to-3SG 2SG

“'I'm going to tell you (or warn you of) something,' [07064.062 07064.wav 245.138 249.013] 

(464) Qet re-vwer mbaqsiq tey re-vwer mworot yig ke-s-mewur then 3PL-say ahead FOC 3PL-say man PROX 3SG.IRR-NEG-healthy
ndal veq lis.
back NEG again

'They will predict that this man will not come back to health' [JS02.025 JS02.wav 83.393 87.690 JS02.wav 80.315 83.393]

\subsubsection{Mood PVM1}

\subsubsection{Gcow' 'confirm/emphasis'}

The meaning of gcow is difficult to analyse. At least one of its functions is to give extra force to imperatives. This is evident in (465), an exchange that I frequently overheard in the field. Examples (466), (467), and (468) also demonstrate gcow in imperative sentences.

\section{$\begin{array}{lll}\text { (465) A: } N d o-\log & \text { B: Ndo-log } & \text { gcow! } \\ \text { 1INC.PL-go } & \text { 1 INC.PL-go EMPH }\end{array}$}

'A: Let's go. B: Okay, let's go then!'

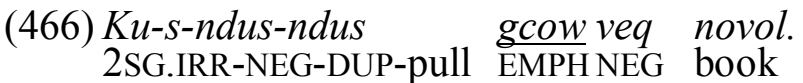

'Don't always pull the book!' [07117.496 07117.wav 1501.742 1503.399]

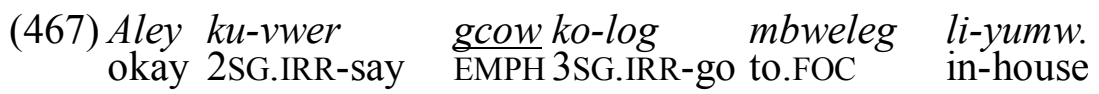

'Okay, tell her to come into the house!' [07082.082 07082.wav 312.742 315.617]

$\begin{array}{rllll}\text { (468) } Q e t & i \text {-vwer, } & \text { 'Ku-tus } & \text { gcow ni-tus-yen } & \text { tiyig.' } \\ \text { then } & \text { 3SG.R-say } & \text { 2SG.IRR-draw } & \text { EMPH N-draw-NOM } & \text { DEF.PROX }\end{array}$

'And he said, 'Draw that drawing!' [KA02.027 KA02.wav 149.220 153.454]

Gcow also commonly occurs in the formula $X$ gcow $X$ as in (469) with an intensifying meaning. This is equivalent to the Bislama phrase $X$ we $i X$ ( $i$ gud we $i$ gud 'it is very good'). A similar construction appears in (470), but without the repetition of the verb.

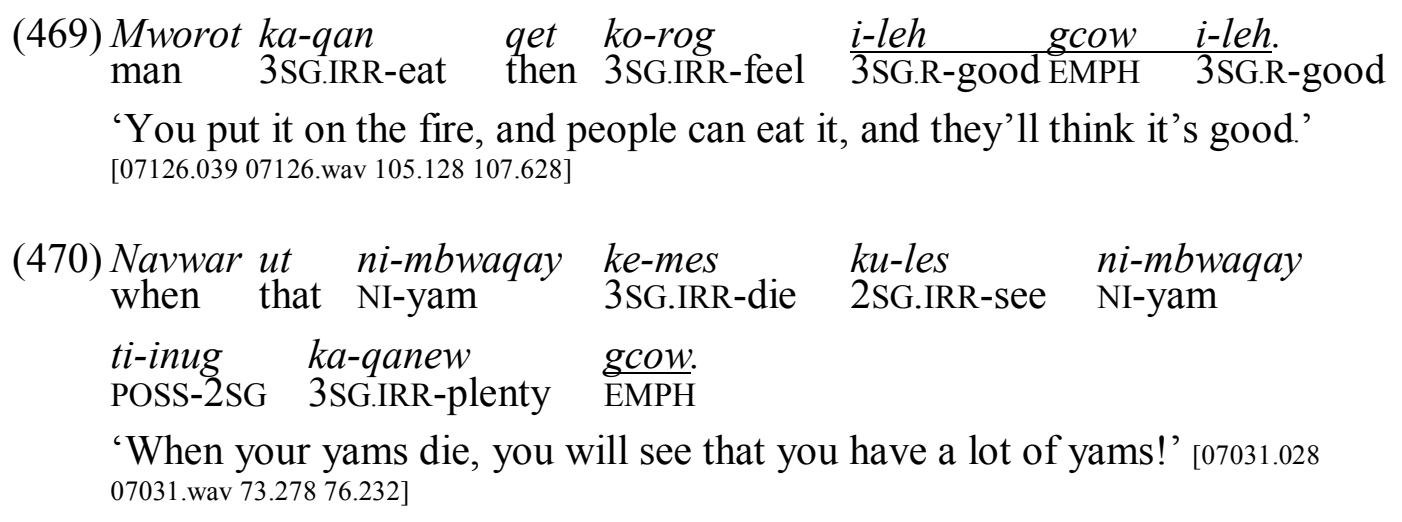

When gcow is used in an intensifying sense as in (469) and (470), it has a distinct intonational pattern with the syllable preceding gcow having a high pitch and long duration (Section 2.6). 
Gcow also occurs on non-verbal elements when they are fronted as described in Sections 6.1 and 6.2. In Examples (471)-(475), gcow seems to occur on elements that are in contrastive focus. Note that in (474), it co-occurs with the contrastive focus marker, $m i$ (described in Section 6.3.1).

(471)Inug gcow qet u-qan mwah ni-mworot qar 2SG EMPH PART 2SG.R-eat all NI-man PL i-leh ut u-mes. 3SG.R-good that 2SG.R-die

'It was you that ate all the people. It is good that you die.' [07081.039 07081.wav 176.225 181.679]

(472) Awaq, hina-m gcow etin qet i-vah inug etin. no mother-2SG EMPH ID then 3SG.R-bear 2SG this

'No, this is your mother here. And she gave birth to you here.' [KO02.019 KO02.wav 106.812110 .558$]$

(473) Na-taq gcow t-ne-vwer en. NV-thing EMPH REL-1SG.R-say ID

'That's what I said!' [07073.051 07073.wav 226.616 230.498]

(474) Barabas gcow mi qey i-p-morot nin Barabbas EMPH FOCUS 3SG 3SG.R-be-man ASS ni-mbwil-mbwil-morot-yen. NI-DUP-hit-man-NOM

'Barabas on the other hand was a murderer.' [JON.18:40]

(475) Oveh, qorig gcow etin qet nde-qvey mi ambeh? whoa now EMPH ID PART 1IN.PL-go FOCUS where

'Whoa, but where will we go now?' [TB03.054 TB03.wav 271.473 275.925]

Gcow frequently follows the subordinator gcen 'because' as in (476)-(477), and the combination seems to discount other possible reason.

$\begin{array}{clllll}\text { (476) } A w a q, & \text { gcen } & \text { gcow } & \text { nigcim } & \text { a-rirog } & \text { ni-mahal } \\ \text { no } & \text { because EMPH } & \text { 2PL } & \text { 2PL-want } & \text { NI-fish } & \text { always simply }\end{array}$ tey qet a-gcur kinagna-gcahal vwovwoh en. FOC then 2PL-cause 1SG 1SG.R-go.far must ID

'No, that's because you guys always want fish, so I have to go far away.' [07063.228 07063.wav 758.912 764.740]

(477) Talay ... awaq, mi-s-les veq. Na-mbwaq mi-s-les veq. clam no 1EX.PL-NEG-see NEG NV-turtle 1EX.PL-NEG-see NEG Gcen gcow mi-log ohoy tey gcen mi-yip-yip gcen because EMPH 1EX.PL-go simply FOC because 1EX.PL-DUP-dive for mahal.

fish

'Clams ... no, we didn't see any. We didn't see any turtles either. That's because we were just diving for fish. [07117.119-120 07117.wav 439.515 444.827] 
4.7.5.2. Mbwaq 'sorry'

In (478)-(481) mbwaq 'sorry' expresses regret.

(478) Qet mamah Marino ke-vwer ka-rar taq sut then mama Marino 3SG.IRR-intend 3SG.IRR-make thing NONSP

qet Lily mbwaq, i-vwowus mbwaq Lily.

then Lily sorry 3SG.R-carrysorry Lily

'What if Mama Marino had wanted to do something, but what about poor

Lily, she has to carry Lily.' [07117.283 07117.wav 945.155 950.998]

(479) Wa-log mbwaq i-mbarap qor.

2DU-go sorry 3SG.R-long today

“"You two have gone too far today."، [07073.013 07073.wav 45.427 50.594]

$\begin{array}{lllll}\text { (480) Ne-s-les } & \text { mbwaq } & \text { veq } & \text { sivir } & \text { sut. } \\ \text { 1SG.R-NEG-see } & \text { sorry } & \text { NEG } & \text { rainbow.lorikeet NONSP }\end{array}$

'I don't see a rainbow lorikeet.' [07117.806 07117.wav 2132.772 2134.616]

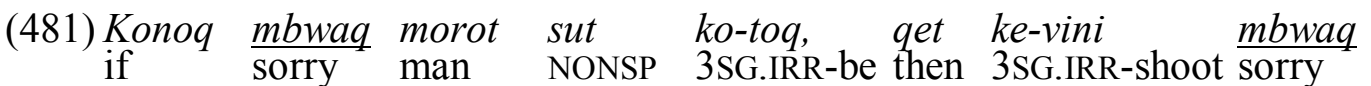

tey ne-men yig migce-n nigcin.

FOC NV-bird PROX for-3SG 1IN.PL

'If only there was someone here, then he could shoot that bird for us.' [EC02.076-077 EC02.wav 300.685 307.842]

In (482), mbwaq seems to have a pleading function. This could be the same function as the regret-function above if it is interpreted that the speaker regrets that they have to ask a favour. In (483) the speaker is referring to a favour already completed.

(482)En ru-vwer, 'Ni-ruqumbwaq muq-luqluq mbwaq gcen inug.' and 3DU.R-say NV-crab 1EX.DU.IRR-hide sorry to 2SG

'And they said to the sargassum crab, "Can we please hide with you.", [07073.058 07073.wav 251.232 255.264]

(483) I-leh ndoh gcen u-lip mbwaq kinag mbweleg verqeh. 3SG.R-good PERF because 2SG.R-take sorry $1 \mathrm{SG}$ to.FOC shore

'Thank you for bringing me to the shore.' [07117.408-409 7117.wav 1285.646 1291.053]

\subsubsection{Ohoy 'simply, freely, insignificant'}

Ohoy (variant: ohey) most commonly occurs followed by the focus particle tey.

Based on frequency, this may be a compound modifier. The meaning of ohoy tey is 'simply', 'just', 'only' or 'nothing special'.

(484) Ra-qan tartar ohoy tey na-qavwus.

3PL-eat always simply FOC NV-cabbage

'They always just ate cabbage.' [07063.022 07063.wav 143.133 146.320] 
(485)En no-roghur ohoy tey nevey.mbileq. and 1SG.R-know simply FOC spotted.eagle.ray

'I only know the spotted eagle ray.' [07117.307 07117.wav 1042.964 1045.762]

(486)Ro-qoy ohoy tey ni-metu ra-n ne-tu. 3PL-scrape simply FOC NI-coconut INSTR-3SG NV-bivalve 'They used to simply scrape coconuts with shells.' [07112.079 07112.wav 430.979 433.932]

Ohoy sometimes occurs as a PVM1 without tey, though this is much less common than with tey. When occurring alone, ohoy has a meaning of 'simply' or 'without assistance' or 'without restriction'.

\begin{tabular}{|c|c|c|c|c|}
\hline $\begin{aligned} \text { (487) } & \text { Ku-les } \\
& \text { 2SG.IRR-see }\end{aligned}$ & $\begin{array}{l}\text { mworot } \\
\text { man }\end{array}$ & $\begin{array}{l}\text { ka-qambwiq } \\
\text { 3SG.IRR-plant }\end{array}$ & $\begin{array}{l}\text { len } \\
\text { in }\end{array}$ & $\begin{array}{l}\text { ne-hew, } \\
\text { NV-garden }\end{array}$ \\
\hline $\begin{array}{l}i-s-q a m b w i q \\
\text { 3SG.R-NEG-p }\end{array}$ & & $\begin{array}{lll} & v e q & e n . \\
\text { ly NEG } & \text { ID }\end{array}$ & & \\
\hline
\end{tabular}

'When you see someone planting in his garden, he doesn't simply plant.' [07031.004 07031.wav 18.034 20.456]

(488) Gce-log ohoy vwovwoh tey. 1SG.IRR-go simply OBLIG FOC

'I should just go.' [07063.302 07063.wav 1016.022 1019.366]

(489) Ro-log mbeyasig i-gcilew mbey ran qet i-rog 3PL.R-go to PERS.PROX 3SG.R-look to on-3SG then 3SG.R-feel i-noq ke-mi-mim ohoy gcen ut i-mataq. 3SG.R-like 3SG.IRR-DUP-pee simply because that 3SG.R-afraid 'They went and the man looked inside and he felt like peeing (freely) because he was scared.' [LS01.094 LS01.wav 387.872 394.996]

(490) Qey i-leseles qar, en i-her. ndal qar, ro-log ohoy. 3SG 3SG.R-look.after 3PL and 3SG.give back 3PL 3PL-go simply 'He looked after them, and he gave them back, so they can go free.' [LUK.01:68]

Ohoy tey can also modify nouns with a meaning 'only $\mathrm{X}$ and nothing else' (Section 3.4.9.7).

\subsubsection{Mwin 'first'}

Mwin 'first' has multiple functions. It can be used to describe something as happening before something else (491). However, it is also frequently used on imperatives (492) (493) and may help to give an imperative interpretation rather than another function of irrealis mood (see Section 5.2.3 on ambiguity of imperatives and other irrealis statements). 
(491) Ko-toq ka-mbarap ke-mehmeh mwin gcen ut 3SG.IRR-be 3SG.IRR-long 3SG.IRR-dry first because that $\begin{array}{lll}\text { mworot } & k a-q a n & \text { qin. } \\ \text { man } & \text { 3SG.IRR-eat } & \text { 3SG }\end{array}$

'It will sit for a long time and dry out first so that people can eat it.' [07120.032 07120.wav 90.194 93.972]

(492) Ku-log mwin mbweleg ku-vwa-les na-taq tuwan. 2SG.IRR-go first to.FOC 2SG.IRR-come-see NV-thing INDEF

'Come here and come see something.' [AT01.014 AT01.wav 74.285 87.228]

$\begin{array}{llll}\text { (493) } \begin{array}{l}\text { Ndu-q-log } \\ \text { 1IN.DU-IRR-go }\end{array} & \text { mwin } & \text { ndu-q-metemet } & \text { ni-vinmarlam. } \\ \text { 1IN.DU-IRR-black } & \text { NI-old.woman }\end{array}$

'Let's go visit the old woman.' [07074.052 07074.wav 227.601 231.086]

Mwin may also be used in other situations where the speaker is asserting some kind of authority (494)-(498) and may have a politeness/reducing function.

(494) No-rog ku-rar mwin ne-revuh mbaragcin sut 1SG.R-feel 2SG.IRR-make first NV-bow true NONSP migce- $n$ kinag. for-3SG $\quad 1 \mathrm{SG}$

'I want you to make me a bow.' [07009.035-036 07009.wav 100.440 104.237]

(495) I-vwer, "Ku-yipyep gce-les mwin 3SG.REAL-say 2SG.IRR-wait 1SG.IRR-see first ni-vi-hala-n-yen ti-inug. ", NI-become-sibling-3SG-NOM POSS-2SG

'He said, "You wait. I'm just going to see your sister."' [LS01.046 LS01.wav 187.665 192.056]

(496) Gce-sekem mwin ni-tumbwel ti-inug qar. 1SG.IRR-check first NV-arrow POSS-2SG PL

'I'll just check your arrows.' [DK01.053 DK01.wav 343.955 345.893]

(497) No-rog konoq marlam yig ke-viyal $\frac{\text { mwin }}{\text { ni-mahal }}$ 1SG.R-feel if old.man PROX 3SG.IRR-gather first NI-fish migce-n nigcin. for-3SG 1INC.PL

'I would like the old man to get some fish for us.' [07063.032 07063.wav 174.235 $179.251]$

(498) Gce-lip-kas mwin na-qapsu-n kinag, en 1SG.IRR-take-out first NV-penis.wrapper-3SG 1SG and nigco-qom ni-mahal yig. 1SG.IRR-throw NI-fish PROX

'I'll just take off my penis wrapper and throw out this fish.' [07063.272 07063.wav 899.930 905.180] 


\subsubsection{Mbeq 'maybe'}

Mbeq indicates doubt. It often co-occurs with other phrases to express uncertainty such as no-s-roghur veq 'I don't know' (499)-(500) or i-noq '(3SG.R-like) perhaps' (501)- (502) or ne-mbwit 'I don't know' (502). But in example (503) only mbeq expresses the uncertainty. In (502) and (503) mbeq modifies a fronted noun phrase and could be seen as a predicate modifier rather than only a verbal modifier.

(499) Ro-qorqor mbeq na-taq ti-qar qar, no-s-roghur veq. 3PL-make.signmaybe NV-thing POSS-3PL PL 1SG-NEG-know NEG They might use them as a taboo sign, but I don't know. [07131.011 07131.wav 38.882 45.648]

\begin{tabular}{llllll} 
(500) & No-s-roghur veq & ke-viyag & qaw ke-viyag & mbeq & veq. \\
\hline 1SG.R-NEG-know NEG & 3SG.IRR-light & or & 3SG.IRR-light & maybe & NEG
\end{tabular} 'I don't know whether or not it will light.' [07095.036 07095.wav 210.986 215.564]

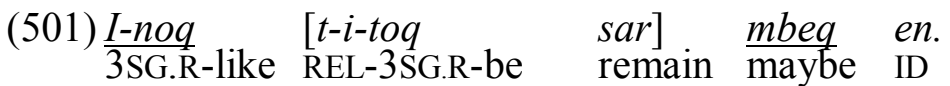
'This may be the last one.' [07113.005 07113.wav 29.736 31.642]

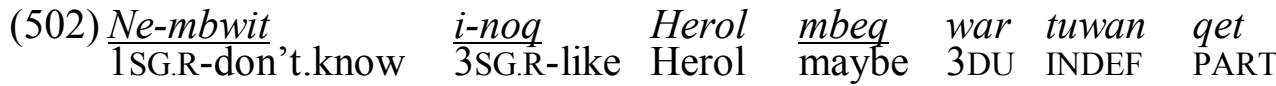
i-lip i-tu eyig. 3SG.R-take 3SG.R-put PROX

'I'm not sure, maybe Herol or his wife put it here.' [07131.016 07131.wav 61.571 65.852]

(503) Tatay mbeq t-nuqum qet i-roghur neqhe-n father maybe POSS-2DU PART 3SG.R-know name-3SG mbwumbwaqaw nin qar. critter DEM PL'

'Maybe your father knows what those critters are called.' [07117.568 07117.wav 1644.980 1647.788]

\subsubsection{Sam 'beware'}

Sam 'beware' indicates a danger or a warning about a possible future event.

(504) Inug mi ndu-vi-vagas qet ni-mwomwoq ti-inug 2SG focus 1INC.DU.R-become-talk then NI-woman POSS-2SG

ke-mbwil sam kinag. 3SG.IRR-hit beware 1SG

'What about you? If we are talking, your wife might hit me.' [07074.035 07074.wav 160.877 166.252]

(505) $k u$-s-logo-log veq mbi-siley $k u$-tal-tal ndal gcen 2SG.IRR-NEG-DUP-go NEG to-far 2SG.IRR-DUP-return back because ut ... na-taq sut ka-qan sam inug hur nahal. that... NV-thing NONSP 3SG.IRR-eat beware 2SG along road 'Hey, don't go far away, come back because maybe something will eat you on the road.' [KO02.007 KO02.wav 34.13141 .521 ] 
(506) "Ku-nden sam!" I-vwer “Awaq, nigca-hop mwindey en." 2SG.IRR-sink beware 3SG.R-say no 1SG.IRR-hope further ID “"You might drown!" He said, "No, I'm just going to bathe."” [07072.112 07072.wav 663.463 669.509]

\subsubsection{Miscellaneous PVM1s}

The PVM1s described in this section do not fit into the other semantic categories of result, manner, degree, aspect, or mood.

\subsubsection{Ndal 'back'}

(For the use of $n d a l$ 'back' in reflexive constructions, see Section 3.1.2.1.3). Ndal 'back' is a PVM1 that indicates movement toward a place where something has been before. It is related to the verb tal 'return', but may co-occur with tal as in (508).

(507) $\begin{aligned} & \text { I-qombw } \\ & \text { 3SG.R-throw } \\ & \text { back }\end{aligned}$ to-3SG Madlen

'She throws it back to Madlen.' [07068.274 07068.wav 870.922 873.156]

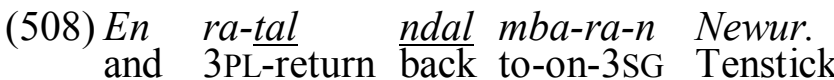

'And they returned to Tenstick Island.' [TB03.085 TB03.wav 430.082 432.395]

\subsubsection{Sombo-n 'alone'}

Sombo-n 'alone' can occur in the PVM1 position between a verb head and the second negative marker as seen in (511). It has a function of specifying that something is alone or that only something (exclusive of other things) was involved. The reference of exactly what is 'alone' varies greatly. In (509)-(510), the subject of the verb is alone. In (511)-(512), sombo- $n$ has an exclusivity function and refers to the object of the verb. Example (513) also has an exclusivity function that refers to the locational adjunct which follows. Sombo- $n$ can also occur as a nominal modifier with an exclusivity function as described in Section 3.4.9.3. Note that as a nominal modifier, it can have different singular suffixes: sombo-m 'alone-2SG' and sombo- $q$ 'alone-1SG'. For that reason I present sombo- $n$ as if it contains a 3 SG suffix.

(509) Konoq mi ko-toq sombo-n, na-qay yig i-pwaras. if FOC 3SG.IRR-be alone-3SG NV-tree PROX 3SG.R-strong 'But if it grows alone, this tree is strong.' [07124.006 07124.wav 15.328 17.562]

(510) I-vagas sombo-n migce-n ne-vet. 3SG.R-talk alone-3SG to-3SG NV-stone

'He talked alone to the stone. (i.e. He was alone at the time of talking.)' [07098.043 07098.wav 235.235 238.938]

$\begin{array}{lllll}\text { (511) I-s-noq } & \text { sombo-n } & \text { veq } & \text { ni-marlam t-nigcin } & \text { Sinesip. } \\ \text { 3SG.R-NEG-like } & \text { alone-3SG } & \text { NEG } & \text { NI-old.man POSS-1IN.PL } & \text { Sinesip }\end{array}$ 'It's not only like it was only the ancestors of us Sinesip people.' [07115.006 07115.wav 27.184 33.418] 
(512) Ra-qan sombo-n tey na-qavwus luqur... na-taq. 3PL-eat alone-3SG FOC NV-cabbage with NV-thing

'They ate only cabbage with ... things.' [07063.025 07063.wav 153.602 156.899]

(513) Na-qay yig i-kokoh sombo-n tey le-mbusmbwar. NV-tree PROX 3SG.R-DUP-be alone-3SG FOC LOC-swamp

'This tree only grows in swamps.' [07127.004 07127.wav 11.026 13.995]

\subsection{Post-verbal-modifier-2 (PVM2)}

Post-verbal-modifers-2 (PVM2s) are modifiers that occur after the second negative marker, but before the direct object of a verb. Note that malas was discussed in the section on PVM1s, but that it could also be considered a PVM2 as it sometimes occurs after the second negative element (see Section 4.7.4.4).

\subsection{1. $\mathrm{Ndoh}^{111}$ (perfect aspect)}

Ndoh represents perfect aspect. Ndoh cannot co-occur with veq. Therefore, the classification of $n d o h$ as a PVM2 is tentative. Ndoh 'PERF' indicates that an event is finished before a point of reference. The point-of-reference may be the time of utterance as in (514), or the timeframe of a narrative (515), or another event (516).

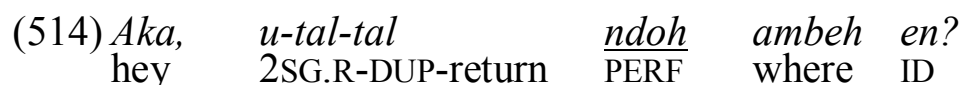
'Hey, where have you come back from? (on seeing someone arrive home)' [07063.191 07063.wav 648.537 650.990]

(515)En Elesabet en Sakaraia ruwar ru-v-marlamb ndoh. and Elizabeth and Zechariah 3DU 3DU-become-old.man PERF

'And Elizabeth and Zechariah were already old.' [LUK.01:07]

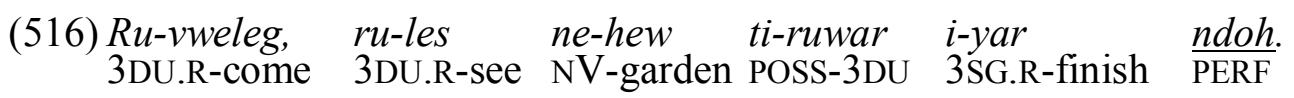

'When the two girls came, they saw that their garden was already finished.' [07072.013 07072.wav 72.58576 .257 ]

Example (517) shows $n d o h$ modifying a verb in an imperative sentence. It is not clear what its function is here since the event is certainly not completed from the reference point of the utterance. $\begin{array}{llllll}\text { (517) Ku-ndus } & \text { gcow } & \text { qin } & \text { mbi-livwaqa-n-tes } & \text { eyag } & k u \text {-tag-ndin } \\ \text { 2SG.IRR-pull } & \text { EMPH } & \text { 3SG } & \text { to-middle-3SG-Sea } & \text { DIST } & \text { 2SG.IRR-shove-sink }\end{array}$

ndoh qin livwaqa-n-tes

PERF 3SG middle-3SG-sea

'Okay, pull her out to sea there. Push her under the water.' [07080.068 07080.wav $271.935276 .450]$

$N d o h$ can modify non-verbal elements as well. In (518)-(521), ndoh modifies a fronted noun phrase (as described in Section 6.2), and therefore may be considered a predicate modifier rather than simply a verbal modifier. In these cases, $n d o h$ specifies that the noun it modifies is in some sence already determined or decided on. Ndoh

${ }^{111}$ Note that a few older speakers still retain the prenasalised trill in this word, $n d r o h /{ }^{\mathrm{n}} \mathrm{d}^{\mathrm{r}} \mathrm{oh} /$. 
also frequently modifies the temporal noun, lavuq 'tomorrow' (522)-(523) and indicates that a plan for tomorrow has already been decided on.

(518) Mahal ndoh nin ti-larap en. fish PERF ASS POSS-afternoon ID

'These are fish for dinner.' [nihumbwen2.060 nihumbwen.wav 637.726 640.211]

$\begin{array}{llll}\text { (519) } I \text {-vwer } & \text { vilam } & \text { ndoh } & \text { yig en } \\ \text { 3SG.R-say } & \text { girl } & \text { PERF } & \text { PROX ID }\end{array}$

'He said, “That's the girl.”، [07064.157 07064.wav 566.982 569.685]

(520) Nigcim ndoh qet a-veqen ne-hew ti-re-mbumbow qar. 2PL PERF PART 2PL-have NV-garden REL-3PL-DUP-big PL

'You guys have big gardens.' [TB03.098 TB03.wav 480.658 484.611]

(521) Qey ndoh na-yal-yal ne-vwere-vwer qin en. 3SG PERF 1SG.R-DUP-sing 1SG.R-DUP-say 3SG ID

'That's what I was singing to say."' [07063.365 07063.wav 1216.366 1219.553]

(522) Lavuq ndoh qet ... nde-q-sug. tomorrow PERF PART $\ldots$ 1IN.PL-IRR-roast

'Tomorrow ... we will roast.' [DK01.033-034 DK01.wav 286.554 289.710]

(523) Ndu-log. en lavuq ndoh ndu-vweleg ndu-raq mwah. 1IN.DU-go and tomorrow PERF 1INC.DU-come 1INC.DU-work all

'Let's go, tomorrow we'll come back and finish the work.' [07072.009 07072.wav $52.00660 .194]$

\subsubsection{Lis 'again'}

Lis 'again' is used to indicate that an event or state is repeated.

(524) Ni-yar ni-mbwati-n ka-vwariq lis . Vinmbwumbwaqaw $\mathrm{NV}$-ironwood NI-head-3SG 3SG.IRR-small again Vinmbwumbwaqaw ka-haq lis. 3SG.IRR-climb again

'The ironwood trunk became small again, and Vinmbwumbwawaw climbed it again.' [07076.021 07076.wav 83.824 87.809]

(525) En aleq ti-qey i-lip lis ne-tel mbweleg. and brother-in-law POSS-3SG 3SG.R-take again NV-rope to.FOC

'And his brother-in-law brought another rope,' [ТВ01.096 TB01.wav 368.718 371.890]

When Lis occurs with a negative verb phrase, it means 'no longer' and lis occurs after the second negative marker, veq (526)-(527).

(526) Mworot yig ke-s-mewur $\quad$ ndal veq lis. Man PROX 3SG.IRR-NEG-healthy back NEG again

'This man will not return to health' [JS02.025 JS02.wav 80.315 83.393] 
(527) Nigcin nda-s-qan-qan veq lis . ni-mahal en.

1 IN.PL 1IN.PL-NEG-DUP-eat NEG again NI-fish ID

'We can't eat fish anymore.' [07117.133 07117.wav 493.226 498.539]

Ndal 'back' and lis 'again' frequently occur together as in (528)-(529). There is some evidence that these two form a compound ndal-lis or ndalis 'again'. Ndal normally occurs before the second negative marker veq, and lis after veq as in (526) above. However, it is also possible for the compound ndalis 'again' to occur after veq (530).

(528) En i-silew ndal lis qin. and 3SG.R-kick back again 3SG

'And he kicked it again.' [TB01.107 TB01.wav 398.025 399.790]

(529) Ru-vey ndal lis len ne-hew t-ruwar ra-n Lemetu. 3DU-go back again in NV-garden POSS-3DU on-3SG Lemetu

'They would go back to their garden in Lemetu.' [MR01.014 MR01.wav 192.113 195.942]

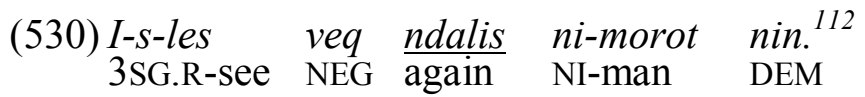

'She didn't see that man again.'

(Ndal)lis can also modify a noun, meaning 'another' (Section 3.4.9.2).

\subsubsection{Gceyip}

Gceyip means 'yet, still'. It is often preceded by the focus particle tey as in (534).

Elicitations showed that it occurs after veq 'NEG', but some younger speakers also allow it before veq, so it may be that gceyip 'yet' is changing to become a PVM1.

(531)Re-les ne-hew i-siq, i-ru, i-tul i-kohsar 3PL-see NV-garden 3SG.R-one 3SG.R-two 3SG.R-three3SG.R-remain gceyip. yet

'And they saw one, two, three gardens still left.' [TВ03.057 TB03.wav 293.083 298.880]

(532) Kinag ne-sisiq gceyip mbwunog. $1 \mathrm{SG}$ 1SG.R-lack yet child

'I don't have children yet.' [07009.051 07009.wav 138.030 140.546]

(533) Mwamwah i-log gceyip taq. en. mother SG.R-go yet behind ID

'My mother is still on her way.' [07009.059 07009.wav 163.021 164.420]

(534) Ni-mbunogti-qey qar ro-koh tey gceyip qorig en. NI-child POSS-3SG PL 3PL.R-be FOC yet now ID

'And that man's children are still living now.' [KA02.032 KA02.wav 186.767 195.042]

\footnotetext{
${ }^{112}$ I do not have a record of any such constructions, but I have a memory of hearing them and asking about them. (530) is constructed from my memory.
} 
Example (535) shows tey gceyip modifying an qet-fronted temporal noun. It could therefore be considered a predicate modifier rather than strictly a verbal modifier.
(535) Livaqat tey gceyip qet mbunog nin i-makas i-rop. night FOC yet then child DEM 3SG.R-come.out 3SG.R-hurry
'When it was still night, they boy ran away.' [KJ01.048 KJ01.wav 249.022 253.131]

\subsection{Object}

Nahavaq does not have object marking morphology. Direct objects are expressed with a noun phrase occurring directly after the verb complex, or they can be omitted. The following examples show the verb qombw 'throw', which semantically must be transitive, ${ }^{113}$ with a canonical NP object (536), with a personal pronoun object (537)(538) with a third person object marked with qin (539)-(540), and with no overt object (541)-(542).

(536) En i-qombw ni-mbwunog mbe-len na-vwam. and 3SG.R-throw NI-child to-in NV-hole

'And she threw her child into the hole,' [07132.021 07132.wav 117.681 119.822]

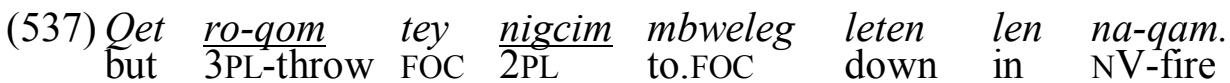
'You will be thrown down to hell!' [MAT.11:23]

(538) A-qos-tutu ni-vara-n en ni-mbulu-n,en a-lip qey mbi-siley 2PL-tie-tight NI-hand-3SG and NI-leg-3SG and 2PL-take 3SG to-far ehun wutig, en a-qom qey mbi-siley mbe-len ni-mismbug. away.from here and 2PL-throw 3SG to-far to-in NI-dark

'Tie him up hand and foot, and throw him outside in the dark.' [MAT.22:13]

(539) Gce-les ke-sig ra-n ni-mbataqhaw eyig 1SG.IRR-see 3SG.IRR-come.ashore on-3SG NI-reef PROX $\begin{array}{ll}\text { asig } & \text { ko-qom qin. } \\ \text { PERS.PROX } & \text { 3SG.IRR-throw 3SG }\end{array}$

'I will see it washed up on the reef there because that girl will have thrown it.' [07064.240 07064.wav 820.128 825.237]

(540) Qet i-s-leh veq gcen wut re-lip ni-wundi-n na-qanyen but 3SG.R-NEG-good NEG for that 3PL-take NI-part-3SG NV-food

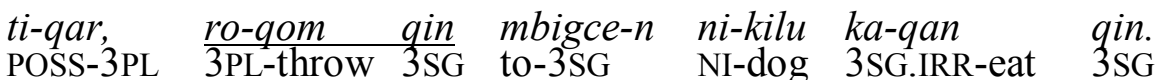
'It isn't right to take the children's food and throw it to the dogs.' [MRK.07:27]

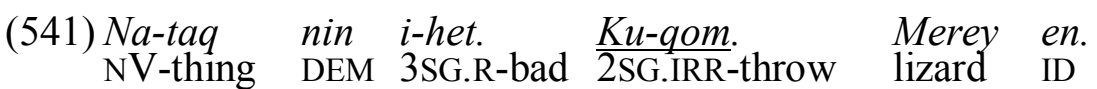

'That thing is bad. Throw it away. It's a lizard.' [07080.009 07080.wav 32.741 37.898]

113 'Throw' could be intransitive with a sense of 'do the throwing', but in Nahavaq, such senses would be marked with reduplication. 
(542) Qet no-qom mbele-n ne-wey nin qet ra-qan.

then 1SG.R-throw into-3SG NV-water DEM then 3PL-eat

'And I threw [the fish] into the water and [the turtles] ate it.' [07117.689 07117.wav 1876.576 1880.389] 


\section{Chapter 5: Clause structure}

There is no single feature that can define the clause in Nahavaq. Instead I define clauses by the general functions that they can serve. Clauses can function:

1. Alone as a proposition

2. As a modifier of a noun (See Section 3.4.7 on relative clauses)

3. As an argument (object of a preposition, object of a verb, subject of a verb, or adverbial adjunct) within a larger clause (Sections 5.4.2.2, 5.4.1, and 5.6.45.6.6).

4. As an adverbial adjunct to another clause (Section 5.4.2)

Section 5.1 outlines different types of clauses (verbal and non-verbal). Section 5.2 describes the characteristics of different sentences types (declarative, interrogative, imperative). Section 5.3 covers topics of modification within the clause, including negation, adjunction, and directional particles. Section 5.4 describes subordinate clauses, and Section 5.5 deals with coordination of clauses. Section 5.6 discusses structures that could be considered under the label of core-layer serial verb constructions.

\subsection{Predicate types}

\subsubsection{Verbless clauses}

While Nahavaq has a copular verbal prefix that can allow nouns to be used as verbal predicates (Section 4.4.3), it is rarely used. Clauses without verbal morphology of any type are fairly common. I have identified three types of verbless clause: identificational, equational, and possessive.

\subsubsection{Identificational clauses}

Identificational clauses (543)-(546) consist of a noun phrase and an identificational particle. As explained in Section 6.4.1, identificational particles are used in presenting, identifying, and indicating. Identificational particles do not function as noun phrases themselves and can occur on all clause types including equational (553) and verbal clauses (570). However, a single noun phrase cannot serve as a complete clause alone and requires an identification particle to form a complete proposition. ${ }^{114}$

$$
\begin{aligned}
& \text { (543)Re-vwer, “Wowow, ni-gcigcaplew etig." } \\
& \text { 3PL-say older.brother NI-spider ID.PROX } \\
& \text { 'And they said, "Big brother, here is a spider."' [07076.037 07076.wav } 142.769 \text { 147.894] }
\end{aligned}
$$

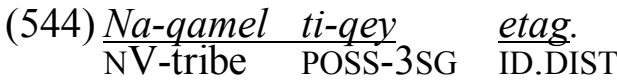

$$
\begin{aligned}
& \text { 'That's his tribal area.' [KA02.005 KA02.wav } 26.219 \text { 35.828] }
\end{aligned}
$$

\footnotetext{
${ }^{114}$ I learned of the importance of identification particles when looking at a picture book with Nahavaqspeaking children. My early attempts at identification statements ('a bird!') with a single noun phrase such as ne-men 'NV-bird' seemed to confuse the children. They didn't understand my point. It wasn't long before they had taught me to do it correctly: ne-men en 'NV-bird ID'.
} 
(545) Na-lambut en.

NV-rat ID

'She's a rat.' [07082.081 07082.wav 310.476312 .742$]$

(546) $\frac{\text { Merey }}{\text { lizard }} \frac{e n}{\mathrm{ID}}$.

'It's a lizard.' [07080.009 07080.wav 32.741 37.898]

\subsubsection{Equational clauses}

Equational clauses are either formed by the juxtaposition of two noun phrases (547)(551) or with an qet-fronting structure (described in 6.1) as in (552)-(553).

(547) I-s-roghur veq wut ni-vinmarlam ti-qey no-qoyit. 3SG.R-NEG-know NEG that NI-old.woman POSS-3SG NV-octopus

'He didn't know that his mother-in-law was an octopus.' [07074.064 07074.wav 277.996 284.300]

(548) Qet qar-yen t-i-metemet, qet tiyigc qet ambwat then 3PL-nom REL-3SG.R-black then DEF.PROX COMPL foreigner qey-yen eg. 3 SG-NOM ID.PROX

'The black one is theirs, and this one is whiteman's.' [07131.008 07131.wav 31.919 34.419]

(549) Gca-s-veqen veq ni-mbwati-n. Nagcon na-vwanevus. 1SG.IRR-NEG-have NEG NI-head-3SG POSS.1SG NV-heart

'I won't take the head. The heart is mine.' [07065.179 07065.wav 687.508 690.336]

(550) Ndo-q-roghur ni-mwelgcil na-taq t-i-het. 1 IN.PL-IRR-know NI-magic NV-thing REL-3SG.R-bad

'We will know that magic is a bad thing.' [07064.284 07064.wav 977.466 980.278]

(551) $\frac{\text { Na-qamel Metenewut }}{\text { NV-tribe }} \quad \begin{array}{llll}\text { Metenewut } & \text { lamamel } t \text {-i-mbow } \\ \text { NV-tribe } & \text { REL-3SG.R-big INTENS }\end{array}$

'The tribe, Metenewut, is a big tribe.' [07111.079 07111.wav 303.424 306.705]

(552) $\frac{\text { Neqhe-n }}{\text { name-3SG }}$ 1SG $\quad \begin{array}{llll}\text { COMPL } & \text { Krivet } & \text { Oped. } \\ \text { Krivet } & \text { Oped }\end{array}$

'My name is Krivet Oped' [KO01.001 KO01.wav 1.836 5.805]

(553) Tinin qet vwinyeh karakar en. DEF COMPL vase.shell ID

'That is a vase shell.' [07117.741 07117.wav 1980.615 1984.286]

\subsubsection{Associative clauses}

There are also clauses consisting of two noun phrases joined by the associative marker nin (Section 3.2.2.4) as in (554)-(556). In all such examples in my corpus, the construction has an origin interpretation. 
(554) Qey nin wut Qoriq.

3SG ASS place Malfaxal

'He was from Qoriq (Malfaxal).' [07086.008 07086.wav 36.430 41.508]

(555) Kinagc veq nin ne-ten tiyigc.

1SG NEG ASS NV-ground DEF.PROX

'I am not from this world.' [JON.08:23]

(556) inugc nin wut ambeh?

2SG ASS place where

'Where do you come from?' [JON.19:09]

\subsubsection{Verbal clauses}

Verbal clauses are the most common kind of clause. Examples (557)-(560) are sequences of clauses taken from texts with each subsequent clause given in a separate line for ease of reference. As can be seen in (558d), (559a), and (560a), the subject of a verbal clause may be overtly stated before the verb. Or if the subject is understood, it can be non-overt as in (557a-b), (558a-c) (559b), and (560b-c). In either case, the person and number of the subject is obligatorily marked on a verbal prefix along with mood. Nahavaq does not have any object marking morphology. Objects simply follow transitive verbs as in (557a), (558a), (559b), and (560c). But as with subjects, objects may not be overtly stated if they are understood (557b), (558b-c). For more information on the verb phrase, see Chapter 4.

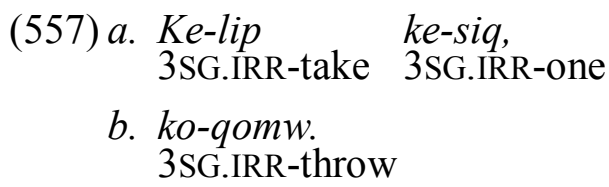

'She would take one and throw it.' [07064.220 07064.wav 765.060 766.935]

(558)a. I-lip ne-men nin, 3SG.R-take NV-bird DEM

b. $i$-mbon mwah i-yar, 3SG.R-pluck all 3SG.R-finish

c. $i$-visig qin. 3SG.R-roast $3 \mathrm{SG}$

d. Ni-mbunog nin i-qan. NI-child DEM 3SG.R-eat

'She took the bird, she completely plucked it, and she roasted it. The child ate it.' [EC01.040 EC01.wav 187.650 194.821]

(559)a. Kinag no-log siley, 1SG 1SG.R-go far

b. qet nigce-s-veqen mbwaq veq ni-mbwati-n." then 1SG.IRR-NEG-have sorry NEG NI-head-3SG

'I have come from far away, so I shouldn't take the (pig's) head.' [07065.178 07065.wav 681.636 687.508] 
(560)a. Qet vanmbug tin, teme-n qar re-makas ndoh levahat, then time DEF father-3SG PL 3PL-out PERF morning

b. re-log

3PL-go

c. gcen re-gcilew na-qanyen.

for 3PL-look.for $\mathrm{NV}$-food

'And that day, his parents left in the morning and went out to look for food.' [KJ01.033 KJ01.wav 156.753 160.721]

\subsection{Sentence types}

\subsubsection{Declarative}

Rather than specifically describing declarative sentences, I will treat them as standard and describe how interrogative and imperative sentences differ from them in Sections 5.2.2 and 5.2.3.

\subsubsection{Interrogative}

\subsubsection{Polar questions}

Polar questions do not differ syntactically from declarative sentences (561), but they have a distinct prosody (Section 2.6). Polar questions often contain the focus particle tey (discussed in 6.3.2) (562)-(564). However, it is not always present (565)-(567).

$$
\begin{aligned}
\text { (561)a. } & \text { Ne-wuh i-vop. } \\
& \text { NV-rain 3SG.R-rain } \\
& \text { 'It is raining.' [08016.wav] } \\
\text { b. } & \text { Ne-wuh i-vop? } \\
& \text { NV-rain 3SG.R-rain } \\
& \text { 'Is it raining?' [08016.wav] }
\end{aligned}
$$

(562) Mwarlamb yigc i-vini tey mahal sut? old.man PROX 3SG.R-shoot FOC fish NONSP

'Did this old man shoot a fish?' [07063.065 07063.wav 269.424 271.752]

(563) T-siley tey en? REL-different $\overline{\text { FOC }}$ and

'Is that a different one?' [07117.595 07117.wav 1696.579 1697.485]

$\begin{array}{lll}\text { (564) U-les } & \text { tey } & \text { no-qonlin? } \\ \text { 2SG.R-see } & \text { FOC NV-egg }\end{array}$

'Do you see the eggs?' [07117.762 07117.wav 2038.079 2039.359]

(565) Ku-rog mor sut ke-mbwil inug? 2SG.IRR-feel man NONSP 3SG.IRR-hit 2SG

'Do you want someone to kill you?' [07063.194 07063.wav 655.361 658.595]

(566) A-s-les veq talay sut qaw na-mbwaq? 2PL-NEG-See NEG clam NONSP or NV-turtle

'Didn't you guys see any clams or turtles?' [07117.118 07117.wav 436.203439 .515 ] 
(567) Ne-vey mbileq etig?
NV-spotted.eagle.ray ID.PROX
'Is this the spotted eagle ray?' [07117.308 07117.wav 1045.762 1047.184]

Examples (568)-(571) show questions using the coordinator qaw 'or' between given options. Again, they are not syntactically distinct from declarative sentences, but they are prosodically distinct (Section 2.6).

(568) Re-mewur tey gceyip qaw re-mes ndoh?

3PL-live FOC yet or 3PL-die PERF

‘Are they still alive, or are they already dead?' [07089.207 07089.wav 974.635 977.369]

(569) U-rirog ne-tes qaw u-rirog ne-wey? 2SG.R-like NV-sea or 2SG.R-like NV-water

'Do you prefer the sea or fresh water?' [07117.057 07117.wav 271.248 274.998]

(570) I-vwer, "Maraw, aleq i-temwin? i-leh tey en? 3SG.R-say you.guys son.in.law 3SG.R-how 3SG.R-good FOC ID qaw aleq. i-liley?"

or son-in-law 3SG.R-crazy

'He said, "You guys, what's my son-in-law like? Is he okay? Or is he crazy?' [LS01.124 LS01.wav 527.473 532.082]

(571) qet u-rirog $k u$-huk ni-mahal t-i-temwin, mahal then 2SG.R-like 2SG.IRR-hook NI-fish REL-3SG.R-like.what fish ti-ko-mbow qaw mahal t-i-vwariq? REL-3SG.IRR-big or fish REL-3SG.R-small

'But what kind of fish do you like to catch, big fish or small fish?' [07117.069 07117.wav 294.935 299.685]

Tag question use either the tag particle $a q$ as in (572)-(573) or qaw 'or' as in (574)(575).

(572) Marlam qar noh re-s-yusum veq ni-mansis, aq? old.man PL long.ago 3PL-NEG-use NEG NI-matches TAG

'The old people before didn't use matches, did they?' [07095.004 07095.wav 18.782 21.661]

(573) A: Na-qup en, aq? B: Na-qup en.

$$
\text { NV-ghost.crab ID TAG NV-ghost.crab ID }
$$

A: 'That's a ghost crab, right?' B: 'Yeah, it's a ghost crab.' [07117.108-109 07117.wav 406.109 408.968]

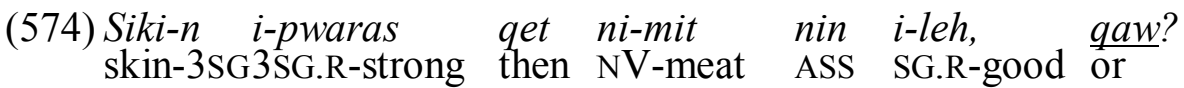

'The skin is strong, but the meat is good, right?' [07117.165 07117.wav 604.433 606.573]

(575) Tinin i-noq re-vwer nigcin-yen ti-vivew, qaw?

DEF 3SG.R-like 3PL-say 1IN.PL-POSS REL-recent or

'This is like ours from before, right?' [07117.792 07117.wav 2097.324 2099.434] 


\subsubsection{Content questions}

Question words (Table 84 below) can occur either in the default position for their grammatical category (576a) or with the question constituent qet-fronted (Section 6.1) as in (576b-c). When an qet-fronted question constituent functions as an object, the resumptive pronoun qin may optionally be used in the object position (576b-c). It is also possible for nominal question words to undergo simple noun phrase fronting (Section 6.2), which requires the resumptive pronoun for objects (576d-e).

$$
\begin{array}{cll}
\text { (576) a. U-qan } & \text { na-havaq? } \\
\text { 2SG.R-eat } & \text { NV-what } \\
\text { b. Nahavaq } & \text { qet u-qan? } & \\
\text { what } & \text { PART } \quad \text { 2SG.R-eat } & \\
\text { c. Nahavaq } & \text { qet } \quad \text { u-qan } & \text { qin? } \\
\text { what } & \text { PART 2SG.R-eat 3SG } \\
\text { d. Nahavaq } & \text { u-qan } \quad \text { qin? } \\
\text { what } & \text { 2SG.R-eat 3SG } \\
\text { e. *Nahavaq } & \text { u-qan? } \\
\text { what } & \text { 2SG.R-eat } \\
\text { 'What did you eat?' [08NB1.074] }
\end{array}
$$

The question words in Table 84 are exemplified in (577)-(595) below.

Table 84: Question words

\begin{tabular}{llll}
\hline Word & Gloss & Grammatical category & Section \\
\hline ne-heve-n 'NV-what-3SG & directly possessed noun & 3.1 .1 \\
na-havaq 'NV-what' & & \\
havaq 'what/what kind' & indirectly possessed noun & 3.1 .2 .3 \\
timbeh & 'which' & post-nominal modifier & 3.4 \\
sep- & 'what/which' & nominal prefix & 3.4 \\
iyaq & 'who' & indirectly possessed noun (human & 3.1 .2 .3 \\
i-vih & 'how many' & quantifier & $4.1 .6,3.4 .1$ \\
temwin 'how/like what' & verb & $4.1,5.6 .4$ \\
$\begin{array}{l}\text { ambeh 'where' } \\
\text { mambeh 'where to' }\end{array}$ & locational noun & 5.3 .2 .1 \\
mbambeh & directional + local noun & 5.3 .2 .4 \\
geyih & 'when' & temporal noun & \\
\hline
\end{tabular}

(577) $O, \quad$ i-tapw $\quad$ ne-heve-m?

oh 3SG.R-prick NV-what-2SG

'Oh, where did it stick you?' [07063.363 07063.wav 1210.522 1212.272] $\begin{array}{cccllll}\text { (578) I-vwer, } & \text { "ne-heve-n } & \text { inug } & \text { etag?” } & \text { I-vwer, } & \text { 'Ndilge-n } & \text { kinag.' } \\ \text { 3SG.R-say } & \text { NV-what-3SG } & \text { 2SG } & \text { ID.DIST } & \text { 3SG.R-say } & \text { ear-3SG } & 1 \mathrm{SG}\end{array}$

'She said, "What part of you is that?" He said, "My ear."' [EC02.049-050 EC02.wav 219.059 222.028] 
(579) Na-havaq qet ne-vwer migce-n inug qor?

NV-what COMPL 1SG.R-say to-3SG 2SG today

'What did I tell you today?' [07064.162 07064.wav 580.498 582.842]

(580) I-vwer, "U-viyal na-havaq?"

3SG.R-say 2SG.R-search.for NV-what

'She said, "What are you looking for?"' [07089.120 07089.wav 564.959 571.267]

(581) A-hermahal havaq?

2PL-take fish what

'What kind of fish did you guys get?' [07117.094 07117.wav 364.417 366.385]

(582) U-yar len yiyah havaq?

2SG.R-finish in year what

'What year did you finish in?' [07117.036 07117.wav 195.095 201.830]

(583) Nuqum timbeh ke-vwer monig nyus ti-qey?

2DU which 3SG.IRR-say (morning news) POSS-3SG

'Which of you two will tell their morning news?' [07048.1179 07048.wav 3508.841 3511.661]

(584) Sep-mbwunog etig?

what-child ID.PROX

'Hey, what boy is that?' [MR01.079 MR01.wav 416.950420 .466 ]

(585) Ku-log mbi-Vilah, qet ku-to-toq gcen iyaq?

2SG.IRR-go to-Vila then 2SG.IRR-DUP-be GOAL who

'When you go to Vila, who will you stay with?' [07117.522 07117.wav 1549.534 1551.753]

(586) Iyaq qet i-huq migce-n inug?

who COMPL 3SG.R-give to-3SG 2SG

'Who gave it to you?' [07090.082 07090.wav 290.724 292.883]

(587) Mbetep i-vih mwah?

breadfruit 3SG.R-how.many all

'How many breadfruit were there all together?' [07044.016 07044.wav 37.750 40.906]

(588) Mweney i-vih ra-n kato i-siq?

money 3SG.R-how.many on-3SG donut 3SG.R-one

'How much money for one donut?' [07048.1326 07048.wav 3764.885 3766.275]

(589) I-vwer, "Maraw, aleq. i-temwin?

3SG.R-say you.guys son.in.law 3SG.R-like.what

'He said, "You guys, what's my son-in-law like?"' [LS01.124 LS01.wav 527.473 532.082] 
(590) mor ke-lesur

vovoh na-qayew ke-meh man 3SG.IRR-recognise INTENS NV-pudding 3SG.IRR-cooked

ke-temwin en? 3SG.IRR-how ID

'How does one know for sure that the pudding is done?' [RF-MF01.017 RFMF01.WAV 83.410 92.895]

(591)Ku-qan kinag ke-temwin? 2SG.IRR-eat $1 \mathrm{SG}$ 3SG.IRR-how

'How will you eat me?' [07133.023 07133.wav 99.745 104.417]

(592) A-her-her taq yig qar ambeh en? 2PL-DUP-take thing PROX PL where ID

'Where do you get these things?' [07132.008 07132.wav 44.975 50.255]

(593) Ambeh qet gce-vwul pistas ti-kinag? where COMPL 1SG.IRR-buy peanut POSS-1SG

‘Where will I buy my peanuts?' [07058.049 07058.wav 183.566 185.629]

(594) Qet i-rop $\frac{m \text {-ambeh? }}{\text { to-where }}$

'But where did it run to?' [07048.0508 07048.wav 932.294 933.724]

(595) Geyih ndoh qet ke-mes. when PERF COMPL 3SG.IRR-die

'When will she die?' [07081.014 07081.wav 60.438 64.188]

\subsubsection{Non-interrogative uses of question words}

Interrogative sentences have a goal of eliciting information. However, there are at least two uses of question-like constructions in Nahavaq that do not have this goal. The first is when an interrogative clause functions as the complement to a larger clause (5.4.1.1). Another use of question words without interrogative purpose in a nonspecific 'any' sense as in the declarative sentences in (596)-(598).

(596) Ru-log ru-log, mbunog ko-rog ke-sum-ndew ambeh, 3DU-go 3DU-go boy 3SG.IRR-feel 3SG.IRR-sit-rest where

vene-n ko-log tey ke-sum hur. sister-3SG 3SG.IRR-go FOC 3SG.IRR-sit near

'They walked and walked, and anywhere the boy wanted to sit down, his sister would just go and sit next to him.' [07064.174-175 07064.wav 616.733 622.968]

(597) U-roghur ku-huq ni-ndis qaw na-havaq tinin t-u-siriq 2SG.R-can 2SG.IRR-put NI-dish or NV-what DEF REL-2SG.R-stick

na-qanyen t-inug len

$\mathrm{NV}$-food POSS-2SG in

'You can put a dish or anything that you put your food in.' [07051.629-630 07051.wav 2300.133 2304.243] 
(598) Mbetep naqay-ru-yen ke-sep, ke-qep-pet naqay-ru-yen. breadfruit ORD-two-NOM 3SG.IRR-fall 3SG.IRR-bend-break ORD-two-NOM

Naqay-tul-yen ke-sep, ke-qep-pet naqay-tul-yen. ORD-three-NOM 3SG.IRR-fall 3SG.IRR-bend-break ORD-three-NOM

Mbetep ke-vih, ko-log ko-log kolog... breadfruit 3SG.IRR-how.many 3SG.IRR-go 3SG.IRR-go 3SG.IRR-go

'When the second breadfruit falls, he breaks the second (leaf). When the third breadfruit falls, he breaks the third. For any number of breadfruit, it goes on and on.' [07044.011-014 07044.wav 25.915 33.032]

\subsubsection{Imperative}

Imperatives for all persons and numbers are constructed using the irrealis mood (Section 4.2.2.2), but no other special morphology is necessary. Examples are given below of imperative constructions for different subjects: second person singular (599), dual (600), and plural (601) and first person inclusive dual (602) and plural (603).

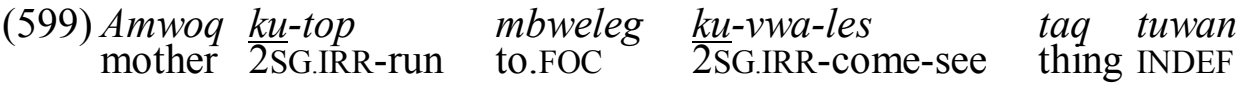
etig.
ID.PROX
'Mother, come here and look at this.' [EC01.045 EC01.wav 214.994 220.775]
(600) Wa-q-s-mbwal gcow veq. Wa-q-koh-lalaq. 2DU.R-IRR-NEG-fight EMPH NEG 2DU.R-IRR-be-quiet
'Don't (you two) fight! Be quiet.' [07117.826]
(601) I-vwer 'A-q-gcilew ni-gcigcaplew.'
3SG.R-say 2PL-IRR-look.for NI-spider
'He said, “(You guys) look for a spider.”' [07076.033 07076.wav 128.816 133.832]

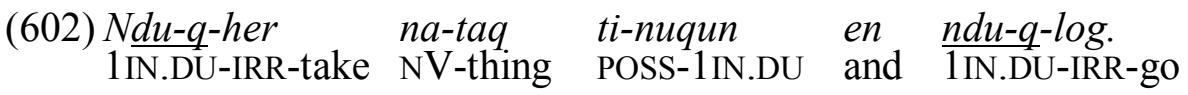
'Let's get our things and go.' [EC01.048 EC01.wav 230.102 233.414]
(603) En i-vwer $\quad$ nda-q-yal-yal mwin lis. and 3SG.R-say 1IN.PL-IRR-DUP-sing first again
'And he said, "Let's sing again.”" [тв01.046 TB01.wav 204.850 208.083]
There is no syntactic difference between imperatives and irrealis declarative sentences, and sometimes, there can be semantic or pragmatic ambiguity between the two interpretations as in (604) taken from a narrative text. While imperatives may have distinctive intonation patterns which can distinguish them from declarative sentences (Section 2.6), this is not always the case, and many clearly imperative statements have intonation that seems similar to default declarative sentences. The use of modifiers such as mwin 'first' (Section 4.7.5.4), tey 'FOCUS' (Section 6.3.2), and gcow 'EMPHATIC' (Section 4.7.5.1) may help to give an imperative interpretation 
to some utterances. These modifiers may be seen in Examples (600), (603), and (605), and even in (607), which has debatable status as an imperative. ${ }^{115}$

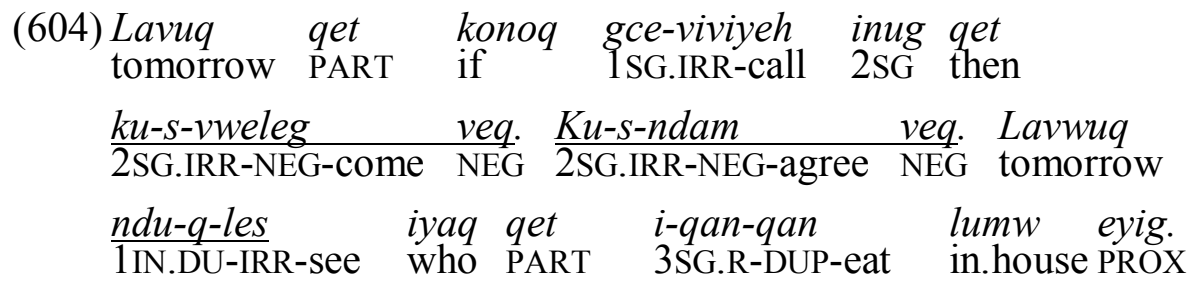

'Tomorrow when I call you, don't come/you won't come. Don't answer/you won't answer. Tomorrow we will see/let's see who it is that has been eating here in our house.' [07082.048-049 07082.wav 197.969 207.155]

Prohibitive statements are made exactly as imperatives, but with a negated verb as in (605)-(606) and (600) above.

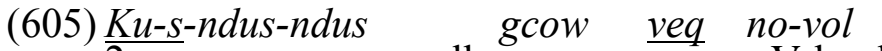

$$
\begin{aligned}
& \text { 2SG.IRR-NEG-DUP-pull EMPH NEG NV-book }
\end{aligned}
$$

$$
\text { (606) } \frac{K u-s-\operatorname{logo}-\log }{2 \text { SG.IRR-NEG-DUP-go }} \quad \begin{array}{ll}
\text { NEG } & \text { mbi-siley. } \\
\text { to-far }
\end{array}
$$

'Don't go far.' [KO02.007 KO02.wav 34.13141 .521 ]

While definitions of imperatives are often limited to constructions involving an addressee, there are constructions in Nahavaq such as (607) and (608) which refer to first or third persons, but are similar to imperatives in that they use irrealis mood to talk about future events that will happen under the speaker's authority. I cannot see any reason to consider the constructions in (607) and (608) differently from (599)(605) above.

$$
\begin{aligned}
& \text { (607)I-vwer, "Ku-hapw tey. Gco-log gargar mwin." } \\
& \text { 3SG.R-say 2SG.IRR-dance FOC 1SG.IRR-go quick first }
\end{aligned}
$$

\footnotetext{
${ }^{115}$ Note that for some speakers, irrealis mood is not marked on verbs with non-singular subjects (Section 4.2.1), so imperative meaning cannot be conveyed through mood for non-singular subject. For these speakers, mwin 'first', tey 'FOC', and gcow 'EMPH' may have added importance in conveying imperative meaning.
} 


\subsection{Clause modification}

\subsubsection{Negation}

When verbal clauses are negated, there are normally two negative elements present (609)-(611), an $s$ - prefix directly to the right of the subject/mood prefix and veq which occurs after the verb root and PVM1s (Section 4.7) such as ndal 'back' in (610).

(609) En ru-s-les $\quad \underline{v e q}$ ni-mbetep nin. and 3DU.R-NEG-see NEG NI-breadfruit DEM

'But they didn't see the breadfruit.' [07088.010 07088.wav 70.179 73.413]

(610) Re-s-wul ndal veq migce-n. 3PL-NEG-whine back NEG to-3SG

'They didn't whine back to her.' [07089.224 07089.wav 1036.555 1045.819]

$\begin{array}{lllll}\text { (611) Avwuraraq i-qan } & \text { qet } & \text { i-s-mbwar } & \text { veq } & n i-m b o g o-n . \\ \text { Avwuraraq 3SG.R-eat } & \text { but } & \text { 3SG.R-NEG-wipe } & \text { NEG } & \text { NI-mouth-3SG }\end{array}$ 'Avwuraraq ate it, but he didn't wipe his mouth.' [07065.281-282 07065.wav 1022.792 1026.439]

However, some speakers omit the $s$ - prefix (612)-(613). This is particularly common among younger speakers (under 30), but the speakers of Examples (612) and (613) are 65 and 43-years-old respectively. Both of them produce the $s$ - prefix more often than they omit it. The omission of $s$ - does not change the meaning in any way, and many other speakers consider such constructions ungrammatical.

(612) Gce-lip $\begin{array}{lll}\text { Gas } & \text { gargar } & \text { veq. } \\ \text { 1SG.IRR-take } & \text { out } & \text { quick }\end{array}$

'I won't take it out quickly.' [07112.199 07112.wav 1153.388 1156.669]

$\begin{array}{llllll}\text { (613) No-s-roghur veq } & \text { ke-viyag } & \text { qaw } & \text { ke-viyag } & \text { mbeq } & \text { veq. } \\ \text { 1SG.R-NEG-know NEG } & \text { 3SG.IRR-light } & \text { or } & \text { 3SG.IRR-light } & \text { maybe } & \text { NEG }\end{array}$ 'I don't know whether or not it will light.' [07095.036 07095.wav 210.986 215.564]

Example (614) shows a nominalised negated verb. The negative prefix $s$ - occurs before the verb root while the second negative marker veq occurs after the nominalising suffix.

(614) En qey ke-viqis ndal ni-s-rogndew-yen veq qar ndal and 3SG 3SG.IRR-turn back NI-NEG-believe-NOM NEG PL back

lis mbweleg hur na-hal t-i-leh again to.FOC near NV-road REL-3SG.R-good

'And he will turn the non-believers back to the good road.' [LUK.01:17]

Other elements such as prepositions and nouns can also be negated. Example (615) shows a negated preposition. The negative marker veq occurs between the preposition and its nominal object. 
(615) Re-seger 3PL-disappear

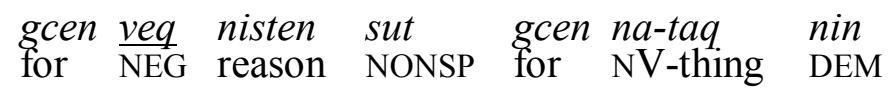

'They disappeared for no reason and this is what I am going to tell here.' [KJ01.009 KJ01.wav 32.248 36.607]

When noun phrases are negated, veq occurs directly after the nominal head. Negation on nouns is most common in identification clauses (616)-(617), equational clauses (618), and qet-fronted noun phrases (619)-(620). (621) shows a negated associative clause.

(616) Qet na-mwat veq en, ne-tel en.

but NV-snake NEG ID NV-vine ID

'But it's not a snake, it's a vine.' [07037.016 07037.wav 35.906 41.094]

$\begin{array}{clll}\text { (617) I-vwer, “awaq } & \text { kinag veq en." } \\ \text { 3SG.R-say no } & \text { 1SG NEG ID }\end{array}$

'He said, "No, it wasn't me."” [07082.029 07082.wav 121.314 123.642]

(618) Ni-mbuyaq yig ni-mbuyaq veq t-morot ka-qan eg. NI-water.taro PROX NI-water.taro NEG REL-man 3SG.IRR-eat ID.PROX

This water taro is not a water taro that people eat. [07047.002 07047.wav 5.640 8.922]

(619)Kinag veq qet ne-lip ni-mbetep $t$-nuqumw.

1SG NEG COMPL 1SG.R-take NI-breadfruit POSS-2DU

'It was not me who took your breadfruit.' [07088.014 07088.wav 89.554 97.726]

(620) Awaq, mbwuhmbwuh veq qet nag ne-vwer.

no puffer.fish

'No, I didn’t say pufferfish.' [07131.030 07131.wav 105.634 108.853]

(621)En qar veq nin ne-ten tiyigc.

and 3PL NEG ASS NV-earth DEF.PROX

'They do not belong to the world.' [JON.17:16]

When modified nouns are negated, veq occurs after the nominal head and before postnominal modifiers. ${ }^{116}$ Example (622) shows an identificational clause that contains a

\footnotetext{
${ }^{116}$ There are a few items in my corpus that appear to be negated nouns with veq occurring after postnominal modifiers. This includes the phrases taq sut veq 'thing NONSP NEG' and mor sut veq 'man NONSP NEG'. However, because these contain the monosyllabic forms rather than the disyllabic na-taq 'nV-thing' and morot 'man' (see Section 2.8.2 on the subject of monosyllabic content words), I suspect that taq-sut and mor-sut are compounds rather than examples of productive nominal modification.

Another is the following in which two nouns appear to be coordinated with a post-nominal modifier, ruwar (See Section 4.5 on nominal coordination).

$\begin{array}{lllllllll}\text { gcen } & \text { ni-mbe-n } & \text { en } & \text { ne-ndey } & \text { ruwar veq } & \text { qet } & \text { ru-vihigc } & \text { qin } & \text { inugc, } \\ \text { because } & \text { NI-body-3SG } & \text { and } & \text { NV-blood } & \text { DU NEG } & \text { PART } & \text { 3DU-show } & \text { OBL } & \text { 2SG }\end{array}$

'It was not flesh and blood that showed it to you.' [MAT.16:17]

Unlike (622)-(626), this involves negation of an qet-fronted constituent. It may be the case that the negator always occurs after the phrase rather than after the head in such cases. Further investigation is needed.
} 
negated noun phrase with veq occurring before the associative nin modifier. Example (623) shows $t i$ - possession in a negative noun phrase. Examples (624) and (625) show negated noun phrases modified by relative clauses, and (626) shows a negated noun phrase with the non-specific modifier, sut. Interestingly, in many of these cases of negated post-modified nouns, it is in fact the modifiers (which occur after veq) that are semantically negated. For example, in (624) the item identified is in fact a peniswrapper, but it is not a small one. In (625) the man takes things, but they are not his things, and he takes food from a garden, but it is not his garden.

(622) Ni-ligleg veq nin ni-solop etig!

NI-oil NEG ASS NI-eel ID.PROX

'This is not eel broth!' [KJ01.058 KJ01.wav 301.160 309.519]

(623) Neqhe-n i-noq tey re-vwer mbwuhmbwuh ti-law, qet name-3SG 3SG.R-like FOC 3PL-say mbwuhmbwuh POSS-sea but mbwuhmbwuh veq ti-law en. mbwuhmbwuh NEG POSS-sea ID

'Its name is just like the pronunciation of the Mbwuhmbwuh of the sea (pufferfish), but it is not the Mbwuhmbwuh of the sea (referring to a plant called Mbwuhmbwuh.' [07131.027 07131.wav 94.587 98.118]

(624) Na-qapsu-n veq ti-i-vwariq sut en. Awaq, NV-penis.wrapper-3SG NEG REL-3SG.R-small NONSP ID no

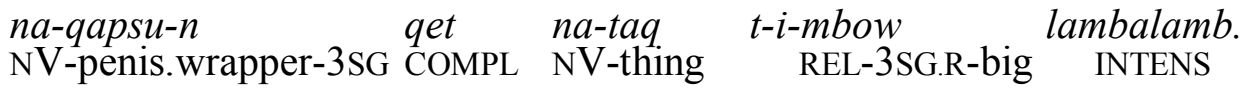

'His penis-wrapper was not a small one. No, his penis-wrapper was a very big thing.' [07063.107 07063.wav 401.356 409.309]

(625) Inugcu-log u-lip na-taq veq t-inugc u-qambwiq 2SG 2SG.R-go 2SG.R-take NV-thing NEG REL-2SG 2SG.R-plant $\begin{array}{lllll}\text { qin, en } & \text { inugc u-log } & \text { u-lip } & \text { na-qanyen len } & \text { ne-hew } \\ \text { 3SG and } & \text { 2SG 2SG.R-go } & \text { 2SG.R-take NV-food in }\end{array}$ t-inugc.

POSS-2SG

'You go and take things that you did not plant, and you go and take food from a garden that is not yours.' [LUK.19:21]

$\begin{array}{lllllll}\text { (626) Inugc u-vwer } & \text { wut inugcveq } & \text { qet } & \text { Kristo, qor Elisah } & \text { qor } \\ \text { 2SG 2SG.R-say that 2SG NEG COMPL Christ } & \text { or } & \text { Elisah or }\end{array}$

Provet veq sut. prophet NEG NONSP

"You say that you are not Christ or Elisah, or a prophet." [JON.01:25]

\subsubsection{Spatial and temporal adjuncts to clauses}

I define adjuncts as elements that can be added to a clause but are syntactically optional. A wide range of elements fit this definition, including adverbial clauses which are discussed separately in Section 5.4.2. This section describes spatial and temporal adjuncts. They are grouped into three morphosyntactic categories: locational and temporal nouns (Section 5.3.2.1), lV-prefixed nouns (Section 5.3.2.2), 
and prepositions (Section 5.3.2.3). In addition, another class of adjuncts, directional particles, can be used in combination with any of the spatial adjuncts or independently (Section 5.3.2.4).

Spatial adjuncts usually occur at the end of clause as in (627). Most temporal adjuncts occur more freely in a range of positions. For example, in the elicited sentence (628), lambwum 'yesterday' can occur in any position without any discernable change in meaning. However, note that the option for lambwum after newey ' $\mathrm{NV}$-water' involves possessive modification of a noun phrase rather than adjunction to the clause (i.e. 'yesterday's water').

(627) U-rirog tey ku-vwahupw law? 2SG.R-like FOC 2SG.IRR-bathe shore

'You like to bathe in the sea?' [07117.057 07117.wav 271.248 274.998]

(628)(Lambwum) hala-q (lambwum)i-vwer (lambwum) yesterday brother-1SG yesterday 3SG.R-say yesterday

ne-wey (t-lambwum) i-malqah (lambwum). $\mathrm{NV}$-water POSS-yesterday 3SG.R-cold yesterday

'My brother said that the water was cold yesterday.' [06NB6.008 $]^{117}$

\subsubsection{Locational and temporal nouns}

Locational and temporal nouns include those listed in Table 85 and Table 86 below and also place names and the demonstrative locational adjuncts, which are discussed in Section 6.4.1. Example (629) shows two locative nouns, the place name Mbenewur, and the distal locative, eyag.

$\begin{array}{llll}\text { (629) I-tip-tip } & \text { ra-n } & \text { ne-vet } & \text { Mbenewur eyag. } \\ \text { 3SG.R-DUP-sprout } & \text { on-3SG } & \text { NV-stone } & \text { Mbenewur }\end{array}$

'And it grows on the rocks over there at Mbenewur.' [07131.010 07131.wav 37.044 38.882]

Unlike canonical nouns, locational and temporal nouns do not usually function as arguments of verbs. However, they have some nominal properties. For example, many locational and temporal nouns can act as possessors in $t i$ - possession constructions as in (630)-(632).

(630)En Aimbel, ni-vi-lawa-n-yen t-mbenewur, $i$-veqen and Aimbel NI-COP-nephew-3SG-NOM POSS-Mbenewur 3SG.R-have ni-momoq nin wut Qonevet. NI-woman ASS place Qonevet

'And Aimbel, a nephew of Mbenewur, he married a woman of Qonevet,' [07098.082 07098.wav 417.063 426.017]

(631) Ne-les ndoh mbunog ti-qor war. 1SG.R-see PERF child POSS-today DU

'I have seen those two boys from (earlier) today.' [07010.052 07010.wav 135.651 138.649]

${ }^{117}$ Example (628) was elicited using Dahl's (1985) questionnaire, question number 113. 
(632) Neqhe-n i-noq tey re-vwer mbwuhmbwuh ti-law, qet name-3SG 3SG.R-like FOC 3PL-say mbwuhmbwuh POSS-shore then mbwuhmbwuh veq ti-law en mbwuhmbwuh NEG POSS-shore ID

'Its name is just like the pronunciation of the Mbwuhmbwuh of the sea (pufferfish), but it is not the Mbwuhmbwuh of the sea (referring to a plant called Mbwuhmbwuh.' [07131.027 07131.wav 94.587 98.118]

Table 85: Temporal nouns

\begin{tabular}{llll}
\hline qor & 'today' & masasag & 'near future' \\
qorigc & 'now' & tartar & 'always' \\
noh & 'long ago' & vales valyes 'occasion' \\
nuyih & 'long ago' & vwanmbwug 'occasion' \\
vivew & 'recently' & mbonos & 'occasion' \\
\hline
\end{tabular}

The temporal nouns from Table 85 are demonstrated in Examples (633)-(642). The temporal nouns vales, vwanmbwug, and mbonos, all meaning 'occasion' are only attested clause-initially with a post nominal modifier as exemplified in (640)-(642) below.

(633) Mahal yigc qet mi-lip len net qor. fish PROX COMPL 1EX.PL.R-take in net today

'This is the kind of fish we caught in the net today.' [07117.156 07117.wav 576.978 580.447]

(634) Qorig kinag ohoy ndoh no-toq-sar. now $1 \mathrm{SG}$ simply PERF 1SG.R-be-remain

'Now only I remain.' [07089.138 07089.wav 646.539 653.039]

(635) Ne-yumw yigc $\mathrm{NV}$-house PROX old.woman 3SG.R-DUP-make long.ago INSTR-3SG

ni-mberep. NI-pandanas

'This house the old ladies used to make long ago from pandanas.' [07099.002 07099.wav 8.638 12.373]

(636) Nuyih qet mi-yusum nuwuryet qet mi-rah-rah long.ago COMPL 1EX.PL-use sago.branch then 1EX.PL-DUP-grate

$r a-n$.

INSTR-3SG

'In the past we grated with the sago palm.' [07091.008 07091.wav 49.337 52.384]

(637) Mi-log vivew mi-vene-ven ne-men ra-n ni-ruquh 1EX.PL-go recent 1EX.PL.R-DUP-hunt NV-bird on-3SG NI-hill

utin.

PLACE

'We went hunting earlier for birds on the hill up there.' [07117.287 07117.wav 967.185 972.060] 
(638)I-vivar tartar tey ruwar.

3SG.R-warn always FOC 3DU

'She always warned them.' [07073.034 07073.wav 123.999 126.890]

(639) Tartar ohoy tey, ro-log gcen hapw-hapw-yen qet war always simply FOC 3PL-go for DUP-dance-NOM then 3DU ru-q-log mbonombon. 3DU-IRR-go together

'Every time when people went to dances, the two of them went together.' [07064.022-023 07064.wav 102.871 108.698]

(640) En ni-vilamb nin, vales tuwan, ru-vweleg gcen ru-vwahupw. and NI-girl DEM time INDEF 3DU.R-come for 3DU.R-bathe

'And the girls once came to bathe.' [07111.017 07111.wav 72.915 75.603]

(641)En vwanmbwug tinin, ni-vingcowum i-rog ko-noq wut and time DEF NI-vingcowum3SG.R-feel 3SG.IRR-like that $\begin{array}{ll}\text { ru-les } & \text { qin. } \\ \text { 3DU.R-see } & \text { 3SG }\end{array}$

'And on that occasion, Nivingcowum wanted them to see him.' [07072.036 07072.wav 219.349 224.787]

(642) Mbonos tuwan, ni-marlam i-log i-vwer ke-vey time INDEF NI-old.man 3SG.R-go 3SG.R-say 3SG.IRR-go

len gcurtaq-yen tuwan sun.

in celebrate-NOM INDEF somewhere

'One time, the old man left to go to a celebration somewhere.' [08009.068 08009.wav 383.414 390.367]

Table 86: Locational nouns

\begin{tabular}{llll}
\hline law & 'shore (from land)' & vusar & 'outdoors' \\
verqeh & 'shore (from sea)' & mwasasag 'near' \\
eraqay & 'uphill/left facing sea' & siley & 'far' \\
eyten & 'downhill/right facing sea' & sund & 'somewhere/anywhere' \\
eyumw & 'in the village' & ambeh & 'where' \\
\hline
\end{tabular}

The locational nouns from Table 86 are exemplified in (643)-(652):

(643) Ku-log ku-vene-ven mahal law. 2SG.IRR-go 2SG.IRR-DUP-shoot fish shore

'Go and shoot fish in the sea.' [07089.022 07089.wav 138.698 142.011]

(644)I-hupw, i-hupw, ni-vilamb ru-taris tey vergeh. 3SG.R-wade 3SG.R-wade NI-girl 3DU.R-stand FOC shore

'Then he swam and swam and the girls just stood on the shore.' [07072.110 07072.wav 653.845659 .110$]$

(645) Kamem mi-koh len yat skul eraqay.

1EX.PL 1EX.PL-be in yard school inland

'We were in the school yard inland.' [07086.043 07086.wav 177.873 180.083] 
(646) En na-vwa-n re-lepe-lep hur ne-wey eyten. and $\mathrm{NV}$-fruit-3SG 3PL-DUP-spill near $\mathrm{NV}$-water down

'And the fruits spilled down near the river below.' [07111.016 07111.wav 69.352 72.915]

(647) I-toq lembunqay, en mwamwah ti-qey i-toq tey 3SG.R-be bush and mother POSS-3SG 3SG.R-be FOC evumw. village

'He went into the bush. He was in the bush and his mother just stayed home.' [07082.011 07082.wav 47.427 52.537]

(648) Gcen misis i-sumbw tey vusar utin en. because white.woman 3SG.R-sit FOC outside PLACE ID

'Because the white woman is sitting there outside.' [07048.0340 07048.wav 613.797 615.867]

(649) Ru-vwer, "mwur-logo-log tey mwasasag." 3DU.R-say 1EX.DU-DUP-go FOC near

"And they told their lie, "We just walked around nearby." [07073.029 07073.wav 103.966 108.201]

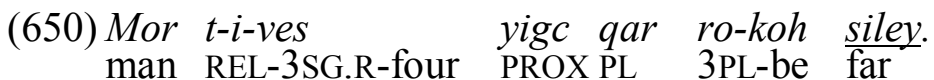

'These four guys were sitting far off.' [07065.105 07065.wav 439.977 443.259]

$\begin{array}{llll}\text { (651) I-vwer } & \text { ke-vey len gcurtaq-yen tuwan } & \text { sund. } \\ \text { 3SG.R-intend } & \text { 3SG.IRR-go in } & \begin{array}{l}\text { selebrate-NOM INDEF } \\ \text { somewhere }\end{array}\end{array}$

'He was going to go to a celebration somewhere.' [08009.068 08009.wav 383.414 390.367]

$\begin{array}{llll}\text { (652) } K u \text {-vwul } & \text { pistas } & \text { t-inugc } & \text { ambeh? } \\ \text { 2SG.IRR-buy } & \text { peanut } & \text { POSS-2SG } & \text { where }\end{array}$

‘Where will you buy your peanuts?' [07058.083 07058.wav 312.564 318.626]

\subsubsection{2. $l \mathrm{~V}$-prefixed nouns}

(Section 3.1.2.4.1 describes some proper place names that can fit into this category.) There is a set of locational noun-like words such as la-qamb 'LOC-fire' that have an apparent $l \mathrm{~V}$ - prefix. However, I am undecided on how to analyse these words. One possible analysis would be that $l \mathrm{~V}$ - is a locative case prefix. However, a case can be made for the $l \mathrm{~V}$ - prefix being a reduced form of the transitive prepositional adjunct len 'in' (Section 5.3.2.3.8). Example (653a-b) shows an $l \mathrm{~V}$ - prefixed form in a parallel with a len prepositional phrase. For all the items in Table 87, a $l \mathrm{~V}$ - prefixed word is syntactically equivalent to a len + NOUN prepositional phrase. However, the set of nouns that can have the $l \mathrm{~V}$ - prefixes is restricted. Many nouns that frequently occur after len, such as ne-hew 'NV-garden' or ne-tes ' $\mathrm{NV}$-sea', cannot be prefixed with $l \mathrm{~V}$-: *le-hew, *le-tes. For now, I will consider $l \mathrm{~V}$ - to be a locative prefix (glosses as LOC), but I feel there is also a relationship to the len preposition. 
$\begin{array}{lll}\text { a.tu len } & \text { na-qamb. } \\ \text { 3SG.R-put in NV-fire } & \text { in }\end{array}$

'She put it in the fire.' [07088.026 07088.wav 163.328 173.437]

b. Wa-q-s-lip veq mbetep tiyig wa-tu 2DU-IRR-NEG-take NEG breadfruit DEF.PROX 2DU-put

$\frac{\text { la-qamb }}{\text { LOC-fire fon }} \begin{aligned} & \text { nigca-qan len. } \\ & \text { for }\end{aligned}$

'Don't take breadfruit wood and put it in the fire for me to eat from.' [07088.021 07088.wav 135.123 145.286]

Table 87: Morphologically transparent $l V$ - locational adjuncts

\begin{tabular}{llll}
\hline Locational noun & \multicolumn{2}{l}{ Argument noun } \\
\hline leten & 'down' & ne-ten & 'ground' \\
laqamb & 'in fire' & na-qamb & 'fire' \\
lendiq & 'in bed' & ne-ndiq & 'NV-bed' \\
liqimel & 'in meeting house' na-qamel & 'NV-meeting house' \\
luwey & 'in river & $n e-$-wey & 'river' \\
liyumw & 'in house' & ne-yumw & 'NV-house' \\
lombogo- $n$ & 'in mouth-3SG' & $($ ni-)mbogo-n & 'mouth-3SG' \\
lombogo- $q$ & 'in mouth-1SG' & $($ ni-)mbogo- $q$ & 'mouth-1SG' \\
lendagndag & 'in chrysalis' & $($ ni-)ndagndag & 'chrysalis' \\
levetevet & 'in yam bed' & $($ ni-)vetevet & 'yam bed' \\
lembusmbwar & 'in swamp' & $($ ni-)mbusmbwar & 'swamp' \\
leveti- $n$ & 'in belly-3SG' & $($ ni-)veti-n & 'belly-3SG' \\
levulus livulus 'in oven' & $($ ni-)vulus & 'earth oven' \\
lembunqay & 'in bush' & $($ ni-)mbunqay & 'plantation' \\
\hline
\end{tabular}

Note that the vowel in the locative prefix is not fully predictable from the nominal root or the $n V$-nominal prefix of the argument form. But there is a tendency for the vowel in the locative prefix to match the first vowel of the root (as with $n V$ - nominal prefixation discussed in Section 2.4.7), and for many of the nouns with optional $n i$ prefixation, the locative prefix appears as le-. In the case of luwey 'in river' and liyumw 'in house', the vowel of the prefix appears to be influenced by an initial glide of the root even when that is not the case in the argument form. Liqimel 'in meeting house' shows different vowels in both the prefix and the root compared to the argument form naqamel. This remains unexplained. While the composition of the words in Table 87 is transparent, the $l \mathrm{~V}$ - prefixed words in Table 88 are less transparent because they do not have synchronic canonical noun cognates.

Table 88: Morphologically opaque $l$ - adjuncts

\begin{tabular}{llll}
\hline Temporal & & Local & \\
\hline lambwum & 'yesterday' & livwaqa-n & 'in the middle-3SG' \\
lavuq & 'tomorrow' & livwaqa-n-tes & 'at sea' \\
levwaqhat & 'morning' & livwaqa-n-mehep & 'up' \\
livwaqat & 'night' & livwuq & 'among' \\
lereg & 'dawn' & lembwitqey & 'uncultivated bush' \\
larap & 'evening' & & \\
livwaqalyes & 'midday' & & \\
\hline
\end{tabular}


Since a non-prefixed form of the words in Table 88 does not exist, my criteria for interpreting them as prefixed are: 1 . they begin with $/ \mathrm{lV} /$ and 2. they function as temporal or locative adjuncts as do the forms in Table 87. Law 'seaward', while it begins with $/ 1 /$, is included with the nominal adjuncts rather than the $l \mathrm{~V}$ - prefixed adjunct because it appears to have derived as a single morpheme from POc *laur 'seaward', which was also a local noun (Ross 2004: 186), and also because if la-were a prefix, $w$ could not constitute a nominal root, as all nominal roots synchronically contain at least one syllable.

\subsubsection{Prepositions}

I define prepositions as elements that take a direct object (but have no subject-related morphology) and function as the head of a prepsotional phrase, which acts as an adjunct to a clause. ${ }^{118}$ Objects may be overtly realised as noun phrases as in (654) or non-overt if the reference is understood as in (655).

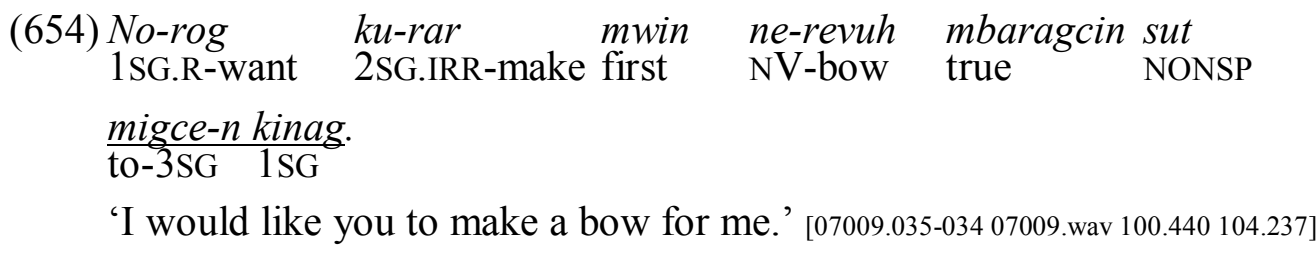

$\begin{array}{llllll}\text { (655) I-log } & \text { gcen } i \text {-vwer } & \text { ko-vowus hine-n } & \text { mbwilqey } \\ \text { 3SG.R-go } & \text { because 3SG.R-intend } & \text { 3SG.IRR-carry mother-3SG tamtam } \\ \text { ti-qey } & \text { qet i-les } & \text { vene-n } n & \text { i-metur. } & \text { i-metur tey len. } \\ \text { POSS-3SG } & \text { then } & \text { 3SG.R-see } & \text { sister-3SG } & \text { 3SG.R-sleep3SG.R-sleepFOC in }\end{array}$

'He went to get his big tam-tam drum but he saw his sister sleeping. She was sleeping inside it.' [07064.264-265 07064.wav 905.268 913.158]

Nahavaq's prepositions can be divided into those which take a suffix resembling those of direct possession (Table 89 below) and those that do not (Table 90 below).

(Section 3.2.1 describes direct possession suffixes that occur on nouns).

\begin{tabular}{llll}
\multicolumn{2}{c}{ Table 89: } & Prepositions with direct possession suffixes \\
\hline 1SG & 2SG & 3SG & gloss \\
$r a-q$ & $r a-m w$ & $r a-n$ & 'on' \\
& & $n d i l q i-n$ & 'away from' \\
& & $e h u-n$ & 'away from' \\
embu-q & embu-mw & embu- $n$ & 'down in' \\
& & $e v u-n$ & 'with, under' \\
& & silevu- $n$ & 'underneath' \\
& & & \\
& &
\end{tabular}

\footnotetext{
${ }^{118}$ Note that $n i-n$ 'associative-3SG' (Section 3.2.2.4) is preposition-like in that it is a non-verbal, nonnominal element that takes an object, and it also has the direct possession suffix that many prepositions have. However, it occurs as a modifier on noun phrases rather than a clausal adjunct, and is therefore excluded from my definition of prepositions.

${ }^{119}$ Some of the prepositions in Table 89 are listed with only 3SG forms. In an unrecorded elicitation session, I investigated prepositions ending in $n$ and found that only len, qin, and gcen were invariable (at least synchronically). Therefore, I include $n$ dilqi- $n$, ehu- $n$, evu- $n$, and silevu- $n$ in Table 89 despite having no record of their $1 \mathrm{SG}$ and $2 \mathrm{SG}$ forms. It seems possible that the $n$ in len, qin, and gcen was originally a 3SG suffix that has now been frozen as part of the preposition.
} 
Table 90: Prepositions without suffixes

\begin{tabular}{ll}
\hline len & in ; at (point in time) \\
hur & near ; about (topic); for (duration) \\
luqur & with (accompany) \\
(war/mbon) qin & with (accompany) \\
qin & (oblique) \\
gcen & for (purpose), because of (reason) \\
\hline
\end{tabular}

Several related languages such as Lolovoli (Hyslop 2001: 134), V'ënen Taut (Fox 1979: 43), Naman (Crowley 2006b: 155), Tape (Crowley 2006d: 173), and Nāti (Crowley 1998b: 126) also have direct possession suffixes on a portion of their prepositions. These prepositions may have evolved from directly possessed nouns. In Nahavaq, direct possession prepositions, like direct possession nouns, can occur with $-q$ ' $1 \mathrm{SG}$ ' $-m w$ ' $2 \mathrm{SG}$ ' or $-n$ ' $3 \mathrm{SG}$ ' suffixes (656), but most often occur with the $-n$ ' $3 \mathrm{SG}$ ' ending followed by an NP denoting the object even if the object is not $3 \mathrm{SG}$ as in Examples (657)-(658). These prepositions can even occur with the 3SG suffix with a non-overt non-3SG object as in (659). So while I continue to gloss $-n$ as ' $3 \mathrm{SG}$ ', it functions more as a neutral suffix in most cases.

$\begin{array}{lllll}\text { (656) A-lip } & \text { na-taq } & \text { sut } & \text { migca-q gcen gce-wusewus } & \text { na-lag } \\ \text { 2PL-take } & \text { NV-thing } & \text { NONSP } & \text { to-1SG for 1SG.IRR-fan NV-fly }\end{array}$

ra-n ni-solop tiyigc.

on-3SG NI-eel DEF.PROX

'Bring me something so I can brush flies away from this eel.' [KJ01.020 KJ01.wav 92.077 97.123]

(657) Ku-s-top veq ndilqi-n kinag. ku-vweleg gce-vagas 2SG.IRR-NEG-run NEG away-3SG 1SG 2SG.IRR-come 1SG.IRR-talk $\frac{\text { migce-n inug. }}{\text { to-3SG 2SG }}$

'Don't run away from me. Come, I will talk to you." [KJ01.029 KJ01.wav 135.157 138.626]

(658) Gapman t-i-ru re-gcilew ra-n nigcin government REL-3SG.R-two 3PL-look on-3SG 1IN.PL

'Two governments were looking after us.' [07116.003 07116.wav 15.860 20.532]

(659) Na-vaqur-pis gco-rovo-ropw gcen ni-mbwulu-q 1SG.R-try-unfinished ISG.IRR-DUP-run because NI-leg-1SG $i$-sisiq $\quad$ ra-n. 3SG.R-lack on-3SG

'I can't run away because I don't have legs.' (Lit. 'there are no legs on [me].') [07133.024 07133.wav 104.417 112.104]

The following sections (5.3.2.3.1-5.3.2.3.13) provide examples and discussion of each of the preposition in turn. 


\subsubsection{1. $R a-n$ 'on'}

While there are no examples of $r a-m w$ 'on-2SG' or $r a-q$ 'on-1SG' in the corpus, elicitation confirmed that they are possible inflections of this pronoun. Therefore, ran should be analysed as having a 3 SG object suffix. The core meaning of $r a-n$ is 'on'. This includes 'on top of' (660)-(661) and 'in contact with' (662). It is also often used with an instrumental meaning (663)-(664). And in example (665), $r a-n$ has a destination or target meaning.

$\begin{array}{llllll}\text { (660) Na-qay } & \text { yigc } & \text { qet } & \text { i-tip-tip } & \text { ra-n } & \text { metu } o \\ \text { NV-plant } & \text { PROX } & \text { PART } & \text { 3SG-DUP-grow } & \text { on-3SG } & \text { coconut or } \\ \text { i-tip-tip } & & \text { ra-n } & \text { na-qay. } & & \\ \text { 3SG-DUP-grow } & \text { on-3SG } & \text { NV-tree } & & \end{array}$

'It grows on coconut trees or other trees.' [07131.025 07131.wav 88.930 92.727]

(661) I-mbut $\quad$ ra-n $\quad$ mbwitgeymeh i-top: 3SG-step on-3SG stonefish 3SG-jump

'She stood on the stonefish and jumped.' [07081.036 07081.wav 163.382 166.772]

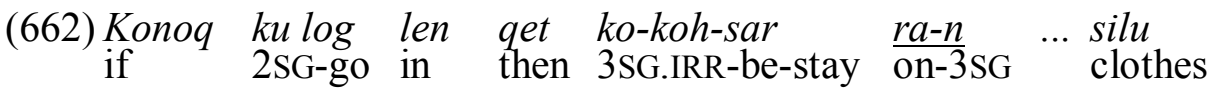
'If you walk in it, it can stick to your clothes.' [07121.010 07121.wav 26.838 30.556]

(663) Qet re-vene-ven mahal ra-n then 3SG-DUP-shoot fish INSTR-2SG

'And they shoot fish with it.' [07124.012 07124.wav 29.156 30.406]

(664) No-roghur gce-yipyip $\quad$ ra-n spiagan 1SG.R-can 1SG.IRR-dive INSTR-3SG speargun 'I can dive with a spear gun.' [07117.137 07117.wav 513.527 516.011]

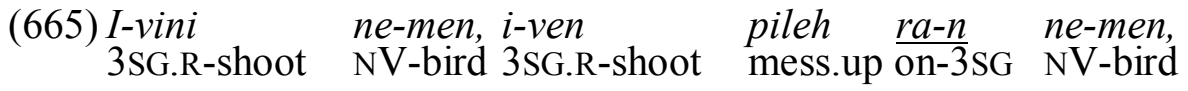
ne-men i-top. NV-bird 3SG.R-fly

'He shot at the bird, but he missed the bird and the bird flew away.' [EC02.085 EC02.wav 337.422 340.969]

$R a-n$ is the preposition used with geographical locations such as villages (666)-(667), regions (668)-(669), islands (670), and countries (671).

(666) Ro-koh ra-n mbwasar tinin.

3PL-be on-3SG village DEF

'They were at the village.' [EC02.006 EC02.wav 30.268 35.301]

$\begin{array}{llll}\text { (667) Ni-morot tuwan } & i \text {-toq } & \text { ra-n } & \text { wut Mbenewur. } \\ \text { NI-man INDEF } & \text { 3SG.R-be } & \text { on-3SG place Mbenewur }\end{array}$ 'There was a man in Mbenewur.' [MAHR.002 MAHR01.wav 257.899 264.774] 
(668)Ruq-vey ndal lis len ne-hew t-ruwar ra-n Lemetu. 3DU.IRR-go back again in NV-garden POSS-3DU on-3SG Lemetu

'They went back to their garden at Lemetu.' [MR01.014 MR01.wav 192.113 195.942]

(669) En na-qamel tinin i-toq $\quad$ ra-n wut eriya t-Sinesip. and NV-tribe DEF 3SG.R-be on-3SG place area POSS-Sinesip

'And this tribe is in the Sinesip area.' [07098.004 07098.wav 23.430 31.430]

(670) Qey i-toq ra-n ni-wurewur, en ni-vilamnin i-toq 3SG 3SG.R-be on-3SG NI-island and NI-girl DEM 3SG.R-be

ra-n ne-ten t-i-mbow. on-3SG NV-land REL-3SG.R-big

'He was on the offshore island, and the girl was on the mainland.' [07064.017-018 07064.wav 79.617 85.070]

(671) Qet mi-rar no-vol migce-n hay komisina ra-n wut then 1EX.PL-make NV-letter to-3SG high commissioner on-3SG place

Kaldoni.

New.Caledonia

'And we wrote a letter to the High Commissioner of New Caledonia.' [07116.029 07116.wav 138.769 145.597]

$R a-n$ also has the function of altering the semantics of some verbs that it is paired with. In such cases, I consider $r a-n$ to be part of the verbal predicate rather than an adjunct to it, but I discuss it in this section because of its similarity to other $r a-n$ phrases. For example, vwer means 'say' when it occurs alone (672a), but vwer paired with $r a-n$ has the meaning 'to call something or somebody something' $(672 b-c)$. The primary meaning of gcilew is 'look for' (673a), but when it is paired with $r a-n$, it has the meaning of 'raise, look after' as in (673b). The primary meaning of sep is 'fall' (674a), but when paired with $r a-n$, it means 'find' as in (674b).

(672)a. Ambwat i-vwer 'yellow' nigcin nde-vwer 'i-lutlut'. foreigner 3SG.R-say yellow 1IN.PL 1IN.PL-say 3SG.R-yellow 'White people say “yellow", we say "ilutlut”.' [07048.2157 07048.wav 5292.758 5295.852]

b. En ni-marlam t-re-vwer Aimbel ra-n, qey and NI-man REL-3PL-say Aimbel prep-3SG 3SG

qet i-vurvur ni-nal Mbenewur. PART 3SG-carry NI-sun Mbenewur

'The man who is called Aimbel, it was he who brought the sun to Mbenewur.' [07098.111 07098.wav 578.826 586.982]

c. Ku-silak mbe-mbun ne-tes, qet i-noq 2SG.IRR-slacken to-under NV-sea PART 3SG-like

ndoh t-ambwat re-vwer tanmay ra-n en. PERF REL-white.man 3SG-say dynamite on-3SG ID

'When you slacken it into the water, it is like what the white people call dynamite.' [07083.120 07083.wav 1717.193 1721.804] 
Re-sip
3PL-descend to-sea-law gcen re-q-gcilew be-tu.

'One time they went to the beach to look for shellfish.' [LS01.006 LS01.wav 20.181 24.618]

b. Amwoq t-nuqumem i-gcilew ra-n nuqumem. mother REL-1EX.DU 3SG-look.for on-3SG 1EX.DU

'Our mother looked after us.' [07117.015 07117.wav 94.269 98.331]

$\begin{array}{llll}\text { (674)a. I-var pileh qet } & i \text {-sep } & \begin{array}{l}\text { mbe-len } \\ \text { 3SG-mbwilyel }\end{array} & \text { nin } \\ & \text { mess.up then } & \text { 3SG.R-fall to-in NI-hole } & \text { DEM }\end{array}$ 'He mis-stepped and fell into the hole.' [07089.050 07089.wav 276.206 280.316]

b. Re-metur ro-rog i-leh mbwutaqay gcen re-sep 3PL-sleep 3PL-feel 3SG-good INTENS because 3PL-fall ra-n na-qanyen t-re-leh qar. on-3SG NV-food REL-3PL-good PL

'They slept and they felt very good because they had found good food.' [TB03.037 TB03.wav 189.528 193.481]

\subsection{Ehu-n 'away from'}

(675)-(676) show the use of ehu-n meaning 'away from'.

$\begin{array}{llllll}\text { (675) } U \text {-vwer } & k u \text {-rop } & \text { ehu-n } & \text { kinag? } & \text { Ku-s-rop } & v e q \\ \text { 2SG.IRR-want } & \text { 2SG.IRR-run } & \text { from-3SG } & \text { 1SG } & \text { 2SG.IRR-NEG-run NEG }\end{array}$ ehu-n kinag! from-3SG $1 \mathrm{SG}$

'You want to run away from me? You can't run away from me!' [07064.268-269 07064.wav 922.985 927.939]

(676) Re-gcilew ne-revuh, en re-her ka-kas ne-revuh ehu-n. 3PL-look.for NV-gun and 3PL-take DUP-out NV-gun from-3SG 'They looked for guns, and they took the guns out of [the houses].' [07086.039 07086.wav 164.974 168.162]

\subsection{Ndilqi-n 'away from'}

(677)-(678) demonstrate the use of ndilqi- $n$, which also means 'away from'.

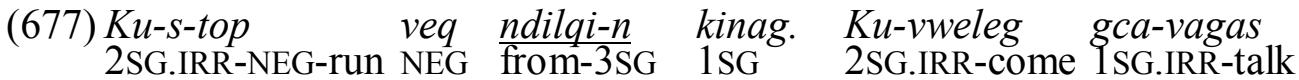
migce-n inug.

to-3SG 2SG

'Don't run away from me. Come, I will talk to you.' [KJ01.029 KJ01.wav 135.157 138.626] 
$\begin{array}{llllll}\text { (678) Ka-makas } & \text { ndilqi-n } & \text { na-qamel } & \text { ti-qey } & \text { qet } & \text { ko-ropw } \\ \text { 3SG.IRR-out } & \text { from-3SG } & \text { NV-nakamal } & \text { POSS-3SG then } & \text { 3SG.IRR-run } \\ \text { ko-log } & \text { mbweleg } & \text { ka-vwa-toq } & \text { eyigc. } & \\ \text { 3SG.IRR-go } & \text { to.FOC } & \text { 3SG.IRR-come-be } & \text { PROX }\end{array}$

'He would come out from his tribe and run and come here to come stay here.' [07115.038 07115.wav 141.902 147.824]

\subsection{Embu-n 'down in'}

The meaning of embu- $n$ is 'down in' as exemplified in (679)-(680).

(679) $N$-ivwusvwus ke-vey human ko-toq embu-n na-mbu, NI-milk 3SG.IRR-go first 3SG.IRR-be down.in-3SG NV-bamboo

'The milk goes first and sits in the bottom of the bamboo.' [RF-MF01.044 RFMF01.WAV 201.923 209.063]

(680)I-ndum embu-n ne-tes, en i-mes, en i-pwuq 3SG.R-fall down.in-3SG NV-sea and 3SG.R-die and 3SG.R-change

na-qahaw.

$\mathrm{NV}$-reef

'She fell into the sea and died and changed into a reef.' [07076.094 07076.wav 370.140 375.765]

\subsection{Evu-n 'under, carrying'}

The core meaning of evun is 'under' as in example (681). This is the meaning that speakers give to define evun. However in my corpus it is much more frequently used with a meaning 'carrying' as in (682) and (683).

(681)I-luqluq evu-n ne-ndiq-mbwat-mbwaqay i-metur lalaq tey. 3SG.R-hide under-3SG NV-food.scraps.mat 3SG.R-lay quiet FOC

'He hid under the yam-head-mat (food scraps mat) and just lay quietly.' [07082.056 07082.wav 228.452 234.140]

(682) Avwuraraq i-log human evu- $n$ ne-tel nin mbwuwes Avwuraraq 3SG.R-go first carrying-3SG NV-rope ASS pig nin.

DEM

'Avwuraraq went first carrying the pig's rope.' [TB01.040 TB01.wav 180.321 185.461]

$\begin{array}{llll}\text { (683) } \begin{array}{l}\text { I-tal } \\ \text { 3SG.R-return }\end{array} & \text { evu-n } & \text { ni-mahal } & \text { tinin } \\ \text { carrying-3SG } & \text { NI-fish } & \text { DEF PL }\end{array}$

'He went back with the fish.' [07063.110 07063.wav 413.669 415.778]

\subsection{Silevu-n 'under'}

Silevu-n is clearly derrived from the verb sil 'dive in/under' and the preposition evu- $n$ 'under', however, it appears synchronically without verbal morphology and can also occur with the verb sil (684), suggesting that silevu- $n$ has lost any verbal status it may have had. Silevu- $n$ is used much more often than $e v u-n$ in the corpus to mean 'under'. While the verb sil describes quick movement to a place under something, silevu- $n$ may be used whether there is movement (685) or not (686). 
$\begin{array}{ll}\text { (684) } I \text {-sil } & \text { mbi-silevun. } \\ \text { 3SG.R-go.in } & \text { to-under }\end{array}$

'It went under.' (07NB01.101)

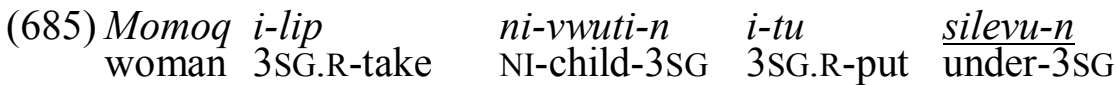

ne-ndiq mbwatmbwaqay.

$\mathrm{NV}$-food.scraps.mat

'The woman took her child and put him under the food scraps mat.' [07082.051 07082.wav 211.061215 .093$]$

(686) Ku-les ni-mbwilyel tuwan i-toq silevu-n ne-vet. 2SG.IRR NI-hole INDEF 3SG.R-be under-3SG NV-stone

'You will see a hole under the stone.' (07074.004 07074.wav 15.062 20.812)

\subsection{Mbigce-n 'beneficiary'}

This preposition has a few variants (Table 91), but the most common is migce- $n$. The forms beginning with $m b$ are mainly found in the speech of speakers born prior to 1940. This sound change is discussed in Section 2.7.5. It seems likely that $m b i g c e-n$ was derived from the directional particle $m b i$ - 'toward' (Section 5.3.2.4) and gcen 'for' (Section 5.3.2.3.13). However it is interesting to note that while $m b i g c e-n$ can occur with $1 \mathrm{SG}$ and $2 \mathrm{SG}$ suffixes, I found through elicitation that gcen cannot (at least synchronically).

Table 91: Variants of migce-n

\begin{tabular}{lll}
\hline Older speakers & Younger speakers & Gloss \\
mbigca- $q$ & $m i g c a-q \sim$ magca- $q$ & 'to/for me' \\
mbigca- $m w$ & migca-mw magca-mw & 'to/for you' \\
mbigce- $n$ & migce- $n \sim$ megce- $n$ & 'to/for him/her/it' \\
\hline
\end{tabular}

Migce- $n$ is used with a variety of meanings in the corpus, but most of them have some kind of directional and benefactive semantic element. This preposition is often used to indicate the recipient of a giving act as in (687) and (688).

$\begin{array}{llllll}\text { (687) I-yaq } & \text { qet } & \text { ke-lip } & \text { mbwuwes } & \text { migca-q } & \text { gcen } \\ \text { 3SG.R-who } & \text { PART } & \text { 3SG.IRR-give } & \text { pig } & \text { to-1SG } & \text { for }\end{array}$

'Who would give me a pig to eat?' [07080.039 07080.wav 148.204 154.783]

(688) Ndu-q-log ndu-q-les ni-vinmarlam. Ndu-q-her

1IN.DU-IRR-go 1IN.DU-IRR-see NI-old.woman 1IN.DU-IRR-take

$\begin{array}{lll}\text { na-qanyen } & \text { sut } & \text { migce-n. } \\ \mathrm{NV} \text {-food } & \text { NONSP } & \\ \text { to-3SG }\end{array}$

'Let's go visit the old woman. Let's bring her some food.' [07074.045 07074.wav 199.173 203.721]

It is also used to indicate the intended audience of some kind of talking act as in (689) and (690). This occurs with verbs such as -vwer 'say,' -vagas 'speak' -ndighur 'tell (a story),' -yal 'sing,' and -vihig 'teach.' 

$\begin{array}{lllll}\text { (689) Ku-vweleg mwin, gce-vwer taq } & \text { tuwan } & \text { migce- } n & \text { inug. } \\ \text { 2SG.IRR-come first } & \text { 1SG.R-say thing } & \text { INDEF } & \frac{\text { to-3SG }}{2 \mathrm{SG}}\end{array}$

'Come, I'm going to tell you something.' [7064.059 7064.wav 236.202 238.967]

$\begin{array}{rllll}\text { (690) En } & n i-m b w i & \text { tinin qet } & \text { ra-yal } & \text { migce-n kamem. } \\ \text { and NV-song } & \text { DEF PART } & \text { 3PL-sing } & \text { to-3SG } 1 \mathrm{EX} . \mathrm{PL}\end{array}$

'And this song is sung to us.' [KA01.014 KA01.wav 94.703 98.949]

Migce- $n$ can be used to indicate the person for whom an act is performed (691)-(693). However, in the corpus, all such examples also had some kind of giving act implied.

(691)No-rog ku-rar mwin ne-revuh mbaragcin sut 1SG.R-want 2SG.IRR-make first NV-bow true NONSP migce-n kinag. to-3SG $1 \mathrm{SG}$

'I want you to make me a bow.' [07009.035-036 07009.wav 100.440 104.237]

(692) En i-rar ne-revuh mbaragcin migce-n ni-mbunog and 3SG.R-make NV-bow true to-3SG NI-child $t-i$-vwariq yig. REL-3SG.R-small PROX

'And she made a bow for the little boy.' [EC01.027 EC01.wav 131.693 139.100]

(693) Qet ke-vini mbaq tey ne-men yig migce-n nigcin. then 3SG.IRR-shoot POLITE FOC NV-bird PROX to-3SG 1EX.DU

'Then he could shoot that bird for us.' [EC02.077 EC02.wav 304.623 307.842]

Migce- $n$ can be used to indicate a destination such as a person or a thing. Note that fixed locations use $m b e y / m b V$ - (Section 5.3.2.4) rather than migce-n, and if the person or object destination is in focus, mbweleg gcen 'toward.FOC for' is used (Section 5.3.2.4). ${ }^{120}$ Examples (694) and (695) show migce- $n$ used with a person destination, and (696) with a thing destination.

(694)Aley, ku-tal gcow. Ku-tal migce-n a-hap. okay, 2SG-return EMPH. 2SG.IRR-return to-3SG 2DU-dance

'Okay, you go back. Go back to her, and (you two) dance.' [07064.167 07064.wav $598.748601 .436]$

(695)I-s-tal vwovwoh veq lis migce-n ni-vwugo-n qar 3SG.R-NEG-return definitely NEG again to-3SG NI-in.law-3SG PL

ra-n wut Umaqas. at-3SG place Umaqas

'She wasn't allowed to return to the in-laws in Umaqas.' [DK01.007 DK01.wav 179.621 186.292]

\footnotetext{
${ }^{120}$ The contrast with mbweleg gcen 'toward for' provides further evidence that migce- $n$ was derived from $m b i$ - 'toward' + gcen 'for'.
} 
(696) Ni-vuti-n Ni-vinmbumbaqaw ro-top migce-n no-qon. NI-child-3SG NI-Vinmbwumbwaqaw 3PL-run to-3SG NV-basket 'Vinmbumbaqaw's children ran to get the basket.' [EC02.079 EC02.wav 316.702 319.186]

The last sense in which migce- $n$ is used is in phrases that talk about something being hard or easy for someone (697)-(699).

(697) I-noq re-vwer i-s-pwaris veq migca-m. 3SG.R-like 3PL-say 3SG.R-NEG-hard NEG for-2SG

'It's not hard for you.' [nihumbwen.007 nihumbwen.wav 31.83533 .991 ]

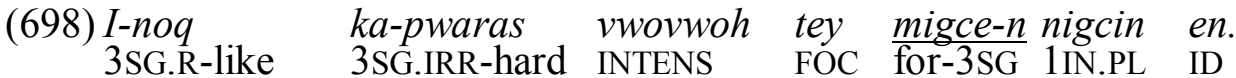

'Yes, it'll be very hard for us.' [07095.047 07095.wav 295.794 299.153]

(699)I-p-muwar-yen migce-n nigcin gcen nde-lesur nde-gcur 3SG.R-come-easy-NOM for-3SG 1IN.PL because 1IN.PL-can 1IN.PL-make na-qam. $\mathrm{NV}$-fire

'It is a convenience for us because we can make fire.' [07095.023-024 07095.wav 102.850 107.381]

\subsection{Len 'in'}

The core meaning of len is 'in' or 'inside' (700). However, it is used with other extended or abstract meanings such as specifying the language used in an interaction (701), or referring to a time (702)-(704).

$\begin{array}{clllll}\text { (700) I-vwer, } & \text { "i-toq } & \text { tey } & \text { len } & \text { mbwilyel } & \text { un." } \\ \text { 3SG.R-say } & \text { 3SG.R-be } & \text { FOC } & \text { in } & \text { hole } & \text { place.DEM }\end{array}$

'She said, "She's just in that hole there."” [LS01.093 LS01.wav 384.965 387.872]

(701)Ne-vwer gce-vwer story tuwan len Nahavaq. 1SG.R-want 1SG.IRR-say story INDEF in Nahavaq

'I want to tell a story in Nahavaq.' [TB01.002 TB01.wav 6.391 12.407]
(702) Len ni-mbwug tinin, ni-morot tinin re-siqsiq na-taq in NI-day DEF NI-man DEF 3PL-lack NV-thing t-re-vutuq ne-wey len. REL-3PL-fetch $\mathrm{NV}$-water in

'At the time, these people didn't have anything to fetch the water in.' [EC01.007 EC01.wav 26.867 37.087]

(703) Ku-mwas ku-log vovoh tey migce-n papap 2SG.IRR-must 2SG.IRR-go definitely FOC to-3SG uncle

qar len wiken ohoy tey. $\mathrm{PL}$ in weekend simply FOC

'You will have to go to your uncle and company on the weekends.' [07117.530 07117.wav 1562.653 1567.966] 
(704) Len 1980 qet mi-koh ra-n utig. in 1980 PART 1EX.PL-be on-3SG PLACE.PROX

'In 1980, we were here.' [07086.001 07086.wav 1.479 7.650]

\subsection{Hur 'near, about'}

The spatial meanings of hur include proximity ('near, around') as in (705) and path ('along') as in (706). However hur is also commonly used to indicate subject matter ('about') as in (707) and (708) and measurements of durative time ('for') as in (709) and (710).

(705) Ku-sum hur na-qam qet ku-mindig tartar tey na-mbwu. 2SG.IRR-sit near $\mathrm{NV}$-fire and 2SG.IRR-watchalways FOC NV-bamboo

'You must sit down near the fire and always watch the bamboo.' [07112.110 07112.wav 604.598 608.660]

(706) I-vwer tartar tey hur na-hal. 3SG.R-say always FOC along NV-road

'He said it all the time along the road.' [TB01.041 TB01.wav 185.461 187.305]

(707)No-rog gce-ndighur ni-stori tuwan hur Ambwat. 1SG.R-want 1SG.IRR-tell NI-story INDEF about Ambwat

'I want to tell a story about Ambwat.' [LS01.002 LS01.wav 4.322 9.196]

(708) Qet i-yar en i-ndimndim hur na-havaq qet then 3SG.R-finish ID 3SG.R-think about NV-what COMPL

ka-rar gin.

3SG.IRR-make 3SG

'Anyhow, he thought about what he would do.' [07064.183 07064.wav 648.155 653.030]

(709) Konoq re-hewhew hur ni-mbwug ke-tul qaw ke-ves if 3PL-infuse for NI-day 3SG.IRR-three or 3SG.IRR-four qet i-vwonos en. PART 3SG.R-enough ID

'If he has been infused for three or four days, that is enough.' [07122.044 07122.wav $118.701120 .858]$

$\begin{array}{ccllll}\text { (710) Ni-vinsumsum } & \text { i-mbow } & \text { ra-n } & \text { wut Isrel len } & \text { ni-mbwug nin } \\ \text { NI-widow } & \text { 3SG.R-big } & \text { at-3SG } & \text { place Israel in } & \text { NI-day } & \text { ASS }\end{array}$ 3sG.R-big at-3sG place Israelin Nath i-titeg

Elisah, wut Na-mwap i-titeq hur ne-tew i-tul en Elijah time NV-sky 3SG.R-closed for NV-year 3SG.R-three and ne-vul i-sowsiq. $\mathrm{NV}$-moon 3SG.R-six

'There were many widows in Israel during the time of Elijah, when there was no rain for three and a half years.' [LUK.04:25]

\subsection{Luqur 'with'}

Luqur 'with' can be used to coordinate noun phrases as discussed in Section 3.6.4. However, luqur 'with' is most commonly used after a verb rather than between two noun phrases. 
(711) En Paylat i-log mbi-vusar luqurqar. and Pilate 3SG.R-go to-outside with 3PL

'So Pilate went outside to them (i.e. to be with them).' [JON.18:29]

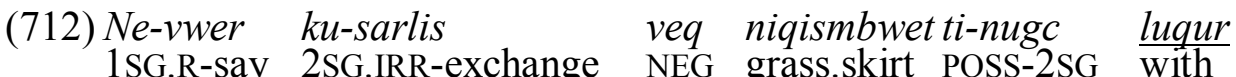
ni-vilam sut.

NI-girl NONSP

'I said don't trade your skirt with another girl.' [07064.164 07064.wav 585.452 589.670]

(713) Mu-koh luquramoq ti-nuqumem

1EX.DU-be with mother poss-1EX.DU

'We lived with our mother' [07117.014 07117.wav 91.956 94.269]

\subsection{Qin 'with'}

As with luqur in the previous section, qin 'with' can act as a coordinator between two noun phrases as in Section 3.6.3 or adjoined after a verb as in (714)-(715).

(714) Konoq ku-log wa-q-ndipneq qin mor sut ...

if 2SG.IRR-go 2DU.R-IRR-meet with man NONSP

'If you go and meet someone ...' [07090.023 07090.wav 94.306 100.399]

(715) Momoq ru-leq qin morot.
woman 3DU-marry with man

'The woman married the man.' [s0804]

\subsection{Qin (OBLIQUE)}

The oblique preposition qin, which is homophonous with a third person singular pronoun (Section 3.1.2.1.2), has a variety of uses. In the most general terms, it can occur before a verbal argument that is neither the subject nor object of the verb. Argument/oblique alternation is shown in Examples (716) and (717), indicating that there is some flexibility in argument marking.

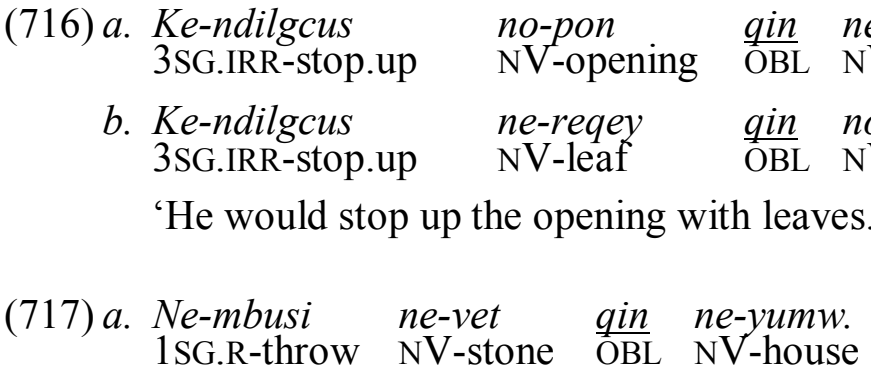

$$
\begin{aligned}
& \text { b. Ne-mbusi ne-yumw qin ne-vet. } \\
& \text { 1SG.R-throw NV-house OBL NV-stone }
\end{aligned}
$$

The following examples from the corpus show a variety of semantic roles covered by oblique arguments marked with qin. In (718) the qin-phrase is the material that something is made from. In (719), it is the substance that something is covered in. In 
(720), it is the items something is filled with. In (721) it is the item that is set on fire (N.B. the verb ndis 'light' always has na-qam 'fire' as its direct object). In (722), the qin-phrase marks a beneficiary.

(718) Ku-lip na-taq yig ku-log ku-tu len ni-suspen 2SG.IRR-take NV-thing PROX 2SG.IRR-go 2SG.IRR-put in NI-pot t-i-noq re-vwer ra-rar qin ne-ten. REL-3SG.R-like 3PL-say 3PL-make OBL NV-earth

'Take this thing and go put it in an earth pot.' [07128.115 07128.wav 639.101 649.444]

(719) Inet ra-qambus gcor mwah qin ne-reqey. then 3PL-cover block all OBL NV-leaf

'And then you cover it up with leaves.' [RF-MF01.011 RF-MF01.WAV 50.330 54.439]

(720) I-qohon ni-vindasin tinin qin ni-mbuwes t-re-mbow-mbow qar 3 SG.R-fill NV-sow DEF OBL NI-pig REL-3PL-DUP-big PL

'He filled the sow with big pigs.' [TВ01.014 TB01.wav 51.674 56.674]

(721) Re-ndis na-qam qin ne-reqey na-hul. 3PL-light $\mathrm{NV}$-fire $\mathrm{OBL} \quad \mathrm{NV}$-leaf $\mathrm{NV}$-coconut.leaf

'They set fire to the coconut leaves.' [07009.074 07009.wav 203.324 207.043]

$\begin{array}{llll}\text { (722) Ko-log gcen ke-huq } & \text { qin } & \text { ni-morot. } \\ \text { 3SG.IRR-go for } & \text { 3SG.IRR-give OBL NI-man }\end{array}$

'He goes to give it to the man.' [07032.021 07032.wav 62.670 66.045]

There are some verbs that occur so frequently with qin oblique markers, that I will describe them separately. The first of these is wuswus 'ask'. The addressee is preceded by qin. The direct object of the verb is not normally overtly stated, but it is presumably the question, which is often referred to in a previous or subsequent clause.

(723)En i-wuswus qin ni-morot tinin t-ro-log hur ne-tes, and 3SG.R-ask OBL NI-man DEF REL-3PL-walk along NV-sea $i$-vwer, 'A-vey ambeh?' 3SG.R-say 2PL-go where

'And she asked the people who were walking along the sea, "Where are you going?"' [MAHR.037-038 MAHR01.wav 397.743 405.462]

(724)En i-wuswus qin ni-mbwunog i-vwer, 'u-log ambeh and 3SG.R-ask OBL NI-child 3SG.R-say 2SG.R-walk where mbweleg?' to.FOC

'And she asked the child, "Where did you come from?"' [07082.072 07082.wav $279.535285 .586]$

The verb vihigc 'show/teach' marks the beneficiary with qin. The direct object if present is the object or subject matter being shown or taught (726). 
(725)Utin ne-vwer gce-vihig qin nigcim gcen a-mbwit. PLACE 1SG.R-intend 1SG.IRR-show OBL 2PL because 2PL-not.know 'I wanted to teach you this because you didn't know,' [07065.153 07065.wav 596.824 600.605]

(726) Asin i-vihig mwah na-taq qar qin ruwar. PERS 3SG.R-show all NV-thing PL OBL 3DU

'This man showed everything to the two of them.' [KO01.029-030 KO01.wav 86.429 91.116]

The comparative verb noq 'like (similar)' is usually followed by qin and then the entity or situation that something is similar to (727)-(729). However, noq 'like (similar)' also occurs without qin (730)-(733), and there is no clear difference in meaning.

(727) Ni-silu ti-qey i-mevus i-noq qin na-mbwansi NV-clothes POSS-3SG 3SG.R-white 3SG.R-like OBL NV-fog i-mevus paqpaq. 3SG.R-white INTENS

'His clothes were as white as fog.' [MAT.28:03]

(728) Nigcim a-nog qin na-mwat.

2PL 2PL-like OBL NV-snake

'You are like snakes.' [MAT.23:33]

(729) Na-qayew ka-pwaras, ka-pwaras vetevet. Ko-noq qin $\mathrm{NV}$-pudding 3SG.IRR-hard 3SG.IRR-hard INTENS 3SG.IRR-like OBL ne-vet.

$\mathrm{NV}$-stone

'The pudding would be very hard. It would be rock-hard.' [07112.025-026 07112.wav 127.898 133.914]

(730) Ru-log ru-senis war ru-noq morot. 3DU.R-go 3DU.R-change 3DU 3DU.R-like man

'They went and they changed themselves into people.' [07010.026 07010.wav 68.263 71.826]

(731) Na-taq yigc ra-rar tey i-noq ni-mweyil ti-qor. NV-thing PROX 3PL-make FOC 3SG.R-like NI-cycad POSS-today 'This thing is used like the cycad from earlier today.' [07044.004 07044.wav 11.368 13.634] 
(732) I-viqis gey i-vweleg i-noq ne-vet. 3SG.R-change 3SG 3SG.R-come 3SG.R-like NV-stone

'He changed himself to become like a stone.' [07098.035 07098.wav 199.673 207.110]

(733)En re-les Yesu no-qo-n i-har i-noq ni-nal, en and 3PL-see Jesus NV-face-3SG 3SG.R-shine 3SG.R-like NV-sun and ni-silu ti-qey $\quad$-har $\quad i$-noq qin na-lamp. NV-clothes POSS-3SG 3SG.R-shine 3SG.R-like OBL NV-lamp

'And they saw Jesus's face shone like the sun, and his clothes shone like a lamp.' [MAT.17:02]

\subsection{Gcen 'for/because of'}

Gcen can indicate a reason (734) or a goal/destination (735)-(736). Gcen frequently takes a clause as its object and this pattern is discussed in Section 5.4.2.2.1.

(734) Mas ke-tu ndalis marhawtuwan gcen ekspens ti-qey. must 3SG.IRR-put again price INDEF for expense POSS-3SG

'He has to put another price because of his expenses.' [07058.178 07058.wav 692.482 695.420]

(735) Tartar ohoy tey, ro-log gcen hap-hap-yen ... always simply FOC 3PL-go for DUP-dance-NOM

'Every time when people went to dances...' [07064.022 07064.wav 102.871 106.308]

$\begin{array}{llll}\text { (736) I-log } & \text { mbweleg } & \text { i-tagcaw } & \text { gcen. } \\ \text { 3SG.R-go } & \text { toward.FOC } & \text { 3SG.R-reach } & \text { for }\end{array}$

'She walked toward him and reached him.' [07064.wav 569.685572 .716 07064.158]

When gcen has a goal/destination meaning, it is either used with a verb of motion as in Examples (735)-(736), or with a directional particle (Section 5.3.2.4) as in Examples (737)-(738), which show gcen preceded by the toward-focus directional particle, mbweleg. The toward-non-focus directional particle, mbey seems to have combined with gcen to form the preposition migce-n (Section 5.3.2.3.7) which has a wider range of functions than just goal/destination.

$\begin{array}{llll}\text { (737) I-qom } & \text { gcalu } & \text { mbweleg } & \text { gcen } \\ \text { 3SG.R-throw } & \text { Nesli. }\end{array}$

'She throws it (volleyball) away toward Nesli.' [07068.292 07068.wav 928.281 931.485]

$\begin{array}{lllll}\text { (738) Ku-lip } & \text { qin } & \text { mbweleg } & \text { gcen } & \text { kinagc. } \\ \text { 2SG.IRR-take } & \text { 3SG } & \text { toward.FOC } & \text { for } & \text { 1SG }\end{array}$

'Bring him to me.' [MAT.17:17]

\subsubsection{Directional particles (mbey and mbweleg)}

Nahavaq has two directional particles, mbweleg 'toward deictic centre' and mbey 'toward other destination'. They are clearly related to the directional verbs (Section 
4.1.2), vweleg 'go toward deictic centre' and vey 'go toward other destination'. ${ }^{121}$ The semantics of deictic focus are discussed in Section 6.4. This section deals with constructions in which these particles occur. Mbweleg and mbey often occur without any object as in (739).

$\begin{array}{cclllll}\text { (739) "A-lip } & \text { na-qay } & \text { sut } & \text { mbweleg, inet nigca-rar } & \text { a-les." } \\ \text { 2PL-take } & \text { NV-wood } & \text { NONSP } & \text { to.FOC } & \text { then } & \text { 1SG.IRR-make } & \text { 2PL-see } \\ \text { re-lip mbwityeh } & \text { mbey, } & \text { Ambwat i-gcisim } & \text { mwah } & \text { qin. } \\ \text { 3PL-take digging.stick } & \text { to } & \text { Ambwat3SG.R-dehusk all } & \text { 3SG }\end{array}$
"'Bring a stick here and then I will make you see." They brought a pointed stick and Ambwat removed the husk.' [07065.131-132 07065.wav 520.152 530.446]

However, these directional particles may also take complements in the form of locational nouns (740), temporal nouns (741), lV-prefixed nouns (742), or prepositions (743).

$\begin{array}{lll}\text { (740) No-qoyit } & \text { i-ropw } \\ \text { NV-octopus } & \text { 3SG.R-run } & \text { mbweleg } \\ \text { to.FOC } & \begin{array}{l}\text { verqeh. } \\ \text { shore }\end{array}\end{array}$

'And the octopus swam to the shore.' [07074.092 07074.wav 399.321 401.649] $\begin{aligned} & \text { (741) } R \text { u-koh } \text { mbweleg } \\ & \text { 3DU-be to.FOC } \text { qor. } \\ & \text { today }\end{aligned}$

'The two of them live there to this day.' [KO01.041 KO01.wav 118.508 120.617]

$\begin{array}{lll}\text { (742) } \mathrm{Ku} \text { - } \log \\ \text { 2SG.IRR-go to } & \text { mbey } & \begin{array}{l}\text { le-ndiq } \\ \text { in-bed }\end{array} \text { POSS-ng! } \\ \text { in-bed }\end{array}$

'You go to your bed!' [07064.191 07064.wav 671.639 675.764]

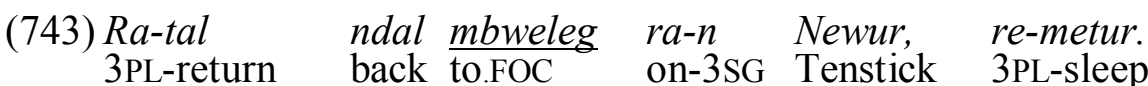

'They went back to Tenstick Island and slept.' [TB03.048 TB03.wav 245.377 248.283]

When used in combination with a transitive verb, directional particles most often occur after the direct object of the verb as in (739) above and (744) below, but may also occur before the direct object (745).

\footnotetext{
${ }^{121}$ Just as there is a verb vwel 'come' suggesting that vweleg 'come' may have derived from vwel 'come' and eg 'ID.PROX', there is a directional particle, mbwel which is equivalent to mbweleg, but occurs very rarely in the data.
} 
(744) Ku-lip ne-vet mbweleg.

2SG.IRR-take $\mathrm{NV}$-stone to.FOC

'Bring that stone here.' [07093.032 07093.wav 234.318 236.255]

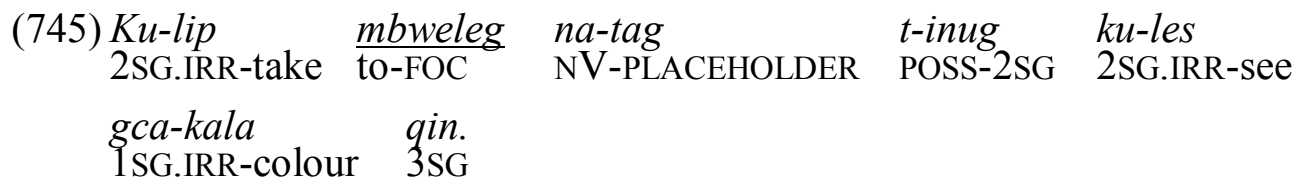

'Bring your thingy here and watch me colour it.' [07048.0318 07048.wav 566.210 570.340]

When mbey has a locational complement, it is frequently abbreviated into a phonologically dependent form, $m b-, m b \mathrm{~V}$-, or $m b i$-. If the object begins with a vowel, mbey is usually abbreviated to $m b$ - (Table 92a). For a small set of objects, the directional prefix has the form $m b \mathrm{~V}$ - and the vowel is identical to that in the root. Note that in all four cases I have found (Table 92b), the base begins with $l, h$, or $r$, which are the same beginning sounds that take a $n V$ - nominal prefix rather than $n i$ (Section 2.4.7). However, most bases take $m b i$-, including several with $l \mathrm{~V}$-prefixes (Table $92 \mathrm{c}$ ). The $m b i$ - prefix is highly productive and can be used with any place name.

Table 92: Mbey-type prefixes

\begin{tabular}{lllll}
\hline a & mb-embu-n & 'to-down.in-3SG' & mb-eyten & 'to-downhill' \\
& mb-evu-n & 'to-under-3SG' & mb-esip & 'to-Esip' \\
& mb-eraqay & 'to-uphill' & mb-ewut & 'to-Ewut' \\
& mb-eyumw & 'to-home' & mb-eyumwqoran & 'to-Eyum Qoran' \\
& mb-eyag & 'to LOC.DIST' & mb-ewur & 'to Ewur' \\
& mb-ambeh & 'to where' & & \\
\hline b & mba-ra-n & 'to-on-3SG' & mbe-len & 'to-in' \\
& mbu-hur & 'to-near' & mba-law & 'to-sea' \\
\hline c & mbi-lu-wey & 'to-in-water' & mbi-livwaqantes & 'to-out.at.sea' \\
& mbi-leten & 'to-down' & mbi-lembunqay & 'to-bush' \\
& mbi-li-yumw & 'to-in-house' & mbi-livwaqan & 'to-middle' \\
& mbi-siley & 'to-far' & mbi-humwan & 'to-front' \\
& mbi-la-qamb & 'to-in-fire' & mbi-silevu-n & 'to-under-3SG' \\
mbi-taq & 'to-behind' & mbi-santo & 'to-Santo' \\
\hline
\end{tabular}

The vowel in the mbi- prefix can be deleted (see Section 2.4.3.3 on high vowel deletion), leaving $m b$ - as in mbi-lembinwen > mblembinwen 'to Lembinwen'. The only cases where this is not possible is if the base begins with a bilabial plosive (Section 2.4.3.3). If the base begins with $/ \beta^{\mathrm{j} /}$ and the vowel in the prefix is deleted, the sequence $/{ }^{\mathrm{m}} \mathrm{b}^{\mathrm{j}} \mathrm{\beta}^{\mathrm{j}} /$ can be simplified to $/{ }^{\mathrm{m}} \mathrm{b}^{\mathrm{j}} /$ (mbivusar $>$ mbusar 'to-outside', mbiverqeh $>$ mberqeh 'to inland'). ${ }^{122}$

\footnotetext{
${ }^{122}$ It is possible that mbweleg and mbey derived historically from vweleg and vey through prefixation of some kind of $m b$ - element and subsequent $m b v(w)>m b(w)$ simplification. And if that is the case, the prefixes in Table 92 might be considered a directional prefix in its own right rather than simply a reduced form of mbey.
} 


\subsubsection{Clause-initial modifiers}

There are a few modifiers such as mwas 'must' in (746) that occur clause-initially and may take limited verbal morphology in the form of a third person singular realis prefix as in (747).

(746) $\frac{\text { Mwas }}{\text { must }} \quad \begin{array}{ll}n a-q a y & \text { ru-vaqayndag. } \\ \text { NV-wood } & \text { 3DU-same }\end{array}$

'The two pieces of wood must be the same.' [07095.042 07095.wav 257.793 263.903]

$\begin{array}{lll}\text { (747) } \frac{\text { I-mwas }}{3 \text { SG.R-must }} & \text { ni-mbwunog } & \text { ra-qan } \\ \text { NI-child } & \text { 3PL-eat. }\end{array}$

'The children must eat.' [08NB01.058]

While many of these clause-initial modifiers occur with similar meaning as verbs which take complement clauses (Section 5.4.1), there are a number of differences between these two constructions as illustrated in (748)-(749). Clause-initial modifiers have either no subject prefix or an impersonal third person singular subject prefix (749b). Verbs that take complement clauses take prefixes that reference a subject (748a). Another difference is in the position of these units relative to a subject NP. A verb which takes a complement clause occurs after a noun phrase subject as in (748a). However, in the clause-initial modifier construction, an NP subject occurs after the clause initial modifier (749a). The two constructions also differ in the use of complementisers. While many verbs that take complement clauses optionally use the complementiser wut as in (748b-c) (see Section 5.4.1 for more examples), clause initial modifiers do not (749b). The two constructions also differ in negation. In a verb+complement clause construction, either the main verb $(748 \mathrm{~b})$ or the complement clause (748c) may be negated independently. Clause-initial modifiers cannot be negated, but the clause that follows can be $(749 \mathrm{c})$. Even with so many criteria to distinguish complement clause constructions from clause-initial modifier constructions, examples such as (750) are ambiguous as to which kind of construction is involved.

(748) Verb + complement clause

a. Ni-mbwunog ra-mwas ra-qan. NI-child 3PL-must 3PL-eat

'The children must eat.' [08NB01.058]

b. No-s-roghur veq wut a-koh eyigc.

'I didn't know that you guys were here.' [07089.165 07089.wav 768.762 773.179]

c. Ro-rogndew wut ke-s-meqet veq.

3PL-believe COMPL 3SG.IRR-NEG-break NEG

'They believed that it wouldn't break.' [07076.068 07076.wav 270.122 272.560] 
(749) Clause-initial modifier + clause

a. Mwas ni-mbwunog ra-qan

must NI-child 3PL-eat

I-mwas ni-mbwunog ra-qan.

3SG.R-must NI-child 3PL-eat

*Ra-mwas ni-mbwunog ra-qan.

3PL-must NI-child 3PL-eat

'The children must eat.' [08NB01.058]

b. Mwas (*wut) ku-qan.

must COMPL 2SG.IRR-eat

'You must eat.' [08NB01.059]

$\begin{array}{lll}\text { c. I-mwas } & k a-\underline{s}-q a n & \text { veq. } \\ \text { 3SG } & \text { 3SG-must }\end{array}$

*I-s-mwas veq ka-qan.

3SG.R-NEG-must NEG 3SG.IRR-eat

*I-s-mwas ka-qan veq.

3SG.R-NEG-must 3SG.IRR-eat NEG

'He mustn't eat.' [08NB01.058]

(750) I-mwas ka-kat-mbaqher mwah wut tinin qar.

3SG.R-must 3SG.IRR-cut-clean all place DEF PL

'He has to cut all these parts clean.' [07083.054 07083.wav 262.057 267.292]

Table 93 lists clause-initial modifiers and an example of each is given in (751)-(756) below.

Table 93: Clause-initial modifiers ${ }^{123}$

\begin{tabular}{llll}
\hline & $\begin{array}{l}\text { Gloss as clause- } \\
\text { initial modifier }\end{array}$ & $\begin{array}{l}\text { Gloss as verb with } \\
\text { clause complement } \\
\text { must }\end{array}$ & $\begin{array}{l}\text { Gloss as } \\
\text { main verb }\end{array}$ \\
$(i-)$ mwas & must & might & - \\
$(i-)$ mwayt & might & - & - \\
laki & luckily & nearly & - \\
$(i-)$ mwasasag & nearly & nearly & be close to \\
$(i-)$ mwal & nearly & - & - \\
$i-n o q$ & maybe & & be like \\
\hline
\end{tabular}

$\begin{array}{lllll}\text { (751) I-minim } & \text { mwas } & \text { ni-pistas } & \text { t-inug } & \text { ke-leh. } \\ \text { 3SG.R-mean } & \text { must } & \text { NI-peanut } & \text { POSS-2SG } & \text { 3SG.IRR-good }\end{array}$

'It means that your peanuts must be good.' [07058.155 07058.wav 590.531 594.172]

(752) Mwayt ko-noq ku-ndimndim ku-vwer, "Ne-rirog maybe 3SG.IRR-like 2SG.IRR-think 2SG.IRR-say 1SG.R-like

gca-tagcaw gcen ten."

1SG.IRR-arrive DEST ten

'Maybe you think "I'd like to reach ten."' [07058.087 07058.wav 329.216 333.404]

${ }^{123}$ The gaps in Table 93 may be due to incomplete knowledge. 
(753) Mari i-huq tuwan etig qet laki i-top mbweleg Mari 3SG.R-give INDEF ID.PROX then lucky 3SG.R-jumpto.FOC

vwisar.

outside

'Mari gives one here and luckily it jumps outside.' [07069.070 07069.wav 238.710 241.444]

(754) Mwasasag tipwtapw ko-toq la-qamb en. near vegetables 3SG.IRR-be in-fire ID

'Soon the root vegetable chunks should be in the fire.' [07065.286 07065.wav 1035.454 1038.623]

(755) Mwal Laura ke-sep.

near Laura 3SG.IRR-fall

'Laura nearly fell.' [08NB1.059]

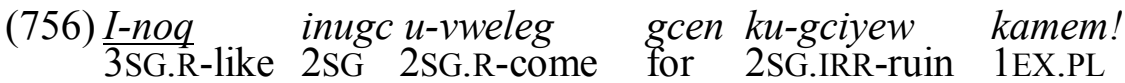

'Maybe you have come to destroy us!' [MRK.01:24]

Interestingly, many of the clause-initial modifiers that I am aware of (mwas, mwayt, and laki) are lexical items borrowed from Bislama. Crowley (2003) classifies Bislama mas as a preverbal auxiliary, maet as a clause initial adverbial, and laki as a clause initial marker. Constructions such as example (746) above closely resemble Bislama constructions such as (757). Since I have not come across similar constructions in grammars of related languages, it seems plausible that these clauseinitial modifier structures came into Nahavaq from Bislama.

(757) Bislama (Crowley 2004: 143) ${ }^{124}$

maet hem $i \quad \mathrm{kam}$ perhaps 3SG 3SG come

'Perhaps he will come.'

Tow of the concepts represented by the borrowed clause-initial modifiers, mwas and mwayt, can be expressed through native post-verbal modifiers: vovoh 'must' (Section 4.7.3.1.4) and mbeq 'maybe' (Section 4.7.5.5). Some older speakers had the perception that the 'must' use of vovoh is no longer used by younger speakers, and may not even be understood by them. Younger speakers intead use only mwas for this meaning.

\subsection{Subordinate clauses}

I define subordinate clauses as clauses that can act as constituents within a larger clause. This includes relative clauses which are discussed in Section 3.4.7. In the following sections, I describe complement clauses (5.4.1) and adverbial clauses (5.4.2). In addition, some of the structures described in Section 5.6 may involve subject clauses.

${ }^{124}$ Interlinear glosses are my own. 


\subsubsection{Complement clauses}

This section describes clauses acting as complements of verbs. For clauses acting as complements of prepositions, see Section 5.4.2. For clauses acting as subjects of verbs, see Section 5.6.

There are a number of verbs that often take clauses as their complements, for example roghur 'can' in (758), rog 'want' in (759), and tumbwatin 'start' in (760). ${ }^{125}$

(758)A-roghur [a-vihig qin morot qar en $]$ gcen morot 2PL-can 2PL-show 3SG man PL ID because man

ro-roghur [re-les].

3PL-can 3PL-see

'You guys can show it to people so that they can see.' [08018.022 08018.wav 120.998 126.982]

(759) No-rog [gce-les nuqumw]. 1SG.R-want 1SG.IRR-see 2DU

'I wanted to see you two.' [07111.028 07111.wav 120.308 124.933]

(760) Mi-tumbwatin $\quad$ [mi-rar $\quad$ klasrum].

'We started to make classrooms.' [07116.067 07116.wav 324.711 334.274]

Table 94 below lists 26 verbs that I have found to occur in similar surface constructions to those in (758)-(760). That is, they can be directly followed by another verb which has a subject prefix. With the exception of $m w a l$ 'nearly' and mwasasag 'nearly', the verbs in Table 94 fit into Noonan's (1985) semantic classes of complement-taking predicates.

\footnotetext{
${ }^{125}$ Crowley (2006d: 188; 2006b: 176; 2006a: 124) describes some similar constructions in Tape, Naman, and Avava as auxiliary verbs because they involve two consecutive verbs with the same subject marking and in some cases can't have any intervening material between the two verbs. Some of the Nahavaq verbs in Table 94 also require a verb with the same subject in the complement, but I see this as a semantic property of certain verbs (i.e. in the case of roghur 'able', one cannot have the ability for another person to do something). I have not elicited information about the range of complement forms that these verbs can take, so all of my information is based on usage in the corpus. However, at this point, I see no need for an auxiliary verb class in Nahavaq. See also Section 5.6 for discussion of whether these constructions could be considered core-layer SVCs.
} 
Table 94: Verbs that take clauses as complements

$\checkmark$ : attested in corpus or in elicitation. - : not attested in corpus or elicitation. ? = only attested in unclear examples (disfluency, child, non-native speaker) or in bible translations only. Noonan's categories are: 3.2.1

utterance predicates, 3.2.2 propositional attitude predicates, 3.2.4 Commentative predicates-factives, 3.2.5

Predicates of knowledge and acquisition of knowledge, 3.2.5 Predicates of knowledge and acquisition of knowledge, 3.2.7 Desiderative predicates, 3.2.8 Manipulative predicates, 3.2.9 Modal predicates, 3.2.11 Phasal predicates, and 3.2.12 Immediate perception predicates, ${ }^{126}$

\begin{tabular}{|c|c|c|c|c|c|c|c|c|}
\hline 范 & Nahavaq & $\begin{array}{l}\text { Gloss with } \\
\text { clausal } \\
\text { complement }\end{array}$ & $\begin{array}{l}\text { Gloss with NP } \\
\text { complement }\end{array}$ & $Q \bar{E}$ & ¿্ট & 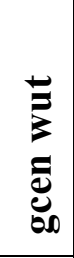 & 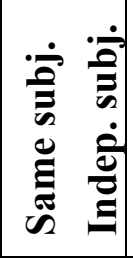 & 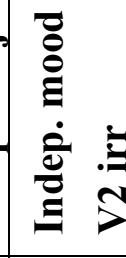 \\
\hline 3.2 .1 & vwer & say & say & $\sqrt{ } \checkmark$ & - & - & $\checkmark$ & $\sqrt{ }-$ \\
\hline 3.2 .2 & rogndew & believe & believe & $\checkmark \checkmark$ & - & - & $\checkmark$ & $\sqrt{ }-$ \\
\hline 3.2 .4 & qimpoten & important & - & $-\quad-$ & $\sqrt{ }$ & - & $\sqrt{ }$ & $\checkmark$ \\
\hline 3.2 .5 & $\begin{array}{l}\text { rog } \\
\text { roghur } \\
\text { mbwit }\end{array}$ & $\begin{array}{l}\text { feel } \\
\text { know } \\
\text { don't know }\end{array}$ & $\begin{array}{l}\text { hear } \\
\text { know } \\
\text { don't know }\end{array}$ & $\begin{array}{ll}\sqrt{ } & \sqrt{ } \\
\sqrt{ } & \sqrt{ } \\
\sqrt{ } & -\end{array}$ & & $\begin{array}{l}- \\
- \\
-\end{array}$ & $\begin{array}{l}\sqrt{ } \\
V \\
V\end{array}$ & $\begin{array}{ll}\sqrt{2} & - \\
\sqrt{ } & - \\
\sqrt{ } & -\end{array}$ \\
\hline 3.2 .7 & $\begin{array}{l}\text { rirog } \\
\text { rog } \\
\text { vwer } \\
\text { ndimsoq }\end{array}$ & $\begin{array}{l}\text { want } \\
\text { want } \\
\text { intend } \\
\text { decide }\end{array}$ & like & $\begin{array}{ll}\sqrt{V} & ? \\
\sqrt{ } & - \\
\sqrt{ } & \sqrt{ } \\
- & -\end{array}$ & & $\begin{array}{l}- \\
- \\
\checkmark \\
-\end{array}$ & $\begin{array}{ll} & \checkmark \\
- & \checkmark \\
- & \checkmark \\
V & -\end{array}$ & 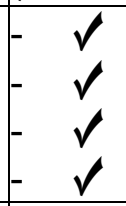 \\
\hline 3.2 .8 & $\begin{array}{l}\text { gcur } \\
\text { vwer } \\
\text { helur } \\
\text { ndam }\end{array}$ & $\begin{array}{l}\text { make } \\
\text { order } \\
\text { allow } \\
\text { allow }\end{array}$ & $\begin{array}{l}\text { say } \\
\text { release } \\
\text { lend }\end{array}$ & $\begin{array}{ll}\sqrt{ } & \sqrt{ } \\
\sqrt{ } & \sqrt{ } \\
\sqrt{ } & - \\
\sqrt{ } & \sqrt{ }\end{array}$ & $\begin{array}{l}\checkmark \\
\checkmark \\
- \\
- \\
\end{array}$ & $\begin{array}{l}- \\
\checkmark \\
- \\
\checkmark\end{array}$ & $\begin{array}{l}\checkmark \\
\checkmark \\
\checkmark \\
\checkmark\end{array}$ & $\begin{array}{ll}\checkmark & - \\
- & \checkmark \\
- & \checkmark \\
- & \checkmark\end{array}$ \\
\hline 3.2 .9 & $\begin{array}{l}\text { roghur } \\
\text { lesur } \\
\text { mbwit } \\
\text { mwas } \\
\text { mwayt } \\
\text { ndimndim }\end{array}$ & $\begin{array}{l}\text { can } \\
\text { can } \\
\text { can't } \\
\text { must } \\
\text { might } \\
\text { need to }\end{array}$ & & $\begin{array}{ll}\sqrt{ } & \sqrt{ } \\
\sqrt{ } & ? \\
\sqrt{ } & - \\
\sqrt{ } & - \\
\sqrt{ } & - \\
\sqrt{ } & \sqrt{ }\end{array}$ & $\begin{array}{l} \\
- \\
- \\
- \\
- \\
\checkmark\end{array}$ & $\begin{array}{l}- \\
- \\
- \\
- \\
- \\
V\end{array}$ & $\begin{array}{l}v \\
v \\
v \\
v \\
v \\
v\end{array}$ & $\begin{array}{l}\sqrt{ } \\
\checkmark \\
\checkmark \\
\checkmark \\
\checkmark \\
\sqrt{ }\end{array}$ \\
\hline 3.2 .11 & tumbwatin & start & & $\sqrt{ }$ & - & - & $-\sqrt{ }$ & $\sqrt{ }$ \\
\hline 3.2 .12 & $\begin{array}{l}\text { les } \\
\text { rog } \\
\text { rog }\end{array}$ & $\begin{array}{l}\text { see } \\
\text { hear } \\
\text { feel }\end{array}$ & & $\begin{array}{ll}\checkmark & \checkmark \\
v & \checkmark \\
v & \checkmark\end{array}$ & $\begin{array}{l}- \\
- \\
-\end{array}$ & $\begin{array}{l}- \\
- \\
-\end{array}$ & {$\left[\begin{array}{l}\checkmark \\
-\quad \checkmark \\
-\quad \checkmark\end{array}\right.$} & $\begin{array}{l}\checkmark \\
\checkmark \\
\checkmark\end{array}$ \\
\hline$?$ & $\begin{array}{l}\text { mwal } \\
\text { mwasasag }\end{array}$ & $\begin{array}{l}\text { nearly } \\
\text { nearly }\end{array}$ & $\begin{array}{l}\text { close to } \\
\text { close to }\end{array}$ & 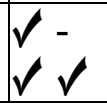 & $\begin{array}{l}- \\
-\end{array}$ & - & $V-$ & $\begin{array}{l}\checkmark \\
\checkmark\end{array}$ \\
\hline
\end{tabular}

Most of the verbs in Table 94 may occur with noun phrase complements as in (761)(763). The exceptions are mwas 'must' and mwayt 'might' which always have clause complements. Mwas 'must', mwayt 'might', mwal 'nearly', and mwasasag 'nearly' are also used as clause initial modifiers with similar meanings (Section 5.3.3).

\footnotetext{
${ }^{126}$ The following categories of complement-taking predicates (Noonan 1985) were not attested in my Nahavaq corpus: 3.2.3 Pretence predicates, , 3.2.6 Predicates of fearing, 3.2.10 Achievement predicates, 3.2.13 Negative predicates, 3.2.14 Conjunctive predicates. These concepts are expressed though other kinds of constructions.
} 
(761)No-roghur [neqhe-n na-qay yigc]. 1SG.R-know name-3SG NV-wood PROX

'I know this tree's name.' [07065.091 07065.wav 389.449 392.308]

(762)Kinag ne-rirog vovoh [no-qonlin na-mbwaq]. $1 \mathrm{SG} \quad$ 1SG.R-like INTENS NV-egg NV-turtle

'I really like turtle eggs. I like to eat turtle eggs.' [07117.786 07117.wav 2086.168 2088.715]

(763)Mi-topw mbweleg verqeh en mi-tumbwatin [ni-raq-yen]. 1EX.PL-jump to.FOC shore and 1EX.PL-start NI-work-NOM

'We jumped ashore and we started the work.' [07116.046 07116.wav 218.536 223.161]

All of the verbs in Table 94 may occur without a complementiser, but some may optionally take complementisers gcen or wut as in (764)-(766).

(764)Momoq ra-traym gcen re-mwindal len na-taq yig. woman 3PL-try COMP 3PL-play in NV-thing PROX

'Women try to play with this thing.' [07083.092 07083.wav 846.253 854.425]

(765) A-vwer wut ne-viqis. 2PL-say COMPL 1SG.R-lie

'You guys said I lied.' [07065.344 07065.wav 1241.629 1244.848]

(766) Re-les
3PL-see COMPL $\begin{gathered}\text { Avuraraq i-s-tal } \\ \text { avuraraq 3SG.R-NEG-return } \\ \text { NEG }\end{gathered}$

'And they saw that Avwuraraq didn't return.' [07089.052 07089.wav 285.816 288.520]

Some of the verbs in Table 94 are attested with the same subject in the complement clause as in Examples (767)-(768). Some are attested with different subjects in the complement clause as in (769)-(771).

(767) No-roghur [gce-yipyip ra-n spiagan]. 1SG.R-can 1SG.IRR-dive INSTR-3SG speargun

'I can dive with a spear gun.' [07117.137 07117.wav 513.527 516.011]

(768) U-mwas $\quad[\mathrm{ku}$-gcilew ne-tel $]$. 2SG.R-must 2SG.IRR-look.for NV-rope

'You have to find a rope.' [07083.114 07083.wav 1500.439 1502.220]

(769) No-got [ $\quad$ ku-sarlis ni-qismbet t-nugc luqur 1SG.R-not.want 2SG.IRR-exchange NI-skirt POSS-2SG with ni-vilamb sut $]$. NI-girl NONSP

'I don't want you trading your skirt with another girl.' [07064.074 07064.wav 286.342 291.419] 
$\begin{array}{lllll}\text { (770) } \frac{\text { A-rog }}{2} & {[\text { gce-vwer }} & \text { neqhe- } n & \text { na-taq } & \text { yig]? } \\ & \text { 1SG.IRR-say } & \text { name -3SG NV-thing } & \text { PROX }\end{array}$

'Do you guys want me to say the name of this thing?' [07065.096 07065.wav 404.413 409.210]

$\begin{array}{lll}\text { (771) } \frac{I-\text { rirog tey }}{3} \text { SG.R-want FOC } & {[\mathrm{ru}-\log ] \text { 3DU.R-go }}\end{array}$

'She wanted them (him and herself) to go.' [07074.040 07074.wav 176.158 180.377]

Some of the verbs in Table 94 always have irrealis mood in their complement clauses. These are the ones which fall into Noonan's (1985) categories of desiderative predicates ( $v w e r$ 'want/intend', rog 'want', rirog 'want', got 'not want'), modal predicates (mwas 'must', mwayt 'might', roghur 'able', lesur 'able', mbwit 'unable'), negative achievement predicates (traym 'try', mwal 'nearly', mwasasag 'nearly'), as well as vwer 'order'. Examples include (759) and (767)-(770) above and (772)-(773) below. ${ }^{127}$ The mood in the complements of other verbs varies. Examples (774)-(776) show realis mood in complement clauses.

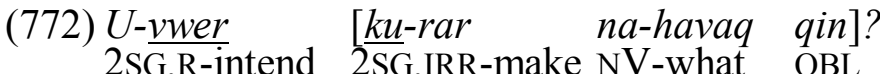

'What are you going to do to her?' [07080.066 07080.wav 262.560 267.810]

(773) Ne-wut i-mwasasag [ke-reg]. $\mathrm{NV}$-place 3SG.R-near 3SG.IRR-light

'It was nearly dawn.' (Lit. 'The place was nearly light.') [07064.179 07064.wav $633.874636 .843]$

(774) No-rog $\quad[$ ne-vutol en $]$.

1SG.R-feel 1SG.R-hungry ID

'I feel hungry.' [07082.027 07082.wav 110.080 115.314]

$\begin{array}{cccc}\text { (775) Nuqumw } & \text { qet } & \text { wa-gcur } & \text { [na-qamb i-ndug-ndug]? } \\ \text { 2DU } & \text { COMPL } & \text { 2DU.R-cause } & \text { NV-fire }\end{array}$

'Was it you two that made the fire smoke?' [08009.125 08009.wav 737.074 742.215]

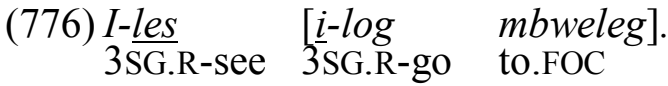

'He saw her coming.' [07064.156 07064.wav 563.201 566.982]

\subsubsection{Interrogative complement clauses}

The following examples show interrogative clauses acting as complements to verbs. ${ }^{128}$ As with interrogative clauses (Section 5.2.2.2), the interrogative constituent may remain in its default position (777)-(778) or be qet-fronted (779)-(782) or be noun-

\footnotetext{
${ }^{127}$ In Examples (758), (764), and (771), irrealis mood is not marked despite having verbs that take irrealis complement clauses. This is because the complements contain non-singular subjects, and for many speakers, irrealis mood marking is lost for non-singular subjects (Section 4.2.1). If these examples had singular subjects, they would have irrealis mood marking.

${ }^{128}$ Note that (782) uses the verb ndighur 'tell', which is not in Table 94 because it does not occur with other kinds of complement clauses in the corpus. This may simply be due to limited data.
} 
phrase-fronted as in (783). While declarative complement clauses often contain the complementiser, wut, interrogative complement clauses are not attested with wut.

(777) I-mbwit vovoh [ke-veqen ke-temwin]. 3SG.R-not.know INTENS 3SG.IRR-have 3SG.IRR-how

'He didn't know just how he would get her.' [07064.016 07064.wav 76.429 79.617]

(778) Ku-tus neqhe-n inug ko-toq ra-n gcen gco-roghur 2SG.IRR-write name-3SG 2SG 3SG.IRR-be on-3SG because 1SG.IRR-know [no-vol t-iyaq en]. NV-book POSS-who ID

'Write your name on the paper so that I know whose paper it is.' [07048.0479 07048.wav 875.265 879.217]

(779) $K u$-topw 2SG.IRR-jump

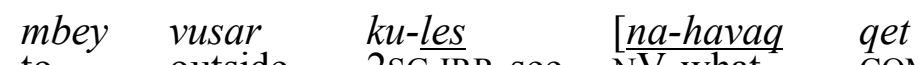

'Go outside and look what is exploding on the house.' [EC02.022 EC02.wav 102.403 106.887]

(780) Ku-toq lalaq ohoy tey ku-les [iyaqqet i-qan 2SG.IRR-be quiet simply FOC 2SG.IRR-see who COMPL 3SG.R-eat qin].

'Just sit quietly and you will see who it was that ate it.' [07082.053 07082.wav 219.265 223.296]

(781) Nug u-s-roghur veq [mweney $\frac{i \text {-vih }}{3 \text { SG }}$ qet you 2SG.R-NEG-know NEG money 3SG.R-how.many COMPL ne-spendem gin qor]. 1SG.R-spend 3SG today

'You don't know how much money I've spent today.' [07058.199 07058.wav 780.226 783.726]

(782) Avwutot i-s-ndighur veq [ambeh qet mwarlamb grandfather 3SG.R-NEG-tell NEG where COMPL old.man $\begin{array}{lll}i \text {-vwer } & k e-v e y & \text { qin] }\end{array}$.

'My grandfather did not tell where the old man wanted to go.' [08009.069 08009.wav 390.367 399.352]

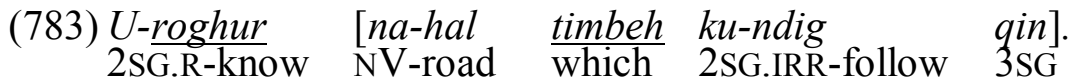

'You know which road you will follow.' [07058.196 07058.wav 767.950 775.398]

\subsubsection{Adverbial clauses}

Adverbial clauses are subordinate clauses that act as modifiers to main clauses. They can give information about reason or time. Adverbial clauses can occur with or without a subordinator. 


\subsubsection{Adverbial clauses without subordinators}

Adverbial clauses of time and reason can be expressed without a subordinator as in (784)-(786). There are numerous cases such as these where the adverbial clause occurs before the main clause. ${ }^{129}$

$\begin{array}{clll}\text { (784) [Mahal } & \text { ke-min-popom } & \text { tey] } & \text { ke-mes. } \\ \text { fish } & \text { 3SG.IRR-recent-twitch } & \text { FOC } & \text { 3SG.IRR-die }\end{array}$

'And the fish would twitch until it died.' [07063.054 07063.wav 243.346 245.252]

(785) Qet [a-yipyip] a-s-mataq veq konoq ka-qas nigcim sut? but 2PL-dive 2PL-NEG-fear NEG if 3SG.IRR-bite 2PL NONSP 'But when you were diving, weren't you scared that it would eat one of you?' [07117.087 07117.wav 351.341 353.825]

(786) $[\mathrm{Ni-megci}$ ko-toq $] \quad$ re-mbwulugc ra-n na-taq yigc. NI-ceremony 3SG.IRR-be 3PL-count INSTR-3SG NV-thing PROX 'If there is going to be a celebration, they count (days) with this thing.' [07027.013 07027.wav 38.563 40.438]

Adverbial clauses without subordinators can also be preceded by the complementiser wut as in (787)-(788).

(787) $[\underline{W u t} \quad i$-ndug $\quad$ mwah i-noq nin] $u$-lesur $\quad k u$-lip when 3SG.R-smoke all 3SG.R-like DEM 2SG.R-can 2SG.IRR-take na-qay $\quad t-i-m b o w$. $\mathrm{NV}$-wood REL-3SG.R-big

'When it smokes like this, you can take a big piece of wood.' [07095.071 07095.wav 529.478 533.525]

(788) $\left[\begin{array}{lll}\text { Wut } & i \text {-vwariq }\end{array}\right]$ ru-logo-log qin tatay ti-qey. when 3SG.R-small 3DU-DUP-walk with father POSS-3SG

'When he was young, he was walking with his father.' [07098.094-095 07098.wav 482.031 495.389]

The conjunction qet is frequently used between an adverbial clause and a following main clause (789)-(792). ${ }^{130}$

\footnotetext{
${ }^{129}$ In the absence of subordinators, I identify adverbial clauses based on intonation patterns and my interpretation of the relationship between clauses in running texts.

${ }^{130}$ The conjunction qet (Section 5.5.3) is homophonous with the particle in qet-fronted constructions (Section 6.1), and the use of qet between an adverbial clause and main clause has some similarity to both of these, but I see this qet as more similar to the conjunction for two reasons. The first is that the en conjunction can also be used in this position as in (808) below. And the second is that these adverbial clause + main clause constructions sometimes have the prosody discussed in Section 6.6.4, where a clause ends in the qet conjunction with a high rise followed by a pause, indicating that the thought is not completed.
} 
(789) [Wut ke-vi mwah ndoh gin] qet ke-vus-kas COMPL 3SG.IRR-weave all PERF 3SG then 3SG.IRR-pull-out na-taq yig, ko-qom. NV-thing PROX 3SG.IRR-throw

'When he is done weaving, he will pull this thing out and throw it away.' [07083.058 07083.wav 373.848 377.129]

(790) $[$ Ne-wut ke-reg] qet ni-morot ra-q-mwas kinag. NV-place 3SG.IRR-light then NI-man 3PL-IRR-laugh 1SG

'When day breaks, the people will laugh at me.' [07064.181 07064.wav 639.765 644.265]

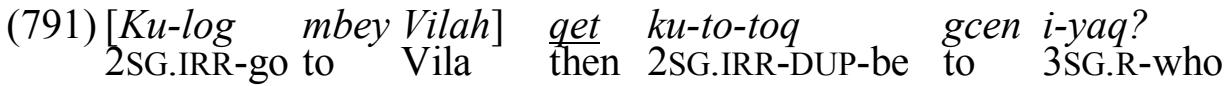
'When you go to Vila, who will you stay with?' [07117.522 07117.wav 1549.534 $1551.753]$

$\begin{array}{lllll}\text { (792) } & \text { [Gca-traympis } & \text { ra-n] } \\ \text { 1SG.IRR-try unfinished } & \text { qet } & \text { mor } & \text { sut } & \text { ke-vweleg ... }\end{array}$ 'If I fail, someone can come ...' [07095.056 07095.wav 399.963 402.744]

In the above examples, the adverbial clause precedes the main clause. However, it is also possible for the adverbial clause to follow the main clause as in (793).

(793) Qet re-hewhew qin morot [wut morot ke-meheq]. then 3PL-steam OBL man when man 3SG.IRR-sick

'People are steamed with it when they are sick.' [07034.006 07034.wav 17.183 19.573]

\subsubsection{Adverbial clauses with subordinators}

Table 95 lists subordinators that head adverbial clauses. All of them are optionally followed by the complementiser, wut. Gcen, which introduces reason clauses as in (794), also functions as a preposition of reason as in (795). Since both prepositions and these adverbial clause subordinators head adjuncts to clauses, I see these subordinators as potentially a sub-class of prepositions. ${ }^{131}$ Sections 5.4.2.2.1-5.4.2.2.4 discuss each of the subordinators from Table 95 in detail.

$\begin{array}{llll}\text { (794) I-log } & \text { [gcen } & \text { i-vutuq } & \text { ne-wey]. } \\ \text { 3SG.R-go } & \text { for } & \text { 3SG.R-fetch } & \text { NV-water }\end{array}$

'She went to fetch water. [EC01.wav 44.978 49.597]

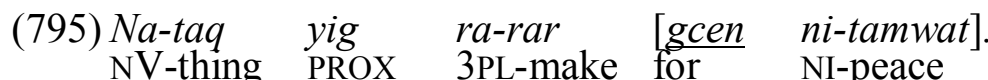

'These things are done for peace.' [07027.021 07027.wav 54.407 56.235]

\footnotetext{
${ }^{131}$ It may even be the case that like prepositions, these 'subordinators' can take nominal objects. My corpus does not contain any such examples. Further investigation would be needed.
} 


\section{Table 95: Subordinators}

The use of complementiser and position of adverbial clauses is based on my corpus. There may be other possible positions that were not attested in the corpus.

\begin{tabular}{lll}
\hline & Gloss & Position \\
\hline gcen & 'because' & after main clause \\
konoq & 'if' & before main clause \\
navwar & 'when' & before main clause \\
mbaqnder & 'until' & after main clause \\
taym & 'when' & before main clause \\
\hline
\end{tabular}

\subsection{Gcen 'because'}

Gcen expresses reason or purpose, and gcen clauses occur after main clauses (796)(799). Translations in English include 'because/to/so that'. Example (799) shows an adverbial clause with the subordinator gcen and the complementiser wut.

$\begin{array}{llll}\text { (796) I-log } & \text { [gcen } & \text { i-vutuq } & \text { ne-wey]. } \\ \text { 3SG.R-go because } & \text { 3SG.R-fetch } & \text { NV-water }\end{array}$

'She went to fetch water.' [EC01.wav 44.978 49.597]

(797) Avuraraq i-teg [gcen i-les ni-mworot i-lam $] \quad$ qet Avuraraq 3SG.R-cry because 3SG.R-see NI-man 3SG.R-many then i-mimaqan vwovwoh.

3SG.R-shy very

'Avuraraq cried because he saw many people, and he was very shy.' [LS01.131 LS01.wav 560.894 566.206]

(798) Qet re-q-viqis tartar tey qin [gcen na-mbwu but 3PL-IRR-turn always FOC 3SG because NV-bamboo ko-s-kon veq]. 3SG.IRR-NEG-burnt NEG

'And it must be turned continuously so that the bamboo doesn't burn.' [07112.046 07112.wav 285.174 291.268]

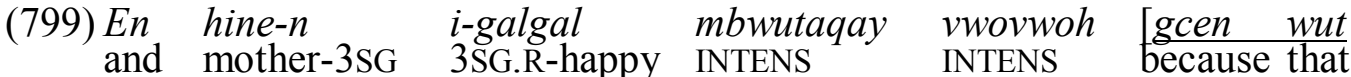
ni-mbwunog ti-qey i-tal ndal]. NI-child POSS-3SG 3SG.R-return back

'And the mother was very happy because her son had come back.' [KO02.027 KO02.wav 138.830 142.736]

\subsection{Konoq 'if'}

Konoq is clearly composed of two morphemes: ko-noq '3SG.IRR-like'. However, it seems to have grammaticalised into a subordinator marking a hypothetical clause, which I gloss as 'if'. Example (801) shows konoq followed by the complementiser, wut. Konoq clauses normally occur before a main clause and may occur with the conjunction qet introducing the main clauses as in Examples (802)-(803).

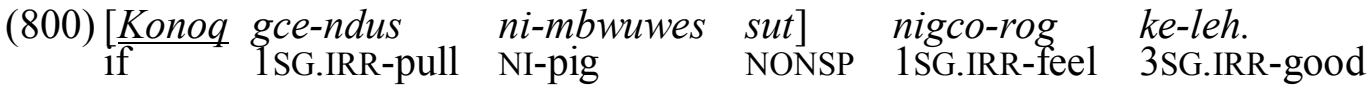
'If I were pulling a pig, I would feel fine.' [TB01.043 TB01.wav 192.692 195.630] 
(801) [ Konoq wut ku-sisiq pistas] $k u$-vwul pistas $t$-inugc if COMPL 2SG.IRR-lack peanut 2SG.IRR-buy peanut POSS-2SG ambeh?

where

'And then if you don't have peanuts, where will you buy your peanuts?' [07058.083 07058.wav 312.564 318.626]

(802)Lavwuq qet [konoq gce-vi-viyeh inugc] qet tomorrow COMPL if 1SG.IRR-DUP-call 2SG then

$k u$-s-vweleg veq.

2SG.IRR-NEG-come NEG

‘Tomorrow if I call you, don’t come.’ [07082.048 07082.wav 197.969 202.500]

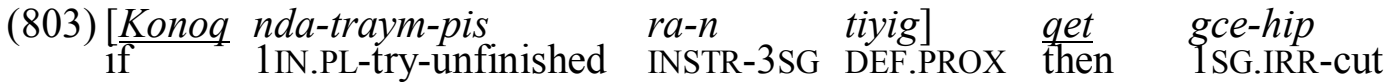
ndalis tiyag. again DEF.DIST

'If I can't do it with this one, then I will cut another one.' [07095.044 07095.wav 266.294 268.997]

\subsection{Navwar 'when'}

Navwar 'when' can occur with or without the complementiser wut. Navwar clauses precede main clauses and en or qet conjunctions may occur between the two clauses (808)-(809).

(804)[Navwar ne-wut i-reg], mworot re-vweleg gcen ra-hapw. when NV-place 3SG.R-light man 3PL-come for 3PL-dance 'When the day broke, people came to dance.' [07064.076 07064.wav 294.763 298.935]

(805)[Navwar i-ndon], i-vwer, 'A-lipmbweleg.' when 3SG.R-empty 3SG.R-say 2PL-taketo-FOC

'When it (the liquid) ran out, he said, "Bring it here."' [07065.140 552.024 554.508]

(806) $[$ Navwar wut i-vwun], i-tal. when COMPL 3SG.R-full 3SG.R-return

'When it was full, he went back.' [07063.163 07063.wav 556.882 558.898]

(807) $\begin{array}{lllllll}\text { [Navwar } & \text { wut } & \text { ke-lip } & \text { ndalis } & \text { ni-tumbwel nin }] & k e \text {-ven } \\ \text { when } & \text { COMPL } & \text { 3SG.IRR-take } & \text { again } & \text { NI-arrow } & \text { DEM } & \text { 3SG.IRR-shoot }\end{array}$ ndalis. again

'When he would get the arrow again, he would shoot it again.' [EC01.055 EC01.wav 273.004 281.775]

(808)En [navwar wut gey i-les mor tinin i-metur tey and when COMPL 3SG 3SG.R-see man DEF 3SG.R-sleepFOC wutin], en qey i-log mba-ra-n tispsu-n na-hal. there and 3SG 3SG.R-go to-on-3SG side-3SG NV-road 'But when he saw the man, he walked on by, on the other side.' [LUK.10:31] 
(809) En [navwar wut qey i-log] qet ni-morot qar and when COMPL 3SG 3SG.R-go then NI-man PL re-susul mbwutaqay qey. 3PL-crowd INTENS 3SG

'As Jesus went along, the people were crowding him from every side.' [LUK.08:42]

\subsection{Mbaqnder 'until'}

Mbaqnder 'until' clauses occur after the main clause. In Examples (810)-(811) mbaqnder is followed by the wut complementiser. In (812) there is no complementiser.

(810) Ko-toq tey li-yumw [mbaqnder wut ke-mehmeh]. 3SG.IRR-be FOC in-house until COMPL 3SG.IRR-dry

'It will just stay in the house until it is dry.' [07122.039 07122.wav 104.857 109.139]

(811) U-lesur tey ku-qombw mbe-len na-mol nembug 2SG.R-can FOC 2SG.IRR-throw to-in NV-school mackerel ka-vaq-siq, ka-vaq-ru ka-vaq-tul ka-vaq-ves 3SG.IRR-time-one 3SG.IRR-time-two3SG.IRR-time-three 3SG.IRR-time-four ko-noq nin [mbaqnder tey wut ni-mahal ka-lambw]. 3SG.IRR-like DEM until FOC COMPL NI-fish 3SG.IRR-many 'You can throw it into the school of mackerel once, twice, three times, four times like this until there are many fish.' [nihumbwen2.057 nihumbwen.wav 616.063 623.103]

(812) Ro-noq ohoy ndoh nin [mbaqnder re-mbwu-mbwow]. 3PL-like simply PERF DEM until 3PL-DUP-big

'They are simply like that until they grow up.' [07117.825 07117.wav 2171.098 2173.911]

\subsection{Taym 'when'}

Taym 'when' is a borrowed word, derived from Bislama taem which has a similar 'when' function. As with other Nahavaq subordinators, it can be used with or without the complementiser wut, and qet may occur between the adverbial clause and the following main clause as in (814).

(813)Aley, [taym ku-qoros mwah] qet a-her nigcim-yen qar mbweleg. okay when 2SG.IRR-cutall then 2PL-take2PL-POSS PL to.FOC

'Okay, when you have finished cutting, bring all yours here.' [07051.673 07051.wav 2601.918 2605.652]

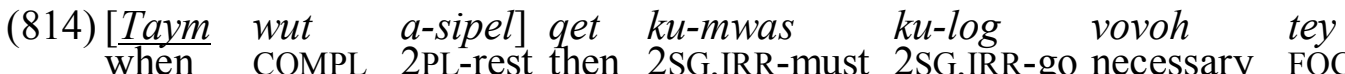
migce-n pwapwapw qar len wiken ohoy tey qet to-3SG uncle PL in weekend simply FOC then ku-tal ndal.

2SG.IRR-return back

'When you have a break, you must just go to your uncle's just for the weekend, and then you will go back.' [07117.530 07117.wav 1562.653 1567.966] 


\subsection{Coordination}

When talking about coordination of clauses, it is first necessary to distinguish clauses which occur in sequence without any kind of conjunction from those that are in some way joined. In cases where there is a coordinator, it is fairly easy to say that the two clauses are conjoined. ${ }^{132}$ In cases where there is a completely finished intonation phrase with a drop in pitch (Section 2.6) followed by a pause and another complete intonation phrase, it is fairly easy to say that the two clauses are not conjoined and that they constitute separate 'sentences'. However, between those two extremes, there are grey areas. For example, (815) describes three events that occur in sequence. The clauses are simply juxtaposed without coordinators, but I consider this a case of conjunction because the ends of clauses do not show a fall in frequency that is associated with a complete utterance. Instead, there is a notable rise-fall at least between $i$-met '3SG.R-wake' and $i$-topw '3SG.R-jump' (Figure 30).

\begin{tabular}{|c|c|c|c|}
\hline $\begin{array}{l}\text { (815) Vene-n } \\
\text { sister-3SG }\end{array}$ & $\begin{array}{l}i \text {-met } \\
\text { 3SG.R-wake }\end{array}$ & $\begin{array}{l}\text { i-topw } \\
\text { 3SG.R-jump }\end{array}$ & $\begin{array}{l}i \text {-vwer, } \\
\text { 3SG.R-say }\end{array}$ \\
\hline $\begin{array}{l}k u \text {-ropw } \\
\text { 2SG.IRR-run }\end{array}$ & $\begin{array}{l}\text { ehun kinc } \\
\text { from } 1 \mathrm{sG}\end{array}$ & & \\
\hline
\end{tabular}

'And his sister woke up, jumped up, and said, "You think you can run away from me?"” [07064.267-268 07064.wav 919.298 925.689]

Figure 30: Pitch diagram for Example (815)

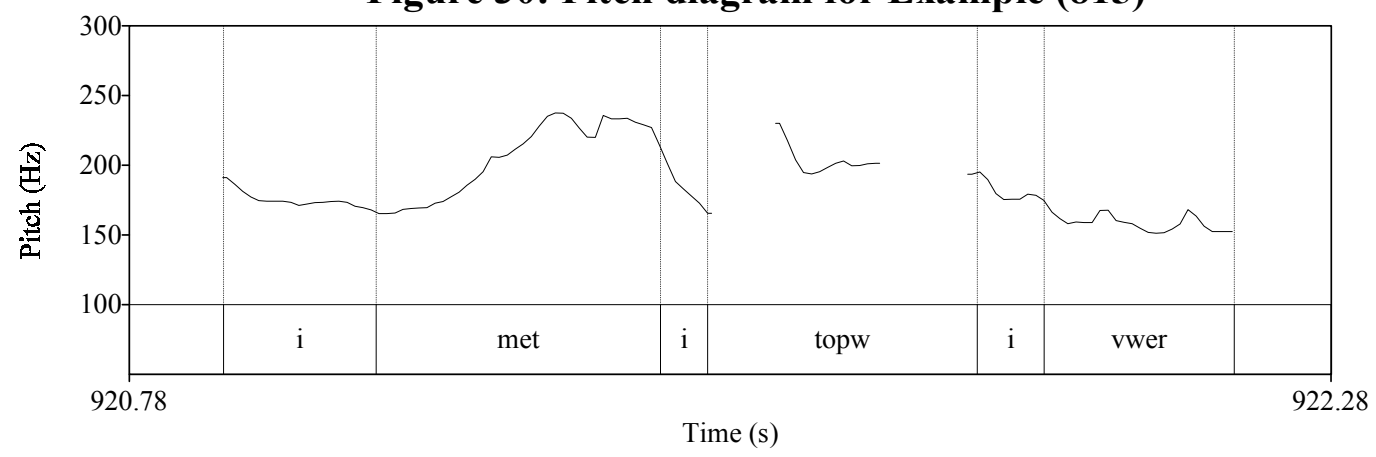

This clause final rise in frequency is associated with adverbial clauses as well. For example, in Section 5.4.2.1, I stated that Example (785), repeated here as (816), contained a subordinate adverbial clause. But Figure 31 shows a similar intonational pattern to Figure 30. They both have a rise on the final syllable of the clause and a fall in the first syllable of the following clause. Neither (815) nor (816) has any syntactic marking of subordination or coordination.

(816) Qet [a-yipyip] a-s-mataq veq konoq ka-qas nigcim sut? but 2PL-dive 2PL-NEG-fear NEG if 3SG.IRR-bite 2PL NONSP 'But when you were diving, weren't you scared that it would eat one of you?' [07117.087 07117.wav 351.341 353.825]

\footnotetext{
132 There seem to be some cases where a sentence begins with en 'and' or qet 'then' without any relationship to previous clauses. This could be seen as a discourse marker (perhaps a pause filler) rather than syntactic conjunction.
} 
Figure 31: Pitch diagram for Example (816)

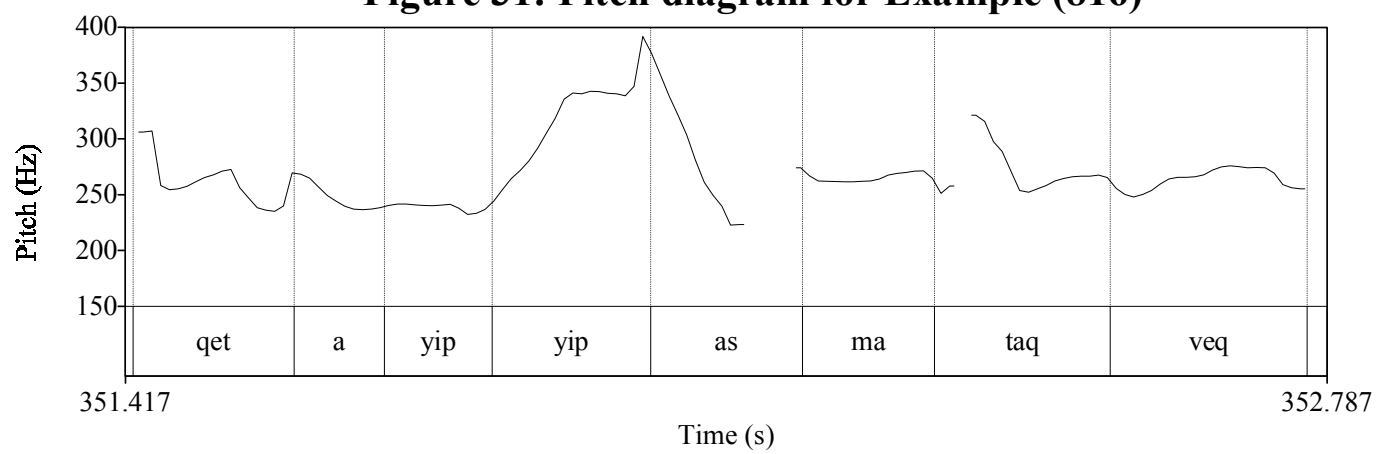

Without syntactic or prosodic differences, I cannot say that there is a definable difference between subordination and coordination of clauses in Nahavaq. I make the distinction based on whether I see a hierarchy in the semantic relationship between clauses, but this is my perception and could be rather arbitrary.

The following sections describe coordinators that mark a juncture between clauses. The clausal coordinators, en 'and', inet 'then' and qaw 'or' can also be used in nominal coordination (Section 3.6). The coordinator qet 'then/but', is only found in clausal coordination.

\subsubsection{En 'and'}

$E n$ can be seen as the neutral coordinator because it can be used for a variety of relationships between clauses. In Example (817), en is used between three events that happen in sequence. Example (818) has three instances of en. The first clause is a logical preliminary for the second clause. The third clause is not clearly related to the first or second. It refers to different participants in a different location. But there is a relationship because Vinmbumbaqaw is the owner of the house mentioned in the first clause, and all these clauses together form a background for events that are about to happen. The relationship between the third and fourth clauses involves a degree of contrast: Vinbumbaqaw is in the bush while her children stay home.

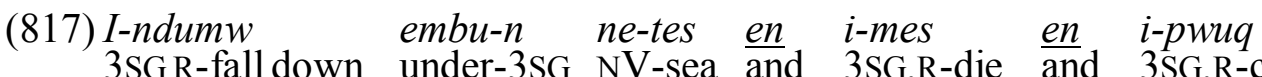
3SG.R-fall.down under-3SG NV-sea and 3SG.R-die and 3SG.R-change naqhaw. reef

'She fell down into the water, died, and changed into a reef.' [07076.094 07076.wav 370.140 375.765]

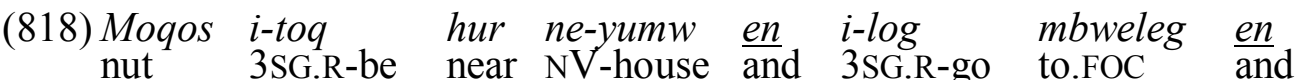
Ni-vinmbwumbaqawi-log lembunqay en ni-vuti-n qar NI-Vinmbumbaqaw 3SG.R-go bush and NI-child-3SG PL ro-koh tey eyumw. 3PL-be FOC village

'The nut tree was near the house and he went to it, and Vinmbumbaqaw was walking in the forest and her children just stayed at home.' [EC02.010 EC02.wav 47.441 54.770] 


\subsubsection{Inet 'then'}

While the general coordinator en 'and' can be used in cases of event sequencing, inet 'then' indicates event sequence more specifically as in (819)-(821).

(819)Mi-kuk mbonombon qin inet mi-qan mbonombon. 1EX.PL-cook together 3SG then 1EX.PL-eat together

'We cooked it together and then we ate it together.' [07117.153 07117.wav 572.650 575.431]

(820) I-vit gcisgcesqin inet i-tu la-qamb. 3SG.R-fasten tight $3 \mathrm{SG}$ then 3SG.R-put in-fire

'He tied it up and then put it in the fire.' [07065.209 07065.wav 794.954 797.298]

(821) Na-raraq inet nuqumwqet wa-raraq wundipw 1SG.R-clear.garden then 2DU PART 2DU.R-clear.garden extend ne-hew ti-kinag. $\mathrm{NV}$-garden POSS-1SG

'I cleared my garden, and then it was you two who cleared my garden further.' [08009.046 08009.wav 266.726 272.601]

However, not all uses of inet involve sequencing. In example (822), inet occurs in a case of contrast or comparison.
(822) Inugcku-hapw
$\begin{array}{llll}\text { len nagcon } & \text { inet kinaggca-hapw } & \text { len } \\ \text { in } & \text { POSS.1SG then } & \text { 1SG 1SG.IRR-dance } & \text { in }\end{array}$ 2SG 2SG.IRR-dance
namon.
POSS.2SG
'You dance in mine, and I will dance in yours.' [07064.094 07064.wav 363.218 366.671]

\subsubsection{Qet 'then/but'}

Note that qet 'then/but' is homophonous with the particle described in Section 6.1.

Qet is used for a variety of relationships between clauses, but one of the main ones is where there is some contradiction or something that goes against expectations. This sense is glossed as 'but' in Examples (823)-(826).

(823) Nde-vwer nda-mban wowow qet nda-s-mban gcow 1 IN.PL-say 1IN.PL-beat older.brother but 1IN.PL-NEG-beat EMPH veq qin.

NEG 3 SG.

'We thought we could beat him, but we couldn't beat him.' [07065.401 07065.wav 1439.312 1442.015]

(824)I-rirog ke-veqen qet i-mbwit vovoh ke-veqen 3SG.R-like 3SG.IRR-have but 3SG.R-not.know INTENS 3SG.IRR-have ke-temwin. 3SG.IRR-how

'He wanted to marry her, but he didn't know how he would get her.' [07064.015$01673.82076 .42979 .617]$ 
(825) Avwuraraq i-qan, qet i-s-mbwar veq ni-mbogo-n. Avwuraraq 3SG.R-eat but 3SG.R-NEG-wipe NEG NI-mouth-3SG

'Avwuraraq ate it, but he didn't wipe his mouth.' [07065.281-282 07065.wav 1022.792 1026.439]
(826) Morot ke-les ke-vwer tey na-mwat ra-n qet man 3SG.IRR-see 3SG.IRR-say FOC NV-snake on-3SG then
na-mwat veq en. Ne-tel en.
$\mathrm{NV}$-snake NEG ID NV-rope ID

'If one sees it, one might call it a snake. But it's not a snake, it's a vine.' [07037.016 07037.wav 35.906 41.094]

However, qet is also used in sequencing as in (827), and for other kinds of general coordination as in (828)-(829). In these cases, I gloss it as 'then'.

(827) Ra-rar ne-hew qet ra-qambwiq ni-gcut len ne-hew 3PL-make NV-garden then 3PL-plant NV-banana in NV-garden ti-qar. POSS-3PL

'They made a garden and they planted bananas in their garden.' [07089.018 07089.wav 109.029 117.512]

(828) Ambwat qey i-kar qet i-to-toq. Ambwat3SG 3SG.R-have.rash then 3SG.R-DUP-be

'Ambwat had skin disease, and he stayed home.' [07065.036 07065.wav 178.397 181.767]

(829) Mi-qan qin qet i-leh gcow! 1EX.PL-eat 3SG then 3SG.R-good EMPH

'We ate it and it was good!' [07117.610 07117.wav 1724.343 1727.934]

Qet is also frequently used in combination with subordinators as described in Sections 5.4.2.2, and it is used as a discourse particle at the ends of clauses to signal that the thought is not completed (Section 6.6.4).

\subsubsection{Qaw, o 'or'}

There are two coordinators, qaw and $o$, that mark a relationship between alternates. They are glossed as 'or'. $O$ is derived from Bislama $o$, which has the same function. It is phonotactically marked because it ends in a non-high vowel which is a pattern only seen in borrowed words (Section 2.3.3). Qaw can also function as a tag question particle (Section 5.2.2.1).

(830) U-lesur ku-rar ke-ru qaw ku-rar ke-siq. 2SG.R-can 2SG.IRR-make 3SG.IRR-two or 2SG.IRR-make 3SG.IRR-one 'You can make two or one.' [nihumbwen2.014 nihumbwen.wav 280.328 283.859] 
(831) U-rirog ne-tes qaw u-rirog ne-wey? 2SG.R-like NV-sea or 2sG.R-like $\mathrm{NV}$-water

'Do you prefer the sea or fresh water?' [07117.057 07117.wav 271.248 274.998]

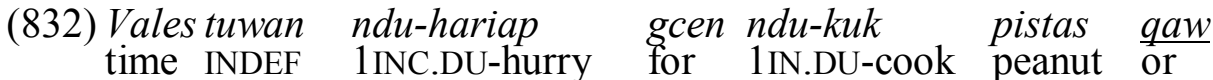
ndu-rar na-taq tuwan ko-noq nin. 1IN.DU-make NV-thing INDEF 3SG.R-like DEM

'Sometimes this thing will happen, sometimes we hurry up to cook the peanuts or we do something like that.' [07058.146 07058.wav 560.554 565.929]

(833)...gcen mbwunog ka-qan-qan qaw inug tey ku-qan-qan. for child 3SG.IRR-DUP-eat or 2SG FOC 2SG.IRR-DUP-eat

'... for a child to eat or for you to eat.' [07126.025 07126.wav 69.285 74.738]

(834) Na-qay yigc qet i-tip-tip $\quad$ ra-n metu $\underline{o}$ $\mathrm{NV}$-wood PROX COMPL 3SG.R-DUP-grow on-3SG coconut or i-tip-tip ra-n na-qay. 3SG.R-DUP-grow on-3SG NV-wood

'This plant grows on coconut trees or it grows on other trees.' [07131.025 07131.wav 88.930 92.727]

(835) Kinag no-roghur tey gca-qambwiq pistas $\underline{o}$ gca-salem. 1SG 1SG.R-can FOC 1SG.IRR-plant peanut or 1SG.IRR-sell

'I can plant peanuts or sell them.' [07058.032 07058.wav 117.675 124.691]

\subsection{Core-layer serial verb constructions}

The concept of serial verb constructions (SVC) is discussed in more detail in Section 4.6. The existence of core-layer SVCs in Nahavaq is debatable. Potential examples are easily distinguishable from potential nuclear-layer SVCs by the fact that nuclearlayer SVCs have subject prefixes only on the first verbal element as in (836) while potential core-layer SVCs have prefixes on both verbal elements as in (837). ${ }^{133}$

(836) Nuclear-layer SVC

I-vur-pet na-qay.

3SG.R-bend-break NV-wood

'He snapped a stick.' [08009.118 08009.wav 698.089 704.745]

(837) Core-layer SVC

Ndo-q-log nde-q-gcilew.

1IN.PL-IRR-go 1IN.PL-IRR-look.for

'Let's go look for it.' [EC02.097 EC02.wav 388.438 391.983]

This discussion of core-layer SVCs is included in this chapter on clause structure rather than the verb phrase chapter because most of the potential core-layer SVCs have something in common with clausal coordination or subordination. Crowley (2002b: 18) describes core-layer SVCs as lying on a structural continuum in terms of

\footnotetext{
${ }^{133}$ While it is be possible to have more than two verbs in SVCs, I limit my discussion to examples with only two verbs in potential SVC constructions for the sake of simplicity.
} 
degree of syntactic juncture: verbal compounds $>$ nuclear SVC $>$ core SVC $>$ clause chain $>$ subordinate clauses $>$ coordinate clauses.

There are many definitions of SVCs, but most require two (or more) verbs that occur without any syntactic or prosodic marking of subordination or coordination. Example (838) below contains a potential candidate under this broad definition. The verbs $i$ $\log$ '3SG.R-go' and i-metur '3SG.R-lie down' are used to describe a single act of going to a bed and lying down with the intention of sleeping, which could be glossed as 'lie down' or 'go to bed'. Figure 32 shows no change in intonation between the two verbs. This sequence of two verbs fits many definitions of SVCs.

$\begin{array}{clllll}\text { (838) En } & \text { livwaqat, } & \text { i-log } & \text { i-metur } & \text { i-teq-kas ne-vet } & \text { tinin. } \\ \text { and } & \text { night } & \text { 3SG.R-go } & \text { 3SG.R-lie } & \text { 3SG.R-pull-out NV-stone } & \text { DEF }\end{array}$ 'And in the night, when he went to bed, he took out the stone.' [07098.050-051 07098.wav 269.953 275.609]

Figure 32: Pitch diagram from Example (838)

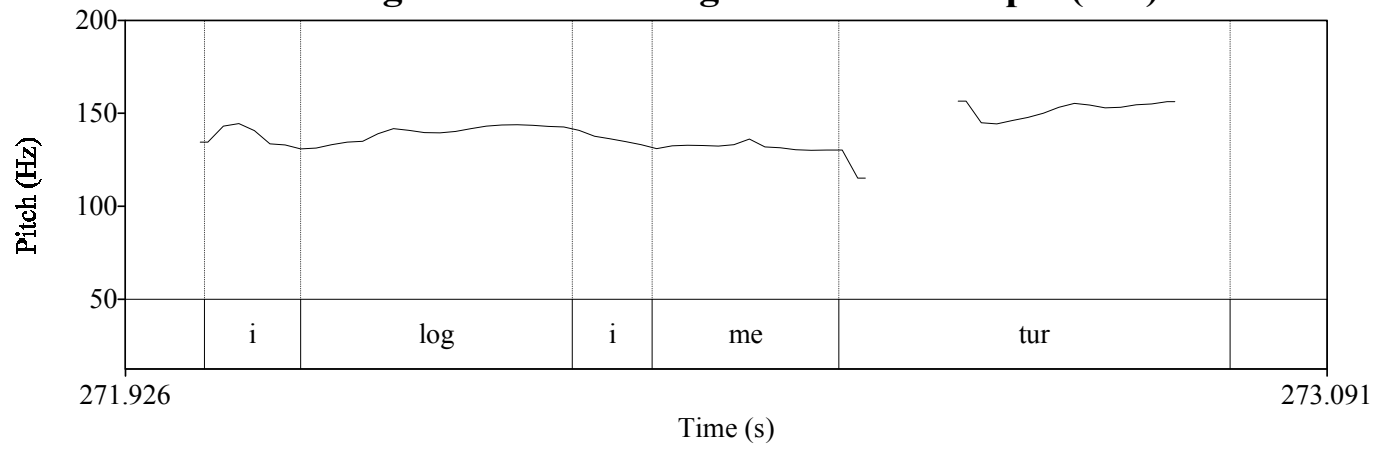

However, (839) contains the same sequence of two verbs with the same meaning of 'go to bed'. However, as shown in Figure 33, there is a rise in pitch after $i$-log '3SG.R-go' which is typical of coordinate or subordinate clauses (Section 5.5).

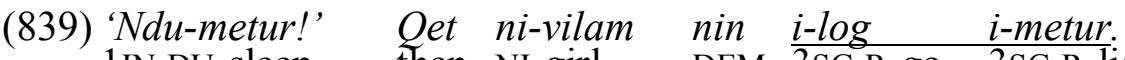
1IN.DU-sleep then NI-girl DEM 3SG.R-go 3SG.R-lie
'Ku-log mbeyle-ndiq t-inug!'
2SG.IRR-go to in-bed POSS-2SG
“"Let's sleep!" And the girl lay down (in her brother's bed). "Get into your own bed!"” [07064.191 07064.wav 671.639 675.764]

Figure 33: Pitch diagram from Example (839)

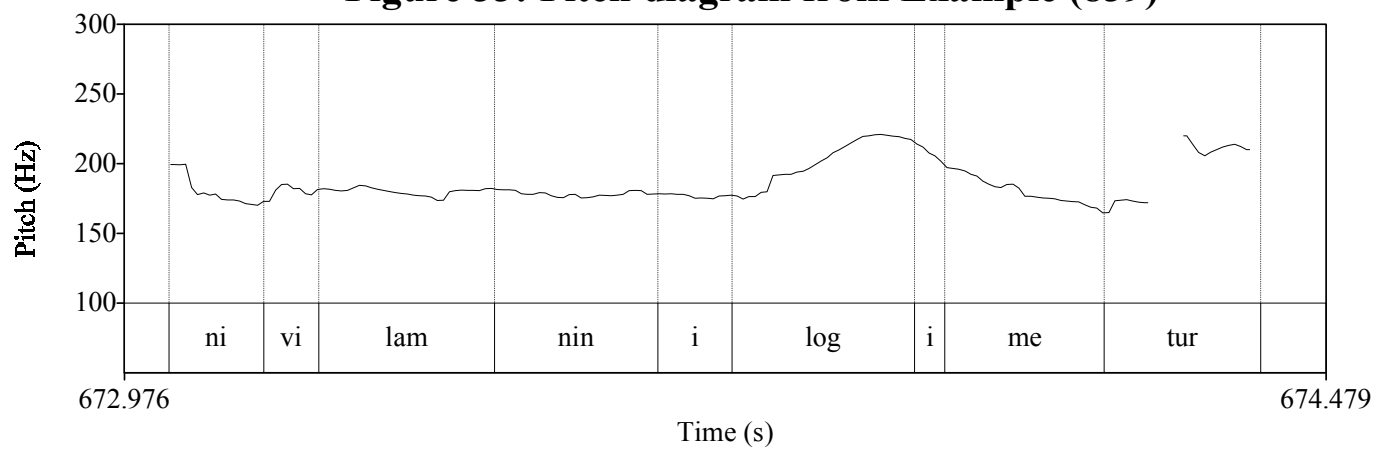


Either the two above examples are structural alternatives, where $i$-log $i$-metur constitutes a single clause in (838) but two separate clauses in (839), or they contain the same structure and difference is simply in prosody. I cannot answer this question. I will address the issue of core-layer SVCs in Nahavaq by describing structures that resemble what have been termed core-layer SVCs in other languages. These are grouped into the following eight sections. The first two (5.6.1-5.6.2) refer to structures that have been described elsewhere, but their membership in the class of SVC is debated below. Sections 5.6.3 and 5.6.4 describe somewhat productive patterns that resemble core-layer SVCs. Sections 5.6.5-5.6.7 describe individual verbs that have specialised grammatical functions that resemble core-layer SVCs.

\subsubsection{Clause-initial modifiers}

Section 5.3.3 describes clause-initial modifiers such mwas 'must' in (840).

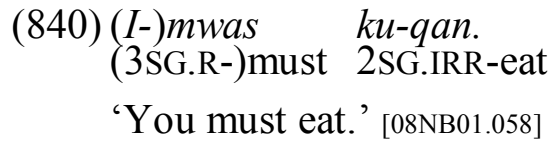

The status of mwas as a verb in this construction is debatable because it frequently occurs without any subject prefix. This appears to be a recently borrowed construction, so the grammatical category of mwas may not yet be standardised within the community.

\subsubsection{Verb + complement clause}

Section 5.4.1 describes complement clause constructions such as (841). Musgrave (2007: 92) labels similar constructions in Neve'ei as core-layer SVCs while Crowley (2002b: 62-63) considers similar constructions in Paamese as involving subordination and therefore not being SVCs. In the case of Nahavaq, I see (841) as a case of subordination which is related to constructions such as (842) that have overt marking of subordination in the form of the complementiser, wut.

(841) Na-mwat i-vwer ka-qan-qan ruwar. NV-snake 3SG.R-say 3SG.IRR-DUP-eat 3DU

'The snake wanted to eat them.' [07073.053 07073.wav 233.482 236.435]

$\begin{array}{rllll}\text { (842) En } & i \text {-vwer } & \text { wut } & \text { ka-qan-qan } & \text { qar. } \\ \text { and } & \text { 3SG.R-Say } & \text { COMPL } & \text { 3SG.IRR-DUP-eat } & \text { 3PL }\end{array}$

'And she wanted to eat them.' [07076.006 07076.wav 24.731 28.231]

\subsubsection{Verb of motion + activity}

A common construction involves a verb of motion followed by another verb which has the same subject and mood prefix. The meaning of these verb combinations in Examples (843)-(846) is that the subject goes to a place in order to do the activity of the second verb. As with examples (838) and (839) above, these constructions may or may not have prosodic juncture between the two verbs. These constructions are probably the most convincing case of core-layer SVCs in Nahavaq, and a parallel can be seen in Lolovoli (Hyslop 2001: 292-294). 
$\begin{array}{lllll}\text { (843) } \frac{\text { I-vweleg }}{3 \text { SG.R-come }} & \frac{i \text {-her }}{3 \text { SG.R-take old.man }} & \text { PoSS-1EX.PL } & \text { INDEF } & \text { Par }\end{array}$

'It came and took some of our old people.' [07116.092 07116.wav 449.458 452.067]
(844) Ni-momoq t-i-het tiyigc $\quad$ i-vweleg $\quad$-lip-kas NI-woman REL-3SG.R-bad DEF.PROX $\quad \frac{i-1 \text { SG.R-come }}{3 \text { SG.R-take-out }}$
ni-morot t-i-leh.
NI-man REL-3SG.R-good

'That bad woman came and took away the good man.' [MAHR.085 MAHR01.wav $610.206613 .753]$

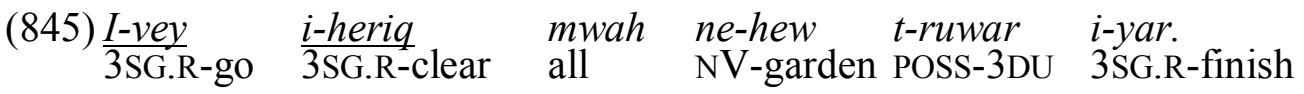

'He went and weeded their whole garden.' [07072.022 07072.wav 126.113 134.207]

(846) Ra-mwas
3PL-must
3PL-run

'They have to go hide.' [nihumbwen2.071 nihumbwen.wav 816.344 819.063]

\subsubsection{Clause + duration/multiplicative/manner}

There are a few verbs that can occur at the end of a clause that give information about the duration, repetition, or manner of the event described by the other verb in the clause. In all examples in this section, the verb of duration, iteration, or manner has a third person singular subject marker. The preceding clause could be interpreted as the subject of these verbs, i.e. (847) could be interpreted as 'Our talk has been long'. In examples (847)-(849) mbarap 'long' is used to describe the duration of the event in brackets.

$\begin{array}{ll}\text { (847) }[\text { Ndur-vi-vagas }] & \text { i-mbarap. } \\ \text { 1INC.DU-DUP-talk } & \text { 3SG.R-long }\end{array}$

'We have been talking for a long time.' [JS01.033 JS01.wav 178.214 187.698]

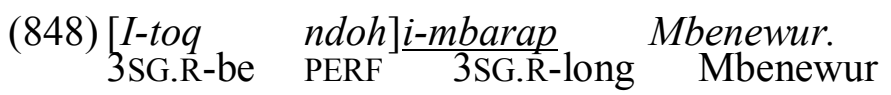

'He had lived at Mbenewur for a long time.' [07098.008 07098.wav 50.525 58.040]

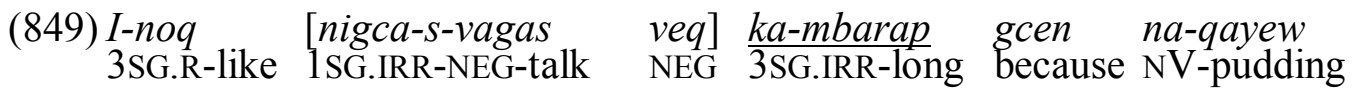
yigc ke-meh. PROX 3SG.IRR-cooked

'I might not talk for long because this pudding will be cooked.' [07112.062 07112.wav 350.617 355.914]

Iterative constructions are formed with a third person subject prefix then the prefix $v a q$ - on a quantifier base as in (850)-(851). Again, the preceding clause could be interpreted as the subject of the iterative verb. 
(850) [I-rar i-noq nin $]$ i-vaq-lam.

3SG.R-make 3SG.IRR-like DEM 3SG.R-time-many

'She did this many times.' [JS01.025 JS01.wav 133.806 136.947]

(851) [En gco-topwtopw ndalis $]$ ka-vaq-siq. and 1SG.IRR-try again 3SG.IRR-time-one

'I will try once more.' [07095.058 07095.wav 408.978 411.447]

Examples (852)-(856) show leh 'good/well' and temwin 'how' used to describe the manner in which the preceding clause was performed. Crowley (2002b: 74) describes similar constructions in Paamese as involving ambient core-layer SVCs.

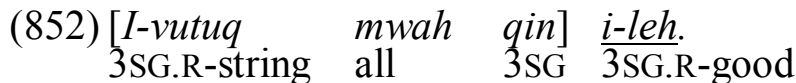

'He strung (his bow) up well.' [07063.035 07063.wav 188.782 193.298]

(853)I-mbwit vovoh [ke-veqen] ke-temwin.

3SG.R-not.know INTENS 3SG.IRR-have 3SG.IRR-how

'He didn’t know just how he would get her.' [07064.016 07064.wav 76.429 79.617]

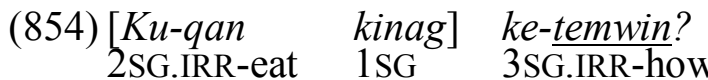

'How will you eat me?' [07133.023 07133.wav 99.745 104.417]

(855) $[$ Ku-vagas len Nahavaq] ke-leh!

2SG.IRR-talk in Nahavaq 3SG.IRR-good

‘Speak Nahavaq well!' [07048.2452 07048.wav 5828.027 5830.217]

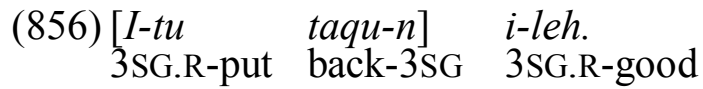

'He put his back in a good position' [EC02.108 EC02.wav 446.995 450.776]

Example (857) seems structurally different from (852)-(856) because the second verb occurs between the first verb and its direct object. This is the typical position for the second verb of a nuclear-layer SVC (Section 4.6.1) as in (858). It may be the case that the speaker in (857) has made a kind of construction intermediate between the two. All other examples in my corpus have these manner verbs occurring after direct objects as in (852), (854), and (856) above.

(857) Ku-mwas ku-lumwus ke-leh $\quad$ ni-musun. 2SG.IRR-must 2SG.IRR-wash 3SG.IRR-good NI-inside

'You must wash the middle out well.' [07117.211 07117.wav 734.359 738.656]

(858) Ku-vwur leh-leh kinag! 2SG.IRR-hold DUP-good 1SG

'Hold me well!' [07048.1896 07048.wav 4789.771 4791.383] 


\subsubsection{Causative (gcur)}

Gcur 'cause' is a verb that can take a complement clause as in Example (859), and is discussed in Sections 5.4.1 and 5.6.2. However, like many of the verbs discussed in Section 5.6.4, it can be seen as having a clause as a subject in Examples (860) and (861). Crowley (2002b: 81) describes similar constructions in Paamese as a corelayer SVC with special discourse function.

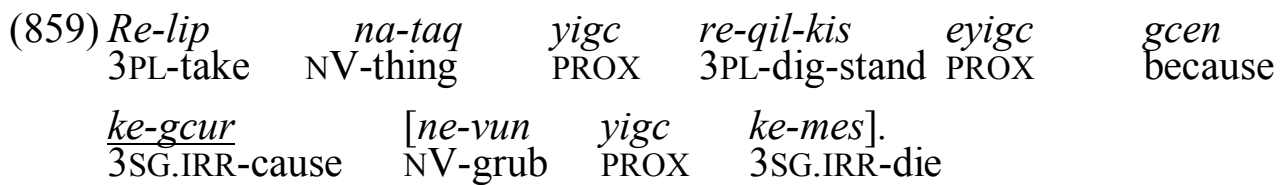

'They take this thing and stick it in the ground so that it will make the grubs die.' [07047.006 07047.wav 18.266 21.329]

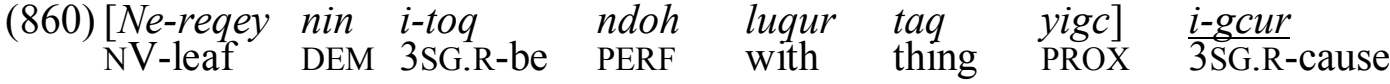 [ni-mbwaqay i-qanew en]. NI-yam 3SG.R-plenty ID

'That's because the leaf was there with this thing, and it made your yams plentiful.' [07031.029 07031.wav 76.232 79.950]

$\begin{array}{rlllll}\text { (861) }\left[\begin{array}{lll}\text { I-sumbw } & n d u-n d u & n i-s i l u\end{array}\right] & i \text {-gcur } & {[\text { gcen }} & \text { namwu-nitil } \\ \text { 3SG.R-sit } & \text { DUP-tight } & \text { NI-clothes } & \text { 3SG.R-cause } & \text { for } & \text { POSS.2SG-needle }\end{array}$ $i$-meqet].

3SG.R-broken

'It sits tight on your fabric causing your needle to break.' [07051.257 07051.wav 946.858 950.090]

\subsubsection{Completitive (yar)}

The verb yar 'finish' is used at the ends of clauses in a kind of completive construction. ${ }^{134}$ In all clear examples of this usage in the corpus, mwah was also used earlier in the clause as shown in Examples (862)-(864). Crowley (2002b: 82) describes some similar constructions in Paamese as ambient core-layer SVCs.

(862) [Ra-qambwiq mwah ni-mbwaqay] $\frac{i \text {-yar. }}{3 \text { SG.R- }}$

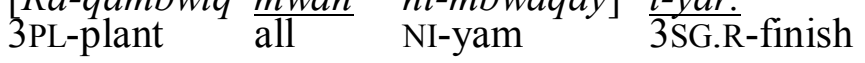

'The yams had all been planted.' [07072.026 07072.wav 158.112 164.921]

(863) I-lip ne-men nin, [i-mbon mwah] i-yar, i-visig 3SG.R-take NV-bird DEM 3SG.R-pluck all 3SG.R-finish 3SG.R-roast qin. Ni-mbwunog nin i-qan.

3SG NI-child DEM 3SG.R-eat

She took the bird and plucked it all and roasted it. The boy ate it.' [EC01.040 EC01.wav 187.650 194.821]

\footnotetext{
${ }^{134}$ Note that $i$-yar ' 3 SG.R-finish' is also used in a different kind of construction as a discourse marker (Section 6.6.3).
} 
(864) [Ka-qan mwah] ka-yar, en nimbug ti-siley ko-log 3SG.IRR-eatall 3SG.IRR-finish and day REL-far 3SG.IRR-go

ndalis.

again

'He would finish eating it, and on another day he would go again.' [KO02.005 KO02.wav 27.037 30.037]

\subsubsection{Quotative marker (vwer)}

As an independent verb, vwer means 'say'. Its use as a quotative marker is described in detail in Section 6.11. As shown in Example (865), vwer occurs directly before quoted speech. Similar constructions in Lolovoli are described as core-layer SVCs (Hyslop 2001: 298-300). However, for Nahavaq, I feel like there is a substantial syntactic juncture between the quotative marker vwer and the preceding clause. There can be a major change in pitch at this point (see Section 2.6), and there can also be a pause at this point. For example, in (866), there is a pause of 0.75 seconds before $i$ vwer '3SG.R-say'.

(865) $\frac{\text { Re-wuswus }}{3 P L-\text {-vwer, }}$ ["I-temwin?" 3PL-ask 3PL-say 3SG.R-how

'They asked, "How is it?”“ [TB03.144 TB03.wav 781.382 788.570]

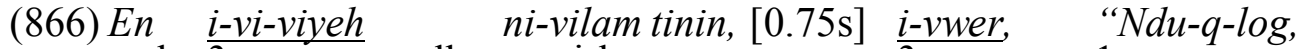
and 3SG.R-DUP-call NI-girl DEF 3SG.R-say 1IN.DU-IRR-go $n d u-q-\log ! "$ $1 \mathrm{IN} . \mathrm{DU}-\mathrm{IRR}-\mathrm{go}$

‘And he called the girl, saying, "Let's go!"” [07074.072 07074.wav 313.285 318.957] 


\section{Chapter 6: Discourse}

This chapter does not attempt to give a comprehensive description of Nahavaq discourse. Instead it contains selected topics of interest and importance in the area of discourse.

\subsection{Qet-fronting}

This section describes a type of fronting for discourse salience where the fronted phrase is separated from the rest of the clause by the particle qet as in (867)-(868).

(867) En tatay ti-qey qet Tereqlew.

and father POSS-3SG PART Tereqlew

'And his father was Tereqlew.' [MAHR.018 MAHR01.wav 322.071 326.102]

$\begin{array}{clll}\text { (868) I-yaq } & \text { qet } & \text { i-mwas } & \text { kinag? } \\ \text { who } & \text { PART } & \text { 3SG.R-laugh } & \text { 1SG }\end{array}$

'Who is laughing at me?' [LS01.082 LS01.wav 335.335 336.882]

This form of fronting does not fit neatly into definition of either topic or focus. Focus refers to non-presupposed information (Sornicola 1999: 376). In most cases of qetfronting in a verbal clause, the qet-fronted constituent is the focus. For example, (869) is said in response to the statement, 'If only there was a man here, then he could shoot that bird for us.' So the shooting of the bird is an old concept. In (870), the addressee had been stabbed and had accused the speaker of shooting her. The new information is that it was a spike (of a sea creature) rather than an arrow.

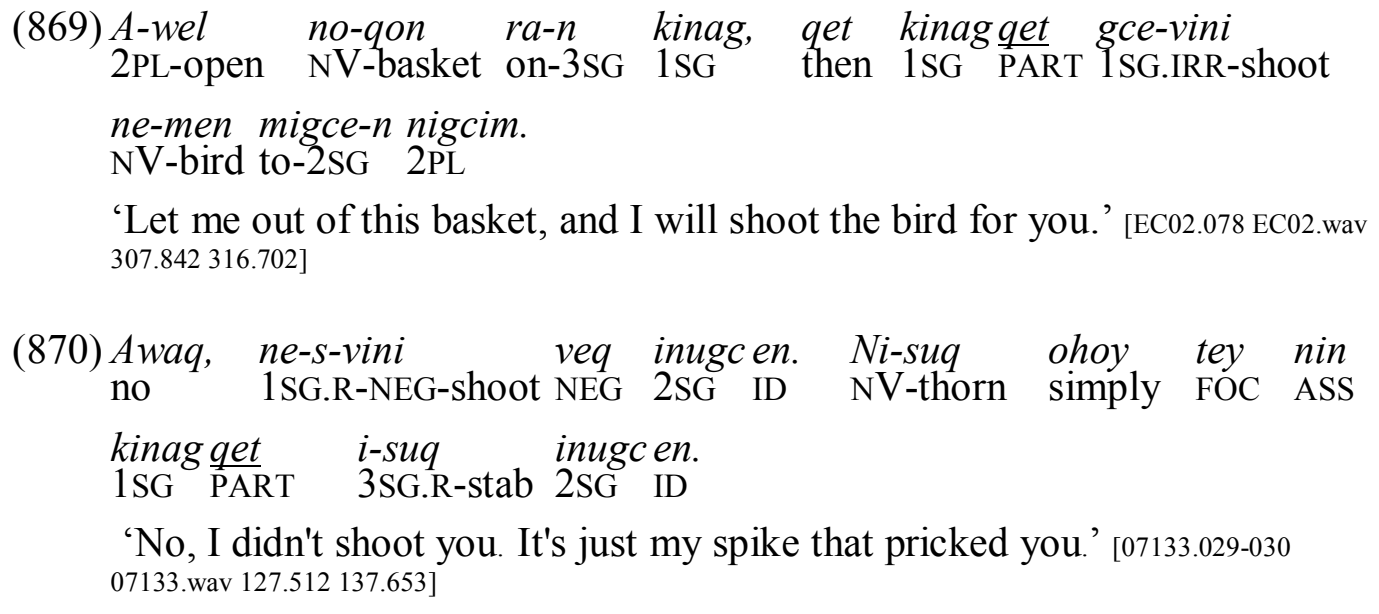

However, some cases of qet-fronting with verbal clauses such as (871) appear to have presupposed information in the qet-fronted phrase and new information in the following verbal clause, which is consistent with topic constructions rather than focus (Sornicola 1999: 376). This is also true of most cases of qet-fronting with non-verbal clauses such as (871) and (873). However, (874) provides an example of new information (focus) in the qet-fronted constituent in a non-verbal clause. 
(871)A: Qet tayvwariq gcen kava ... kava qet ra-ra-rar temwin then small.daddy for kava kava PART 3PL-DUP-makehow

$\begin{array}{llll}\text { qin gcen re-simsim qin? } & \text { B: Kava qet re-vus mwah qin, } \\ \text { 3SG because 3PL-pound 3SG } & \text { kava PART 3PL-pull all } & \text { 3SG }\end{array}$

ra-kat-mbaqher qin ...

3PL-touch-clean 3SG

'A: But Small Daddy, for kava ... how do they prepare kava for pounding? B:

For kava, they pull it all up and clean it off ...' [RF-MF01.050-051 RF-MF01.WAV

228.329 238.188]

(872) Neqhe-n kinag qet Alison Gidion Aimbel. name-3SG 1SG PART Alison Gidion Aimbel

'My name is Alison Gidion Aimbel.' [07098.002 07098.wav 11.024 16.289]

(873) Na-qay-lim-yen qet ni-mbwunog morot. NV-ORD-five-NOM PART NI-child man

'The fifth (child) was a boy.' [07063.007 07063.wav 65.009 68.337]

$\begin{array}{lll}\text { (874) Kinag } & \text { qet } & \text { ni-mbetep. } \\ \text { 1SG } & \text { PART } & \text { NI-breadfrui }\end{array}$

'I am the breadfruit.' (said to two girls looking for a certain breadfruit). [07088.016 07088.wav 104.444 108.241]

Because the information structure does not clearly fit the definition of either topic or focus, I will avoid these terms and use qet-fronting instead. Note that these Nahavaq constructions are equivalent to the Naman constructions that Crowley (2006b: 205210) describes as topicalisation. And Naman topicalisation can involve the particle at, which appears to be cognate with Nahavaq qet (although Crowley describes many other uses of the Naman particle which do not occur in Nahavaq).

If the qet-fronted phrase functions as the object of a verb or preposition, its place in the following clause can optionally be filled with the resumptive pronoun, qin (875).

$$
\begin{array}{clll}
\text { (875) a. Nahavaq } & \text { qet } & \text { u-qan? } & \\
\text { what } & \text { PART } & \text { 2SG.R-eat } & \\
\text { b. Nahavaq } & \text { qet } & \text { u-qan } & \text { qin? } \\
\text { wat } & \text { PART } & \text { 2SG.R-eat } & \text { 3SG }
\end{array}
$$

'What did you eat?' [08NB1.074]

Examples (876)-(881) below demonstrate qet-fronting of phrases with different roles. In (876), the qet-fronted consituent is a verbal subject. Example (877) shows an qetfronted object of a transitive verb. Equational sentences (Section 5.1.1.2) such as (878)-(879) are frequently presented with this qet-fronting. Adjuncts such as temporal nouns (880) and prepositional phrases (881) may also be qet-fronted.

(876) Aimbel qet i-veqen ne-vet nin ni-nal. Aimbel PART 3SG.R-have NV-stone ASS NV-sun

'It was Aimbel that had the stone of the sun.' [07098.079 07098.wav 397.751 406.563] 
(877) Nahavaq qet u-vwer?

NV-what PART 2SG.R-say

'"What did you say?"' [07132.017 07132.wav 94.227 101.337]

(878) No-qon gcow qet naqapsu-n. $\mathrm{NV}$-basket EMPH PART penis.wrapper-3SG

'The basket was his penis-wrapper.' [07063.162 07063.wav 554.929 556.882]

(879) I-siq qet Nasanal Pati, en i-siq qet Nagcriamel. 3SG.R-one PART NationalParty and 3SG.R-one PART Nanggriamel

'One was the National Party, and one was Nanggriamel' [07116.011 07116.wav 40.219 48.016]

(880) Qorig get gca-rar metu ndivunqarur en. now PART 1SG.IRR-make coconut double.sprout ID

'Now I am going to make the "double-sprouting coconut".' [07108.001 07108.wav $1.0974 .909]$

$\begin{array}{cllll}\text { (881) I-vwer, “Geen } & \text { havaq } & \text { qet } & \text { ndu-q-s-vey } & \text { veq?" } \\ \text { 3SG.R-say for } & \text { what } & \text { PART } & \text { 1IN.DU-IRR-NEG-go NEG }\end{array}$

'He said, "Why can't we go?"، [07074.047 07074.wav 208.925 212.411]

\subsection{Noun-phrase-fronting}

(Noun phrase fronting is also discussed in Sections 5.2.2.2 and 3.2). While Section 6.1 described one structure using preposed phrases, there is another kind which I term noun-phrase-fronting that differs in three ways. Firstly, while a number of different phrase types can be involved in qet-fronting, noun-phrase-fronting applies only to noun phrases. Secondly, while an qet-fronted phrase is preposed at the beginning of a clause, noun-phrase-fronting can involve movement to the front of noun phrase as in (882), (884)-(886) or a clause as in (883), (884), and (886). Thirdly, unlike qetfronting, noun-phrase-fronting can happen recursively as in (884)-(886). Finally, with noun-phrase-fronting, the resumptive pronoun qin is obligatory when the fronted phrase functions as the direct object of a transitive verb (884), (886). In the case of possessors (882), (885), (886), associative constructions (884), and suffixed prepositions (886), other forms of 3SG marking remain in situ. Examples (884) (886) fit the definition of topic constructions.

\footnotetext{
$\begin{array}{llll}\text { (882) Ku-leseles } & k u \text {-sarlis } & \text { luqur Agcew }_{i} & \text { [ni-vilam ti-qey } \\ \text { 2SG.IRR-beware } & \text { 2SG.IRR-exchange } & \text { with Agcew NI-girl POSS-3SG }\end{array}$ qaw ni-vilam sut ndalis. or NI-girl NONSP again

'Be careful of trading your skirt with Agcew's daughter or any other girl.' [07064.070 07064.wav 271.545 277.498]

(883) Qet konoq ni-mworot H $_{i}$ malavwoh ko-toq $\left.\quad r a-n_{i} \ldots\right]$ but if NI-man boil 3SG.IRR-be on-3SG

'If someone has boils ...' [07042.003 07042.wav 4.944 7.413]
} 
(884) $\left[N u \text {-wurqoqor }\left[\text { ne-reqey } n i-n_{j}\right]\right]_{i} \quad\left[\right.$ re-yusum tey qin $\left._{i}\right]$ $\mathrm{NV}$-K.o.plant NV-leaf of-3SG 3PL-use FOC $3 \mathrm{SG}$

gcen ni-meresin

for NI-medicine

'Nuwurqoqor's leaves are used for medicine.' [07030.003 07030.wav 20.638 26.248]

(885)En [Saymon ${ }_{i} \quad\left[\text { ni-mwomwoq } \text { ti-qey }_{i}\right]_{j} \quad$ hine- $n_{j} \quad i$-meheq And Simon NI-woman POSS-3SG mother-3SG 3SG.R-sick ni-malqah. NI-cold

'Simon's mother-in-law was sick with a fever.' [MRK.01:30]

$\begin{array}{cllll}\text { (886) }\left[\text { Madlen }_{j}\right. & [\text { ne-yum ti-qey }]]_{i} & \text { [na-qam } & \text { i-qan } & \left.\text { qin }_{i} \text {. }\right] . \\ \text { Madlen } & \text { NV-house POSS-3SG } & \text { NV-fire } & \text { 3SG.R-eat } & \text { 3SG }\end{array}$

'Madlen's house burnt down.' [07NB1.076]

\subsection{Focus}

\subsubsection{Contrastive focus particle $m i$}

The contrastive focus particle, $m i$, occurs after the element that is being contrasted. In Example (887), it occurs after a noun phrase, contrasting one type of clam from another. Example (888) contrasts two hypothetical situations, and the second condition is marked with $m i$. Example (889) contrasts the number of boys who returned to their home (five) with the number who found their mothers there (four).

(887) Nda-s-nav veq nde-q-her ka-kas qin ran

1IN.PL-NEG-enough NEG 1IN.PL-IRR-take DUP-out 3SG INSTR-3SG

vara-n nigcin. qet tiyig $m i$ war tiyig qet hand-3SG 1IN.PL then DEF.PROX $\overline{\text { FOC }}$ and DEF.PROX PART

i-leh.

3SG.R-good

'We are not able to take it (this clam) off with our hands. But this one and this one are good.' [07117.726 07117.wav 1944.067 1948.208]

(888) Konoq wut ka-s-rar veq ni-tus-yen, en if that 3SG.IRR-NEG-make NEG NI-draw-NOM and

Ni-sapsap ke-vwer migce-n qey ke-vwer, "ku-tal." NI-Sapsap 3SG.IRR-say to-3SG 3SG 3SG.IRR-say 2SG.IRR-return

Ut ku-tus kos mi ni-tus-yen, qet ku-log.

if 2SG.IRR-draw well FOC NI-draw-NOM then 2SG.IRR-go

'If one can't do the drawing, the Sapsap will tell him to return. But if on the other hand, you do the drawing right, then you can go on.' [KA02.011-014 KA02.wav $65.51483 .122]$

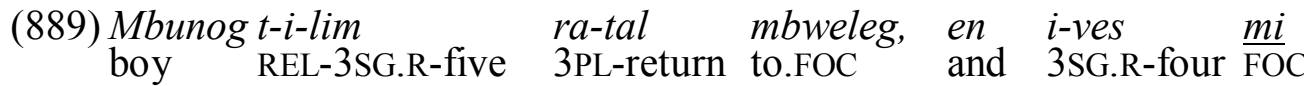
re-sep ra-n inoq revwer hine-n qar i-toq. 3PL-fall on-3SG (you know) mother-3SG PL 3SG.R-be

'The five boys came back, and four of them found their mothers there.' [MR01.072-074 MR01.wav 395.357 400.966] 


\subsubsection{Non-contrastive focus particle tey}

The particle tey is used as a non-contrastive focus marker. It occurs frequently (over 3000 instances in the corpus). Its function is not always clear, but in many cases it seems to put focus on the preceding element. In Examples (890) and (891), there are a number of propositions, but the one marked with tey gives the pertinent information. In (890), there had been speculation as to whether or not the stone would be there, and it is the fact that the stone is there rather than walking or looking that is important. In (891), Vinmbwumbwaqaw had already ordered Avwusagvwulu to go to the house and cook, so the new information is the fact that he followed her orders.

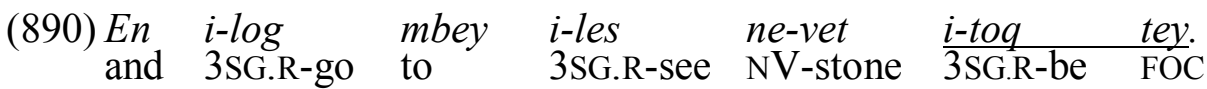

'And he went and saw that the stone was there.' [07098.071 07098.wav 364.641 368.125]

(891) En ru-log mbe-yumw . ru-rar tey i-noq and 3DU-go to-house 3DU-make FOC 3SG.R-like

Ni-vinmbwumbwaqaw i-vwer qin. NI-Vinmbwumbwaqaw 3SG.R-say 3 SG

'And they went to her house, and they did as Vinmbwumbwaqaw said.' [07089.103 07089.wav 485.791 491.978]

Tey is very common in polar questions to mark the element that is being questioned (Section 5.2.2.1). For example, in (892), the speaker knows that his own mouth had been greasy earlier that day, and he is asking whether his brothers had noticed, so tey occurs after $a$-les '2PL-see'. And affirmative answers to these questions generally contain tey as well (893).

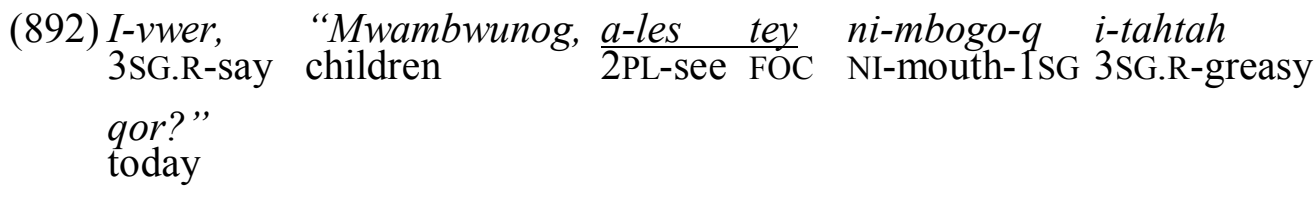

'He said, "You guys, did you see how my mouth was greasy today?"‘ [07065.327 07065.wav 1182.242 1185.976]

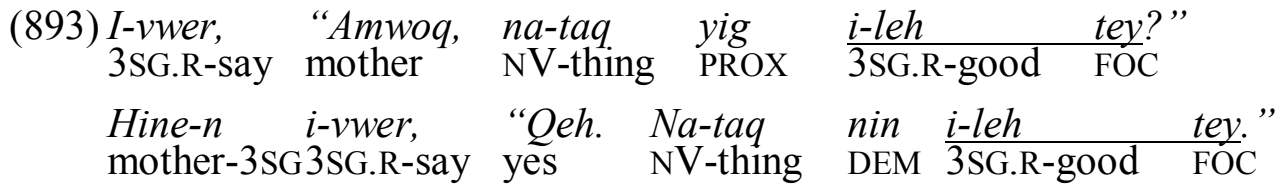

'He said, "Mother, is this thing good to eat?" His mother said, "Yes, the thing is good to eat." " [EC01.039-040 EC01.wav 181.931 194.821]

\subsection{Deixis}

This section describes the semantics of a number of morphemes in Nahavaq that relate to a deictic centre. This includes proximal and distal demonstratives that locate an entity as close to or far from the deictic centre (Section 6.4.1). This section also discusses the directional particles mbweleg and mbey and the related directional verbs $v$ weleg and vey, which indicate movement toward or away from a deictic centre (Section 6.4.2). And the final category discussed here is the directional verbal prefixes, $v w a$ - and $v i$ - that indicate an actor has moved toward or away from the deictic centre to perform an activity (Section 6.4.3). 


\subsubsection{Demonstratives}

There are six categories of words in Nahavaq which show demonstrative morphology (Table 96). In each of these categories, a term with proximal reference ends in -ig, a term with distal reference ends in -ag, and a term with a spatially neutral reference ends in -in. In the case of the demonstrative adverb, a neutral reference is unattested. I have adopted the labels for the first four categories in Table 96 from Diessel (1999). The last two categories in Table 96 function as noun phrases and therefore I have given them the labels 'place nominal' and 'person nominal'.

Apart from the -ig / -ag / -in endings, some further morphology is discernable. The $a$ of the demonstrative personal nominal (asig, asag, asin) is related to the personal prefix discussed in Section 3.4.8.1. The $e$ - in the identificational and locative sets is likely related to the locative prefix discussed in Section 3.1.2.4.1. The place nominals are probably derived from wut 'place' plus the demonstrative endings.

Table 96: Demonstratives

\begin{tabular}{llll}
\hline & Proximal & Distal & Neutral \\
\hline demonstrative pronoun & tiyig & tiyag & tinin \\
demonstrative determiner & $($ ti)yig $\sim$ tig & tiyag $\sim$ tag & $($ ti $)$ nin $\sim$ tin \\
(locational) demonstrative adverbs & eyig & eyag & -- \\
demonstrative identifiers & etig $\sim$ eg & etag & etin $\sim$ en \\
demonstrative place nominal & utig & utag & utin \\
demonstrative person nominal & asig & asag & asin \\
\hline
\end{tabular}

Examples (894)-(896) show proximal forms used with spatial reference near the speaker. In Example (894), the speaker asks her husband to state the bride price for the two girls who are accompanying her. In example (895), utig 'PLACE.PROX' refers to the area where both the speaker and the addressee are located. Tiyig 'DEM.PROX' in Example (896) refers to the tree that the speaker is facing and holding onto while speaking.

(894) Ku-vwer ni-mweney ni-mbuwes nin asig ruwar. 2SG.IRR-say NI-money NI-pig ASS PERS.PROX two

'Say the price in pigs for these two.' [LS01.097 LS01.wav 406.227 410.101]

(895) Neqhe-n utig $\quad$ qet ambeh? name-3SG PLACE.PROX PART where

'What is this place's name?' [07090.033 07090.wav 130.633 132.540]

(896) Na-qay tiyig neqhe-n qet ni-marmbugmbug. $\mathrm{NV}$-tree DEF.PROX name-3SG PART NI-marmbugmbug

'This tree's name is Marmbugmbug.' [07025.002 07025.wav 4.045 6.405]

Examples (897)-(899) show distal forms used with spatial reference far from the speaker. Example (897) is from within a narrative and the basket is located across the room from where the speaker and addressee are seated. In Example (898), two children are speaking to a man in a garden and referring to a bird flying overhead. In Example (899), the speaker is standing in the village of Lembinwen and referring to a 
rock face near the village of Mbenewur, which is approximately 1.5 kilometres away. In the video [v1010], he glances in the direction of Mbenewur at the beginning of the utterance, despite the fact that it is not visible from where he is standing.

(897) Qet $\quad k u$-lip $\quad k u$-log $\quad k u$-tu $\quad$ len no-qond tiyag. then 2SG.IRR-take 2SG.IRR-go 2SG.IRR-put in NV-basket DEF.DIST

'Then take it and go put it in that basket.' [07089.040 07089.wav 237.344 239.860]

(898) Amoq t-nuqumwem qet i-tovwis etag. mother POSS-1IN.DU PART 3SG.R-fly.across ID.DIST

'Our mother is flying there.' [08009.064 08009.wav 368.445 370.320]

$\begin{array}{lllll}\text { (899) I-tiptip } & \text { ra-n } n & \text { ne-vet } & \text { Mbenewur } & \text { eyag. } \\ \text { 3SG.R-grow } & \text { on-3SG } & \text { NV-stone } & \text { Mbenewur } & \text { DIST }\end{array}$

'And they grow on the rocks over there at Mbenewur.' [07131.010 07131.wav 37.044 38.882]

There are also cases where proximal and distal forms seem to have spatial reference, but not in relation to the speaker. Example (900) is part of a narrative. Eyag 'DIST' refers to the mainland of Malakula, but the narrator was located on the mainland at the time of telling this story. However, the content of the story up until this point has focussed on the Toman Island, an offshore island. So it seems that this example has distal spatial reference in relation to the deictic centre of the narrative rather than in relation to the speaker. In (901), four boys return to a house while an old couple is in the garden away from the house. Tiyag 'DET-DIST' is used to describe the boys who are distant in relation to the old couple in the story rather than the speaker (narrator).

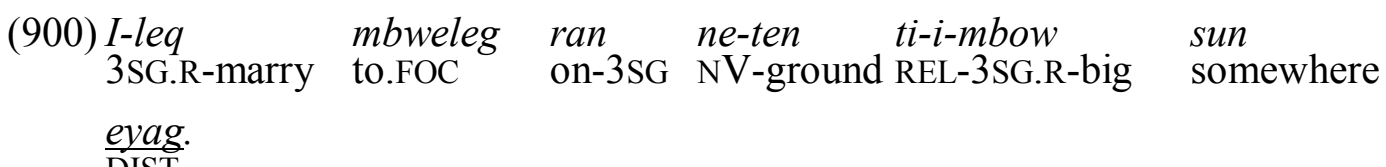

'She was married to the mainland somewhere.' [Тв01.005 TB01.wav 21.42326 .142$]$
(901) Ru-min-koh len ne-hew qet ni-mbwunog tiyag qar 3DU-recent-be in NV-garden then NI-child DEF.DIST PL ra-tal. 3PL-return.

'They were in the garden when the boys returned.' [MR01.071 MR01.wav 390.451 395.357]

There are also cases where proximal and distal forms appear to have non-spatial reference. For example, in (902), the speaker uses asig 'PERS.PROX' to refer to her brother who has run away. I do not know exactly what the term signifies in this example, but it does not seem possible that the intended meaning is spatially proximal. Proximity in terms of discourse topic or social relationship seems more likely. Example (903) is uttered as the first line to introduce a story. The proximal determiner yig seems to be referring to the topic at hand, and cannot be referring to physical space since a story does not have physical existence. In (904), asag 'PERS.DIST' is used as a filler when the speaker cannot remember a person's name. 
(902) I-ropw ndilqi-n kinag. ne-mbwit gcow mi 3SG.R-run away-3SG 1SG 1SG.R-unable EMPH FOCUS

asig i-ropw mb-ambeh.

PERS.PROX 3SG.R-run to-where

'He ran away from me, but I don't know where he went.' [07064.216 07064.wav 747.310 751.279]

(903) Ne-vwer gce-ndig ni-stori yig. 1SG.R-intend 1SG.IRR-tell NI-story PROX

'I'm going to tell this story' [08009.001 08009.wav 3.219 6.516]

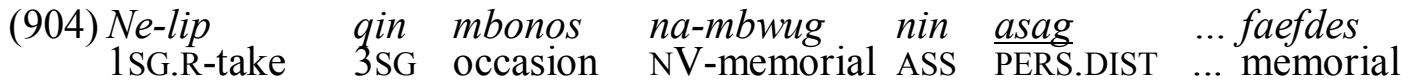 $\begin{array}{llll}t-a- & k a k a p w & a- & \ldots\end{array}$
POSS-FILL- grandmother FILL- ...

'I got one for memorial of who's-it ... Grandma um ...(Note: na-mbwug is a memorial celebration five days after a person's death when family and friends come together to share food.)' [07117.704 07117.wav 1904.098 1908.848]

The neutral forms in Table 96 do not have spatial reference, but have other kinds of deictic reference. Sometimes they are used where the referent is apparent to the participants, as in (905) where an audience member uses asin to refer to a mysterious stranger who just won a competition for two women. Etin en in Example (906) also refers to something apparent: a picture in a book that both participants are looking at. Example (907) uses en to indicate an obvious proposition rather than a physical object. The neutral identifier is very frequently used in constructions like (906) and (907).

(905) Oveh, $\quad \underline{\text { asin }}$ i-her vovoh momoq t-ru-leh yig war. Whoa PERS 3SG.R-take INTENS woman REL-3DU-good PROX DU 'Whoa, that guy got those two nice women.' [07065.198 07065.wav 754.814 758.782]

$\begin{array}{cllll}\text { (906) A: Na-qup } & \text { en, } & a q ? & \text { B: Na-qup } & \text { en. } \\ \text { NV-ghost.crab } & \text { ID } & \text { TAG } & \text { NV-ghost.crab } & \text { ID }\end{array}$ A: 'That's a ghost crab, right?' B: 'It's a ghost crab.' [07117.108-109 07117.wav 406.109 408.968]

$\begin{array}{llll}\text { (907) U-rum-soq } & \text { mata-q, mata-q } & k a-m b w a r & e n . \\ \text { 2SG.R-whip-touch } & \text { eye-1SG eye-1SG } & \text { 3SG.IRR-blind } & \text { ID }\end{array}$

'If you whip my eye, it will be blind.' [KJ01.027 KJ01.wav 125.829 130.204]

In many cases, the neutral forms could be seen as having functions of definiteness rather than the spatial reference of true demonstratives. For example in (908), the existence of a boy is established in the first sentence, and in the next sentence, the head noun is modified by tinin which defines the previously mentioned boy. In Example (909), the adnominal modifier, nin, and the place nominal, utin, are used in similar manner. The phrase mor nin 'person DEF' refers to a person on whom the story has focussed, and utin 'place.DEF' refers to Vinmavis, the village where he had come to live (having originally come from Toman Island). 


\begin{tabular}{|c|c|c|c|c|c|}
\hline $\begin{array}{l}\text { (908) En } \\
\text { and }\end{array}$ & $\begin{array}{l}i \text {-vah, } \\
\text { 3SG.R-give.birth }\end{array}$ & $\begin{array}{l}i \text {-vah } \\
\text { 3SG.R-give.birth }\end{array}$ & $\begin{array}{l}\text { ni-morot. } \\
\text { NI-man }\end{array}$ & $\begin{array}{l}\text { ni-morot } \\
\text { NI-man }\end{array}$ & $\frac{\text { tinin }}{\mathrm{DEF}}$ \\
\hline $\begin{array}{l}\text { neqh } \\
\text { name }\end{array}$ & $\begin{array}{ll}n & q e t \\
\text { 3SG } & \text { PART }\end{array}$ & $\begin{array}{l}\text { alambow. } \\
\text { lambow }\end{array}$ & & & \\
\hline
\end{tabular}

'And she gave birth to a boy. The boy's name was Salambow.' [MAHR.015-016 MAHR01.wav 308.868 317.087]

(909) No-loh ti-mwin Sip qar luqur no-loh NV-language POSS-people Vinmavis PL with NV-language

t-Ewur qet na-taq tuwan re-vi-vaqayndag POSS-Toman PART NV-thing INDEF 3PL.R-DUP-different

tey gcen mor nin i-toq utin.

FOC because man DEM 3SG.R-be PLACE

'The language of Vinmavis with the language of Toman Island, some things are the same because that man lived there.' [07064.280-281 07064.wav 961.122 968.732]

\subsubsection{Directional verbs and directional particles}

The semantics of the directional particles, mbweleg and mbey, and the related directional verbs, vweleg and vey, relate to a point of reference. Mbweleg and vweleg refer to movement toward a point of reference and mbey and vey refer to movement away from a point of reference. In many cases, the point of reference is the location of the speaker at the time of speaking as in (910)-(913).

$\begin{array}{lll}\text { (910) } K u \text {-lip } & \text { ne-vet } & \text { mbweleg. } \\ \text { 2SG.IRR-take } & \text { NV-stone } & \text { to.FOC }\end{array}$

'Bring that stone here.' [07093.032 07093.wav 234.318 236.255]

$\begin{array}{lll}\text { (911) } K u \text {-top } & \text { mbey } & \text { vusar } \\ \text { 2SG.IRR-jump to } & \text { outside }\end{array}$

‘Go outside. (said while inside a house)' [EC02.022 EC02.wav 102.403 106.887]

(912) Tatay ke-vweleg, gce-vwer migce-n.

father 3SG.IRR-come 1SG.IRR-say to-3SG

'When my father comes, I will tell him.' [KJ01.037 KJ01.wav 178.081 181.034]

(913) A-metur tey gceyip en gce-vey.

2PL-sleep FOC yet and 1SG.IRR-go

'When you are still sleeping, I'll go.' [07065.338 07065.wav 1219.898 1222.351]

It may also be the location of the speaker at another time that is being recounted. In (914), the speaker is recounting a previous experience, and the canoe moves toward her position at the time of the incident rather than her position at the time of recounting.

$\begin{array}{lll}\text { (914) Ne-les } & \text { na-wag } & i \text { - } v \text { weleg. } \\ \text { 1SG.R-see } & \text { NV-canoe } & \text { 3SG.R-come }\end{array}$

'I saw a boat coming.' [07086.018 07086.wav 79.806 84.181]

Sometimes the point of reference does not relate to the speaker. This is particularly common in narratives where the point of reference is the location of a protagonist. In 
(915) the protagonist is a child in a tree outside a house, and mbweleg is used to describe the movement of Vinmbwumbwaqaw from inside the house to the outside where the protagonist is. Example (916) is from the same narrative (with the same deictic centre of the child in the tree). The directional particle mbey (in its prefixed form, $m b i-$ ) refers to movement toward a place that is not the deictic centre.

(915) Vinmbumbaqaw i-topw. mbweleg vusar en i-gci-gcilew Vinmbumbaqaw 3SG.R-jump to.FOC outside and 3SG.R-DUP-look i-les ni-vwuti-n mbwunog i-toq ra-n ni-moqos. 3SG.R-see NI-child-3SG child 3SG.R-be on-3SG NI-nut

'Vinmbumbaqaw came outside and she looked around and saw the child in the moqos tree.' [EC02.031 EC02.wav 156.441 163.113] $\begin{array}{cllll}\text { (916) En } & n i-v w u t i-n & \text { mbwunog } & \text { nin re-virgcam } \frac{\text { mbi-li-yumw }}{\text { en }} \\ \text { and } & \text { NI-child-3SG } & \text { child } & \text { DEM 3PL-run } & \text { to-in-house }\end{array}$ re-lip no-qond. 3PL-take NV-basket

'And the boys raced to the house and got a basket.' [EC02.034 EC02.wav 171.878 174.690]

Mbweleg and mbey can also be used in a temporal sense, with the present being the point of reference. In (917), mbweleg cannot have a directional meaning because the verb toq 'be/stay/live' does not involve movement. Instead mbweleg refers to direction toward the temporal reference point qor 'today'. The use of mbey to indicate that a state or activity continues on as in (918)-(919) is very common. This could be seen as a use of mbey meaning movement through time but not toward the reference point of the present (or relative present in recounted events). (918) and (919) are both from recounted narratives, and mbey is used to describe activities that continue on a temporal path from the relative present into the relative future.

(917) I-toq mbweleg qor. 3SG.R-be to.FOC today

'She is there to this day,' [07076.099 07076.wav 392.906 394.374]

$\begin{array}{llllll}\text { (918) Ru-raq } & \text { ni-tugcoh en } & \text { ru-raq } & \text { mbey, } & \text { ru-raq } & \text { mbey. } \\ \text { 3DU-work } & \text { NI-weed } & \text { and } & \text { 3DU-work to } & \text { 3DU-work to }\end{array}$ 'They were weeding, and they worked on and on.' [07072.040 07072.wav 242.230 247.355]

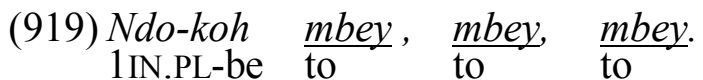

'And we stayed on and on and on.' [07116.008 07116.wav 31.484 33.953]

\subsubsection{Directional verbal prefixes (vwa- and $v i$-)}

The morphosyntax of the verbal prefixes, $v w a-$ (movement toward deictic centre) and $v i$-/pi- (movement toward other place) is discussed in Section 4.4. While the $v i-/ p$ prefix has other meanings (change of state and copular meanings as discussed in Section 4.4.3), this section is only concerned with spatial meaning. 
The elicited examples in (920) reveal the deictic nature of the $v w a$ - and $v i-/ p$-prefixes. The $v i-/ p$ - prefix is compatible with the distal locational adverb eyag (920a), and the $v w a$ - prefix is compatible with the proximal locational adverb eyig (920b). However $(920 \mathrm{c})$ and $(920 \mathrm{~d})$ are mismatched and therefore ungrammatical.

$$
\begin{aligned}
& \text { (920)a. } \begin{array}{l}
\text { I-p-toq } \\
\text { 3SG.R-go-be }
\end{array} \frac{\text { eyag. }}{\text { DIST }} \\
& \text { 'He went and stayed over there.' } \\
& \text { b. I- } \frac{v w a-t o q}{3 \text { SG.R-come-be }} \text { eyig. } \\
& \text { 'He came and stayed here.' } \\
& \text { c. *I-p-toq eyig. } \\
& \text { 3SG.R-go-be PROX } \\
& \begin{array}{ll}
\text { d. } & \text { I-vwa-toq } \\
\text { 3SG.R-go-be } & \text { DIST }
\end{array}
\end{aligned}
$$

Examples (921)-(925) are illustrative examples of these prefixes from the spoken corpus. Example (921) is produced by a speaker who is in the home village of the women in question, and he is talking about an outsider coming to live in the village. In Example (922) a child calls his mother to him. In examples (923)-(925) vi-/prefers to movement toward a location that is not the deictic centre. In fact, all three of these examples use the distal locational adverb eyag in the destination.

(921)A-her momoq nin qar nda-vwa-koh qin qar. 2PL-take woman DEM PL 1IN.PL-come-be with 3PL

'You guys will take these women and go live with them.' [07065.041 07065.wav 202.033 208.954]

(922) Amwoq, ku-top $\quad \frac{\text { mbweleg }}{\text { to }} \quad k u$-vwa-les $\quad$ taq tuwan mother 2SG.IRR-run to.FOC 2SG.IRR-come-see thing INDEF

etig.

ID.PROX

'Mother, come here and look at this.' [EC01.045 EC01.wav 214.994 220.775]

(923) Lavwuq qet i-noq gce-p-tal $\quad$ sund eyten tomorrow PART 3SG.R-like 1SG.IRR-go-return somewhere clockwise

mwindey eyag.

further DIST

'Tomorrow I might go back to some place even further around (to the North) there.' [07063.196 07063.wav 662.111 666.111]

(924) Ro-log en ra-p-taris siley eyag en. 3SG.R-go and 3PL-go-stand far DIST ID

'They went and stood far off.' [07065.193 07065.wav 738.112 742.627]

${ }^{135}$ The material in (920) comes from notes from an unrecorded discussion based on line 103 of the text 07065.wav. 
$\begin{array}{lll}\text { (925) I-p-gcomw } & \text { mbilem eyag. } \\ \text { 3SG.R-go-surface } & \text { proud } & \text { DIST }\end{array}$

'(after diving) He proudly surfaced over there.' [07065.373 07065.wav 1339.949 1345.746]

\subsection{Interjections}

Table 97 lists some common interjections in Nahavaq. Note that the sounds of 'yes' and 'no' are similar and the difference depends partly on the consonant-like sound between two nasal-like sounds. It is a glottal stop in the 'yes' interjections and an hlike sound in the 'no' interjections.

Table 97: Interjections

\begin{tabular}{|c|c|c|c|}
\hline & Notes & English translation & Use \\
\hline opo & & hey & mild surprise \\
\hline$a k a(k a)$ & & hey, watch out & caution \\
\hline $\begin{array}{l}(\text { mwah }) \text { siq } \\
\text { mwin } \sim \text { seqmwin }\end{array}$ & $\begin{array}{l}\text { (literally 'all one } \\
\text { first') }\end{array}$ & wait (a minute), hey & $\begin{array}{l}\text { confusion, mistake, } \\
\text { something is wrong }\end{array}$ \\
\hline igcaq & & whatever, what? & $\begin{array}{l}\text { shock, disagreement, } \\
\text { insulted, to deny }\end{array}$ \\
\hline oveh & & whoa & surprise, alarm \\
\hline $\begin{array}{l}\text { sigceyip } \sim i \text {-siq } \\
\text { (tey) gceyip }\end{array}$ & $\begin{array}{l}\text { (literally '3SG.R- } \\
\text { one yet') }\end{array}$ & $\begin{array}{l}\text { hold your horses, not } \\
\text { yet, patience! }\end{array}$ & $\begin{array}{l}\text { to calm someone, or stop } \\
\text { time pressure }\end{array}$ \\
\hline naqah & & here & $\begin{array}{l}\text { to present something or } \\
\text { give something }\end{array}$ \\
\hline nugcow & & okay & to agree, to concede \\
\hline $\begin{array}{l}\text { eqeh [ə̃?̃̃h] } \\
m q m h[? \mathrm{mPm}]\end{array}$ & & yes & to confirm \\
\hline $\begin{array}{l}\text { eheq [?ว̃hว̃?] } \\
m h m q[\text { [?mmm?] }\end{array}$ & & no & to contradict \\
\hline$a w a q \sim a w$ & & no & to contradict \\
\hline ey ay & & hey & to get someone's attention \\
\hline aley & $\begin{array}{l}\text { (borrowed from } \\
\text { Bislama) }\end{array}$ & okay & to start a new turn/topic \\
\hline okey & $\begin{array}{l}\text { (borrowed from } \\
\text { Bislama) }\end{array}$ & okay & to start a new turn/topic \\
\hline mwan & $\begin{array}{l}\text { (borrowed from } \\
\text { Bislama) }\end{array}$ & man, jeez & $\begin{array}{l}\text { frustration, effort, relief, } \\
\text { astonishment }\end{array}$ \\
\hline fayah & $\begin{array}{l}\text { (borrowed from } \\
\text { Bislama) }\end{array}$ & $\begin{array}{l}\text { shame, (Bislama: faec } \\
\text { (blong yu i ded) }\end{array}$ & $\begin{array}{l}\text { ajeer when somebody has } \\
\text { been put in their place }\end{array}$ \\
\hline
\end{tabular}

Some of these interjections have their own unique prosodic patterns. Most notably oveh also has a jump of approximately an octave between syllables, and the final syllable can be very long.

\subsection{Discourse markers}

This section describes the use of a few common discourse markers.

\subsubsection{Andevwer 'on the contrary'}

Andevwer 'on the contrary' is used at the beginning of a clause when the upcoming information will come as a surprise to the addressee. 

(926) No-s-logo-log veq mwasasag en. Andevwer, no-logo-log 1SG.R-NEG-DUP-go NEG near ID contrary 1SG.R-DUP-go ndoh siley en. PERF far ID
'I did not walk around nearby. On the contrary, I walked a long way.' [07063.135 07063.wav 492.075 495.769]
(927) I-vwer “Wowow u-met tey?” I-vwer, "Gce-gcur 3SG.R-say older.brother 2SG.R-wake FOC 3SG.R-say 1SG.IRR-make ke-temwin, gce-metur? Andevwer ne-met tey en, 3SG.IRR-how 1SG.IRR-sleep contrary 1SG.R-wake FOC ID $\begin{array}{lll}\text { andevwer } & \text { ni-nal } & i \text {-nden en." } \\ \text { contrary } & \text { NI-sun } & \text { 3SG.R-dive ID }\end{array}$

'He said, "Oldest brother, are you awake?" He said, "What would I be doing, sleeping? On the contrary, I'm awake, don't you know it's only sunset?"' [07065.227-228 07065.wav 843.036 851.130]

\subsubsection{Inoq revwer (approximation/hesitation marker)}

There are more than 400 tokens of inoq revwer in the corpus. Its literal compositional meaning is 'it's like they say (3SG.R-like 3PL-say)'. It has multiple discourse functions. One is to give an approximate meaning as in (928) or an approximate comparison as in (929)-(930). It is also used to hesitate or delay as in (931).

(928)En Yesu i-vwer "Aba( and Jesus 3SG.R-say Aba 3SG.R-like 3PL-say father NV-thing every yigc qar i-melim mwah tey mbigce-n inugc." PROX PL 3SG.R-easy all FOC to-3SG 2SG

'And Jesus said, "Aba (which is like 'father'), everything is easy for you.", [MRK.14:36]

(929) Inet ru-koh qin vene-n inoqrevwer momoq ti-qey. then 3DU.R-be with sister-3SG like woman POSS-3SG

'And then he lived with his sister as if she were his wife.' [07064.274-275 07064.wav 941.798 946.086]

$\begin{array}{clllll}\text { (930) Kinag } & \text { ne-les } & \text { inoq revwer } & \text { na-taq } & \text { tuwan } & \text { i-veqen } \\ \text { 1SG } & \text { 1SG.R-see } & \text { like } & \text { NV-thing } & \text { INDEF } & \text { 3SG.R-have }\end{array}$ na-vwa-n, qaw?

$\mathrm{NV}$-fruit-3SG TAG

'It looks to me kind of like something that has fruit, right?' [07048.0589 07048.wav 1092.913 1097.229]

(931) Qet inoq revwer mi- $[0.77 \mathrm{~s}]$ mi-tu ni- $^{-}$ni- fawndesen then like FILL 1EX.PL-put FILL FILL foundation gcen inoq revwer $[0.70 \mathrm{~s}]$ mi-teqes flak nin Nagcriamel. for like 1EX.PL-pullflag ASS nagriamel

'And (you know) we ... put the foundation for (you know) ... we raised the Nanggriamel flag.' [07116.059 07116.wav 282.449 290.934] 


\subsubsection{Iyar en (transition marker)}

I-yar en 'it is finished (3SG.R-finish ID)' is used as a discourse marker when there is a major transition within a text. In Example (932) there is a change in time scale from an explanation of a woman giving birth to two girls and raising them and then to a point later on when they are adults. Example (933) contains two examples of iyar en. The first occurs after a series of very active events just before the texts switches to a topic of waiting and helplessness. The second seems to occur after a list of problems and before a summary of the situation.

(932) I-gcilew ra-n ni-vilamb nin war, ru-mbu-mbow. En 3SG.R-look on-3SG NI-girl DEM DU 3DU.R-DUP-big and i-yar en. Ru-veqen ... ru-vi-veqen ndap ne-hew ... 3SG.R-finish ID 3DU.R-have... 3DU.R-DUP-have plenty NV-garden

'She looked after the two girls until they were big. And it finished. They had many gardens ...' [08009.099-100 08009.wav 592.572 600.181]

(933)I-sep ndalis mbe-len mbwilyel, i-kumbweq gcen Avwuraraq. 3SG.R-fall again to-in hole 3SG.R-startled because Avwuraraq

I-yar en. Ru-koh utin, ru-koh ru-vutol, 3SG.R-finish ID 3DU.R-be PLACE 3DU.R-be 3DU.R-hungry

$\begin{array}{lllll}\text { ru-s-roghur } & \text { veq taq sut. } & \text { I-yar } & \text { en. } \\ \text { 3DU.R-NEG-know } & \text { NEG thing NONSP } & \text { 3SG.R-finish } & \text { ID }\end{array}$

Ru-s-roghur veq ru-mwakas gcen ni-mbwilyel nin. Ru-vaqur 3DU.R-NEG-able NEG 3DU.R-get.out LOC NI-hole DEM 3DU.R-try pis. Ru-haq ndal mbaqanmehep ke-temwin qin? unfinished 3DU.R-climb back to.up 3SG.IRR-how LOC

'He also fell into the hole, and he was startled by Avwuraraq. It finished. They stayed there, they stayed and they were hungry, and they couldn't do anything. It finished. They couldn't get out of the hole. They tried and failed. How could they climb back up?' [07089.083-086 07089.wav 404.314 418.596]

Iyar en is also frequently used at the end of a piece of quoted speech at the point when the speaker returns to his own voice as in (934). This is particularly common if the quoted speech is longer than a couple of intonation phrases.

(934)I-vwer, “Awaq, na-mbwur en. Na-mbwur en. Qet qey 3SG.R-say no NV-mushroomID NV-mushroom ID then 3SG i-mbwig qin, i-tu la-qam, en nag ne-sum yipyep tey 3SG.R-wrap3SG 3SG.R-put in-fire and 1SG 1SG.R-sit wait FOC gin gcen na-qan qin. No-rog ne-vutol liglig vovoh." 3SG because 1SG.R-eat 3SG 1SG.R-feel 1SG.R-hungry INTENS INTENS $\begin{array}{lllllll}\text { I-yar } & \text { en. } & \text { re-sumbw } & \text { hur } & \text { na-taq } & \text { nin re-tu } & \text { qin } \\ \text { 3SG.R-finish } & \text { ID } & \text { 3PL-sit } & \text { near } & \text { NV-thing } & \text { DEM 3PL-put } & \text { 3SG }\end{array}$ la-qamb. LOC-fire

'He said, "No, it was a mushroom. It was a mushroom. And he wrapped it and put it on the fire, and I sat waiting for it so I could eat it. I was really, really hungry." It's finished. They sat around the things they had put in the fire.' [07065.290-295 07065.wav 1051.777 1070.486] 


\subsubsection{Qet (continuation marker)}

Qet is often used at the end of an intonation phrase with rising tone to signify that the thought is not completed. This usage is similar to the use of the coordinator qet (Section 5.5.3), but unlike the standard usage of the coordinator which is prosodically attached to the second clause, this usage of qet as a continuation marker is attached to the preceding clause as can be seen by the 0.67 second pause in Example (935).

(935) Inet ne-gcilew ndalis ra-n
then 1 tuwan,

'I am also looking after another child, I adopted another one ... her name is

Lily Rose.' [07117.029-030 07117.wav 155.450 162.590]

\subsection{Hesitation phenomena ${ }^{136}$ \\ 6.7.1. Fillers}

Nahavaq speakers use different fillers depending on the category of the word they are trying to recall (Table 98).

Table 98: Fillers

\begin{tabular}{lcl}
\hline Target category & Filler & Probable origin \\
\hline common noun & $n i$ & $n i$ - prefix (Section 3.3.1.2) \\
person & $a$ & $a$-prefix (Section 3.4.8.1) \\
location & $e$ & $e$ - prefix (Section 3.1.2.4.1) \\
verb root & $n e, g c e, u, k u, i, k e, m u$, & verbal prefixes (Section \\
& $n d u, w a, r u, m i, n d e, a, r e 4.2 .1)$ \\
\hline
\end{tabular}

The fillers all relate to grammatical prefixes. But nominal prefixes depend on the phonology of the root to which they attach the filler when recalling a noun is invariably $n i$. In (936) the target word ne-men ' $\mathrm{VV}$-bird' contains the $n \mathrm{~V}$ - instead rather than the $n i$ - prefix, but nevertheless, $n i$ is the filler. Most words referring to people and locations do not contain the personal prefix $a$ - or the locational prefix $e$-. But the fillers $a$ and $e$ are used even where the prefixes would not be (937). Some verbal prefixes (ne- '1SG.R', gce- '1SG.IRR', ke- '3SG.IRR', nde- '1IN.PL', re- '3PL') have harmonising vowels that depend on the vowel of the root (Section 2.4.2.2). However, the filler corresponding to these prefixes invariably contains /e/ ${ }^{137}$

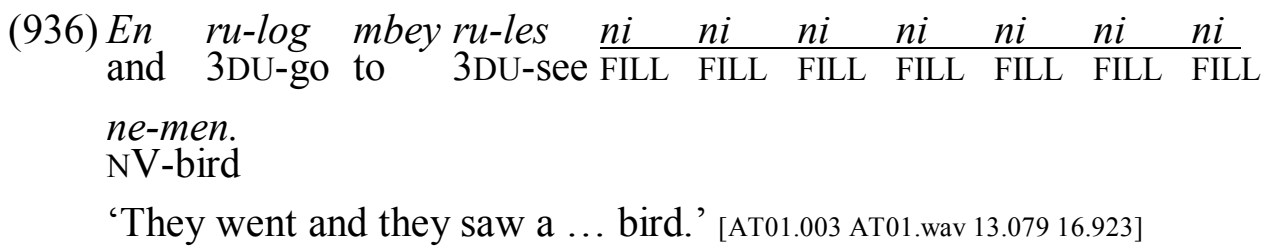

\footnotetext{
${ }^{136}$ In Dimock (forthcoming), I present a more extended description of Nahavaq fillers and placeholders.

${ }^{137}$ There are a few examples in the corpus where a speaker produces an isolated $n \mathrm{~V}$ - form or an isolated verbal prefix with vowel other than /e/. However, based on their prosody, these appear to be a different phenomenon from the fillers described here. They appear to be false starts where the speaker has started to say one word and then stops.
} 
(937) Tatay ti-kinag morot nin ut e Wayles Futuna, father POSS-1SG man ASS place FILL Wallis and Futuna

neqhe-n i-ndamw $\underline{a} \quad$ Patita. name-3SG 3SG.R-named FILL Patita

'My father was from ... Wallis and Futuna. His name was ... Patita.' [07117.003004 07117.wav 49.313 58.173]

(938) Nde nde nda-tagcaw law en.

FILL FILL 1IN.PL-arrive shore ID

'We have ... arrived at the sea.' [тв03.140 TB03.wav 740.958 748.303]

These category-specific fillers maintain the prosody of the phrase. They do not rise or fall much in pitch, and for CV fillers, the filler is repeated to continue the rhythm of the phrase (Figure 34). If recall is still not achieved, the pitch may drop and the rhythm slow. Fillers containing only a vowel are not repeated, and may be elongated while maintaining pitch (Figure 35).

Figure 34: Pitch diagram of Example (936)

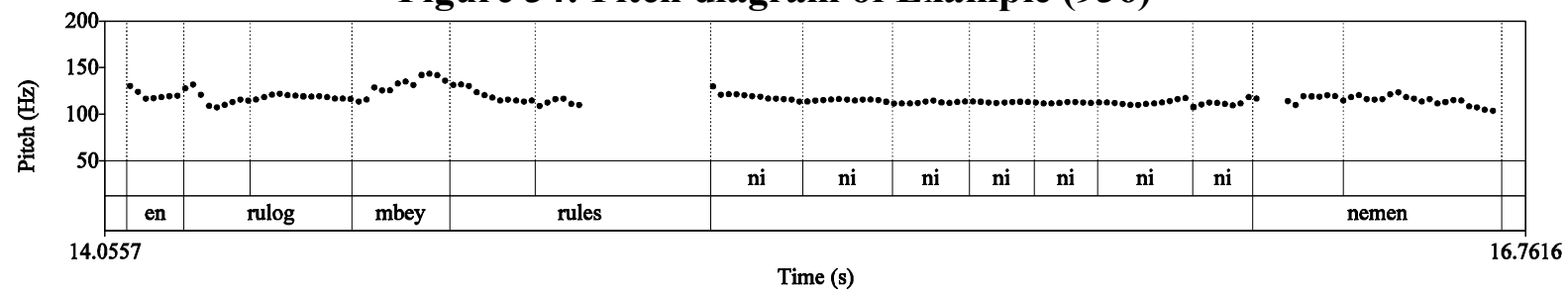

Figure 35: Pitch diagram of Example (937)

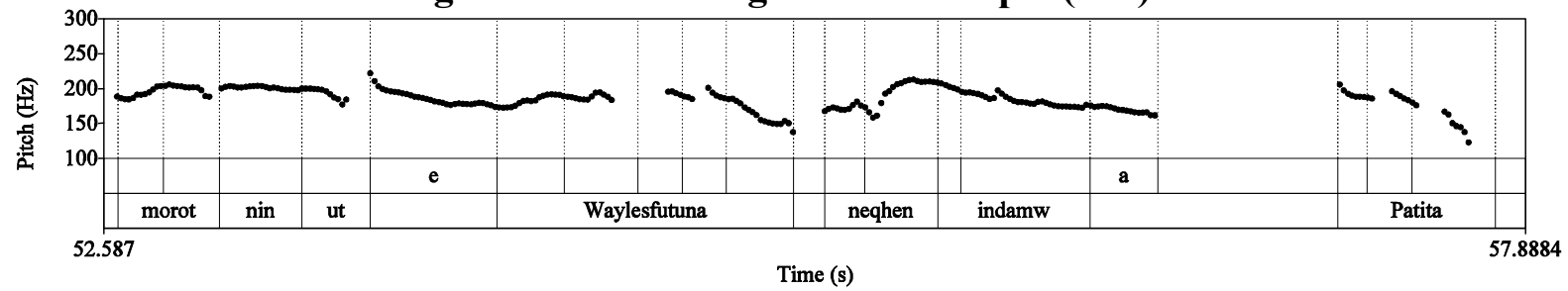

In addition to these category-specific fillers, Nahavaq also has a general filler of the form $a$ (939). It appears to be used when formulating larger structures rather than recalling a lexical item, and it is prosodically distinct from the 2PL subject prefix filler and the person filler, which both have the form $a$. Unlike the category-specific fillers, the general filler usually has a lower pitch than the surrounding text (Figure 36).

\begin{tabular}{|c|c|c|c|c|c|}
\hline $\begin{array}{l}\text { (939) Gce-vwer } \\
\text { 1 SG.IRR-say }\end{array}$ & $\begin{array}{l}\text { iksampol } \\
\text { example }\end{array}$ & $\begin{array}{l}\text { eyigc } \\
\text { PROX }\end{array}$ & $\begin{array}{ll}a & \text { tul } \\
\text { FILL } & \text { tool }\end{array}$ & $\begin{array}{l}q e t \\
\text { PART }\end{array}$ & $\begin{array}{l}\text { konoq } \\
\text { if }\end{array}$ \\
\hline $\begin{array}{l}\text { ku-tumbwatin } \\
\text { 2sG.IRR-start }\end{array}$ & $\begin{array}{l}\text { pisnis nin } \\
\text { business ASS }\end{array}$ & $\begin{array}{l}\text { pistas } \\
\text { peanut }\end{array}$ & $\begin{array}{l}t \text {-inugc. } \\
\text { POSS-2SG }\end{array}$ & & \\
\hline
\end{tabular}


Figure 36: Pitch diagram of Example (939)

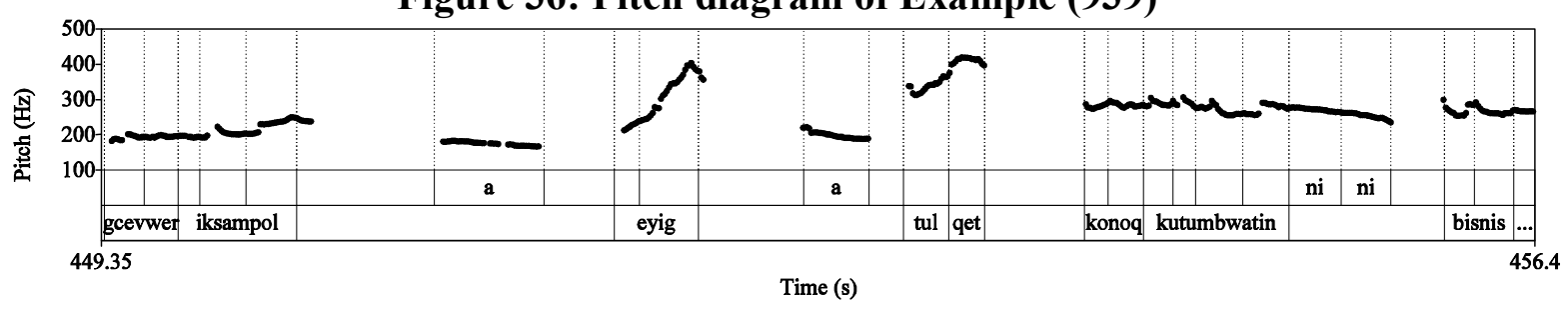

6.7.2. Placeholders

Lexicalised placeholders in Nahavaq have the forms taqtag, tatag, tetag, or qatag. ${ }^{138}$ Any of these forms may be used as a nominal or verbal head to finish a construction when the target head cannot be retrieved quickly enough. (940) and (941) show placeholders used as nominal heads, and (942) and (943) show placeholders used as verbal heads. These placeholders can take a range of nominal or verbal modification. For example (940) has a possessor phrase and (942) has verbal negation.

$\begin{array}{lllll}\text { (940) Ni-mbwunog } & i \text {-sil } & \text { mwah } & \text { ndoh ni } & \text { ni-tatag } \\ \text { NI-child } & \text { 3SG.R-make } & \text { all } & \text { PERF FILL } & \text { 1SG.R-PLACEHOLDER } \\ \text { ti-qey } & \ldots & \text { ni-mwelgcil } & \text { ti-qey. } & \\ \text { POSS-3SG } & \text { NI-magic } & \text { POSS-3SG } & \end{array}$

'And the boy prepared his thing ... his magic potion.' [07064.106-107 07064.wav 403.109 410.546]

(941) En $\quad i \quad$ i-lip $\quad n i \quad n i \quad n a$-gatag $\quad \ldots \quad$ i-lip $n i$ and FILL 3SG.R-take FILL FILL NV-PLACEHOLDER 3SG.R-take FILL ni ni-pen gcen ke-tu-tus. FILL NI-pen because 3SG.IRR-DUP-write

'And he ... he took the ... thingy. He took the ... pen for writing.' [07128.112113 07128.wav 619.187633 .000$]$

(942) En ni ni ni-mbwuwes nin ra-s- ra-s-tatag and FILL FILL NI-pig DEM 3PL-NEG 3PL-NEG-PLACEHOLDER veq. re re-s-wul ndal veq migce-n. NEG FILL 3PL-NEG-howl back NEG to-3SG

'And those ... pigs, they ... they didn't do it. They ... they didn't call back to her.' [07089.223-224 07089.wav 1033.242 1045.819]

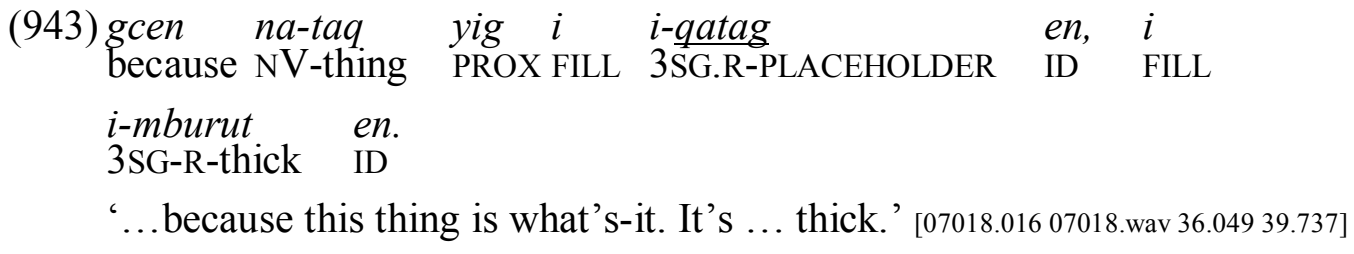

\subsection{Underspecification}

\subsubsection{Unspecified agent}

When the subject of a verb is not known, not important, or refers to people in general, the third person plural subject prefix is used. This can be seen as the equivalent of 'passive' constructions in other languages. In example (944), two girls see that all of

\footnotetext{
${ }^{138}$ The taqtag form appears to be derived from $t a q$ 'thing' + tag 'DIST'. And the other forms may be based on taqtag.
} 
their yams have been planted. But they don't know who did it. The narrator and audience know that it was in fact a single person who did it. But the verb qambwiq 'plant (v.t.)' has a 3PL prefix. In example (945) the person who brought the taro from Fiji is not known and not important.

(944)En ru-vweleg ru-les ne-hew i-yar ndoh. $\frac{\text { ra-qambwiq }}{3 \text { P }}$ and 3DU-come 3DU-see NV-garden 3SG.R-finish PERF 3PL-plant mwah ni-mbwaqay i-yar. all NI-yam 3SG.R-finish.

'And they came back and saw that their garden was finished, the yams were all planted.' [07072.026 07072.wav 158.112 164.921]

(945) $\frac{\text { Re-lip }}{\text { 3PL-take }} \quad$ qin $\quad$ Fiji Fiji

'It (taro) was brought from Fiji.' [07120.038 07120.wav 110.159 113.987]

\subsubsection{Na-lan}

The nominal head na-lan is a pro-form used to refer to an entity that does not have a name or that the speaker intends not to identify. In the following five examples, $n a-$ lan refers to a noose (946), a giant clam (947), a biting coconut (948), two children (949), and hard work (950).

(946) Gcen na-lan i-liq war en malambwug war ru-topw because NV-PRO 3SG.R-tie 3DU and tongue DU 3DU-jump ru-mwakas mbi-leten. 3PL-get.out to-down

'Because the thing strangled them and their tongues were hanging down.' (Lit. 'their tongues jumped out downward.') [07065.397 07065.wav 1423.145 1428.123]

(947) Nde-q-viqis mba-ra-n ko-s-roghur veq. Qet na-lan 1IN.PL-IRR-lie to-on-3SG 3SG.IRR-NEG-know NEG then NV-PRO ka-qas qin. 3SG.IRR-bite 3SG

'We will lie to him, he won't know. And that thing will bite him' [07065.369-370 07065.wav 1324.780 1329.499]

(948) $\frac{\text { Na-lan }}{\text { NV-qas }} \quad$ kinagku-les $\quad$ na-lan $i$-qas $\quad k i n a g$. NV-PRO 3SG.R-bite 1SG 2SG.IRR-see NV-PRO 3SG.R-bite 1SG

'And it bit me, you see, it bit me.' [07065.244 07065.wav 900.663 903.773]

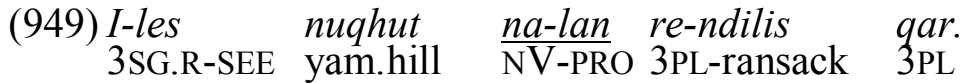

'He saw that something destroyed his yam hills.' [08009.025 08009.wav 137.829 146.204]

$\begin{array}{cllllll}\text { (950) En } & \text { Marta qey } & \text { i-raq } & \text { mbwutaqayen } & \text { qey } & \text { i-rog } \\ \text { and } & \text { Martha } & \text { 3SG } & \text { 3SG.R-work } & \text { INTENS and } & \text { 3SG } & \text { 3SG.R-feel }\end{array}$ i-het. i-rog na-lan i-ndur. qin. 3SG.R-bad 3SG.R-feel NV-PRO 3SG.R-tire 3SG

'Martha worked a lot, and she felt bad. She felt bored.' [LUK.10:40] 
It is not clear whether the use of na-lan in (946) is a case of not knowing terminology or of avoiding a word. In (947), the word for giant clam is well known, and the identity of the clam was known in this text. However, the speaker is making a secret plot, so there may be some strategic avoidance of referring to the clam directly. The narrative that (948) is taken from tells of the first encounter with coconut trees, whose name has only just been declared and whose nature is not yet known, so the use of $n a-$ lan may have something to do with a lack of knowledge. In (949), the identity of the yam-hill-destroyers is known to the narrator and audience, but not to the central character of the narrative, so the use of na-lan could be attributed to a lack of knowledge. The use of na-lan i-ndur in (950) seems to be a set phrase for 'to be bored/tired' (based on my experience with everyday conversation). The reasons that I have stated so far may be the motivation for using na-lan, but another hypothesis is possible: All the referents of na-lan in these examples refer to a cause of death, damage, pain, or suffering. There may be some kind of taboo against saying the actual name of such causes.

\subsection{Taboo avoidance}

There are a number of taboos on Nahavaq speech. Apart from swearing, a general taboo, there are a number of taboos which apply particularly to sons- and daughtersin-law. ${ }^{139}$ Individuals may not refer to a parent-in-law's head or part thereof in the same manner as for other people. Nor may they tell their parents-in-law to eat. Table 99 outlines some alternative ways to express these concepts. In the case of head and ears, there is some kind of metaphorical work-around. In the case of eyes, there is metonymy. I do not know the complete etymology of nilitvet 'tooth', but it seems likely that the vet portion means 'stone'. In the case of nose and mouth, a description of the function of those parts can stand in place of their names. For some directly possessed body parts such as tongue and hair which have an indirectly possessed equivalent, this can be used. And finally, rather than using the root qan 'eat', there seems to be another option, sug-qam, the parts of which mean 'roast' and 'fire' elsewhere in the language. So while used to talk about eating, its referential meaning likely relates to cooking.

${ }^{139}$ A person can be fined for either swearing or breaking in-law language taboos. 
Table 99: Alternatives for taboo language ${ }^{140}$

Most of this information comes from 08NB1.033, but also from general discussion with a number of Nahavaq speakers

\begin{tabular}{llll}
\hline Taboo speech for in-laws & \multicolumn{2}{l}{ Acceptable speech for in-laws } \\
Nahavaq & Gloss & Nahavaq & Gloss \\
\hline mbwatu-mw & 'head-2SG' & livwaqanmehep & 'top' \\
ndilga- $m w$ & 'ear-2SG' & nimbwil nevet & 'holes in stone' \\
mata- $m w$ & 'eye-2SG' & nikilas & 'glasses' \\
nilivo- $m w$ & 'tooth-2SG' & nilitvet & $?$ \\
gcinhu- $m w$ & 'nose-2SG' & wut igaragar qin & 'the place where he breathes' \\
mbogo- $m w$ & 'mouth-2SG' & wut isusugqam qin & 'the place where he (eats)' \\
malambugu-mw & 'tongue-2SG' & malambug & 'tongue (indirect)' \\
siple-mw & 'hair-2SG' & sivul & 'hair (indirect)' \\
ku-qan & '2SG.IRR-eat' & ku-sug-qam & '2SG.IRR-roast-fire' \\
\hline
\end{tabular}

In addition to head and eating taboos, there are a range of people whose name an inlaw is not allowed to say.

\subsection{Repetition}

Besides reduplication, there are two other kinds of repetition that are salient in Nahavaq texts. The first is head-tail linkage which is used in sequencing of events. The second is multiple repetitions of a verb phrase to signify continuation.

\subsubsection{Head-tail linkage}

Head-tail linkage is when a clause occurs once (head) and then occurs a second time (tail) connected to another clause. In Nahavaq, this is a common way of expressing sequences of events that occur in succession. Examples (951) and (952) each contain two examples of clauses repeated in a head-tail linkage. The repetition can be either exact as in the first instance in each example, or contain more or less information. For example in the second instance in Example (951), the head clause does not contain an explicit direct object, but the tail clause does. In Example (952), the subject is implicit in the head clause, but it is explicitly stated in the tail clause.

(951) En re-lip ni-vwiyal, en re-tur-gcor no-pon no-qond. and 3PL-take NI-strap and 3PL-sew-blockNV-opening NV-basket Re-tur-gcor no-pon no-qond, re-gcur i-gcisgces, en 3PL-sew-blockNV-opening NV-basket 3PL-cause 3SG.R-tight and re-tu li-yumw. Re-tu no-qond li-yumw,en Vinmbumbaqaw 3PL-put in-house. 3PL-put NV-basket in-houseand Vinmbumbaqaw $i-v w e r$. 3SG.R-say

'And they got a strap, and they sewed up the opening of the basket. After they sewed up the opening of the basket, they tightened it and put it in the house. After they put it in the house, Vinmbumbaqaw said ...' [EC02.069-071 EC02.wav 270.103 286.054]

\footnotetext{
${ }^{140}$ In my field notes, I have written all of the taboo words with 2 SG endings and most of the acceptable alternatives with 3SG morphology. However, it is my impression that the same taboos apply to referring to someone of this status in the third person and that using second person morphology in the acceptable forms is also acceptable.
} 
$\begin{array}{lllll}\text { (952) Re-lip mbwityeh } & \text { mbey, Ambwat i-gcisim } & \text { mwah qin, } \\ \text { 3PL-take digging.stick to } & \text { Ambat 3SG.R-dehusk } & \text { all } & \text { 3SG }\end{array}$

en $i$-suq gin. $i$-suq qin, $i$-min. Ambwat $i$-min and 3SG.R-Stab 3SG 3SG.R-Stab 3SG 3SG.R-drink Ambat 3SG.R-drink

en i-huq.

and 3SG.R-give

'(talking about a coconut) They brought a pointed stick and Ambwat removed the husk, and punctured it. And after he had punctured it, he drank. After Ambwat had drunk it, he held it out.' [07065.132-134 07065.wav 527.132 535.469]

These head-tail linkage patterns have a distinctive intonation. The head clause has a falling intonation and the tail clause has a rising intonation similar to the subordination or coordination intonation patterns discussed in Section 5.5. This pattern can be seen in Figure 37 below.

Figure 37: Pitch diagram of Example (952)

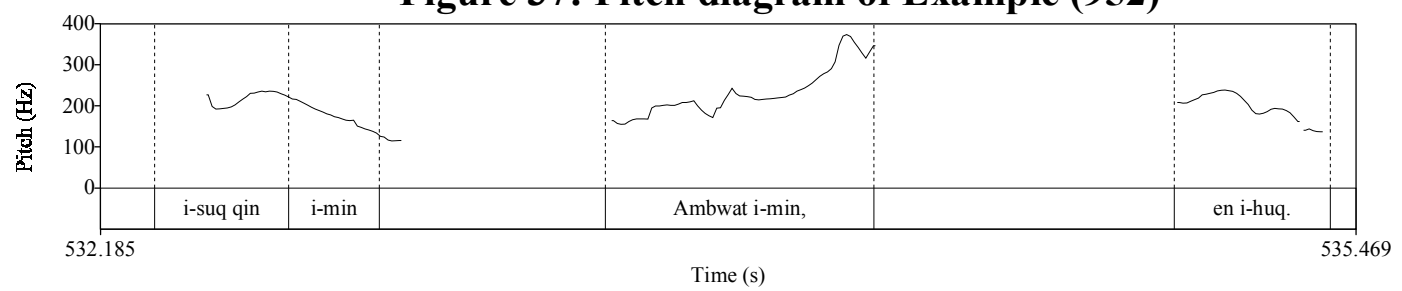

\subsubsection{Verb phrase repetition}

A verb phrase is sometimes repeated several times to represent continuation of a state or activity. This minimally involves a verbal prefix and verb root as in (953). The repeated phrase in (954) also includes a directional particle mbey. In (955) mahal 'fish' may be an incorporated object rather than a full NP direct object (see Section 4.1.9 on incorporated objects). The repeated phrase is often stated in a previous clause before the repetition clause. This is the case in (953) and (954). The final clause after the repeated verb phrase is often the point at which the state or activity ends. This is the case in (953) and (954).

(953) Vinmbumbaqaw i-gara-gar-mbon, re-ndig no-mbon Vinmbumbaqaw 3SG.R-DUP-smell-smell 3PL-follow NV-smell

ni-tuqla-n Nivutin Mbeqey. Re-ndig, re-ndig, re-ndig, NI-tracks-3SG Nivutin Mbeqey 3PL-follow 3PL-follow 3PL-follow

re-ndig, re-ndig, re-ndig, re-ndig, re-ndig, re-ndig, 3PL-follow 3PL-follow 3PL-follow 3PL-follow 3PL-follow 3PL-follow

ra-tagcaw gcen ni-mbwati-n metu.

3PL-arrive LOC NV-head-3SG coconut

'Vinmbumbaqaw smelled something and they followed the smell of Nivutin Mbeqey's tracks. They followed it on and on until they arrived at the stump of a coconut tree.' [EC02.098-099 EC02.wav 391.983 406.001] 
(954) Ru-raq ne-hew gcen wut ru-q-vwul ni-momoq sut 3DU-work NV-garden because COMPL 3DU-IRR-buy NI-woman NONSP $\begin{array}{llllll}\text { migce-n qin, ro-koh, en } \begin{array}{l}i-y a r \\ \text { to-3SG }\end{array} & \text { Ro-koh } & \text { mbey, } & \text { ro-koh } & \text { mbey, } \\ \text { IPL-be } & \text { 3PL-be and 3SG.R-finish }\end{array}$ ro-koh mbey, en ru-pir ni-mbwuwes... 3PL-be to and 3DU-look after NI-pig

'And they made a garden so they could buy him a wife, and they stayed. They stayed on and on, and they raised pigs ...' [MR01.094-097 MR01.wav 472.669 487.435]

(955)I-viyal mahal en. I-vene-ven mahal, $\underline{i-v e n e-v e n}$ 3SG.R-search.for fish ID 3SG.R-DUP-shoot fish 3SG.R-DUP-shoot mahal, i-vene-ven mahal, i-vene-ven mahal, i-tagcaw fish 3SG.R-DUP-shoot fish 3SG.R-DUP-shoot fish 3SG.R-arrive Witavaq. Witavaq

'He searched for fish. He fished and fished until he reached Witavaq.' [07063.153-156 07063.wav 534.628 543.050]

\subsection{Quoted speech}

Quoted speech is frequently preceded by an optional phrase stating who said something to whom, followed by the obligatory quotative marker, vwer 'say', and then the quoted text (956). There is often a rise in pitch at the end of the phrase before the quotative marker and a fall at the end of the quotative marker as discussed in Section 2.6.

$\begin{array}{ccccc}\text { (956) En } & i \text {-vwer } & \text { migce-n } & \text { qar, i-vwer, "A-koh eyig } \\ \text { and 3SG.R-say } & \text { to-3SG } & \text { 3PL 3SG.R-say 2PL-be PROX } \\ \text { no-S-roghur } & \text { veq ut a-koh eyig." } & \\ \text { 1SG.R-NEG-know } & \text { NEG that 2PL-be PROX }\end{array}$

'And he said to them, "You are here? I didn't know that you guys were here."' [07089.165 07089.wav 768.762 773.179]

There are a range of verbs of speech such as viviyeh 'call' (957), wuswus 'ask' (958), vwer 'say' (959), wulewul 'shout', etc. However, the quotative marker immediately before the quoted speech is invariably vwer 'say'. The subject agreement on the quotative marker can mark a full range of number (958), person (959), and mood (960).

(957) En i-vi-viyeh $\quad n i$-vilam tinin, $i$-vwer, "Ndu-q-log, and 3SG.R-DUP-call NI-girl DEF 3SG.R-say 1IN.DU-IRR-go $n d u-q-\log$ !" 1IN.DU-IRR-go

‘And he called the girl, saying, "Let's go!"‘ [07074.072 07074.wav 313.285 318.957]

(958) Ni-marlam ti-qar re-wuswus qin re-vwer, "Wa-log ambeh?" NI-old.man POSS-3PL 3PL-ask 3SG 3PL-say 2DU-go where

'Their elders asked them, "Where did you come from?"' [07111.036 07111.wav 151.482 157.060] 
(959) Ne-vwer migce-n ni-momoq qar, ne-vwer, "Maral ..." 1SG.R-say to-3SG NI-woman 3PL 1SG.R-say you.guys

'I told the women, "You guys ..." [07086.019-020 07086.wav 84.181 96.790] $\begin{array}{rlll}\text { (960) Ke-wuswus, } & \text { ke-vwer, } & \text { "U-log } & \text { ambeh?” } \\ \text { 3SG.IRR-ask } & \text { 3SG.IRR-say } & \text { 2SG.R-go } & \text { where }\end{array}$

'(What if someone) asks, "Where did you come from?"' [07090.020-021 07090.wav 79.541 91.697]

When a long piece of speech including several intonation phrases is directly quoted, the phrase $i$-yar en ' $3 \mathrm{SG}$.R-finish ID' is often used to signal that the speaker has finished the quote and is returning to his own voice (Section 6.6.3).

Reported speech lacks a quotative marker and may optionally have the complementiser wut immediately before the message of the speech (961).

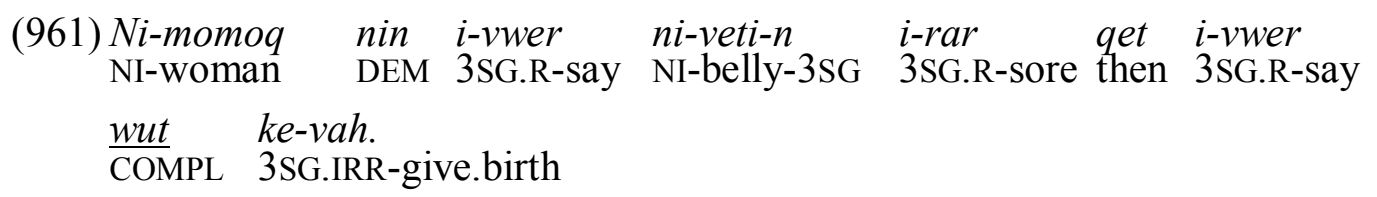

'She said her belly was sore and she said that she was going to give birth.' [EC01.070 EC01.wav 356.408 361.017] 


\section{Appendix 1: Consonant contrasts}

The following tables present minimal pairs (or near-minimal pairs when necessary) to contrast all similar consonants. Where possible, contrasts are shown both in onset position (top half of boxes) and coda position (bottom half of boxes). Many verbs are given with the 3 SG subject prefix, $i$-, and many nouns are given with the $n \mathrm{~V}$ - nominal prefix, but these are not glossed for space reasons.

\section{Labiovelar consonants}

\begin{tabular}{|c|c|c|c|c|c|}
\hline & $/ \mathrm{m}^{\mathrm{w}} /$ & $/ \mathbf{m}^{\mathbf{w}} /$ & $/ \mathrm{p}^{\mathrm{w}} /$ & $/ \beta^{w} /$ & $/ \mathrm{w} /$ \\
\hline \multicolumn{6}{|l|}{$/ \mathrm{m}^{\mathrm{w}} /$} \\
\hline$/{ }^{m} \mathbf{b}^{w} /$ & $\begin{array}{l}\text { i-" }{ }^{\mathrm{m}} \mathrm{b}^{\mathrm{w}} \mathrm{il} / \text { ' } h i t ' \\
\mathrm{i}-\mathrm{m}^{\mathrm{w}} \mathrm{il} / / \text { 'too short' }\end{array}$ & & & & \\
\hline$/ \mathrm{p}^{\mathrm{w}} /$ & $\begin{array}{l}\text { i-p }{ }^{\mathrm{w}} \mathrm{il} / \text { ' 'writhe' } \\
\text { i-mwwil/ 'too short' } \\
\text { i-topw/ 'jump' } \\
\text { i-tomw/ 'itch' }\end{array}$ & $\begin{array}{l}\text { /i-p }{ }^{\mathrm{w}} \mathrm{ir} / \text { 'bowed' } \\
/ \mathrm{i}-\mathrm{w}^{\mathrm{m}} \mathrm{ir} / \text { 'overflow' } \\
/ \mathrm{i}-\mathrm{tap}^{\mathrm{w}} / \text { 'prick' } \\
/ \mathrm{i}-\mathrm{ta}^{\mathrm{m}} \mathrm{b}^{\mathrm{w}} / \text { ' 'fat' }\end{array}$ & & & \\
\hline$/ \beta^{\mathrm{w}} /$ & $\begin{array}{l}\text { i- } \beta^{\mathrm{w}} \mathrm{ul} / \text { 'buy' } \\
\text { i-m } \mathrm{m}^{\mathrm{w}} \mathrm{ulm}{ }^{\mathrm{w}} \mathrm{ul} / \text { 'round' }\end{array}$ & $\begin{array}{l}\text { /i- } \beta^{\mathrm{w}} \mathrm{al} /{ }^{\prime} \text { 'boil' } \\
/ \mathrm{i}-{ }^{\mathrm{m}} \mathrm{b}^{\mathrm{w}} \mathrm{al} / \text { 'beaten' }\end{array}$ & $\begin{array}{l}\beta^{\mathrm{w}} \mathrm{al} / \text { 'boil' } \\
\mathrm{p}^{\mathrm{w}} \mathrm{al} / \text { 'bald' }\end{array}$ & & \\
\hline$/ \mathrm{w} /$ & $\begin{array}{l}\text { i-wa?/ 'bruised' } \\
\text { i-mwa?/ 'level' } \\
\text { i-mew/ 'hairy' } \\
\text { i-rew / ' 'skinny' }\end{array}$ & $\begin{array}{l}\text { /i-war/ 'white-haired' } \\
\text { /i- }{ }^{\mathrm{m}} \mathrm{b}^{\mathrm{w}} \mathrm{ar} / \text { ' 'wipe' } \\
/ \mathrm{i}-\mathrm{Pa}^{\mathrm{m}} \mathrm{b} \mathrm{w}^{\mathrm{w}} / \text { 'swollen' } \\
\text { /i-?aw/ '(fire) spread' }\end{array}$ & $\begin{array}{l}\text { i-wijew/ 'worry' } \\
\text { /i-p"iwijew/ 'fall down' } \\
\text { /ni-jew/ 'tide' } \\
\text { /ni-jep" / 'empty shell' }\end{array}$ & $\begin{array}{l}\text { i-wel/ 'unravel' } \\
\text { /i- } \beta^{\mathrm{w}} \mathrm{el} / \text { 'come' }\end{array}$ & \\
\hline
\end{tabular}

\section{Bilabial consonants}

\begin{tabular}{|c|c|c|c|c|c|}
\hline & $/ \mathrm{m}^{\mathrm{j}} /$ & $/{ }^{\mathrm{m}} \mathrm{b}^{\mathrm{j}} /$ & $/ \mathrm{p}^{\mathrm{j}} /$ & $/ \beta^{\mathrm{j}} /$ & $/ \mathrm{w} /$ \\
\hline$/ \mathrm{m}^{\mathrm{j}} /$ & & & & & \\
\hline$/{ }^{m} b^{\mathrm{j}} /$ & & & & & \\
\hline$/ \mathrm{p}^{\mathrm{j}} /$ & $\begin{array}{l}\text { i- }{ }^{\mathrm{j}} \mathrm{ilp} \mathrm{p}^{\mathrm{j}} \mathrm{il} / \text { 'hot' } \\
\text { i-m'mil/' 'wet' }\end{array}$ & 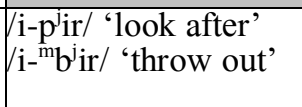 & & & \\
\hline$/ \beta^{\mathrm{j}} /$ & $\begin{array}{l}\text { i-m }{ }^{\mathrm{j}} \mathrm{es} / \text { 'die' } \\
\mathrm{i}-\beta^{\mathrm{j}} \mathrm{es} / \text { 'four' }\end{array}$ & $\begin{array}{l}\text { ( }{ }^{\mathrm{j}} \text { ara-n/ 'hand-3SG' } \\
\mathrm{m}^{\mathrm{j}} \mathrm{b}^{\mathrm{j}} \text { ara-n/ 'onto-3SG' }\end{array}$ & $\begin{array}{l}/ \mathrm{i}-\beta^{\mathrm{j}} \mathrm{ah} / \text { 'give birth' } \\
/ \mathrm{i}-\mathrm{p}^{\mathrm{j}} \mathrm{ah} \mathrm{p}^{\mathrm{j}} \mathrm{ah} / \text { 'look for crajfish' }\end{array}$ & & \\
\hline$/ \mathrm{w} /$ & $\begin{array}{l}\text { i-wel//'unravel' } \\
\text { i-miel/'wilted' }\end{array}$ & $\begin{array}{l}\text { i-wa?/ 'bruised' } \\
\text { i-mbja?/ 'atone' } \\
\text { i-jew/ 'melt' } \\
\text { i-jeje }{ }^{\mathrm{m}} \mathrm{b}^{\mathrm{j}} / \text { 'spread out' }\end{array}$ & $\begin{array}{l}\text { /i-wul/' 'howl' } \\
\text { /i-p pul/ 'braid' } \\
\text { /ne-tep'/ 'table' } \\
\text { /ne-tew/ 'chicken' }\end{array}$ & $\begin{array}{l}\text { i-wel//'unravel' } \\
\text { i- } \beta^{\mathrm{j}} \mathrm{el} / \text { 'taboo' }\end{array}$ & \\
\hline
\end{tabular}




\section{Alveolar consonants}

\begin{tabular}{|c|c|c|c|c|c|c|}
\hline & $/ \mathrm{n} /$ & $/{ }^{\mathrm{n}} \mathrm{d} /$ & $/ \mathrm{t} /$ & $/ \mathrm{s} /$ & $/ \mathrm{r} /$ & $/ 1 /$ \\
\hline$/ \mathrm{n} /$ & & & & & & \\
\hline$/{ }^{\mathrm{n}} \mathrm{d} /$ & $\begin{array}{l}\text { i-ndis/ 'tear' } \\
\text { i-nis/ 'flick' }\end{array}$ & & & & & \\
\hline$/ \mathrm{t} /$ & $\begin{array}{l}/ \mathrm{i}-\mathrm{ti}^{\mathrm{m}} \mathrm{b}^{\mathrm{j}} / \text { 'swell' } \\
/ \mathrm{i}-\mathrm{ni}^{\mathrm{m}} \mathrm{b}^{\mathrm{j}} / \text { 'stagnant' } \\
/ \mathrm{i}-\beta^{\mathrm{w}} \mathrm{ut} / \text { 'shallow' } \\
\mathrm{i}-\beta^{\mathrm{w}} \mathrm{un} / \text { 'full' }\end{array}$ & $\begin{array}{l}\text { /i-tom }{ }^{w} / \text { 'itch' } \\
\text { /i- }{ }^{n} \text { dom } / \text { 'rotten' } \\
\text { /sut/ 'NONSP' } \\
\text { /sund/ 'somewhere' }\end{array}$ & & & & \\
\hline$/ \mathrm{s} /$ & $\begin{array}{l}\text { i-so?/'reach' } \\
\text { i-no?/ 'similar' } \\
\text { i-ndes/'slip' } \\
\text { /i-nden/ 'drown' }\end{array}$ & 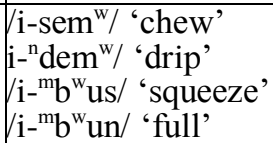 & $\begin{array}{l}\text { i-sal//'hunt' } \\
\text { /i-tal/ 'return' } \\
\text { /i-les/ 'see' } \\
\text { /i-let/ 'stake up' }\end{array}$ & & & \\
\hline$/ \mathrm{r} /$ & $\begin{array}{l}\text { i-ris/'few' } \\
\text { /i-nis/ 'flick' } \\
\text { /i-sir/ 'scatter' } \\
\text { /i-sin/ 'shine' }\end{array}$ & 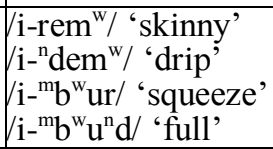 & $\begin{array}{l}\text { /i-rey/ 'dawn' } \\
/ \text { i-ten/ 'cry' } \\
/ \text { i- } \beta^{\mathrm{w}} \mathrm{ur} / \text { 'hold' } \\
/ \mathrm{i}-\beta^{\mathrm{w}} \text { ut/ 'shallow' }\end{array}$ & $\begin{array}{l}\text { i-rem }{ }^{\mathrm{w}} / \text { 'skinny' } \\
\text { /i-sem }{ }^{\mathrm{w}} / \text { 'chew' } \\
\text { /i-tur/ 'sew' } \\
\text { /i-tus/ 'write' }\end{array}$ & & \\
\hline$/ 1 /$ & $\begin{array}{l}\text { i-lislis/ '(eye) sore' } \\
\text { /i-nis/ 'flick' } \\
\text { i-wul/ 'howl' } \\
\text { i-wun/ 'join' }\end{array}$ & $\begin{array}{l}\text { /i-les/'see' } \\
/ \mathrm{i}-{ }^{\mathrm{n}} \mathrm{des} / \text { 'slip' } \\
/ \mathrm{i}-{ }^{\mathrm{m}} \mathrm{b}^{\mathrm{w}} \mathrm{ul} / \text { 'bend' } \\
/ \mathrm{i}-{ }^{\mathrm{m}} \mathrm{b}^{\mathrm{w}} \mathrm{u}^{\mathrm{n}} \mathrm{d} / \text { ' 'full' }\end{array}$ & $\begin{array}{l}/ \mathrm{i}-\mathrm{lip} \mathrm{j}^{\mathrm{j} /} \text { 'take' } \\
/ \mathrm{i}-\mathrm{tip} \mathrm{j} / \text { 'sprout' } \\
/ \mathrm{i}-\mathrm{p}^{\mathrm{w}} \mathrm{il} / \text { 'writhe' } \\
/ \mathrm{i}-\mathrm{p}^{\mathrm{w}} \mathrm{it} / \text { 'underripe' }\end{array}$ & $\begin{array}{l}\text { i-lep }{ }^{j /} \text { 'spill' } \\
/ \mathrm{i}-\mathrm{sep} \text { '/ 'fall down' } \\
/ \mathrm{i}-\beta^{\mathrm{j}} \mathrm{el} / \text { 'taboo' } \\
/ \mathrm{i}-\beta^{\mathrm{j}} \mathrm{es} / \text { 'four' }\end{array}$ & $\begin{array}{l}\text { i-loy/ 'walk' } \\
\text { i-roy/ 'hear', } \\
\text { i-hal/ 'float' } \\
\text { /i-har/ 'shine', }\end{array}$ & \\
\hline
\end{tabular}

\section{Velar and glottal consonants}

\begin{tabular}{|c|c|c|c|c|c|}
\hline & $/ \mathrm{y} /$ & $/{ }^{p} \mathrm{~g} /$ & $/ \mathrm{k} /$ & $/ \mathrm{h} /$ & /P/ \\
\hline$/ \mathrm{y} /$ & & & & & \\
\hline$/{ }^{m} \mathrm{~g} /$ & $\begin{array}{l}/ \mathrm{i}-{ }^{\mathrm{y}} \mathrm{gor} / \text { 'block' } \\
/ \mathrm{i}-\text {-yor/ 'grunt' }\end{array}$ & & & & \\
\hline$/ \mathbf{k} /$ & $\begin{array}{l}\text { i-kar/'skin disease' } \\
\text { /i-nar/ 'have cold' }\end{array}$ & $\begin{array}{l}\text { i-kar/ 'skin disease' } \\
\text { i- }{ }^{\mathrm{y}} \mathrm{gar} / \text { 'swim' }\end{array}$ & & & \\
\hline$/ \mathrm{h} /$ & $\begin{array}{l}\text { /i-har/ 'shine' } \\
\text { /i-nar/ 'have cold' } \\
\text { /i-ndih/ 'shift over' } \\
\text { /i-ndin/ 'follow' }\end{array}$ & $\begin{array}{l}\text { /i-har/ 'shine' } \\
\text { /i-"gar/ 'swim' } \\
\mathrm{m}^{\mathrm{p}} \mathrm{b}^{\mathrm{w}} \mathrm{irjah} / \text { 'hole' } \\
\mathrm{m}^{\mathrm{w}} \mathrm{b}^{\mathrm{w}} \mathrm{irja} \mathrm{a}^{\mathrm{n}} \mathrm{g} / \text { 'breadfruit' }\end{array}$ & $\begin{array}{l}\text { i-har/ 'shine' } \\
\text { /i-kar/ 'skin disease' } \\
\text { /i-kih/ 'shift over' } \\
\text { /i-kik/ 'chirp' }\end{array}$ & & \\
\hline$/ ? /$ & $\begin{array}{l}\text { /i-2oros/ 'cut' } \\
\text { /i-noros/ 'scrape' } \\
\text { /i-si?/ 'one' } \\
\text { /i-siy/ 'come ashore' }\end{array}$ & $\begin{array}{l}\text { /i-Pur/'turn (canoe)' } \\
\text { /i- }{ }^{\mathrm{p}} \mathrm{gur} / \text { 'cause' } \\
\text { i-si?/ 'one' } \\
\text { /i-si' } \mathrm{g} / \text { 'split' }\end{array}$ & $\begin{array}{l}\text { i-Pan/'eat' } \\
\text { i-kan/ 'sharp' }\end{array}$ & $\begin{array}{l}\text { i-Pur/ 'turn (canoe)' } \\
\text { /i-hur/ 'splinter' } \\
\text { i-le?/ 'married' } \\
\text { i-leh/ 'good' }\end{array}$ & \\
\hline
\end{tabular}

Nasal consonants

\begin{tabular}{|c|c|c|c|c|}
\hline & $/ \mathrm{m}^{\mathrm{w}} /$ & $/ \mathrm{m}^{\mathrm{j}} /$ & $/ \mathrm{n} /$ & $/ \mathrm{n} /$ \\
\hline \multicolumn{5}{|c|}{$/ \mathrm{m}^{\mathrm{w}} /$} \\
\hline$/ \mathrm{m}^{\mathrm{j}} /$ & 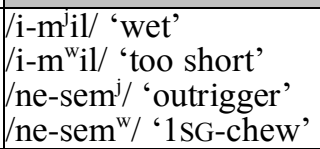 & & & \\
\hline$/ \mathrm{n} /$ & $\begin{array}{l}\text { i-napw/'enough' } \\
\text { /i-mwapw/ 'heal' } \\
\text { /i-nden/ 'drown' } \\
\text { /i-ndemw / 'drip' }\end{array}$ & $\begin{array}{l}\text { ne-nen/ 'pus' } \\
\text { ne-mien/ 'bird' } \\
\text { (i-pen/'paint' } \\
\text { /i-pem'/ ' 'quiver' }\end{array}$ & & \\
\hline$/ \mathrm{y} /$ & $\begin{array}{l}\text { /i-nal/ 'happy' } \\
\text { /i-mwal/ 'fasten' } \\
\text { /i-rey/ 'dawn' } \\
\text { /i-rem/ 'skinny' }\end{array}$ & $\begin{array}{l}\text { i-nar/ 'have cold' } \\
\text { i-miar/ 'have famine' } \\
\text { i-lin/ 'fetch' } \\
\text { i-lim/j/ 'five' }\end{array}$ & $\begin{array}{l}\text { /i-narayar/ 'breathe' } \\
\text { /na-rayar/ 'top of head' } \\
\text { /asiy/ 'person.PROX' } \\
\text { /asin/ 'person.MED' }\end{array}$ & \\
\hline
\end{tabular}




\section{Prenasalised stops}

\begin{tabular}{|c|c|c|c|c|}
\hline & $/{ }^{m} b^{w} /$ & $/{ }^{\mathrm{m}} \mathbf{b}^{\mathrm{j}} /$ & $/{ }^{\mathrm{n}} \mathrm{d} /$ & $/{ }^{p} \mathrm{~g} /$ \\
\hline \multicolumn{5}{|l|}{$/{ }^{\mathrm{m}} \mathrm{b}^{\mathrm{w}} /$} \\
\hline$/{ }^{\mathrm{m}} \mathrm{b}^{\mathrm{j}} /$ & 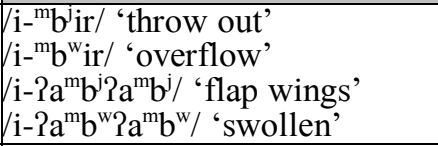 & & & \\
\hline$/{ }^{\mathrm{n}} \mathrm{d} /$ & 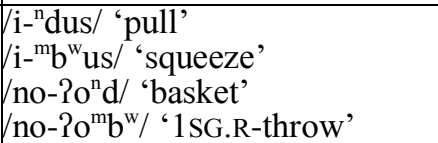 & $\begin{array}{l}\text { i- }{ }^{\mathrm{n}} \text { dilis/ 'ransack' } \\
\mathrm{i}-{ }^{\mathrm{m}} \mathrm{b}^{\mathrm{j}} \mathrm{ilis} / \text { 'tie around' }\end{array}$ & & \\
\hline$/{ }^{p} \mathrm{~g} /$ & 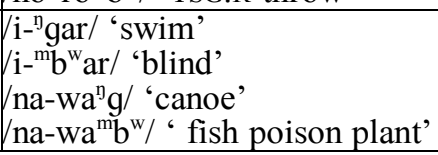 & 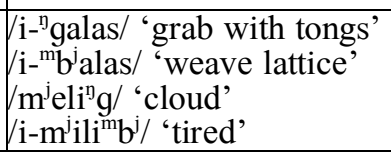 & 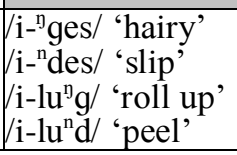 & \\
\hline
\end{tabular}

\section{Voiceless stops}

\begin{tabular}{|c|c|c|c|c|c|}
\hline & $/ \mathrm{p}^{\mathrm{w}} /$ & $/ \mathrm{p}^{\mathrm{j}} /$ & $/ \mathrm{t} /$ & $/ \mathbf{k} /$ & $/ 2 /$ \\
\hline \multicolumn{6}{|c|}{$/ \mathrm{p}^{\mathrm{w}} /$} \\
\hline$/ \mathrm{p}^{\mathrm{j}} /$ & 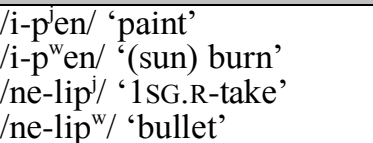 & & & & \\
\hline$/ \mathrm{t} /$ & $\begin{array}{l}\text { i-tal/'return' } \\
\text { /i-p"sal/ 'bald' } \\
\text { /na-mwat/'snake' } \\
\text { /na-mwapw/ 'heaven' }\end{array}$ & $\begin{array}{l}\text { i-tul/ 'three' } \\
\text { i-p pul/'braid' } \\
\text { i-let/'stake up' } \\
\text { i-lep'/ 'spil' }\end{array}$ & & & \\
\hline$/ \mathrm{k} /$ & $\begin{array}{l}\text { i-kit/ 'stir' } \\
\text { /i-p"wit/ 'unripe' } \\
\text { /i-mªkak/ 'break through' } \\
\text { /kakapw/ 'grandmother' }\end{array}$ & $\begin{array}{l}\text { i-kit/ 'stir' } \\
\text { i-p pit/ 'raise' } \\
\text { i-kik/ 'chirp' } \\
\text { i-hipj/ 'cut' }\end{array}$ & $\begin{array}{l}\text { /i-kul/ 'weak' } \\
\text { /i-tul/ 'three' } \\
\text { /i-kik/ 'chirp' } \\
\text { /i-kit/ 'stir' }\end{array}$ & & \\
\hline$/ \mathrm{R} /$ & $\begin{array}{l}\text { i-Pil/' 'dig' } \\
\text { /i-p"il//'writhe' } \\
\text { i-ha?/ 'climb' } \\
\text { /i-hapw/'dance' }\end{array}$ & $\begin{array}{l}\text { i-ipul/ 'wipe' } \\
\text { i-p pul/ 'braid' } \\
\text { i-le?/ 'married' } \\
\text { i-lep'/ 'spil' }\end{array}$ & $\begin{array}{l}\text { /i-Pul/ 'wipe' } \\
\text { /i-tul/ 'three' } \\
\text { /i-le?/ 'married' } \\
\text { /i-let/ 'stake up' }\end{array}$ & 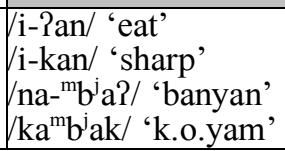 & \\
\hline
\end{tabular}

\section{Fricatives}

\begin{tabular}{|c|c|c|c|c|}
\hline & $/ \beta^{\mathrm{w}} /$ & $/ \beta^{\mathrm{j}} /$ & $/ \mathrm{s} /$ & $/ \mathrm{h} /$ \\
\hline$/ \beta^{w} /$ & & & & \\
\hline$/ \beta^{\mathrm{j}} /$ & $\begin{array}{l}\text { /i- } \beta^{\mathrm{j}} \mathrm{el} / \text { 'taboo' } \\
/ \mathrm{i}-\beta^{\mathrm{w}} \mathrm{el} / \text { 'come' }\end{array}$ & & & \\
\hline$/ \mathrm{s} /$ & $\begin{array}{l}\text { /i-sal/ 'hunt' } \\
/ \mathrm{i}-\beta^{\mathrm{w}} \mathrm{al} / \text { 'boil' }\end{array}$ & $\begin{array}{l}\text { i-sur/ 'send' } \\
\text { i- } \beta^{j} \text { ur/ 'bend', }\end{array}$ & & \\
\hline$/ \mathrm{h} /$ & $\begin{array}{l}\text { /i-hal/ 'float' } \\
\text { i- } \beta^{\mathrm{w}} \mathrm{al} / \text { 'boil', }\end{array}$ & $\begin{array}{l}\text { i-hur/ 'splinter' } \\
\text { i- } \beta^{j} \text { ur/ 'bend'' }\end{array}$ & $\begin{array}{l}\text { /i-hal/ 'float' } \\
\text { /i-sal/ 'hunt' } \\
\text { /i-leh/ 'good' } \\
\text { /i-les/ 'see' }\end{array}$ & \\
\hline
\end{tabular}


Liquids, Glides, glottal stop, and Ø

\begin{tabular}{|c|c|c|c|c|c|c|}
\hline & $/ \mathbf{r} /$ & $/ 1 /$ & $/ \mathrm{w} /$ & $/ \mathrm{j} /$ & $/ P /$ & $\varnothing$ \\
\hline$/ \mathrm{r} /$ & & & & & & \\
\hline$/ \mathbf{1}$ & $\begin{array}{l}\text { /i-loy/ 'walk' } \\
\text { /i-roy/ 'hear' } \\
\text { /i-hal/ 'float' } \\
\text { /i-har/ 'shine' }\end{array}$ & & & & & \\
\hline$/ \mathrm{w} /$ & $\begin{array}{l}\text { /i-wu/ 'high tide' } \\
\text { /i-ru/ 'two' } \\
/ \text { i-ta }{ }^{\mathrm{y}} \mathrm{gaw} / \text { 'arrive' } \\
/ \text { i-tan gar/ 'hang' }\end{array}$ & $\begin{array}{l}\text { i-wu/ 'high tide' } \\
\text { /i-lu/ 'vomit' } \\
\text { /ne-tew/ 'fowl' } \\
\text { /ne-tel/ 'rope' }\end{array}$ & & & & \\
\hline /j/ & $\begin{array}{l}\text { /i-jew/'melt' } \\
\text { /i-rew/ 'hairy' } \\
\text { /i-Roj/ 'scratch' } \\
\text { /i-Ror/ 'cut' }\end{array}$ & $\begin{array}{l}\text { i-jew/ 'melt' } \\
\text { /i-lew/ 'sacred' } \\
\text { i- } \beta^{\mathrm{j}} \mathrm{ej} / \text { 'go' } \\
/ \mathrm{i}-\beta^{\mathrm{j}} \mathrm{el} / \text { 'taboo' }\end{array}$ & $\begin{array}{l}\text { /i-jar/ 'finish' } \\
\text { /i-war/ 'white-haired' } \\
\text { /silej/ 'far away' } \\
\text { /i-silew/ 'kick' }\end{array}$ & & & \\
\hline$/ \mathrm{P} /$ & 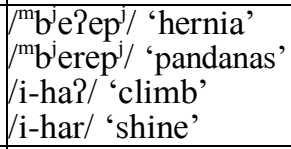 & $\begin{array}{l}\text { i- }-\mathrm{a}^{\mathrm{m}} \mathrm{b}^{\mathrm{w}} / \text { 'swollen' } \\
\text { /i-lam } \mathrm{l}^{\mathrm{w}} / \text { 'many' } \\
\text { i-ha?/ 'climb' } \\
\text { i-hal/ 'float' }\end{array}$ & $\begin{array}{l}\text { /i-iul/ 'wipe' } \\
\text { /i-wul/ 'howl' } \\
\text { /i-le?/ 'married' } \\
\text { /i-lew/ 'sacred' }\end{array}$ & 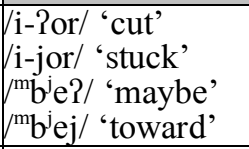 & & \\
\hline$\varnothing$ & $\begin{array}{l}\text { /i-hu/ 'bang head' } \\
\text { /i-hur/ 'splinter' } \\
\text { /i- } \beta^{\mathrm{j} e} \text { eh// 'whisper' } \\
/ \beta^{\mathrm{j}} \text { er?eh/ 'shore' }\end{array}$ & $\begin{array}{l}\text { tuPa-n/ 'older } \\
\text { sibling-3sG' } \\
\text { /tu?la-n/ 'tracks-3sG' } \\
\text { i-susu/ 'pour' } \\
\text { i-sulsul/'warm } \\
\text { oneself' }\end{array}$ & $\begin{array}{l}\text { /i-wuswus/ 'ask' } \\
\text { /mbjusus/'door' } \\
\text { /i-titewul/ 'argue' } \\
\text { /i-tiwtew/ 'joke' }\end{array}$ & $\begin{array}{l}\text { ni-lehjen/'NI- } \\
\text { quality' } \\
\text { /ne-lehen/ 'joint' } \\
\text { /na-Paran/ 'root' } \\
\text { /na-Pajrah/ 'fern' }\end{array}$ & $\begin{array}{l}\text { /i-hu/ 'bang } \\
\text { head' } \\
\text { /i-hu?/ 'give' }\end{array}$ & \\
\hline
\end{tabular}




\section{Appendix 2: Reduplication of monosyllabic roots}

The following table show all verbs (and verb-like elements) known to reduplicate in Nahavaq. The morphophonemic patterns of reduplication are discussed in Section 2.4.6.

\begin{tabular}{|c|c|c|c|c|c|}
\hline Base & Gloss & Reduplicated & Base & Gloss & Reduplicated \\
\hline gal & 'happy' & galgal & koh & 'be' & kokoh \\
\hline gar & 'blow; cough' & garagar & kok & 'cluck' & kokok \\
\hline gaw & 'meow' & gawgaw & komw & 'fall down' & komokom \\
\hline gcah & 'make noise' & gcahgcah & kon & 'burnt' & konokon \\
\hline gcal & 'tong' & gcagcal & kot & 'marry' & kotokot \\
\hline gcal & 'stuck' & gcalagcal & $k u k$ & 'cook' & kukuk \\
\hline gcal & 'hang' & gcalgcal & kur & 'move' & kurkur \\
\hline gcar & 'swim' & gcaragcar & $k u s$ & 'graze (skin)' & kuskus \\
\hline gces & 'grow; hairy' & gcisgces & lambw & 'many' & lambwalambw \\
\hline gcew & 'twist' & gcigcew & leg & 'open' & legeleg \\
\hline gcig & 'scrape out' & gcigcig & lel & 'unable to & lelel \\
\hline gcom & 'come up' & gcomogcom & & come down' & \\
\hline gcun & 'shrink' & gcungcun & lep & 'spill' & lepelep \\
\hline gir & 'whine' & girgir & les & 'see' & leseles \\
\hline gol & 'lick' & gologol & let & 'stake' & letelet \\
\hline got & 'not want' & gotogot & lew & 'holy' & lewelew \\
\hline hal & 'float' & halhal & lig & 'fetch' & liglig \\
\hline hapw & 'dance' & hapwhapw & $\lim$ & 'five' & limlim \\
\hline haq & 'climb' & haqhaq & lip & 'take' & liplip \\
\hline har & 'shine' & harhar & lir & 'take' & lirlir \\
\hline her & 'take' & herher & lir & 'reprimand' & lirlir \\
\hline hew & 'humid' & hewhew & $l u$ & 'vomit' & luwelu \\
\hline$h i$ & 'crush' & hihi & $\operatorname{lug}$ & 'wrap; roll' & luglug \\
\hline hip & 'cut' & hiphip & lum & 'burn low' & lumlum \\
\hline hopw & 'hope' & hophop & lund & 'peel' & lundlund \\
\hline hul & 'light' & hulhul & $l u q$ & 'hide' & luqluq \\
\hline hupw & 'blow' & hupwhupw & lur & 'pop' & lurlur \\
\hline hupw & 'wade' & hupwhupw & mag & 'agape' & magamag \\
\hline huq & 'give' & huqhuq & man & 'bleed' & manaman \\
\hline kambw & 'bend' & kambwakambw & $m a q$ & 'stop halfway' & maqmaq \\
\hline kambw & 'hold; bring' & kambwkambw & mbal & 'light (fire)' & mbalambal \\
\hline kan & 'rocky; sharp' & kanakan & mband & 'beat; win' & mbanamban \\
\hline kas & 'out' & kakas & $m b a q$ & 'atone' & mbaqmbaq \\
\hline kat & 'prick' & katakat & mbar & 'walk along' & mbarambar \\
\hline kel & 'crooked' & kelekel & mbin & 'fold' & mbinmbin \\
\hline kik & 'chirp' & kikik & mbir & 'wag; swing' & mbirembir \\
\hline kil & 'fall on' & kilkil & mbir & 'throw out' & mbirmbir \\
\hline kis & 'stand' & kiskis & mbir & 'weave & mbirmbir \\
\hline kit & 'stir' & kitkit & & bamboo' & \\
\hline kit & 'start working' & kitkit & mbon & 'together' & mbonombon \\
\hline
\end{tabular}




\begin{tabular}{|c|c|c|c|c|c|}
\hline Base & Gloss & Reduplicated & Base & Gloss & Reduplicated \\
\hline mbop & 'flat' & mbopmbop & ndig & 'follow' & ndigndig \\
\hline \multirow[t]{3}{*}{ mbow } & 'big' & mbwimbow; & ndig & 'straighten' & ndigndig \\
\hline & & mbumbow; & ndiq & 'turn' & ndiqndiq \\
\hline & & mbombow & ndis & 'tear' & ndisndis \\
\hline mbul & 'catch up to' & mbulmbul & ndomw & 'rotten' & ndomwndomw \\
\hline mbum & 'grow' & mbumbum & ndond & 'dry up' & ndondond \\
\hline mbut & 'step' & mbutmbut & ndoq & 'bend down' & ndondoq \\
\hline mbwal & 'beaten' & mbwalambwal & $n d u$ & 'pull' & $n d u n d u$ \\
\hline mbwar & 'wipe' & mbwarambwar & $n d u g$ & 'smoke' & ndugndug \\
\hline mbwet & 'lean over' & mbwetembwet & $n d u l$ & 'swallow' & ndulndul \\
\hline mbwil & 'hit' & mbwilmbwil & ndumw & 'pound' & ndumwndumw \\
\hline mbwir & 'hang' & mbwirmbwir & ndumw & 'suck up' & ndumwndumw \\
\hline mbwir & 'overflow' & mbwirmbwir & $n d u n$ & 'shrink' & ndundun \\
\hline mbwit & 'bend' & mbwitmbwit & $n d u q$ & 'stick in' & nduqnduq \\
\hline mbwul & 'bend' & mbwulmbwul & ndur & 'tired of' & ndurndur \\
\hline mbwund & 'full' & mbwunmbwun & ndur & 'through' & turtur \\
\hline \multirow[t]{2}{*}{ mbwur } & 'have & mbwurmbwur & $n d u s$ & 'pull' & ndusndus \\
\hline & elephantiasis' & & nimb & 'stagnant' & nimbnimb \\
\hline mbwur & 'squeeze' & mbwurmbwur & $n i s$ & 'pinch' & nisnis \\
\hline mbwus & 'squeeze' & mbwusmbwus & $n u$ & 'bored' & пипu \\
\hline mbwut & 'stop crying' & mbwutmbwut & peg & 'put apart' & pegepeg \\
\hline mel & 'sing (of bird)' & melemel & pem & 'shake' & ререт \\
\hline mel & 'wilted' & melemel & pen & 'paint' & penepen \\
\hline \multirow[t]{2}{*}{ mem } & 'ripe' & memem; & pen & 'run; race' & penepen \\
\hline & & meтетет & pet & 'break' & petepet \\
\hline mes & 'die' & mismes & pir & 'look after' & pirpir \\
\hline met & 'wake' & metemet & pir & 'fail' & pirpir \\
\hline met & 'visit' & metemet & pis & 'unfinished' & pispis \\
\hline mil & 'wet' & milmil & pit & 'lift' & pitpit \\
\hline $\min$ & 'drink' & minmin & pit & 'surface' & pitpit \\
\hline mis & 'piss' & mimis & pon & 'constipated' & ponopon \\
\hline momw & 'rotten' & momomw & por & 'split' & poropor \\
\hline mwal & 'almost' & mwalamwal & pot & 'colourful' & potopot \\
\hline mwamw & 'suck' & mwamwamw & pow & 'surprise' & popow \\
\hline$m w a q$ & 'level' & mwaqmwaq & pul & 'stir' & pulepul \\
\hline mwas & 'laugh' & mwasamwas & pul & 'braid' & pulpul \\
\hline mwas & 'break' & mwasamwas & pun & 'fish' & punpun \\
\hline mwil & 'too short' & mwilamwil & puy & 'pick' & риуриу \\
\hline mwut & 'short' & mwutmwut & pwaq & 'explode' & pwaqpwaq \\
\hline ndam & 'agree' & ndamandam & pwen & 'burn' & pwenepwen \\
\hline ndand & 'look up' & ndandand & pwil & 'writhe' & pwilpwil \\
\hline ndel & 'coil' & ndilndel & pwit & 'break (boils)' & pwitpwit \\
\hline$n d e m w$ & 'drip' & ndemwndemw; & pwuq & 'change' & ржиqржиq \\
\hline & & ndimwndemw; & $q a m b w$ & 'swollen' & qambwqambw \\
\hline & & ndemwendemw & $q a m w$ & 'fat' & qamwqamw \\
\hline nden & 'sink' & ndinden & qan & 'eat' & qanqan \\
\hline ndes & 'slip' & ndisndes & qas & 'bite' & qasqas \\
\hline ndey & 'dip' & ndindey & qaw & 'spread' & qawqaw \\
\hline
\end{tabular}




\begin{tabular}{|c|c|c|c|c|c|}
\hline Base & Gloss & Reduplicated & Base & Gloss & Reduplicated \\
\hline qep & 'bend' & qepqep & son & '(cicada) & sonson \\
\hline qil & 'dig' & qilqil & & chirp' & \\
\hline qin & 'pinch' & qinqin & soq & 'touch; nudge' & sosoq \\
\hline qombw & 'throw' & qoqombw; & sug & 'roast' & sugsug \\
\hline & & qombwqombw & sul & 'tired of' & sulsul \\
\hline qor & 'cut' & qorqor & suq & 'stab' & suqsuq \\
\hline qos & 'tie; tight' & qosqos & sur & 'send' & sursur \\
\hline qoy & 'scrape' & qoyqoy & sus ndal & 'walk & susus ndal \\
\hline$q u l$ & 'rub; wipe' & qulqul & & backward' & \\
\hline qund & 'wiggle' & qundqund & sut & 'whistle' & sutsut \\
\hline$q u s$ & 'make kissing & qusqus & $\operatorname{tag}$ & 'press' & tagtag \\
\hline & sound' & & tal & 'return' & taltal \\
\hline rah & 'grate; saw' & rahrah & tapw & 'prick' & tapwtapw \\
\hline rap & 'land' & raparap & tar & 'cut' & tartar \\
\hline$r a q$ & 'work' & raraq & teg & 'cry' & tigteg \\
\hline rar & 'sore' & rarar & tep & 'blow; gust' & tiptep \\
\hline rar & 'work' & rarar & teq & 'pull hard' & tiqteq \\
\hline reg & 'light' & regereg; rigreg & teq & 'close' & tiqteq \\
\hline remw & 'skinny' & remweremw & tes & 'skim' & testes; tistes \\
\hline rew & 'hairy' & rewerew & tes & 'slip' & tistes \\
\hline rig & 'heat' & rigrig & tig & 'roast' & tigtig \\
\hline rip & 'light-skinned' & riprip & timb & 'swell' & timbtimb \\
\hline ris & 'few' & risris & tip & 'sprout' & tiptip \\
\hline rit & 'read' & ritrit & tiq & 'tear down & tiqtiq \\
\hline ropw & 'help' & ropworopw & & with knife' & \\
\hline ropw & 'run' & ropworopw & tol & 'cut' & toltol \\
\hline rumbw & 'whip; split' & rumbwrumbw & tomw & 'itch' & tomwtomw; \\
\hline sag & 'perch; hang' & sagasag & & & titomw \\
\hline sal & 'hunt' & salsal & topw & 'jump' & topwotopw \\
\hline samw & 'lose road' & samwasamw & topw & 'intens' & topwotopw \\
\hline sar & 'straighten' & sarsar & tor & 'burp' & tortor \\
\hline semw & 'chew' & semwesemw & tu & 'put' & tutu \\
\hline sep & 'strain' & sevesep & tu sar & 'leave' & tutu sar \\
\hline sep & 'fall' & sipsep & tul & 'three' & tultul \\
\hline sig & 'split' & sigsig & tuq & 'beat' & tuqtuq \\
\hline sig & 'make fun of' & sigsig & tur & 'sew' & turtur \\
\hline sig & 'come ashore' & sigsig & tus & 'draw' & tutus \\
\hline sil & 'hide' & silsil & tut & 'transport fire' & tutut \\
\hline sil & 'make' & silsil & vah & 'give birth' & vahvah \\
\hline $\operatorname{sim}$ & 'stab' & simsim & var & 'step' & varavar \\
\hline $\operatorname{sim}$ & 'not let' & simsim & vel & 'discus' & velvel \\
\hline $\sin$ & 'shine' & $\sin \sin$ & vel & 'taboo' & velevel \\
\hline sipw & 'bail' & sipwsipw & vemb & 'fly' & vivemb \\
\hline sipw & 'put down' & sipwsipw & ver & 'cut into & verever \\
\hline sipw & 'go down' & sipwsipw & & serving sizes' & \\
\hline $\operatorname{siq}$ & 'one' & siqsiq & ves & 'four' & visves \\
\hline sir & 'scatter' & sirsir & vey & 'go' & veyevey \\
\hline sol & 'salt' & solsol & $v i$ & 'weave' & vivi \\
\hline
\end{tabular}




\begin{tabular}{lll|}
\hline Base & Gloss & Reduplicated \\
vih & 'how many' & vihvih \\
vit & 'fasten' & vitvit \\
vopw & 'rain' & vwupwvopw \\
vos & 'plant' & vosovos \\
vos & 'slap' & vosovos \\
vur & 'bend' & vurvur \\
vus & 'pull' & vusvus \\
vuy & 'sow' & vuyvuy \\
vwal & 'boil; hiss' & vwalavwal \\
vwan & 'bear fruit' & vwanavwan \\
vwar & 'run(of water)'vwaravwar \\
vwel & 'go' & vwelevwel \\
vwer & 'say' & vwerevwer \\
vwul & 'buy' & vwulvwul \\
vwur & 'hold' & vwurvwur \\
wambw & 'snore' & wambwawambw \\
wapw & 'not clear' & wapwapw \\
waq & 'bruised' & waqwaq \\
war & 'white-haired' & warawar \\
wel & 'open' & welewel \\
wu & 'high tide' & wuwu \\
wul & 'howl' & wulewul \\
wund & 'join' & wundwund \\
wupw & 'blow' & wupwwupw \\
wur & 'beat' & wurwur \\
wur & 'steer' & wurwur \\
yah & 'push aside' & yahyah \\
yal & 'sing' & yalyal \\
yar & 'drag' & yaryar \\
yat & 'strew' & yatyat \\
yeg & 'walk with & yigyeg; yegyeg; \\
& legs apart' & yegeyeg \\
yemb & 'spread out' & yembeyemb \\
yes & 'touch' & yisyes \\
yew & 'dissolve' & yiwyew \\
yig & 'shake out' & yigyig \\
yip & 'dive' & yipyip \\
yir & 'gut' & yiryir \\
yoq & 'tired' & yoqyoq \\
yor & 'stuck' & yoroyor \\
'scratch; dig' & yuhyuh \\
try; test' & titraym \\
ving & &
\end{tabular}




\section{Appendix 3: Adjectives}

Adjectives are described in Section 4.1.5.

(1) *ma-adjectives. Verb form = attributive form with one exception: mogcologcol is the verb form of 'loose', but the adjective form has mogcologcol mogcolgcol $\sim$ mogcol.

\begin{tabular}{llll}
\hline adjective & gloss & adjective & gloss \\
\hline mambwit & 'bent over' & mindisndes & 'hard, smooth' \\
matar & 'dried up' & mogcol & 'loose' \\
mandas & 'has holes (torn)' & $\sim$ mogcologcol & \\
mandur & 'has holes (pierced)' & mogcolgcol & \\
maqundqund & 'loose, shaky' & mogcungcun & 'bent' \\
marasras & 'light (weight)' & mopoy & 'disassembled' \\
me(piq)piq & 'swaying' & motogtog & 'skinny' \\
meleqleq & 'tasteless' & mundus & 'decomposed' \\
melevelep & 'rotten' & muwar & 'easy' \\
meloqloq & 'soft' & muwas & 'clear' \\
meluglug & 'crumpled' & mwalit & 'shrunken, constricted' \\
membinmbin & 'misshapen' & mwambwumbwuq & 'slack' \\
memburmbur & 'knicked' & mwandil & 'dimpled' \\
menembenemb & 'thin' & mwereperep & 'nearly gone' \\
mepul & 'sprained' & mwilislis & 'messy' \\
meqet & 'broken' & makan & 'sharp' \\
mevuyvuy & 'crumbled' & mevus & 'white' \\
mewel & 'unravelled' & mamal & 'red' \\
miligleg & 'slippery' & & \\
\hline
\end{tabular}

(2) Apparent-reduplication adjectives. Verb form = attributive form

\begin{tabular}{llll}
\hline adjective & gloss & adjective & gloss \\
\hline gohgoh & 'lazy' & milmil & 'sour' \\
kanakan & 'rocky' & mwulmwul & 'round' \\
kaskas & 'sweet' & pilpil & 'hot' \\
kelekel & 'crooked' & ponopon & 'burnt black' \\
konkon & 'funny' & posopos & 'flat' \\
lutlut & 'yellow' & potopot & 'multicoloured' \\
mbogmbog & 'purple' & pwalapwal & 'clean' \\
mbuqmbuq & 'short' & tartar & 'tight/strong' \\
mbwunambwun & 'fermented' & tigteg & 'rusty' \\
mehmeh & 'dry' & tutus & 'straight' \\
metemet & 'black' & & \\
\hline
\end{tabular}


(3) Other polysyllabic adjectives that don't require reduplication. Verb form = attributive form

\begin{tabular}{llll}
\hline Adjective & Gloss & Adjective & Gloss \\
\hline malaw & 'tame' & ndamwat & 'peaceful' \\
malqah & 'cold' & pwaras & 'strong', \\
mbarap & 'long' & pwisir & 'forked' \\
mbisnep & 'gray' & qasen & 'green' \\
mbwulu & 'deep' & vaqayndag & 'same' \\
mbwurut & 'thick' & vivew & 'new' \\
molol & 'dirty' & & \\
\hline
\end{tabular}

(4) Adjectives requiring reduplication in the attributive form.

\begin{tabular}{llllll}
\hline $\begin{array}{l}\text { Verb } \\
\text { form }\end{array}$ & $\begin{array}{l}\text { Adjective } \\
\text { form }\end{array}$ & Gloss & $\begin{array}{l}\text { Verb } \\
\text { form }\end{array}$ & Adjective form Gloss \\
\hline timb & timbtimb & 'swollen' & vwut & vwutvwut & 'shallow' \\
rus & rusrus & 'overripe' & mbwu & mbwumbwu & 'stinky' \\
pwit & pwitpwit & 'not ripe' & $($ qambw) & qambwqambw & 'swollen' \\
nim & nimnim & 'stagnant' & ndipw & ndipwndipw & 'heavy' \\
mom & momom & 'waterlogged' & ndom & ndomndom & 'rotten' \\
mwaq & mwaqmwaq 'level' & (mil)mil & milmil & 'wet' \\
mah & mahmah & 'dull' & qanew & qaqanew & 'plenty' \\
kar & karkar & 'not fully cooked' & mbow & mbwumbow (pl) 'big' \\
mwut & mwutmwut & 'short (of nose)' & vwariq & vwariqriq (pl) 'small' \\
\hline
\end{tabular}




\section{Appendix 4: Vestigial *ma- prefixes}

Verbs with vestiges of POc *ma- are discussed in Section 4.1.4. The forms in the table below are judges to have reflexes of *ma- if they:

1. Reduplicate as $m \mathrm{~V}$-DUP-ROOT

2. Have a clear cognate in Nahavaq without a *ma- prefix

3. Appear to be reflexes of a reconstructed form that was not prefixed or was reconstructed as having a prefix.

PAN and PMP reconstructions are from Zorc (1995). POc constructions are from Evans and Ross (2001). PNCV reconstructions are from Clark (2005).

\begin{tabular}{|c|c|c|c|c|}
\hline mV-root & gloss & mV-dup-root & Nahavaq cognate & $\begin{array}{l}\text { reconstructed } \\
\text { forms }\end{array}$ \\
\hline & light & marasras & & \\
\hline & $\begin{array}{l}\text { skinny. Strong, but } \\
\text { not bulky (person) }\end{array}$ & mwaragarag & & \\
\hline & newborn & magandagand & & \\
\hline & (face) sunken & makankan & & \\
\hline & & matavatap & & \\
\hline & all of them are ripe & mandarndar & & \\
\hline & $\begin{array}{l}\text { very dry (or burnt) } \\
\text { so that it breaks } \\
\text { easily) }\end{array}$ & malatalat & & \\
\hline & rotten ; too soft & melepelep & & \\
\hline & nearly gone & mwereperep & & \\
\hline & $\begin{array}{l}\text { bend over (under } \\
\text { heavy load) }\end{array}$ & mwendeqndeq & & \\
\hline & crunchy (like apple) & mereneren & & \\
\hline & slippery & miligleg & niligleg 'fat, oil' & $\begin{array}{l}\text { PMP *láña[h] } \\
\text { 'oil' }\end{array}$ \\
\hline & messy (of hair) & mwilislis & & \\
\hline & $\begin{array}{l}\text { (of wood) bad for } \\
\text { walking on because } \\
\text { bendy }\end{array}$ & mwiliwlew & & \\
\hline & $\begin{array}{l}\text { loose, wiggly, } \\
\text { swaying, unbraced } \\
\text { (trees, houses) }\end{array}$ & miliwlew & & \\
\hline & rough surface & mwigirgir & & \\
\hline & soft & meloqloq & & $\begin{array}{l}\text { POc *maluas } \\
\text { 'soft' }\end{array}$ \\
\hline & broken at joint & metohtoh & & \\
\hline & slippery & mokoyokoy & & \\
\hline & $\begin{array}{l}\text { loose, can fall down } \\
\text { (rope etc) }\end{array}$ & mokorokor & $\begin{array}{l}\text { kor 'removed } \\
\text { (clothes)' }\end{array}$ & \\
\hline & $\begin{array}{l}\text { many packed } \\
\text { together }\end{array}$ & mogcosgcos & & \\
\hline & slack & mambwuqmbwuq & & \\
\hline & loose ; shaky & maqundqund & $\begin{array}{l}\text { qundqund (v.t) } \\
\text { 'wiggle, shake' }\end{array}$ & \\
\hline & loose & maqulqul & & \\
\hline & nearly finished & manduqnduq & $\begin{array}{l}\text { (possible variant } \\
\text { mendiqndiq) }\end{array}$ & \\
\hline
\end{tabular}




\begin{tabular}{|c|c|c|c|c|}
\hline mV-root & gloss & mV-dup-root & Nahavaq cognate & $\begin{array}{l}\text { reconstructed } \\
\text { forms }\end{array}$ \\
\hline & crumpled & meluglug & $\begin{array}{l}\text { luglug 'roll ; wavy; } \\
\text { wrinkle' }\end{array}$ & $\begin{array}{l}\text { PMP *lukut } \\
\text { 'crumple up' }\end{array}$ \\
\hline & crumbled & mеvиуvиу & $\begin{array}{l}\text { (vuy)vuy '1. break into } \\
\text { pieces } 2 . \text { sew seeds' }\end{array}$ & \\
\hline & $\begin{array}{l}\text { broken into tiny } \\
\text { pieces }\end{array}$ & mevwusvwus & & \\
\hline & $\begin{array}{l}\text { transparent; has } \\
\text { holes where light } \\
\text { comes through }\end{array}$ & miturtur & $\begin{array}{l}\text { tur 'sew' ndur } \\
\text { 'through' }\end{array}$ & \\
\hline$(i-m w i-m w a r a w)$ & spotted & marawraw & & \\
\hline magas & fibrous & magasgas & & \\
\hline magcah & make noise (dry) & magcahgcah & & \\
\hline mahar & clear; light & maharhar & & \\
\hline makan & sharp & & kan 'sharp' & $\begin{array}{l}\text { PNCV *makani; } \\
\text { *ka=kani 'sharp' }\end{array}$ \\
\hline makas & come out & & (ka)kas (v2) 'out' & \\
\hline makat & skinny & makatkat & & \\
\hline malag & $\begin{array}{l}\text { (skin) comes off } \\
\text { easily }\end{array}$ & malagalag & & \\
\hline malah & tie around loosely & malahlah & & \\
\hline malap & broken and hanging & malaplap & & \\
\hline malund & $\begin{array}{l}\text { (skin) peeling off } \\
\text { (after death) }\end{array}$ & malundlund & & \\
\hline mambwir & go over (hill etc) & & mbwir 'overflow' & \\
\hline mambwit & stoop ; bend & mambwitmbwit & $\begin{array}{l}\text { (mbwete)mbwet 'lean } \\
\text { over' }\end{array}$ & \\
\hline manamb & $\begin{array}{l}\text { skinny; concave } \\
\text { (stomach, bag) }\end{array}$ & manambanamb & & \\
\hline mandam & very wet & mandamndam & ? (ndemwe)ndemw & \\
\hline mandas & have a hole & mandasndas & ndis 'tear' & $\begin{array}{l}\text { PMP *tas 'tear, } \\
\text { rip' }\end{array}$ \\
\hline mandraq & $\begin{array}{l}\text { (tree) start to crack } \\
\text { before falling }\end{array}$ & mandraqndraq & & \\
\hline mandun & gone back inside & & ndun 'shrink inside' & \\
\hline mandus & gone back inside & & ndus 'pull' & \\
\hline maqus & cracked ; chapped & maqusqus & & \\
\hline marah & $\begin{array}{l}\text { distant exploding } \\
\text { sound }\end{array}$ & marahrah & & \\
\hline maram & $\begin{array}{l}\text { skinny; suck in gut } \\
\text { (man) }\end{array}$ & maramaram & & \\
\hline matah & broken & matahtah & & \\
\hline mataq & scared & $\begin{array}{l}\text { matataq (v2- } \\
\text { manner) 'scaredly' }\end{array}$ & & $\begin{array}{l}\text { PAN *ma-tákut } \\
\text { POc *matakut }\end{array}$ \\
\hline matar & dry limp shrivelled & matartar & ? Tartar 'tight' & \\
\hline megcig & pushed to the side & & gcig 'scrape' & \\
\hline mehep & all broken ; rotten & mehephep & & \\
\hline mekihiq & $\begin{array}{l}\text { shift over ; give } \\
\text { way }\end{array}$ & & kihiq (v.t) 'shift over' & \\
\hline meleq & tasteless ; unsalted & meleqleq & & \\
\hline melimb & slack; soft ; easy & melimblimb & & $\begin{array}{l}\text { PMP *[ma]lumu } \\
\text { 'soft tender, } \\
\text { gentle } \\
\text { PNCV *ma-lumu } \\
\text { 'soft' }\end{array}$ \\
\hline
\end{tabular}




\begin{tabular}{|c|c|c|c|c|}
\hline mV-root & gloss & mV-dup-root & Nahavaq cognate & $\begin{array}{l}\text { reconstructed } \\
\text { forms }\end{array}$ \\
\hline melop & very soft & meloplop & $\begin{array}{l}\text { qoyqoylop } \\
\text { 'k.o.dessert', nolop } \\
\text { 'squishy sea plant' }\end{array}$ & \\
\hline membin & misshapen & membinmbin & mbinmbin 'fold' & \\
\hline membiqis & turn in one's sleep & membimbiqis & $\begin{array}{l}\text { viqis (v.t) 'turn' } \\
\text { (variant meviqis) }\end{array}$ & \\
\hline membur & knicked' & memburmbur & $\begin{array}{l}\text { (mbur)mbur (v2) } \\
\text { 'knicked' }\end{array}$ & \\
\hline mendeg & $\begin{array}{l}\text { having loose } \\
\text { threads }\end{array}$ & mendegndeg & & \\
\hline mendep & $\begin{array}{l}\text { too ripe ; fall down; } \\
\text { soft on ground }\end{array}$ & mendepndep & & \\
\hline mendes & smooth ; flat ; hard & mindisndes & (ndis)ndes 'slip' & \\
\hline mendew & stop (of weather) & & ndew (v2) 'rest' & \\
\hline mendin & stuck in & & $\begin{array}{l}\text { ndin (v2) 'go in ... } \\
\text { buried', nden 'dive' }\end{array}$ & \\
\hline mendis & sparky (of fire) & & ndis 'light fire (v.t.) & \\
\hline menem & thin & menemenem & & $\begin{array}{l}\text { PAN *ma-ni+pís } \\
\text { 'thin' } \\
\text { PNCV *ma- } \\
\text { nivi=nivi 'thin' }\end{array}$ \\
\hline mepel & chipped at edge & mepelepel & & \\
\hline mepes & breakable & mepesepes & $\begin{array}{l}\text { (pes)pes (v.t) 'snap } \\
\text { off }\end{array}$ & \\
\hline mepiq & sway; spill easily & mepiqpiq & & \\
\hline mepit & teetering & mepitpit & & \\
\hline mepul & sprained ; twisted & mepulpul & pul (v.t) 'turn, plait' & \\
\hline meqet & broken & meqetqet & & \\
\hline mesigc & fibrous & mesigcsigc & & \\
\hline metur & sleep & & & $\begin{array}{l}\text { PAN * } \text { túd }_{2} \mathrm{uR} \\
\text { POc *turuR } \\
\text { PNCV *maturu } \\
\text { 'sleep' }\end{array}$ \\
\hline meves & $\begin{array}{l}\text { strongly pushing / } \\
\text { washing over }\end{array}$ & mevesves & & \\
\hline mevit & $\begin{array}{l}\text { 1. shine in } \\
\text { someone's eyes } 2 \text {. } \\
\text { cross-eyed }\end{array}$ & mevitvit & & \\
\hline mevur & breaks easily & mevurevur & & \\
\hline mwewel & unravelled & & wel 'untie' & \\
\hline mewur & alive ; healthy & & & $\begin{array}{l}\text { PMP *ma-qúdip, } \\
\text { POc *maqurip } \\
\text { PNCV *ma?uri } \\
\text { 'alive, healthy' }\end{array}$ \\
\hline milim & $\begin{array}{l}\text { tired ; slack (NB } \\
\text { can be trans) }\end{array}$ & milimlim & & \\
\hline mogcol & loose (clothing etc.) & mogcologcol & & \\
\hline mogcun & bent & mogcungcun & & \\
\hline mogon & breakable & mogonogon & & \\
\hline monop & squeezably soft & monopnop & & \\
\hline mopoq & (rotten until) watery & mopoq & & \\
\hline mopoy & disassembled & moроуороу & & \\
\hline motog & very skinny & motogotog & ? Notog 'mangrove' & \\
\hline
\end{tabular}




\begin{tabular}{|c|c|c|c|c|}
\hline mV-root & gloss & mV-dup-root & Nahavaq cognate & $\begin{array}{l}\text { reconstructed } \\
\text { forms }\end{array}$ \\
\hline mundus & decomposed & mundusndus & & \\
\hline mwagcay & skinny & mwagcaygcay & & \\
\hline mwalit & $\begin{array}{l}\text { shrunken ; } \\
\text { constricted }\end{array}$ & mwalitlit & $\begin{array}{l}\text { (lit)lit 'squeeze out } \\
\text { between fingers' }\end{array}$ & \\
\hline mwambwaq & $\begin{array}{l}\text { skinny (i.e. banana } \\
\text { not ready yet or bag } \\
\text { not full enough) }\end{array}$ & mwambwaqmbwaq & & \\
\hline mwandil & dimpled & mwandilndil & & \\
\hline mwandur & have holes & mwandurndur & $\begin{array}{l}\text { tur 'sew' ndur } \\
\text { 'through' (variant } \\
\text { mwiturtur) }\end{array}$ & \\
\hline mwaqumwqumw & 1. swell 2. breathe & mwaqumwqumw & & \\
\hline mwarag & (sky) starts to clear & & reg 'dawn (v.i.) & \\
\hline mwarap & skinny & mwaraparap & & \\
\hline mwaray & skinny & mwarayray & & \\
\hline mwasal & very straight & mwasalsal & & \\
\hline mwasaw & skinny & mwasawsaw & & \\
\hline mwavwuq & can easily fall over & тжаvжиqvжиq & & \\
\hline mwegew & $\begin{array}{l}\text { only the bones are } \\
\text { left }\end{array}$ & mwegewgew & & \\
\hline mweheg & stick out separately & mwehegheg & & \\
\hline mwekew & skinny & mwekewkew & & \\
\hline mwendep & $\begin{array}{l}\text { (of fruit) rotten, fall } \\
\text { down, squishy }\end{array}$ & mwendepndep & & \\
\hline mwender & $\begin{array}{l}\text { not fastened. } \\
\text { Something shakes } \\
\text { inside }\end{array}$ & mwendernder & $\begin{array}{l}\text { ndernder (v.t) 'shake } \\
\text { to hear something } \\
\text { inside' }\end{array}$ & \\
\hline mwereg & loosely woven & mwregereg & & \\
\hline mwigis & $\begin{array}{l}\text { packed full and } \\
\text { overflowing }\end{array}$ & mwigisgis & & \\
\hline mwiqir & $\begin{array}{l}\text { 1. boom 2. shaky, } \\
\text { unballanced }\end{array}$ & mwiqirqir & & \\
\hline mwisir & crumbly & mwisirsir & & \\
\hline meheq & sick & & & PMP sakít 'sick' \\
\hline mevus & white & & & $\begin{array}{l}\text { PMP *ma-putíq } \\
\text { 'white' }\end{array}$ \\
\hline mopor & split & & por 'split' & $\begin{array}{l}\text { PNCV *vora } \\
\text { 'split' }\end{array}$ \\
\hline
\end{tabular}




\section{Appendix 5: Audio text metadata}

The table below lists some basic metadata for the audio texts of my Nahavaq corpus. Compressed .wav files of these are included in the attached DVD-ROM. Where a birth year is not known, and approximate decade with '?' is given, i.e. 192?.

\begin{tabular}{|c|c|c|c|c|c|}
\hline$\frac{\text { refer- }}{\text { ence }}$ & $\begin{array}{l}\text { speaker (gender.birth } \\
\text { year) }\end{array}$ & type & $\underline{\text { topic }}$ & date & location \\
\hline$\overline{07009}$ & Sendry Alick (m.1966) & custom story & $\begin{array}{l}\text { The village down in the } \\
\text { well }\end{array}$ & $2007-07-23$ & Lembinwen \\
\hline 07010 & Sendry Alick (m.1966) & custom story & Two pig-boys & $2007-07-23$ & Lembinwen \\
\hline 07011 & $\begin{array}{l}\text { Sendry Alick (m.1966). } \\
\text { Singing by Alick Rogsin } \\
\text { (m.192?) }\end{array}$ & custom story & $\begin{array}{l}\text { Two boys in a devil's } \\
\text { cave }\end{array}$ & $2007-07-23$ & Lembinwen \\
\hline 07018 & Kalmar Jacobus (m.1944) & informative & Norovohon & $2007-08-03$ & Bush \\
\hline 07019 & Aisul Manwei (m.1936) & informative & Naqaviwaq & $2007-08-03$ & Bush \\
\hline 07020 & Kalmar Jacobus (m.1944) & informative & naqavwus mbalaq & 2007-08-03 & Bush \\
\hline 07021 & Aisul Manwei (m.1936) & informative & nililrop & 2007-08-03 & Bush \\
\hline 07023 & Alick Rongsin (m.192?) & informative & mbulmbulsagc & $2007-08-03$ & Bush \\
\hline 07024 & Aisul Manwei (m.1936) & informative & nalag & $2007-08-03$ & Bush \\
\hline 07025 & Alick Rongsin (m.192?) & informative & marmbugmbug & $2007-08-03$ & Bush \\
\hline 07026 & Kalmar Jacobus (m.1944) & informative & naqay moloy & 2007-08-03 & Bush \\
\hline 07027 & Kalmar Jacobus (m.1944) & informative & nimweyil (cycad) & $2007-08-03$ & Bush \\
\hline 07028 & Aisul Manwei (m.1936) & informative & mwemweg & $2007-08-03$ & Bush \\
\hline 07029 & Alick Rongsin (m.192?) & informative & nimbwiryag & $2007-08-03$ & Bush \\
\hline 07030 & Aisul Manwei (m.1936) & informative & Nuwurqoqor & $2007-08-03$ & Bush \\
\hline 07031 & Kalmar Jacobus (m.1944) & informative & nigcigciyaq & $2007-08-03$ & Bush \\
\hline 07032 & Aisul Manwei (m.1936) & informative & naqari tamwat & $2007-08-03$ & Bush \\
\hline 07034 & Alick Rongsin (m.192?) & informative & nalap temes & $2007-08-03$ & Bush \\
\hline 07035 & Alick Rongsin (m.192?) & informative & nisivug & $2007-08-03$ & Bush \\
\hline 07036 & Alick Rongsin (m.192?) & informative & naqay livwasiran & $2007-08-03$ & Bush \\
\hline 07037 & Kalmar Jacobus (m.1944) & informative & nimiyen & 2007-08-03 & Bush \\
\hline 07038 & Alick Rongsin (m.192?) & informative & naqay malqah & $2007-08-03$ & Bush \\
\hline 07039 & Alick Rongsin (m.192?) & informative & naqay konokon & $2007-08-03$ & Bush \\
\hline 07040 & Kalmar Jacobus (m.1944) & informative & naqay gculmoqot & $2007-08-03$ & Bush \\
\hline 07041 & Kalmar Jacobus (m.1944) & informative & nitilmbwatwupwup & 2007-08-03 & Bush \\
\hline 07042 & Alick Rongsin (m.192?) & informative & nisivwug & 2007-08-03 & Bush \\
\hline 07043 & Kalmar Jacobus (m.1944) & informative & tilqey mevus & $2007-08-03$ & Bush \\
\hline 07044 & Kalmar Jacobus (m.1944) & informative & marhewmbarap & 2007-08-03 & Bush \\
\hline 07045 & Aisul Manwei (m.1936) & informative & naqay rahmbwar & 2007-08-03 & Bush \\
\hline 07046 & Kalmar Jacobus (m.1944) & informative & $\begin{array}{l}\text { nimbulqun tlembunqay } \\
\text { (wild kava) }\end{array}$ & $2007-08-03$ & Bush \\
\hline 07047 & Kalmar Jacobus (m.1944) & informative & $\begin{array}{l}\text { nimbuyaq } \\
\text { vinmbumbaqaw }\end{array}$ & $2007-08-03$ & Bush \\
\hline 07048 & $\begin{array}{l}\text { Kelina Namah (f.1958), } \\
\text { Nesly Alick (f.1987), } \\
\text { children }\end{array}$ & classroom & kindergarten class & 2007-08-07 & Lembinwen \\
\hline 07049 & $\begin{array}{l}\text { Kelina Namah (f.1958), } \\
\text { Nesly Alick (f.1987), } \\
\text { children }\end{array}$ & classroom & kindergarten class & $2007-08-07$ & Lembinwen \\
\hline 07051 & $\begin{array}{l}\text { Ellenie Silas (f.1972); } \\
\text { Reydion Kamah ; Nancy } \\
\text { Aiel Massing ; Daina } \\
\text { Albert ; Krisel Simeon }\end{array}$ & instruction & sewing & $2007-08-13$ & Lembinwen \\
\hline
\end{tabular}


Reydion Kamah ; Nancy

Aiel Massing ; Daina

Albert ; Krisel Simeon

07052 Ellenie Silas (f.1972);

Reydion Kamah ; Nancy

Aiel Massing ; Daina

Albert ; Krisel Simeon

07053 Ellenie Silas (f.1972);

Reydion Kamah ; Nancy

Aiel Massing ; Daina

Albert ; Krisel Simeon

07054 Ellenie Silas (f.1972);

Reydion Kamah ; Nancy

instruction sewing

2007-08-13 Lembinwen

Aiel Massing ; Daina

Albert ; Krisel Simeon

07056 Ellenie Silas (f.1972);

Reydion Kamah ; Nancy

Aiel Massing ; Daina

Albert ; Krisel Simeon

07057 Ellenie Silas (f.1972);

Reydion Kamah ; Nancy

instruction sewing

2007-08-13 Lembinwen

Aiel Massing ; Daina

Albert ; Krisel Simeon

07058 Ellenie Silas (f.1972);

Reydion Kamah ; Nancy

instruction sewing

2007-08-13 Lembinwen

Aiel Massing ; Daina

Albert ; Krisel Simeon

07059 Ellenie Silas (f.1972);

Reydion Kamah ; Nancy

Aiel Massing; Daina

Albert ; Krisel Simeon

07063 Tohdal Bellam (m.1932) custom story \begin{tabular}{l}
$\begin{array}{l}\text { Ambwat Malqun puts a 2007-08-22 Lembinwen } \\
\text { spiky fish in his nambas }\end{array}$ \\
\hline
\end{tabular}

07064 Kelina Namah (f.1958) $\quad$ custom story $\quad$ Love magic and incest $2007-08-22$ Lembinwen

07065 Tohdal Bellam (m.1932) custom story Naming the coconut, 2007-08-22 Lembinwen

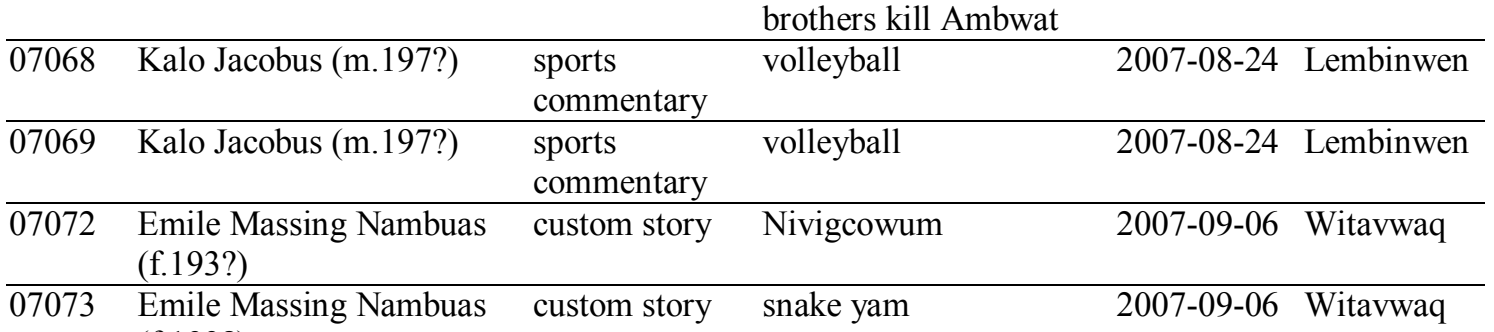
(f.193?)

07074 Emile Massing Nambuas custom story octopus mother-in-law 2007-09-06 Witavwaq (f.193?)

07075 Emile Massing Nambuas custom story crescent grunter in the 2007-09-06 Witavwaq (f.193?) laplap

07076 Emile Massing Nambuas custom story Ambwat, the spider web, 2007-09-06 Witavwaq (f.193?) and Vinmbwumbwaqaw

reef

\begin{tabular}{llllll}
\hline 07077 & Massing Lessless (m.192?) & history & WWII false start & 2007-09-07 & Witava \\
\hline 07078 & Massing Lessless (m.192?) & history & WWII false start & 2007-09-07 & Witava \\
\hline 07079 & Massing Lessless (m.192?) & history & WWII & 2007-09-07 & Witava \\
\hline 07080 & $\begin{array}{l}\text { Peter Ainding Luan } \\
\text { (m.1945) }\end{array}$ & custom story & $\begin{array}{l}\text { Nivinmbwul is nearly } \\
\text { drowned }\end{array}$ & 2007-09-07 & Witavwaq \\
\hline 07081 & $\begin{array}{l}\text { Peter Ainding Luan } \\
\text { (m.1945) }\end{array}$ & custom story & $\begin{array}{l}\text { Nivinmbwumbwaqaw } \\
\text { eats all the people }\end{array}$ & 2007-09-07 & Witavwaq \\
\hline
\end{tabular}




\begin{tabular}{|c|c|c|c|c|c|}
\hline 07082 & $\begin{array}{l}\text { Peter Ainding Luan } \\
(\mathrm{m} .1945)\end{array}$ & custom story & Ainder Lambut & 2007-09-07 & Witavwaq \\
\hline 07083 & Sam Atis Joshua (m.1964) & demonstration & $\begin{array}{l}\text { How to make a fish trap } \\
\text { (part 1) }\end{array}$ & 2007-09-12 & $\begin{array}{l}\text { Caroline } \\
\text { Bay }\end{array}$ \\
\hline 07084 & Kenneth Aisoh (m.1920) & costom story & coming from a pig & 2007-09-11 & Luqumow \\
\hline 07085 & Kenneth Aisoh (m.1920) & informative & birth mark & 2007-09-11 & Luqumow \\
\hline 07086 & Matta Kennet (f.1954) & history & nanggriamel arrests & 2007-09-12 & Luqumow \\
\hline 07087 & $\begin{array}{l}\text { Lisulvere Aimbwas } \\
\text { (f.1947) }\end{array}$ & custom story & The moon & 2007-09-12 & Luqumow \\
\hline 07088 & $\begin{array}{l}\text { Maddy Aimbel Totah } \\
\text { (f.1942) }\end{array}$ & custom story & breadfruit, nivigcowum & 2007-09-12 & Luqumow \\
\hline 07089 & $\begin{array}{l}\text { Kessel Aimbel (f.1983); } \\
\text { Maddy Aimbel Totah } \\
\text { (f.1942) }\end{array}$ & custom story & $\begin{array}{l}\text { V. lies a trap for } \\
\text { Ambwats }\end{array}$ & 2007-09-12 & Luqumow \\
\hline 07090 & $\begin{array}{l}\text { Maddy Aimbel Totah } \\
\text { (f.1942) }\end{array}$ & custom story & Mbenewur Mbenesag & 2007-09-12 & Luqumow \\
\hline 07091 & Matta Kennet (f.1954) & demonstration & $\begin{array}{l}\text { how to make laplap (part } \\
\text { 1) }\end{array}$ & $2007-09-13$ & Luqumow \\
\hline 07092 & Matta Kennet (f.1954) & demonstration & $\begin{array}{l}\text { how to make laplap (part } \\
\text { 2) }\end{array}$ & $2007-09-13$ & Luqumow \\
\hline 07093 & Matta Kennet (f.1954) & demonstration & $\begin{array}{l}\text { how to make laplap (part } \\
\text { 3) }\end{array}$ & $2007-09-13$ & Luqumow \\
\hline 07095 & Sam Atis Joshua (m.1964) & demonstration & $\begin{array}{l}\text { nivereveryen (making } \\
\text { fire by rubbing sticks) }\end{array}$ & $2007-09-13$ & Luqumow \\
\hline 07097 & Massosoh Robert (m.1942) & history & $\begin{array}{l}\text { The history of } \\
\text { nivereveryen } \\
\text { (firemaking) }\end{array}$ & 2007-09-13 & Luqumow \\
\hline 07098 & $\begin{array}{l}\text { Alison Gideion Aimbel } \\
(\mathrm{m} .1961)\end{array}$ & $\begin{array}{l}\text { custom } \\
\text { story/history }\end{array}$ & Sun stone & 2007-09-13 & Luqumow \\
\hline 07099 & $\begin{array}{l}\text { Louise Aisig Mbuwas } \\
\text { (f.1960) }\end{array}$ & demonstration & String pictures: house & 2007-09-16 & Luqumow \\
\hline 07100 & $\begin{array}{l}\text { Louise Aisig Mbuwas } \\
\text { (f.1960) }\end{array}$ & demonstration & $\begin{array}{l}\text { String pictures: boneless } \\
\text { fish (not good) }\end{array}$ & 2007-09-16 & Luqumow \\
\hline 07101 & $\begin{array}{l}\text { Louise Aisig Mbuwas } \\
\text { (f.1960) }\end{array}$ & demonstration & $\begin{array}{l}\text { String pictures: flying } \\
\text { fox (not good) }\end{array}$ & 2007-09-16 & Luqumow \\
\hline 07102 & $\begin{array}{l}\text { Louise Aisig Mbuwas } \\
\text { (f.1960) }\end{array}$ & demonstration & $\begin{array}{l}\text { String picutures: flying } \\
\text { fox }\end{array}$ & $2007-09-16$ & Luqumow \\
\hline 07103 & $\begin{array}{l}\text { Louise Aisig Mbuwas } \\
\text { (f.1960) }\end{array}$ & demonstration & $\begin{array}{l}\text { String pictures: boneless } \\
\text { fish }\end{array}$ & 2007-09-16 & Luqumow \\
\hline 07104 & $\begin{array}{l}\text { Louise Aisig Mbuwas } \\
\text { (f.1960) }\end{array}$ & demonstration & $\begin{array}{l}\text { String pictures: bony } \\
\text { fish }\end{array}$ & 2007-09-16 & Luqumow \\
\hline 07105 & $\begin{array}{l}\text { Louise Aisig Mbuwas } \\
\text { (f.1960) }\end{array}$ & demonstration & $\begin{array}{l}\text { String pictures: bony } \\
\text { fish }\end{array}$ & 2007-09-16 & Luqumow \\
\hline 07106 & $\begin{array}{l}\text { Louise Aisig Mbuwas } \\
\text { (f.1960) }\end{array}$ & demonstration & $\begin{array}{l}\text { String pictures: fruit of } \\
\text { miyen }\end{array}$ & 2007-09-16 & Luqumow \\
\hline 07107 & $\begin{array}{l}\text { Louise Aisig Mbuwas } \\
\text { (f.1960) }\end{array}$ & demonstration & $\begin{array}{l}\text { String pictures: } \\
\text { melqumes (shell) }\end{array}$ & 2007-09-16 & Luqumow \\
\hline 07108 & $\begin{array}{l}\text { Louise Aisig Mbuwas } \\
\text { (f.1960) }\end{array}$ & demonstration & $\begin{array}{l}\text { String pictures: double } \\
\text { sprouting coconut }\end{array}$ & $2007-09-16$ & Luqumow \\
\hline 07109 & $\begin{array}{l}\text { Louise Aisig Mbuwas } \\
\text { (f.1960) }\end{array}$ & demonstration & $\begin{array}{l}\text { String pictures: } \\
\text { maltiqndar and octopus }\end{array}$ & 2007-09-16 & Luqumow \\
\hline 07110 & $\begin{array}{l}\text { Louise Aisig Mbuwas } \\
\text { (f.1960) }\end{array}$ & demonstration & $\begin{array}{l}\text { String pictures: } \\
\text { Mbenewur fire }\end{array}$ & 2007-09-16 & Luqumow \\
\hline 07111 & $\begin{array}{l}\text { Taylor Aitip Masing Buas } \\
(\mathrm{m} .1961)\end{array}$ & custom story & story from Luhaq & $2007-09-16$ & Luqumow \\
\hline 07112 & $\begin{array}{l}\text { Maddy Aimbel Totah } \\
\text { (f.1942) }\end{array}$ & demonstration & Bamboo laplap (part 1) & 2007-09-16 & Luqumow \\
\hline 07113 & $\begin{array}{l}\text { Maddy Aimbel Totah } \\
\text { (f.1942) }\end{array}$ & demonstration & Bamboo laplap (part 2) & 2007-09-16 & Luqumow \\
\hline
\end{tabular}




\begin{tabular}{|c|c|c|c|c|c|}
\hline 07115 & $\begin{array}{l}\text { Aimbel Gidion Totah } \\
\text { (m.1937) }\end{array}$ & history & History of Luqmow 1 & 2007-09-16 & Luqumow \\
\hline 07116 & Massosoh Robert (m.1942) & history & History of Luqmow 2 & $2007-09-16$ & Luqumow \\
\hline 07117 & $\begin{array}{l}\text { Antony Sailon (m.1989), } \\
\text { Marklin Sailon (f.1970), } \\
\text { Raymon Ross Sailon } \\
\text { (f.1997), Sailon (m.196?) }\end{array}$ & conversation & Sailon Family chat & $2007-09-22$ & Lembinwen \\
\hline 07120 & Kalmar Jacobus (m.1944) & informative & Nahalag mbwaqay & $2007-09-27$ & Bush \\
\hline 07121 & Kalmar Jacobus (m.1944) & informative & mwosmwosyap & $2007-09-27$ & Bush \\
\hline 07122 & Kalmar Jacobus (m.1944) & informative & Vinumaras & $2007-09-27$ & Bush \\
\hline 07123 & Kalmar Jacobus (m.1944) & informative & mbwitmbwimbwoy & $2007-09-27$ & Bush \\
\hline 07124 & Kalmar Jacobus (m.1944) & informative & Nuqulip palmtree & $2007-09-27$ & Bush \\
\hline 07125 & Kalmar Jacobus (m.1944) & informative & Nuqulas (nawalas) & $2007-09-27$ & Bush \\
\hline 07126 & Kalmar Jacobus (m.1944) & informative & Nigey (nanggae) & $2007-09-27$ & Bush \\
\hline 07127 & Kalmar Jacobus (m.1944) & informative & Tumbwi (navelwud) & $2007-09-27$ & Bush \\
\hline 07128 & Lisbet (f.196?) & sermon & Presbyterian sermon & $2007-09-30$ & Lembinwen \\
\hline 07131 & Kalmar Jacobus (m.1944) & informative & $\begin{array}{l}\text { naqayvwutmeley and } \\
\text { nimbwuhmbwuh }\end{array}$ & $2007-10-05$ & Lembinwen \\
\hline 07132 & Kalmar Jacobus (m.1944) & custom story & Boy lost in hole in reef & $2007-10-06$ & Lembinwen \\
\hline 07133 & Kalmar Jacobus (m.1944) & custom story & $\begin{array}{l}\text { Nimbuleh Ranewen } \\
\text { defeats } \\
\text { Nivinmbwumbwaqaw } \\
\end{array}$ & $2007-10-06$ & Lembinwen \\
\hline 08009 & Maxime Apal (m.1952) & custom story & Origin of Uraquh & $2008-09-19$ & Witavaq \\
\hline 08011 & CLC Singers & song & Ndagalgal leten & $2008-10-14$ & Lembinwen \\
\hline 08012 & CLC Singers & song & arog nisambyen rendip & $2008-10-14$ & Lembinwen \\
\hline 08018 & Aiel Massing (m.1953) & explanation & Temes Malaw's tooth & $2008-10-25$ & Lembinwen \\
\hline AT01 & $\begin{array}{l}\text { Aimbel Gidion Totah } \\
\text { (m.1937) }\end{array}$ & custom story & A devil egg & $2006-08-24$ & Luqumow \\
\hline AT02 & $\begin{array}{l}\text { Aimbel Gidion Totah } \\
\text { (m.1937) }\end{array}$ & song & Song about devil egg & $2006-08-24$ & Luqumow \\
\hline DK01 & Dialy Kenneth (m.1947) & custom story & $\begin{array}{l}\text { Attemped homicide } \\
\text { from a whale }\end{array}$ & $2006-08-27$ & Luqumow \\
\hline$\overline{\mathrm{EC} 01}$ & Elling Charley (f.1953) & custom story & $\begin{array}{l}\text { The village down in the } \\
\text { well }\end{array}$ & $2006-08-26$ & Witavwaq \\
\hline EC02 & Elling Charley (f.1953) & custom story & Nivwutin Mbeqey & $2006-08-26$ & Witavwaq \\
\hline JS01 & Jolly Simeon (m.1945) & custom story & $\begin{array}{l}\text { founding of Loqor- } \\
\text { Lagcalat (part 1) }\end{array}$ & $2006-07-25$ & Lembinwen \\
\hline JS02 & Jolly Simeon (m.1945) & custom story & $\begin{array}{l}\text { Founding of Loqor- } \\
\text { Lagcalat (part 2) }\end{array}$ & $2006-08-30$ & Lembinwen \\
\hline$\overline{\mathrm{KA} 01}$ & Kenneth Aisoh (m.1920) & history & $\begin{array}{l}\text { Atis Vimbam who went } \\
\text { to Bethlehem }\end{array}$ & $2006-07-20$ & Mbenewur \\
\hline KA02 & Kenneth Aisoh (m.1920) & custom story & Airog kills Sapwsapw & $2006-07-20$ & Mbenewur \\
\hline KJ01 & Kalmar Jacobus (m.1944) & custom story & $\begin{array}{l}\text { The devil eel of Dixon } \\
\text { Reef }\end{array}$ & $2006-07-10$ & Lembinwen \\
\hline KO01 & Krivet Oped (m.1950) & custom story & $\begin{array}{l}\text { Two sisters, their } \\
\text { husband, and his multi- } \\
\text { coloured animals }\end{array}$ & $2006-08-25$ & Witavwaq \\
\hline $\mathrm{KO} 2$ & Krivet Oped (m.1950) & custom story & Born-again boy & $2006-08-25$ & Witavwaq \\
\hline KO03 & Krivet Oped (m.1950) & custom story & $\begin{array}{l}\text { A bird who lost her } \\
\text { wings }\end{array}$ & $2006-08-25$ & Witavwaq \\
\hline LS01 & Lesley Salei (m.1940) & custom story & $\begin{array}{l}\text { Ambwat and the two } \\
\text { white sisters }\end{array}$ & $2006-06-30$ & Lembinwen \\
\hline $\begin{array}{l}\text { MAHR } \\
1\end{array}$ & $\begin{array}{l}\text { Maddy Aimbel Totah } \\
\text { (f.1942), Heta Robert } \\
\text { (f.1953) }\end{array}$ & custom story & Salambow & $2006-08-27$ & Luqumow \\
\hline
\end{tabular}




\begin{tabular}{|c|c|c|c|c|c|}
\hline MR01 & Massosoh Robert (m.1942) & custom story & $\begin{array}{l}\text { The founding of } \\
\text { Mbenewur }\end{array}$ & $2006-08-27$ & Luqumow \\
\hline nendiq & $\begin{array}{l}\text { Maklen Tom (f.195?), } \\
\text { Neslie Alick (f.1987), } \\
\text { Votselyn Alick (f.198?) }\end{array}$ & instruction & weaving & $2007-08-25$ & Vorlesles \\
\hline $\begin{array}{l}\text { nihumb } \\
\text { wen }\end{array}$ & Sam Atis Joshua (m.1964) & demonstration & $\begin{array}{l}\text { How to make a fish trap } \\
\text { (part 2) }\end{array}$ & $2007-09-12$ & $\begin{array}{l}\text { Caroline } \\
\text { Bay }\end{array}$ \\
\hline $\begin{array}{l}\text { RF- } \\
\text { MF01 } \\
\end{array}$ & $\begin{array}{l}\text { Ronald Fredson (m.1966), } \\
\text { Marianne Fred (f.1986) }\end{array}$ & conversation & $\begin{array}{l}\text { Converstation about } \\
\text { making food and kava }\end{array}$ & 2006-08-01 & Mbenewur \\
\hline song01 & Nagconen Stringband & song & Vorlesles & 2006-09-18 & Lembinwen \\
\hline song02 & Nagconen Stringband & song & $\begin{array}{l}\text { Noroqvwun iraq } \\
\text { nimbwasar tuwan }\end{array}$ & 2006-09-18 & Lembinwen \\
\hline song03 & Ndologcen Stringband & song & Rahun Nambwaq & 2007-10-06 & Lembinwen \\
\hline song04 & Ndologcen Stringband & song & $\begin{array}{l}\text { netesmehyen } \\
\text { neteswuyen }\end{array}$ & $2007-10-06$ & Lembinwen \\
\hline song05 & Ndologcen Stringband & song & Atuwa irar novwor tiyig & 2007-10-06 & Lembinwen \\
\hline song06 & Ndologcen Stringband & song & (Jesus, remember me) & $2007-10-06$ & Lembinwen \\
\hline song07 & Ndologcen Stringband & song & Netew Malaw & $2007-10-06$ & Lembinwen \\
\hline TB01 & Tohdal Bellam (m.1932) & custom story & $\begin{array}{l}\text { Ambwat brothers buy } \\
\text { back their sister }\end{array}$ & 2006-06-29 & Lembinwen \\
\hline ТВ02 & Tohdal Bellam (m.1932) & song & $\begin{array}{l}\text { Tree hauling song and } \\
\text { explanation }\end{array}$ & 2006-07-12 & Lembinwen \\
\hline ТВ03 & Tohdal Bellam (m.1932) & custom story & Birds in a famine & 2006-07-19 & Lembinwen \\
\hline
\end{tabular}




\section{REFERENCES}

Aikhenvald, Alexandra Y. 2006. Serial Verb Constructions in Typological Perspective. In Alexandra Y. Aikhenvald and R.M.W. Dixon (eds.), Serial Verb Constructions: A Cross-Linguistic Typology. Oxford: Oxford University Press: $1-68$.

Aikhenvald, Alexandra Y. and R.M.W. Dixon, Eds. (2006). Serial Verb Constructions: A Cross-Linguistic Typology. Oxford: Oxford University Press.

Allen, Gerald R. and Roger Steene 1998. Indo-Pacific Coral Reef Field Guide Singapore: Sea Challengers.

anon. 1918. Nambi tiravelawo, nimbu tirelaw, nomboi tatloh [Hymnal]. Melbourne: Brown, Prior and Co.

Audacity Team (2007). Audacity. (Version 1.2.6) [Computer program]. Retrieved February, 2007, from http://audacity.sourceforge.net/.

Barras, Claude (1998). Transcriber. (Version 1.5.1) [Computer program]. Retrieved February, 2006, from http://sourceforge.net/projects/trans/files/.

Bender, Byron W. 1968. Marshallese Phonology. Oceanic Linguistics 7(1): 16-35.

Billerey-Mosier, Roger (2002). JPlotFormants. (Version 1.4) [Computer program]. Retrieved January, 2007, from www.linguistics.ucla.edu/people/grads/billerey/PlotFrog.htm.

Boersma, Paul and David Weenink (2006). Praat: Doing Phonetics by Computer. (Version 4.4.07) [Computer program]. Retrieved November, 2006, from www.praat.org.

Boyd, Robert 1905. Naval relau [Mark, Epistles of John, and Book of Jonah]. Sydney: Samuel E. Lees.

Bregulla, Heinrich L. 1991. Birds of Vanuatu. Oswestry: Anthony Nelson Ltd.

Charpentier, Jean- Michel 1979. La langue de Port-Sandwich (Nouvelles-Hébrides). Paris: SELAF.

Charpentier, Jean- Michel 1982. Atlas Linguistique du Sud-Malakula. Paris: SELAF.

Clark, Ross 1985. Languages of North and Central Vanuatu. In Andrew Pawley and Lois Carrington (eds.), Austronesian linguistics at the 15th Pacific Science Congress. Canberra: Dept. of Linguistics, Research School of Pacific Studies, Australian National University. no. 88: 199-236.

Clark, Ross 2005. "Proto North-Central Vanuatu Reconstructions" ms. University of Auckland.

Clements, G. N. and Sylvester Osu 2002. Explosives, Implosives and Nonexplosives: The Linguistic Function of Air Pressure Differences in Stops. In Carlos Gussenhoven and Natasha Warner (eds.), Laboratory Phonology 7. Berlin and New York: Mouton de Gruyter: 299-350.

Crowley, Terry 1982. The Paamese language of Vanuatu. Canberra: Pacific Linguistics.

Crowley, Terry 1991. Parallel Development and Shared Innovations: Some Developments in Central Vanuatu Inflectional Morphology. Oceanic Linguistics 30(2): 179-222.

Crowley, Terry 1995. Melanesian Languages: Do They Have a Future? Oceanic Linguistics 34(2): 325-344.

Crowley, Terry 1998a. An Erromangan (Sye) grammar. Honolulu: University of Hawaii Press.

Crowley, Terry 1998b. A Salvage Sketch of Nāti (Southwest Malakula, Vanuatu). In D. T. Tryon (eds.), Papers in Austronesian Lingusitics No. 5. Canberra: Pacific Linguistics: 101-148.

Crowley, Terry 2002a. Port Sandwich. In John Lynch, Malcolm Ross and Terry Crowley (eds.), The Oceanic Languages. Richmond, Surrey: Curzon: 650-659.

Crowley, Terry 2002b. Serial Verbs in Oceanic : A Descriptive Typology. New York: Oxford University Press.

Crowley, Terry 2003. A New Bislama Dictionary. Vila, Vanuatu: Pacific Languages Unit, University of the South Pacific. 
Crowley, Terry 2004. Bislama Reference Grammar. Honolulu: University of Hawai i Press.

Crowley, Terry 2006a. The Avava Language of Central Malakula (Vanuatu). Canberra: Pacific Linguistics.

Crowley, Terry 2006b. Naman: A Vanishing Language of Malakula (Vanuatu). Canberra: Pacific Linguistics.

Crowley, Terry 2006c. Nese: A Diminishing Speech Variety of Northwest Malakula (Vanuatu). Canberra: Pacific Linguistics.

Crowley, Terry 2006d. Tape: A Declining Language of Malakula (Vanuatu) Canberra: Pacific Linguistics.

Dahl, Östen 1985. Tense and Aspect Systems. New York: Basil Blackwell.

Deacon, Bernard 1934. Malekula: A Vanishing People in the New Hebrides. Oosterhout N.B., The Netherlands: Anthropological Publications.

Diessel, Holger 1999. The Morphosyntax of Demonstratives in Synchrony and Diachrony. Linguistic Typology 3: 1-49.

Dimitriadis, Alexis and Martin Everaert (2002). "Anaphora Typology Questionnaire." version 0.50 (draft). Retrieved 24 November, 2008, from http://www.let.uu.nl/ alexis.dimitriadis/personal/database/Questions.pdf.

Dimock, Laura 2005. The Bilabial Trill in Unua. Wellington Working Papers in Linguistics 17: 17-33.

Dimock, Laura forthcoming. Fillers and Placeholders in Nahavaq. In Nino Amiridze, Boyd Davis and Margaret McLagan (eds.), Fillers in Discourse and Grammar. Amsterdam: John Benjamins (provisional).

Dixon, R.M.W. 1991. The Endangered Languages of Australia, Indonesia and Oceania. In R.H. Robins and E.M. Uhlenbeck (eds.), Endangered Languages. Oxford: Berg: 229-255.

Elbert, Samuel H. 1974. Puluwat Grammar. Canberra: Pacific Linguistics.

Evans, Bethwyn and Malcolm Ross 2001. The History of Proto-Oceanic *ma-. Oceanic Linguistics 40(2): 269-290.

Fox, G. J. 1979. Big Nambas grammar. Canberra: Pacific Linguistics.

François, Alexandre 2002. Araki : A Disappearing Language of Vanuatu. Canberra: Pacific Linguistics.

François, Alexandre 2006. Serial Verb Constructions in Mwotlap. In Alexandra Y. Aikhenvald and R.M.W. Dixon (eds.), Serial Verb Constructions: A CrossLinguistic Typology. Oxford: Oxford University Press: 223-238.

Goodenough, J. G. 1876. Journal of Commodore Goodenough, R.N., C.B., C.M.G., During his Last Command as Senior Officer on the Australian Station, 18731875. England: Henry S. King.

Gowers, Sheila 1976. Some Common Trees of the New Hebrides and their Vernacular Names. Port Vila: Education Department, British Residency.

Greenhill, Simon, Robert Blust and Russell Gray 2008. The Austronesian Basic Vocabulary Database: From Bioinformatics to Lexomics. Evolutionary Bioinformatics 4: 271-283.

Hyslop, Catriona 2001. The Lolovoli dialect of the North-East Ambae language, Vanuatu. Canberra: Pacific Linguistics.

Ladefoged, Peter and Ian Maddieson 1996. The Sounds of the World's Languages. Oxford: Blackwell.

Lewis, M. Paul 2009. Ethnologue: Languages of the World, Sixteenth edition. Dallas: SIL International.

Lynch, John 2000a. Linguistic Subgrouping in Vanuatu and New Caledonia. In Bill Palmer and Paul Geraghty (eds.), SICOL: Proceedings of the Second International Conference on Oceanic Linguistics: vol.2, Historical and Descriptive Studies. Canberra: Pacific Linguistics: 155-185.

Lynch, John 2000b. Reconstructing Proto-Oceanic Stress. Oceanic Linguistics 39(1): 53-82.

Lynch, John 2002. The Proto-Oceanic Labiovelars: Some New Observations. Oceanic Linguistics 41: 310-362. 
Lynch, John 2006. Some Notes on the Linguistic History of Malakula. Terry Crowley Memorial Workshop on Vanuatu Languages. Wellington.

Lynch, John 2007. The Malakula Linkage of Central Vanuatu. Seventh International Conference on Oceanic Linguistics. Noumea.

Lynch, John and Terry Crowley 2001. Languages of Vanuatu: A New Survey and Bibliography. Canberra: Pacific Linguistics.

Lynch, John, Malcolm Ross and Terry Crowley, Eds. (2002). The Oceanic Languages. Richmond, Surrey: Curzon.

Maddieson, Ian 1989a. Aerodynamic Constraints on Sound Change: The case of Bilabial Trills. UCLA Working Papers in Phonetics 72: 91-115.

Maddieson, Ian 1989b. Linguo-labials. In Ray Harlow and Robin Hooper (eds.), VICAL 1: Papers from the Fifth International Conference on Austronesian Linguistics. Auckland: Te Reo: 349-375.

Max-Planck-Institute for Psycholinguistics (2006). ELAN Linguistic Annotator. (Version 3.0) [Computer program]. Retrieved December, 2006, from http://www.lat-mpi.eu/tools/elan/.

McKerras, Ross 2001. "Uripiv Phonology and Grammar." ms.

Millar, J. Graham 1989. Live, a History of Church Planting in the New Hebrides to 1880. vol.6. Lawson, NSW: Mission Publications of Australia.

Musgrave, Jill 2007. A Grammar of Neve'ei, Vanuatu. Canberra: Pacific Linguistics.

Muysken, Pieter and Tonjes Veenstra 2005. Serial Verbs. In Martin Everaert and Henk van Riemsdijk (eds.), The Blackwell Companion to Syntax. Malden, MA, USA: Blackwell. 4: 234-270.

Nichols, Johanna 2007. Lexical Valence Typology Project. Accessed February, 2006, from http://lingweb.eva.mpg.de/fieldtools/pdf/JohannaNichols/TransDetrans elic.pdf

Noonan, Michael 1985. Complementation. In Timothy Shopen (eds.), Language Typology and Syntactic Description: Vol 2: Complex constructions. Cambridge: Cambridge University Press.

Pearce, Elizabeth in preparation. "A Grammar of Unua (draft)." ms. VUW.

Pearce, Elizabeth n.d. "(Unua Phonology)." ms.

Ray, Sidney Herbert 1893. Sketch of Aulua Grammar with Vocabularies of Aulua and Lamangkau, Malekula, New Hebrides. Journal of the Anthropological Institute 22: 386-397.

Ray, Sidney Herbert 1926. A Comparative Study of the Melanesian Island Languages. Cambridge: Cambridge University Press.

Rehg, Kenneth L. and Damian G Sohl 1981. Ponapean Reference Grammar. Honolulu: University of Hawaii Press.

Riehl, Anastasia 2008. The Phonology and Phonetics of Nasal Obstruent Sequences. $\mathrm{PhD}$ Thesis, Cornell University.

Ross, Malcolm 2004. Demonstratives, Local Nouns and Directionals in Oceanic Languages. In Gunter Senft (eds.), Deixis and Demonstratives in Oceanic Languages. Canberra: Pacific Linguistics: 175-204.

SIL International (2006). Field Linguist's Toolbox. (Version 1.5.0) [Computer program]. Retrieved September 2006 from http://www.sil.org/computing/toolbox/.

Sony Corporation (2006). Sonic Stage. (Version 4.0) [Computer program]. Retrieved May, 2006, from www.sony.com.

Sornicola, Rosanna 1999. Topic, Focus, and Word Order. In Keith Brown and Jim Miller (eds.), Concise encyclopedia of grammatical categories. Oxford: Elsevier: 375-383.

Syntrillium Software Corp (2000). Cool Edit Pro. (Version 1.2a) [Computer program]. Retrieved August, 2001.

Thieberger, Nicholas Augustus 2004. Topics in the Grammar and Documentation of South Efate, an Oceanic Language of Central Vanuatu. Thesis, University of Melbourne.

Thieberger, Nicholas Augustus 2006. A Grammar of South Efate: An Oceanic Language of Vanuatu. Honolulu: University of Hawaii Press. 
Tryon, D. T. 1976. New Hebrides Languages: an Internal Classification. Canberra: Pacific Linguistics.

UNESCO, Ad Hoc Expert Group on Endangered Languages (2003). "Language Vitality and Endangerment." Retrieved 6 December, 2006.

Vanuatu National Language Council 2006. Vanuatu National Language Policy (5th draft).

Zorc, R. David 1995. A Glossary of Austronesian Reconstructions. In Darrell T. Tryon (eds.), Comparative Austronesian Dictionary: an Introduction to Austronesian Studies. Berlin: Mouton de Gruyter. part 1: fascile 2: 1105-1197. 